\title{
Nuevos materiales carbonosos como catalizadores heterogéneos y su aplicación en procesos de oxidación avanzada
}

\author{
TESIS DOCTORAL \\ Presentada por: \\ Juan Carlos Espinosa López \\ Dirigida por: \\ Prof. Mercedes Álvaro Rodríguez \\ Dr. Sergio Navalón Oltra
}

Valencia, septiembre 2018 

Lista de símbolos y abreviaturas 

Ángulo de difracción

$\lambda \quad$ Longitud de onda

$\mathbf{\Omega}$

Ohmio

$\Delta \mathbf{E} \quad$ Incremento de energía

(B)G Grafeno dopado con boro

(B,N)G Grafeno dopado con boro y nitrógeno

(N)G Grafeno dopado con nitrógeno

(P)G Grafeno dopado con fósforo

(S)G Grafeno dopado con azufre

AC Carbón activo

AE Análisis elemental

AFM Microscopía de fuerza atómica

BOD $_{5}$ Demanda biológica de oxígeno (en 5 días)

CA Centro activo

CNT Nanotubos de carbono

COD Demanda química de oxígeno

CPS Cuentas por segundo

CVD Deposición química de vapor

D Diamante

DF Campo oscuro 
DF-STEM Microscopía electrónica de transmisión por barrido en campo oscuro

DFT Teoría del funcional de la densidad

DMPO 5,5-dimetil-1-pirrolidona N-óxido

DMSO Dimetilsulfóxido

d Distancia interplanar

EDS Espectroscopía de rayos X de energía dispersada

EDX Análisis por dispersión de energía de rayos X

EPR Resonancia paramagnética electrónica

Ea Energía de activación

$\mathbf{e}^{-} \quad$ Electrón

eV Electronvoltio

FTIR Espectroscopía de infrarrojo por transformada de

Fourier

G Grafeno

GC Cromatografía de gases

GC-MS Cromatografía de gases con espectroscopía de masas

$\mathbf{G H z} \quad$ Gigahercio

GIC Compuestos de intercalación de grafito

GO Óxido de grafeno

Gr Grafito

HPLC Cromatografía líquida de alta resolución

Hz Hercio 


\begin{tabular}{|c|c|}
\hline $\mathbf{h}^{+}$ & Huecos/Protones \\
\hline hv & Cuantos de energía \\
\hline ICP-AES & $\begin{array}{l}\text { Espectroscopía de emisión de plasma de acoplamiento } \\
\text { inductivo }\end{array}$ \\
\hline IR & Infrarrojo \\
\hline $\mathbf{M}$ & Metal \\
\hline MNP & Nanopartícula metálica \\
\hline MWCNT & Nanotubos de carbono de pared múltiple \\
\hline $\mathbf{m M}$ & Milimolar \\
\hline $\mathbf{m W}$ & Milivatios \\
\hline $\mathbf{N}$ & Newton \\
\hline NASA & $\begin{array}{l}\text { Administración Nacional de la Aeronáutica y del } \\
\text { Espacio }\end{array}$ \\
\hline $\mathbf{N P}$ & Nanopartícula \\
\hline NT & Nanotubos \\
\hline PBN & fenil tert-butilnitrona \\
\hline POA & Procesos de oxidación avanzada \\
\hline ppm & Partes por millón \\
\hline $\mathbf{R M N}$ & Resonancia magnética nuclear \\
\hline ROS & Especies reactivas de oxígeno \\
\hline $\mathbf{r}_{0}$ & Velocidad de reacción inicial \\
\hline rGO & Óxido de grafeno reducido \\
\hline SEM & Microscopía electrónica de barrido \\
\hline
\end{tabular}


TEM Microscopía electrónica de transmisión

TGA Análisis de termogravimetría

TOC Carbón orgánico total

TON Número de ciclos catalíticos

UV Ultravioleta

UV-Vis Ultravioleta-Visible

u.a. Unidades arbitrarias

V Voltio

W Vatio

XPS Espectroscopía electrónica de rayos X

XRD Difracción de rayos X 


\section{Índice}

Capítulo 1. Introducción . .1

1.1. Procesos de oxidación avanzada (POA) .......................................

1.2. Reacción de Fenton ............................................................. 9

1.3. Catalizadores heterogéneos de la reacción de Fenton ...............12

1.4. Nanopartículas de diamante ....................................................16

1.5. Sostenibilidad en catálisis heterogénea ..................................18

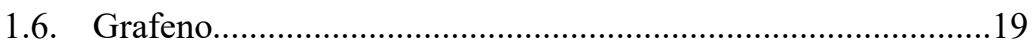

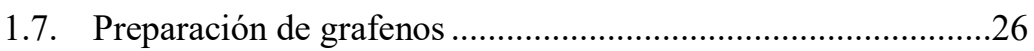

1.8. Pirólisis de polisacáridos filmogénicos naturales.......................35

1.9. Técnicas de caracterización de grafeno.....................................4

1.10. Carbocatálisis por grafenos defectuosos .....................................

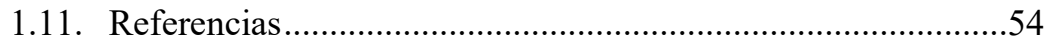

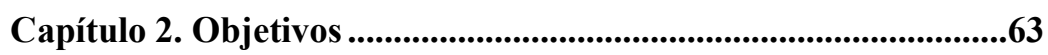

Capítulo 3. Nanopartículas de plata soportadas sobre nanopartículas de diamante como catalizadores eficientes de la reacción de Fenton por irradiación con luz solar natural ..............67

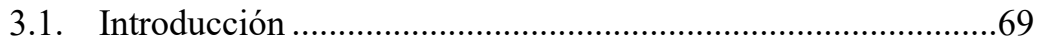

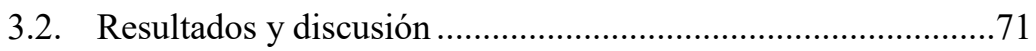

3.2.1. Preparación de muestras y caracterización.....................71

3.2.2. Experimentos fotocatalíticos ..........................................

3.2.3. Estabilidad y reusabilidad del catalizador ......................90

3.2.4. Mecanismo de reacción ................................................93

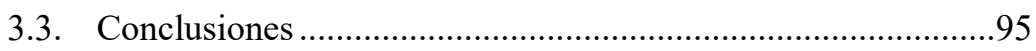


Capítulo 4. Nanopartículas de cobre soportadas sobre nanopartículas de diamante como catalizador eficiente y de buena relación de coste-actividad para la reacción de Fenton asistida por luz solar natural .................................................................................99

4.1. Introducción .................................................................. 101

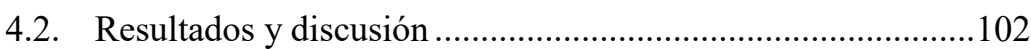

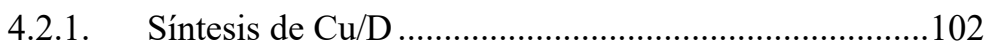

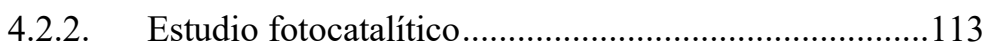

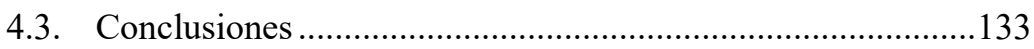

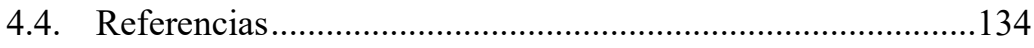

Capítulo 5. Nanopartículas de óxido de hierro soportadas sobre nanopartículas de diamante como catalizador en la reacción de Fenton foto-asistida por luz visible...........................................137

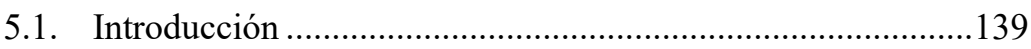

5.2. Resultados y discusión ........................................................ 141

5.2.1. Preparación y caracterización de catalizadores ............141

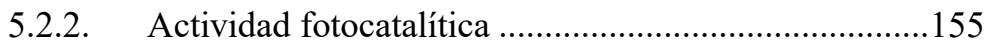

5.2.3. Mecanismo de reacción ............................................. 172

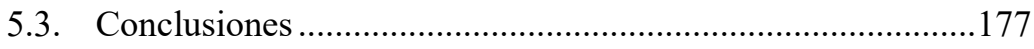

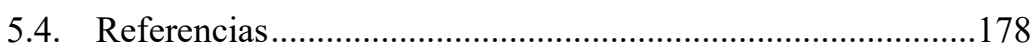

Capítulo 6. Grafenos como carbocatalizadores de la reacción de Fenton ........................................................................................181

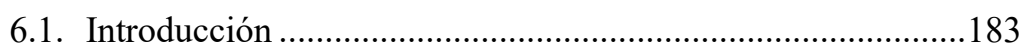

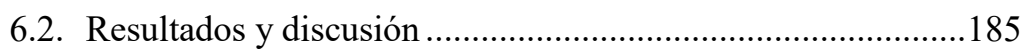

6.2.1. Preparación y caracterización de catalizadores ............185

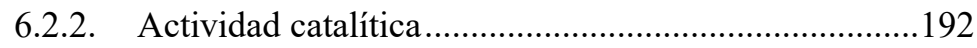

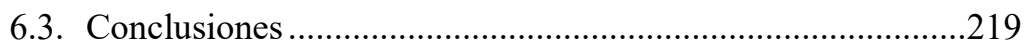

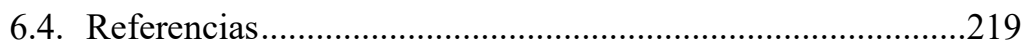

Capítulo 7. Óxido de grafeno reducido como catalizador libre de metales en la reacción tipo Fenton asistida por luz.

7.1. Introducción

7.2. Resultados y discusión. 
7.3. Conclusiones

8.1. Síntesis de materiales .253

8.1.1. Funcionalización de materiales carbonosos empleados como soporte

8.1.2. Deposición de nanopartículas metálicas......................253

8.1.3. Síntesis de nanopartículas metálicas sin soporte .........254

8.1.4. Síntesis de grafeno de alginato $(\mathrm{G})$...............................254

8.1.5. Síntesis de grafeno dopado con nitrógeno ((N)G).......254

8.1.6. Síntesis de grafeno dopado con boro $((\mathrm{B}) \mathrm{G})$...............254

8.1.7. Síntesis de grafeno dopado con nitrógeno y boro

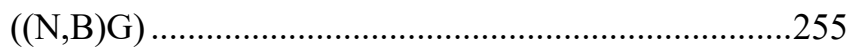

8.1.8. Síntesis de óxido de grafeno (GO) ...............................25

8.1.9. Síntesis de óxido de grafeno reducido (GO) ...............255

8.1.10. Síntesis de MWCNT purificados..................................256

8.1.11. Síntesis de MWCNT purificados-acortados .................256

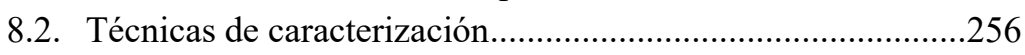

8.2.1. Microscopía electrónica de transmisión (TEM) ..........256

8.2.2. Microscopía electrónica de barrido (SEM) ..................257

8.2.3. Microscopía de fuerza atómica (AFM) y perfilometría

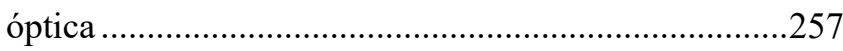

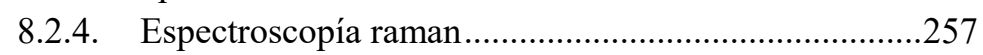

8.2.5. Difracción de rayos X (XRD).......................................258

8.2.6. Espectrofotometría fotoelectrónica de rayos X (XPS). 258

8.2.7. Espectroscopía de infrarrojo por Transformada de

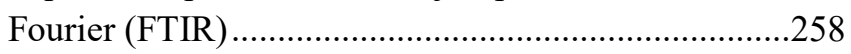

8.2.8. Análisis elemental por combustión (AE)......................258

8.2.9. Espectroscopía de plasma ICP-OES .............................259

8.2.10. Análisis de termogravimetría (TGA)...........................259

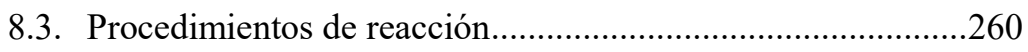

8.3.1. Procedimiento general para la reacción de Fenton ......260

8.3.2. Procedimiento general para la reacción de foto-Fenton ....

8.3.3. Procedimiento general para la determinación del mecanismo de reacción por inhibición .260 
8.3.4. Procedimiento general para la determinación del mecanismo de reacción por atrapamiento de radicales.....

8.4. Procedimientos de análisis de las muestras de reacción..........261

8.4.1. Análisis de las muestras de reacción por HPLC...........261

8.4.2. Análisis de las muestras de reacción por espectrofotometría de UV-Vis......................................261

8.4.3. Procedimiento para la determinación de la demanda biológica de oxígeno $\left(\mathrm{BOD}_{5}\right)$........................................262

8.4.4. Procedimiento para la determinación de la demanda química de oxígeno (COD) .262

8.4.5. Análisis del atrapamiento de radicales por resonancia paramagnética electrónica (EPR) .................................263

8.4.6. Análisis de carbón orgánico total (COT).....................263

Capítulo 9. Conclusiones .......................................................................265

Resúmenes de la tesis ................................................................269

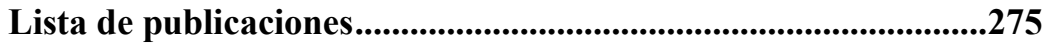


Capítulo 1

\section{Introducción}



La superpoblación que caracteriza al mundo actual junto con la creciente actividad económica y la sobreexplotación de recursos ha generado una situación en la que, por causas antropogénicas, se ha contaminado en grado no aceptable el medio ambiente. Esta contaminación ha ocurrido tanto en la atmósfera, donde es la responsable del efecto invernadero y el calentamiento global del planeta, como en suelos y en recursos hídricos. ${ }^{1}$

En el caso de aguas superficiales, la contaminación por uso doméstico en aglomeraciones urbanas es el motivo por el cual la legislación en los países industrializados obliga a los municipios al tratamiento de todas las aguas residuales generadas. Estos tratamientos de aguas residuales urbanas consisten en procesos físicos de sedimentación y filtración, y en un tratamiento biológico aeróbico, donde se reduce de forma significativa el porcentaje de contaminantes orgánicos. ${ }^{2}$ La figura 1.1 muestra un esquema general de una estación de tratamiento de aguas residuales urbanas donde los procesos claves de sedimentación y tratamiento biológico, suelen ir acompañados de un tratamiento terciario de desinfección.

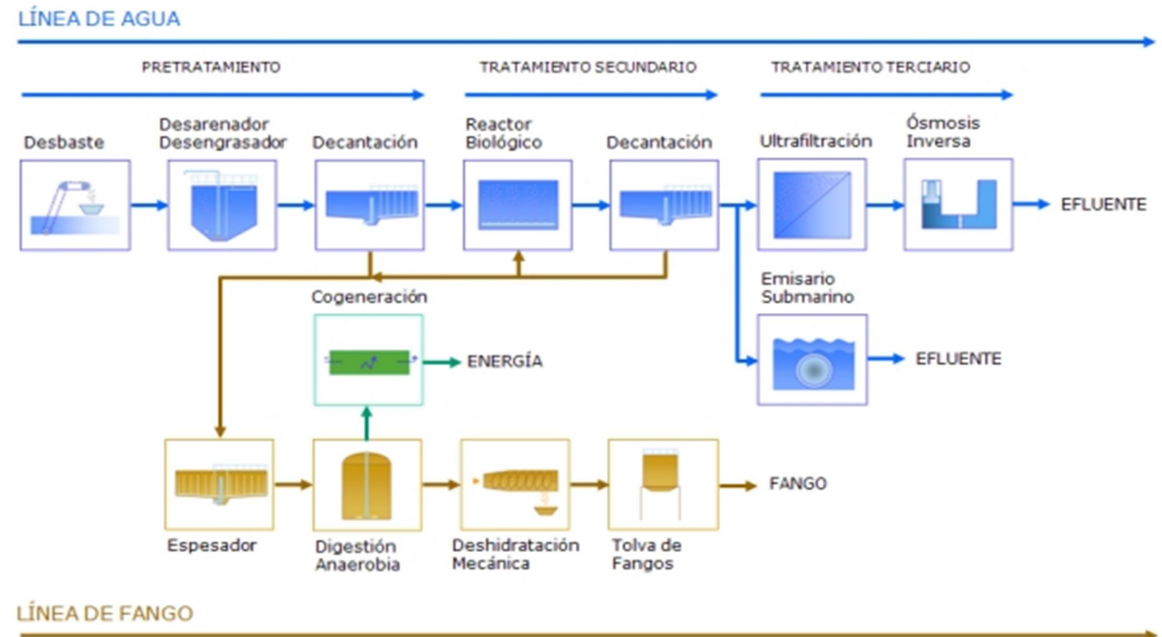

Figura 1.1. Diagrama de bloques de una estación de tratamiento de aguas residuales urbanas, en el cual se presenta los procesos que tienen lugar tanto en la línea de aguas como en la línea de fangos. 
Aunque estos tratamientos de aguas residuales son en general bastante eficientes, existe un creciente número de contaminantes emergentes de origen antropogénico que son resistentes a procesos de contaminación biológica. Por otra parte, las aguas residuales de origen industrial pueden igualmente contener compuestos orgánicos en disolución que bien no sufren degradación biológica o incluso pueden ser tóxicos para las bacterias responsables de la fermentación aeróbica, que son los agentes responsables de la descontaminación biológica, pudiendo provocar la muerte de estas bacterias. ${ }^{3}$ En estos casos los tratamientos biológicos no son eficientes, siendo necesario el tratamiento de estas aguas residuales con otro tipo de procedimientos, especialmente de naturaleza química.

\subsection{Procesos de oxidación avanzada (POA)}

Dependiendo del grado de contaminación de estos efluentes acuosos, se pueden llevar a cabo diferentes tratamientos. El esquema 1.1 resume los diferentes tipos de tratamiento químico que son aplicables para la degradación de contaminantes no biodegradables en función de su contenido en agua. ${ }^{4,5}$

\section{Tratamientos Químicos}

- Neutralización: Ajuste y control del pH

- Coagulación: Eliminación de partículas

coloidales por desestabilización y floculación

- Precipitación: Eliminación de sólidos en

suspensión, fosfatos, metales pesados, etc.

- Oxidación: Destrucción de moléculas orgánicas no biodegradables, eliminación de nitratos, desodorización, etc.

- Desinfección: Eliminación de patógenos

Esquema 1.1. Procesos químicos empleados comúnmente en las instalaciones de tratamiento de aguas residuales. 
Así, para aguas extremadamente contaminadas, con un porcentaje de carbono en disolución superior a los $1000 \mathrm{ppm}\left(1 \mathrm{~g} \mathrm{~L}^{-1} \mathrm{de}\right.$ carbono disuelto) es aconsejable proceder a procesos del tipo "oxidación húmeda". En estos procesos, el efluente se somete a temperaturas superiores a $100{ }^{\circ} \mathrm{C}$, y típicamente a $150{ }^{\circ} \mathrm{C}$, bajo atmósfera de oxígeno a presión. El esquema 1.2 ilustra estos procesos de oxidación húmeda, donde el objetivo es la mineralización de la materia orgánica en medio acuoso por generación de especies reactivas de oxígeno (ROS, de sus siglas en inglés, Reactive Oxygen Species) en estas condiciones drásticas. ${ }^{6}$

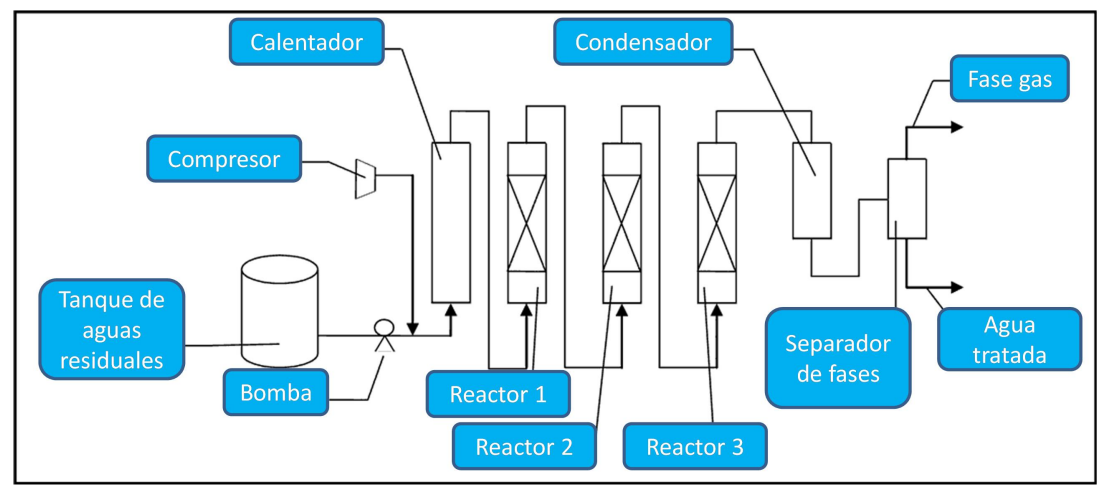

Esquema 1.2. Diagrama de bloques de una instalación de tratamiento de aguas residuales por oxidación húmeda.

Estas especies ROS derivan del ion superóxido, el cual genera radicales hidroperoxilo, peróxido de hidrógeno y finalmente radical hidroxilo. Las ecuaciones 1.1 a 1.3 ilustran los tipos de radicales de oxígeno que pueden estar implicados en los procesos de oxidación en vía húmeda. ${ }^{7,8}$
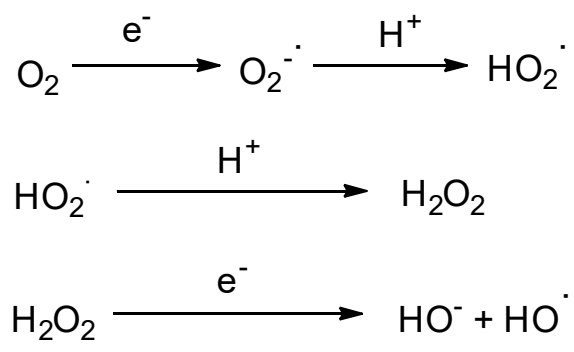

(ec. 1.3) 
El origen de los electrones y protones necesarios en las ecuaciones 1.1 a 1.3 son compuestos orgánicos con bajo potencial de oxidación y el agua u otros ácidos presentes, respectivamente.

Muchos de estos ROS son capaces de atacar, a las temperaturas de proceso, los contaminantes orgánicos presentes en el agua iniciando reacciones en cadena que conducen a intermedios orgánicos oxigenados y finalmente a $\mathrm{CO}_{2} \mathrm{y} \mathrm{H}_{2} \mathrm{O}$. Las ecuaciones 1.4 a 1.7 resumen este tipo de ataques a algunas moléculas modelo presentes en aguas residuales industriales contaminadas. $^{7-9}$

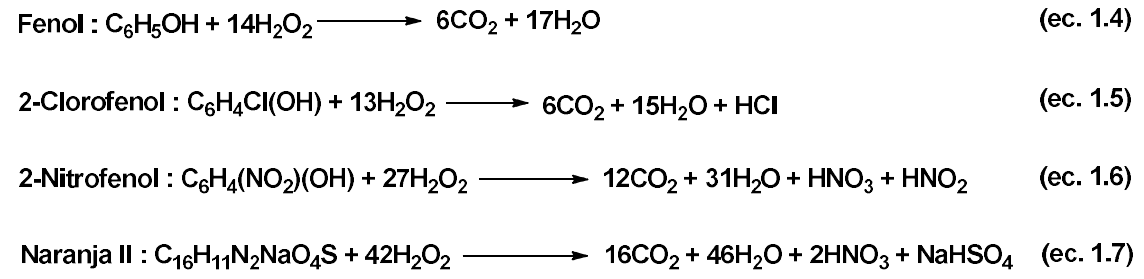

Para efluentes orgánicos con un porcentaje de carbono aún superior, en el rango de $10000 \mathrm{ppm}$ o mayor $\left(\geq 10 \mathrm{~g} \mathrm{~L}^{-1}\right)$, es posible llevar a cabo la descontaminación del agua mediante reacciones de pirólisis y combustión donde la materia orgánica es quemada por una llama tras evaporación del agua. Este tipo de procesos pirolíticos requiere de un elevado contenido en materia orgánica, de manera que el calor de combustión de estos compuestos permita sostener una llama que provoca la combustión de la materia orgánica al mismo tiempo que la evaporación del agua. La figura 1.2 ilustra este proceso de combustión para efluentes industriales altamente contaminados. 


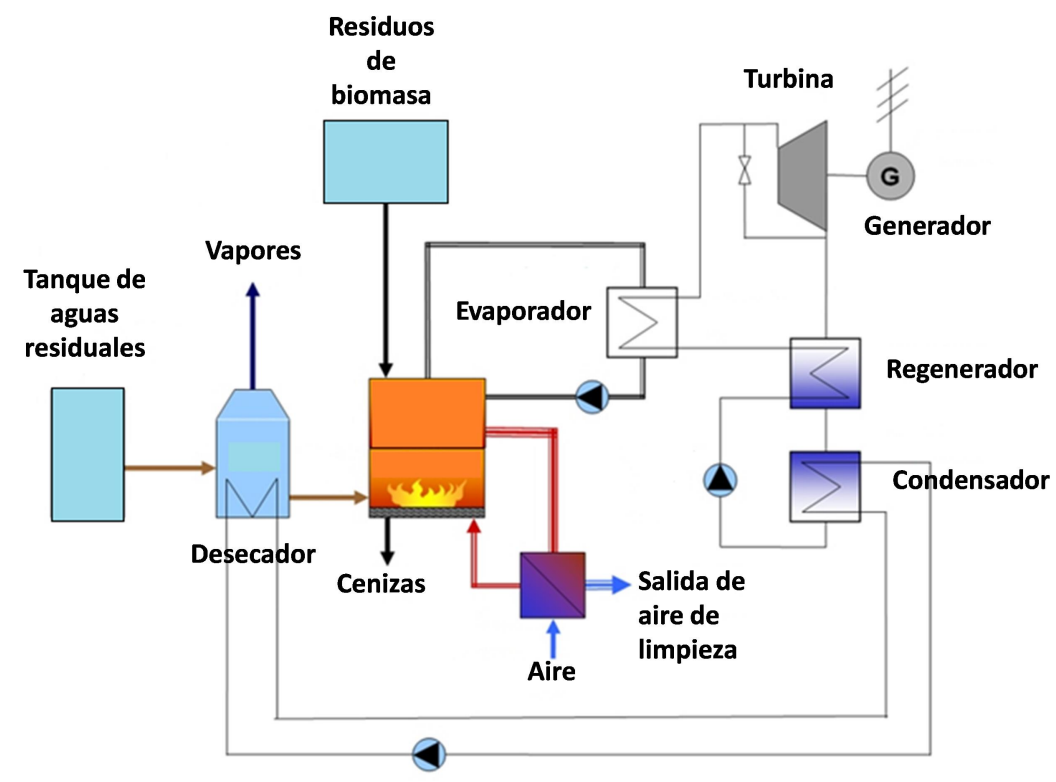

Figura 1.2. Diagrama de flujo de una instalación de tratamiento de aguas residuales por combustión de la materia orgánica tras la evaporación del agua.

Existe, sin embargo un rango de concentración de contaminantes por debajo de 1000 ppm donde tanto la oxidación por vía húmeda como la pirólisis son procesos inadecuados o serían sumamente costosos. En estos casos se puede proceder a oxidaciones químicas empleando un reactivo químico que promueva la oxidación y mineralización de los contaminantes orgánicos. Entre estos tipos de procesos destacan los denominados "Procesos de Oxidación Avanzada" donde el objetivo es la generación de radicales hidroxilo en medio acuoso. Este tipo de procesos de oxidación avanzada se pueden promover mediante el empleo de diferentes reactivos tal como indica el esquema 1.3. ${ }^{10,11}$ 


Procesos
de
$\begin{gathered}\text { Oxidación } \\ \text { (POAzzada }\end{gathered}$$\left\{\begin{array}{l}\text { Procesos oscuros } \\ \text { Ozonización }\left(\mathrm{O}_{3}\right) \\ \text { Oxidación combinada } \\ \text { con ozono y peróxido de } \\ \text { hidrógeno }\left(\mathrm{O}_{3} / \mathrm{H}_{2} \mathrm{O}_{2}\right) \\ \text { Reacción de Fenton } \\ \left(\mathrm{Fe}^{2+} / \mathrm{H}_{2} \mathrm{O}_{2}\right) \\ \text { Procesos con luz } \\ \text { Irradiación } \mathrm{UV} \text { con ozono } \\ \text { y peróxido de hidrógeno } \\ \left(\mathrm{O}_{3} / \mathrm{UV} / \mathrm{H}_{2} \mathrm{O}_{2}\right) \\ \text { FotoFenton } \\ (\text { Fe } \\ \left.\text { Fo } / \mathrm{UV} / \mathrm{H}_{2} \mathrm{O}_{2}\right) \\ \text { Fotocatálisis }\left(\mathrm{TiO} \mathrm{O}_{2} / \mathrm{hv}\right)\end{array}\right.$

Esquema 1.3. Cuadro resumen de los diferentes tipos de procesos de oxidación avanzada así como los reactivos típicamente empleados en cada uno de los mismos.

Entre estos procesos hay tratamientos de oxidación avanzada más adecuados para muestras con un bajo contenido en carbono disuelto y para efluentes transparentes, tales como la irradiación con luz ultravioleta de ozono. La irradiación del ozono da lugar a una serie de reacciones indicadas en las ecuaciones 1.8 - 1.10 que acaban en la generación de radical hidroxilo. ${ }^{10,12,13}$

$$
\begin{aligned}
& \mathrm{O}_{3} \stackrel{\mathrm{hv}}{\longrightarrow} \mathrm{O}(1 \mathrm{D})+\mathrm{O}_{2} \\
& \mathrm{O}(1 \mathrm{D})+\mathrm{H}_{2} \mathrm{O} \longrightarrow \mathrm{H}_{2} \mathrm{O}_{2} \\
& \mathrm{O}_{3}+\mathrm{H}_{2} \mathrm{O} \stackrel{\mathrm{hv}}{\longrightarrow} \mathrm{O}_{2}+\mathrm{H}_{2} \mathrm{O}_{2} \stackrel{\mathrm{hv}}{\longrightarrow} 2 \mathrm{HO}
\end{aligned}
$$


Frente a estos procesos que requieren la asistencia de luz ultravioleta, existen otros procesos de oxidación avanzada donde no es necesaria la irradiación y se generan igualmente radicales hidroxilo a partir del peróxido de hidrógeno. Esta reacción, que viene denominándose reacción de Fenton cuando es promovida por la adición de cantidades estequiométricas de una sal de $\mathrm{Fe}^{2+}$, es sumamente eficiente y puede transcurrir a temperatura ambiente. ${ }^{14,15}$

A continuación comentaremos con más detalle la reacción de Fenton que constituye el objeto de la presente tesis doctoral.

\subsection{Reacción de Fenton}

La mezcla de peróxido de hidrógeno en medio ácido con cantidades estequiométricas de una sal de $\mathrm{Fe}^{2+}$, tal como la sal de Mohr (sulfato ferroso amónico), da lugar a una reacción violenta de descomposición del agua oxigenada en agua y la oxidación de la sal ferrosa a férrica. Las ecuaciones 1.11 y 1.12 describen la estequiometría del proceso. ${ }^{16}$

$$
\begin{aligned}
& \mathrm{Fe}^{2+}+\mathrm{H}_{2} \mathrm{O}_{2} \longrightarrow \mathrm{Fe}^{3+}+\mathrm{HO}^{-}+\mathrm{HO}^{-} \\
& \mathrm{Fe}^{3+}+\mathrm{H}_{2} \mathrm{O}_{2} \longrightarrow \mathrm{Fe}^{2+}+\mathrm{HO}_{2}{ }^{\circ}+\mathrm{H}^{+}
\end{aligned}
$$

Esta reacción es termodinámicamente espontánea, transcurre con desprendimiento de calor y es extremadamente rápida cuando se lleva a cabo en el rango de pHs entre 0 y 4 . El mecanismo de reacción implica la reducción monoelectrónica del peróxido de hidrógeno por un ion ferroso, lo que provoca la ruptura del enlace peroxi con la formación de un anión hidróxido y un radical hidroxilo.

Esta reacción de Fenton se puede llevar a cabo también en cantidades de $\mathrm{Fe}$ (II) subestequiométricas. En este caso los iones férricos formados en la reacción de Fenton sufren una reducción por parte del $\mathrm{H}_{2} \mathrm{O}_{2}$ a iones ferroso (ecuación 1.12), lo que vuelve a regenerar iones ferroso, que descomponen de nuevo otra molécula de agua oxigenada. Sin embargo, debido a los potenciales redox, la reducción de iones férrico a ferroso por parte de $\mathrm{H}_{2} \mathrm{O}_{2}$ es desfavorable termodinámicamente y tiene 
lugar en concentraciones muy bajas, por lo que el proceso de descomposición del $\mathrm{H}_{2} \mathrm{O}_{2}$ en estas condiciones es extremadamente lento.

Una variante de la reacción de Fenton donde también se requieren cantidades subestequiométricas de iones ferroso es la denominada reacción de foto-Fenton donde el proceso de reducción de $\mathrm{Fe}^{3+}$ en medio ácido es promovido por irradiación con luz ultravioleta de $300 \mathrm{~nm}$ de los iones férrico hidratados. ${ }^{17}$ En este proceso de foto-Fenton se produce la excitación electrónica en la banda metal-ligando de iones $\mathrm{Fe}^{3+}$ hidratados, los cuales poseen un espectro de absorción con una banda característica a $300 \mathrm{~nm}$ y que se extiende hasta la parte de mayor energía del espectro visible (hasta $380 \mathrm{~nm}$ ), y que es la responsable del color amarillo que caracteriza estas disoluciones. ${ }^{10}$ Tras excitación electrónica, los aquocomplejos de $\mathrm{Fe}(\mathrm{III})$ sufren una transferencia electrónica ligando-metal viniendo a formar un ion ferroso y un radical hidroxilo tal como indican las ecuaciones $1.11,1.13$ y $1.14 .^{18}$

$$
\begin{aligned}
& \mathrm{Fe}\left(\mathrm{H}_{2} \mathrm{O}\right)_{6}{ }^{3+} \stackrel{\mathrm{hv}}{\longrightarrow} \mathrm{Fe}(\mathrm{OH})^{2+}+\mathrm{H}^{+}+5 \mathrm{H}_{2} \mathrm{O} \\
& \mathrm{Fe}(\mathrm{OH})^{2+} \underset{\mathrm{pH} 3}{\stackrel{\mathrm{hv}}{\longrightarrow}} \mathrm{Fe}^{2+}+\mathrm{HO}^{\circ}
\end{aligned}
$$

De esta manera, la combinación de agua oxigenada, una sal de hierro, bien ferroso o férrico, e irradiación ultravioleta da lugar a una reacción cíclica de generación de radicales hidroxilo donde la parte fotoquímica promueve la transformación de $\mathrm{Fe}(\mathrm{III})$ a $\mathrm{Fe}(\mathrm{II})$ y la parte en la oscuridad consiste en la oxidación de Fenton del Fe(II) a Fe(III). Esta reacción de foto-Fenton requiere disoluciones transparentes puesto que la absorción del aquocomplejo de Fe(III) en concentraciones milimolares posee un bajo coeficiente de extinción y ocurre en la zona del ultravioleta, ${ }^{19}$ por lo que no es aplicable en el caso de efluentes con elevada turbidez o que posean colorantes en disolución.

Tanto la reacción de Fenton como su variante fotoasistida requieren valores de $\mathrm{pH}$ ácidos inferiores a 4 unidades y típicamente entre valores de $\mathrm{pH} 1$ y 4 . El principal motivo para este requerimiento es la solubilidad de las sales de hierro y la especiación de las mismas en función del pH. Debido a su extremada acidez, las sales de $\mathrm{Fe}^{3+}$ precipitan a valores de $\mathrm{pH}$ superior a 4 en forma de hidróxidos u oxihidróxidos, los 
cuales son ineficientes para promover la reacción de Fenton a la misma velocidad que los iones disueltos. ${ }^{10,18}$ Este requerimiento de valores de $\mathrm{pH}$ ácidos puede ser una limitación en el tratamiento de ciertas aguas residuales, particularmente aquellas que poseen un valor de $\mathrm{pH}$ en otro rango o que poseen un porcentaje elevado de aniones tamponantes tales como carbonatos, fosfatos, acetatos u otros. En cualquier caso es frecuentemente necesario acondicionar el valor del $\mathrm{pH}$ de las aguas tratadas a valores neutros antes del vertido definitivo de las mismas.

El principal inconveniente de la reacción de Fenton es la generación de fangos y lodos con un alto contenido en iones de hierro que deben ser separados durante el proceso de tratamiento de las aguas residuales. Además, dependiendo del $\mathrm{pH}$, los iones hierro tienden a formar coloides, los cuales son de floculación lenta y pueden tardar largos periodos de tiempo en precipitar. ${ }^{20}$ Esta limitación de la reacción de Fenton consistente en la formación de lodos es solo mitigada parcialmente en la reacción de foto-Fenton. En efecto, aunque la reacción de foto-Fenton utiliza menores cantidades de hierro, estas son aún elevadas, típicamente en torno a un $20 \%$ de la cantidad estequiométrica con respecto al agua oxigenada, ${ }^{21-23}$ lo que aun genera cantidades apreciables de coloides y fangos en el proceso.

Aunque el hierro es un metal abundante, de bajo coste y no tóxico, los problemas derivados de su separación en la reacción de Fenton han ocasionado un interés por desarrollar procesos catalíticos alternativos a las reacciones de Fenton y foto-Fenton. Estos procesos catalíticos se basan en la mayoría de los casos en el empleo de sólidos insolubles que son fácilmente separables de los efluentes acuosos. 


\subsection{Catalizadores heterogéneos de la reacción de Fenton}

Una de las posibilidades que ha sido más ampliamente explorada consiste en soportar sales de hierro y óxidos de hierro en óxidos inorgánicos de elevada área superficial, ${ }^{24,25}$ de manera que estos catalizadores sólidos puedan ser fácilmente separados de la fase acuosa. Sin embargo, en la mayoría de los casos descritos, estos catalizadores a base de sales, óxidos o nanopartículas de hierro son muy poco activos comparados con el proceso de Fenton homogéneo, por lo que se requieren cantidades muy elevadas de $\mathrm{H}_{2} \mathrm{O}_{2}$ y/o temperaturas superiores a la ambiente. $^{26}$

Uno de los problemas generales del empleo de catalizadores heterogéneos es el lixiviado de las sales de hierro desde el sólido a la disolución acuosa. ${ }^{26,27}$ De esta manera, el catalizador sólido actúa más como un precursor de sales de hierro, manteniendo una concentración constante de estos iones en disolución, que como un verdadero catalizador heterogéneo. Cuando el catalizador consiste en óxidos de hierro y los valores de $\mathrm{pH}$ de la disolución acuosa son ácidos, se produce la transformación de los óxidos en iones que resultan solubles en estas condiciones. ${ }^{28}$ En el caso de nanopartículas de hierro, éstas sufren oxidación bien por contacto con el ambiente o especialmente por reacción con el $\mathrm{H}_{2} \mathrm{O}_{2}$ que actúa como un agente oxidante. ${ }^{28}$ Por ello, aunque inicialmente el estado de oxidación del hierro sea cero, se produce una transformación gradual en iones férricos.

Los ciclos catalíticos (turnover) de los catalizadores de Fenton poseen una etapa similar a la ecuación 1.11 , donde se genera el radical hidroxilo a partir del $\mathrm{H}_{2} \mathrm{O}_{2}$ por reducción de este peróxido con oxidación del metal, seguido de otra etapa donde el $\mathrm{H}_{2} \mathrm{O}_{2}$ actúa como un agente reductor promoviendo la reducción del hierro a su estado inicial. ${ }^{29}$ Dado el estado de oxidación del oxígeno en el peróxido, el cual es intermedio entre el del agua y el del oxígeno molecular, el peróxido de hidrógeno puede actuar tanto como oxidante como reductor, sufriendo un proceso de dismutación transformándose en agua y oxígeno, tal como indican las ecuaciones 1.15 y $1.16 .^{30}$ 


$$
\begin{aligned}
& \mathrm{H}_{2} \mathrm{O}_{2}+2 \mathrm{H}^{+}+2 \mathrm{e}^{-} \longrightarrow 2 \mathrm{H}_{2} \mathrm{O} \\
& \mathrm{H}_{2} \mathrm{O}_{2} \longrightarrow \mathrm{O}_{2}+2 \mathrm{e}^{-}+2 \mathrm{H}^{+}
\end{aligned}
$$

Los soportes que han sido más comúnmente empleados para depositar las nanopartículas de hierro o sus óxidos han sido los óxidos inorgánicos, particularmente la sílice, ${ }^{25,31}$ pero también aluminosilicatos, en gran número de casos, porosos. Entre ellos, los sólidos porosos cristalinos tales como zeolitas ${ }^{32,33}$ y materiales MCM $41^{34-36}$ con un alto nivel de intercambio iónico se encuentran entre los preferidos.

Otros aluminosilicatos ampliamente utilizados como soportes han sido arcillas naturales y sintéticas. De entre ellas, arcillas laminares de tipo montmorillonita son muy comunes, ${ }^{37,38}$ puesto que estas arcillas naturales poseen un elevado contenido en hierro. Además es posible producir el hinchamiento de las láminas y la incorporación de pilares y nanopartículas de hierro en los espacios interlaminares de estos materiales. ${ }^{38}$ De esta manera, el área superficial del sólido aumenta considerablemente, haciendo accesible las regiones entre las láminas donde normalmente no pueden acceder reactivos. Junto a estos materiales inorgánicos también existe otro tipo de soportes de elevada área específica, especialmente los carbones activos. ${ }^{24,39-41}$

Los carbones activos, incluso en ausencia de iones hierro, pueden poseer cierta actividad catalítica para promover la reacción de Fenton. ${ }^{42,43}$ Aunque este hecho está bien documentado en la literatura, la naturaleza de los centros capaces de llevar a cabo la activación del $\mathrm{H}_{2} \mathrm{O}_{2}$ en radicales hidroxilo en carbones activos no ha sido completamente clarificada.

Uno de los inconvenientes de la catálisis heterogénea es el elevado exceso de $\mathrm{H}_{2} \mathrm{O}_{2}$ que es necesario para promover la descomposición de contaminantes orgánicos, incluso a valores de $\mathrm{pH}$ ácidos. Así, aunque la justificación habitual de requerimiento de valores de $\mathrm{pH}$ ácidos es la solubilidad de las sales de hierro, también los catalizadores heterogéneos soportados operan más eficientemente a valores de $\mathrm{pH}$ ácidos. Se ha descrito que estos catalizadores sólidos pueden promover la reacción de Fenton en medios próximos a la neutralidad, pero entonces las cantidades de $\mathrm{H}_{2} \mathrm{O}_{2}$ empleadas son de 1000 equivalentes o superior, no siendo infrecuentes estudios que emplean 
valores de 10000 equivalentes de $\mathrm{H}_{2} \mathrm{O}_{2}$. Ello da idea de la baja eficiencia de este tipo de catalizadores heterogéneos conteniendo óxidos de hierro.

Aunque la reacción de Fenton es promovida fundamentalmente por hierro, otros metales de transición tales como manganeso, ${ }^{44,45}$ cobre, ${ }^{46,47}$ cobalto ${ }^{48,49}$ han sido descritos también como promotores de la reacción de foto-Fenton, tanto en disolución como soportados en sólidos insolubles. El requerimiento fundamental para la actividad catalítica parece ser la existencia de un par redox del metal entre los dos potenciales redox definidos por el par $\mathrm{H}_{2} \mathrm{O}_{2} / \mathrm{H}_{2} \mathrm{O}$ y $\mathrm{O}_{2} / \mathrm{H}_{2} \mathrm{O}_{2}$ tal como indica el esquema $1.4 .^{30,50}$

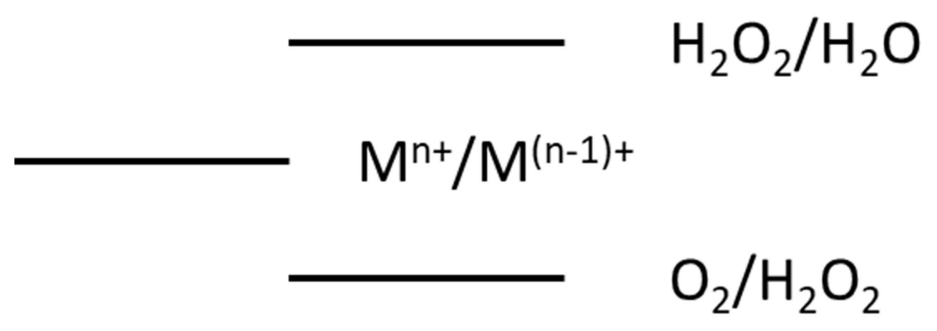

Esquema 1.4. Requerimiento termodinámico de los valores de potencial redox para los iones metálicos $\left(\mathrm{M}^{\mathrm{n}+}\right)$ capaces de promover la reacción catalítica de Fenton.

En este sentido, nuestro grupo de investigación describió en 2010 un catalizador a base de nanopartículas de oro que es posiblemente uno de los catalizadores heterogéneos más activos descritos en la literatura hasta la fecha ${ }^{50}$ Estas nanopartículas de oro se encuentran soportadas sobre nanopartículas de diamante $(\mathrm{Au} / \mathrm{D})$ comercialmente disponibles provenientes de detonación de explosivos. Las nanopartículas de diamante se preparan en cantidades elevadas puesto que resultan como residuo en la detonación de explosivos orgánicos. ${ }^{51}$ Las muestras de este origen contienen las nanopartículas de diamante embebidas en una matriz de carbono amorfo que las aglomera y que es necesario eliminar para, de esta manera, liberar y desagregar las nanopartículas de diamante, ${ }^{51}$ de forma que sean fácilmente dispersables como nanopartículas individuales. Nuestro grupo puso a punto una forma de eliminación del residuo carbonoso amorfo que acompaña a estas nanopartículas de diamante comerciales mediante el empleo de la reacción de Fenton que, como se ha 
comentado anteriormente, es capaz de llevar a cabo la mineralización de la materia orgánica. La naturaleza cristalina del diamante y su gran estabilidad química determina que mientras el carbono amorfo es completamente degradado en el tratamiento de Fenton de las muestras comerciales, las nanopartículas de diamante sólo sufren una erosión superficial como se deduce de la disminución del tamaño de las mismas, que pasa de un promedio de $9 \mathrm{~nm}$ a $7 \mathrm{~nm}$ como consecuencia de este tratamiento. ${ }^{51}$ Estas nanopartículas de diamante liberadas del componente de carbono amorfo son las que se emplean como soporte de las nanopartículas de oro. La figura 1.3 muestra imágenes de microscopía electrónica de transmisión (TEM, de sus siglas en inglés, Transmission Electron Microscopy), tanto de las muestras comerciales de diamante como de las nanopartículas que resultan tras el tratamiento de Fenton y posterior deposición de nanopartículas de oro. ${ }^{50,51}$
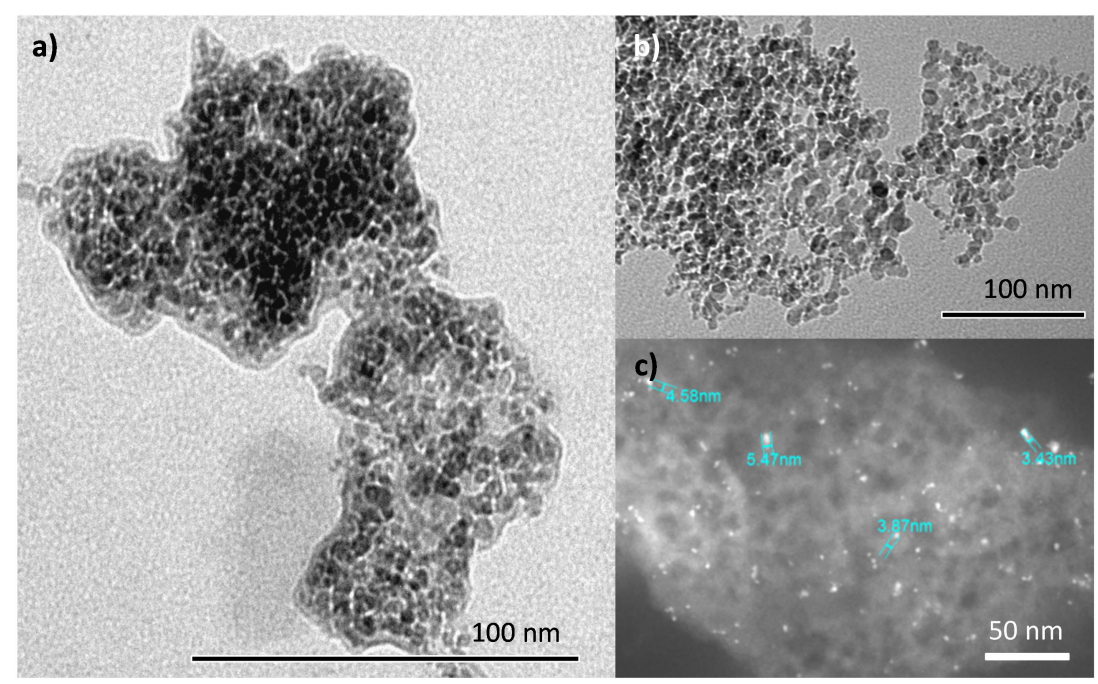

Figura 1.3. Imágenes de microscopía electrónica de a) nanopartículas de diamante comerciales; b) nanopartículas de diamante tras el tratamiento de Fenton, donde se observa la eliminación de la matriz de carbono amorfo, y c) nanopartículas de oro depositadas sobre las nanopartículas de diamante pretratadas con la oxidación de Fenton.

La preparación de nanopartículas de oro sobre diamante se lleva cabo mediante el procedimiento denominado deposición-precipitación. ${ }^{52}$ Éste consiste en poner contacto el soporte sólido con una disolución acuosa de $\mathrm{HAuCl}_{4}$ a un $\mathrm{pH}$ controlado típicamente superior a 4 y más 
habitualmente en torno a 7. En estas condiciones, el anión $\mathrm{AuCl}_{4}{ }^{-}$ intercambia iones cloruro por hidróxido, formando una distribución de aniones de oro hidroxicloruro tales como $\mathrm{AuCl}_{3}(\mathrm{OH})^{-}, \mathrm{AuCl}_{2}(\mathrm{OH})_{2}{ }^{-}$y $\mathrm{AuCl}(\mathrm{OH})_{3}{ }^{-}$, cuya proporción varía en función del pH. Estas especies de $\mathrm{Au}(\mathrm{III})$ se depositan sobre la superficie del soporte sólido permaneciendo adsorbidas en la etapa de deposición simplemente dejando en contacto la disolución acuosa de la sal de oro con el soporte sólido con un valor de pH 5. A continuación el sólido, conteniendo un porcentaje de oro adsorbido, se recupera por filtración, se lava y se reduce por métodos químicos en la etapa de deposición, dando lugar a nanopartículas de oro que se encuentran fuertemente ancladas sobre la superficie del material inorgánico.

Entre los agentes de reducción, los más habituales son alcoholes tales como etanol y 2-feniletanol, así como dioles, ocurriendo la reducción química a temperaturas entre 60 y $180{ }^{\circ} \mathrm{C} .{ }^{53,54}$ De esta manera se pueden conseguir nanopartículas de oro con un tamaño promedio en torno a $5 \mathrm{~nm}^{50}$

El material $\mathrm{Au} / \mathrm{D}$ exhibe una alta actividad catalítica para promover la degradación de fenol con un exceso de agua oxigenada en torno a 5 equivalentes. Se han conseguido valores de número de ciclos en torno a $450000,,^{55}$ pero estos valores podrían haber llegado a ser más altos con una reactivación del catalizador. Un hecho destacable es que el catalizador $\mathrm{Au} / \mathrm{D}$ exhibe fotorespuesta en el rango de luz visible, y más específicamente, por irradiación con luz solar, aumentando la actividad del material cuando éste es iluminado en esta zona del espectro electromagnético. ${ }^{55}$ Un punto importante en el estado del arte es explorar si otros metales de transición, particularmente los análogos de la misma familia del sistema periódico IB, exhiben igualmente una actividad catalítica en este proceso, además de explorar la actividad de especies de hierro soportadas sobre el diamante.

\subsection{Nanopartículas de diamante}

La funcionalización de nuevas formas alotrópicas del carbono es una corriente de mucho interés que puede llevar al desarrollo de una larga variedad de materiales con diferentes propiedades. 
En los últimos años, las nanopartículas de diamante preparadas por detonación controlada se han convertido en un material ampliamente disponible.

Esta síntesis consiste en la detonación de explosivos orgánicos en deficiencia de oxígeno, resultando en una combustión incompleta. Típicamente se introducen en un contenedor cerrado una mezcla de 2,4,6-trinitrotolueno (TNT) y ciclotrimetilentrinitramina (RDX), donde este último aporta en su mayor medida la energía y el TNT pasa a generar el hollín producto de la deficiencia de oxígeno. La energía de detonación genera una temperatura y presión suficientemente altas para formar la estructura sp3 del diamante en el hollín obtenido. Las partículas resultantes suelen estar envueltas en una capa de carbono grafítico que se forma al bajar la energía de la detonación y es necesaria una purificación para la obtención de diamante puro que generalmente se realiza por oxidación con ácidos inorgánicos. ${ }^{56}$ De esta forma el proceso ha sido escalado para la producción industrial y por ello se trata de un material ampliamente disponible. ${ }^{57}$

Teniendo en cuenta que estas nanopartículas de diamante exhiben propiedades específicas diferentes al resto de materiales, se ha desarrollado una importante línea de investigación en relación a la modificación química de dichas nanopartículas por la formación de un enlace covalente con otras moléculas orgánicas o grupos funcionales oxigenados que puedan introducir nuevas propiedades en este material.

En comparación con otras formas alotrópicas del carbono como fulerenos o nanotubos de carbono, las nanopartículas de diamante, constituidas por carbono con hibridación sp3, son notablemente inertes y desprovistas de reactividad química. ${ }^{58}$

Por ello, es de interés el desarrollo de nuevas estrategias para hacer de este tipo de nanopartículas de carbono un material susceptible de funcionalización con la cantidad apropiada o deseada de sustituyente en cada nanopartícula.

En la presente tesis doctoral se muestra una vía de funcionalización por medio de la reacción de Fenton y posterior reducción por hidrogenación de las nanopartículas de diamante que permite introducir un aumento de la densidad de grupos hidroxilo en la 
superficie de las nanopartículas. Además, la oxidación de Fenton permite la eliminación de la capa amorfa de carbono que suele envolver a estas nanopartículas, facilitando así su separación, ya que se suelen encontrar en aglomeración envueltas en dicha capa de carbono. Este hecho se puede observar en la figura 1.3, descrita en el apartado anterior.

Este material ha sido explotado en diferentes campos de investigación incluyendo liberación de fármacos, formulación de composites altamente resistentes, empleado en pulido de materiales de alta dureza, como componente en formulación de lubricantes y en componentes de microelectrónica. ${ }^{56-58}$

\subsection{Sostenibilidad en catálisis heterogénea}

La mayoría de los procesos industriales, particularmente los que se llevan a cabo a gran escala en la industria petroquímica, son procesos catalíticos, fundamentalmente empleando catalizadores heterogéneos. Se estima que en torno al $80 \%$ de los procesos químicos industriales utilizan un catalizador, ${ }^{59,60}$ en la mayoría de casos heterogéneos, donde existe una interfase entre el medio de reacción y el catalizador que contiene los centros activos. Gran parte de estos catalizadores contienen metales de transición y frecuentemente de entre ellos metales nobles (Pt, Ir, Pd, Ag, $\mathrm{Rh}, \mathrm{Au})^{61-64}$ o metales considerados como materias primas críticas tales como $\mathrm{Co}, \mathrm{Ru}, \mathrm{Ta}, \mathrm{Re}, \mathrm{Os}, \mathrm{Ce}$ y tierras raras. ${ }^{65}$ Materias primas críticas son aquellas de las que existe un recurso limitado, frecuentemente en áreas geográficas remotas y con situación geopolítica inestable. Por consiguiente, debido a las posibles limitaciones en la disponibilidad de estos metales críticos, existe un gran interés en la búsqueda de alternativas basadas en elementos abundantes. La unión europea lanzó en el 2010 una serie de líneas de financiación para proyectos que busquen reducir la dependencia de la industria europea en materias primas críticas, donde se menciona expresamente la dependencia de la industria química, y particularmente la catálisis, en ciertos metales. ${ }^{66}$ En este contexto, se han desarrollado unas líneas de investigación encaminadas a aplicar en catálisis metales de transición muy abundantes tales como el hierro y el cobre como alternativas a los metales críticos o preciosos. En la presente tesis doctoral dos de los capítulos (4 y 5 ) irán encaminados a determinar la actividad catalítica de nanopartículas de $\mathrm{Cu}$ y $\mathrm{Fe}$ soportadas sobre 
nanopartículas de diamante como catalizadores en la reacción de Fenton y foto-Fenton.

También en este contexto, un frente de investigación muy novedoso y de alto riesgo pretende desarrollar catalizadores sin contener metales para promover reacciones químicas. De entre estos catalizadores, aquellos basados en carbono son los que han sido más desarrollados, habiéndose conseguido un avance notable ${ }^{67-70}$ El empleo de materiales de carbono en catálisis ha dado lugar a dos áreas, organocatálisis ${ }^{71}$ y carbocatálisis, ${ }^{72-74}$ dependiendo de si se trata de catálisis homogénea o heterogénea y del tipo de materiales o compuestos empleados. De entre los carbocatalizadores, los que están siendo objeto de un estudio más intenso son aquellos basados en grafeno y materiales relacionados. ${ }^{73} \mathrm{La}$ presente tesis doctoral describirá en los capítulos 6 y 7 el empleo de materiales basados en grafenos como catalizadores y fotocatalizadores, respectivamente. En la siguiente sección se describe sucintamente las razones que motivan el interés y el estudio del grafeno y las principales propiedades de estos tipos de materiales.

\subsection{Grafeno}

A partir del descubrimiento de los fulerenos en los años 80 del siglo $\mathrm{XX},{ }^{75}$ uno de los frentes de investigación en química ha sido la preparación y el estudio de propiedades de formas alotrópicas del carbono. Con anterioridad al descubrimiento de los fulerenos se pensaba que el carbono podía encontrarse en dos formas alotrópicas, diamante o grafito, dependiendo de la hibridación atómica sp3 o sp2 de este elemento. Sin embargo, mediante los estudios llevados a cabo por la NASA para determinar la presencia de elementos en el universo y sus formas alotrópicas, se llegó al descubrimiento de que el carbono se encontraba presente en estrellas y otros cuerpos celestes en forma de entidades moleculares con un número determinado de átomos. ${ }^{76}$ Posteriormente, este tipo de moléculas de carbono se sintetizaron en el laboratorio mediante diferentes técnicas, como por ejemplo descargas eléctricas de alto voltaje e intensidad, en electrodos de grafito. En estas condiciones el electrodo de grafito sufre una transformación y descomposición convirtiéndose en una mezcla de fulerenos presente en el hollín resultante del proceso, siendo el fulereno $\mathrm{C}_{60}$ el más abundante. ${ }^{77}$ 
Más recientemente, a partir de los trabajos iniciados en el 2004, la academia sueca de ciencias concedió en el 2010 el premio Nobel de física a los investigadores Andre Geim y Konstantin Novoselov por sus estudios con materiales 2D, especialmente el grafeno. ${ }^{78}$

Aunque la existencia del grafeno era conocida desde los primeros años del siglo XX con el desarrollo por Laue y Bragg de la difracción de rayos $\mathrm{X},{ }^{79}$ no fue hasta los primeros años del siglo $\mathrm{XX1}$ donde se procedió al aislamiento y el estudio de las propiedades electrónicas de este material. En efecto, en cristalografía de rayos X, uno de los materiales inicialmente estudiados y que se emplea como patrón en esta técnica es el grafito. $^{80,81}$ El grafito es un material laminar constituido por el apilamiento regular de láminas individuales, denominándose cada una de ellas como grafeno. El grafito pirolítico obtenido por tratamiento térmico a temperaturas elevadas es un material altamente cristalino que presenta un pico de difracción en torno a $2 \theta=26^{\circ}$ que corresponde al modo de difracción de los rayos $\mathrm{X}$ en la dirección de las láminas de grafeno que constituyen este material, ${ }^{80,81}$ y que de acuerdo con la ley de difracción de Bragg $(2 d \operatorname{sen} \theta=n \lambda$, donde $d$ es la distancia interplanar, $\theta$ es el ángulo medido de la difracción, $n$ es un número entero, y $\lambda$ es la longitud de onda de la radiación empleada) ${ }^{79}$ se corresponde a una distancia interplanar entre las láminas de $0.34 \mathrm{~nm} .^{78,82,83} \mathrm{El}$ grafito pirolítico es uno de los materiales que se utilizan como patrón de referencia en las técnicas de difracción. ${ }^{80,81}$ Mediante exfoliación manual del grafito con cinta adhesiva, los premios Nobel fueron capaces de conseguir una única monolámina de grafeno y así pudieron estudiar sus propiedades. ${ }^{84-86} \mathrm{La}$ figura 1.4 muestra la estructura del grafito y un modelo de difracción de rayos $\mathrm{X}$.

a)

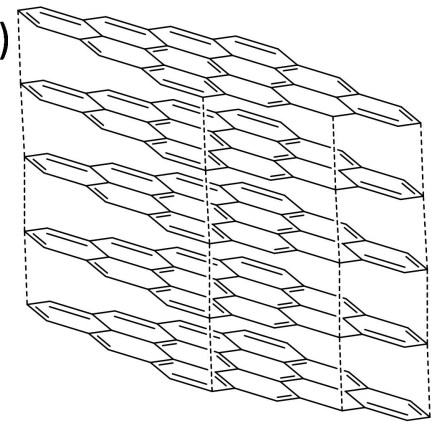

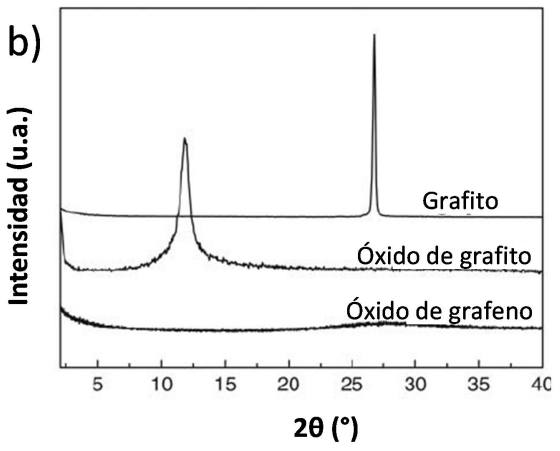


Figura 1.4. a) Estructura química del grafito formada por el apilamiento de láminas de grafeno y b) difracción de rayos $\mathrm{X}$ del grafito, óxido de grafito y óxido de grafeno.

De esta manera, el grafeno se define como una capa indefinida de un átomo de espesor constituida por carbonos con hibridación sp2 y disposición hexagonal. ${ }^{87-91}$ Por consiguiente, el grafeno representa el límite físico de miniaturización de un material bidimensional (2D) donde todos los átomos que lo conforman están expuestos al ambiente y accesibles por su parte superior e inferior. El grafeno se puede encontrar recubriendo la superficie de un sustrato sólido o también disperso en un medio líquido.

La estructura electrónica del grafeno está relacionada con la de compuestos aromáticos de los cuales el benceno es el caso más simple. Al igual que esta molécula, el grafeno posee enlaces de tipo $\sigma$ por el recubrimiento de orbitales $\mathrm{sp} 2$ coplanarios formando un ángulo de $120^{\circ}$ que determina la geometría hexagonal y la planaridad de la molécula, y un segundo enlace más débil de tipo $\pi$ que posee una densidad electrónica en fases opuestas por encima y por debajo del plano que contiene los átomos. La figura 1.5 ilustra la estructura y la configuración electrónica del grafeno. La existencia de este orbital $\pi$ extendido en el grafeno determina un gran número de propiedades electrónicas y optoelectrónicas, así como su comportamiento en fenómenos de adsorción.

a)

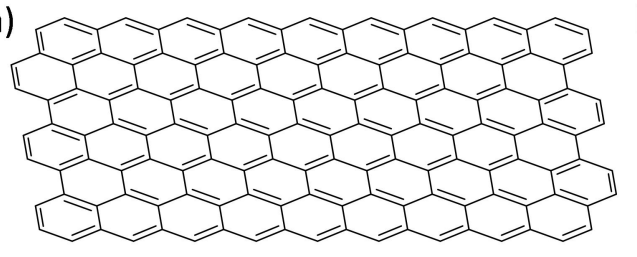

b)

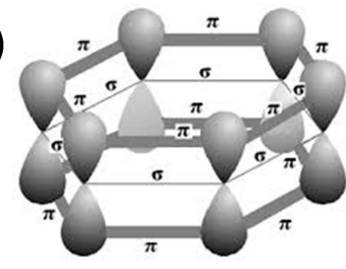

Figura 1.5. a) Estructura química del grafeno formada por una monolámina de carbono formando anillos hexagonales con hibridación sp2 y b) configuración electrónica del anillo de carbonos que integran cada uno de los hexágonos de la lámina de grafeno.

Así, el grafeno es un material conductor de la corriente eléctrica, con una resistividad de $10^{-6} \Omega \mathrm{cm}$ comparable a los elementos metálicos y muy inferior a la del grafito. ${ }^{85}$ Además de la conductividad eléctrica, el 
grafeno es el material en el cual la movilidad de los electrones es más elevada, llegando a $15000 \mathrm{~cm}^{2} \mathrm{~V}^{-1} \mathrm{~s}^{-1} \cdot 78,84,85$ Ello determina que el grafeno sea el material que más rápidamente responde a campos eléctricos y, por tanto, tiene un alto potencial en dispositivos de transmisión de la información, donde se pueden conseguir frecuencias de transmisión de datos del orden de GHz. Desde el punto de vista fisicoquímico, la existencia de estos orbitales $\pi$ extendidos determina que el grafeno puede interaccionar fuertemente con moléculas orgánicas aromáticas mediante interacciones $\pi-\pi$, con átomos metálicos, agregados metálicos e iones mediante interacciones $\mathrm{d}-\pi \cdot{ }^{92-94}$ Además, las interacciones de dispersión de tipos de van der Waals de un adsorbato con el grafeno son también especialmente fuertes. ${ }^{95,96}$ Por ello, las láminas de grafeno contienen generalmente adsorbidas especies que se encuentran en el ambiente y que entran en contacto con este material, y particularmente con moléculas de agua.

Además de propiedades electrónicas, otro tipo de propiedades que han atraído gran interés en el caso del grafeno son su elevada tenacidad frente a la ruptura y su gran flexibilidad, sufriendo deformación a grandes presiones y habiéndose estimado un módulo de Young para este material de $10^{12} \mathrm{~N} \mathrm{~m}^{-2}$, que es dos órdenes de magnitud superior al del acero. $^{97}$

Desde el punto de vista óptico, el grafeno es prácticamente transparente para todas las radiaciones de la región UV y visible, presentando una absorción en la zona del infrarrojo lejano. Esta transparencia está en torno a $99.9 \% .{ }^{98,99}$ Sin embargo, debido justamente a la interacción $\pi$ - $\pi$ y al solapamiento de estos orbitales, dos capas de grafeno interaccionando entre sí reducen significativamente la transparencia, que ya se sitúa en torno al $97 \%$ en toda la zona UV-Vis. Este tipo de materiales se denominan neutros puesto que la transmitancia y absorbancia no depende de la longitud de onda. El apilamiento de cuatro capas de grafeno, que poseen un espesor estimado inferior a $2 \mathrm{~nm}$, ya da lugar a una transmitancia inferior al $80 \%$ que es detectable visualmente por un tono gris en las superficies que recubren. ${ }^{99}$ La figura 1.6 muestra los espectros de transmitancia de grafenos en función del número de capas y que permite de esta manera determinar el apilamiento de láminas de grafeno de una forma simple sobre superficies transparentes. 


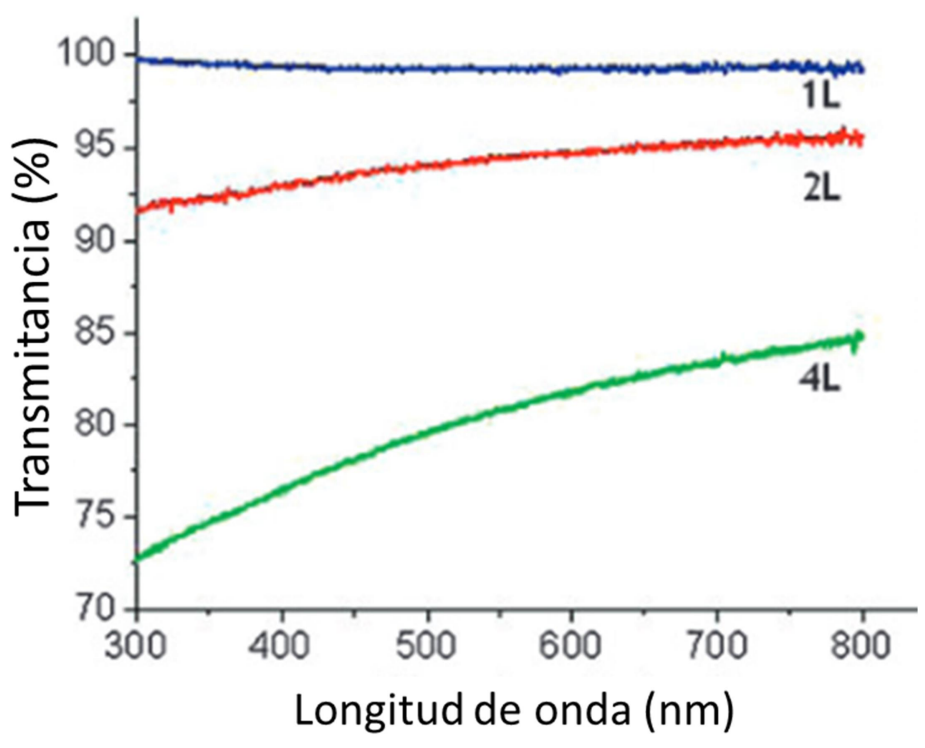

Figura 1.6. Espectros de transmitancia de una única capa de grafeno (en azul), de dos capas de grafeno (en rojo), y de cuatro capas de grafeno (en verde).

Además del grafeno, existen una serie de materiales relacionados que no poseen la estructura ideal perfecta del grafeno obtenido por exfoliación del grafito pirolítico. Así, el grafeno puede contener defectos en su estructura. Entre estos defectos cabe destacar la presencia de anillos de 5 o 7 miembros, así como la existencia de alguna vacante de un carbono o incluso de más de un átomo de carbono, llegando a formar huecos en la lámina de grafeno. ${ }^{73}$ Otro tipo de defectos muy habituales también en la lámina de grafeno es la presencia de heteroátomos, siendo el oxígeno y, en segundo lugar, el nitrógeno, los más comunes. ${ }^{73}$

La presencia de estos defectos influye, obviamente, en las propiedades optoelectrónicas y mecánicas del grafeno, generalmente reduciendo los valores tan elevados que se determinan en el material sin defectos. Es de especial importancia en esta tesis doctoral el hecho de que esos defectos convierten el grafeno de un material con un ancho de banda nulo a materiales semiconductores con un ancho de banda distinto de cero. Esto se traduce en espectroscopía UV-Vis en la aparición de una banda de absorción, generalmente en el UV, extendiéndose hasta la zona visible debido a transiciones electrónicas entre los orbitales frontera del 
material con defectos. ${ }^{100}$ Así, mientras el grafeno ideal no presenta bandas de absorción, y tal como se ha indicado es transparente en toda la región UV-Vis, los defectos pueden generar una banda de absorción, permitiendo por tanto la generación de estados excitados en estos grafenos defectuosos e induciendo un comportamiento de tipo semiconductor. La figura 1.7 muestra los espectros de absorción UV-Vis de algunos de estos materiales constituidos por grafenos imperfectos. ${ }^{101}$

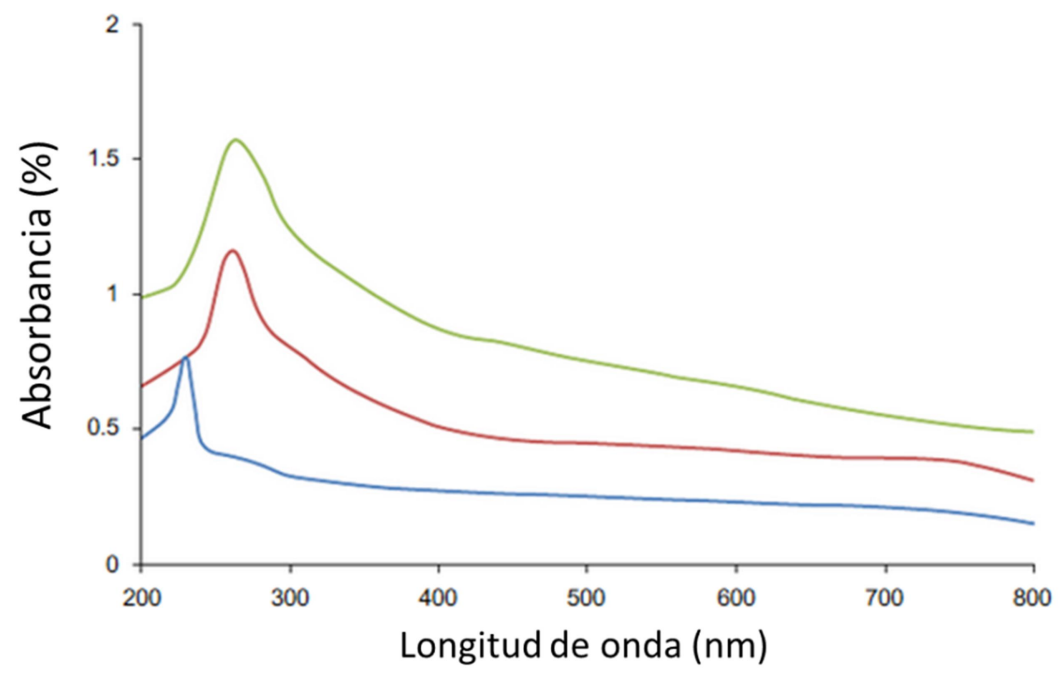

Figura 1.7. Espectros de absorbancia UV-Vis del óxido de grafeno (en azul), y de dos muestras de óxido de grafeno reducido con diferente grado de defectos en su estructura (en rojo, parcialmente reducido; en verde, mayormente reducido).

Estas propiedades ópticas y especialmente el comportamiento semiconductor serán de relevancia en los capítulos 6 y 7 de la presente tesis doctoral, cuando se presenten los resultados del grafeno como fotocatalizador.

Otra propiedad, relacionada también con la fotocatálisis, que se produce al generar defectos es la actividad catalítica en el grafeno. Así, los defectos pueden actuar como centros catalíticos, adsorbiendo sustratos o reactivos, interaccionando con ellos y de esta manera activándolos, haciendo posible mecanismos de reacción que conducen finalmente a productos. La figura 1.8 ilustra diferentes tipos de centros activos que 
pueden estar presentes en grafenos imperfectos y que se han propuesto como centros catalíticos en reacciones de carbocatálisis. ${ }^{73}$

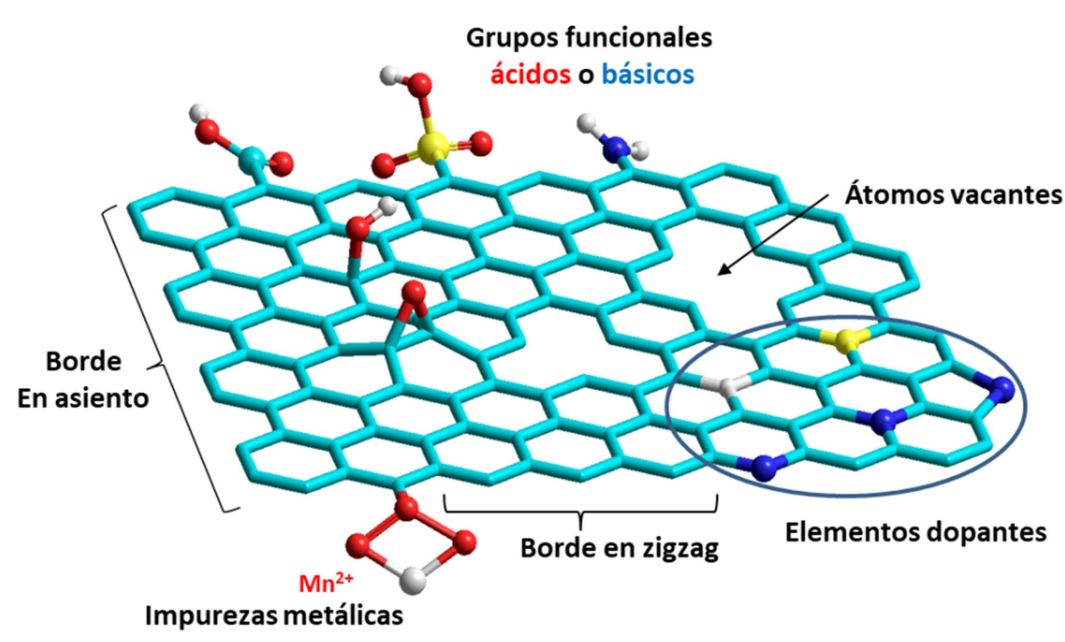

Figura 1.8. Estructura de un grafeno ilustrando los diferentes tipos de defectos que pueden estar presentes en la lámina de carbono y que pueden actuar como centros activos.

De entre ellos, los que son especialmente relevantes en la presente tesis doctoral son las funciones oxigenadas y especialmente los que poseen estructuras del tipo quinona e hidroquinona. Las quinonas e hidroquinonas son organocatalizadores bien conocidos que pueden participar en reacciones redox. ${ }^{102} \mathrm{Al}$ estar presente estas estructuras en el grafeno imperfecto, también este tipo de materiales puede promover reacciones redox, siendo de especial interés la reacción de Fenton que ya ha sido presentada en esta introducción.

A continuación, por ser de interés en la presente tesis doctoral se comentarán brevemente las formas de preparación de grafeno y las técnicas de caracterización específicas para este tipo de materiales. De especial importancia en nuestro caso es la descripción de las formas de preparación pirolíticas desarrolladas por nuestro grupo y que han sido empleadas en la presente tesis doctoral para la preparación de los materiales que han sido objeto de estudio. 


\subsection{Preparación de grafenos}

Existen dos estrategias generales denominadas como "bottom up",103-107 o "top down" (de abajo arriba o de arriba abajo) para la preparación de grafenos. Desde el punto de vista de la preparación a escala de gramos de estos materiales las técnicas de top down han sido las de mayor aplicación. ${ }^{85,108} \mathrm{El}$ esquema 1.5 resume las diferentes formas de obtención del grafeno.
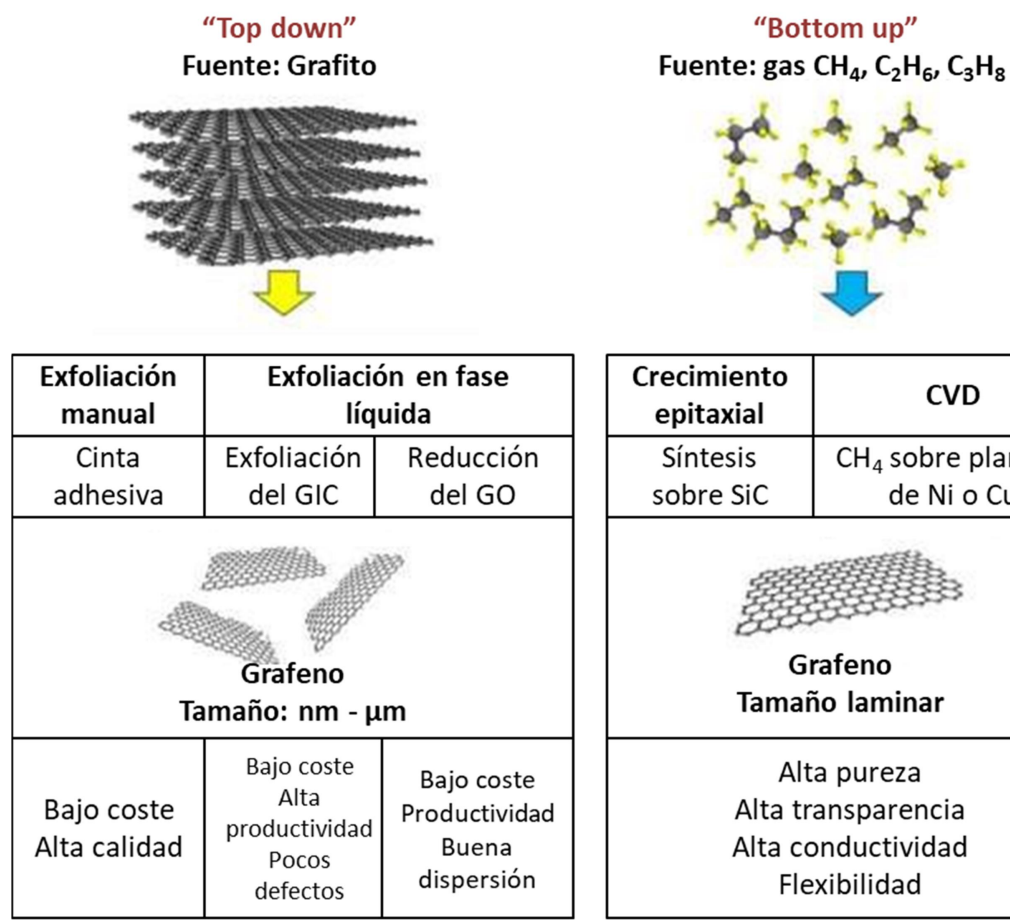

\begin{tabular}{|c|c|}
\hline $\begin{array}{l}\text { Crecimiento } \\
\text { epitaxial }\end{array}$ & CVD \\
\hline $\begin{array}{l}\text { Síntesis } \\
\text { sobre SiC }\end{array}$ & $\begin{array}{c}\mathrm{CH}_{4} \text { sobre plantilla } \\
\text { de } \mathrm{Ni} \text { o } \mathrm{Cu}\end{array}$ \\
\hline \multicolumn{2}{|c|}{$\begin{array}{c}\text { Grafeno } \\
\text { Tamaño laminar }\end{array}$} \\
\hline $\begin{array}{r}\text { A } \\
\text { Alta } \\
\text { Alta } \\
\text { F }\end{array}$ & $\begin{array}{l}\text { pureza } \\
\text { nsparencia } \\
\text { iductividad } \\
\text { ibilidad }\end{array}$ \\
\hline
\end{tabular}

Esquema 1.5. Dos aproximaciones complementarias para la síntesis y producción de grafeno.

En las estrategias bottom up, se parte de moléculas orgánicas con estructuras bien definidas y mediante reacciones de ciclo adición se van ensamblando estas moléculas para obtener entidades con un mayor número de átomos y eventualmente con un número indefinido de átomos. Esta estrategia ha sido desarrollada fundamentalmente por el grupo del 
profesor Klaus Müllen y la figura 1.9 muestra un ejemplo de la formación de estructuras grafénicas mediante síntesis orgánica. ${ }^{107}$

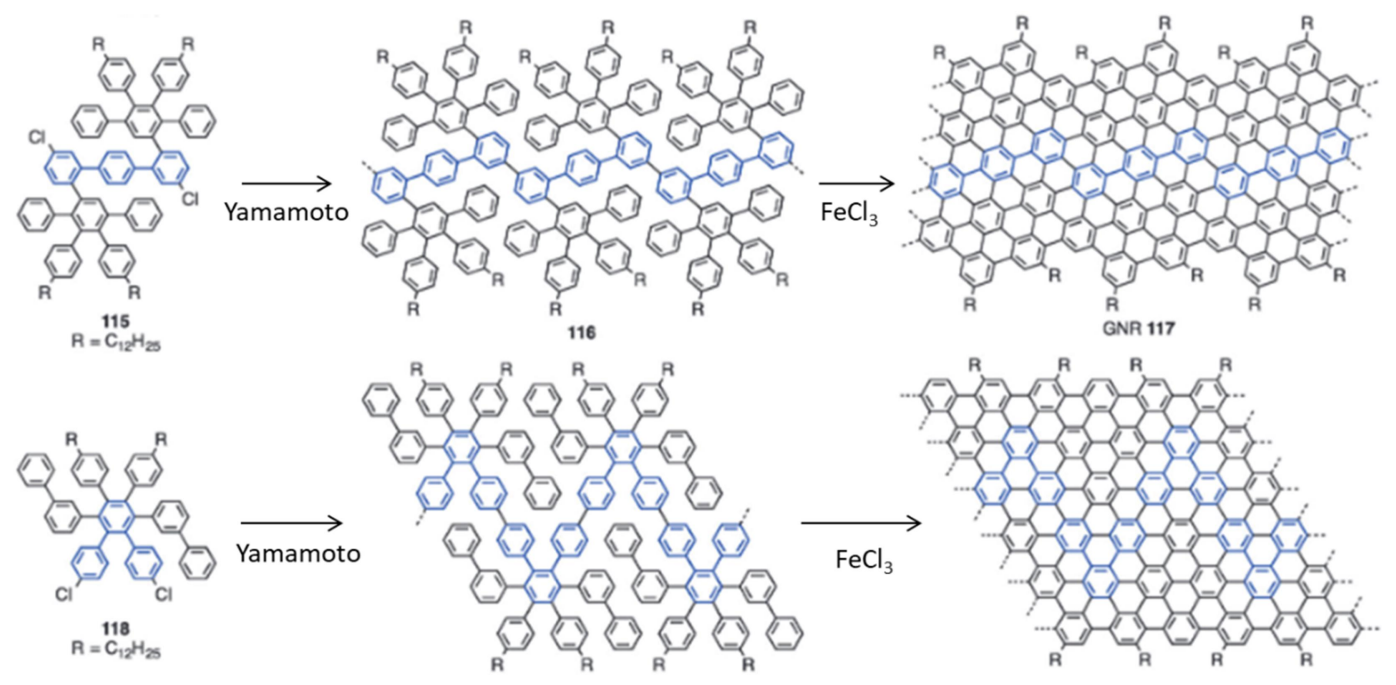

Figura 1.9. Ilustración del crecimiento de la lámina de grafeno mediante los procesos de bottom up. ${ }^{107}$

La gran ventaja de la técnica bottom up es el empleo de reacciones de síntesis orgánica en la construcción del grafeno. Sin embargo, muchas de estas reacciones orgánicas requieren el empleo de catalizadores, gran número de ellos metálicos, y especialmente paladio, que finalmente pueden resultar adsorbidos en el grafeno resultante. Además, otro problema es la posibilidad de que se generen gran cantidad defectos consistentes en muchos casos en grupos funcionales presentes en los precursores y que no han reaccionado completamente durante el proceso de formación del grafeno.

La forma de preparación de grafeno más empleada para aplicaciones en microelectrónica se basa en la patente de Samsung de preparación de grafeno por condensación deshidrogenante de compuestos orgánicos, fundamentalmente hidrocarburos, sobre superficies metálicas a altas temperaturas. Esta técnica se denomina "Chemical Vapor Deposition (CVD)" y consiste en el tratamiento de metano $\mathrm{u}$ otros hidrocarburos en presencia de hidrógeno sobre superficies metálicas, generalmente cobre y níquel a temperaturas de $1500{ }^{\circ} \mathrm{C}$ o superior..$^{109-112}$ Estos metales poseen actividad catalítica deshidrogenante y a estas 
temperaturas tan elevadas descomponen el metano dando lugar a átomos de carbono que se depositan sobre el metal junto con evolución de hidrógeno. Estos átomos de carbono van uniéndose siguiendo la estructura cristalina definida por el cobre o por el níquel. Conviene indicar que tanto el cobre como el níquel no forman carburos metálicos y por tanto no reaccionan con el carbono, y, especialmente, el cobre posee una baja capacidad de disolver carbono, por lo que estos átomos se depositan sobre la superficie y no penetran hacia el interior del metal. Al ir colocándose sobre la superficie, cada átomo metálico se rodea de una corona de hasta seis átomos de carbono con disposición hexagonal y que finalmente condensarán en la lámina de grafeno. La figura 1.10 ilustra el mecanismo aceptado para la formación de grafeno mediante esta técnica.

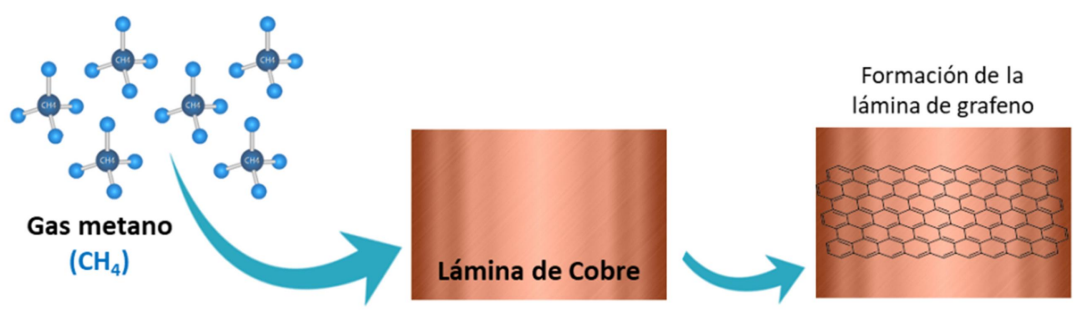

Figura 1.10. Ilustración de la formación de una lámina de grafeno sobre una superficie de cobre por deposición del carbono mediante la técnica de CVD.

Un inconveniente de la técnica de CVD en la formación de grafeno es que el tiempo requerido es elevado, la cantidad de material obtenido es muy baja y además requiere de dispositivos de elevado coste dedicados totalmente a la preparación del material, que también requiere de personal adecuado para su manejo. Sin embargo, el grafeno que se obtiene mediante CVD puede llegar a ser de alta calidad al no contener heteroátomos, particularmente oxígeno, al limitar el número de defectos debido al ordenamiento hexagonal, por lo que hace que la conductividad eléctrica y movilidad en este tipo de grafeno sea próxima a la esperable para el grafeno ideal. Por otra parte, los tamaños de lámina que se obtienen con la técnica top down son siempre nanométricos y no llegan a dimensiones de micras. 
Frente a las técnicas bottom up, la ventaja de las técnicas top down es que muchas de ellas parten de materiales accesibles de los que se disponen en grandes cantidades y, de esta manera, sin el empleo de catalizadores, se pueden llegar a obtener gramos de grafeno. De hecho, el desarrollo de la carbocatálisis y el papel predominante del grafeno en esta área deriva en gran medida de la disponibilidad de cantidades suficientes de grafeno y de la posibilidad de modificar la estructura del mismo. Ello se refleja también en los costes de preparación de grafeno que en muchos casos es muy inferior al de fulerenos y otras formas alotrópicas del carbono. El esquema 1.6 resume las formas de preparación del grafeno basadas en la estrategia top down. De entre ellas, las más ampliamente usadas son las que parten de grafito, ${ }^{113}$ material que, como ya hemos indicado, contiene grafeno en su estructura, procediéndose a la extracción del grafeno de la misma. De entre estas técnicas, la exfoliación manual del grafito, permite obtener muestras de grafeno de alta calidad, pero la cantidad disponible de este tipo de grafenos es muy baja, limitándose su uso solamente a estudio para determinar propiedades físicas de este material. $^{78}$

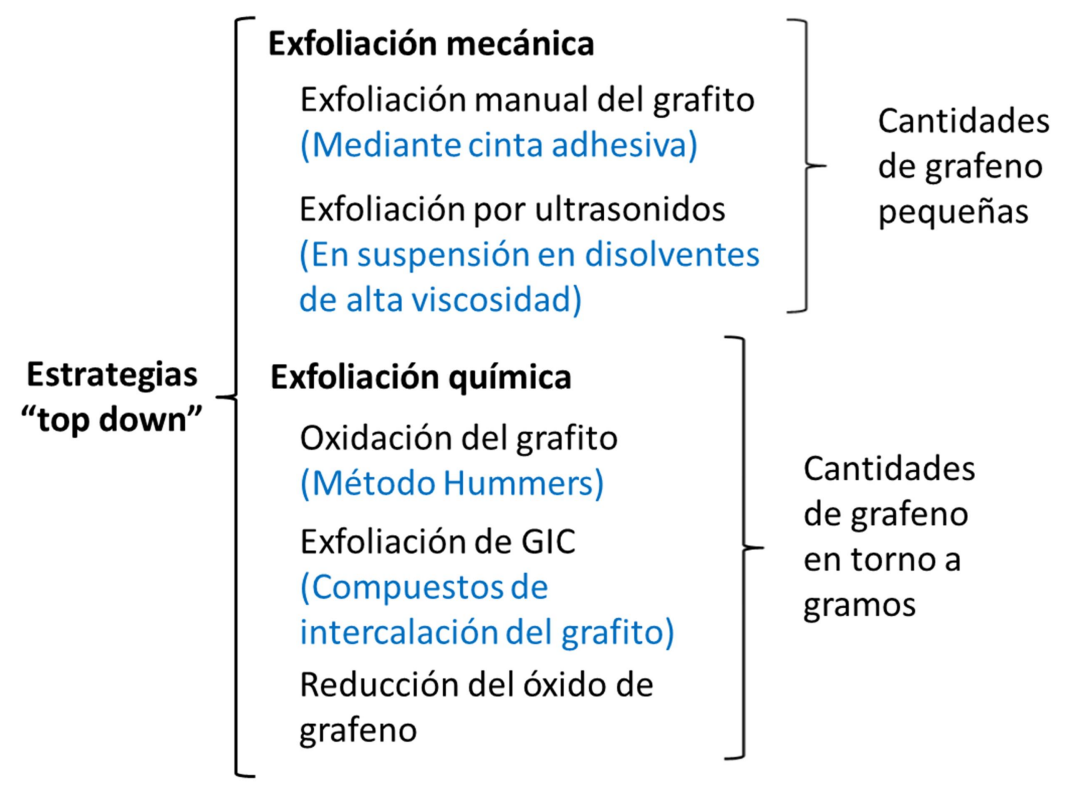

Esquema 1.6. Diferentes formas de obtención de grafeno mediante las estrategias top down. 
Frente a la exfoliación manual, otro procedimiento de separación de láminas de grafeno en el grafito consiste en el tratamiento del grafito con ultrasonidos en disolventes generalmente muy viscosos y de elevado peso molecular y puntos de ebullición elevados, que, por interacción fuerte con las láminas, producen la deslaminación en el grafito. Entre los disolventes que han sido empleados para este propósito se incluyen líquidos iónicos derivados del imidazolio, $n$-metil pirrolidona, sulfóxidos, etc. ${ }^{14,115}$ Sin embargo, este procedimiento presenta grandes inconvenientes, entre ellos el empleo de disolventes tóxicos y difíciles de separar tras la exfoliación. Otro factor limitante son los bajos rendimientos que se obtienen en este tipo de exfoliación. Se entiende por rendimiento el porcentaje del peso inicial de grafito que sufre exfoliación y que en este tipo de técnicas es frecuentemente inferior al $0.1 \%$ del peso inicial. $^{73}$

Debido a estos bajos rendimientos, entre las técnicas más preferidas para llevar a cabo la exfoliación del grafito en escala de gramos se encuentran los tratamientos químicos y, en particular, la oxidación química profunda del grafito a óxido de grafito y que fue descrita a final de los años cincuenta por Hummers y Offerman, ${ }^{108}$ seguido de exfoliación del óxido de grafito. En efecto, puesto que la exfoliación viene limitada por la fuerte interacción $\pi$ - $\pi$ que establecen las láminas de grafeno, y por su máximo empaquetamiento, es posible proceder a la exfoliación con eficiencias prácticamente completas si se eliminan estos obstáculos. Esto se consigue con la oxidación química del grafito, que transforma la lámina de grafeno en óxido de grafeno, donde la conjugación $\pi$ se encuentra prácticamente eliminada y el contenido en oxígeno es comparable o incluso superior al de carbono. Una estructura de óxido de grafeno compatible con los datos espectroscópicos ha sido la propuesta por Klinowski y que se muestra en la figura 1.11. ${ }^{116}$ 


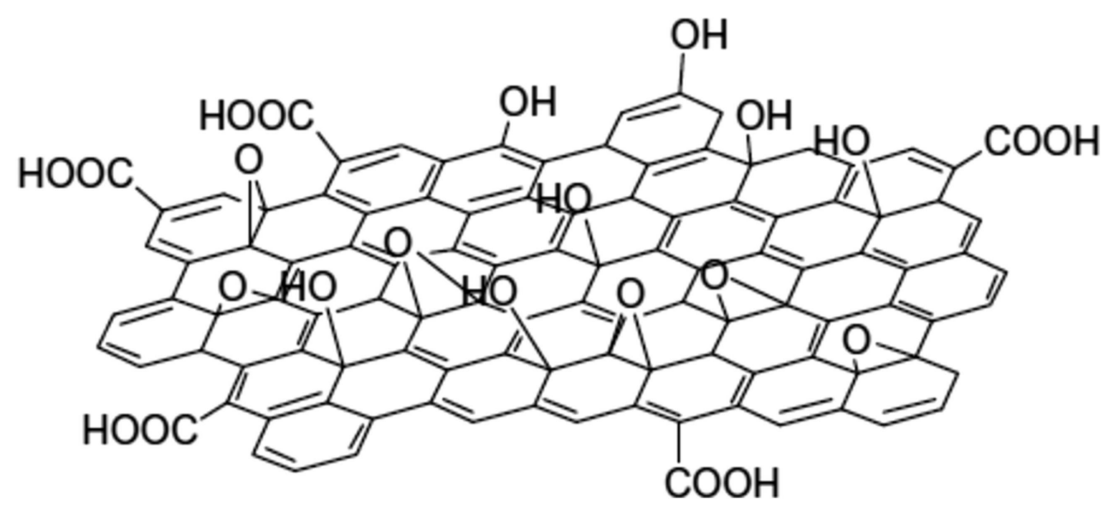

Figura 1.11. Estructura química del óxido de grafeno en la que se muestra los diferentes tipos de grupos funcionales oxigenados presentes en la lámina de carbono y que es compatible con los datos analíticos y espectros ópticos para este material.

Como se ve en esta estructura, la lámina de grafeno sufre oxidación formando grupos funcionales oxigenados a lo largo de toda la lámina que pueden ser grupos epóxido, hidroxilo, carbonilo y en la periferia de la lámina ácidos carboxílicos. El grado de oxidación es tan severo que la relación atómica oxígeno/carbono puede llegar a ser incluso superior a la unidad. Esta oxidación se consigue con agentes químicos fuertemente oxidantes, siendo el preferido una mezcla de ácido sulfúrico y nítrico conteniendo elevadas concentraciones de permanganato. ${ }^{108}$ En estas condiciones, el grafito sufre una transformación casi cuantitativa en óxido de grafito. Una consecuencia adicional de la oxidación es que los espesores de las láminas aumentan, aumentando el espaciado interlaminar que pasa a ser de $0.34 \mathrm{~nm}$ en el grafito a algo más del doble $(0.69 \mathrm{~nm})$ en el óxido de grafito. ${ }^{17}$ Es sabido que las fuerzas intermoleculares muestran una elevada dependencia con la distancia, disminuyendo exponencialmente en una potencia de dos o superior cuando aumenta ésta. Por consiguiente, las láminas de óxido de grafeno presentes en el óxido de grafito interaccionan mucho más débilmente que las de grafeno en el grafito, debido a la no existencia de interacciones $\pi-\pi$ y a la mayor distancia interplanar. Más aún, en medios acuosos, donde los ácidos carboxílicos se encuentran parcialmente disociados, existe una repulsión coulómbica entre las láminas. Por estos motivos, en contraste con el grafito, el óxido de grafito sufre una exfoliación casi cuantitativa cuando 
este material es sometido a ondas de presión intensas ocasionadas por una fuente de ultrasonidos en medio acuoso.

El óxido de grafeno puede ser, una vez exfoliado, reducido parcialmente para dar lugar a un material grafénico, que es habitualmente descrito como óxido de grafeno reducido ( $\mathrm{rGO}$, de sus siglas en inglés, reduced Graphene Oxide). El uso de este término alude a que el material grafénico obtenido de esta manera posee una cantidad de defectos estructurales elevada y que, por consiguiente, las propiedades electrónicas y ópticas son significativamente diferentes de las que presenta el grafeno ideal. En particular, el óxido de grafeno reducido posee una cantidad de oxígeno residual que puede llegar a ser tan elevada como el $20 \%$ en peso y que en cualquier caso es superior al $10 \%{ }^{113,118,119}$ Este oxígeno se encuentra covalentemente unido al carbono formando grupos carbonilo, hidroxilo y ácidos carboxílicos, principalmente. Otros defectos estructurales consisten en vacantes de carbono e incluso agujeros en la lámina que aparecen como consecuencia de la evolución de $\mathrm{CO}_{2}, \mathrm{CO}$ y otros gases en el proceso de reducción del óxido de grafeno. El esquema 1.7 ilustra el proceso de obtención de $\mathrm{rGO}$ a partir de grafito, el cual puede llevarse a cabo en escala de gramos permitiendo, de esta manera, la obtención de grandes cantidades de rGO. 


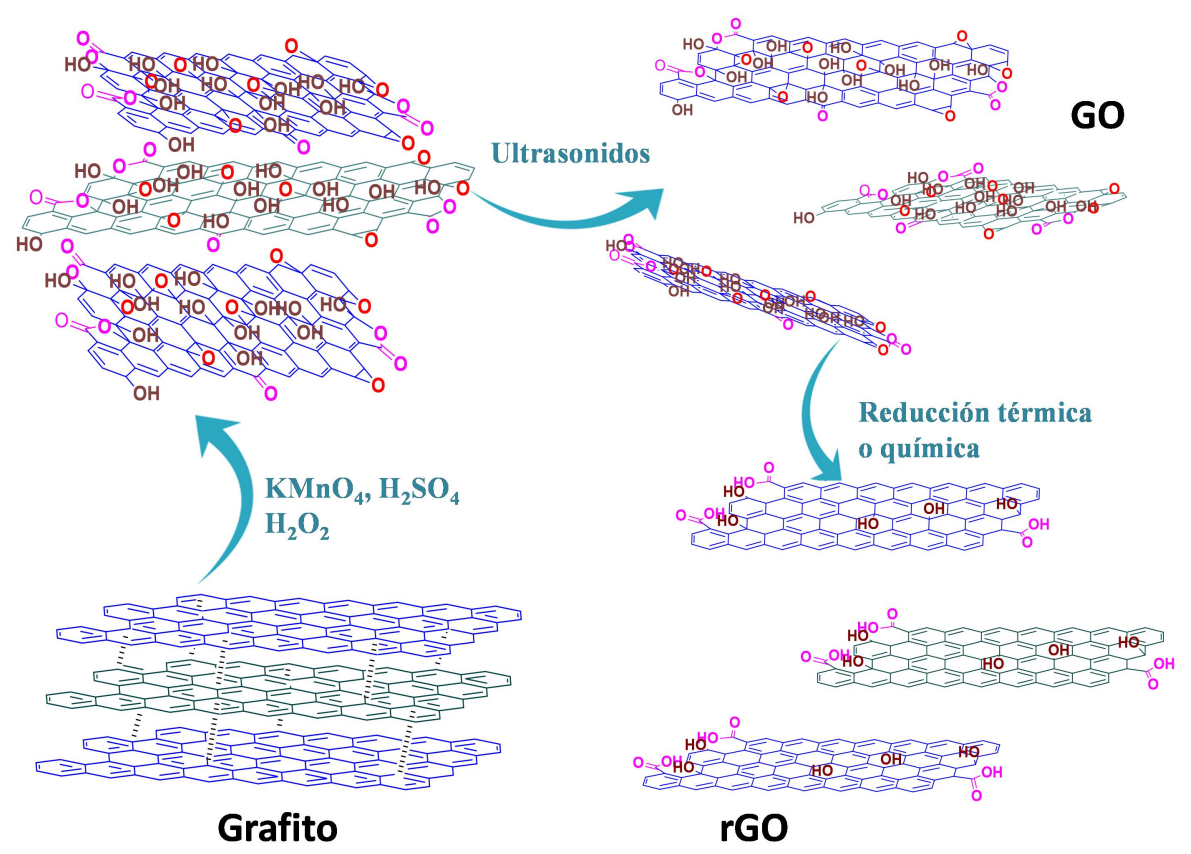

Esquema 1.7. Esquema de la producción de óxido de grafeno reducido a partir de grafito utilizando el método de Hummers seguido de exfoliación.

Entre los métodos de formación del rGO algunos emplean agentes químicos reductores, siendo el más común la hidracina, pero también otros como los hidruros metálicos. El esquema 1.8 ilustra el mecanismo más ampliamente aceptado de reducción de óxido de grafeno a óxido de grafeno reducido mediante el uso de hidracina. 


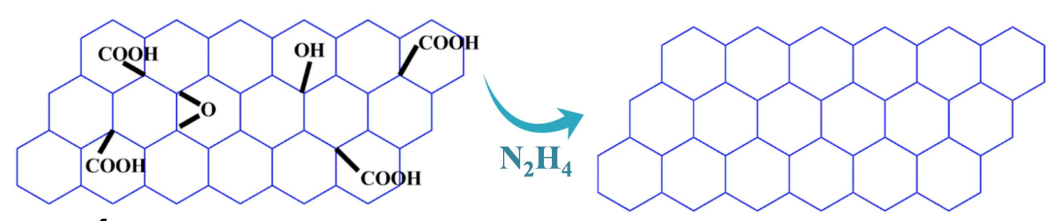

Óxido de grafeno
Grafeno

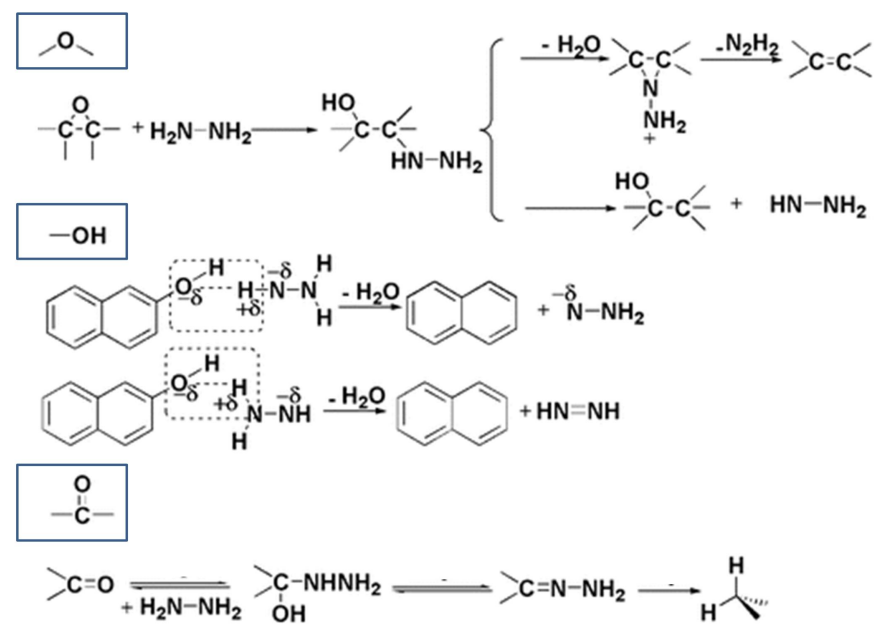

Esquema 1.8. Preparación de óxido de grafeno reducido a partir de grafeno mediante la reducción por hidracina.

En este proceso la hidracina puede también ocasionar la introducción de defectos que corresponden a un porcentaje, en torno al $2 \%$ o inferior, de grupos funcionales nitrogenados. Una de las ventajas de la reducción química es que transcurre a temperatura ambiente y es rápida, aunque puede contaminar la muestra de grafeno con especies químicas no deseadas.

Otras formas de reducción que han sido también ampliamente utilizadas consisten en tratamientos físicos o químico-físicos tales como el calentamiento a temperaturas superiores a $300{ }^{\circ} \mathrm{C}$ en diferentes entornos y el tratamiento hidrotermal del óxido de grafeno. ${ }^{119}$ Este último proceso tiene la ventaja de que puede llevarse a cabo directamente con la dispersión resultante del tratamiento por ultrasonidos del óxido de grafito. La reducción hidrotermal se lleva a cabo en autoclaves a temperaturas en torno a $150{ }^{\circ} \mathrm{C}$ durante varias horas, produciéndose una evolución de gases, fundamentalmente $\mathrm{CO}_{2}$, procedente del óxido de grafito y que 
originan la reducción de éste. Mientras que el óxido de grafeno es fácilmente dispersable en agua debido a su elevada hidrofilicidad, su reducción y transformación en óxido de grafeno reducido origina que durante el proceso este material se separe de la fase acuosa debido a su mayor hidrofobicidad y su considerablemente menor afinidad por el agua. Así, mientras es probable preparar dispersiones de $10 \mathrm{mg} \mathrm{mL}^{-1}$ de óxido de grafeno en agua, las concentraciones másicas máximas que pueden conseguirse de óxido de grafeno reducido en agua son inferiores en más de un orden de magnitud, siendo habituales valores de $0.1 \mathrm{mg} \mathrm{mL}^{-1}{ }^{120}$

Frente a estos métodos de preparación de grafenos, nuestro grupo de investigación describió un método novedoso que, dada la importancia en esta tesis doctoral, se describe a continuación.

\subsection{Pirólisis de polisacáridos filmogénicos naturales}

La mayoría de compuestos moleculares no pueden someterse a procesos de pirólisis sin que descompongan en compuestos volátiles que son arrastrados por el flujo de gas inerte en la pirólisis o por los sistemas de vacío empleados. Una situación similar ocurre en gran número de polímeros sintéticos que a temperaturas elevadas sufren roturas de enlace C-C y C-heteroátomo para dar lugar a compuestos de bajo peso molecular que se evapora en el proceso, no obteniéndose residuos apreciables en la pirólisis.

Frente a este comportamiento de moléculas y de algunos polímeros, existe otro tipo de polímeros que a temperaturas elevadas y una atmósfera inerte dan lugar a su carbonización formándose residuos con elevado contenido en carbono. Entre ellos, es conocido que muchos carbohidratos sufren deshidratación térmica dando lugar a residuos carbonosos, proceso que es responsable del nombre de carbohidratos con el que son generalmente descritos. Así, era conocido que polisacáridos naturales tales como alginato y quitosano sufren al pirolizarse una transformación a residuos carbonosos. Estos residuos carbonosos eran conocidos con anterioridad y se describen con el término general de "residuos grafíticos turboestráticos", 99,121 indicando que su estructura tiende a ser la de un grafito con una baja cristalinidad debido a que las láminas (estratos) estaban desorganizadas (turbo). La originalidad de nuestro grupo fue doble. Por un lado, demostramos que la exfoliación de 
estos residuos grafíticos turboestráticos, por tratamiento en ultrasonidos, daba lugar, con un rendimiento superior al $70 \%$, a su transformación en materiales grafénicos conteniendo defectos. Este hecho deriva de la falta de cristalinidad del residuo grafítico que, por tanto, hace que no presente los problemas comentados anteriormente para el caso del grafito pirolítico con la alta cristalinidad y de imposible exfoliación por ultrasonidos.

Por otra parte, muchos de estos polímeros naturales son el constituyente habitual de las pieles de insectos y crustáceos. Este hecho se debe a que durante miles de años de evolución, la naturaleza ha seleccionado estos polímeros naturales como los más adecuados para recubrir superficies debido a su casi nula rugosidad y a la facilidad para formar películas de dimensiones indefinidas y sin defectos, sin que sean susceptibles de rotura.

Así, nuestro grupo preparó películas sobre sustratos arbitrarios de estos polímeros naturales filmogénicos mediante diversas técnicas, por ejemplo, el recubrimiento por giro. De esta manera se pueden obtener películas de espesores inferiores a $50 \mathrm{~nm}$ y muy habitualmente inferiores a $20 \mathrm{~nm}$, habiéndose conseguido incluso espesores de unos pocos $\mathrm{nm}$ sin que estas películas presenten agujeros, grietas $\mathrm{u}$ otro tipo de imperfecciones. Además, la rugosidad de estas películas es subnanométrica. La figura 1.12 presenta ejemplos de imágenes obtenidas por perfilometría óptica mostrando vistas y determinando espesores de estas películas de polisacáridos filmogénicos. 

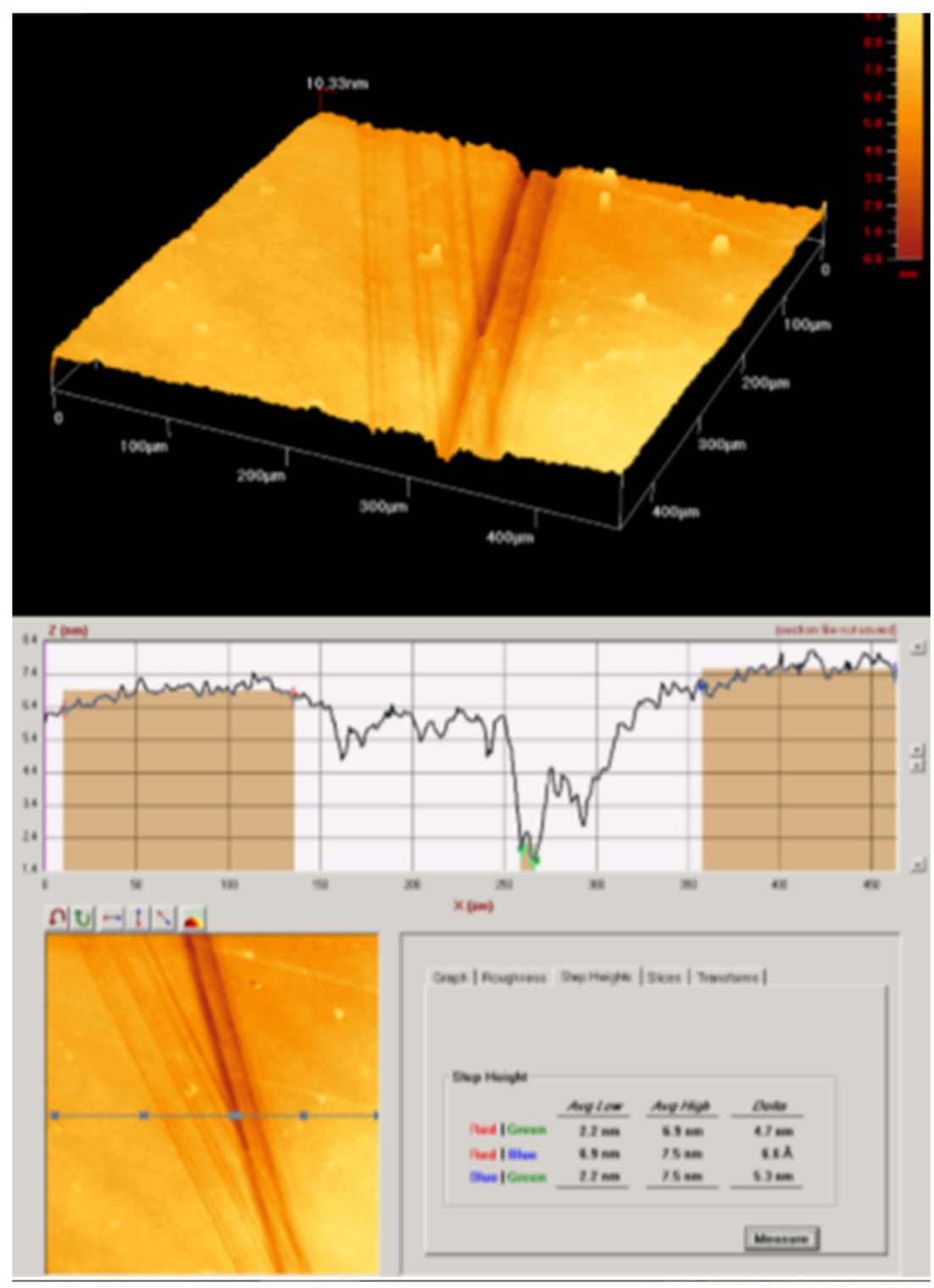

Figura 1.12. Perfilometría óptica de una película de quitosano de $5 \mathrm{~nm}$ de espesor. $^{96}$ 
Cuando se somete a pirólisis estas películas se produce la grafitización de las mismas, observándose una disminución en el espesor de las películas por un factor de entre 5 y 10 dependiendo del espesor. ${ }^{96}$ Esta disminución de espesor deriva de la transformación de estos biopolímeros en láminas de grafeno y del empaquetamiento de estas láminas. Así, tal como se observa en la figura 1.13, la pirólisis de películas de polisacárido en torno a $4 \mathrm{~nm}$ da lugar a grafeno monolámina sobre el sustrato elegido. Es posible controlar el número de láminas de grafeno formadas mediante el control del espesor de la película del precursor, siendo posible preparar mediante esta técnica películas de grafeno de una o varias capas de grafeno. 
a)
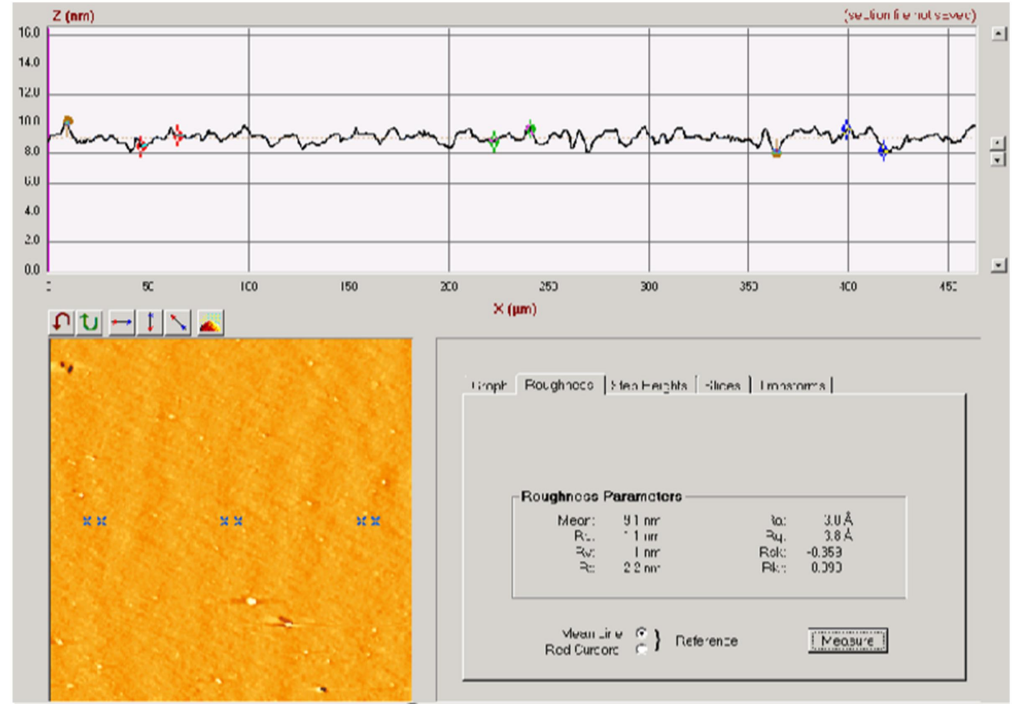

$x(u m)$

b)

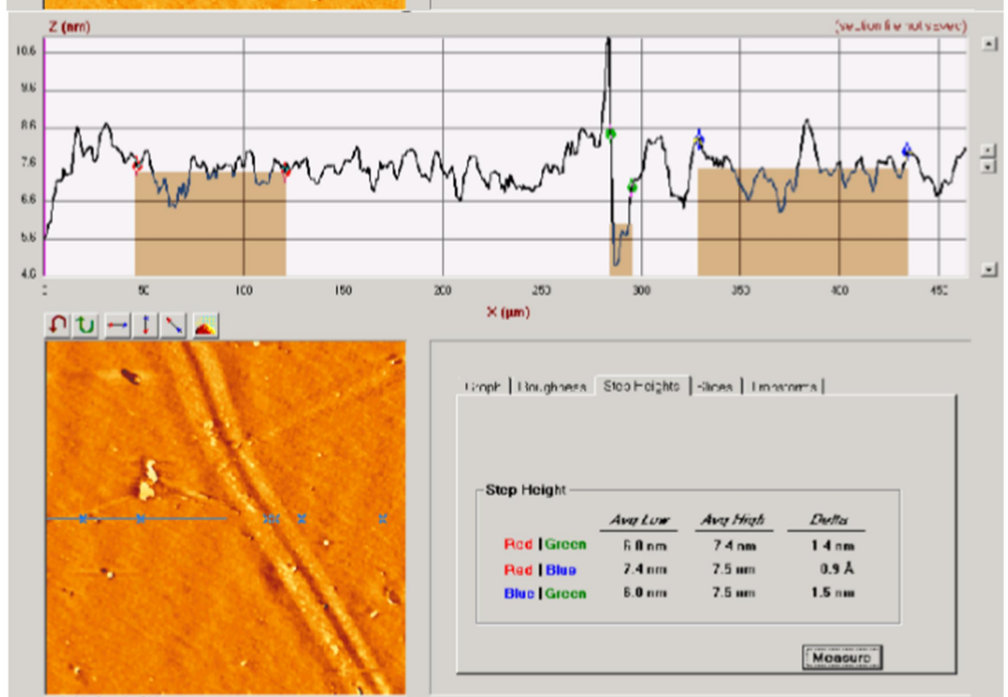

Figura 1.13. Perfilometría óptica de a) una lámina de grafeno obtenida por pirólisis de una película de quitosano de $5 \mathrm{~nm}$ de espesor, y b) dos láminas de grafeno obtenidas por pirólisis de una película de quitosano de $10 \mathrm{~nm}$ de espesor. $^{96}$

Entre los polisacáridos naturales filmogénicos, nuestro grupo estudió principalmente el alginato, que se extrae fundamentalmente del alga marrón (sargazo), el quitosano, que se obtiene de la piel de crustáceos y es el principal desecho de la industria pesquera, y 
carragenanos procedentes de algas. Estos polisacáridos naturales presentan estructuras en hebras sin ramificar con uniones glucosídicas $\alpha$ 1-4, diferenciándose en los monosacáridos constitutivos. La figura 1.14 presenta la estructura de algunos de estos polisacáridos naturales.

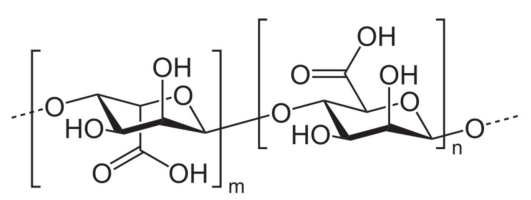

Alginato

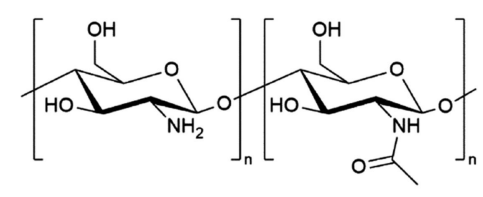

Quitosano

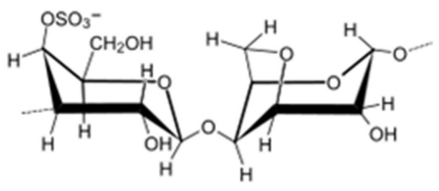

K-Carragenano

Figura 1.14. Ilustración de las estructuras químicas de los tres biopolímeros filmogénicos más estudiados por nuestro grupo para la preparación de grafeno.

Entre las numerosas ventajas de este método de pirólisis de biopolímeros considerados desechos, las más importantes son la valorización de residuos, la posibilidad de preparar muestras en cantidades de multigramo, la posibilidad de recubrir superficies arbitrarias tales como cerámicas, vidrios, metales, etc., y la posibilidad de preparación de grafenos conteniendo heteroátomos y heterouniones de grafenos con otros elementos. El esquema 1.9 resume las ventajas competitivas que posee el método de pirólisis de biopolímeros naturales en la preparación de grafenos. 
Ventajas competitivas de la pirólisis de biopolímeros naturales

- Valorización de residuos: Eliminación de desechos de biomasa, como las algas o la piel de los crustáceos.

- Facilidad de exfoliación y alto rendimiento: Capacidad de producción a escala de gramos, con un alto rendimiento y gran capacidad de exfoliación.

- Capacidad de introducir elementos dopantes: Introducción de heteroátomos en función de la naturaleza del biopolímero y la incorporación de reactivos adicionales al proceso.

- Capacidad de controlar la cantidad de dopado: Mediante la temperatura de pirólisis y la cantidad y composición de reactivos añadidos al proceso.

- Capacidad de recubrimiento de superficies en forma de película: Mediante la pirólisis sobre materiales como la cerámica o el cuarzo.

Esquema 1.9. Enumeración de las principales ventajas de la obtención de grafeno por la pirólisis de biopolímeros naturales filmogénicos.

Así, el quitosano es un polisacárido derivado de la glucosamina, el cual contiene un porcentaje en torno al $15 \%$ de nitrógeno. La pirólisis de este polisacárido da lugar a un grafeno dopado con nitrógeno. ${ }^{122} \mathrm{El}$ nitrógeno, juntamente con el boro y el oxígeno, se encuentra entre los elementos que han sido utilizados más ampliamente para alterar las propiedades del grafeno mediante dopaje. Empleando el quitosano como fuente natural de carbono y nitrógeno, los análisis químicos revelan que el grafeno resultante contiene un porcentaje de nitrógeno en torno al $7 \%$ o inferior dependiendo de las condiciones de pirólisis. ${ }^{122}$ De forma similar, el $\kappa$-carragenano, que contiene una elevada densidad de glucosildisulfatos, cuando se piroliza origina un grafeno que contiene un porcentaje de azufre del $4 \%$ o inferior. ${ }^{123}$

A parte de la presencia natural de heteroátomos en el precursor, y considerando la gran reactividad de los polisacáridos y particularmente su tendencia a formar ésteres, es posible introducir también otros heteroátomos en el grafeno resultante, incluso cuando éstos no se encuentran presentes en el polímero de forma natural. Es sobradamente conocido, como un ejemplo muy destacado, que los ácidos nucleicos están constituidos por cadenas donde los grupos fosfato unen dos anillos 
de ribosa o desoxirribosa. Así, mediante esterificación con ácidos inorgánicos como el fosfórico, el bórico, o el silícico, es posible obtener derivados de estos polisacáridos que, al ser sometidos a pirólisis, dan lugar a grafenos defectuosos conteniendo como agente dopante fosforo, ${ }^{124}$ boro ${ }^{122}$ y silicio, ${ }^{125,126}$ entre otros. Además si se parte de quitosano o de carragenano, que ya contienen de forma natural nitrógeno o azufre se pueden obtener de forma simple grafenos codopados con dos elementos diferentes. El esquema 1.10 ilustra la facilidad con la que es posible formar grafenos dopados en la pirólisis de biopolímeros naturales, y la tabla 1.1 muestra una lista de los grafenos dopados obtenidos de esta forma.

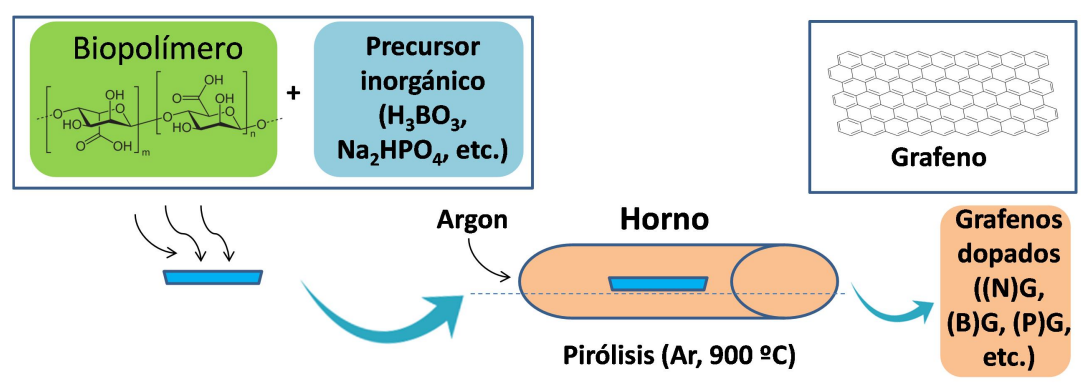

Esquema 1.10. Esquema de la producción de grafenos dopados a partir de la pirólisis de biopolímeros naturales modificados por esterificación con ácidos inorgánicos. 
Tabla 1.1. Lista de los grafenos obtenidos en función del biopolímero de partida y el ácido inorgánico añadido.

\begin{tabular}{|c|c|c|}
\hline $\begin{array}{l}\text { Biopolímero } \\
\text { natural }\end{array}$ & $\begin{array}{c}\text { Aditivo } \\
\text { (sal inorgánica) }\end{array}$ & Tipo de grafeno obtenido \\
\hline Alginato & --- & $\begin{array}{l}\text { Grafeno } \\
\text { G }\end{array}$ \\
\hline Alginato & $\mathrm{H}_{3} \mathrm{BO}_{3}$ & $\begin{array}{l}\text { Grafeno dopado con boro } \\
\text { (B)G }\end{array}$ \\
\hline Alginato & $\mathrm{Na}_{2} \mathrm{HPO}_{4}$ & $\begin{array}{l}\text { Grafeno dopado con fósforo } \\
\text { (P)G }\end{array}$ \\
\hline Quitosano & --- & $\begin{array}{l}\text { Grafeno dopado con nitrógeno } \\
\text { (N)G }\end{array}$ \\
\hline Quitosano & $\mathrm{HBO}_{3}$ & $\begin{array}{l}\text { Grafeno dopado con nitrógeno y boro } \\
\qquad(\mathbf{B}, \mathbf{N}) \mathrm{G}\end{array}$ \\
\hline Carragenano & --- & $\begin{array}{l}\text { Grafeno dopado con azufre } \\
\text { (S)G }\end{array}$ \\
\hline
\end{tabular}

Se ha ido mencionando en esta sección que los grafenos que se obtienen son defectuosos. Así, análisis químico de combustión revela que estos materiales contienen un porcentaje de oxígeno residual, que deriva del oxígeno que se encuentra en los precursores, y en éstos alcanza un porcentaje superior al 50\%. En el proceso de pirólisis, la evolución del agua y algún otro gas reduce este porcentaje considerablemente, pero aun así, dependiendo de las condiciones de pirólisis, es superior al $10 \%$. Además de grupos funcionales oxigenados, otros defectos son vacantes de átomos de carbono y huecos. ${ }^{127,128}$ Finalmente, aunque no es objeto de la presente tesis doctoral, la técnica de pirólisis de polisacáridos naturales ha sido adaptada para la preparación de uniones con nanopartículas metálicas $\mathrm{y}$ heterouniones con otros materiales 2D tales como heterouniones $\mathrm{BN}$-grafeno ${ }^{129,130}$ y $\mathrm{MoS}_{2}$-grafeno. ${ }^{131,132} \mathrm{La}$ figura 1.15 resume los procedimientos de formación de estos materiales híbridos de grafeno con otro componente. 

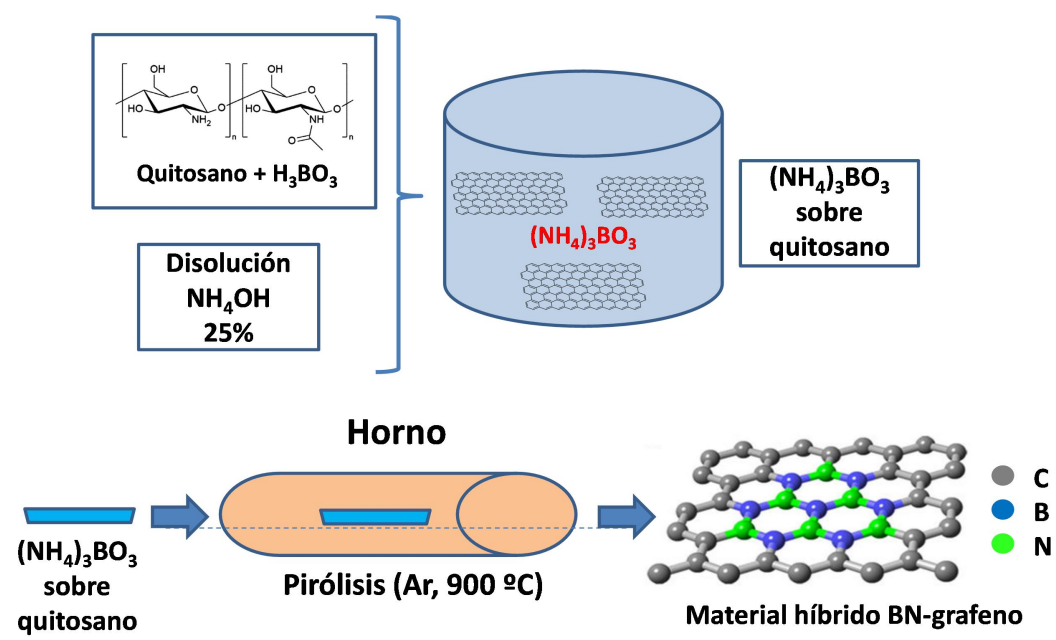

Figura 1.15. Proceso de producción de un material híbrido de grafeno y nitruro de boro (BN-grafeno). De forma análoga se obtendría un material híbrido de grafeno y disulfuro de molibdeno $\left(\mathrm{MoS}_{2}\right.$-grafeno) sustituyendo el quitosano por alginato y el $\mathrm{H}_{3} \mathrm{BO}_{3}$ por $\mathrm{H}_{2} \mathrm{MoS}_{4}$.

Las secciones anteriores relativas al grafeno han destacado convenientemente cuando estos grafenos son considerados en el estado del arte como defectuosos. A continuación se describirá brevemente las técnicas de caracterización más habituales que se utilizan para establecer la composición elemental, estructura y presencia de defectos en grafenos y materiales relacionados $2 \mathrm{D}$, y que son de interés en la presente tesis doctoral.

\subsection{Técnicas de caracterización de grafeno}

La composición química del grafeno puede determinarse mediante técnicas de análisis químico y, fundamentalmente, análisis de combustión. El análisis de combustión determina el porcentaje de carbono, hidrógeno, nitrógeno y azufre, estimándose el contenido en oxígeno de forma indirecta por diferencia.

La estructura laminar del grafeno se determina de forma inequívoca mediante técnicas microscópicas de transmisión. Dependiendo de la magnificación de la imagen, se puede obtener una vista de las láminas independientes caracterizadas por la presencia de arrugas $\mathrm{y}$ 
dobleces debido a la flexibilidad característica del grafeno. ${ }^{133}$ Aumentando la magnificación a escala de $5 \mathrm{~nm}$ o inferior es posible observar el alineamiento de los hexágonos en las láminas. Con esta magnificación, modelos de difracción de electrones muestran una disposición hexagonal. ${ }^{133}$ La figura 1.16 muestra un conjunto de imágenes de TEM y difracción de electrones para muestras similares a las estudiadas en la presente tesis doctoral.
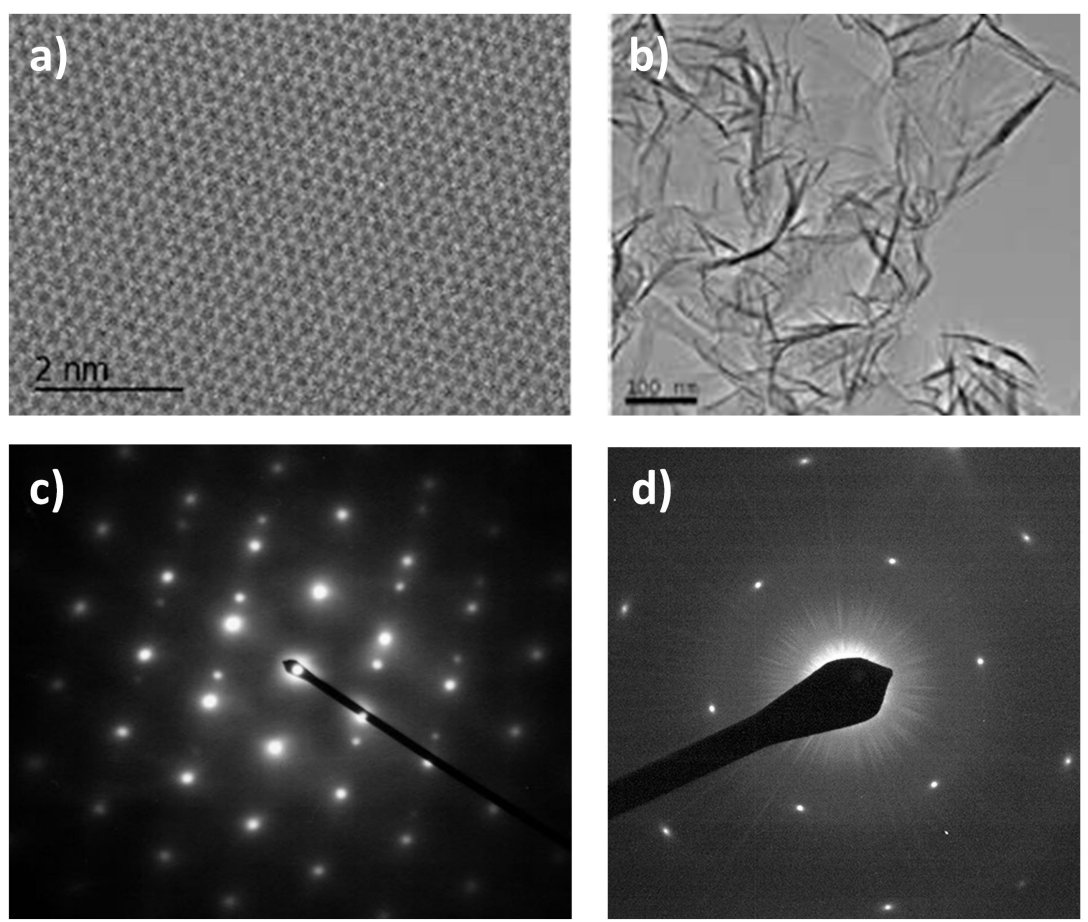

Figura 1.16. Imágenes de microscopía electrónica de transmisión de alta resolución $(\mathrm{a}, \mathrm{b})$ y de difracción de electrones $(\mathrm{c}, \mathrm{d})$ de una lámina de grafeno.

El espesor monoatómico o la composición de varias capas de grafeno puede ser establecida, además de por microscopía electrónica, mediante microscopia de fuerza atómica. Esta microscopía posee una resolución vertical subnanométrica y es posible, por tanto, determinar el número de capas presentes en una película de grafeno midiendo su espesor. ${ }^{134,135} \mathrm{La}$ figura 1.17 muestra imágenes frontales por AFM de muestras de grafeno similares a las empleadas en la presente tesis 
doctoral, mientras que el seguimiento del perfil de las mismas permite determinar la diferencia de altura desde el soporte a la lámina $\mathrm{y}$, de esta manera, establecer el número de capas.

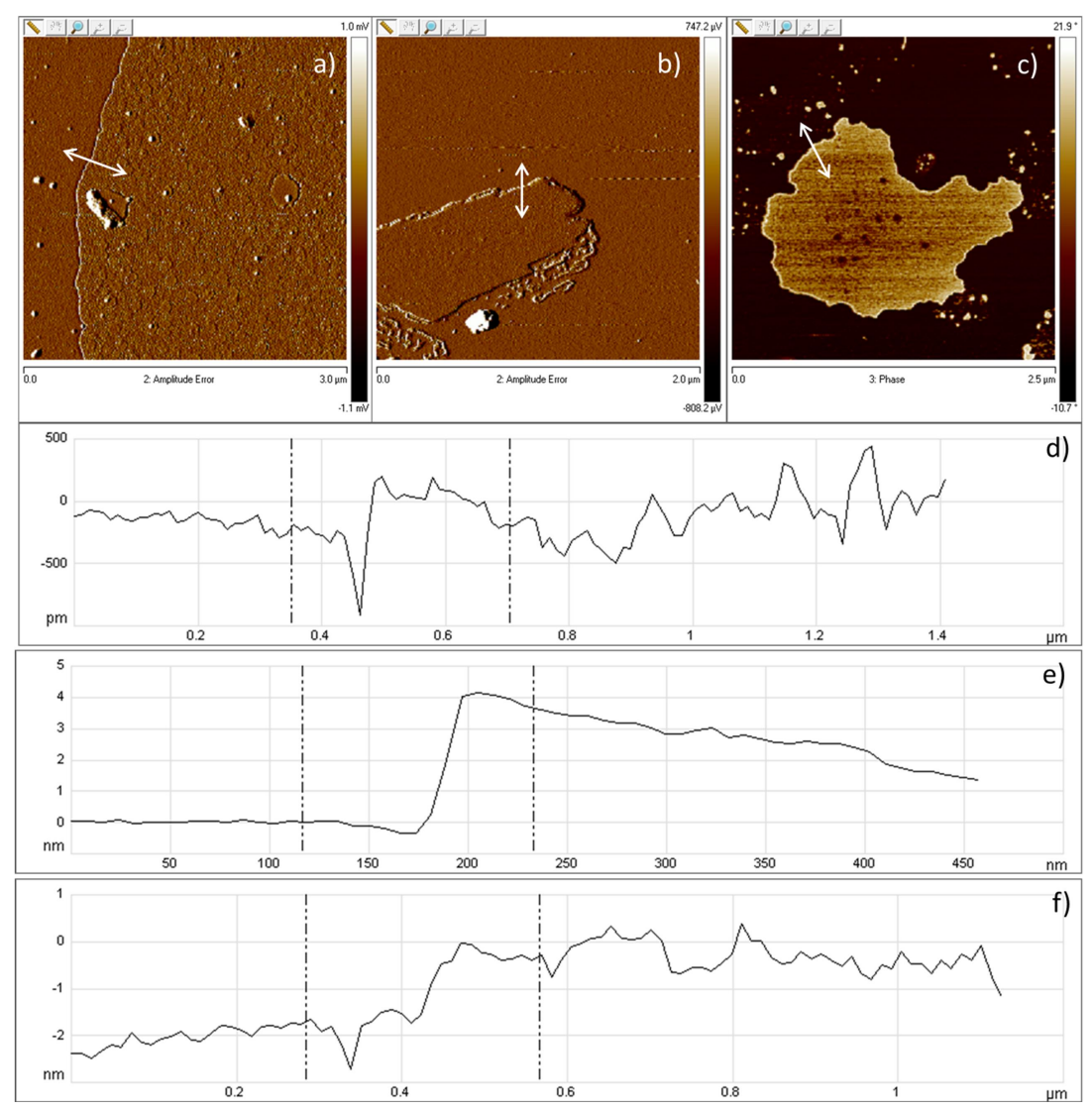

Figura 1.17. Imágenes de microscopía de fuerza atómica de (B)G (a), G de alginato (b), y $(\mathrm{B}, \mathrm{N}) \mathrm{G}$ (c). Los perfiles d, e y f muestran las variaciones de altura representadas en línea blanca en las imágenes a, b y c, respectivamente.

La espectroscopía fotoelectrónica de rayos X (XPS, de sus siglas en inglés, X-ray Photoelectron Spectroscopy) es una técnica de análisis de superficies debido a que los rayos $\mathrm{X}$ que se emplean en las medidas son de baja energía y poseen una capacidad de penetración inferior al nanómetro. Sin embargo, puesto que el grafeno es un material de un átomo de espesor, la técnica de XPS es capaz de analizar todo el grafeno cuando este se encuentra como película. ${ }^{136}$ La técnica de XPS no sólo proporciona la composición elemental de un grafeno, siendo por tanto 
complementaria con el análisis de combustión, aunque en este caso posee la ventaja de que sí cuantifica el contenido en oxígeno, sino que además permite establecer las diferentes familias que constituyen cada heteroátomo. La determinación del número de familias para cada elemento y su contribución al porcentaje total se consigue mediante el ajuste de los picos de XPS característicos de cada elemento a componentes individuales con un valor de energía de enlace definido y con una anchura inferior a $0.5 \mathrm{eV}$. Así, la figura 1.18 muestra un espectro general de XPS donde pueden observarse los diferentes elementos que se encuentran presentes en el grafeno, mientras que la figura 1.19 presenta el pico $\mathrm{C} 1 \mathrm{~s}$ de esta muestra con alta resolución de manera que sea posible su deconvolución en componentes individuales. Estos componentes individuales corresponden a átomos de carbono con diferente hibridación $\mathrm{o}$ átomos de carbono con la misma hibridación pero enlazados a elementos diferentes.
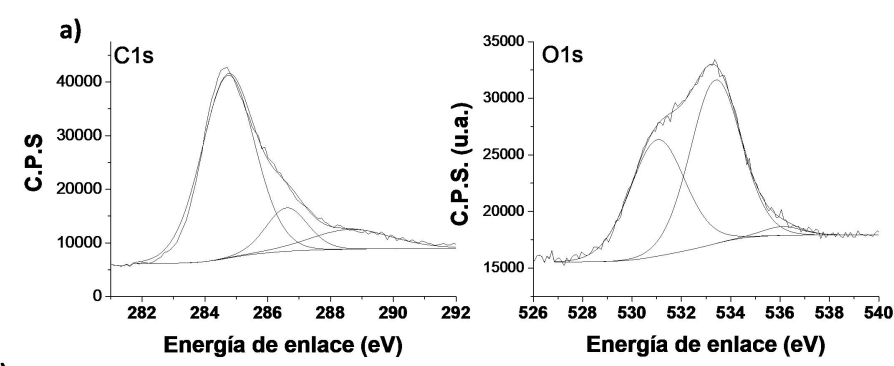

b)

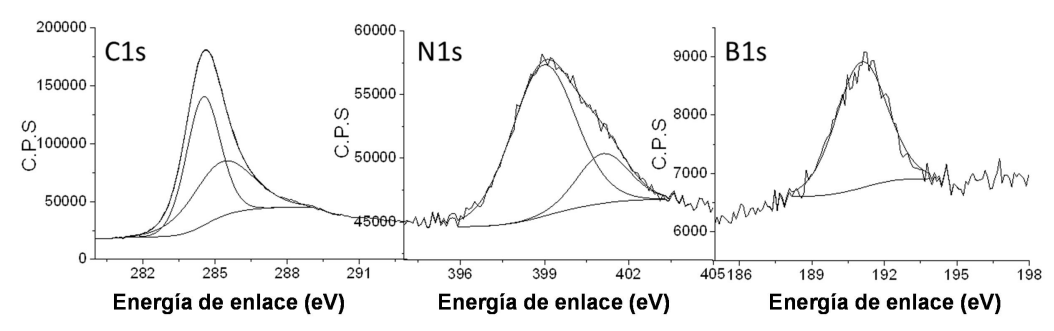

Figura 1.18. Espectros de XPS de a) un óxido de grafeno reducido en el que se muestran los picos de $\mathrm{C} 1 \mathrm{~s}$ y $\mathrm{O} 1 \mathrm{~s}$, y b) un grafeno dopado con boro y nitrógeno, en el que se muestran los picos de C1s, N1s y B1s. 


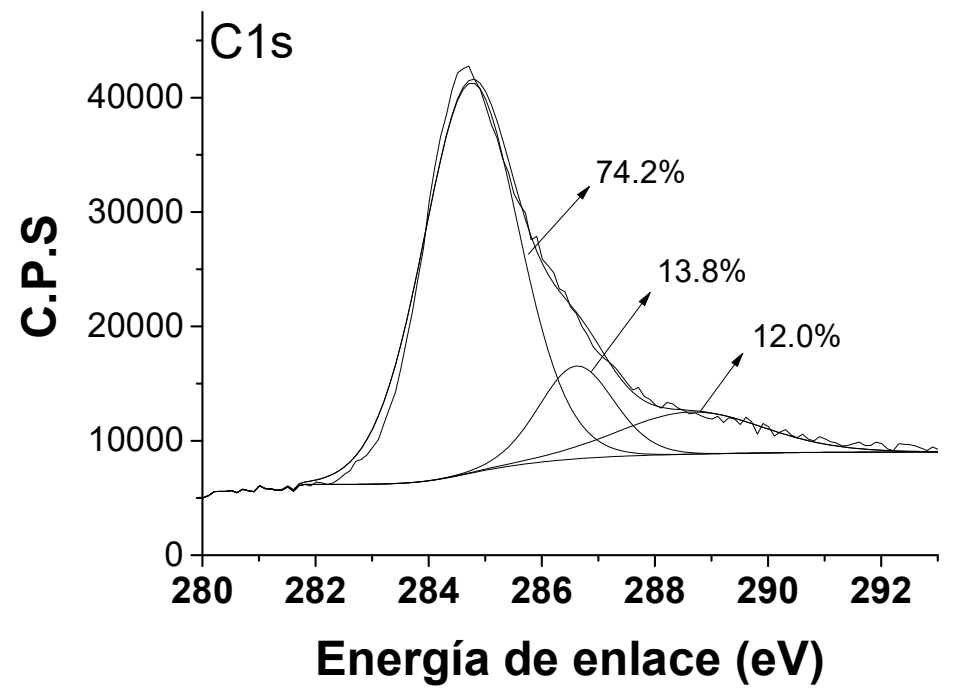

Figura 1.19. Espectro de XPS de un óxido de grafeno reducido en el que se muestra la deconvolución y la cuantificación de los picos $\mathrm{C} 1 \mathrm{~s}$ que hacen referencia a los diferentes tipos de átomos de carbono presentes en la estructura: $74.2 \%$ carbono grafítico $(284.5 \mathrm{eV}), 13.8 \%$ enlace simple carbono a oxígeno $(286.2 \mathrm{eV}), 12.0 \%$ grupo carboxílico $(289.2 \mathrm{eV})$.

Así, en el caso más general del elemento de carbono, el pico de XPS que se analiza es el 1s y este pico se ajusta a picos individuales que corresponden a carbono grafítico, que aparece con una energía de enlace de $284.5 \mathrm{eV}$; carbono sp2 unido a oxígeno, con enlace simple o doble, que aparece con una energía de enlace de $286.2 \mathrm{eV}$ y $287.8 \mathrm{eV}$, respectivamente, o carbono sp2 de un grupo carboxílico, que aparece a una energía de enlace de $289.2 \mathrm{eV} .{ }^{136}$ De forma similar, la figura 1.20 muestra el análisis de un pico de XPS correspondiente al nitrógeno y que indica la existencia de nitrógeno grafénico $(401.3 \mathrm{eV})$, nitrógeno pirrólico $(400 \mathrm{eV})$ y nitrógeno piridínico $(398.3 \mathrm{eV}) .{ }^{136,137}$ De esta manera, la técnica de XPS proporciona una información fundamental sobre la presencia de defectos en su naturaleza. El grafeno ideal constituido exclusivamente por carbonos sp2 debería presentar un XPS con un solo pico simétrico y estrecho centrado en $284.5 \mathrm{eV}$ y con una anchura inferior a $1 \mathrm{eV}$. 


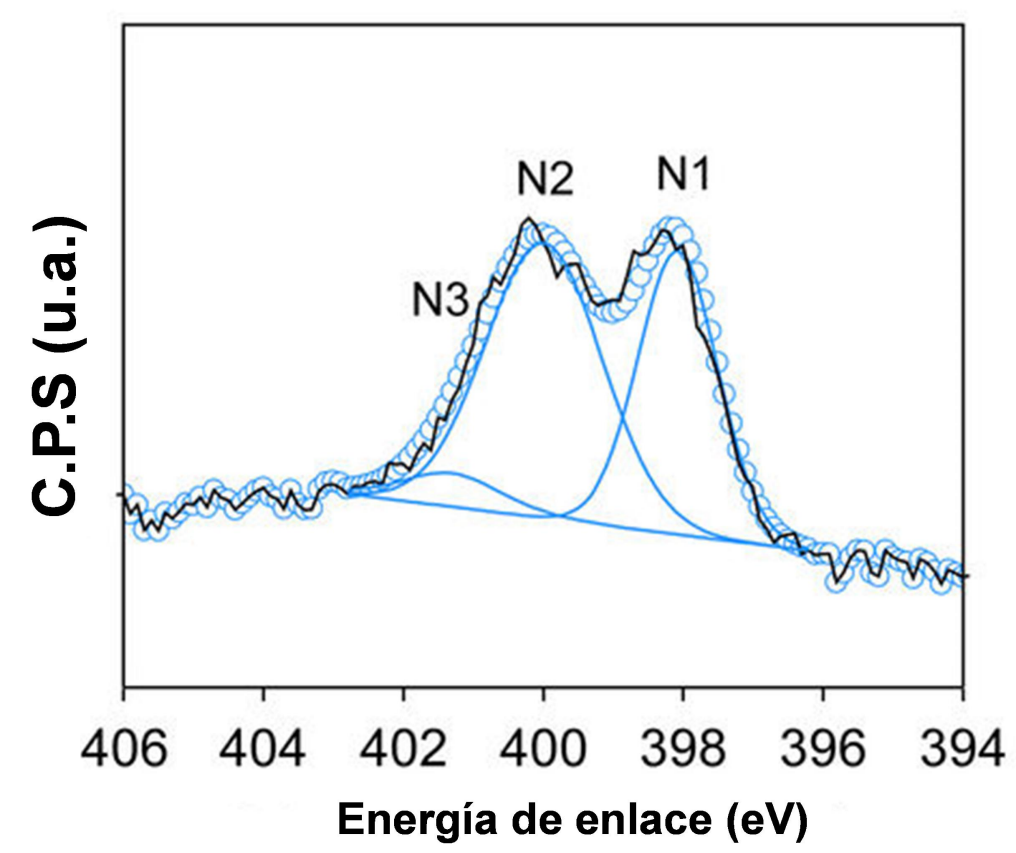

Figura 1.20. Espectro de XPS de un grafeno dopado con nitrógeno en el que se muestra la deconvolución de los picos N1s que hacen referencia a los diferentes tipos de enlace del nitrógeno presentes en la estructura: nitrógeno piridínico $(\mathrm{N} 1,398.3 \mathrm{eV})$, nitrógeno pirrólico $(\mathrm{N} 2,400 \mathrm{eV})$, nitrógeno grafénico $(\mathrm{N} 3,401.3 \mathrm{eV})$.

Otra técnica espectroscópica fundamental para el estudio del grafeno, por su simplicidad, facilidad de adquisición e información que proporciona es la espectroscopía vibracional raman. Mientras que la espectroscopía infrarroja, debido a la simetría y falta de transparencia, no proporciona ningún pico característico, en la espectroscopía de vibración raman aparecen picos en la zona de sobretono, sobre $2750 \mathrm{~cm}^{-1}$, y el pico $\mathrm{G}$ a $1590 \mathrm{~cm}^{-1}$, muy intensos y agudos que indican la no existencia de defectos y la formación de monocapas. ${ }^{134,135,138,139} \mathrm{Si}$ el grafeno presenta una apilación de varias láminas, entonces el pico de sobretono en torno a $2750 \mathrm{~cm}^{-1}$ sufre un ensanchamiento y pérdida de simetría. Más importante es la aparición de una banda $\mathrm{D}$ en torno a $1350 \mathrm{~cm}^{-1}$ característica de la presencia de carbonos sp3, que van asociados a defectos. ${ }^{122}$ La intensidad relativa de la banda $\mathrm{G}$ frente a la banda $\mathrm{D}$ proporciona también un valor cuantitativo para estimar cual es la densidad de estos defectos. A modo de 
ejemplo, la figura 1.21 presenta el espectro raman de una muestra de grafeno defectuoso obtenida por pirólisis de un biopolímero natural, donde se observa la anchura y falta de simetría del sobretono, la anchura de la banda $\mathrm{G}$ y la presencia de una banda $\mathrm{D}$ asociada a defectos, siendo la intensidad relativa de la banda $G$ respecto a la $D$ de 1.15. Para óxidos de grafenos reducidos, esta intensidad relativa puede estar en torno a 0.85 , lo que indica que estos materiales poseen aún más defectos que los grafenos obtenidos por pirólisis de polisacáridos. Conviene destacar que la espectroscopía de raman se puede realizar para muestras expuestas al ambiente, no siendo necesario como en el caso de la técnica de XPS la evacuación del ambiente con alto vacío. Además, la espectroscopía raman posee la sensibilidad adecuada para detectar una única capa de grafeno, aunque la relación señal-ruido aumenta, obviamente, con el número de capas.

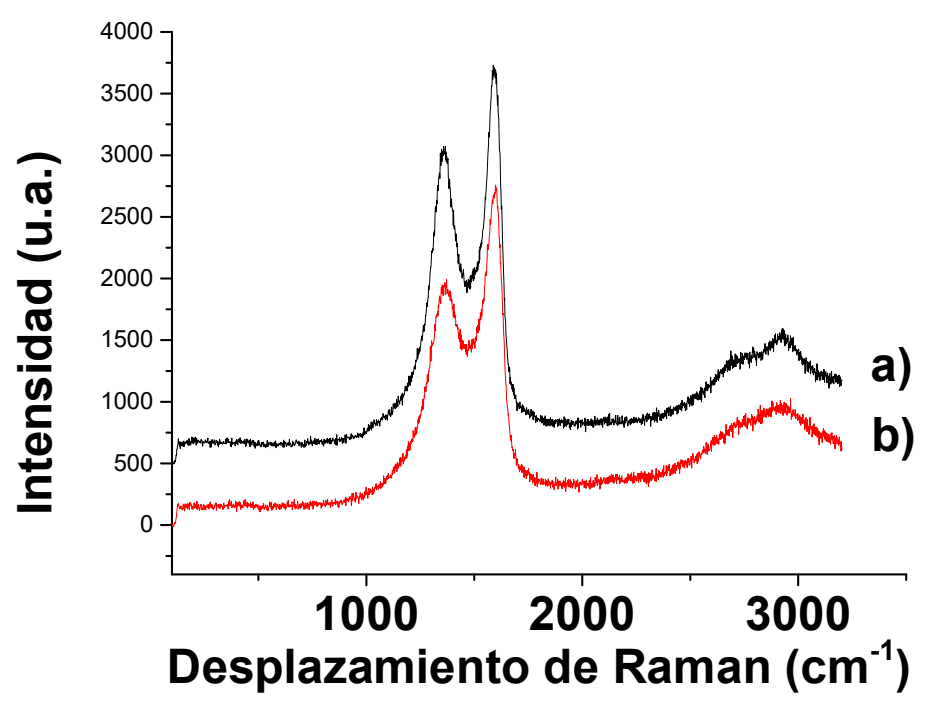

Figura 1.21. Espectro raman de dos muestras de grafeno con un elevado porcentaje de defectos, en el que se muestra las bandas $D\left(1350 \mathrm{~cm}^{-1}\right)$ y G $\left(1590 \mathrm{~cm}^{-1}\right)$, así como la banda de sobretono a $2750 \mathrm{~cm}^{-1}$. a) Espectro del óxido de grafeno reducido ( $\mathrm{rGO}$ ); b) espectro del grafeno obtenido por pirólisis de alginato $(\mathrm{G})$.

Conviene destacar que técnicas habituales de caracterización de catalizadores sólidos, tales como son medidas de área superficial y difracción de rayos $\mathrm{X}$, no son en principio aplicables a materiales 
grafénicos 2D. Así, la difracción de rayos $\mathrm{X}$ en polvo de materiales grafénicos muestra una banda muy ancha en torno a $24^{\circ}$ para el valor de $2 \theta$ que corresponde al apilamiento imperfecto y parcial de las láminas como consecuencia de que no existe un medio que los disperse. ${ }^{121,140} \mathrm{La}$ figura 1.22 muestra un ejemplo de esta difracción de rayos $\mathrm{X}$ para materiales en polvo derivados de grafeno en suspensión. Igualmente, la medida de área superficial requiere de muestras sólidas evacuadas donde se produce un apilamiento más o menos perfecto de estas láminas y, por tanto, no sirven para estimar cual sería el área de un grafeno completamente dispersado en un líquido o recubriendo un superficie.

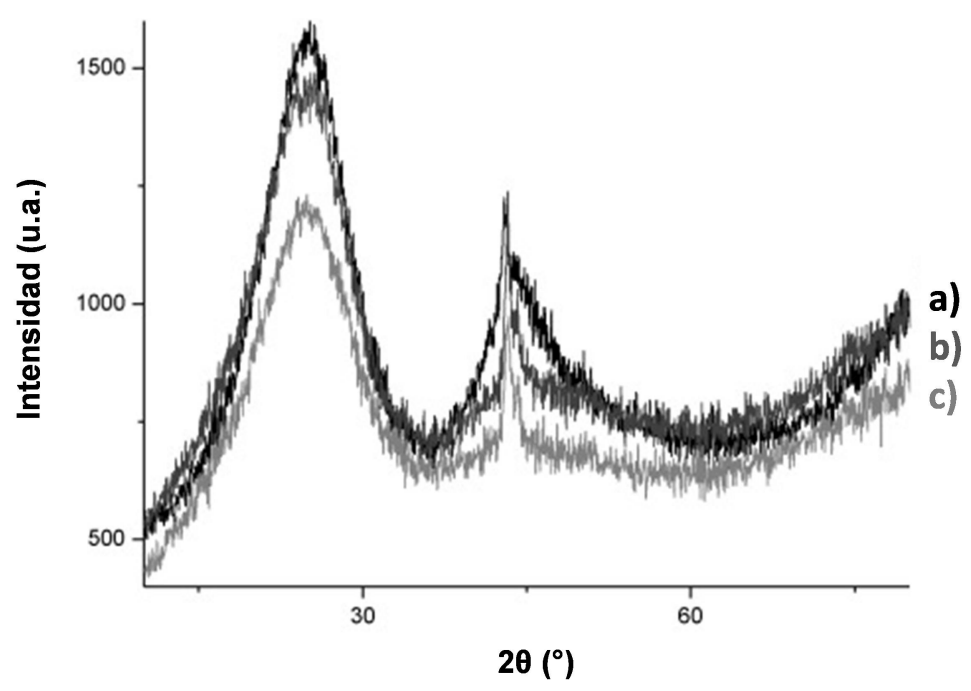

Figura 1.22. Espectro de difracción de rayos $X$ de diferentes muestras de grafeno obtenido por la pirólisis de quitosano pirolizado a a) 800 , b) 600 y c) $400{ }^{\circ} \mathrm{C} .{ }^{117}$

\subsection{Carbocatálisis por grafenos defectuosos}

Tal como se ha comentado anteriormente, y en vista de la capacidad del grupo de preparar grafeno en cantidades suficientes, una línea de investigación de nuestro grupo ha sido el empleo de grafenos como carbocatalizadores. El grafeno ideal no posee centros activos y, aunque excelente para otras propiedades, no posee interés para promover reacciones químicas. En contraste, la presencia de defectos lleva asociada 
la introducción de centros ácido-base o redox que pueden participar en reacciones orgánicas.

Así, nuestro grupo ha demostrado que los grafenos obtenidos por pirólisis de biomasa son buenos catalizadores en reacciones de hidrogenación selectiva de alquinos, ${ }^{141}$ hidrogenación de alquenos, ${ }^{141,142}$ hidrogenación de grupos nitro, ${ }^{143}$ oxidación de hidrocarburos bencílicos, ${ }^{144,145}$ oxidación de dobles enlaces conjugados, ${ }^{122}$ oxidación de bencilaminas, ${ }^{145}$ entre otras reacciones. El esquema 1.12 ilustra las reacciones que han sido promovidas por grafenos como catalizadores libres de metales con indicación de la naturaleza de los defectos propuestos como centros activos. ${ }^{146}$ 


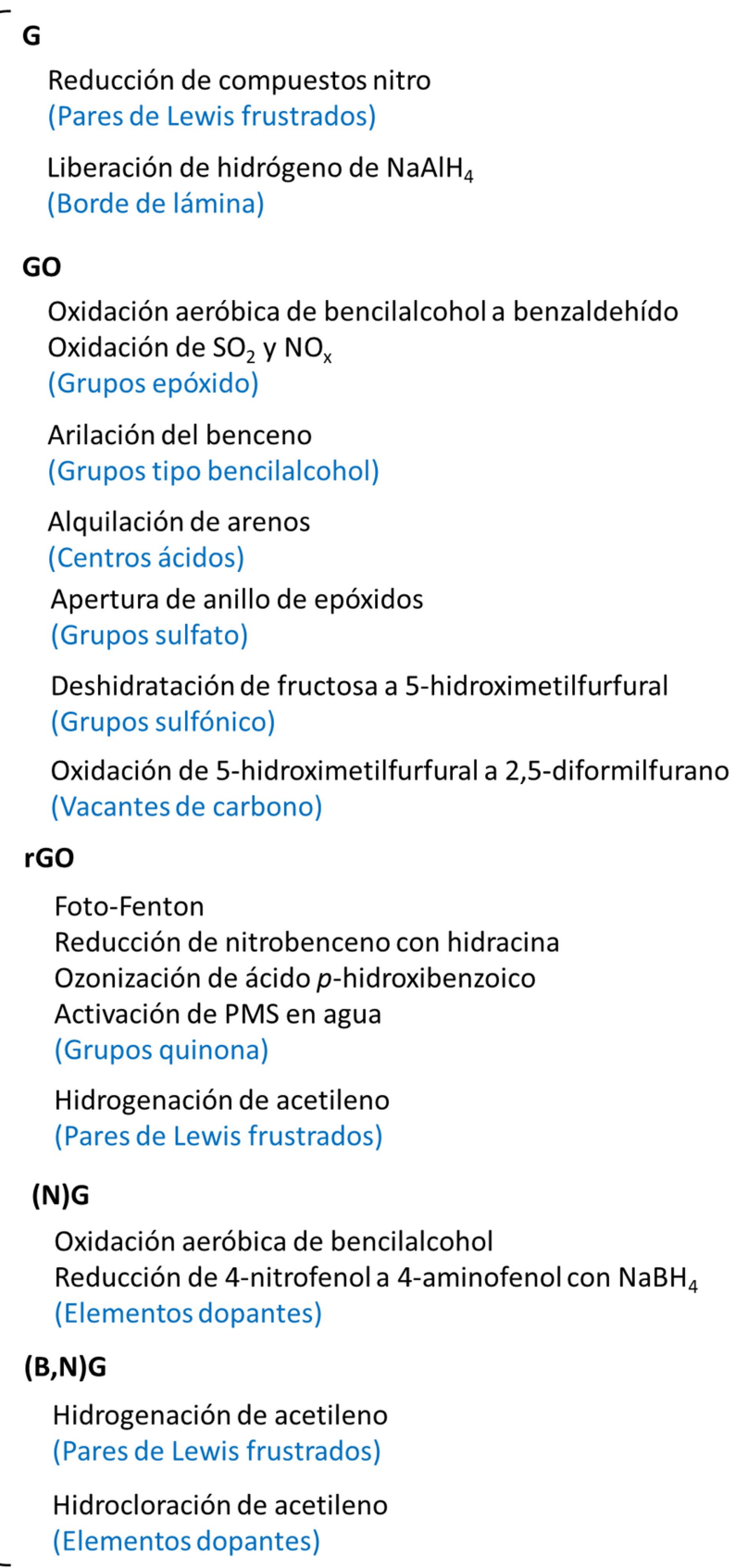

Esquema 1.12. Esquema que muestra una serie de reacciones que pueden ser llevadas a cabo con materiales grafénicos, indicando los defectos descritos como centros activos (en azul) para promover dichas reacciones. ${ }^{146}$ 
Continuando en esta línea y tal como se ha comentado anteriormente, al describir la reacción de Fenton y foto-Fenton, la presente tesis doctoral va encaminada a expandir la aplicación de grafenos en catálisis y en fotocatálisis, específicamente a su empleo como catalizadores de la reacción de Fenton y foto-Fenton (capítulos 6 y 7). Estos estudios complementan otros que describen el empleo de grafenos como catalizadores de oxidación sin el empleo de metales. Además, estos resultados se contrastarán con los que se obtengan empleando nanopartículas metálicas sobre superficies de diamante previamente tratadas. 


\subsection{Referencias}

[1] Nordell, B. Global and Planetary Change 2003, 38, 305-312.

[2] Jon, P. S.; David, F. O. Environmental Progress 1995, 14, 88-103.

[3] Marco, A.; Esplugas, S.; Saum, G. Water Science and Technology 1997, 35, 321-327.

[4] Gupta, V. K.; Ali, I.; Saleh, T. A.; Nayak, A.; Agarwal, S. RSC Advances 2012, 2, 6380-6388.

[5] Legrini, O.; Oliveros, E.; Braun, A. M. Chemical Reviews 1993, 93, 671-698.

[6] Kolaczkowski, S. T.; Plucinski, P.; Beltran, F. J.; Rivas, F. J.; McLurgh, D. B. Chemical Engineering Journal 1999, 73, 143-160.

[7] Luck, F. Catalysis Today 1996, 27, 195-202.

[8] Luck, F. Catalysis Today 1999, 53, 81-91.

[9] Li, L.; Chen, P.; Gloyna Earnest, F. AIChE Journal 1991, 37, 16871697.

[10] Loures, C.; Alcantara, M.; Izario Filho, H.; Teixeira, A. C.; Silva, F.; Paiva, T.; Lamas Samanamud, G. Advanced Oxidative Degradation Processes: Fundamentals and Applications, 2013.

[11] Oller, I.; Malato, S.; Sanchez-Perez, J. A. Science of The Total Environment 2011, 409, 4141-4166.

[12] Glaze, W. H.; Kang, J.-W.; Chapin, D. H. Ozone: Science \& Engineering 1987, 9, 335-352.

[13] Hoigné, J.; Bader, H. Water Research 1976, 10, 377-386.

[14] Greenwald, R. A. CRC Revivals 2018.

[15] Neyens, E.; Baeyens, J. Journal of Hazardous Materials 2003, 98, 33-50.

[16] Pignatello, J. J.; Oliveros, E.; MacKay, A. Critical Reviews in Environmental Science and Technology 2006, 36, 1-84.

[17] Zepp, R. G.; Faust, B. C.; Hoigne, J. Environmental Science \& Technology 1992, 26, 313-319.

[18] Clarizia, L.; Russo, D.; Di Somma, I.; Marotta, R.; Andreozzi, R. Applied Catalysis B: Environmental 2017, 209, 358-371.

[19] Boyle, J. W.; Mahlman, H. A. C. F. p. d. A. Radiation Research 1962, 16, 416-421.

[20] Ren, S.; Chen, C.; Zhou, Y.; Dong, Q.; Ding, H. Research on Chemical Intermediates 2017, 43, 3307-3323.

[21] Kavitha, V.; Palanivelu, K. Chemosphere 2004, 55, 1235-1243.

[22] Tokumura, M.; Sekine, M.; Yoshinari, M.; Znad, H. T.; Kawase, Y. Process Biochemistry 2007, 42, 627-633.

[23] Zapata, A.; Velegraki, T.; Sanchez-Perez, J. A.; Mantzavinos, D.; Maldonado, M. I.; Malato, S. Applied Catalysis B: Environmental 2009, 88, 448-454.

[24] Castro, C. S.; Guerreiro, M. C.; Oliveira, L. C. A.; Gonçalves, M.; Anastacio, A. S.; Nazzarro, M. Applied Catalysis A: General 2009, 367, 53-58. 
[25] Lim, H.; Lee, J.; Jin, S.; Kim, J.; Yoon, J.; Hyeon, T. Chemical Communications 2006, 463-465.

[26] Martínez, F.; Calleja, G.; Melero, J. A.; Molina, R. Applied Catalysis B: Environmental 2007, 70, 452-460.

[27] Ramirez, J. H.; Maldonado-Hodar, F. J.; Perez-Cadenas, A. F.; Moreno-Castilla, C.; Costa, C. A.; Madeira, L. M. Applied Catalysis $B$ : Environmental 2007, 75, 312-323.

[28] Morgan, B.; Lahav, O. Chemosphere 2007, 68, 2080-2084.

[29] Navalon, S.; Alvaro, M.; Garcia, H. Applied Catalysis B: Environmental 2010, 99, 1-26.

[30] Qiang, Z.; Chang, J.-H.; Huang, C.-P. Water Research 2002, 36, 8594.

[31] Pham, A. L.-T.; Lee, C.; Doyle, F. M.; Sedlak, D. L. Environmental Science \& Technology 2009, 43, 8930-8935.

[32] Thomas, B.; Mia, H.; Peter, A. J. Berichte der Bunsengesellschaft fur physikalische Chemie 1986, 90, 395-398.

[33] Wang, W.; Zhou, M.; Mao, Q.; Yue, J.; Wang, X. Catalysis Communications 2010, 11, 937-941.

[34] Lam, F. L. Y.; Yip, A. C. K.; Hu, X. Industrial \& Engineering Chemistry Research 2007, 46, 3328-3333.

[35] Liu, C.; Shan, Y.; Yang, X.; Ye, X.; Wu, Y. Journal of Catalysis 1997, 168, 35-41.

[36] Wang, Y.; Zhang, Q.; Shishido, T.; Takehira, K. Journal of Catalysis 2002, 209, 186-196.

[37] Bhowmick, S.; Chakraborty, S.; Mondal, P.; Van Renterghem, W.; Van den Berghe, S.; Roman-Ross, G.; Chatterjee, D.; Iglesias, M. Chemical Engineering Journal 2014, 243, 14-23.

[38] Li, S.; Wu, P.; Li, H.; Zhu, N.; Li, P.; Wu, J.; Wang, X.; Dang, Z. Applied Clay Science 2010, 50, 330-336.

[39] Liu, X.-L.; Guo, J.-X.; Chu, Y.-H.; Luo, D.-M.; Yin, H.-Q.; Sun, M.-C.; Yavuz, R. Fuel 2014, 123, 93-100.

[40] Rey, A.; Faraldos, M.; Casas, J. A.; Zazo, J. A.; Bahamonde, A.; Rodriguez, J. J. Applied Catalysis B: Environmental 2009, 86, 6977.

[41] Zhu, H.; Jia, Y.; Wu, X.; Wang, H. Journal of Hazardous Materials 2009, 172, 1591-1596.

[42] Lucking, F.; Koser, H.; Jank, M.; Ritter, A. Water Research 1998, 32, 2607-2614.

[43] Sergio, N.; Amarajothi, D.; Mercedes, A.; Hermenegildo, G. ChemSusChem 2011, 4, 1712-1730.

[44] Richard, J. W.; Judith, S.; Frank, J. L.; Amy, L. T. Journal of Environmental Engineering 2005, 131, 158-164.

[45] Valdes-Solis, T.; Valle-Vigon, P.; Alvarez, S.; Marban, G.; Fuertes, A. B. Catalysis Communications 2007, 8, 2037-2042.

[46] Lloyd, D. R.; Phillips, D. H. Mutation Research/Fundamental and Molecular Mechanisms of Mutagenesis 1999, 424, 23-36. 
[47] Pham, A. N.; Xing, G.; Miller, C. J.; Waite, T. D. Journal of Catalysis 2013, 301, 54-64.

[48] Bandala, E. R.; Pelaez, M. A.; Dionysiou, D. D.; Gelover, S.; Garcia, J.; Macias, D. Journal of Photochemistry and Photobiology A: Chemistry 2007, 186, 357-363.

[49] Yao, Y.; Cai, Y.; Wu, G.; Wei, F.; Li, X.; Chen, H.; Wang, S. Journal of Hazardous Materials 2015, 296, 128-137.

[50] Navalon, S.; Martin, R.; Alvaro, M.; Garcia, H. Angewandte Chemie 2010, 122, 8581-8585.

[51] Martín, R.; Heydorn, P. C. n.; Alvaro, M.; Garcia, H. Chemistry of Materials 2009, 21, 4505-4514.

[52] Haruta, M.; Yamada, N.; Kobayashi, T.; Iijima, S. Journal of Catalysis 1989, 115, 301-309.

[53] Pal, A.; Shah, S.; Devi, S. Materials Chemistry and Physics 2009, 114, 530-532.

[54] Bonet, F.; Delmas, V.; Grugeon, S.; Herrera Urbina, R.; Silvert, P. Y.; Tekaia-Elhsissen, K. Nanostructured Materials 1999, 11, 12771284.

[55] Navalon, S.; de Miguel, M.; Martin, R.; Alvaro, M.; Garcia, H. Journal of the American Chemical Society 2011, 133, 2218-2226.

[56] Krueger, A. Advanced Materials 2008, 20, 2445-2449.

[57] Shenderova, O. A.; Zhirnov, V. V.; Brenner, D. W. Critical Reviews in Solid State and Materials Sciences 2002, 27, 227-356.

[58] Martin, R.; Heydorn, P. C. n.; Alvaro, M.; Garcia, H. Chemistry of Materials 2009, 21, 4505-4514.

[59] Jiang, P.; Bao, X.; Salmeron, M. Accounts of Chemical Research 2015, 48, 1524-1531.

[60] Okuhara, T. Chemical Reviews 2002, 102, 3641-3666.

[61] Chinchilla, R.; Nájera, C. Chem. Rev. 2007, 107, 874-922.

[62] Gelin, P.; Primet, M. Applied Catalysis B: Environmental 2002, 39, $1-37$.

[63] Jana, R.; Pathak, T. P.; Sigman, M. S. Chem. Rev. 2011, 111, 14171492.

[64] Stratakis, M.; Garcia, H. Chem. Rev. 2012, 112, 4469-4506.

[65] Aneggi, E.; de Leitenburg, C.; Dolcetti, G.; Trovarelli, A. Catalysis Today 2006, 114, 40-47.

[66] Comisión Europea 2010.

[67] Pyun, J. Angew. Chem. Int. Ed. 2011, 50, 46-48.

[68] Schaetz, A., Zeltner, M., Stark, W.J. ACS Catal. 2012, 2, $1267-$ 1284.

[69] Su, D. S.; Zhang, J.; Frank, B.; Thomas, A.; Wang, X.; Paraknowitsch, J.; Schlogl, R. ChemSusChem 2010, 3, 169-180.

[70] Titirici, M.-M.; Antonietti, M. Chem. Soc. Rev. 2010, 39, 103-116.

[71] Schreiner, P. R. Chemical Society Reviews 2003, 32, 289-296.

[72] Dreyer, D. R.; Bielawski, C. W. Chem. Sci. 2011, 2, 1233-1240. 
[73] Navalon, S.; Dhakshinamoorthy, A.; Alvaro, M.; Garcia, H. Chemical Reviews 2014, 114, 6179-6212.

[74] Su, C.; Loh, K. P. Acc. Chem. Res. 2013, 46, 2275-2285.

[75] Fernando Langa, J.-F. N. RSC Nanoscience \& Nanotechnology 2011.

[76] Cami, J.; Bernard-Salas, J.; Peeters, E.; Malek, S. E. Science 2010, 329, 1180-1182.

[77] K. Saidane; M. Razafinimanana; H Lange; A Huczko; M Baltas; A Gleizes; Meunier, J.-L. Journal of Physics D: Applied Physics 2004, 37, 232-240.

[78] Geim, A. K.; Novoselov, K. S. Nature Materials 2007, 6, 183-191.

[79] Bragg, W. H. B., W. L. Proceedings of the Royal Society of London. Series A 1913, 88, 428-438.

[80] Mishra, S. K.; Tripathi, S. N.; Choudhary, V.; Gupta, B. D. Sensors and Actuators B: Chemical 2014, 199, 190-200.

[81] Tan, J. C.; Cheetham, A. K. Chemical Society Reviews 2011, 40, 1059-1080.

[82] Castro Neto, A. H.; Guinea, F.; Peres, N. M. R.; Novoselov, K. S.; Geim, A. K. Reviews of Modern Physics 2009, 81, 109-162.

[83] Ni, Z. H.; Wang, H. M.; Kasim, J.; Fan, H. M.; Yu, T.; Wu, Y. H.; Feng, Y. P.; Shen, Z. X. Nano Letters 2007, 7, 2758-2763.

[84] Novoselov, K. S.; Geim, A. K.; Morozov, S. V.; Jiang, D.; Katsnelson, M. I.; Grigorieva, I. V.; Dubonos, S. V.; Firsov, A. A. Nature 2005, 438, 197.

[85] Novoselov, K. S.; Geim, A. K.; Morozov, S. V.; Jiang, D.; Zhang, Y.; Dubonos, S. V.; Grigorieva, I. V.; Firsov, A. A. Science 2004, 306, 666-669.

[86] Novoselov, K. S.; Jiang, D.; Schedin, F.; Booth, T. J.; Khotkevich, V. V.; Morozov, S. V.; Geim, A. K. Proceedings of the National Academy of Sciences of the United States of America 2005, 102, 10451-10453.

[87] Allen, M. J.; Tung, V. C.; Kaner, R. B. Chem. Rev. 2010, 110, 132145.

[88] Bianco, A.; Cheng, H.-M.; Enoki, T.; Gogotsi, Y.; Hurt, R. H.; Koratkar, N.; Kyotani, T.; Monthioux, M.; Park, C. R.; Tascon, J. M. D.; Zhang, J. Carbon 2013, 65, 1-3.

[89] Dreyer, D. R.; Ruoff, R. S.; Bielawski, C. W. Angew. Chem. Int. Ed. 2010, 49, 9336 - 9344.

[90] Guest Editorial Carbon 2012, 50, 741-747.

[91] Geim, A. K. Science 324 2009, 324, 1530-1534.

[92] Georgakilas, V.; Otyepka, M.; Bourlinos, A. B.; Chandra, V.; Kim, N.; Kemp, K. C.; Hobza, P.; Zboril, R.; Kim, K. S. Chemical Reviews 2012, 112, 6156-6214.

[93] Navalon, S.; Dhakshinamoorthy, A.; Alvaro, M.; Garcia, H. Coordination Chemistry Reviews 2016, 312, 99-148.

[94] Sabater, S.; Mata, J. A.; Peris, E. ACS Catalysis 2014, 4, 2038-2047. 
[95] Cao, M.; Fu, A.; Wang, Z.; Liu, J.; Kong, N.; Zong, X.; Liu, H.; Gooding, J. J. The Journal of Physical Chemistry C 2014, 118, 2650-2659.

[96] Xu, Y.; Bai, H.; Lu, G.; Li, C.; Shi, G. Journal of the American Chemical Society 2008, 130, 5856-5857.

[97] Lee, C.; Wei, X.; Kysar, J. W.; Hone, J. Science 2008, 321, 385-388.

[98] Nair, R. R.; Blake, P.; Grigorenko, A. N.; Novoselov, K. S.; Booth, T. J.; Stauber, T.; Peres, N. M. R.; Geim, A. K. Science 2008, 320, 1308-1308.

[99] Primo, A.; Atienzar, P.; Sanchez, E.; Delgado, J. M.; García, H. Chem. Commun. 2012, 48, 9254-9256.

[100] Yeh, T. F.; Teng, C. Y.; Chen, S. J.; Teng, H. Advanced Materials 2014, 26, 3297-3303.

[101] Gurunathan, S.; Han, J.; Hyun Park, J.; Eppakayala, V.; Kim, J.-H. International Journal of Nanomedicine, 2014, 9, 363 - 377.

[102] Parker, V. D. Journal of the Chemical Society D: Chemical Communications 1969, 716-717.

[103] Chen, L.; Hernandez, Y.; Feng, X.; Mullen, K. Angewandte Chemie International Edition 2012, 51, 7640-7654.

[104] Lee, Y.; Bae, S.; Jang, H.; Jang, S.; Zhu, S.-E.; Sim, S. H.; Song, Y. I.; Hong, B. H.; Ahn, J.-H. Nano Letters 2010, 10, 490-493.

[105] Li, X.; Cai, W.; An, J.; Kim, S.; Nah, J.; Yang, D.; Piner, R.; Velamakanni, A.; Jung, I.; Tutuc, E.; Banerjee, S. K.; Colombo, L.; Ruoff, R. S. Science 2009, 324, 1312-1314.

[106] Mattevi, C.; Kim, H.; Chhowalla, M. Journal of Materials Chemistry 2011, 21, 3324-3334.

[107] Narita, A.; Wang, X.-Y.; Feng, X.; Mullen, K. Chemical Society Reviews 2015, 44, 6616-6643.

[108] Hummers, W. S.; Offeman, R. E. J. Am. Chem. Soc. 1958, 80, 13391339.

[109] Muñoz, R.; Gómez-Aleixandre, C. Chem. Vap. Deposition 2013, 19, $1-26$.

[110] Murdock, A. T.; Koos, A.; Britton, T. B.; Houben, L.; Batten, T.; Zhang, T.; Wilkinson, A. J.; Dunin-Borkowski, R. E.; Lekka, C. E.; Grobert, N. ACS Nano 2013, 7, 1351-1359.

[111] Wei, D.; Wu, B.; Guo, Y.; Yu, G.; Liu, Y. Acc. Chem. Res. 2013, 46, 106-115.

[112] Zhang, Y.; Zhang, L.; Zhou, C. Acc. Chem. Res. 2013, 46, 23292339.

[113] Dreyer, D. R.; Park, S.; Bielawski, C. W.; Ruoff, R. S. Chem. Soc. Rev. 2010, 39, 228-240.

[114] Bhunia, P.; Hwang, E.; Yoon, Y.; Lee, E.; Seo, S.; Lee, H. Chem. Eur. J 2012, 18, 12207-12212.

[115] Zhang, S.; Miran, M. S.; Ikoma, A.; Dokko, K.; Watanabe, M. J.Am.Chem.Soc. 2014, 136, 1690-1693. 
[116] Lerf, A.; He, H.; Forster, M.; Klinowski, J. The Journal of Physical Chemistry B 1998, 102, 4477-4482.

[117] Hontoria-Lucas, C.; López-Peinado, A. J.; López-González, J. d. D.; Rojas-Cervantes, M. L.; Martín-Aranda, R. M. Carbon 1995, 33, 1585-1592.

[118] Bagri, A.; Mattevi, C.; Acik, M.; Chabal, Y. J.; Chhowalla, M., Shenoy, V.B. Nat. Chem. 2010, 2, 581-587.

[119] Choudhary, S.; Mungse, H. P.; Khatri, O. P. Chem. Asian. J. 2013, 8, 2070-2078.

[120] Li, D.; Muller, M. B.; Gilje, S.; Kaner, R. B.; Wallace, G. G. Nature Nanotechnology 2008, 3, 101.

[121] Primo, A.; Forneli, A.; Corma, A.; García, H. ChemSusChem 2012, $5,2207-2214$.

[122] Dhakshinamoorthy, A., Primo, A., Concepcion, P., Alvaro, M., Garcia, H. Chem. Eur. J. 2013, 19, 7547-7554.

[123] Dhakshinamoorthy, A.; Latorre-Sanchez, M.; Asiri, A. M.; Primo, A.; Garcia, H. Catalysis Communications 2015, 65, 10-13.

[124] Latorre-Sánchez, M.; Primo, A.; García, H. Angewandte Chemie International Edition 2013, 52, 11813-11816.

[125] Chen, Y., Liu, Y.-J., Wang, H.-X., Zhao, J.-X., Cai, Q.-H., Wang, X.-Z., Ding, Y.-H. ACS Appl. Mater. Interfaces 2013, 5, 5994-6000.

[126] Chen, Y.; Gao, B.; Zhao, J.-X.; Cai, Q.-H.; Fu, H.-G. J. Mol. Model. 2012, 18, 2043-2054.

[127] Liu, L.-M., Car, R., Selloni, A., Dabbs, D.M., Aksay, I.A., Yetter, R.A. J. Am. Chem. Soc. 2012, 134, 19011-19016.

[128] Sabourin, J. L.; Dabbs, D. M.; Yetter, R. A.; Dryer, F. L.; Aksay, I. A. ACS Nano 2009, 3, 3945-3954.

[129] Dean, C. R.; Young, A. F.; Meric, I.; Lee, C.; Wang, L.; Sorgenfrei, S.; Watanabe, K.; Taniguchi, T.; Kim, P.; Shepard, K. L.; Hone, J. Nature Nanotechnology 2010, 5, 722.

[130] Esteve-Adell, I.; He, J.; Ramiro, F.; Atienzar, P.; Primo, A.; Garcia, H. Nanoscale 2018, 10, 4391-4397.

[131] Chang, K.; Chen, W. ACS Nano 2011, 5, 4720-4728.

[132] Latorre-Sánchez, M.; Esteve-Adell, I.; Primo, A.; García, H. Carbon 2015, 81, 587-596.

[133] Jia, X., Campos-Delgado, J., Terrones, M., Meunier, V., Dresselhaus, M.S. Nanoscale 2011, 3, 86-95.

[134] Kuila, T.; Bose, S.; Mishra, A. K.; Khanra, P.; Kim, N. H.; Lee, J. H. Prog. Mater. Sci. 2012, 57, 1061-1105.

[135] Soldano, C.; Mahmood, A.; Dujardin, E. Carbon 2010, 48, $2127-$ 2150.

[136] Wang, H.; Maiyalagan, T.; Wang, X. ACS Catalysis 2012, 2, 781794.

[137] Quan, B.; Yu, S.-H.; Chung, D.; Jin, A.; Park, J. H.; Sung, Y.-E.; Piao, Y. Advances in Engineering 2014, 5639.

[138] Ferrari, A. C.; Basko, D. M. Nat. Nanotechnol. 2013, 8, 235-246. 
[139] Zhu, Y.; Murali, S.; Cai, W.; Li, X.; Suk, J. W.; Potts, J. R.; Ruoff, R. S. Adv. Mater. 2010, 22, 3906-3924.

[140] Stobinski, L.; Lesiak, B.; Malolepszy, A.; Mazurkiewicz, M.; Mierzwa, B.; Zemek, J.; Jiricek, P.; Bieloshapka, I. Journal of Electron Spectroscopy and Related Phenomena 2014, 195, 145-154.

[141] Primo, A.; Neatu, F.; Florea, M.; Parvulescu, V.; Garcia, H. Nature Communications 2014, 5, 5291.

[142] Dhakshinamoorthy, A.; He, J.; Franconetti, A.; Asiri, A. M.; Primo, A.; Garcia, H. Catalysis Science \& Technology 2018, 8, 1589-1598.

[143] Trandafir, M.-M.; Florea, M.; Neatu, F.; Primo, A.; Parvulescu Vasile, I.; Garcia, H. ChemSusChem 2016, 9, 1565-1569.

[144] Espinosa Juan, C.; Navalon, S.; Primo, A.; Moral, M.; Sanz Javier, F.; Alvaro, M.; Garcia, H. Chemistry: A European Journal 2015, 21, 11966-11971.

[145] Primo, A.; Puche, M.; Pavel, O. D.; Cojocaru, B.; Tirsoaga, A.; Parvulescu, V.; Garcia, H. Chemical Communications 2016, 52, 1839-1842.

[146] Navalon, S.; Dhakshinamoorthy, A.; Alvaro, M.; Antonietti, M.; Garcia, H. Chemical Society Reviews 2017, 46, 4501-4529. 



\section{Capítulo 2}

\section{Objetivos}



A la vista de lo indicado en el apartado anterior, el objetivo general de la presente tesis doctoral es desarrollar nuevos catalizadores heterogéneos para la reacción de Fenton y foto-Fenton, con el objetivo de que estos catalizadores sean más asequibles, baratos y eficientes, permitiendo particularmente realizar la oxidación avanzada a valores de pH próximos a la neutralidad y con cantidades casi estequiométricas de peróxido de hidrógeno.

En concreto, los objetivos específicos de cada uno de los capítulos de la presente tesis doctoral son los siguientes:

Preparación y caracterización de nanopartículas de plata soportadas sobre nanopartículas de diamante estableciendo una correlación entre la actividad de estos materiales y los pretratamientos a los que se ha sometido la superficie del diamante. Se prestará especial atención a la comparación de la actividad catalítica de estos catalizadores a base de plata con la de una muestra análoga ya preparada basada en nanopartículas de oro. El estudio incluye la estabilidad del catalizador y la existencia o no de lixiviado de metal del sólido a la disolución acuosa.

Preparación de un catalizador de Fenton y foto-Fenton basado en nanopartículas de cobre soportadas sobre nanopartículas de diamante. Al igual que en el objetivo anterior, se correlacionarán los tamaños de partícula y la actividad catalítica de los materiales con los procesos de pretratamiento a los que se somete la nanopartícula de diamante. Igualmente se determinará el modo de desactivación del catalizador con el reúso, diseñándose un procedimiento de reactivación en caso de que sea necesario.

Preparación de nanopartículas de diamante conteniendo óxidos de hierro soportado como catalizador de la reacción de Fenton y fotoFenton, determinándose la comparación de la actividad relativa de este material basado en hierro respecto a los anteriormente preparados conteniendo $\mathrm{Ag} \mathrm{y} \mathrm{Cu}$. El mecanismo de reacción se estudiará mediante el empleo de inhibidores selectivos y de atrapamiento con radicales que permitan determinar su espectro de EPR. La estabilidad del material se estudiará llevando a cabo reacciones de productividad en condiciones de un gran exceso de sustrato y mediante la recuperación del catalizador y su reúso. 
Estudio del grafeno proveniente de pirólisis de la biomasa como catalizador para la reacción de Fenton, determinando las especies activas implicadas en el proceso y estableciendo la posible naturaleza de los centros activos. Se llevarán a cabo cálculos para determinar la posibilidad de que moléculas orgánicas actúen como carbocatalizadores homogéneos de la reacción de Fenton, al promover la reducción monoelectrónica de peróxido de hidrógeno.

Empleo de grafeno como catalizador de la reacción de fotoFenton, estableciendo especialmente el rango de valores de $\mathrm{pH}$ en los que este materia puede promover la degradación de fenol con cantidades limitadas de peróxido de hidrogeno. Se determinará la eficiencia de la reacción de foto-Fenton en comparación con la misma reacción llevada a cabo en la oscuridad. Se empleará luz solar natural para llevar a cabo algunos ensayos de manera que se pueda demostrar la posibilidad de su aplicación por irradiación con luz natural.

En el caso de que los resultados de la presente tesis doctoral sean positivos y algunos de los materiales tengan elevada eficiencia como catalizador de la reacción de Fenton, se habría avanzado de forma sustanciosa en el desarrollo de catalizadores más sostenibles y basados en metales más abundantes, o incluso catalizadores en ausencia de metales para promover estos procesos. Teniendo en cuenta la creciente presión sobre los recursos hídricos y la necesidad de desarrollar tratamientos eficientes, los estudios que se llevarán a cabo en la presente tesis doctoral podrían contribuir a desarrollar procesos eficientes y más tolerables para la eliminación de contaminantes no biodegradables en aguas residuales. 


\section{Capítulo 3}

Nanopartículas de plata soportadas sobre nanopartículas de diamante como catalizadores eficientes de la reacción de Fenton por irradiación con luz solar natural 



\subsection{Introducción}

Como se ha venido comentando, la reacción de foto-Fenton en fase homogénea es un proceso de oxidación avanzada en el que se produce la generación de radicales hidroxilo altamente reactivos por irradiación de disoluciones acuosas de sales de hierro y peróxido de hidrógeno utilizando luz ultravioleta y valores de $\mathrm{pH}$ ácidos. Las ecuaciones 3.1 y 3.2 describen los procesos químicos que tienen lugar empleando estas sales de hierro. ${ }^{1-5}$ La principal aplicación de la reacción de foto-Fenton es la degradación de contaminantes orgánicos en agua. ${ }^{1,2,6}$

$$
\begin{aligned}
& \mathrm{Fe}^{2+}+\mathrm{H}_{2} \mathrm{O}_{2} \underset{\mathrm{pH} 3\left(\mathrm{H}_{2} \mathrm{SO}_{4}\right)}{\longrightarrow} \mathrm{Fe}^{3+}+\mathrm{HO}^{\circ}+\mathrm{HO}^{-} \quad \text { (ec. 3.1) } \\
& \mathrm{Fe}(\mathrm{OH})_{2}^{+} \frac{\mathrm{UV} \text {-Vis }}{\mathrm{pH} 3\left(\mathrm{H}_{2} \mathrm{SO}_{4}\right)} \mathrm{Fe}^{2+}+\mathrm{HO}^{\circ} \quad \text { (ec. 3.2) }
\end{aligned}
$$

También se ha comentado en la introducción que la reacción de foto-Fenton clásica promovida por sales de hierro tiene una serie de limitaciones que impiden la aplicación generalizada de este proceso. ${ }^{4,7}$ Entre las mismas, las más importantes son:

i) La necesidad de valores de $\mathrm{pH}$ fuertemente ácidos que permitan que las especies de hierro presentes en solución sean los cationes hidratados que promuevan de forma eficiente la fotorreacción;, ${ }^{2,7}$

ii) El elevado consumo de $\mathrm{H}_{2} \mathrm{O}_{2}$ debido a que ocurren en paralelo reacciones laterales indeseadas de descomposición de agua oxigenada $;^{2}$

iii) La necesidad de eliminar los óxidos de hierro que se forman en la reacción de la fase acuosa mediante su precipitación y el manejo de cantidades elevadas de fangos; ${ }^{2,7}$

iv) La necesidad de irradiación con luz ultravioleta para excitar las sales de hierro $3^{+}$hidratadas presentes a $\mathrm{pH}$ ácido que poseen un máximo de absorción sobre $300 \mathrm{~nm}^{2,7}$

A fin de superar algunas de las limitaciones mencionadas anteriormente, se han llevado a cabo numerosos estudios para desarrollar catalizadores sólidos eficientes para promover la reacción de fotoFenton. ${ }^{5,9,10}$ En este contexto, tal como se ha indicado anteriormente, nuestro grupo de investigación describió que las nanopartículas de oro 
Nanoparticulas de plata soportadas sobre nanopartículas de diamante como catalizadores eficientes de la reacción de Fenton por irradiación con luz solar natural.

soportadas sobre muestras comerciales de nanopartículas de diamante previamente tratadas con la reacción de Fenton son catalizadores eficientes para promover la reacción de foto-Fenton por irradiación con luz solar natural, incluso a valores de $\mathrm{pH}$ casi neutros y usando una relación molar $\mathrm{H}_{2} \mathrm{O}_{2}$ /fenol de 5.5, que es un valor notablemente bajo para los descritos en la literatura. ${ }^{11,12}$

La actividad fotocatalítica de las nanopartículas de oro soportadas sobre nanopartículas de diamante tratadas $(\mathrm{Au} / \mathrm{D} 2)$ fue atribuida a la eyección de electrones fotoinducida que ocurre por excitación de las Au NPs a longitudes de onda que corresponden con la absorción de la banda de plasmón superficial de las Au NPs. ${ }^{12}$ Esos electrones por emisión fotoinducida serían atrapados por moléculas de $\mathrm{H}_{2} \mathrm{O}_{2}$ viniendo a resultar la generación de radicales hidroxilo. Recientemente nuestro grupo ha demostrado también que el tratamiento térmico con hidrógeno de las nanopartículas de diamante oxidadas en la reacción de Fenton a temperaturas en torno a $500{ }^{\circ} \mathrm{C}$ aumenta la población de grupos hidroxilo sobre la superficie de las muestras de diamante por reducción de los grupos carbonílicos y lactonas superficiales. Este tratamiento con hidrógeno resulta en la deposición de Au NPs de menor tamaño que son más efectivos en la reacción de fotoFenton. ${ }^{13,14}$ El tamaño de partícula menor de las Au NPs soportadas sobre muestras de diamante oxidadas por la reacción de Fenton e hidrogenadas (D3) se cree que es responsable de esta alta actividad de la muestra como catalizador en la reacción de foto-Fenton. ${ }^{13}$ De acuerdo con esta hipótesis basada en la influencia de tamaño de partícula de las Au NPs, los intentos de depositar Au NPs sobre muestras de diamante con muy pequeña funcionalización superficial de grupos oxigenados da lugar a la formación de nanopartículas de Au NPs de mayor tamaño, las cuales presentan una actividad mucho menor como catalizadores del proceso de foto-Fenton. ${ }^{13}$

En este contexto, se ha descrito que las NPs de plata también pueden ser activas en la generación de radicales hidroxilo a partir de $\mathrm{H}_{2} \mathrm{O}_{2}$ bajo condiciones ácidas, de acuerdo con un mecanismo general de la reacción de Fenton. ${ }^{15}$ En contraste la evolución de oxígeno molecular ocurre a valores de $\mathrm{pH}$ básicos. Además las nanopartículas de plata depositadas en óxidos metálicos semiconductores tales como $\mathrm{TiO}_{2}{ }^{16} \mathrm{o}$ $\mathrm{ZnO},{ }^{17}$ disminuyen los procesos de recombinación electrón-hueco que 
ocurren en el estado de separación de cargas de semiconductor tras la absorción de un fotón de energía superior a su band gap. De esta manera las Ag NPs aumentan la eficiencia fotocatalítica de estos óxidos metálico tanto en ausencia como en presencia de $\mathrm{H}_{2} \mathrm{O}_{2}$ y otros oxidantes. Más aún, las Ag NPs exhiben, de manera similar al oro, una banda de plasmón superficial alrededor de $410 \mathrm{~nm}$ y la irradiación en esta banda puede conducir a actividad fotocatalítica. Esta mayor actividad fotocatalítica surgiría del papel de las Ag NPs como recolectores de luz y a la inyección de los electrones generados en la citación de las Ag NPs a la banda de conducción de semiconductor. ${ }^{18,19}$

A la vista de estos precedentes, y tal como se ha indicado en el capítulo de objetivos, en el presente capítulo se describe el uso Ag NPs soportadas sobre NPs de diamante tratadas con hidrógeno (D3). Este material Ag/D3 constituye una alternativa eficiente y menos costosa al catalizador $\mathrm{Au} / \mathrm{D} 3$ para promover la reacción de foto-Fenton bajo irradiación con luz solar natural. Además se presentará que la actividad fotocatalítica de las muestras de $\mathrm{Ag} / \mathrm{D} 3$ es superior a las que presentan muestras análogas de Ag NPs soportadas sobre D NPs o soportadas sobre carbón activo (AC), o grafito (Gr) así como soportadas sobre $\mathrm{TiO}_{2}$.

\subsection{Resultados y discusión}

\subsubsection{Preparación de muestras y caracterización}

En la primera parte del presente estudio se procedió a la funcionalización de muestras comerciales de D NPs (D1) con grupos oxigenados por tratamiento de Fenton en fase homogénea sin (D2) o con posterior tratamiento térmico con una corriente de hidrógeno a $500{ }^{\circ} \mathrm{C}$ (D3). Como describimos para el caso del oro, el tratamiento de Fenton introduce sobre la superficie de D diferentes grupos funcionales oxigenados, los cuales controlan el tamaño de las NPs metálicas en la etapa de su formación, lo cual resulta en NPs de $\mathrm{Au}$ o Ag de menor tamaño cuando se usa D3 como soporte en comparación con la muestra comercial no tratada D1. ${ }^{13}$ El tratamiento térmico con una corriente de hidrógeno de D2 aumenta la población de grupos hidroxilo sobre la superficie de D, lo cual favorece la deposición de NPs metálicas más pequeñas y que, por tanto, exhiben en general mejor actividad catalítica que aquellas formadas sobre $\mathrm{D}$ como soporte. ${ }^{13}$ Basados en estos 
Nanoparticulas de plata soportadas sobre nanopartículas de diamante como catalizadores eficientes de la reacción de Fenton por irradiación con luz solar natural.

antecedentes, en el presente capítulo se llevó a cabo la deposición de NPs de Au o Ag sobre muestras de D3 como soporte siguiendo el método del poliol. De esta manera se obtuvieron distribución de tamaños promedios para las NPs metálicas de 3.2 y $2.9 \mathrm{~nm}$ para el $\mathrm{Au}$ y el Ag respectivamente (ver tabla 3.1). En contraste y de acuerdo con los resultados previos con $\mathrm{Au}$ NPs, si se usan como soporte para la deposición de Ag NPs muestras de D1 o D2, se obtienen tamaños de partícula promedios para las Ag NPs mayores. En concreto las dimensiones promedio son de 10.2 y $5.9 \mathrm{~nm}$ para las muestras de D1 y D2, respectivamente. ${ }^{13,20}$ Es digno de hacer notar que una tendencia similar, esto es, menores tamaños de partícula promedio para las Ag NPs se obtienen cuando las muestras de $\mathrm{AC}$ o $\mathrm{Gr}$ son funcionalizadas en su superficie por tratamiento de Fenton en fase homogénea seguido de reducción a altas temperaturas con hidrógeno ( $\mathrm{AC} 3$ o Gr3) que son catalizadores análogos a los de la serie $\mathrm{Ag} / \mathrm{D}$, pero soportados sobre $\mathrm{Gr}$ o AC.

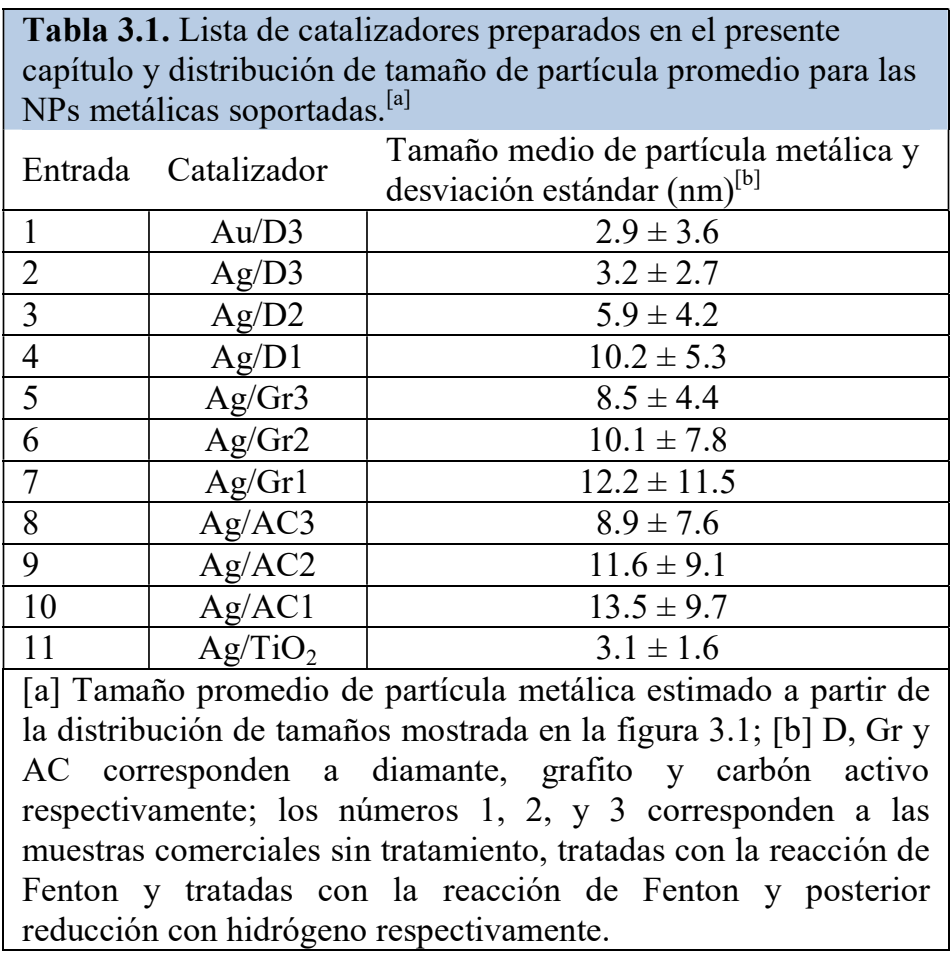


A efectos de comparación, $\mathrm{TiO}_{2}$ ( $\left.\mathrm{P} 25\right)$ fue usado como un fotocatalizador de referencia sobre el cual se procedió a la deposición de Ag NPs (aproximadamente $3.1 \mathrm{~nm}$ de tamaño de partícula promedio) una colección representativa de imágenes obtenidas mediante microscopía electrónica de transmisión por barrido en campo oscuro (DF-STEM) así como análisis estadístico de la distribución del tamaño de las partículas de $\mathrm{Au}$ o Ag para cada catalizador estudiado en el presente capítulo se muestra en las figuras 3.1 a 3.5. La presencia de NPs de Au o Ag soportadas sobre cada sólido fue confirmada mediante la técnica de espectroscopía de rayos X de energía dispersada (EDS) acoplada con la técnica de DF-STEM. La figura 3.6 muestra estos análisis. 
Nanoparticulas de plata soportadas sobre nanopartículas de diamante como catalizadores eficientes de la reacción de Fenton por irradiación con luz solar natural.

a)

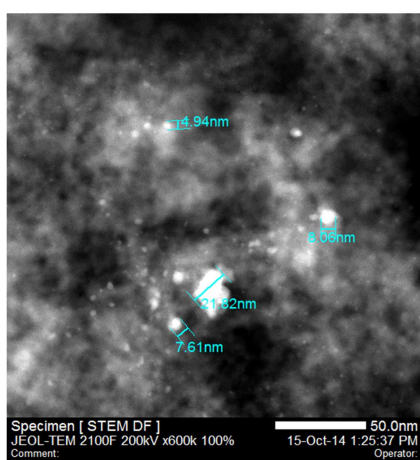

b)

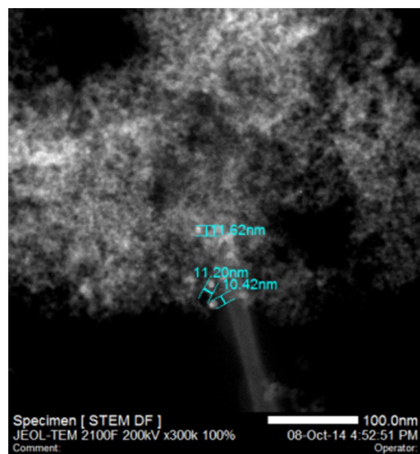

c)

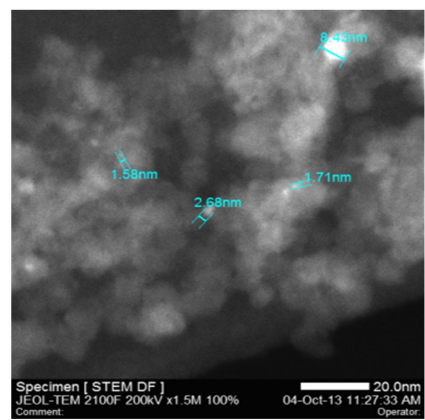

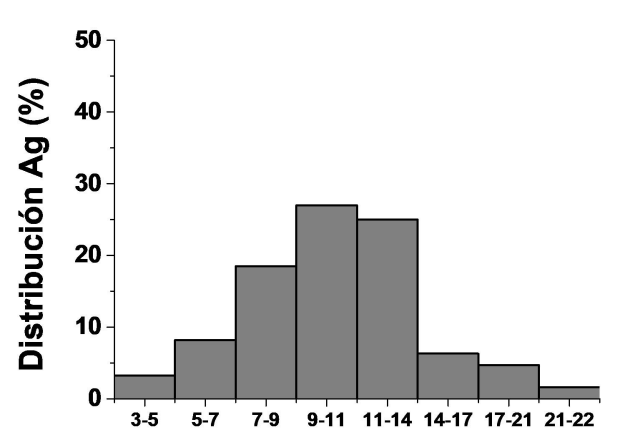

50 Tamaño de partícula Ag (nm)

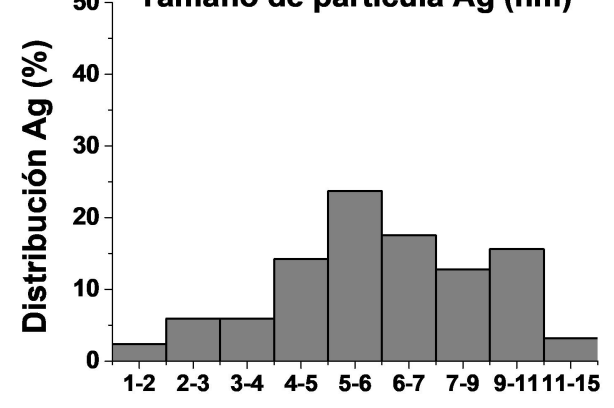

Tamaño de partícula Ag (nm)

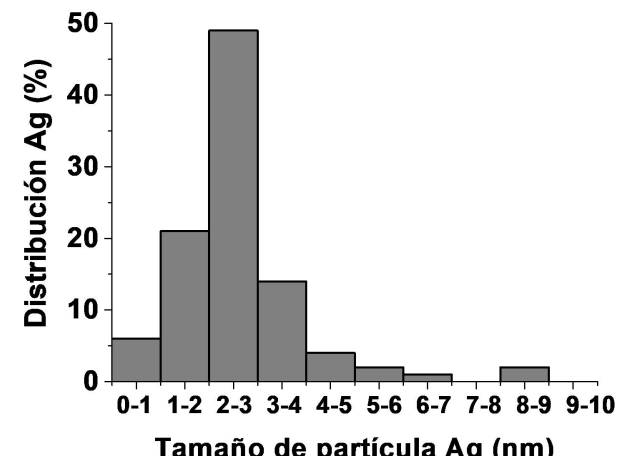

Figura 3.1. Imágenes de DF-STEM y distribuciones de tamaño de partícula de Ag/D1 (a), Ag/D2 (b) y Ag/D3 (c). El tamaño medio de partícula de la plata metálica para Ag/D1, Ag/D2 y Ag/D3 es de $10.2 \pm 5.3,5.9 \pm 4.2$ y $3.2 \pm$ $2.7 \mathrm{~nm}$, respectivamente. Nota: Carga de Ag $0.2 \%$ en peso. 

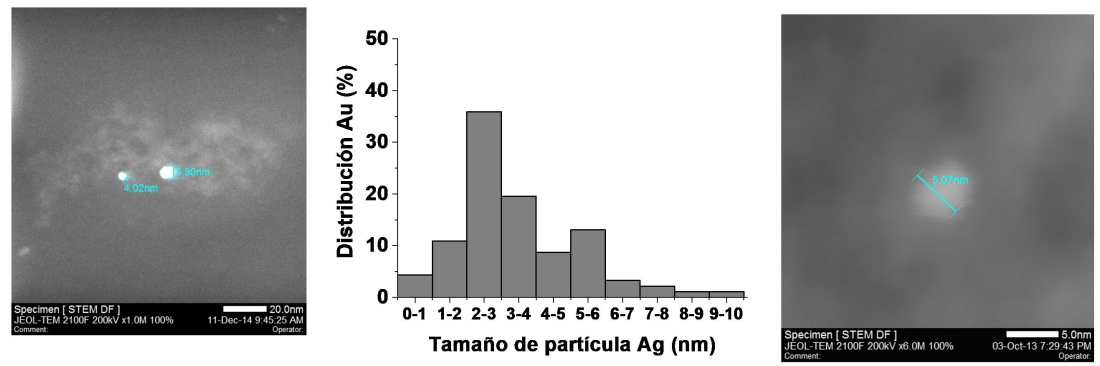

Figura 3.2. Imágenes de DF-STEM y distribuciones de tamaño de partícula de Au/D3. Tamaño medio de partícula del oro de $2.9 \pm 3.6 \mathrm{~nm}$. Nota: Carga de $\mathrm{Au} 0.2 \%$ en peso.
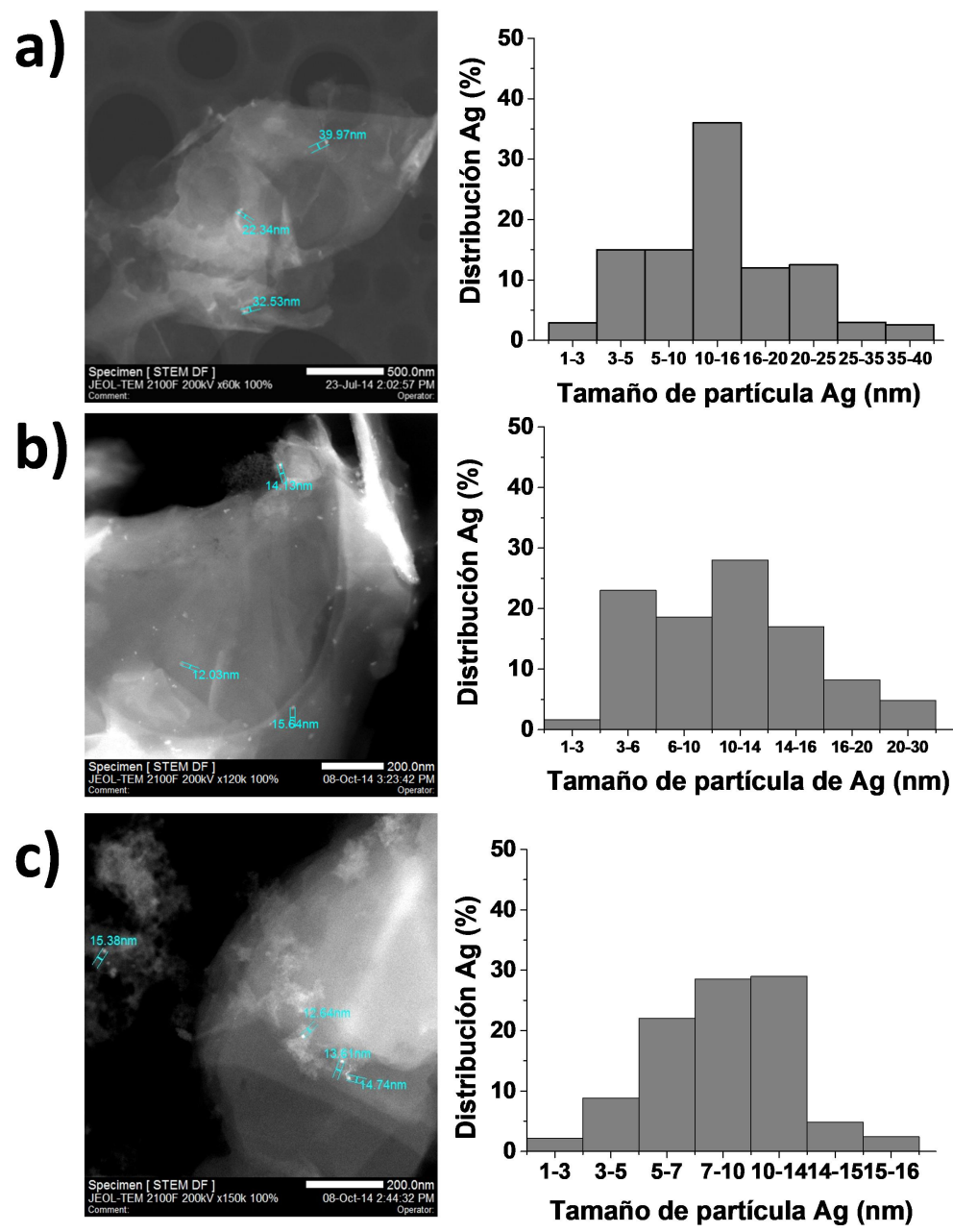
Nanoparticulas de plata soportadas sobre nanopartículas de diamante como catalizadores eficientes de la reacción de Fenton por irradiación con luz solar natural.

Figura 3.3. Imágenes de DF-STEM y distribuciones de tamaño de partícula de $\mathrm{Ag} / \mathrm{Gr} 1$ (a), $\mathrm{Ag} / \mathrm{Gr} 2$ (b) y Ag/Gr3 (c). El tamaño medio de partícula de la plata metálica para $\mathrm{Ag} / \mathrm{Gr} 1, \mathrm{Ag} / \mathrm{Gr} 2$ y Ag/Gr3 es de $12.2 \pm 11.5,10.1 \pm 7.8$ y $8.5 \pm 4.4 \mathrm{~nm}$, respectivamente. Nota: Carga de $\mathrm{Ag} 0.2 \%$ en peso.
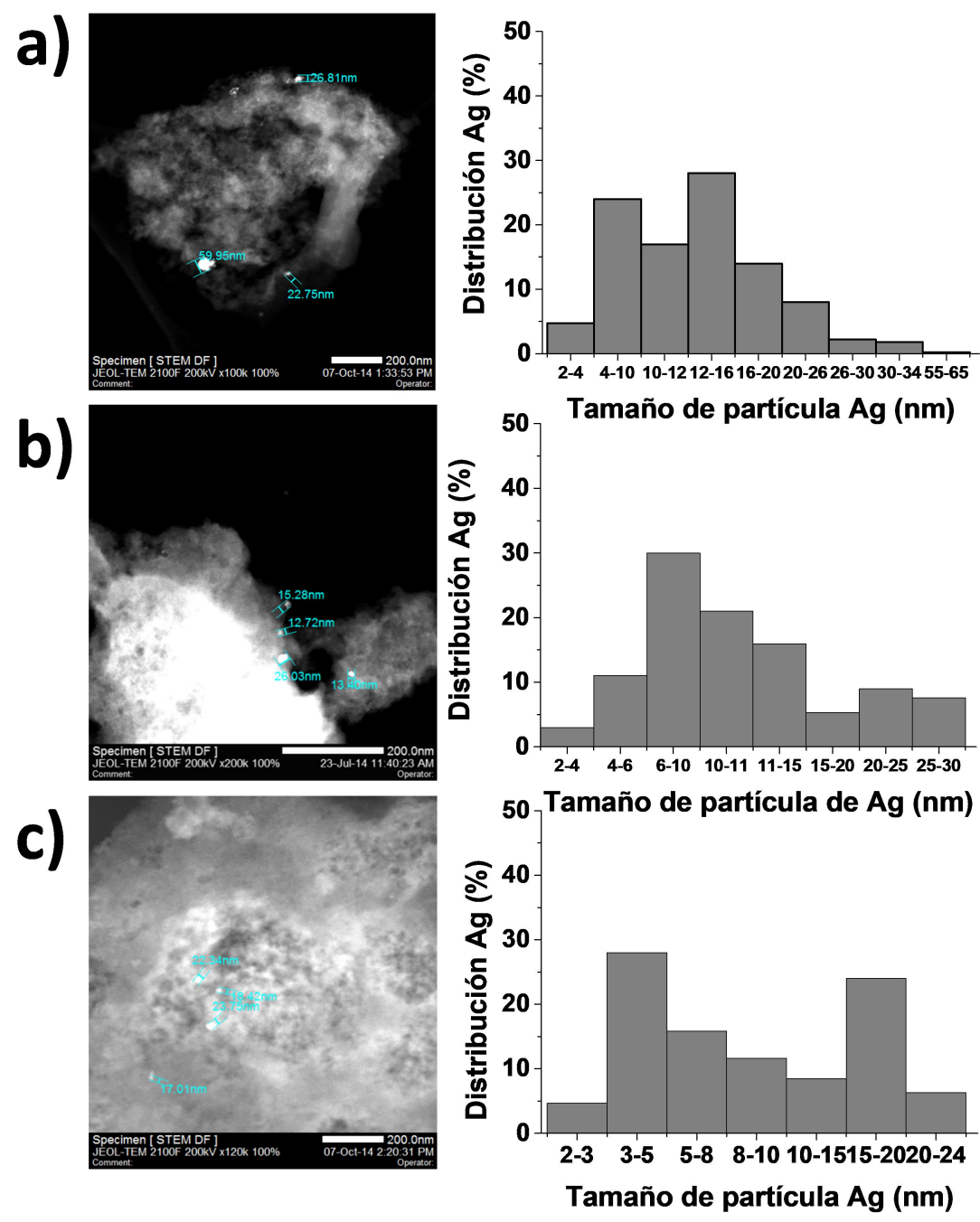

Figura 3.4. Imágenes de DF-STEM y distribuciones de tamaño de partícula de $\mathrm{Ag} / \mathrm{AC} 1$ (a), Ag/AC2 (b) y Ag/AC3 (c). El tamaño medio de partícula de la plata metálica para $\mathrm{Ag} / \mathrm{AC} 1, \mathrm{Ag} / \mathrm{AC} 2$ y $\mathrm{Ag} / \mathrm{AC} 3$ es de $13.5 \pm 9.7,11.6 \pm$ 9.1 y $8.9 \pm 7.6 \mathrm{~nm}$, respectivamente. Nota: Carga de Ag $0.2 \%$ en peso. 

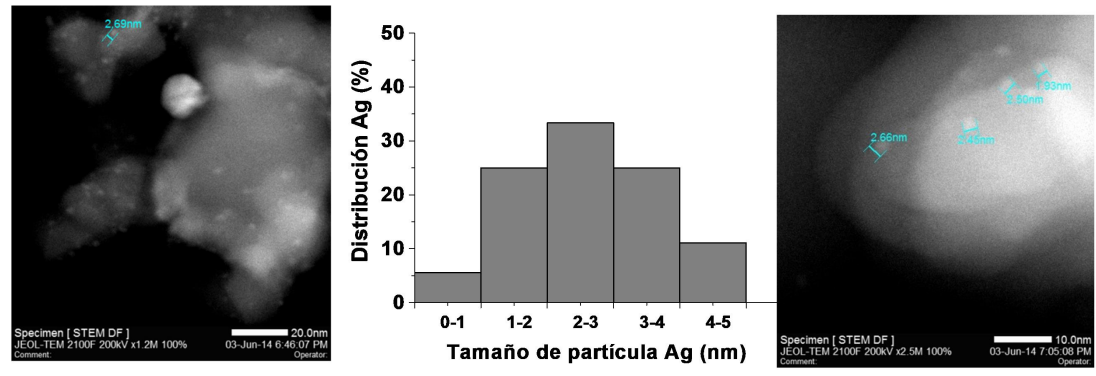

Figura 3.5. Imágenes de DF-STEM y distribuciones de tamaño de partícula de $\mathrm{Ag} / \mathrm{TiO}_{2}$. Tamaño medio de partícula de la plata de $3.1 \pm 1.6 \mathrm{~nm}$. Nota: Carga de Ag $0.2 \%$ en peso.
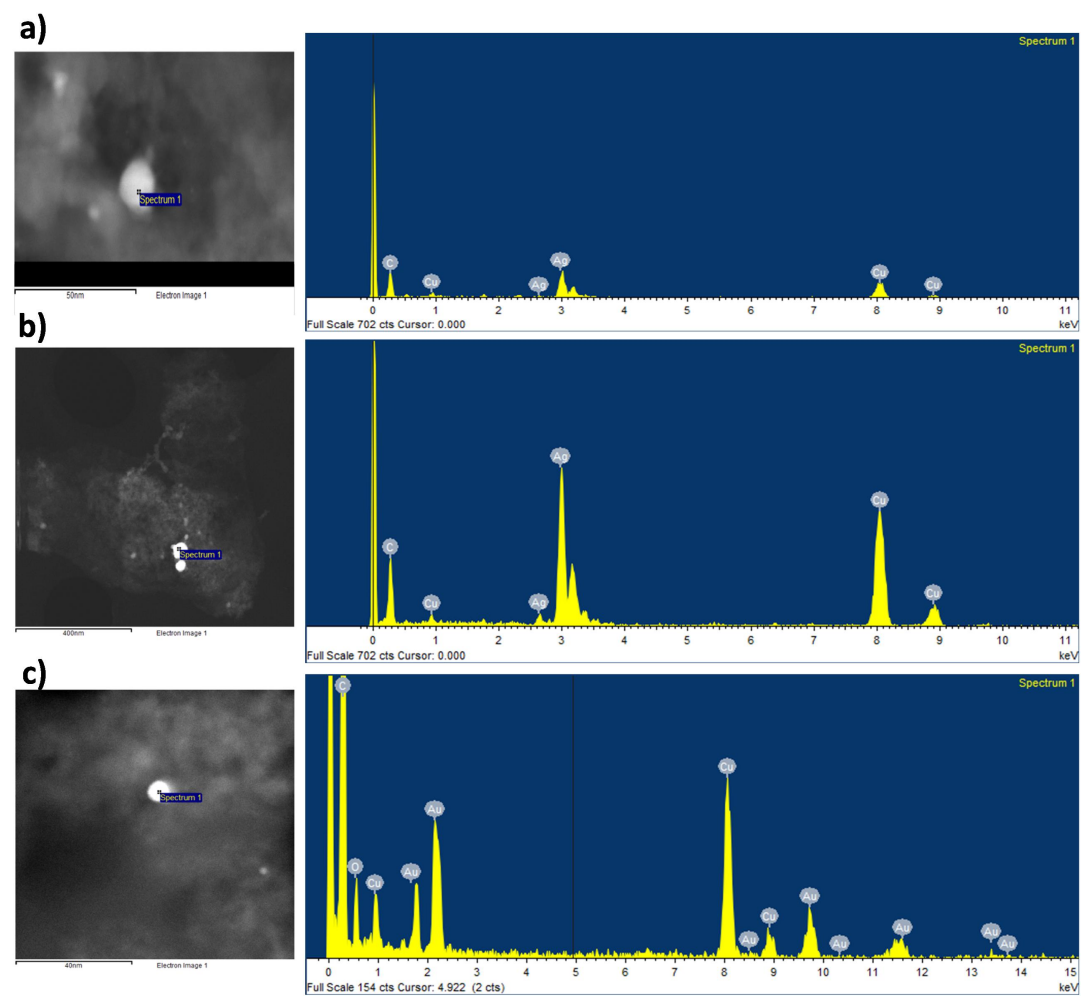

Figura 3.6. Imágenes de DF-STEM con sus correspondientes microanálisis representativos EDS para (a) $\mathrm{Ag} / \mathrm{D} 1$, (b) $\mathrm{Ag} / \mathrm{AC} 1$ y (c) $\mathrm{Au} / \mathrm{D} 3$. Nota: Carga de $\mathrm{Ag}$ o $\mathrm{Au}$ de $0.2 \%$ en peso. 
Nanoparticulas de plata soportadas sobre nanopartículas de diamante como catalizadores eficientes de la reacción de Fenton por irradiación con luz solar natural.

Como consecuencia del bajo contenido en metal presente en las muestras de fotocatalizadores evaluadas $(0,2 \%$ en peso), la difracción de rayos $\mathrm{X}$ no fue capaz de detectar ninguno de los picos de difracción característicos de $\mathrm{Au}$ y $\mathrm{Ag}$ metálicos. Las figuras 3.7 a 3.11 muestran estos difractogramas. ${ }^{13} \mathrm{La}$ ausencia de picos característicos de $\mathrm{Ag}$ y $\mathrm{Au}$ en difracción de rayos X, junto con las imágenes de DF-STEM que muestran una distribución homogénea de NPs metálicas de tamaño pequeño, entre 3 y $10 \mathrm{~nm}$ ), indican una buena dispersión del metal sobre los diferentes soportes. La influencia de la carga de metal sobre el soporte fue estudiada comparando muestras en las que el contenido de $\mathrm{Ag}$ depositado sobre D3 fue del $1 \%$ en peso. Para esta muestra con un contenido mayor de Ag sí fue posible observar el modelo de difracción correspondiente a la Ag metálica, tal como se puede observar en la figura 3.10 .

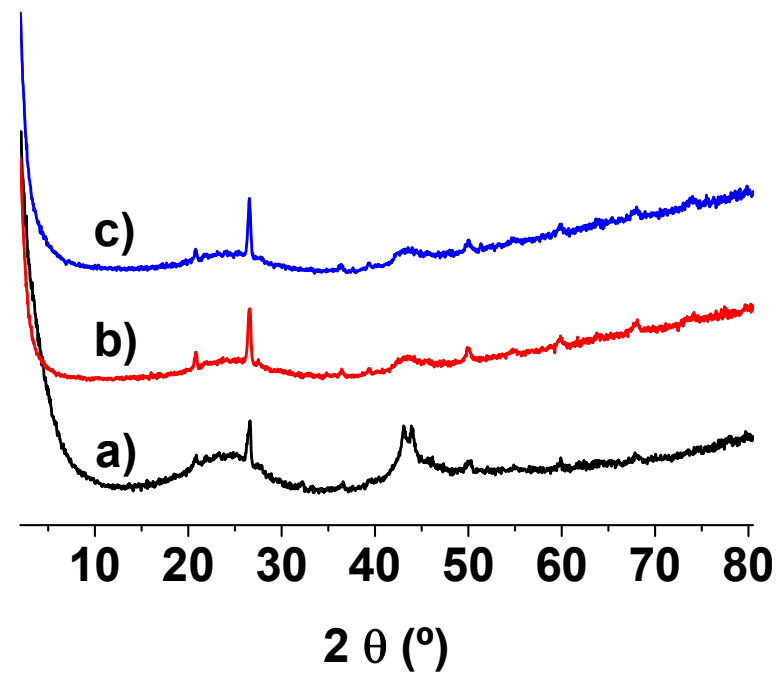

Figura 3.7. Difractogramas de rayos $\mathrm{X}$ de $\mathrm{Ag} / \mathrm{AC} 1$ (a), $\mathrm{Ag} / \mathrm{AC} 2$ (b) $\mathrm{y}$ $\mathrm{Ag} / \mathrm{AC} 3$ (c). Nota: Carga de Ag de $0.2 \%$ en peso. 


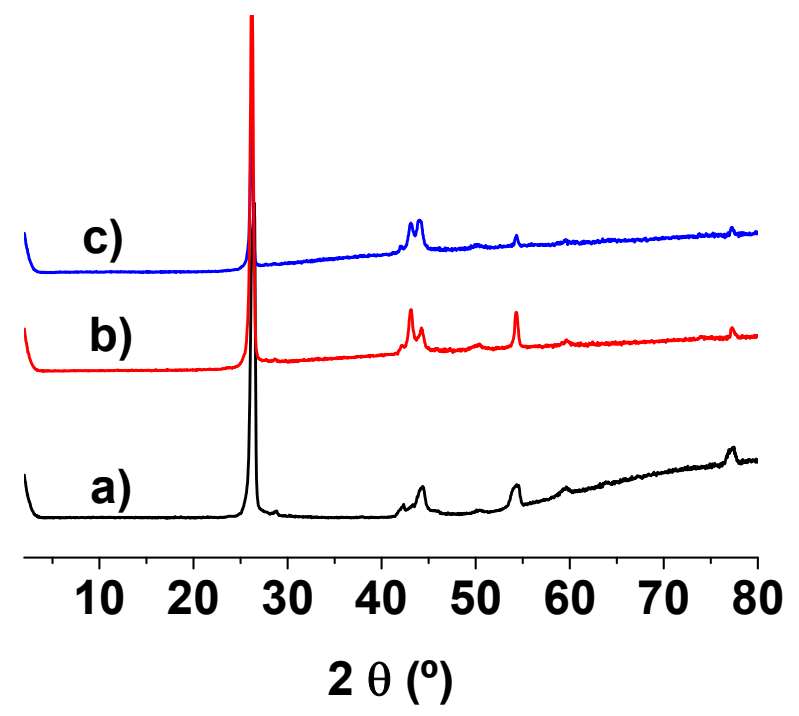

Figura 3.8. Difractogramas de rayos $\mathrm{X}$ de $\mathrm{Ag} / \mathrm{Gr} 1$ (a), Ag/Gr2 (b) y Ag/Gr3 (c). Nota: Carga de Ag de $0.2 \%$ en peso.

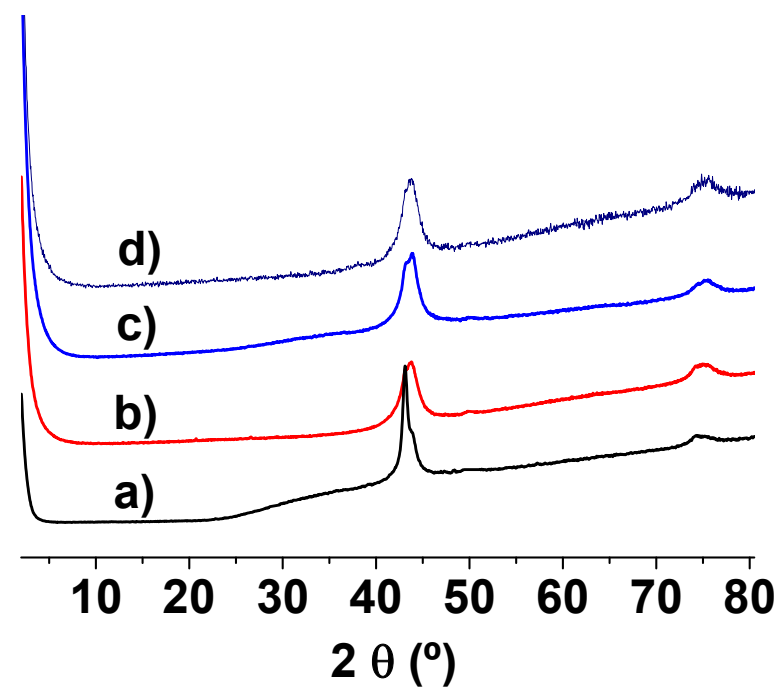

Figura 3.9. Difractogramas de rayos $\mathrm{X}$ de $\mathrm{Ag} / \mathrm{D} 1$ (a), $\mathrm{Ag} / \mathrm{D} 2$ (b), $\mathrm{Ag} / \mathrm{D} 3$ (c) y Au/D3 (d). Nota: Carga de Ag de $0.2 \%$ en peso 
Nanoparticulas de plata soportadas sobre nanopartículas de diamante como catalizadores eficientes de la reacción de Fenton por irradiación con luz solar natural.

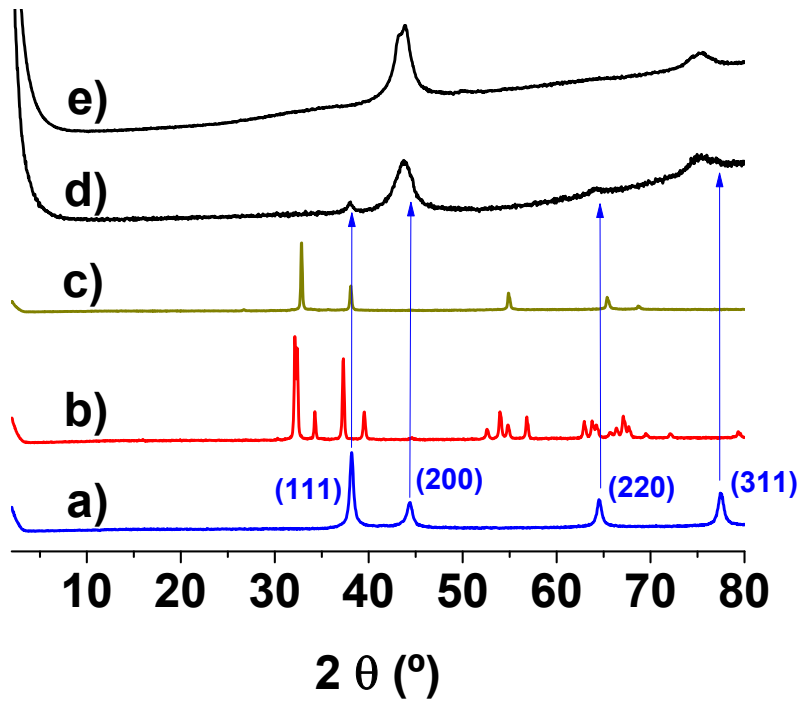

Figura 3.10. Difractogramas de rayos $X$ de $A g$ comercial (a), $\operatorname{Ag}_{2} \mathrm{O}$ comercial (b), $\mathrm{AgO}$ comercial (c), $\operatorname{Ag}(1 \%$ en peso)/D3 (d) y $\operatorname{Ag}(0.2 \%$ en peso)/D3 (e).

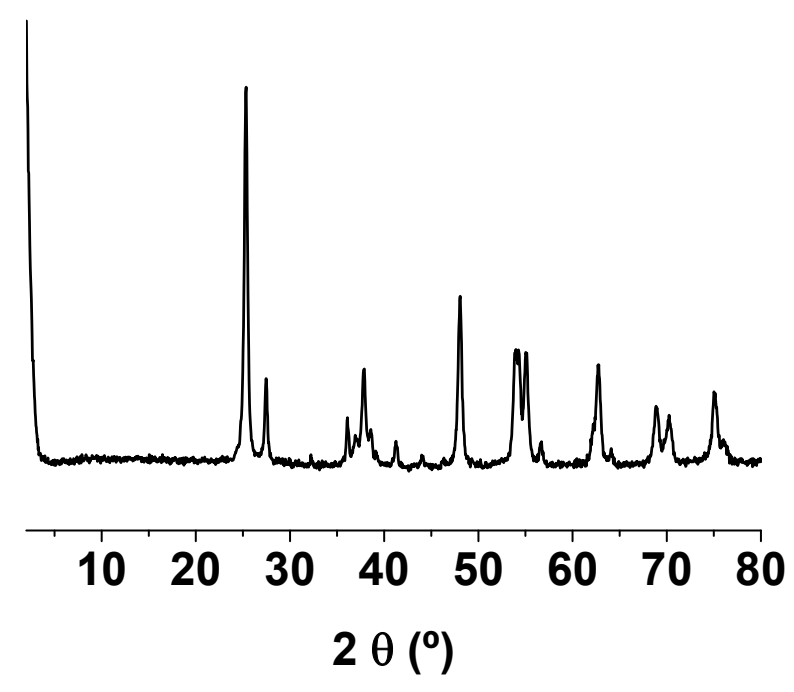

Figura 3.11. Difractograma de rayos $\mathrm{X}$ de $\mathrm{Ag}(0.2 \%$ en peso $) / \mathrm{TiO}_{2}$. 


\subsubsection{Experimentos fotocatalíticos}

La muestra Ag/D3 fue casi tan activa para promover la reacción de foto-Fenton por irradiación con luz solar natural que la muestra $\mathrm{Au} / \mathrm{D} 3$. La figura 3.12 muestra los perfiles temporales para la degradación de fenol y de agua oxigenada medido para estas muestras. Aunque la actividad catalítica de la muestra Au/D3 es ligeramente más elevada que la de la muestra $\mathrm{Ag} / \mathrm{D} 3$, ésta última es también capaz de degradar completamente el fenol presente en disoluciones acuosas como molécula sonda en un tiempo corto. Por consiguiente, la muestra Ag/D3 puede ser una alternativa eficiente y más barata para este proceso. Es interesante hacer notar que la actividad del proceso promovido por $\mathrm{Ag} / \mathrm{D} 3$ como catalizador aumenta significativamente por irradiación con luz solar natural con respecto a un proceso análogo llevado a cabo en la oscuridad. Tal como se ha descrito por nuestro grupo en trabajos anteriores para la muestra $\mathrm{Au} / \mathrm{D} 2$, este aumento de actividad por iluminación de la muestra Ag/D3 como catalizador es probablemente causado por la excitación de la banda de plasmón superficial de la plata $\left(\lambda_{\max }\right.$ aproximadamente $410 \mathrm{~nm}$ ) por los fotones presentes en la luz solar natural de longitudes de onda correspondiente. ${ }^{12,19,21}$ La excitación de la banda de plasmón de Ag debe conducir a la emisión fotoinducida de electrones los cuales podrían ser capturados por $\mathrm{H}_{2} \mathrm{O}_{2}$, resultando en la producción de radicales hidroxilo.
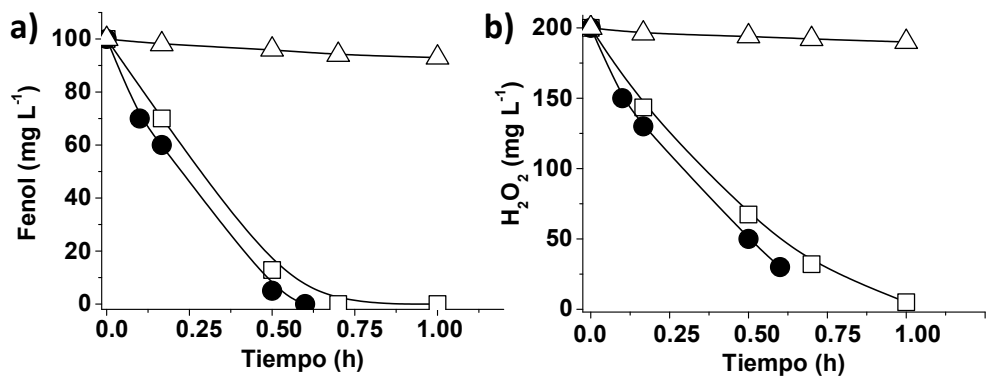

Figura 3.12. Perfil temporal de degradación del fenol (a) y descomposición de $\mathrm{H}_{2} \mathrm{O}_{2}$ (b) usando bien $\mathrm{Au} / \mathrm{D} 3(\bullet)$ o $\mathrm{Ag} / \mathrm{D} 3$ (口) bajo irradiación solar natural. La eficiencia del catalizador $\mathrm{Ag} / \mathrm{D} 3$ en la oscuridad $(\Delta)$ también se indica en la figura. Condiciones de reacción: catalizador (15 mg de Au NPs sobre D3, u $8.4 \mathrm{mg}$ de Ag NPs sobre D3; $0.0063 \mathrm{mM}$ de NPs metálicas en ambos casos), fenol (100 mg L $\left.\mathrm{m}^{-1}, 1.06 \mathrm{mM}\right), \mathrm{H}_{2} \mathrm{O}_{2}\left(200 \mathrm{mg} \mathrm{L}^{-1} ; 5.8 \mathrm{mM}\right), \mathrm{pH}$ inicial 4. Concentración de fenol obtenida por HPLC y de $\mathrm{H}_{2} \mathrm{O}_{2}$ por espectrofotometría, como se indica en el capítulo 8 , sección experimental. 
Nanoparticulas de plata soportadas sobre nanopartículas de diamante como catalizadores eficientes de la reacción de Fenton por irradiación con luz solar natural.

Una comparación de todos los catalizadores basados en Ag NPs que han sido estudiados en el presente capítulo muestra que el material Ag/D3 es el que exhibe la actividad catalítica más elevada para la reacción de foto-Fenton por irradiación con luz natural (figuras 3.13 a la 3.16). Un ajuste de los perfiles temporales de la concentración de fenol a una cinética de primer orden fue relativamente satisfactorio (ver figura 3.14), lo cual permite estimar constantes de velocidad para la degradación de fenol empleando como catalizadores Ag/D1, Ag/D2 y Ag/D3. Los valores obtenidos de constante de velocidad fueron de $0.11,1.83$ y 4.73 $\mathrm{s}^{-1}$, respectivamente. Se propone que la distribución de tamaño de partícula menor para la muestra $\mathrm{Ag} / \mathrm{D} 3$ con respecto a las otras Ag NPs soportadas en diferentes materiales de carbono podría ser la razón de esta mayor actividad catalítica.
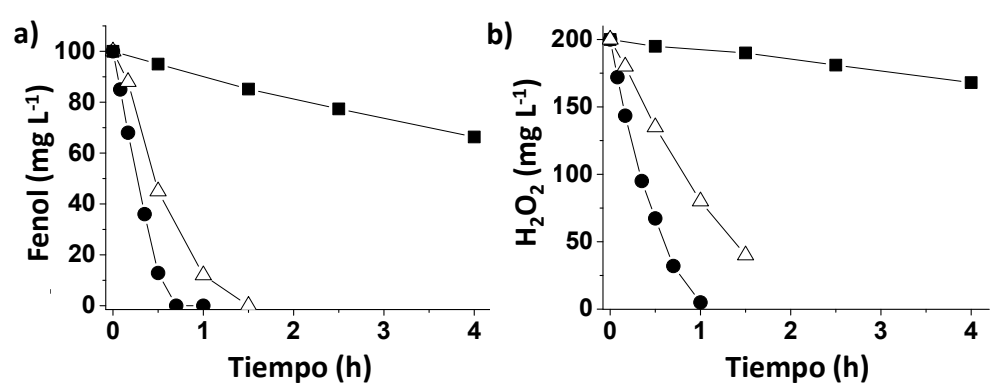

Figura 3.13. Perfil temporal de degradación del fenol (a) y descomposición de $\mathrm{H}_{2} \mathrm{O}_{2}$ (b) usando Ag/D3 (•), Ag/D2 ( $\Delta$ ) y Ag/D1 (•) bajo irradiación solar natural. Condiciones de reacción: catalizador $\left(8.4 \mathrm{mg}, 336 \mathrm{mg} \mathrm{L}^{-1} ; 0.0063\right.$ $\mathrm{mM}$ de Ag NPs soportadas), fenol (100 mg L $\left.\mathrm{m}^{-1}, 1.06 \mathrm{mM}\right), \mathrm{H}_{2} \mathrm{O}_{2}\left(200 \mathrm{mg} \mathrm{L}^{-1}\right.$; $5.8 \mathrm{mM}$ ), pH inicial 4. Concentración de fenol obtenida por HPLC y de $\mathrm{H}_{2} \mathrm{O}_{2}$ por espectrofotometría, como se indica en el capítulo 8 , sección experimental. 

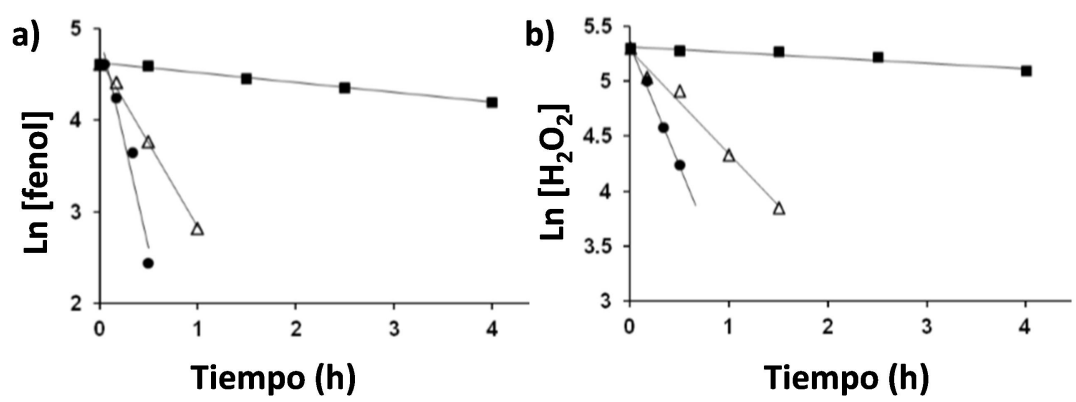

Figura 3.14. Representación de $\operatorname{Ln}[\mathrm{fenol}]$ con respecto al tiempo (izquierda) y de $\mathrm{Ln}\left[\mathrm{H}_{2} \mathrm{O}_{2}\right]$ respecto al tiempo (derecha) correspondiente a la figura 3.13, donde se muestra que las cinéticas de reacción siguen aparentemente una cinética de primer orden. Leyenda: $\mathrm{Ag} / \mathrm{D} 3(\bullet), \mathrm{Ag} / \mathrm{D} 2(\Delta)$ y Ag/D1 (•). Condiciones de reacción: catalizador $\left(8.4 \mathrm{mg}, 336 \mathrm{mg} \mathrm{L}^{-1} ; 0.0063 \mathrm{mM}\right.$ de $\mathrm{Ag}$ NPs soportadas), fenol (100 mg L$\left.{ }^{-1}, 1.06 \mathrm{mM}\right), \mathrm{H}_{2} \mathrm{O}_{2}\left(200 \mathrm{mg} \mathrm{L}^{-1} ; 5.8 \mathrm{mM}\right)$, pH inicial 4. Concentración de fenol obtenida por HPLC y de $\mathrm{H}_{2} \mathrm{O}_{2}$ por espectrofotometría, como se indica en el capítulo 8, sección experimental.
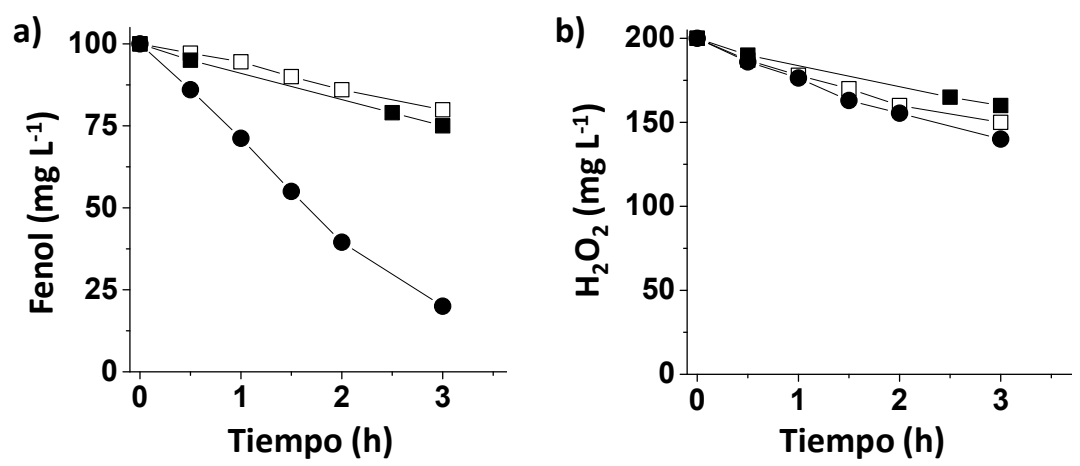

Figura 3.15. Perfil temporal de degradación del fenol (a) y descomposición de $\mathrm{H}_{2} \mathrm{O}_{2}$ (b) usando $\mathrm{Ag} / \mathrm{Gr} 3(\bullet), \mathrm{Ag} / \mathrm{Gr} 2(\bullet)$ y Ag/Gr1 (口) bajo irradiación solar natural. Condiciones de reacción: catalizador $\left(8.4 \mathrm{mg}, 336 \mathrm{mg} \mathrm{L}^{-1}\right.$; $0.0063 \mathrm{mM}$ de Ag NPs soportadas), fenol (100 mg L $\left.{ }^{-1}, 1.06 \mathrm{mM}\right), \mathrm{H}_{2} \mathrm{O}_{2}(200$ $\mathrm{mg} \mathrm{L}^{-1} ; 5.8 \mathrm{mM}$ ), $\mathrm{pH}$ inicial 4. Concentración de fenol obtenida por HPLC y de $\mathrm{H}_{2} \mathrm{O}_{2}$ por espectrofotometría, como se indica en el capítulo 8 , sección experimental. 
a)

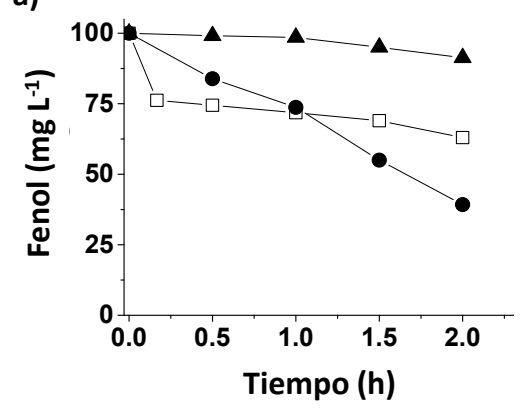

b)

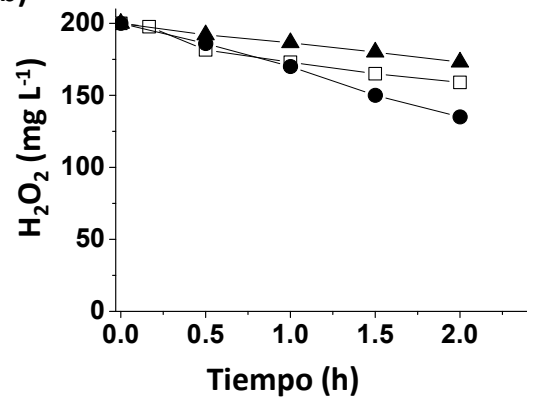

Figura 3.16. Perfil temporal de degradación del fenol (a) y descomposición de $\mathrm{H}_{2} \mathrm{O}_{2}$ (b) usando $\mathrm{Ag} / \mathrm{AC} 3(\bullet), \mathrm{Ag} / \mathrm{AC} 2$ ( $\boldsymbol{\Delta}$ ) y $\mathrm{Ag} / \mathrm{AC} 1$ ( $\square$ ) bajo irradiación solar natural. Condiciones de reacción: catalizador $(8.4 \mathrm{mg}, 336$ $\mathrm{mg} \mathrm{L}{ }^{-1} ; 0.0063 \mathrm{mM}$ de Ag NPs soportadas), fenol (100 mg L $\left.\mathrm{L}^{-1}, 1.06 \mathrm{mM}\right)$, $\mathrm{H}_{2} \mathrm{O}_{2}\left(200 \mathrm{mg} \mathrm{L}{ }^{-1} ; 5.8 \mathrm{mM}\right), \mathrm{pH}$ inicial 4. Concentración de fenol obtenida por HPLC y de $\mathrm{H}_{2} \mathrm{O}_{2}$ por espectrofotometría, como se indica en el capítulo 8, sección experimental.

A fin de apoyar esta hipótesis, la actividad catalítica para la degradación de fenol y descomposición del agua oxigenada para la muestra Ag/D3 (3.2 nm) se comparó con la de las muestras más activas de Ag NPs soportadas sobre muestras de AC y Gr que presentaban el tamaño de partícula promedio menor en sus series, es decir Ag/AC3 (8.9 $\mathrm{nm})$ y Ag/G3 (8.5 nm). Los resultados se muestran en la figura 3.17.
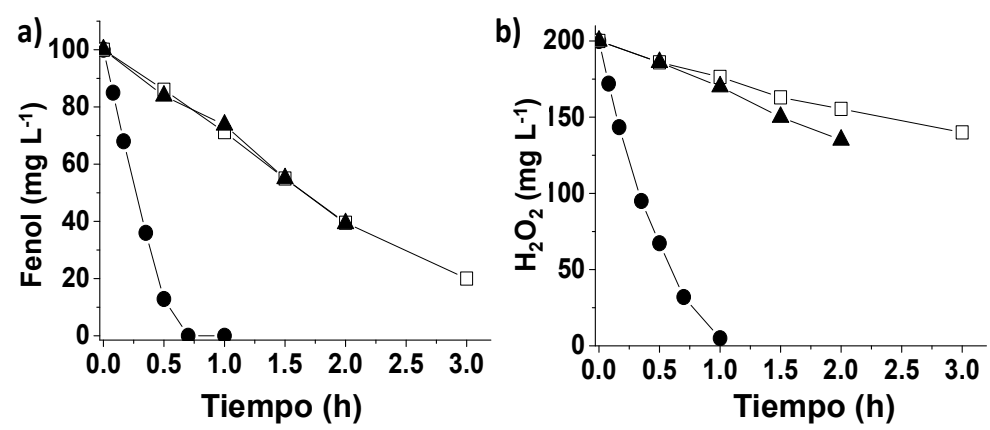

Figura 3.17. Perfiles temporales de degradación del fenol (a) y descomposición de $\mathrm{H}_{2} \mathrm{O}_{2}$ (b) usando Ag NPs soportadas en diferentes materiales carbonaceos como catalizador bajo irradiación con luz solar 
natural. Leyenda: $\mathrm{Ag} / \mathrm{D} 3(\bullet), \mathrm{Ag} / \mathrm{AC} 3(\boldsymbol{\Delta})$ y $\mathrm{Ag} / \mathrm{Gr} 3(\square)$. Condiciones de reacción: catalizador ( $8.4 \mathrm{mg}, 336 \mathrm{mg} \mathrm{L}^{-1}, 0.0063 \mathrm{mM}$ de Ag NPs soportado) fenol (100 mg L $\left.\mathrm{m}^{-1}, 1.06 \mathrm{mM}\right), \mathrm{H}_{2} \mathrm{O}_{2}\left(200 \mathrm{mg} \mathrm{L}^{-1} ; 5.88 \mathrm{mM}\right), \mathrm{pH}$ inicial 4. Concentración de fenol obtenida por HPLC y de $\mathrm{H}_{2} \mathrm{O}_{2}$ por espectrofotometría, como se indica en el capítulo 8, sección experimental.

Es interesante hacer notar que de manera similar a lo observado en las muestras empleando D como soporte, el tratamiento de los soportes a base de carbono AC o Gr con la reacción de Fenton en fase homogénea seguida de tratamiento térmico con hidrógeno a alta temperatura presenta una influencia positiva sobre la distribución de tamaño de nanopartícula en la deposición de Ag NPs (ver figuras 3.3 y 3.4) lo cual conduce a una actividad catalítica mayor tal como se puede observar en las figuras 3.15 y 3.16. La actividad catalítica de Ag/D3 (3.2 nm de tamaño de partícula promedio) como catalizador de la reacción de foto-Fenton fue también mayor que la observada para la muestra $\mathrm{Ag} / \mathrm{TiO}_{2}$ que posee un tamaño de $\mathrm{Ag}$ promedio muy similar $(3.1 \mathrm{~nm})$. La figura 3.18 muestra esta comparación. La mayor eficiencia de $\mathrm{Ag} / \mathrm{D} 3$ con respecto a $\mathrm{Ag} / \mathrm{TiO}_{2}$ en la activación de $\mathrm{H}_{2} \mathrm{O}_{2}$ a radical hidroxilo se manifiesta también en una eficiencia mayor en la relación molar $\mathrm{H}_{2} \mathrm{O}_{2}$ consumida/ fenol degradado, obteniendo valores de 4.5 y 6.5 para $\mathrm{Ag} / \mathrm{D} 3$ y $\mathrm{Ag} / \mathrm{TiO}_{2}$, respectivamente. De hecho experimentos control en la oscuridad usando $\mathrm{Ag} / \mathrm{TiO}_{2}$ o incluso $\mathrm{TiO}_{2}$ solo como fotocatalizadores dieron lugar a degradaciones despreciables de fenol, pero donde se observa la descomposición ineficiente de $\mathrm{H}_{2} \mathrm{O}_{2}$, probablemente en $\mathrm{H}_{2} \mathrm{O}$ y $\mathrm{O}_{2}$. La figura 3.19 presenta estos resultados.
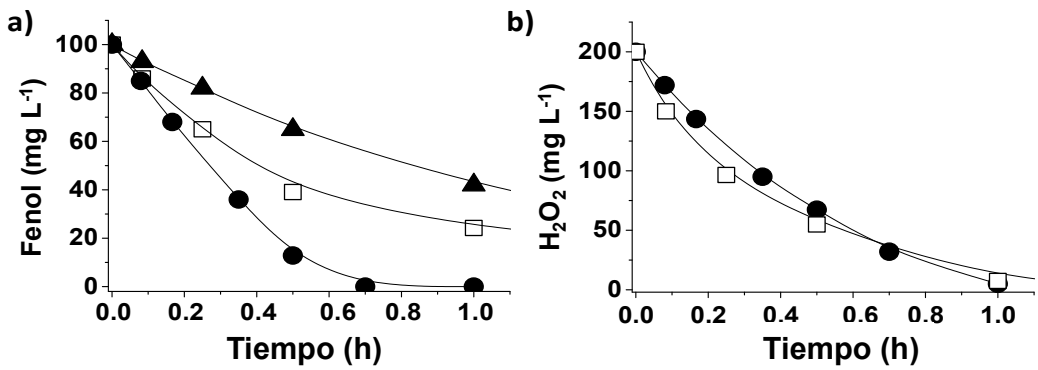

Figura 3.18. Perfiles temporales de degradación del fenol (a) y descomposición de $\mathrm{H}_{2} \mathrm{O}_{2}$ (b) usando $\mathrm{Ag} / \mathrm{D} 3(\bullet), \mathrm{Ag} / \mathrm{TiO}_{2}$ ( $\left(\right.$ ), $\mathrm{y} \mathrm{Ag} / \mathrm{TiO}{ }_{2} \sin$

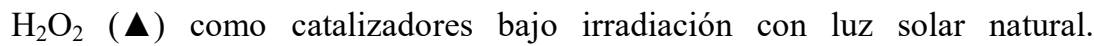


Nanoparticulas de plata soportadas sobre nanopartículas de diamante como catalizadores eficientes de la reacción de Fenton por irradiación con luz solar natural.

Condiciones de reacción: catalizador $\left(8.4 \mathrm{mg}, 336 \mathrm{mg} \mathrm{L}^{-1} ; 0.0063 \mathrm{mM}\right.$ de Ag NPs soportadas), fenol (100 mg L $\left.{ }^{-1} ; 1.06 \mathrm{mM}\right), \mathrm{H}_{2} \mathrm{O}_{2}\left(200 \mathrm{mg} \mathrm{L}^{-1} ; 5.88 \mathrm{mM}\right)$, $\mathrm{pH}$ inicial 4. Concentración de fenol obtenida por HPLC y de $\mathrm{H}_{2} \mathrm{O}_{2}$ por espectrofotometría, como se indica en el capítulo 8, sección experimental.
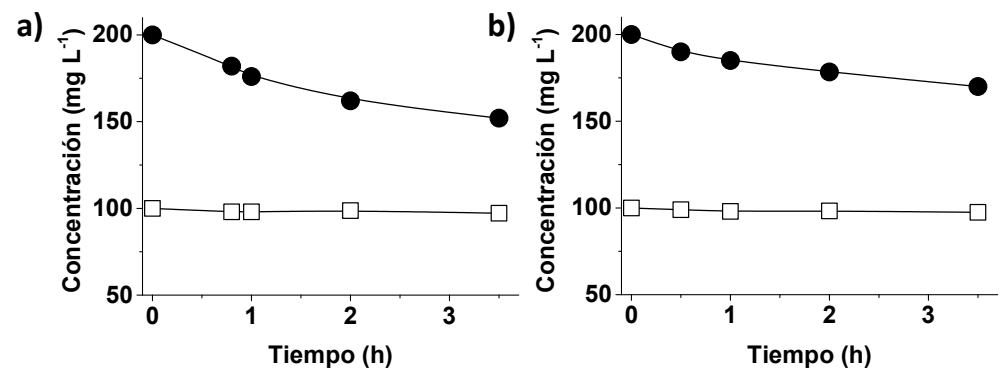

Figura 3.19. Perfiles temporales de degradación del fenol ( $\square$ ) y descomposición de $\mathrm{H}_{2} \mathrm{O}_{2}(\bullet)$ usando $\mathrm{Ag} / \mathrm{TiO}_{2}$ (a) o $\mathrm{TiO}_{2}($ b) en ausencia de irradiación. Condiciones de reacción: catalizador $\left(8.4 \mathrm{mg}, 336 \mathrm{mg} \mathrm{L}^{-1} \mathrm{y} / \mathrm{o}\right.$ $0.0063 \mathrm{mM}$ de Ag NPs soportadas), fenol (100 mg L $\left.\mathrm{mg}^{-1} ; 1.06 \mathrm{mM}\right), \mathrm{H}_{2} \mathrm{O}_{2}(200$ $\left.\mathrm{mg} \mathrm{L}^{-1} ; 5.88 \mathrm{mM}\right), \mathrm{pH}$ inicial 4. Concentración de fenol obtenida por HPLC y de $\mathrm{H}_{2} \mathrm{O}_{2}$ por espectrofotometría, como se indica en el capítulo 8, sección experimental.

La mayor actividad catalítica de $\mathrm{Ag} / \mathrm{D} 3$ con respecto a $\mathrm{Ag} / \mathrm{TiO}_{2}$ se evidencia incluso de forma más clara si se considera la degradación no solo del fenol, sino también la de los intermedios de reacción más tóxicos tales como el catecol, la hidroquinona y la $p$-benzoquinona (ver figura 3.20). ${ }^{22}$ Más aún, la actividad catalítica de $\mathrm{Ag} / \mathrm{D} 3$ usando $\mathrm{H}_{2} \mathrm{O}_{2}$ como oxidante fue mucho mayor que la de $\mathrm{Ag} / \mathrm{TiO}_{2}$ en ausencia de $\mathrm{H}_{2} \mathrm{O}_{2}$ (ver figuras 3.18 y 3.20 ). 


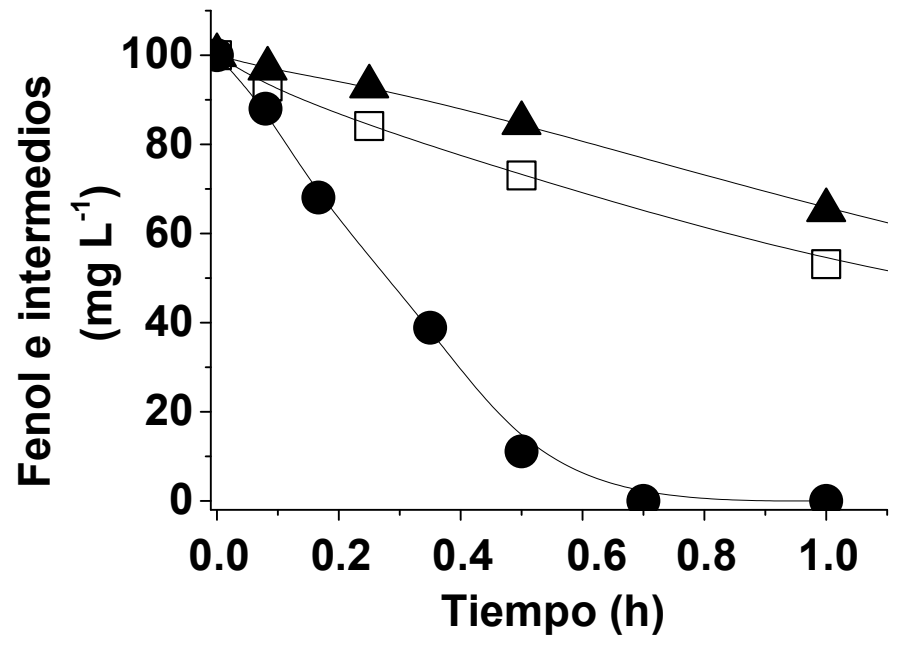

Figura 3.20. Perfil de degradación del fenol y de sus principales intermedios de reacción (catecol, hidroquinona y $p$-benzoquinona) usando Ag/D3 (•), $\mathrm{Ag} / \mathrm{TiO}_{2}(\square)$ y $\mathrm{Ag} / \mathrm{TiO}_{2}$ sin $\mathrm{H}_{2} \mathrm{O}_{2}(\boldsymbol{\Delta})$ como catalizadores bajo irradiación con luz solar natural. Condiciones de reacción: catalizador $(8.4 \mathrm{mg}, 336 \mathrm{mg}$ $\mathrm{L}^{-1} ; 0.0063 \mathrm{mM}$ de Ag NPs soportadas), fenol (100 mg L $\left.{ }^{-1} ; 1.06 \mathrm{mM}\right), \mathrm{H}_{2} \mathrm{O}_{2}$ (200 mg L $\left.{ }^{-1} ; 5.88 \mathrm{mM}\right), \mathrm{pH}$ inicial 4. Concentración de fenol e intermedios obtenida por HPLC y de $\mathrm{H}_{2} \mathrm{O}_{2}$ por espectrofotometría, como se indica en el capítulo 8 , sección experimental.

Empleando Ag/D3 como catalizador se procedió a establecer la influencia de dos parámetros relevantes en la reacción de foto-Fenton heterogénea, a saber, la concentración e $\mathrm{H}_{2} \mathrm{O}_{2}$ y el efecto del valor del $\mathrm{pH}$ inicial de la disolución. En primer lugar, la relación molar inicial $\mathrm{H}_{2} \mathrm{O}_{2}$ /fenol fue optimizada considerando la degradación no solo del fenol sino también la de los intermedios de degradación, es decir, catecol, hidroquinona y $p$-benzoquinona. El resultado se muestra en la figura 3.21. Es interesante recordar que el $\mathrm{H}_{2} \mathrm{O}_{2}$ es un reactivo relativamente costoso que contribuye en gran medida al coste final de la reacción de fotoFenton y, por tanto, es necesario minimizar su consumo a fin de hacer atractivo este proceso en tratamiento de aguas residuales. ${ }^{23,24}$. Por otra parte, un exceso de $\mathrm{H}_{2} \mathrm{O}_{2}$ puede influir negativamente en el proceso de foto-Fenton debido a la inhibición de radicales hidroxilo por reacción con $\mathrm{H}_{2} \mathrm{O}_{2}$, que da lugar a la formación de radicales hidroperoxilo (HOO') que son considerablemente menos reactivos. ${ }^{7,25}$ La degradación del fenol y sus intermedios de reacción puede llevarse a cabo usando una relación 
Nanoparticulas de plata soportadas sobre nanopartículas de diamante como catalizadores eficientes de la reacción de Fenton por irradiación con luz solar natural.

molar inicial $\mathrm{H}_{2} \mathrm{O}_{2} /$ fenol de 5.5 , mientras que solo 4.5 equivalentes son consumidos en el proceso y, por tanto, una concentración residual de oxidante de entorno al $20 \%$ se encuentra presente a tiempos finales de reacción (figura 3.21). Esta baja relación molar $\mathrm{H}_{2} \mathrm{O}_{2} /$ fenol es digna de ser destacada, considerando que estudios en la literatura emplean excesos molares de $\mathrm{H}_{2} \mathrm{O}_{2}$ con fotocatalizadores heterogéneos de hasta 10000 veces superior, principalmente debido a la descomposición espuria de este oxidante en $\mathrm{H}_{2} \mathrm{O}_{2}$ y oxígeno. ${ }^{24}$

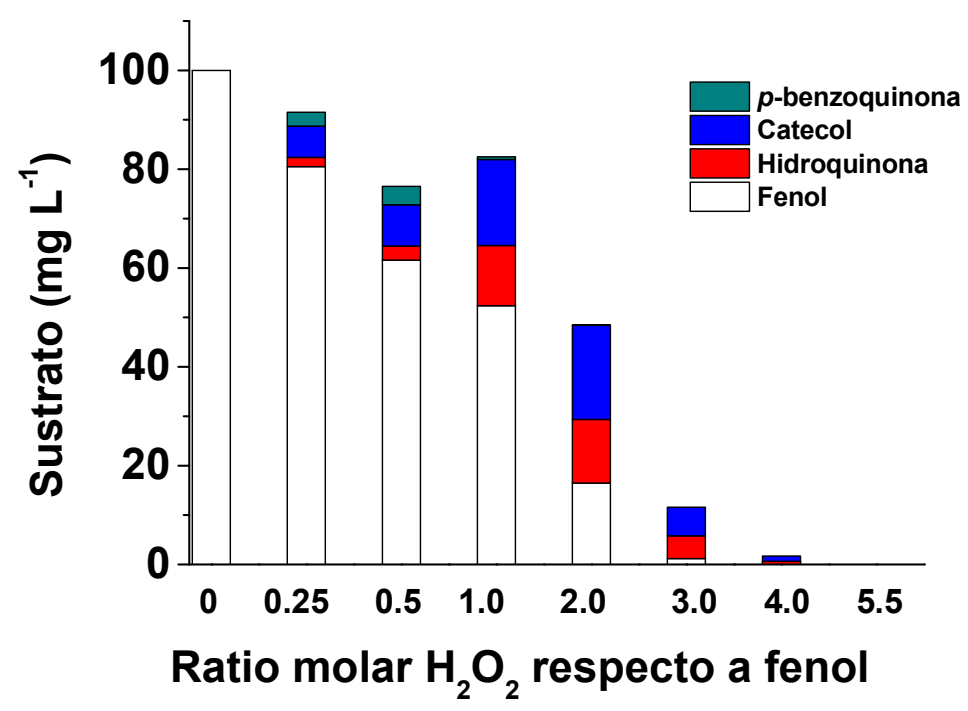

Figura 3.21. Influencia del ratio molar de $\mathrm{H}_{2} \mathrm{O}_{2}$ respecto a fenol para la degradación del fenol y de sus principales intermedios de reacción (catecol, hidroquinona y $p$-benzoquinona) usando $\mathrm{Ag} / \mathrm{D} 3$. Condiciones de reacción: Ag/D3 (8.4 mg, $336 \mathrm{mg} \mathrm{L}^{-1} ; 0.0063 \mathrm{mM}$ de Ag NPs soportadas), fenol (100 $\left.\mathrm{mg} \mathrm{L}^{-1} ; 1.06 \mathrm{mM}\right), \mathrm{H}_{2} \mathrm{O}_{2}$ según se indica en la figura, $\mathrm{pH}$ inicial 4. Leyenda: Fenol (barra blanca), hidroquinona (barra roja), catecol (barra azul), $p$ benzoquinona (barra verde). Concentración de fenol e intermedios obtenida por HPLC y de $\mathrm{H}_{2} \mathrm{O}_{2}$ por espectrofotometría, como se indica en el capítulo 8, sección experimental.

Uno de los principales inconvenientes de la reacción de fotoFenton en fase homogénea es la necesidad de valores de pH ácidos (de 3 o inferior) presumiblemente para maximizar la presencia de la especia fotoactiva $\mathrm{Fe}(\mathrm{OH})^{2+}$ y, por consiguiente, la producción de radicales 
hidroxilo (ecuación 3.2) ${ }^{26}$. Sin embargo, algunos estudios con catalizadores sólidos han mostrado también la necesidad de valores de $\mathrm{pH}$ ácidos para promover la generación de radicales hidroxilo a partir del agua oxigenada. ${ }^{9,23,24}$ Una razón posible para este requerimiento de valores de $\mathrm{pH}$ ácidos podría ser la tendencia del $\mathrm{H}_{2} \mathrm{O}_{2}$ a sufrir desproporción de forma espontánea dando lugar a la formación de $\mathrm{O}_{2} \mathrm{y}$ $\mathrm{H}_{2} \mathrm{O}_{2}$ bajo condiciones de $\mathrm{pH}$ básicas sin producir en este caso la reacción de Fenton. El papel importante del valor de $\mathrm{pH}$ inicial para controlar la actividad fotocatalítica empleando $\mathrm{Ag} / \mathrm{D} 3$ como fotocatalizador $\mathrm{e}$ irradiando con luz solar simulada se pone de manifiesto al comparar los perfiles temporales de reacción a diferentes valores de $\mathrm{pH}$ inicial (figura 3.22). La actividad fotocatalítica tanto para la degradación de fenol como para la descomposición del $\mathrm{H}_{2} \mathrm{O}_{2}$ disminuye a medida que el valor inicial de $\mathrm{pH}$ aumenta. En el rango de valores de $\mathrm{pH}$ entre 4.5 y 7.5 se observa un período de inducción para la degradación del fenol que es atribuible al tiempo necesario para que el valor del $\mathrm{pH}$ inicial disminuya a un valor de $\mathrm{pH}$ 4. A partir de este valor de $\mathrm{pH}$ tiene lugar una aceleración del proceso de Fenton. Esta disminución espontánea en el pH de la reacción frente al tiempo es causada por la formación de ácidos carboxílicos generados por la degradación del fenol. ${ }^{11}$ Con respecto a la descomposición del $\mathrm{H}_{2} \mathrm{O}_{2}$, se observa una tendencia similar en las curvas de conversión frente a tiempo, es decir, las mayores velocidades de reacción se observan a $\mathrm{pH} 4$, y valores superiores a un $\mathrm{pH}$ inicial de 4.5 determina que las curvas presenten un periodo de inducción. Sin embargo, como es digno de hacer notar, la relación de $\mathrm{H}_{2} \mathrm{O}_{2}$ consumido/ fenol degradado en los tiempos de reacción medidos aumenta a medida que el $\mathrm{pH}$ inicial de la reacción aumenta, probablemente debido a la desproporción espuria del $\mathrm{H}_{2} \mathrm{O}_{2}$ a $\mathrm{H}_{2} \mathrm{O}$ y $\mathrm{O}_{2}$ sin generación de radical hidroxilo.
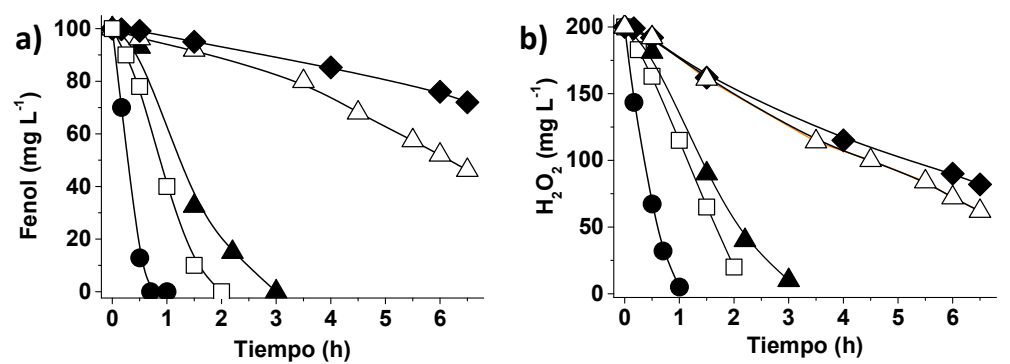

Figura 3.22. Perfiles temporales de degradación del fenol (a) y descomposición de $\mathrm{H}_{2} \mathrm{O}_{2}$ (b) en función del valor de $\mathrm{pH}$ inicial usando $\mathrm{Ag} / \mathrm{D} 3$ 
Nanoparticulas de plata soportadas sobre nanopartículas de diamante como catalizadores eficientes de la reacción de Fenton por irradiación con luz solar natural.

como catalizador bajo radiación con luz solar natural. Leyenda: $\mathrm{pH} 4(\bullet), 4.5$ ( $\square), 5.5(\Delta), 6.5(\Delta), 7.5(\triangleleft)$. Condiciones de reacción: catalizador $(8.4 \mathrm{mg}$, $336 \mathrm{mg} \mathrm{L}^{-1} ; 0.0063 \mathrm{mM}$ de Ag NPs soportadas), fenol (100 mg L $\mathrm{L}^{-1} ; 1.06$ $\mathrm{mM}), \mathrm{H}_{2} \mathrm{O}_{2}\left(200 \mathrm{mg} \mathrm{L}^{-1} ; 5.88 \mathrm{mM}\right), \mathrm{pH}$ inicial 4. Concentración de fenol obtenida por HPLC y de $\mathrm{H}_{2} \mathrm{O}_{2}$ por espectrofotometría, como se indica en el capítulo 8, sección experimental.

\subsubsection{Estabilidad y reusabilidad del catalizador}

Una ventaja importante de la catálisis heterogénea sobre la homogénea es la posibilidad de recuperar el catalizador para ser usado en reacciones consecutivas. En el caso presente, la muestra Ag/D3 fue recuperada del sistema de reacción por filtración, lavándose con abundante agua y usándose para una reacción ulterior. Hasta 8 consecutivos reúsos fueron llevados a cabo, observándose únicamente una pequeña disminución en la actividad catalítica inicial, aunque se consiguió la degradación completa del fenol pero a tiempos de reacción más largos. Los perfiles temporales de degradación del fenol y descomposición de agua oxigenada con el reúso de la muestra se presentan en la figura 3.23. El análisis químico elemental mediante ICPAES reveló que el contenido de $\mathrm{Ag}$ de la disolución acuosa tras la reacción catalítica estaba por debajo del límite de detección $\left(10 \mu \mathrm{g} \mathrm{L}^{-1}\right)$, indicando la ausencia de lixiviado de $\mathrm{Ag}$ en las condiciones de reacción indicadas. La disminución en la actividad catalítica de Ag/D3 con el reúso se puede atribuir principalmente a la agregación parcial de las $\mathrm{Ag}$ NPs depositadas sobre D3 tras 8 usos consecutivos, puesto que el tamaño de partícula promedio para esta muestra usada fue de $4 \mathrm{~nm}$ aproximadamente. Este valor es algo superior al que se determinó para la muestra fresca, que fue de $3.2 \mathrm{~nm}$. La figura 3.24 muestra imágenes de TEM así como el histograma de distribución del tamaño de partícula para las muestras de $\mathrm{Ag} / \mathrm{D} 3$ tras 8 usos consecutivos como catalizador. 

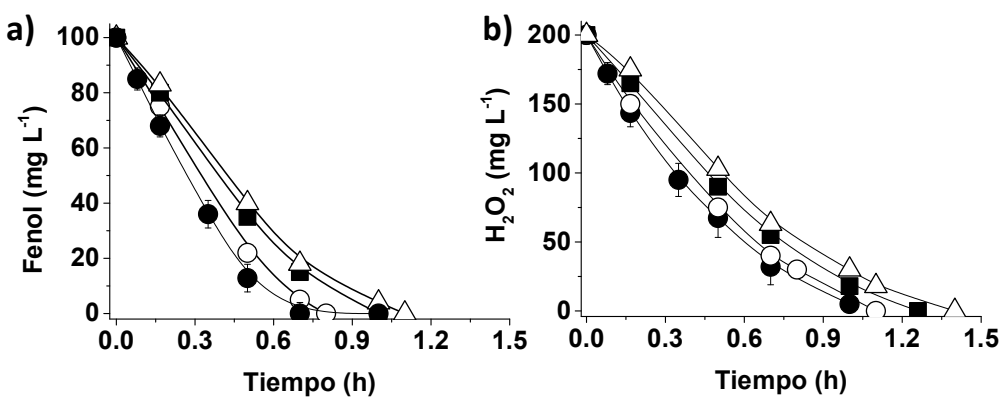

Figura 3.23. Perfiles temporales para la degradación de fenol (a) y descomposición de $\mathrm{H}_{2} \mathrm{O}_{2}$ (b) usando $\mathrm{Ag} / \mathrm{D} 3$ como catalizador. Leyenda: $1^{\circ}$ $(\bullet), 5^{\circ}(\mathrm{o}), 7^{\circ}(\mathbf{\bullet})$ y $8^{\circ}$ uso $(\Delta)$. Condiciones de reacción: catalizador $(8.4 \mathrm{mg}$, $336 \mathrm{mg} \mathrm{L}^{-1} ; 0.0063 \mathrm{mM}$ de Ag NPs soportado), fenol (100 mg L $\left.\mathrm{g}^{-1} ; 1.06 \mathrm{mM}\right)$, $\mathrm{H}_{2} \mathrm{O}_{2}\left(200 \mathrm{mg} \mathrm{L}^{-1} ; 5.88 \mathrm{mM}\right), \mathrm{pH}$ inicial 4. Nota: A fin de tener en cuenta las posibles variaciones de la luz solar natural, los datos correspondientes al primer uso son un promedio de 4 experimentos llevados a cabo durante cada uno de los reúsos del catalizador fresco. Concentración de fenol obtenida por HPLC y de $\mathrm{H}_{2} \mathrm{O}_{2}$ por espectrofotometría, como se indica en el capítulo 8, sección experimental.
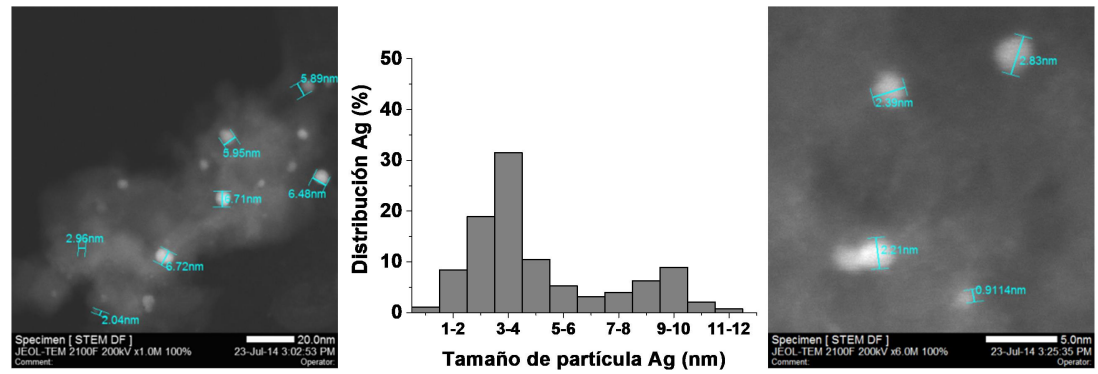

Figura 3.24. Imágenes de DF-STEM y distribución de tamaño de partícula de $\mathrm{Ag}(0.2 \%$ en peso)/D3 tras ocho usos. Tamaño medio de partícula de la plata metálica de $4.1 \pm 3.6 \mathrm{~nm}$.

Otro aspecto importante en catálisis heterogénea es la actividad máxima del catalizador. A fin de determinar el valor de esta productividad máxima, se llevaron a cabo una serie de experimentos empleando excesos elevados de fenol y $\mathrm{H}_{2} \mathrm{O}_{2}$ con respecto a la cantidad de catalizador presente. Bajo estas condiciones el catalizador podría sufrir 
Nanoparticulas de plata soportadas sobre nanopartículas de diamante como catalizadores eficientes de la reacción de Fenton por irradiación con luz solar natural.

desactivación, lo que conduciría a la observación de un plano en la curva de degradación a tiempos avanzados de reacción. En el caso presente la figura 3.25 muestra que esta desactivación ocurre cuando se alcanza aproximadamente un $40 \%$ del valor de degradación del fenol.
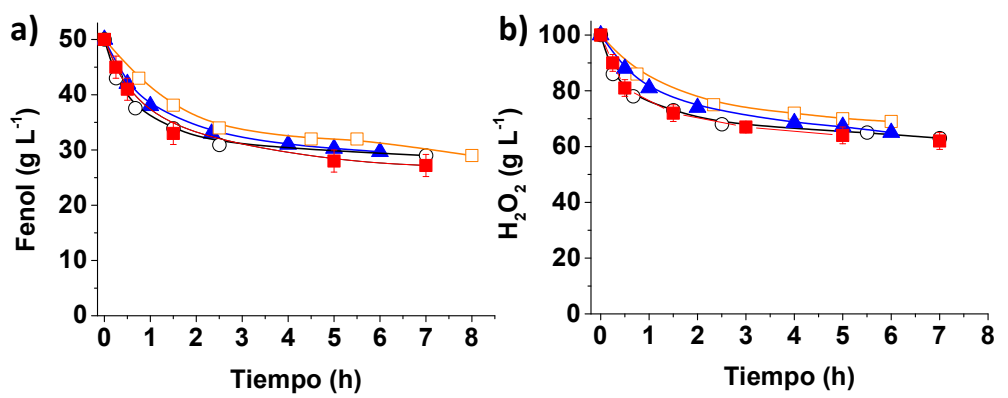

Figura 3.25. Perfiles temporales correspondientes al ensayo de productividad y reusabilidad para la degradación de fenol (a) y para la descomposición de $\mathrm{H}_{2} \mathrm{O}_{2}$ (b) usando $\mathrm{Ag} / \mathrm{D} 3$ como catalizador. Leyenda: $1^{\circ}(\square), 2^{\circ}(\bullet), 3^{\circ}(\Delta)$ y $4^{\circ}$ uso $(\square)$. Condiciones de reacción: catalizador $\left(5 \mathrm{mg}, 100 \mathrm{mg} \mathrm{L}^{-1} ; 0.0018\right.$ $\mathrm{mM}$ de $\mathrm{Ag}$ NPs soportado), fenol $\left(50 \mathrm{~g} \mathrm{~L}^{-1} ; 0.53 \mathrm{M}\right), \mathrm{H}_{2} \mathrm{O}_{2}\left(100 \mathrm{~g} \mathrm{~L}^{-1} ; 2.94\right.$ $\mathrm{M}), \mathrm{pH}$ 4. Nota: A fin de considerar las posibles variaciones asociadas con la irradiación con luz solar natural, los datos representados para el primer uso corresponden a la media de cuatro experimentos que se llevaron a cabo simultáneamente con cada reúso utilizando para ello catalizador fresco. Concentración de fenol obtenida por HPLC y de $\mathrm{H}_{2} \mathrm{O}_{2}$ por espectrofotometría, como se indica en el capítulo 8 , sección experimental.

Sin embargo, si la muestra de Ag/D3 desactivada tras un ensayo de productividad se recupera por filtración, y se lava con agua básica, su actividad catalítica se recupera en gran medida, siendo eficiente para una reacción posterior. Se repitió este proceso tres veces, lo que permitió alcanzar un valor de ciclos acumulado (Turnover Number, TON) de 472000 moléculas de fenol degradadas por átomo de Ag. Este número representa el valor de TON más alto descrito para un catalizador de Fenton hasta el presente. Un valor próximo, pero inferior, ha sido conseguido para un catalizador análogo a base de oro $(\mathrm{Au} / \mathrm{D} 3)$ para el cual el valor de TON acumulado fue de $458000 .^{27}$ Por otra parte la eficiencia del proceso queda de manifiesto también si se considera que en 
estos ensayos de productividad se requieren solo 4.5 equivalentes de $\mathrm{H}_{2} \mathrm{O}_{2}$ para degradar un equivalente de fenol.

\subsubsection{Mecanismo de reacción}

A fin de elucidar el mecanismo de reacción en el proceso de fotoFenton usando Ag/D3 como catalizador, la reacción de degradación de fenol por agua oxigenada bajo iluminación con luz solar natural se llevó a cabo en presencia de dimetilsulfóxido (DMSO) como un inhibidor selectivo de radicales hidroxilo. ${ }^{11,28}$ Estudios previos han demostrado que los radicales hidroxilo reaccionan con DMSO (ver ecuaciones 3.3 y 3.4), lo que da lugar a la inhibición de la reacción de Fenton. Por otra parte, la inhibición por DMSO es selectiva y si otras especies radicalarias tales como el radical hidroperoxilo (HOO-) son generadas, la presencia de DMSO no causa ningún efecto en el proceso.

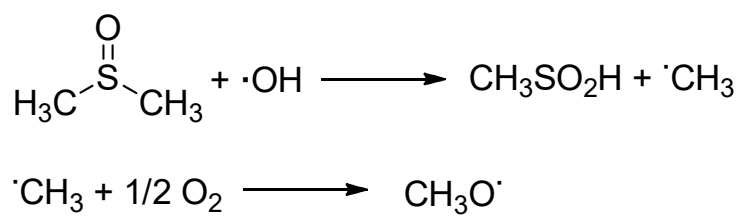

La presencia de DMSO en la mezcla de reacción para completamente la degradación de fenol y, por consiguiente, la generación de radical hidroxilo en nuestro sistema se basa indirectamente en este efecto de inhibición observado para el DMSO (figura 3.26a). Además, a fin de establecer firmemente la generación de radicales hidroxilo, se llevó a cabo un ensayo en presencia de fenil tert-butil nitrona (PBN) como agente atrapador de radicales. Se pudo registrar el espectro de EPR

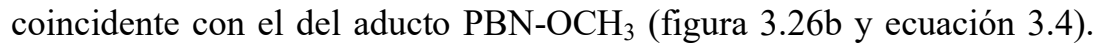
La estructura de este aducto viene confirmada en base a las constantes de acoplamiento hiperfinas, las cuales coinciden con las descritas en la bibliografía para este aducto. ${ }^{28}$ Los ensayos de inhibición por DMSO y la detección del espectro de EPR correspondiente al aducto $\mathrm{PBN}_{-}-\mathrm{OCH}_{3}$ indican que los radicales hidroxilo son la principal especie reactiva de oxígeno generada en nuestro sistema fotocatalítico basado en $\mathrm{Ag} / \mathrm{D} 3$. 


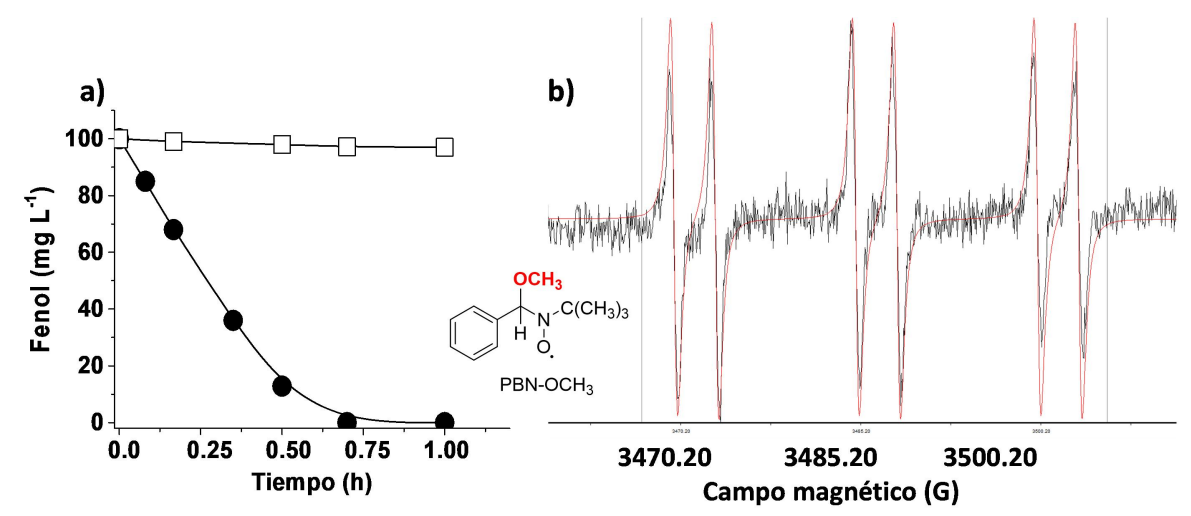

Figura 3.26. a) Perfil temporal para la degradación de fenol usando Ag/D3 como catalizador sin $(\bullet)$ y con $(\square)$ DMSO como inhibidor selectivo de radical hidroxilo irradiando ambas muestras con luz solar natural. b) espectro de EPR experimental (línea negra) y simulado (línea roja) usando las constantes de acoplamiento hiperfinas descritas para el aducto $\mathrm{PBN}-\mathrm{OCH}_{3}$ (ver estructura en la figura), a saber $A_{H} G=3.4$ y $A_{N} G=15.1 \mathrm{~Hz}$.

Considerando el mecanismo general de reacción del fenol con radicales hidroxilo que conduce a la formación de dihidroxibencenos y quinonas (figura 3.27a), es posible realizar una estimación de la eficiencia mínima con la que se produce la descomposición de $\mathrm{H}_{2} \mathrm{O}_{2}$ en radicales hidroxilo mediante la cuantificación de la cantidad de catecol, hidroquinona y para-benzoquinona formadas con $\mathrm{Ag} / \mathrm{D} 3$ en experimentos con una relación molar $\mathrm{H}_{2} \mathrm{O}_{2}$ /fenol de 0.5 , tanto en la oscuridad como al ser iluminado el sistema con luz solar (figura 3.27b). De esta manera se estimó una eficiencia del 49 y $88 \%$ para la generación de radical hidroxilo en la oscuridad y por iluminación, respectivamente. ${ }^{29}$ Esta diferencia en eficiencia no es sorprendente si se considera que la velocidad de reacción para la descomposición de $\mathrm{H}_{2} \mathrm{O}_{2}$ a radical hidroxilo es mucho mayor bajo iluminación con luz solar. ${ }^{11,12}$ 

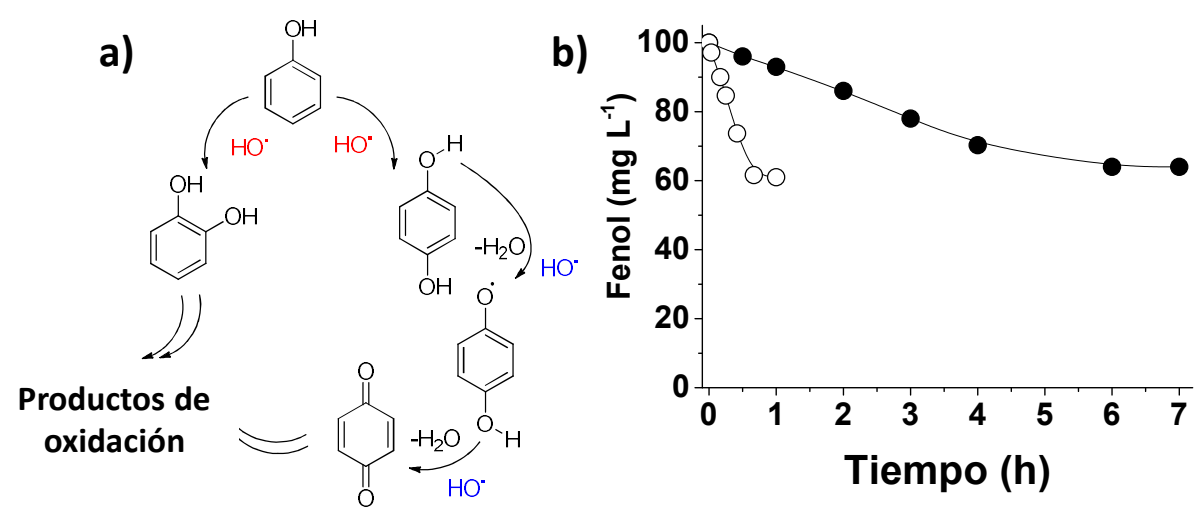

Figura 3.27. a) Mecanismo general para la reacción de fenol con radicales hidroxilo, y b) perfil temporal de degradación de fenol en la oscuridad y con iluminación de luz solar natural en condiciones de fenol en exceso. Condiciones de reacción: catalizador $\left(8.4 \mathrm{mg}, 330 \mathrm{mg} \mathrm{L}^{-1} ; 0.006 \mathrm{mM}\right.$ de $\left.\mathrm{Ag}\right)$, fenol $\left(100 \mathrm{mg} \mathrm{L}^{-1} ; 1.06 \mathrm{mM}\right), \mathrm{H}_{2} \mathrm{O}_{2}\left(18 \mathrm{mg} \mathrm{L}^{-1} ; 0.53 \mathrm{mM}\right), \mathrm{pH} 4$. Concentración de fenol obtenida por HPLC y de $\mathrm{H}_{2} \mathrm{O}_{2}$ por espectrofotometría, como se indica en el capítulo 8 , sección experimental.

\subsection{Conclusiones}

En el presente capítulo se han proporcionado datos cinéticos que demuestran que las nanopartículas de Ag soportadas sobre nanopartículas de diamante oxidadas previamente por la reacción de Fenton y posteriormente reducidas con hidrogeno (D3) es un catalizador altamente eficiente y con una relación de coste favorable que es capaz de promover la reacción de Fenton heterogénea bajo irradiación de luz solar natural. La irradiación de la banda de plasmón superficial de las Ag NPs favorece la reacción de Fenton la cual puede llevarse a cabo incluso a valores de $\mathrm{pH}$ próximos a la neutralidad.

La eficiencia del catalizador $\mathrm{Ag} / \mathrm{D} 3$ es mayor que la que presentan catalizadores análogos basados en Ag NPs soportadas sobre carbón activo y grafito, y se demuestra por la observación de una degradación completa no sólo del fenol, sino también de compuestos intermedios, principalmente catecol, hidroquinona y para-benzoquinona, empleando tan sólo 4.5 equivalentes de $\mathrm{H}_{2} \mathrm{O}_{2}$.

La eficiencia superior que muestra el catalizador $\mathrm{Ag} / \mathrm{D} 3$ puede ser atribuida al menor tamaño de las Ag NPs en D3 y a la superficie inerte 
Nanoparticulas de plata soportadas sobre nanopartículas de diamante como catalizadores eficientes de la reacción de Fenton por irradiación con luz solar natural.

de este tipo de diamante. Además la actividad catalítica de Ag/D3 fue también mejor que la que se observó para $\mathrm{Ag} / \mathrm{TiO}_{2}$, debido principalmente a la mayor eficiencia y la descomposición de $\mathrm{H}_{2} \mathrm{O}_{2}$ en radicales hidroxilo libres. Experimentos de inhibición con DMSO y espectros de EPR revelan la generación de radicales hidroxilo que parecen ser la especie reactiva de oxígeno implicada en el proceso de oxidación de fenol por $\mathrm{H}_{2} \mathrm{O}_{2}$ usando $\mathrm{Ag} / \mathrm{D} 3$ como catalizador.

La estabilidad catalítica de Ag/D3 fue establecida llevando a cabo 8 reúsos consecutivos de la misma muestra, observándose tan sólo una ligera disminución de la actividad catalítica inicial, la cual fue atribuida a la aglomeración parcial de Ag NPs sin que se observara lixiviado de $\mathrm{Ag}$. Finalmente, $\mathrm{Ag} / \mathrm{D} 3$ alcanza un número de ciclos catalíticos acumulados para la degradación del fenol de 472000 que es el más alto descrito hasta la fecha para una reacción de Fenton heterogénea bajo iluminación con luz solar.

\subsection{Referencias}

[1] M. Pera-Titus, V. García-Molina, M. A. Baños, J. Giménez, S. Esplugas, Appl. Catal. B 2004, 47, 219-256.

[2] J. J. Pignatello, E. Oliveros, A. MacKay, Crit. Rev.Environ. Sci. Technol. 2006, 36, 1-84.

[3] K. Ayoub, E. D. van Hullebusch, M. Cassir, A. Bermond, J. Hazard. Mater. 2010, 178, 10-28; S. Malato, P. Fernández-Ibáñez, M. I. Maldonado, J. Blanco, W. Gernjak, Catal. Today 2009, 147, 1-59.

[4] M. N. Chong, B. Jin, C. W. K. Chow, C. Saint, Water Res. 2010, 44, 2997- 3027.

[5] S. Rahim Pouran, A. R. A. Aziz, V.M.A .W. Daud, J. Ind. Eng. Chem. 2015, 21, 53-69.

[6] M. Klavarioti, D. Mantzavinos, D. Kassinos, Environ. Int. 2009, 35, 402- 417; D. Mantzavinos, E. Psillakis, J. Chem. Technol. Biotechnol. 2004, 79, 431-454; A. Zapata, T. Velegraki, J. A. Sánchez-Pérez, D. Mantzavinos, M. I. Maldonado, S. Malato, Appl. Catal. B 2009, 88, 448-454; A. De Luca, R. F. Dantas, A. S. M. Simoes, I. A. S. Toscano, G. Lofrano, A. Cruz, S. Esplugas, Chem. Eng. Technol. 2013, 36, 2155-2162; V. Romero, O. González, B. 
Bayarri, P. Marco, J. Giménez, S. Esplugas, Catal. Today 2015, 240, 86-92.

[7] A. D. Bokare, W. Choi, J. Hazard. Mater. 2014, 275, 121-135.

[8] S. Chiron, A. Fernandez-Alba, A. Rodríguez, E. García-Calvo, Water Res. 2000, 34, 366-377.

[9] J. Herney-Ramirez, M. A. Vicente, L. M. Madeira, Appl. Catal. B 2010, 98, 10-26.

[10] C. Wang, H. Liu, Z. Sun, Int. J. Photoenergy 2012, 801694; A. N. Soon, B. H. Hameed, Desalination 2011, 269, 1-16.

[11] S. Navalón, R. Martín, M. Álvaro, H. García, ChemSusChem. 2011, $4,650-657$.

[12] S. Navalón, M. De Miguel, R. Martín, M. Álvaro, H. García, J. Am. Chem. Soc. 2011, 133, 2218-2226.

[13] S. Navalón, D. Sempere, M. Álvaro, H. García, ACS Appl. Mater. Interfaces 2013, 5, 7160-7169.

[14] D. Sempere, S. Navalón, M. Dancikova, M. Álvaro, H. García, Appl. Catal. B 2013, 142-143, 259-267.

[15] W. He, Y.-T. Zhou, W. G. Wamer, M. D. Boudreau, J.-J. Yin, Biomaterials 2012, 33, 7547-7555; D.He, C. J. Miller, T. D. Waite, J. Catal. 2014, 317, 198-205.

[16] M. Sobana, M. Muruganadham, M. Swaminathan, J. Mol. Catal. A 2006, 258, 124-132; S. Anandan, P. Sathish Kumar, N. Pugazhenthiran, J. Madhavan, P. Maruthamuthu, Sol. Energy Mater. Sol. Cells 2008, 92, 929-937.

[17] E. Kaviya, E. Prasad, RSC Adv. 2015, 5, 17179-17185.

[18] B. Subash, B. Krishnakumar, M. Swaminathan, M. Shanthi, Langmuir 2013, 29, 939-949; C. Mondal, J. Pal, M. Ganguly, A. K. Sinha, J. Jana, T. Pal, New J. Chem. 2014, 38, 2999-3005.

[19] J. C. Scaiano, K. G. Stamplecoskie, G. L. Hallett-Tapley, Chem. Commun. 2012, 48, 4798-4808.

[20] A. Dhakshinamoorthy, S. Navalón, D. Sempere, M. Álvaro, H. García, Chem. Commun. 2013, 49, 2359-2361.

[21] J. C. Scaiano, J. C. Netto-Ferreira, E. Alarcon, P. Billone, C. J. Bueno-Alejo, C. O. L. Crites, M. R. Decan, C. Fasciani, M. Gonzalez-Bejar, G. L. Hallett-Tapley, M. Grenier, K. L. McGilvray, N. L. Pacioni, A. Pardoe, L. Rene-Boisneuf, R. Narbonne-Schwartz, J. Silvero, K. G. Stamplecoskie, T. L. Wee, Pure Appl. Chem. 2011, 83, 913-930.

[22] J. A. Zazo, J. A. Casas, C. B. Molina, A. Quintanilla, J. J. Rodríguez, Environ. Sci. Technol. 2007, 41, 7164-7170. 
Nanoparticulas de plata soportadas sobre nanopartículas de diamante como catalizadores eficientes de la reacción de Fenton por irradiación con luz solar natural.

[23] A. Dhakshinamoorthy, S. Navalón, M. Álvaro, H. García, ChemSusChem 2012, 5, 46-64; S. Navalón, M. Álvaro, H. García, Appl. Catal. B 2010, 99, 1-26.

[24] S. Navalón, A. Dhakshinamoorthy, M. Álvaro, H. García, ChemSusChem 2011, 4, 1712-1730.

[25] E. Neyens, J. Baeyens, J. Hazard. Mater. 2003, 98, 33-50.

[26] I. P. Pozdnyakov, E. M. Glebov, V. F. Plyusnin, W. P. Grivin, Y. V. Ivanov, D. Y. Vorobyev, N. Bazhin, Pure Appl. Chem. 2000, 72, 2187-2197; A . De Luca, R. F. Dantas, S. Esplugas, Water Res. 2014, 61, 232-224.

[27] R. Martín, S. Navalón, J. J. Delgado, J. J. Calvino, M. Álvaro, H. García, Chem. Eur. J. 2011, 17, 9494-9502.

[28] M. J. Burkitt, R. P. Mason, Proc. Natl. Acad. Sci. USA 1991, 88, 8440-8444.

[29] S. Navalón, R. Martín, M. Álvaro, H. García, Angew. Chem. Int. Ed. 2010, 49, 8403-8407; Angew. Chem. 2010, 122, 8581-8585; A. Quintanilla, S. García-Rodríguez, C. M. Domínguez, S. Blasco, J. A. Casas, J. J. Rodríguez, Appl. Catal. B 2012, 111-112, 81-89. 


\section{Capítulo 4}

Nanopartículas de cobre soportadas sobre nanopartículas de diamante como catalizador eficiente y de buena relación de costeactividad para la reacción de Fenton asistida por luz solar natural 



\subsection{Introducción}

Como se ha comentado en el capítulo de introducción, los tratamientos de oxidación avanzados basados en la reacción de Fenton y foto-Fenton se encuentran entre los procesos más importantes para el tratamiento de aguas residuales de origen industrial. ${ }^{1-8}$ Además de las limitaciones en el valor de $\mathrm{pH}$, otro de los principales problemas de la reacción de Fenton es la necesidad de cantidades estequiométricas de metales de transición, comúnmente $\mathrm{Fe}$ (II), que se consumen en el proceso y que dan lugar a la formación de grandes cantidades de fangos. ${ }^{2,9,10}$ Una estrategia general para superar esta limitación consiste en el uso de un catalizador, convirtiendo de esta manera la reacción de Fenton desde un proceso estequiométrico ( $1 \mathrm{~mol} \mathrm{de} \mathrm{Fe}(\mathrm{II})$ por mol de $\mathrm{H}_{2} \mathrm{O}_{2}$ ) en catalítico (relación molar centro activo $\left./ \mathrm{H}_{2} \mathrm{O}_{2}<1\right){ }^{6,11-15}$ Como se ha indicado, nuestro grupo ha descrito catalizadores notablemente eficientes para la reacción de Fenton asistida por luz solar, mediante el empleo de nanopartículas de diamante tratadas (D) como soporte de $\mathrm{Au}^{16-20}$ y Ag NPs (ver capítulo 3). Valores del número de ciclos acumulados (TON) tan altos como 472000 fueron conseguidos para la degradación de fenol por $\mathrm{H}_{2} \mathrm{O}_{2}$ usando $\mathrm{Ag} / \mathrm{D} 3$ como catalizador por irradiación con luz solar natural. Aparentemente, la superficie inerte del diamante es más adecuada que otras alternativas para permitir que los radicales hidroxilos difundan libremente desde la superficie del soporte a la fase líquida, permitiendo que estos radicales ataquen contaminantes orgánicos presentes en disolución. ${ }^{21}$ Se encontró también que la inertización de la superficie de D y la eliminación de grupos ácidos carboxílicos superficiales por tratamiento térmico con hidrógeno tras la purificación de $\mathrm{D}$ con la reacción de Fenton es un tratamiento adecuado que permite la formación de partículas pequeñas (aproximadamente $5 \mathrm{~nm}$ ) de $\mathrm{Au}$ y Ag. ${ }^{20-22}$ Más aún se ha encontrado que $\mathrm{Au} / \mathrm{D}^{18-20,22}$ y $\mathrm{Ag} / \mathrm{D}^{23}$ aumentan la actividad catalítica y expanden el rango de $\mathrm{pH}$ aplicable cuando la reacción de Fenton es asistida por luz solar natural. Esta observación se justifica considerando que tanto las $\mathrm{Au} \mathrm{NPs}{ }^{23,24}$ como las $\mathrm{Ag} \mathrm{NPs}^{23-26}$ presentan bandas de plasmón en la región de luz visible y por absorción de esta radiación se producen efectos de plasmón, pudiéndose promover la reacción de Fenton. ${ }^{19,21} \mathrm{D}$ es disponible en grandes cantidades puesto que se forma en la detonación de explosivos, aunque sería conveniente desarrollar alternativas a los catalizadores de $\mathrm{Au}$ y Ag que sean más 
Nanopartículas de cobre soportadas sobre nanopartículas de diamante como catalizador eficiente y de buena relación de coste-actividad para la reacción de Fenton asistida por luz solar natural

eficientes en relación a su coste. Comparada con la reacción de Fenton convencional en la que se usan grandes cantidades de sales de Fe, estos catalizadores basados en $\mathrm{D}$ podrían ser competitivos, particularmente considerando que los fangos que tienen que ser convenientemente desechados no se producen.

Continuando con esta línea de investigación encaminada a desarrollar catalizadores de Fenton de alta eficiencia, es de interés realizar estudios similares a los presentados en el capítulo 3 usando $\mathrm{Cu}$ NPs como metal activo. De hecho una línea de investigación de gran actualidad en catálisis es la sustitución de metales preciosos y costosos por metales abundantes y asequibles tales como $\mathrm{Cu}^{27}$ Conviene comentar aquí que algunos estudios han descrito el uso de catalizadores de cobre soportados para la reacción de foto-Fenton. ${ }^{9,28-31}$ Específicamente es de interés establecer una comparación entre la actividad catalítica de $\mathrm{Cu}$ NPs respecto a las que presenta $\mathrm{Au} \mathrm{y} \mathrm{Ag} \mathrm{NPs} \mathrm{bajo} \mathrm{condiciones} \mathrm{idénticas.}$

En el presente capítulo se describe ese estudio, demostrando que, aunque algo menos activo que $\mathrm{Ag}$ y $\mathrm{Au}, \mathrm{Cu} / \mathrm{D}$ exhibe un balance bueno entre actividad catalítica y coste y tras procesos de regeneración adecuados puede actuar como un catalizador de Fenton reusable cuya actividad aumenta por iluminación con luz solar natural.

\subsection{Resultados y discusión}

Inicialmente describiremos la preparación de los catalizadores que han sido usados en este capítulo y algún dato de caracterización antes de pasar a describir su actividad como catalizadores de Fenton.

\subsubsection{Síntesis de $\mathrm{Cu} / \mathrm{D}$}

Siguiendo estudios previos, las muestras de D NPs comerciales fueron sometidas a purificación y funcionalización usando la reacción de Fenton homogénea, seguido este tratamiento de una reducción térmica con hidrógeno. Sobre estas muestras de $\mathrm{D}$ tratadas se soportaron $\mathrm{Cu}$ NPs. ${ }^{20,22,32}$ De esta manera muestras de D comerciales (Sigma-Aldrich, ref. $636444, \geq 97 \%$, D1) fueron sometidas a un tratamiento de Fenton (D2) para eliminar de las muestras D NPs la materia carbonosa amorfa presente en las mismas. ${ }^{16,17}$ Este tratamiento de Fenton disminuye algo el tamaño de partícula de $\mathrm{D}$ que resulta en torno a 7-10 nm, debido a la 
erosión de la superficie al eliminar la matriz amorfa. ${ }^{10,33}$ La muestra D3 se obtuvo a partir de la de D2 por tratamiento térmico a $500{ }^{\circ} \mathrm{C}$ bajo atmósfera de hidrógeno. Los análisis termogravimétricos determinando la naturaleza de los gases formados en el calentamiento de las muestras D han determinado que ese tratamiento térmico reductivo disminuye considerablemente la población de ácidos carboxílicos así como la de grupos carbonilo e hidroxilo presentes en la superficie del diamante. ${ }^{20,22}$ En el caso de las muestras $\mathrm{Au} / \mathrm{D}$ y $\mathrm{Ag} / \mathrm{D}$ se estableció que el tratamiento de Fenton y posterior reducción con hidrógeno daba lugar a NPs metálicas de menor tamaño y cabe anticipar que un efecto similar debe ocurrir igualmente para el caso de $\mathrm{Cu}$.

Nuestras hipótesis fueron confirmadas y el tamaño promedio de las $\mathrm{Cu}$ NPs formadas en el método del poliol (ver el capítulo 8 que describe el procedimiento experimental) variaron entre 13.4 y $3.8 \mathrm{~nm}$, siguiendo el orden $\mathrm{Cu} / \mathrm{D} 3<\mathrm{Cu} / \mathrm{D} 2<\mathrm{Cu} / \mathrm{D} 1$. La tabla 4.1 resume los catalizadores evaluados en el presente capítulo y los tamaños promedios para las NPs de los mismos. Estos valores de tamaño de partícula fueron determinados llevando a cabo un análisis estadístico de las imágenes de microscopia electrónica de transmisión.

\begin{tabular}{|c|c|c|}
\hline Entrada & Catalizador & $\begin{array}{l}\text { Tamaño medio de partícula metálica y } \\
\text { desviación estándar }(\mathrm{nm})^{\mathrm{a}}\end{array}$ \\
\hline 1 & $\mathrm{Cu} / \mathrm{D} 3$ & $3.7 \pm 2.7$ \\
\hline $2^{\mathrm{b}}$ & $\mathrm{Ag} / \mathrm{D} 3$ & $3.2 \pm 2.7$ \\
\hline $3^{b}$ & $\mathrm{Au} / \mathrm{D} 3$ & $2.9 \pm 3.6$ \\
\hline $4^{\mathrm{c}}$ & $\mathrm{Cu} / \mathrm{D} 3$ & $11.1 \pm 5.6$ \\
\hline 5 & $\mathrm{Cu} / \mathrm{D} 2$ & $6.3 \pm 4.2$ \\
\hline 6 & $\mathrm{Cu} / \mathrm{D} 1$ & $13.4 \pm 5.3$ \\
\hline 7 & $\mathrm{Cu} / \mathrm{AC} 3$ & $6.0 \pm 3.6$ \\
\hline 8 & $\mathrm{Cu} / \mathrm{AC} 2$ & $9.4 \pm 4.2$ \\
\hline 9 & $\mathrm{Cu} / \mathrm{ACl}$ & $11.4 \pm 5.3$ \\
\hline 10 & $\mathrm{Cu} / \mathrm{NT3}$ & $7.8 \pm 3.6$ \\
\hline 11 & $\mathrm{Cu} / \mathrm{NT} 2$ & $9.9 \pm 4.2$ \\
\hline 12 & $\mathrm{Cu} / \mathrm{NT} 1$ & $12.2 \pm 6.0$ \\
\hline 13 & $\mathrm{Cu} / \mathrm{TiO}_{2}$ & $2.6 \pm 1.6$ \\
\hline
\end{tabular}


Nanopartículas de cobre soportadas sobre nanopartículas de diamante como catalizador eficiente y de buena relación de coste-actividad para la reacción de Fenton asistida por luz solar natural

La figura 4.1 muestra imágenes seleccionadas de STEM para la muestra $\mathrm{Cu} / \mathrm{D} 3$, mientras que imágenes adicionales para el resto de catalizadores se presentan en la figura 4.2. Estas figuras contienen los histogramas de distribución de tamaños en los que se basa la medida del tamaño promedio.

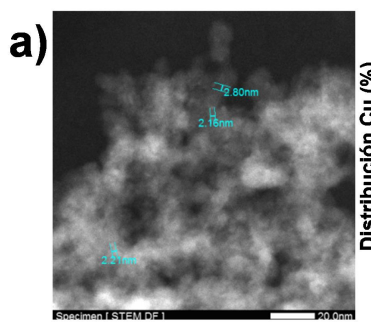

b)
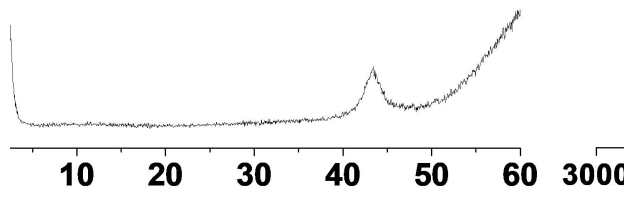
$2 \theta\left({ }^{\circ}\right)$
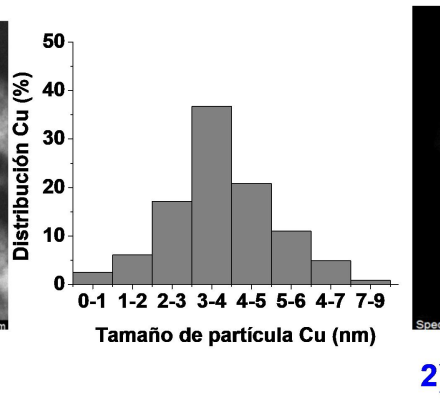

2)

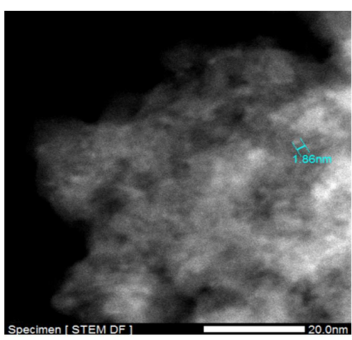

c)

1)

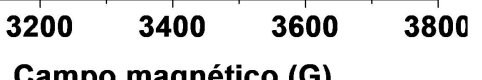

Campo magnético (G)

Figura 4.1. a) Imágenes de DF-STEM y distribución de tamaño de partícula para la muestra $\mathrm{Cu}(0.2 \%$ en peso $) / \mathrm{D} 3$. El tamaño de partícula promedio para el $\mathrm{Cu}$ fue de $3.7 \pm 2.7 \mathrm{~nm}$. b) Difractograma de rayos X de la muestra $\mathrm{Cu}(0.2 \%$ en peso)/D3. c) Espectros de EPR de las muestras de $\mathrm{Cu}(0.2 \%$ en peso)/D3 fresca (1) y tras su uso como catalizador (2). 

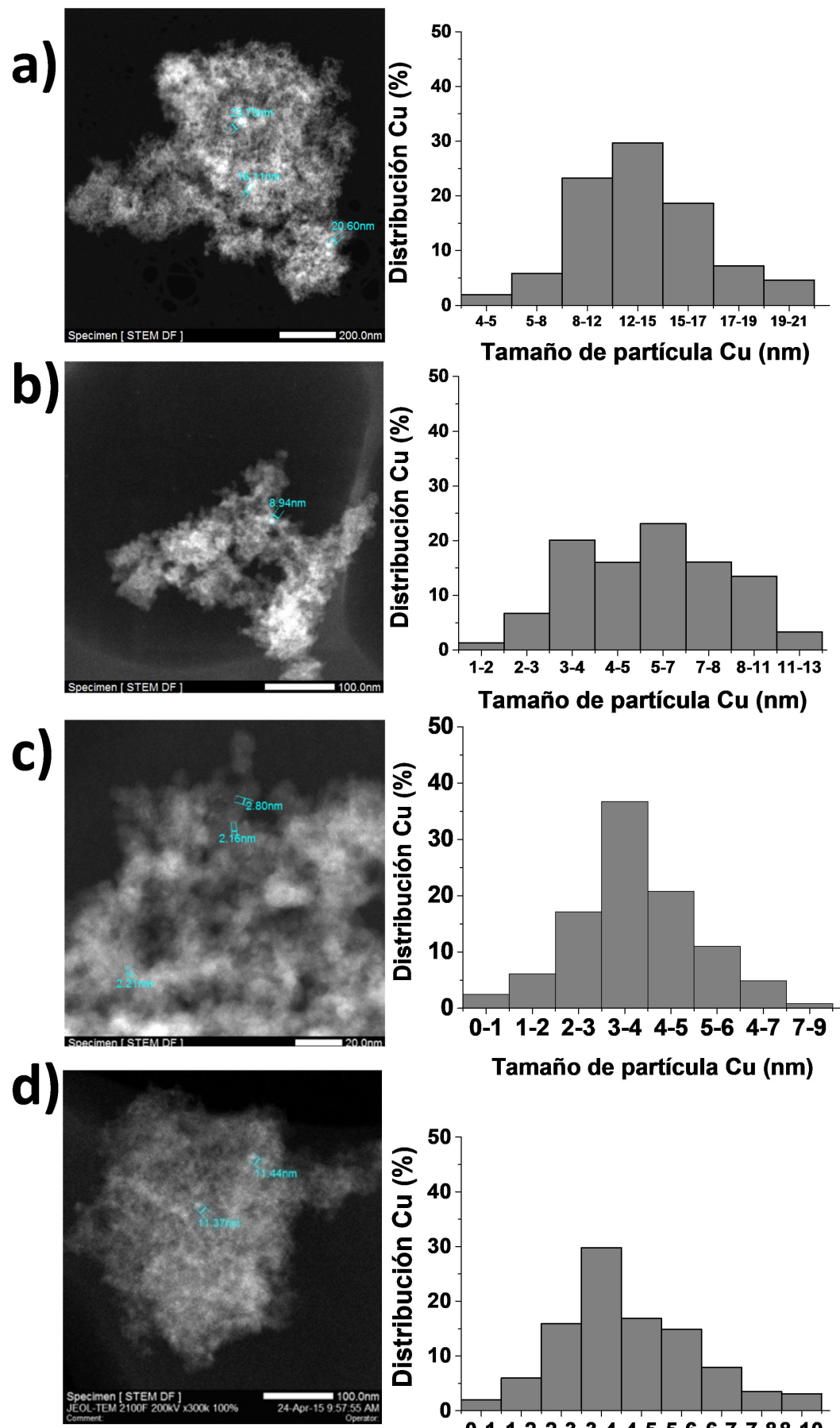

Tamaño de partícula Cu (nm)

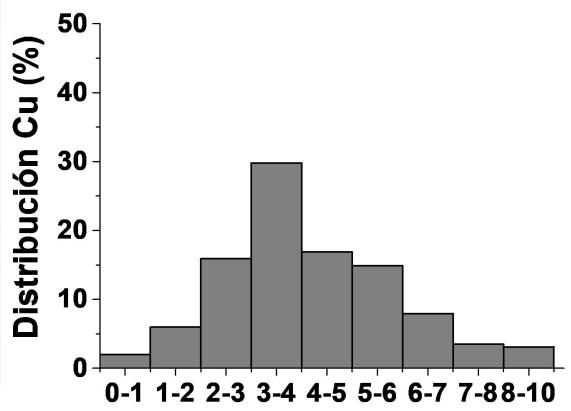

Tamaño de partícula $\mathrm{Cu}(\mathrm{nm})$ 
Nanopartículas de cobre soportadas sobre nanopartículas de diamante como catalizador eficiente y de buena relación de coste-actividad para la reacción de Fenton asistida por luz solar natural

Figura 4.2. Imágenes de DF-STEM y distribuciones de tamaño de partícula de $\mathrm{Cu}(0.2 \%$ en peso)/D1 (a), $\mathrm{Cu}(0.2 \%$ en peso)/D2 (b), $\mathrm{Cu}(0.2 \%$ en peso) $/ \mathrm{D} 3$ (c) y $\mathrm{Cu}(1 \%$ en peso $) / \mathrm{D} 3$ (d). El tamaño medio de partícula del cobre metálico para $\mathrm{Cu}(0.2 \%$ en peso)/D1 (a), $\mathrm{Cu}(0.2 \%$ en peso) $/ \mathrm{D} 2$ (b), $\mathrm{Cu}(0.2 \%$ en peso)/D3 (c) y $\mathrm{Cu}(1 \%$ en peso)/D3 (d) es de $13.4 \pm 5.3,6.3 \pm 4.2$ y $3.7 \pm$ 2.7 y $11.1 \pm 5.6 \mathrm{~nm}$, respectivamente.

A efectos de comparación la tabla 4.1 incluye también el tamaño de partícula promedio para Au NPs y Ag NPs soportadas sobre D3, las cuales poseen dimensiones similares a las de Cu NPs. Además de usar las muestras D1-3 como soportes, se emplearon también con el mismo fin otros materiales basados en carbono tales como carbón activo (AC, de sus siglas en inglés, Activated Carbon) y nanotubos de carbono de pared múltiple (CNTs, de sus siglas en inglés, Carbon NanoTubes). De manera análoga al caso del diamante, las muestras comerciales de AC y CNTs también fueron sometidas al tratamiento de Fenton seguido o no por reducción térmica con hidrógeno a fin de modificar los grupos funcionales superficiales de una manera análoga a las muestras D2-3. ${ }^{21,32}$ De manera análoga a las muestras $\mathrm{Cu} / \mathrm{D} 1-3$, también en el caso de las muestras $\mathrm{Cu} / \mathrm{AC} 1-3$ (figura 4.3) y Cu/CNT1-3 (figura 4.4), el tamaño de partícula promedio del cobre exhibe una clara tendencia, disminuyendo este valor desde el valor promedio para la muestra comercial (alrededor de $13 \mathrm{~nm}$ ) con el tratamiento de Fenton (alrededor de $6 \mathrm{~nm}$ ) y con el tratamiento de Fenton seguido de reducción con hidrógeno (alrededor de $4 \mathrm{~nm}$ ). La información con los valores exactos del tamaño promedio de las $\mathrm{Cu}$ NPs y la desviación estándar correspondiente se encuentra resumida en la tabla 4.1, mientras que las figuras 4.2 - 4.4 presentan imágenes STEM en campo oscuro (DF, de sus siglas en inglés, Dark Field) para estas muestras junto con los histogramas de distribución de tamaños correspondientes. 

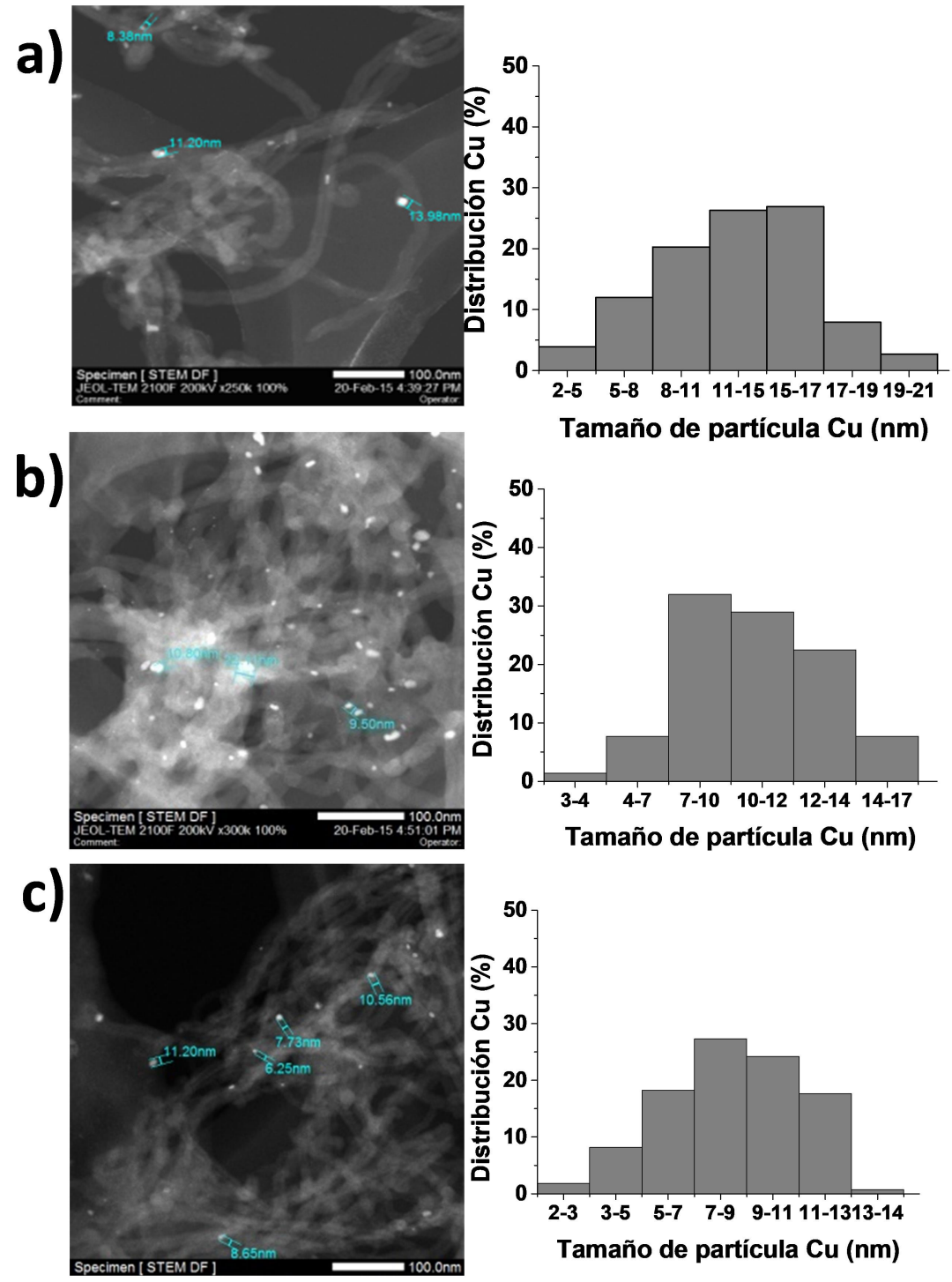

Figura 4.3. Imágenes de DF-STEM y distribuciones de tamaño de partícula de Cu/NT1 (a), Cu/NT2 (b) y Cu/NT3 (c). El tamaño medio de partícula del cobre metálico para Cu/NT1 (a), Cu/NT2 (b) y Cu/NT3 (c) es de $12.2 \pm 6.0$, $9.9 \pm 4.2$ y $7.8 \pm 3.6$, respectivamente. Nota: Carga de $\mathrm{Cu} 0.2 \%$ en peso. 
Nanopartículas de cobre soportadas sobre nanopartículas de diamante como catalizador eficiente y de buena relación de coste-actividad para la reacción de Fenton asistida por luz solar natural
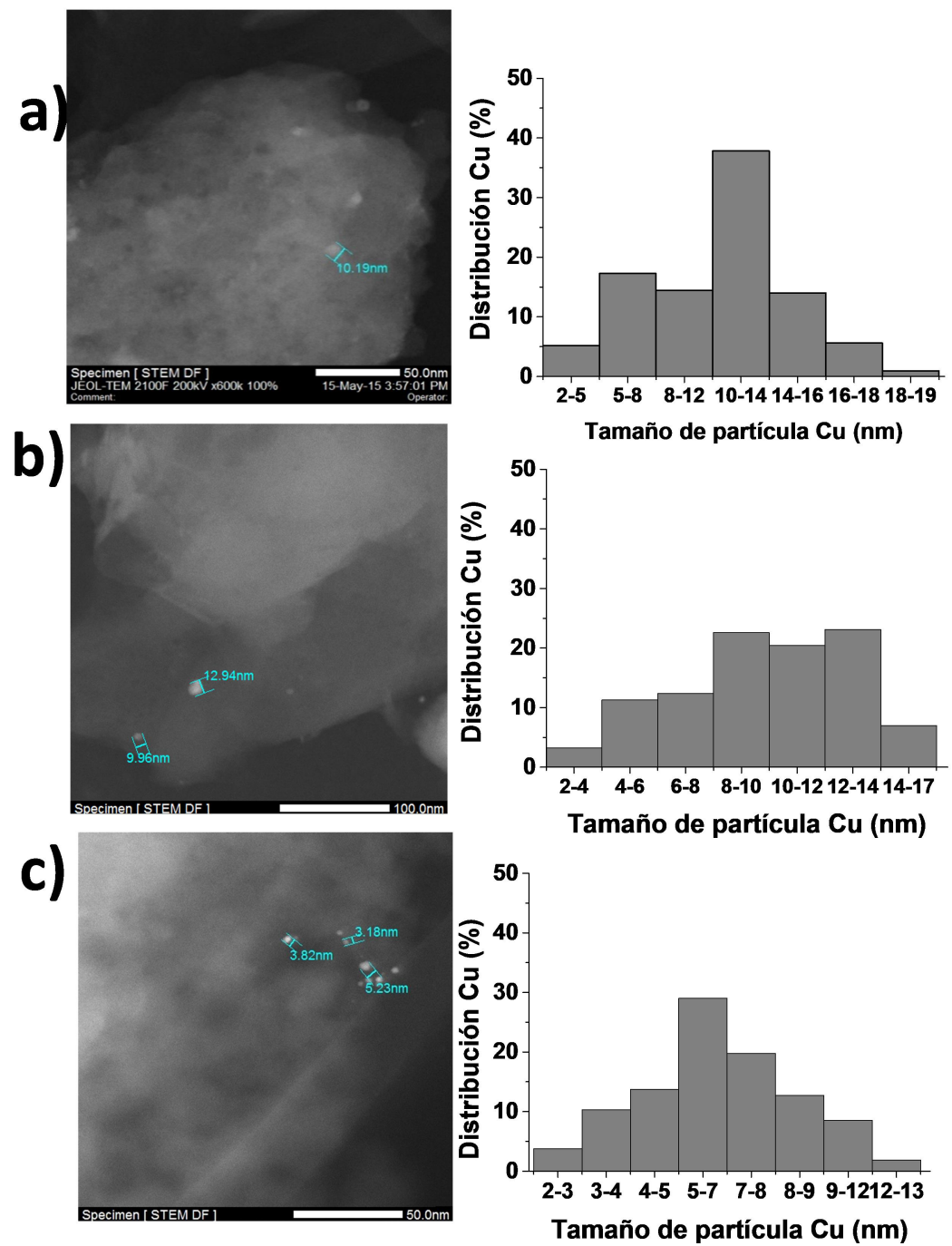

Figura 4.4. Imágenes de DF-STEM y distribuciones de tamaño de partícula de $\mathrm{Cu} / \mathrm{AC} 1$ (a), $\mathrm{Cu} / \mathrm{AC} 2$ (b) y $\mathrm{Cu} / \mathrm{AC} 3$ (c). El tamaño medio de partícula del cobre metálico para $\mathrm{Cu} / \mathrm{AC} 1$ (a), $\mathrm{Cu} / \mathrm{AC} 2$ (b) y $\mathrm{Cu} / \mathrm{AC} 3$ (c) es de $11.4 \pm 5.3$, $9.4 \pm 4.2$ y $6.0 \pm 3.6$, respectivamente. Nota: Carga de $\mathrm{Cu} 0.2 \%$ en peso.

Considerando que la asistencia por irradiación con luz solar natural es un fenómeno que ha sido previamente observado tanto para las muestras $\mathrm{Au} / \mathrm{D}^{18,19}$ como para las muestras $\mathrm{Ag} / \mathrm{D}$ (capítulo 3), la lista de catalizadores a evaluar se completó con una muestra de $\mathrm{Cu} / \mathrm{TiO}_{2}$. $\mathrm{La}$ 
sección de este soporte de $\mathrm{TiO}_{2}$ en el presente estudio se basa en la actividad fotocatalítica conocida para el $\mathrm{TiO}_{2}$. De esta manera $\mathrm{Cu} / \mathrm{TiO}_{2}$ podría igualmente exhibir un aumento en actividad catalítica de Fenton al ser irradiada con luz solar natural. ${ }^{21}$ La tabla 4.1 y la figura 4.5 contiene el tamaño de partícula promedio para las $\mathrm{Cu}$ NPs soportadas sobre $\mathrm{TiO}_{2}$, presentando también las correspondiente imágenes DF-STEM y el histograma de distribución que deriva de ella.
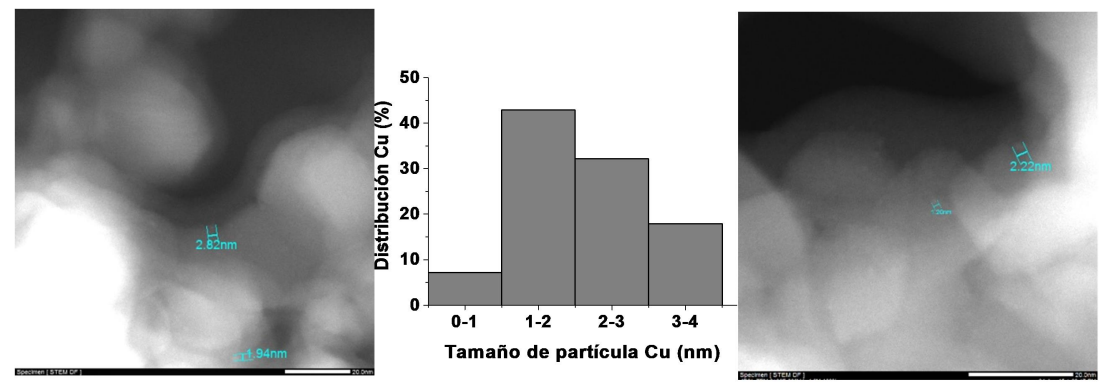

Figura 4.5. Imágenes de DF-STEM y distribución de tamaño de partícula de $\mathrm{Cu} / \mathrm{TiO}_{2}$. El tamaño medio de partícula del cobre metálico es de $2.6 \pm 1.6 \mathrm{~nm}$. Nota: Carga de $\mathrm{Cu} 0.2 \%$ en peso.

Debido al contenido tan bajo en cobre y a su elevada dispersión sobre el soporte, no fue posible detectar en difracción de rayos $\mathrm{X}$ la presencia de $\mathrm{Cu}$ NPs para ninguna de las muestras indicadas en la tabla 4.1. En todos los casos, los modelos de difracción de rayos $\mathrm{X}$ de los catalizadores de $\mathrm{Cu}$ corresponden exclusivamente al soporte (ver figura 4.1 para el caso de $\mathrm{Cu} / \mathrm{D} 3$ y las figuras $4.6-4.10$ para el resto de los materiales). ${ }^{20-22} \mathrm{La}$ imposibilidad de detectar el cobre por difracción de rayos $\mathrm{X}$ no es totalmente inesperada teniendo en cuenta el bajo porcentaje de $\mathrm{Cu}$ en el soporte y el tamaño pequeño de las Cu NPs. En un intento de detectar picos correspondientes al $\mathrm{Cu}$ en XRD se preparó una muestra adicional con un porcentaje de $\mathrm{Cu}$ del $1 \%$ sobre D3 (figura 4.7) y el tamaño de partícula promedio se determinó mediante imágenes de STEM-DF (figura 4.2), encontrándose este valor indicado en la tabla 4.1. Sin embargo, incluso para esta muestra conteniendo $1 \%$ en peso de cobre fue imposible detectar ninguno de los picos característicos de $\mathrm{Cu}$ en XRD (ver figura 4.7). Adicionalmente, los modelos de difracción de muestras comerciales en polvo de $\mathrm{Cu}, \mathrm{Cu}_{2} \mathrm{O}$ y $\mathrm{CuO}$ se midieron y se observaron los modelos de difracción esperables para cada uno de estos materiales. Las 
Nanopartículas de cobre soportadas sobre nanopartículas de diamante como catalizador eficiente y de buena relación de coste-actividad para la reacción de Fenton asistida por luz solar natural

figuras 4.6 - 4.10 muestran el conjunto de los difractogramas de rayos $\mathrm{X}$ obtenidos para la serie de catalizadores evaluados en el presente capítulo.

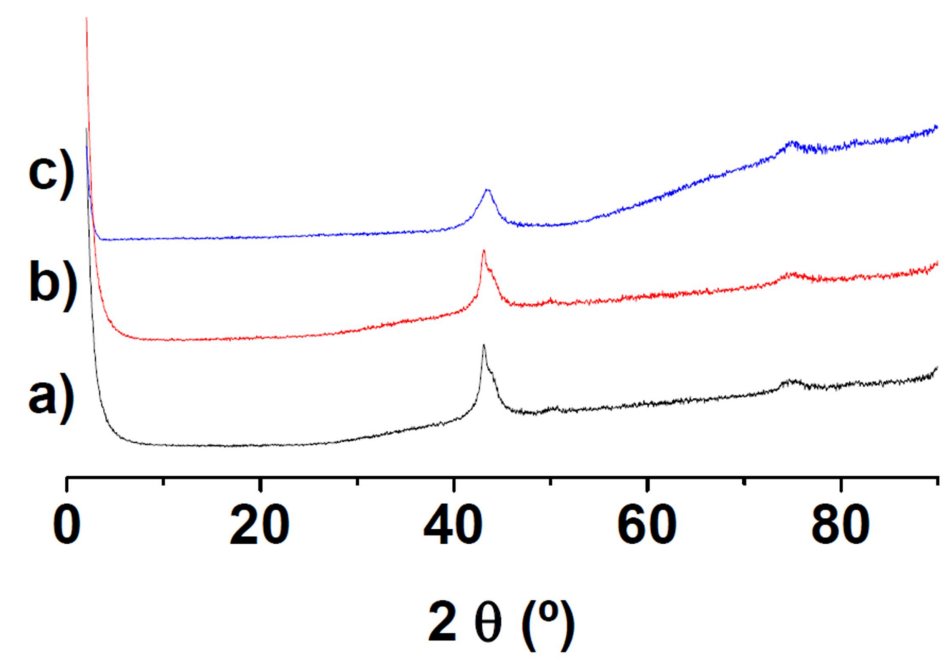

Figura 4.6. Difractogramas de rayos $\mathrm{X}$ de $\mathrm{Cu} / \mathrm{D} 1$ (a), Cu/D2 (b) y Cu/D3 (c). Nota: Carga de $\mathrm{Cu}$ de $0.2 \%$ en peso.

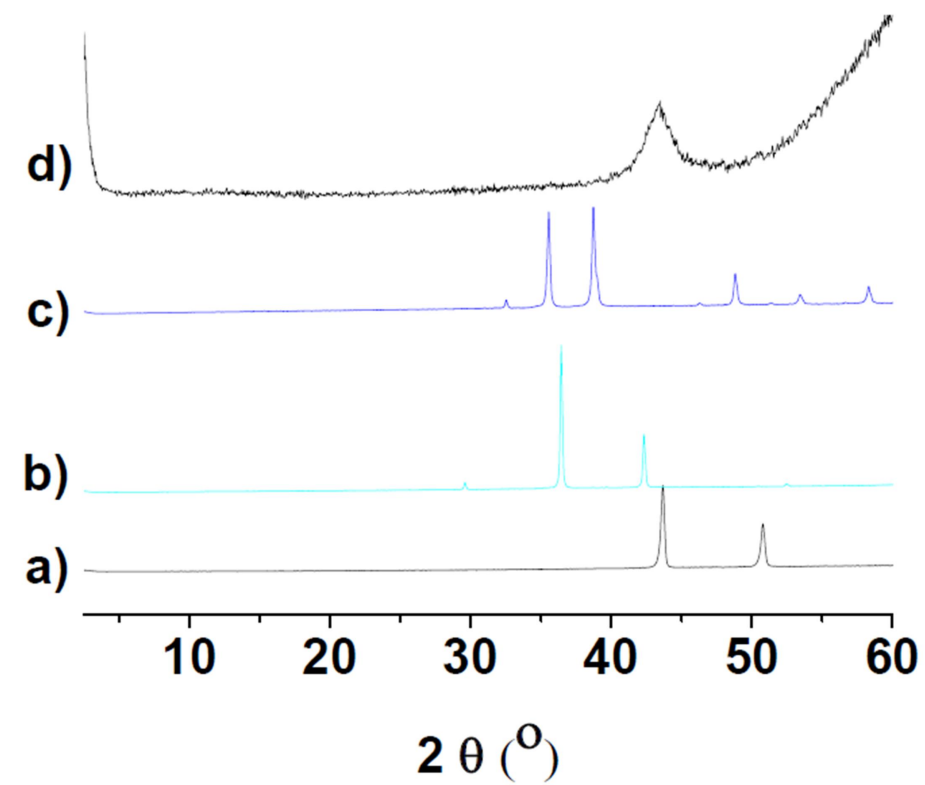

Figura 4.7. Difractogramas de rayos $\mathrm{X}$ de $\mathrm{Cu}$ (a), $\mathrm{Cu}_{2} \mathrm{O}$ (b), $\mathrm{CuO}$ (c) y $\mathrm{Cu}(1 \%$ en peso)/D3 (d). Nota: a, b y c son muestras comerciales de SigmaAldrich. 


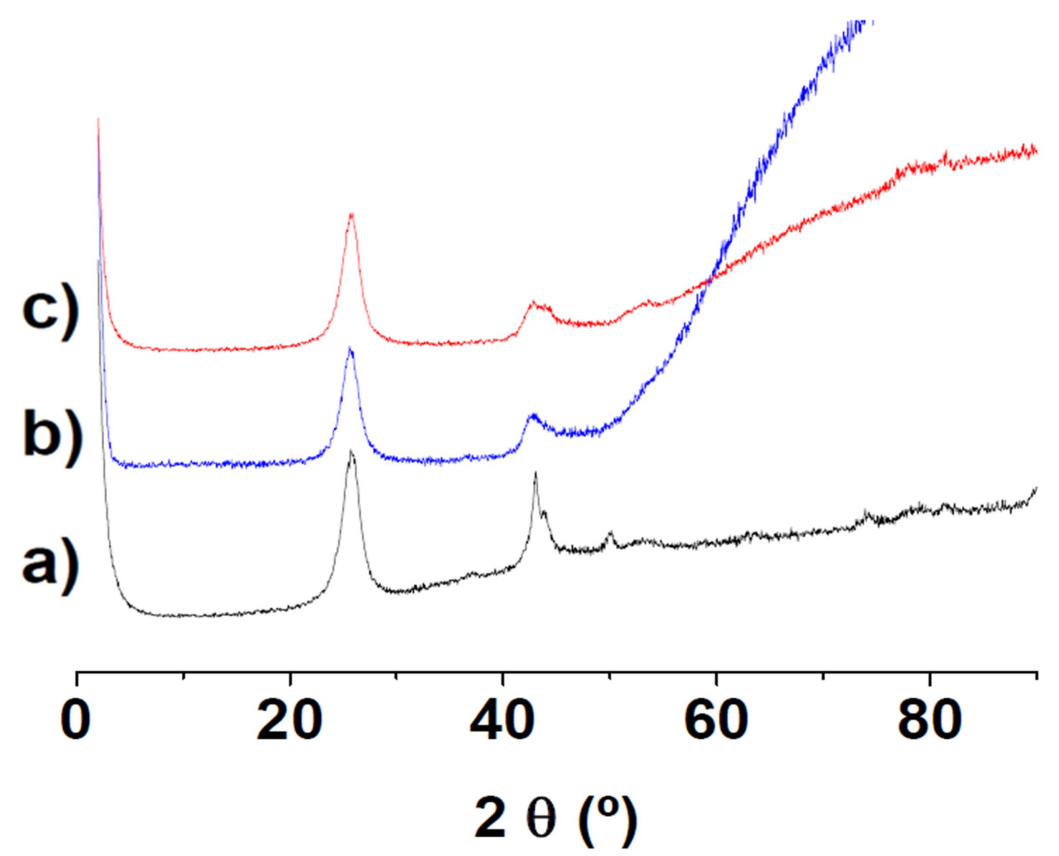

Figura 4.8. Difractogramas de rayos $\mathrm{X}$ de $\mathrm{Cu} / \mathrm{NT} 1$ (a), Cu/NT2 (b) y $\mathrm{Cu} / \mathrm{NT} 3$ (c). Nota: Carga de $\mathrm{Cu}$ de $0.2 \%$ en peso.

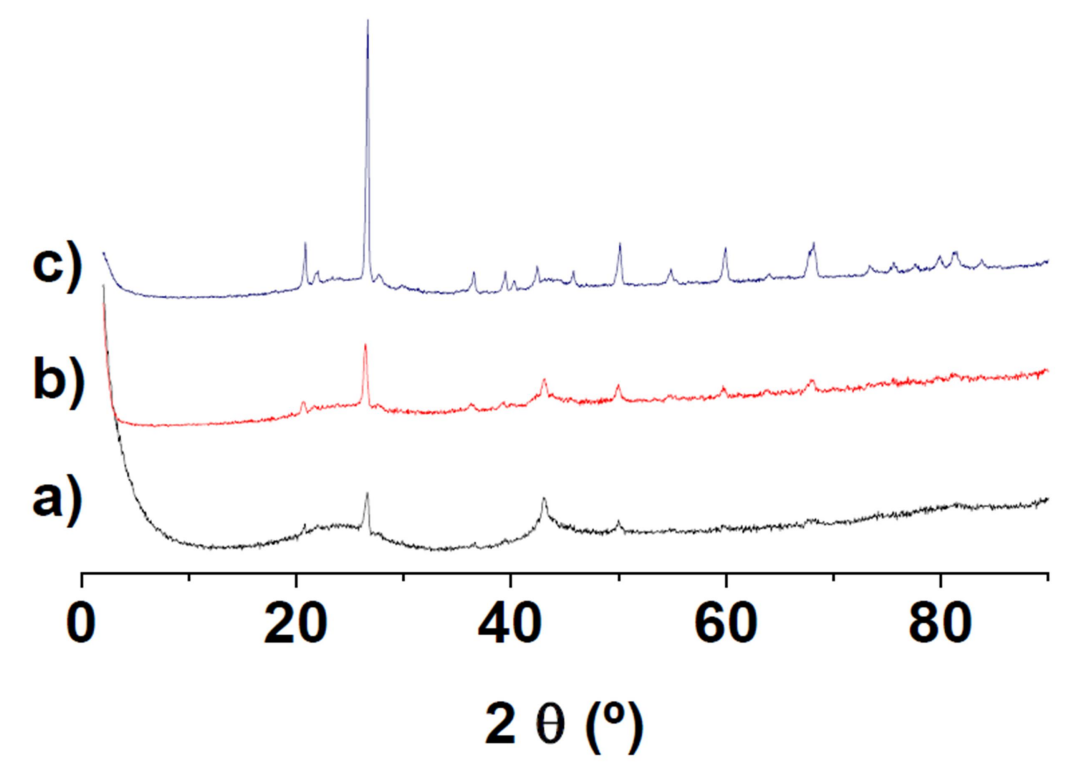

Figura 4.9. Difractogramas de rayos $\mathrm{X}$ de $\mathrm{Cu} / \mathrm{AC} 1$ (a), $\mathrm{Cu} / \mathrm{AC} 2$ (b) $\mathrm{y}$ $\mathrm{Cu} / \mathrm{AC} 3$ (c). Nota: Carga de $\mathrm{Cu}$ de $0.2 \%$ en peso. 


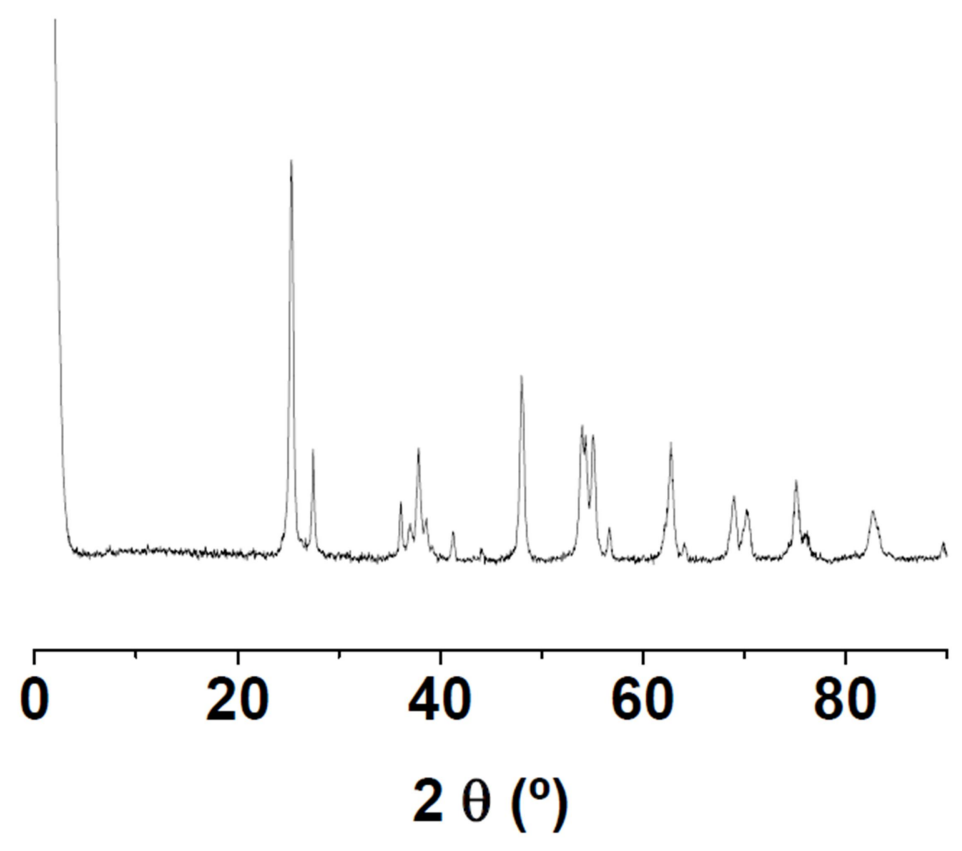

Figura 4.10. Difractograma de rayos $\mathrm{X}$ de $\mathrm{Cu}(0.2 \%$ en peso $) / \mathrm{TiO}_{2}$.

Igual de desafortunado, el análisis de XPS de la muestra $\mathrm{Cu}(0.2 \%$ en peso $) / \mathrm{D}$ tampoco fue capaz de detectar ningún pico de $\mathrm{Cu}$, probablemente debido de nuevo al bajo contenido en $\mathrm{Cu}$ de esta muestra. Sin embargo en estudios anteriores, una señal débil de XPS se registró para una muestra de $\mathrm{Cu} / \mathrm{D} 3$ con un porcentaje de $\mathrm{Cu}$ más elevado $(0.5 \%$ en peso), observando en este caso una distribución de especies de cobre con estados de oxidación cero, uno y dos. ${ }^{35}$ En contraste, empleando espectroscopía de resonancia paramagnética (EPR) que es una técnica más sensible, se pudo determinar la presencia de especies de $\mathrm{Cu}$ (II) para la muestra $\mathrm{Cu}(0.2 \%$ en peso)/D3, tal como muestra la figura 4.1. Además la señal de EPR de la muestra reusada $\mathrm{Cu}(0.2 \%$ en peso)/D3 aumenta de intensidad indicando que la posible causa de desactivación con el reúso que se comentará a continuación es la oxidación de especies de $\mathrm{Cu}$ reducidas tales como $\mathrm{Cu}(0)$ o $\mathrm{Cu}(\mathrm{I})$ en especies de $\mathrm{Cu}(\mathrm{II})$. Conviene recordar que la espectroscopía de EPR es selectiva para la especie paramagnética $\mathrm{Cu}(\mathrm{II})$, mientras que las especies $\mathrm{Cu}(0)$ y $\mathrm{Cu}(\mathrm{I})$ no son detectables por EPR. 


\subsubsection{Estudio fotocatalítico}

A fin de determinar la actividad de las muestras de $\mathrm{Cu}$ como catalizadores heterogéneos en la reacción de foto-Fenton, se empleó la desaparición de fenol como molécula sonda, usando $\mathrm{H}_{2} \mathrm{O}_{2}$ a una relación molar respecto al fenol de 5.5. Existen en la literatura ejemplos de catalizadores de foto-Fenton que usan un exceso de $\mathrm{H}_{2} \mathrm{O}_{2}$ considerablemente mayor, a menudo con relaciones de 1000 o incluso de 100000. ${ }^{13-15}$ Sin embargo, a fin de mostrar la eficiencia de los catalizadores de $\mathrm{Cu}$, en el presente capítulo nos limitamos a ensayos con un exceso de $\mathrm{H}_{2} \mathrm{O}_{2}$ de tan sólo 5.5 equivalentes.

En el presente capítulo se determinaron sistemáticamente de forma simultánea los perfiles temporales de desaparición de fenol y consumo de agua oxigenada a fin de establecer la correlación entre ambos. Estas comparaciones permiten establecer los porcentajes de descomposición de $\mathrm{H}_{2} \mathrm{O}_{2}$ espurios que no conducen a degradación de fenol, determinándose que esta descomposición indeseada es muy pequeña para la mayoría de catalizadores ensayados. Conviene indicar que medidas preliminares de adsorción indican que bajo las condiciones experimentales más comúnmente empleadas en este capítulo $(5 \mathrm{mg}$ catalizador, $25 \mathrm{~mL}$ disolución acuosa de fenol a $100 \mathrm{mg} \mathrm{L}^{-1}$ ) la adsorción de los sustratos sobre el catalizador es despreciable y, por tanto, los perfiles temporales de degradación del fenol no se encuentran influidos por la adsorción. Igualmente, un experimento control mostró que las $\mathrm{Cu}$ NPs coloidales sin estar soportadas sufren una aglomeración rápida bajo las condiciones de reacción, viniendo a resultar en una pérdida de actividad catalítica inmediata empleando las relaciones molares $\mathrm{Cu} /$ sustrato que se emplean para el caso del catalizador óptimo $\mathrm{Cu} / \mathrm{D} 3$ (figura 4.11). 


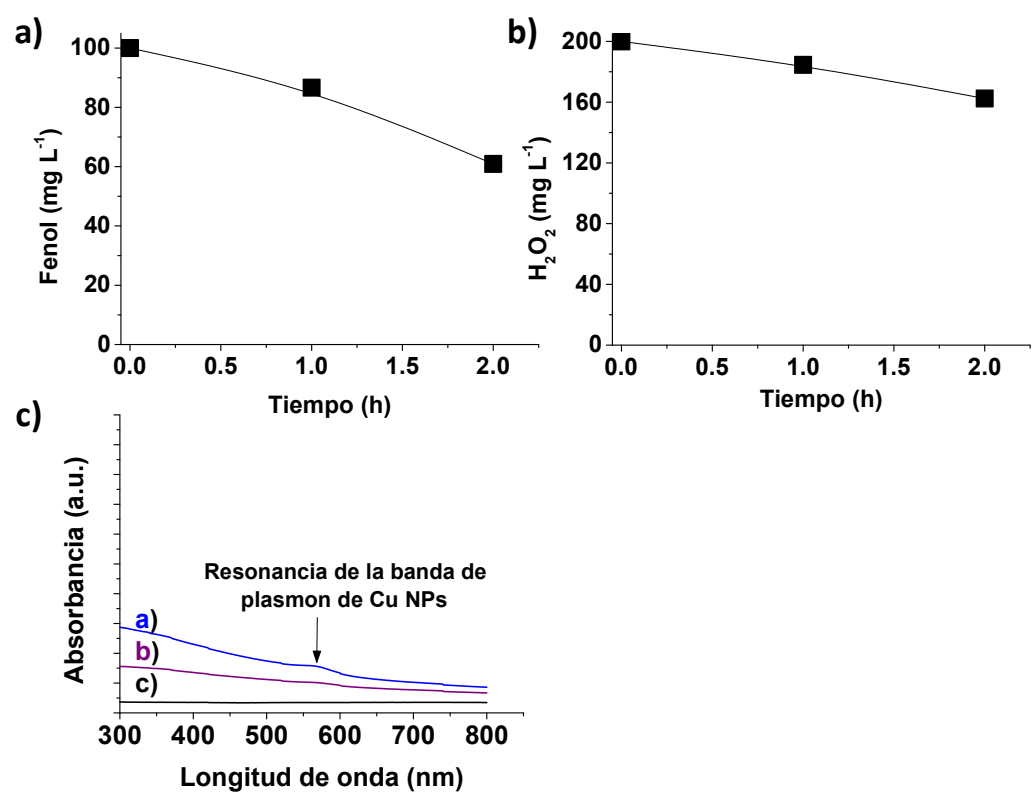

Figura 4.11. Perfil temporal de degradación del fenol (a) y descomposición de $\mathrm{H}_{2} \mathrm{O}_{2}$ (b) usando $\mathrm{Cu}$ NPs como catalizador. c) Espectro de UV-Vis de la síntesis de $\mathrm{Cu}$ NPs utilizando $\mathrm{Cu}^{2+}$ en concentraciones de 125 (1), 62 (2) y $0.4 \mathrm{mg} \mathrm{L}^{-1}$ (3). Condiciones de reacción: catalizador $\left(0.4 \mathrm{mg} \mathrm{L}^{-1}, 0.0063 \mathrm{mM}\right.$ de $\mathrm{Cu}$ NPs soportadas), fenol (100 $\left.\mathrm{mg} \mathrm{L}^{-1}, 1.06 \mathrm{mM}\right), \mathrm{H}_{2} \mathrm{O}_{2}\left(200 \mathrm{mg} \mathrm{L}^{-1} ; 5.88\right.$ $\mathrm{mM}$ ), $\mathrm{pH}$ inicial 4. Concentración de fenol obtenida por HPLC y de $\mathrm{H}_{2} \mathrm{O}_{2}$ por espectrofotometría, como se indica en el capítulo 8 , sección experimental.

Experimentos iniciales compararon la actividad de las $\mathrm{Cu}$ NPs soportadas sobre $\mathrm{D}$ en función de los pretratamientos a los que se somete las D NPs (figura 4.12). Los resultados mostraron que la actividad catalítica disminuye a medida que el tamaño de partícula promedio de las $\mathrm{Cu}$ NPs aumenta. La muestra más activa fue $\mathrm{Cu} / \mathrm{D} 3$, mientras que la muestra $\mathrm{Cu} / \mathrm{D} 1$ exhibió poca actividad. La misma tendencia, es decir, una disminución de la actividad catalítica con el tamaño de partícula promedio para $\mathrm{Cu}$ NPs fue igualmente observada para la serie $\mathrm{Cu} / \mathrm{AC}$ (figura 4.13) y $\mathrm{Cu} / \mathrm{CNT}$ (figura 4.14). Basados en estos resultados, se eligió $\mathrm{Cu} / \mathrm{D} 3$ para estudios ulteriores. 

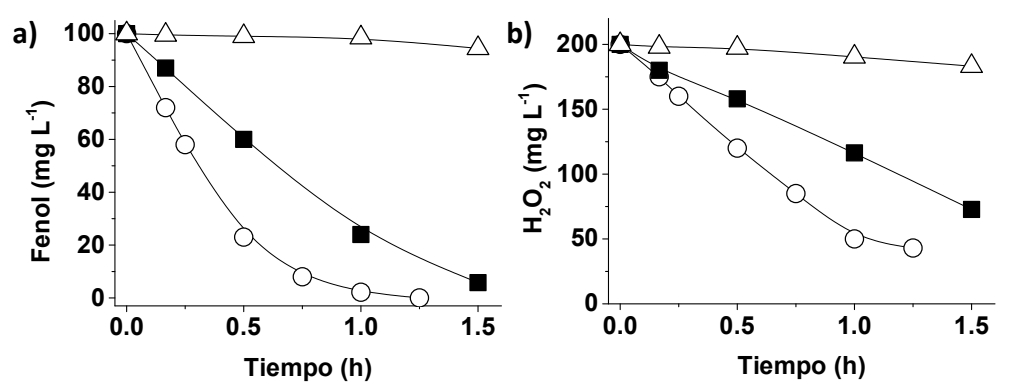

Figura 4.12. Perfil temporal de degradación del fenol (a) y descomposición de $\mathrm{H}_{2} \mathrm{O}_{2}$ (b) utilizando $\mathrm{Cu} / \mathrm{D} 1(\Delta), \mathrm{Cu} / \mathrm{D} 2$ (匹) y $\mathrm{Cu} / \mathrm{D} 3$ (o) como catalizadores bajo irradiación solar natural. Condiciones de reacción: catalizador (5 mg, $200 \mathrm{mg} \mathrm{L}^{-1}, 0.0063 \mathrm{mM}$ de Cu NPs soportadas), fenol (100 $\left.\mathrm{mg} \mathrm{L}{ }^{-1} ; 1.06 \mathrm{mM}\right), \mathrm{H}_{2} \mathrm{O}_{2}\left(200 \mathrm{mg} \mathrm{L}^{-1} ; 5.88 \mathrm{mM}\right)$, $\mathrm{pH}$ inicial 4. Concentración de fenol obtenida por HPLC y de $\mathrm{H}_{2} \mathrm{O}_{2}$ por espectrofotometría, como se indica en el capítulo 8 , sección experimental.
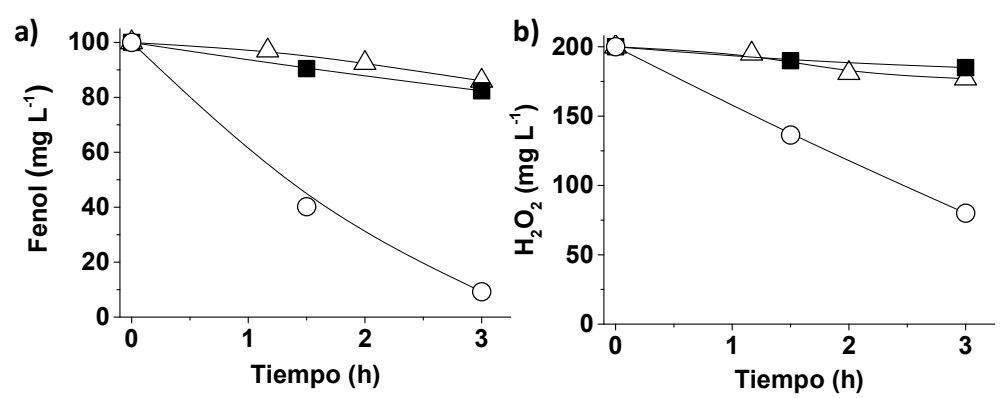

Figura 4.13. Perfil temporal de degradación del fenol (a) y descomposición de $\mathrm{H}_{2} \mathrm{O}_{2}$ (b) utilizando $\mathrm{Cu} / \mathrm{AC} 1(\Delta), \mathrm{Cu} / \mathrm{AC} 2$ (-) y $\mathrm{Cu} / \mathrm{AC} 3$ (o) como catalizadores bajo irradiación solar natural. Condiciones de reacción: catalizador (5 mg, $200 \mathrm{mg} \mathrm{L}^{-1}, 0.0063 \mathrm{mM}$ de Cu NPs soportadas), fenol $\left(100 \mathrm{mg} \mathrm{L}^{-1} ; 1.06 \mathrm{mM}\right), \mathrm{H}_{2} \mathrm{O}_{2}\left(200 \mathrm{mg} \mathrm{L}^{-1} ; 5.88 \mathrm{mM}\right), \mathrm{pH}$ inicial 4. Concentración de fenol obtenida por HPLC y de $\mathrm{H}_{2} \mathrm{O}_{2}$ por espectrofotometría, como se indica en el capítulo 8, sección experimental. 
Nanopartículas de cobre soportadas sobre nanopartículas de diamante como catalizador eficiente y de buena relación de coste-actividad para la reacción de Fenton asistida por luz solar natural
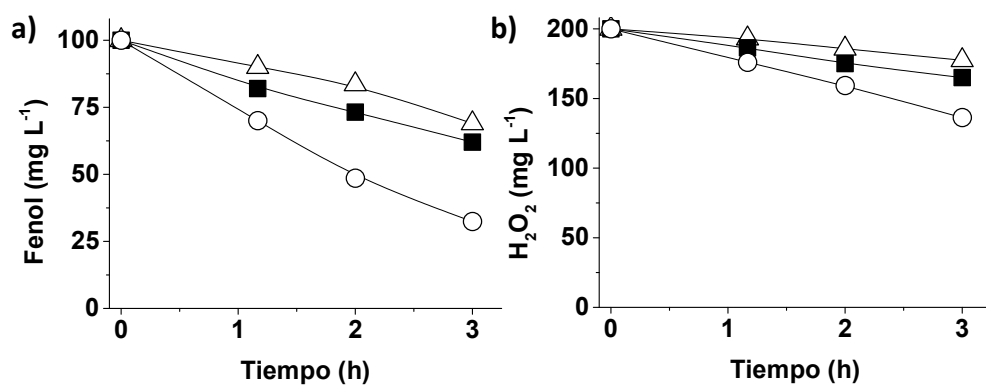

Figura 4.14. Perfil temporal de degradación del fenol (a) y descomposición de $\mathrm{H}_{2} \mathrm{O}_{2}$ (b) utilizando $\mathrm{Cu} / \mathrm{NT} 1(\Delta), \mathrm{Cu} / \mathrm{NT} 2$ (-) y Cu/NT3 (o) como catalizadores bajo irradiación solar natural. Condiciones de reacción: catalizador ( $5 \mathrm{mg}, 200 \mathrm{mg} \mathrm{L}^{-1}, 0.0063 \mathrm{mM}$ de Cu NPs soportadas), fenol $\left(100 \mathrm{mg} \mathrm{L}^{-1} ; 1.06 \mathrm{mM}\right), \mathrm{H}_{2} \mathrm{O}_{2}\left(200 \mathrm{mg} \mathrm{L}^{-1} ; 5.88 \mathrm{mM}\right), \mathrm{pH}$ inicial 4. Concentración de fenol obtenida por HPLC y de $\mathrm{H}_{2} \mathrm{O}_{2}$ por espectrofotometría, como se indica en el capítulo 8, sección experimental.

En este punto se procedió a optimizar el exceso de $\mathrm{H}_{2} \mathrm{O}_{2}$ en la reacción. La figura 4.15 presenta el gráfico de conversión frente al tiempo para la desaparición del fenol y el consumo de $\mathrm{H}_{2} \mathrm{O}_{2}$ empleando la muestra $\mathrm{Cu} / \mathrm{D} 3$ como catalizador a diferentes relaciones molares $\mathrm{H}_{2} \mathrm{O}_{2}$ /fenol. Como puede verse en esa figura, excesos de $\mathrm{H}_{2} \mathrm{O}_{2}$ menores de 5.5 conducen a la desaparición completa de $\mathrm{H}_{2} \mathrm{O}_{2}$ sin haber conseguido la completa eliminación de fenol. Esta figura 4.15 muestra que excesos de $\mathrm{H}_{2} \mathrm{O}_{2}$ entre 4 y 5.5 equivalentes son necesarios para conseguir la completa desaparición del fenol. 

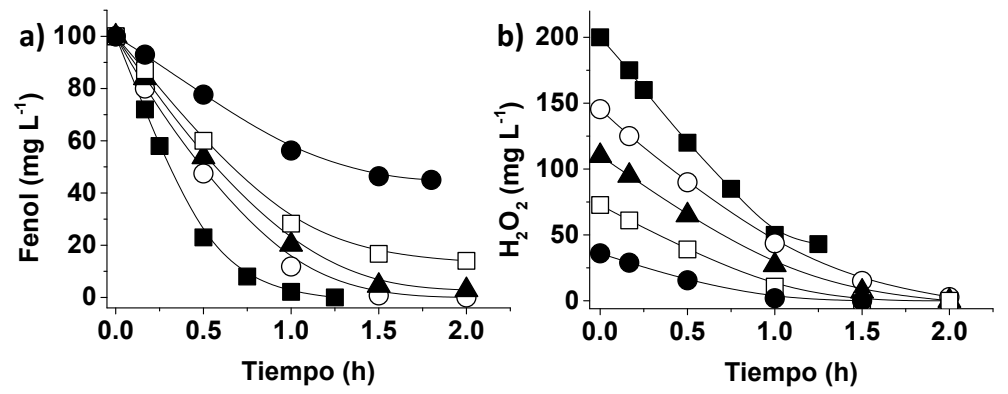

Figura 4.15. Influencia del ratio molar de $\mathrm{H}_{2} \mathrm{O}_{2}$ respecto a fenol para la degradación del fenol (a) y la descomposición de $\mathrm{H}_{2} \mathrm{O}_{2}$ (b) utilizando $\mathrm{Cu} / \mathrm{D} 3$ como catalizador bajo irradiación solar natural. Leyenda: Ratio molar de $\mathrm{H}_{2} \mathrm{O}_{2}$ respecto a fenol de $5.5(\boldsymbol{\bullet}), 4.0(\circ), 3.0(\boldsymbol{\Delta}), 2.0($ (口) y $1.0(\bullet)$. Condiciones de reacción: catalizador $\left(5 \mathrm{mg}, 200 \mathrm{mg} \mathrm{L}^{-1}, 0.0063 \mathrm{mM}\right.$ de $\mathrm{Cu}$ NPs soportadas), fenol $\left(100 \mathrm{mg} \mathrm{L}^{-1} ; 1.06 \mathrm{mM}\right), \mathrm{H}_{2} \mathrm{O}_{2}$ según se indica en la leyenda, $\mathrm{pH}$ inicial 4. Concentración de fenol obtenida por HPLC y de $\mathrm{H}_{2} \mathrm{O}_{2}$ por espectrofotometría, como se indica en el capítulo 8 , sección experimental.

A continuación y teniendo en cuenta que datos previos han mostrado que las Au NPs y Ag NPs cuando se depositan sobre muestras de D3 son catalizadores excelentes para promover la reacción de fotoFenton, era de interés establecer una comparación en las mismas condiciones de la actividad relativa de estos tres metales. La figura 4.16 muestra los perfiles temporales de desaparición de fenol y descomposición de $\mathrm{H}_{2} \mathrm{O}_{2}$ en presencia de cuatro catalizadores a saber, $\mathrm{Au}(0.2 \%$ en peso $) / \mathrm{D} 3, \operatorname{Ag}(0.2 \%$ en peso $) / \mathrm{D} 3, \mathrm{Cu}(0.2 \%$ en peso $) / \mathrm{D} 3$ y $\mathrm{Cu}(1 \%$ en peso)/D3 bajo las mismas condiciones experimentales. Como puede verse un aumento en el contenido de cobre sobre D3 conduce a una disminución significativa de la actividad catalítica. Esta observación puede racionalizarse fácilmente considerando que los porcentajes de cobre más altos conducen a $\mathrm{Cu}$ NPs de mayor tamaño y el hecho bien conocido de la relación inversa entre tamaño de partícula promedio y actividad catalítica (ver valores en tabla 4.1 y figura 4.2 ). ${ }^{22,20}$ Con respecto a la naturaleza del metal, la actividad catalítica sigue el orden $\mathrm{Au}$ $>\mathrm{Ag}>\mathrm{Cu}$, sin embargo, como muestra la figura 4.16, incluso aunque la actividad catalítica de la muestra $\mathrm{Cu} / \mathrm{D} 3$ es menor que la de las otras dos muestras con metales diferentes, la diferencia en los perfiles temporales no son tan destacables y la actividad catalítica de estos tres metales es 
Nanopartículas de cobre soportadas sobre nanopartículas de diamante como catalizador eficiente y de buena relación de coste-actividad para la reacción de Fenton asistida por luz solar natural

comparable. Considerando el coste de cada metal, cabe concluir que el catalizador de foto-Fenton basado en $\mathrm{Cu}$ puede ser competitivo con respecto a los otros dos metales de mayor coste. Los datos experimentales del porcentaje de desaparición de fenol y consumo de $\mathrm{H}_{2} \mathrm{O}_{2}$ usando $\mathrm{Cu} / \mathrm{D} 3$ como catalizador se ajustan relativamente bien a una cinética de primer orden.
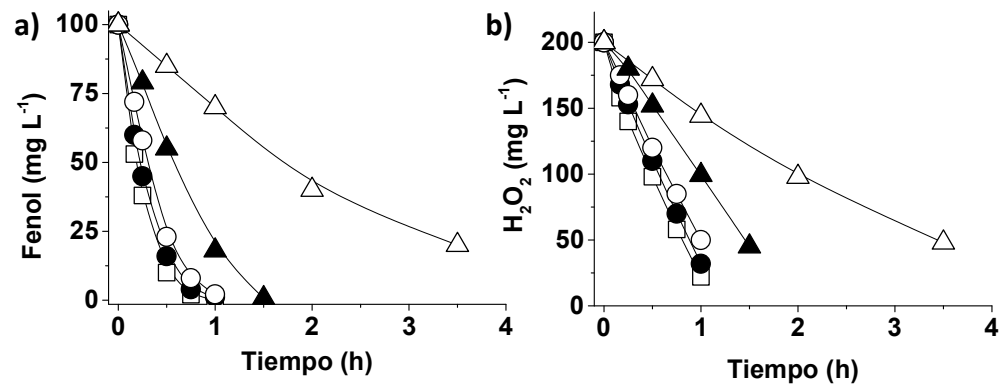

Figura 4.16. Perfiles temporales para la degradación del fenol (a) y descomposición de agua oxigenada (b) usando como catalizador bien $\mathrm{Au}(0.2 \%$ en peso $) / \mathrm{D} 3(\square), \mathrm{Ag}(0.2 \%$ en peso $) / \mathrm{D} 3(\bullet), \mathrm{Cu}(0.2 \%$ en peso $) / \mathrm{D} 3$ (o), o $\mathrm{Cu}(1.0 \%$ en peso)/D3 ( $\mathbf{\Lambda})$ bajo irradiación con luz solar natural. La actividad de $\mathrm{Cu}(0.2 \%$ en peso)/D3 en la oscuridad $(\Delta)$. Condiciones de reacción: Catalizador $(0.0063 \mathrm{mM}$ de $\mathrm{Au}, \mathrm{Ag}$ o $\mathrm{Cu}$ soportado sobre D3), fenol (100 mg L$\left.{ }^{-1} ; 1.06 \mathrm{mM}\right), \mathrm{H}_{2} \mathrm{O}_{2}\left(200 \mathrm{mg} \mathrm{L}^{-1} ; 5.88 \mathrm{mM}\right), \mathrm{pH}$ inicial 4, 25 $\mathrm{mL}$ de reacción. Concentración de fenol obtenida por HPLC y de $\mathrm{H}_{2} \mathrm{O}_{2}$ por espectrofotometría, como se indica en el capítulo 8 , sección experimental.

Bajo las condiciones seguidas para la obtención de los gráficos presentados en la figura 4.16, las constantes de velocidad estimadas a partir del mejor ajuste a una cinética de primer orden para $\mathrm{Au} / \mathrm{D} 3, \mathrm{Ag} / \mathrm{D} 3$ y Cu/D3 al $0.2 \%$ en peso fue de $4.90,4.55$, y $3.89 \mathrm{~h}^{-1}$ respectivamente.

Tras haber mostrado que la actividad catalítica de $\mathrm{Cu}$ NPs se encuentra en el mismo rango que la de otros metales, fue de interés establecer la influencia del soporte en la actividad catalítica de Cu NPs. A fin de discutir este punto, se prepararon catalizadores de $\mathrm{Cu}$ basados en AC y CNTs como soportes, procediéndose a estudiar la actividad catalítica de estos materiales cuando el soporte era tratado con la reacción de Fenton y con posterioridad se procedía o no a la reducción con 
hidrógeno. Los resultados obtenidos se presentan en la figura 4.17. Como puede verse en esa figura, $\mathrm{Cu} / \mathrm{D} 3$ exhibe una velocidad de reacción inicial mucho mayor que la de los otros dos catalizadores de $\mathrm{Cu}$ basados en otros soportes de carbono.
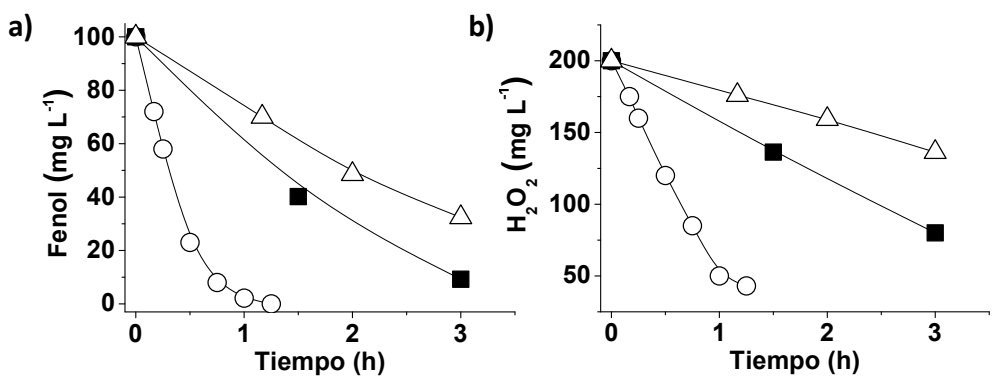

Figura 4.17. Perfiles temporales de degradación del fenol (a) y descomposición de $\mathrm{H}_{2} \mathrm{O}_{2}$ (b) usando $\mathrm{Cu}$ NPs soportadas en diferentes materiales a base de carbono como catalizadores bajo iluminación por luz solar natural. Leyenda: $\mathrm{Cu} / \mathrm{D} 3(\mathrm{o}), \mathrm{Cu} / \mathrm{AC} 3(\mathbf{a})$ y $\mathrm{Cu} / \mathrm{NT} 3(\Delta)$. Condiciones de reacción: Catalizador ( $5 \mathrm{mg}, 200 \mathrm{mg} \mathrm{L}^{-1} ; 0.0063 \mathrm{mM}$ de $\left.\mathrm{Cu} \mathrm{NPs}\right)$, fenol (100 mg L $\left.\mathrm{mg}^{-1} 1.06 \mathrm{mM}\right), \mathrm{H}_{2} \mathrm{O}_{2}\left(200 \mathrm{mg} \mathrm{L} \mathrm{L}^{-1} ; 5.88 \mathrm{mM}\right), \mathrm{pH}$ inicial 4. Concentración de fenol obtenida por HPLC y de $\mathrm{H}_{2} \mathrm{O}_{2}$ por espectrofotometría, como se indica en el capítulo 8, sección experimental.

La energía de la luz solar corresponde principalmente a la región visible e infrarroja con tan solo alrededor de $4 \%$ de luz UV. Por tanto, parece razonable asumir que la excitación por luz solar tiene lugar principalmente sobre las $\mathrm{Cu}$ NPs, las cuales exhibe una banda de plasmón a una longitud de onda alrededor de $560 \mathrm{~nm} .{ }^{24}$ El papel del soporte parece ser de menor importancia o incluso desfavorecer el proceso cuando compite con la absorción de luz por parte de las $\mathrm{Cu}$ NPs. En este contexto, la transparencia característica del diamante comparada con otros soportes de carbón podría ser beneficiosa para una mayor actividad catalítica de las muestras. Una tendencia similar ha sido también observada para el caso del Au y Ag, donde D3 como soporte da lugar al catalizador más activo. Este hecho ha sido atribuido a la inercia química de la superficie de D que permitiría que los radicales hidroxilo difundieran libremente a la superficie acuosa, en lugar de ser atrapados inmediatamente por los grupos funcionales superficiales. Probablemente 
Nanopartículas de cobre soportadas sobre nanopartículas de diamante como catalizador eficiente y de buena relación de coste-actividad para la reacción de Fenton asistida por luz solar natural

en el caso de otros soportes carbonosos debe ocurrir alguna reacción de la superficie de los mismos con los radicales hidroxilo.

De manera análoga se procedió a comparar la actividad catalítica de $\mathrm{Cu} / \mathrm{D} 3$ con otros catalizadores de $\mathrm{Cu}$ en los cuales las $\mathrm{Cu}$ NPs habían sido soportadas en $\mathrm{TiO}_{2} \mathrm{P} 25$. La idea detrás de la selección de $\mathrm{TiO}_{2} \mathrm{P} 25$ como soporte fue la bien conocida actividad catalítica de este material bajo irradiación ultravioleta. ${ }^{34}$ Dos experimentos usando $\mathrm{Cu} / \mathrm{TiO}_{2}$ en presencia y en ausencia de 5.5 equivalentes de $\mathrm{H}_{2} \mathrm{O}_{2}$ fueron llevados a cabo como mostramos en los resultados en la figura 4.18. Como puede verse en esta figura $\mathrm{Cu} / \mathrm{D} 3$ también presenta mayor actividad que la muestra $\mathrm{Cu} / \mathrm{TiO}_{2}$ tanto en ausencia como en presencia de $\mathrm{H}_{2} \mathrm{O}_{2}$. Es interesante comentar que la comparación de los perfiles temporales de desaparición del fenol y descomposición de $\mathrm{H}_{2} \mathrm{O}_{2}$ para la muestra $\mathrm{Cu} / \mathrm{TiO}_{2}$ indica que para este catalizador basado en un óxido metálico semiconductor tiene lugar en un alto porcentaje la descomposición espuria de $\mathrm{H}_{2} \mathrm{O}_{2}$ que no causa la degradación del fenol (figura 4.18). La comparación de $\mathrm{D} 3$ con otros soportes refuerza propuestas previas de que la superficie inerte de D es apropiada para la generación de radicales hidroxilo libres en la fase acuosa, mientras que para otros soportes parece existir una interacción o reacción de los radicales hidroxilo con la superficie del sólido, viniendo a resultar un flujo menor de radicales hidroxilo libres a la disolución. ${ }^{21} \mathrm{La}$ diferencia en la generación de radicales libres hidroxilo difundiendo a la fase acuosa explica por qué el $\mathrm{H}_{2} \mathrm{O}_{2}$ se descompone en la mayoría de los catalizadores mientras que el fenol es degradado en porcentajes diferentes dependiendo de la naturaleza del soporte de las $\mathrm{Cu}$ NPs. Evidencia de la generación de radicales $\mathrm{HO}^{\circ}$ libres usando $\mathrm{Cu} / \mathrm{D} 3$ como catalizador se presentará más adelante en el capítulo cuando se comenten los experimentos con agente atrapador de radicales y su detección mediante espectroscopia EPR así como otros experimentos de inhibición. 

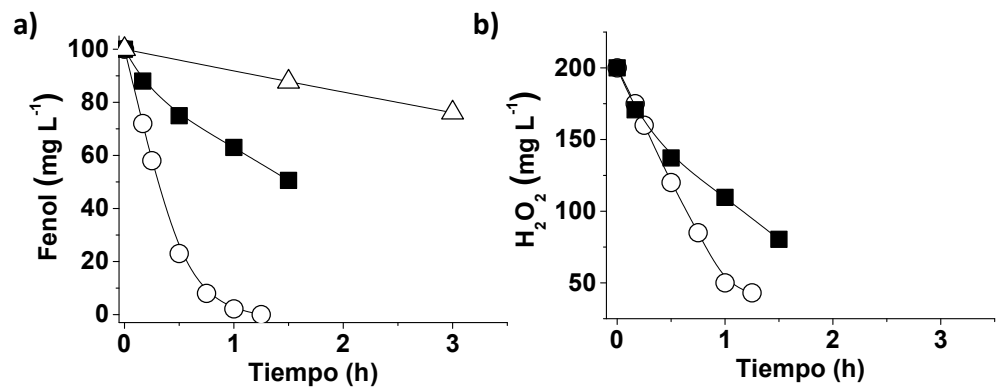

Figura 4.18. Perfiles temporales de degradación del fenol (a) y descomposición de $\mathrm{H}_{2} \mathrm{O}_{2}$ (b) usando $\mathrm{Cu} / \mathrm{D} 3(\mathrm{o}), \mathrm{Cu} / \mathrm{TiO}_{2}$ (a) y $\mathrm{Cu} / \mathrm{TiO}_{2}$ sin $\mathrm{H}_{2} \mathrm{O}_{2}(\Delta)$ como catalizador bajo irradiación con luz solar natural. Condiciones de reacción: catalizador $\left(5 \mathrm{mg}, 200 \mathrm{mg} \mathrm{L}^{-1} ; 0.0063 \mathrm{mM}\right.$ de $\left.\mathrm{Cu}\right)$, fenol (100 $\left.\mathrm{mg} \mathrm{L}{ }^{-1} ; 1.06 \mathrm{mM}\right), \mathrm{H}_{2} \mathrm{O}_{2}\left(200 \mathrm{mg} \mathrm{L}^{-1} ; 5.88 \mathrm{mM}\right)$, $\mathrm{pH}$ inicial 4. Concentración de fenol obtenida por HPLC y de $\mathrm{H}_{2} \mathrm{O}_{2}$ por espectrofotometría, como se indica en el capítulo 8 , sección experimental.

Una de las limitaciones más importantes de la reacción de fotoFenton es la fuerte dependencia con el pH de la disolución. ${ }^{5,9}$ Es bien conocido que la reacción de Fenton homogénea usando sales de Fe(II) tiene que ser llevada a cabo a valores de $\mathrm{pH}$ igual o inferior a $4 .^{7,5,9} \mathrm{El}$ mismo límite de valores de $\mathrm{pH}$ ha sido encontrado cuando se reactiva la actividad catalítica de Au/D3 en ausencia de irradiación. ${ }^{17}$ Sin embargo, nuestro grupo ha descrito que la asistencia de la luz durante la reacción catalítica relaja algo el requerimiento de $\mathrm{pH}$ ácido. Este hecho ha sido atribuido a la eyección fotoinducida de electrones al irradiar a longitudes de onda que producen la excitación de las Au NPs. ${ }^{19,21}$ Por esta razón, es de interés determinar el rango de $\mathrm{pH}$ en el cual $\mathrm{Cu} / \mathrm{D} 3$ puede operar con iluminación con luz solar. La influencia del $\mathrm{pH}$ en los perfiles temporales de desaparición del fenol y descomposición de $\mathrm{H}_{2} \mathrm{O}_{2}$ se presentan en la figura 4.19. Conviene comentar en este momento que el valor de $\mathrm{pH}$ indicado en la figura 4.19 corresponde al valor de $\mathrm{pH}$ inicial y que durante el curso de la reacción, como consecuencia de la formación de ácidos carboxílicos generados en la degradación del fenol, el valor de $\mathrm{pH}$ disminuye por debajo de 3 unidades, independientemente de cuál es el valor de $\mathrm{pH}$ inicial en el rango objeto de estudio. ${ }^{36}$ 

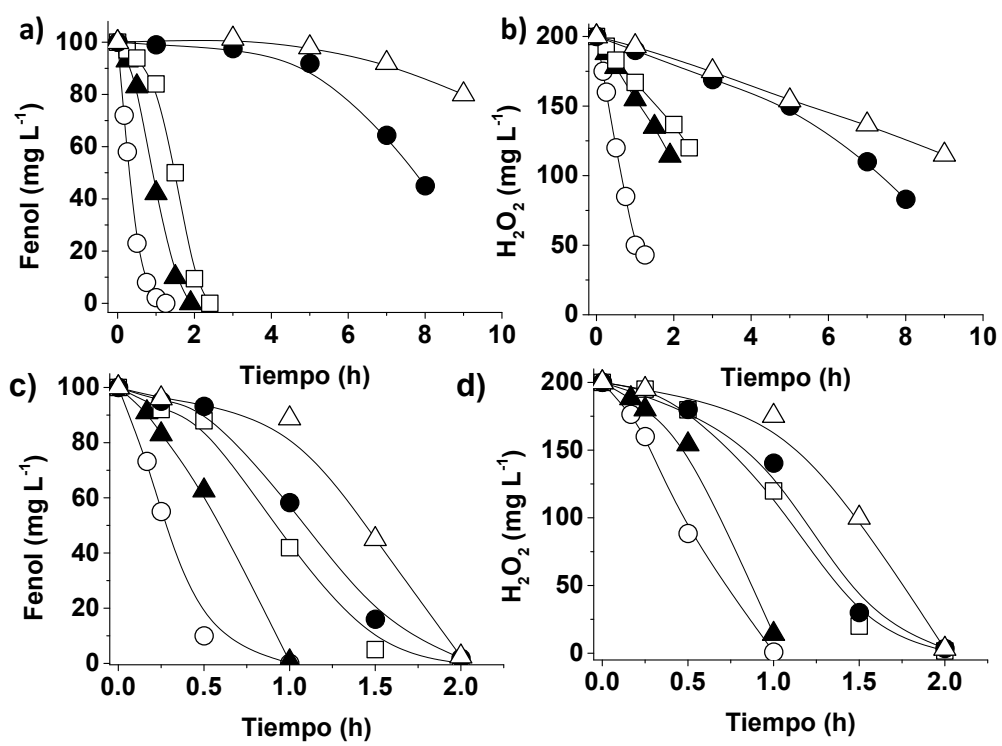

Figura 4.19. Perfiles temporales de degradación del fenol (a, c) y descomposición de $\mathrm{H}_{2} \mathrm{O}_{2}(\mathrm{~b}, \mathrm{~d})$ en función del valor de $\mathrm{pH}$ inicial y de la intensidad de luz/temperatura utilizando $\mathrm{Cu} / \mathrm{D} 3$ como catalizador bajo irradiación solar natural. Leyenda: pH 4 (०), $4.5(\mathbf{\Delta}), 5.5(\square), 6.5(\bullet)$ y 7.5 $(\Delta)$; Irradiación solar natural/temperatura: $(\mathrm{a}, \mathrm{b}) 0.92 \mathrm{~mW} \mathrm{~cm} / 29^{\circ} \mathrm{C} \mathrm{y}(\mathrm{c}, \mathrm{d})$ $1.2 \mathrm{~mW} \mathrm{~cm}^{-2} / 42^{\circ} \mathrm{C}$. Condiciones de reacción: catalizador $\left(5 \mathrm{mg}, 200 \mathrm{mg} \mathrm{L}^{-1}\right.$; $0.0063 \mathrm{mM}$ de $\mathrm{Cu}$ ), fenol (100 $\left.\mathrm{mg} \mathrm{L}^{-1} ; 1.06 \mathrm{mM}\right), \mathrm{H}_{2} \mathrm{O}_{2}\left(200 \mathrm{mg} \mathrm{L}^{-1} ; 5.88\right.$ $\mathrm{mM}), \mathrm{pH}$ inicial e intensidad de irradiación solar natural según se indica en la leyenda. Concentración de fenol obtenida por HPLC y de $\mathrm{H}_{2} \mathrm{O}_{2}$ por espectrofotometría, como se indica en el capítulo 8 , sección experimental.

Sin embargo, a fin de limitar el posible lixiviado de cobre desde el catalizador sólido $\mathrm{Cu} / \mathrm{D} 3$ a la disolución acuosa, el valor de $\mathrm{pH}$ durante la reacción se mantuvo a propósito en valores no inferiores a 4 unidades. Esta disminución espontanea del valor de $\mathrm{pH}$ de la disolución desde el valor inicial durante el transcurso de la degradación de Fenton del fenol origina un período de inducción en los perfiles temporales de desaparición del fenol y consumo de $\mathrm{H}_{2} \mathrm{O}_{2}$. El período de inducción es más largo a medida que el valor de $\mathrm{pH}$ inicial es más alto. ${ }^{21,26}$ Merece comentarse que en general no es aconsejable el empleo de tampones en la reacción de Fenton, puesto que la mayoría de los tampones conocidos son 
excelentes inhibidores de radicales $\mathrm{HO}^{\circ} \mathrm{y}$, por consiguiente, su presencia durante la reacción de Fenton produciría inevitablemente una eficiencia catalítica mucho menor o incluso podría ocasionar la inhibición completa de la degradación. ${ }^{13,37}$ Por consiguiente los pHs de la disolución en la degradación de Fenton son libres y varían en función de la naturaleza de los reactivos y productos presentes en disolución.

Los perfiles temporales de desaparición del fenol y descomposición de $\mathrm{H}_{2} \mathrm{O}_{2}$ a diferentes valores de $\mathrm{pH}$ en el rango entre 4 y 7.5 unidades se muestran en la figura 4.19. Como puede verse en esta figura, la disminución de actividad más notable como consecuencia del aumento de $\mathrm{pH}$ ocurre en el rango entre 5.5 y 6.5. Desde el punto de vista práctico, sería deseable desarrollar un catalizador de Fenton que pudiera operar con el mínimo exceso de $\mathrm{H}_{2} \mathrm{O}_{2}$ a valores de $\mathrm{pH}$ próximos a la neutralidad y en ese sentido sería aún deseable desarrollar un catalizador que presente períodos de inducción más cortos a valores de $\mathrm{pH}$ neutros. Merece comentarse, sin embargo, que el catalizador $\mathrm{Cu} / \mathrm{D} 3$ es capaz de actuar incluso a valores de $\mathrm{pH}$ neutros a temperatura ambiente, aunque en estas condiciones el período de inducción necesario se encuentra entorno a las 5 horas en las condiciones de reacción estudiadas. Este período de inducción disminuye apreciablemente a tan sólo unos 30 min cuando la temperatura de reacción se aumenta desde 24 a $42{ }^{\circ} \mathrm{C}$ (figura 4.19). La figura 4.20 muestra la influencia positiva que la iluminación con luz solar natural causa en la reacción de degradación. Se propone que ello es debido a la presencia en el espectro solar de longitudes de onda alrededor de $560 \mathrm{~nm}$ que corresponden con la absorción de la banda de plasmón de las $\mathrm{Cu}$ NPs. ${ }^{35,38} \mathrm{La}$ excitación de las Cu NPs ocasiona un aumento en la actividad catalítica del material incluso a valores de $\mathrm{pH}$ próximos a la neutralidad. Considerando que los experimentos aquí descritos han sido llevados a cabo usando luz solar natural, el rango de temperatura en el cual tiene lugar una aceleración notable de la reacción corresponde al intervalo de temperaturas que se alcanza en el ambiente durante la estación veraniega en la ciudad de Valencia. 
Nanopartículas de cobre soportadas sobre nanopartículas de diamante como catalizador eficiente y de buena relación de coste-actividad para la reacción de Fenton asistida por luz solar natural
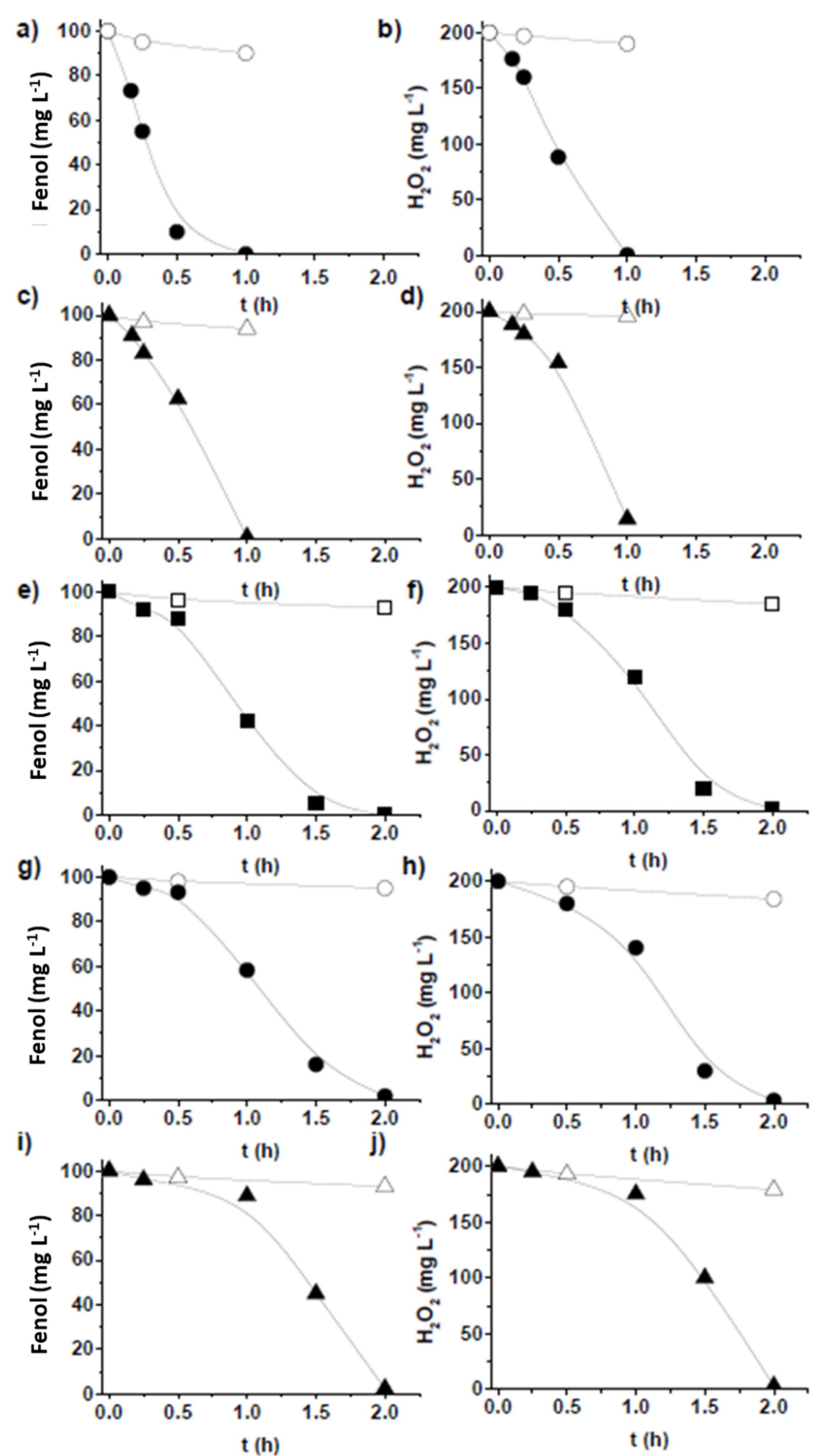
Figura 4.20. Perfiles temporales de degradación del fenol (a, c, e, g, i) y descomposición de $\mathrm{H}_{2} \mathrm{O}_{2}(b, d, f, h, j)$ en función del valor de $\mathrm{pH}$ inicial en ausencia de irradiación (símbolos abiertos) o bajo irradiación solar natural (símbolos cerrados) utilizando $\mathrm{Cu} / \mathrm{D} 3$ como catalizador. Leyenda: $\mathrm{pH} 4$ (a, b), 4.5 (c, d), 5.5 (e, f), $6.5(\mathrm{~g}, \mathrm{~h})$ y $7.5(\mathrm{i}, \mathrm{j})$. Condiciones de reacción: catalizador $\left(5 \mathrm{mg}, 200 \mathrm{mg} \mathrm{L}^{-1} ; 0.0063 \mathrm{mM}\right.$ de $\left.\mathrm{Cu}\right)$, fenol $\left(100 \mathrm{mg} \mathrm{L}^{-1} ; 1.06\right.$ $\mathrm{mM}), \mathrm{H}_{2} \mathrm{O}_{2}\left(200 \mathrm{mg} \mathrm{L}^{-1} ; 5.88 \mathrm{mM}\right), \mathrm{pH}$ inicial según se indica en la leyenda, intensidad de irradiación solar natural $\left(1.2 \mathrm{~mW} \mathrm{~cm}^{-2}\right)$, temperatura $\left(42{ }^{\circ} \mathrm{C}\right)$. Concentración de fenol obtenida por HPLC y de $\mathrm{H}_{2} \mathrm{O}_{2}$ por espectrofotometría, como se indica en el capítulo 8 , sección experimental.

Uno de los puntos más importantes en el desarrollo de un catalizador heterogéneo es estudiar su reciclabilidad en usos continuados del mismo. ${ }^{13-15}$ En la figura 4.21 muestra los perfiles temporales de disminución de las concentraciones de fenol y $\mathrm{H}_{2} \mathrm{O}_{2}$ en cuatro usos consecutivos de $\mathrm{Cu} / \mathrm{D} 3$. De una reacción a la siguiente, el catalizador se recupera por filtración, se lava con una disolución acuosa básica a fin de eliminar los posibles ácidos adsorbidos y con agua destilada para eliminar restos de base del catalizador sólido. A continuación la muestra de $\mathrm{Cu} / \mathrm{D} 3$ usada como catalizador se reduce por calentamiento en etilenglicol, que es el agente reductor ya usado en la preparación de estas muestras. Como puede verse en la figura 4.21, la muestra de $\mathrm{Cu} / \mathrm{D} 3$ sufre una disminución gradual más pequeña en su actividad catalítica con su reúso cuando la recuperación del catalizador incluye una etapa de reducción del cobre presente en el sólido. Una causa probable de la desactivación del catalizador parece ser el cambio en el estado de oxidación del $\mathrm{Cu}$, el cual sufriría una oxidación parcial en las condiciones de reacción de Fenton. $^{32,35}$ Esta propuesta se apoya en el hecho de que si en los experimentos de reutilización no se lleva a cabo el paso de reducción del material con etilenglicol, entonces se observa un alto grado de desactivación del catalizador tal como muestra la figura 4.22. 

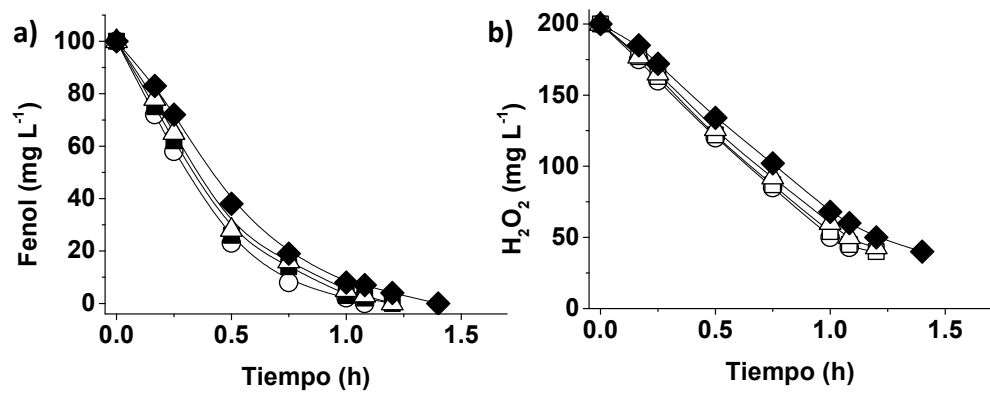

Figura 4.21. Experimentos de reusabilidad para la degradación de fenol (a) y descomposición de $\mathrm{H}_{2} \mathrm{O}_{2}$ (b) usando $\mathrm{Cu} / \mathrm{D} 3$ como catalizador. Leyenda: $1^{\circ}$ uso (o), $2^{\circ}$ uso $(-), 3^{\circ}$ uso $(\Delta)$ y $4^{\circ}$ uso $(\downarrow)$. Condiciones de reacción: catalizador $\left(5 \mathrm{mg}, 200 \mathrm{mg} \mathrm{L}^{-1} ; 0.0063 \mathrm{mM}\right.$ de $\left.\mathrm{Cu}\right)$, fenol $\left(100 \mathrm{mg} \mathrm{L}^{-1} ; 1.06\right.$ $\mathrm{mM}), \mathrm{H}_{2} \mathrm{O}_{2}\left(200 \mathrm{mg} \mathrm{L}{ }^{-1} ; 5.88 \mathrm{mM}\right), \mathrm{pH}$ inicial 4. Nota: a fin de tener en cuenta las posibles variaciones en la intensidad de la luz solar natural empleada en los reúsos, los datos del primer uso corresponden con el promedio de 4 experimentos llevados a cabo cada uno en paralelo con el reúso del catalizador. Concentración de fenol obtenida por HPLC y de $\mathrm{H}_{2} \mathrm{O}_{2}$ por espectrofotometría, como se indica en el capítulo 8, sección experimental.
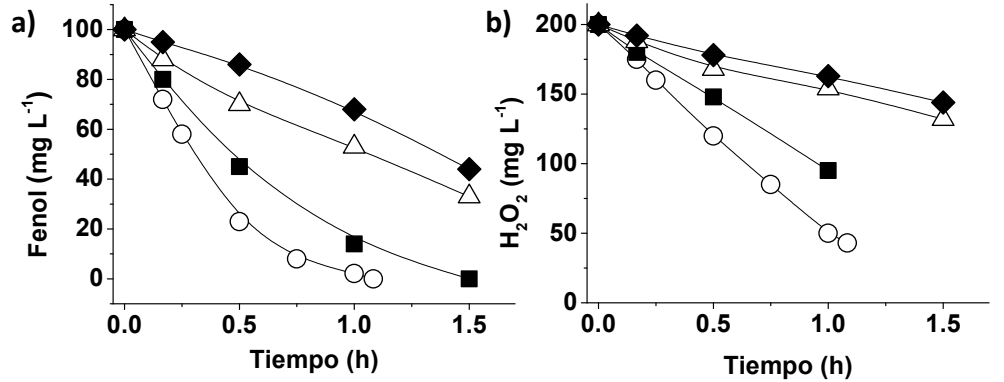

Figura 4.22. Experimentos de reusabilidad para la degradación de fenol (a) y descomposición de $\mathrm{H}_{2} \mathrm{O}_{2}$ (b) usando $\mathrm{Cu} / \mathrm{D} 3$ como catalizador. Leyenda: $1^{\mathrm{o}}$ uso (o), $2^{\circ}$ uso ( $\left.\square\right), 3^{\circ}$ uso $(\Delta)$ y $4^{\circ}$ uso $(\diamond)$. Condiciones de reacción: catalizador (5 mg, $200 \mathrm{mg} \mathrm{L}^{-1} ; 0.0063 \mathrm{mM}$ de $\mathrm{Cu}$ ), fenol (100 mg L $\mathrm{m}^{-1} ; 1.06$ $\mathrm{mM}), \mathrm{H}_{2} \mathrm{O}_{2}\left(200 \mathrm{mg} \mathrm{L}^{-1} ; 5.88 \mathrm{mM}\right), \mathrm{pH}$ inicial 4. Nota: tras cada uso, el catalizador se recuperó por filtración, lavado con agua básica (pH 10, ajustado con disolución de $\mathrm{NaOH}$ ) y después lavado con agua destilada, para luego ser llevado al próximo uso de reacción sin ningún tratamiento adicional 
al catalizador. Concentración de fenol obtenida por HPLC y de $\mathrm{H}_{2} \mathrm{O}_{2}$ por espectrofotometría, como se indica en el capítulo 8 , sección experimental.

Conviene comentar, sin embargo, que la reducción por etilenglicol del catalizador $\mathrm{Cu} / \mathrm{D} 3$ es un tratamiento no excesivamente costoso, debido a la gran disponibilidad de etilenglicol que, por otra parte, no se consume prácticamente en el proceso teniendo en cuenta la baja proporción de $\mathrm{Cu}$. Las imágenes de TEM de $\mathrm{Cu} / \mathrm{D} 3$ tras ocho usos consecutivos muestran que el tamaño de partícula promedio de las $\mathrm{Cu}$ NPs aumenta ligeramente desde $3.7 \pm 2.7$ a $4.2 \pm 2.9 \mathrm{~nm}$ como se indica en la figura 4.23. Es conocido que frecuentemente un aumento en el tamaño de partícula metálica causa una disminución notable en la actividad catalítica de las mismas y, por consiguiente, el ligero aumento de tamaño de las $\mathrm{Cu}$ NPs con el reúso podría ser la principal causa de la disminución gradual de actividad catalítica mostrada en la figura 4.21. ${ }^{21,32,35}$ Una causa adicional de desactivación podría ser el lixiviado de cobre a la disolución, pero los análisis químicos de la fase líquida no proporcionan evidencia de que ocurra este mecanismo de desactivación puesto que el contenido de $\mathrm{Cu}$ en la fase líquida se encuentra por debajo del límite de detección y los análisis de cobre para $\mathrm{Cu} / \mathrm{D} 3$ reusado indican esencialmente el mismo porcentaje de $\mathrm{Cu}$.
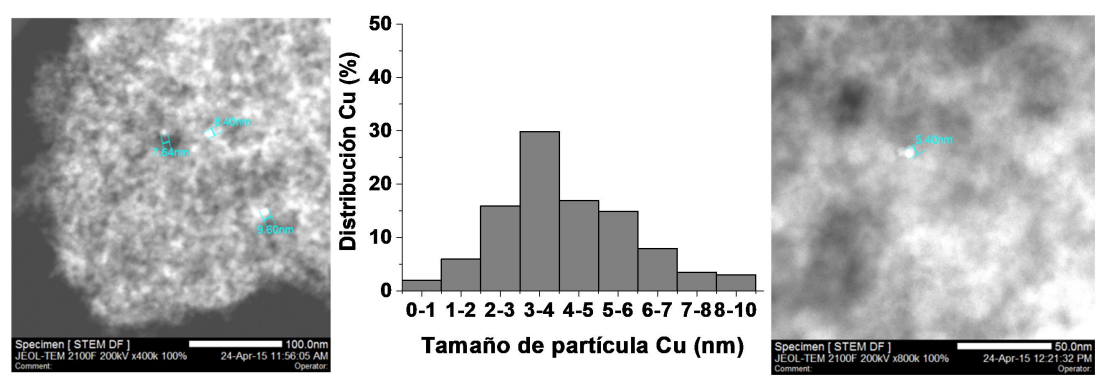

Figura 4.23. Imágenes de DF-STEM y distribución de tamaño de partícula de $\mathrm{Cu}(0.2 \%$ en peso)/D3 tras ocho usos consecutivos. El tamaño medio de partícula del cobre metálico es de $4.2 \pm 2.9 \mathrm{~nm}$.

Una vía alternativa de establecer la estabilidad del catalizador es llevar a cabo un experimento usando relaciones molares catalizador/sustrato muy bajas. ${ }^{16,17,21}$ En este tipo de experimentos generalmente denominadas "test de productividad", ${ }^{14}$ la reacción se permite que ocurra por un tiempo suficientemente largo hasta que se 
Nanopartículas de cobre soportadas sobre nanopartículas de diamante como catalizador eficiente y de buena relación de coste-actividad para la reacción de Fenton asistida por luz solar natural

observe que el catalizador resulta completamente desactivado debido al gran exceso de sustrato y a la cantidad limitada de catalizador. ${ }^{16,17,21}$ En el caso presente, el test de productividad se encuentra limitado por la máxima solubilidad del fenol en agua a valores de $\mathrm{pH}$ ácidos. De esta manera, se llevó a cabo un experimento usando una concentración de fenol y $\mathrm{H}_{2} \mathrm{O}_{2} 250$ veces más elevada usando la misma cantidad de $\mathrm{Cu} / \mathrm{D} 3$ (figura 4.24). La cantidad máxima de fenol descompuesto tras acumular dos ensayos consecutivos fue de $15.58 \mathrm{~g} \mathrm{~L}^{-1}$ (7.8 y $7.78 \mathrm{~g} \mathrm{~L}^{-1}$ en el primer y segundo uso, respectivamente) usando sólo $200 \mathrm{mg} \mathrm{L}^{-1} \mathrm{de} \mathrm{Cu} / \mathrm{D} 3$ con una carga de $\mathrm{Cu}$ de $0.2 \%$ en peso. Estos datos conducen a estimar un valor mínimo de ciclos (Turnover Number) de 52627, indicando que cada átomo de $\mathrm{Cu}$ es capaz de degradar este número de moléculas de fenol. Este valor de TON es, sin embargo, más bajo que los que han sido conseguidos para Au/D3 en la oscuridad (458000) ${ }^{16}$ y Ag/D3 (472000) por irradiación con luz solar natural ${ }^{21}$ que son los catalizadores más activos en este tipo de materiales. Por tanto, parece que aunque la actividad catalítica de la muestra $\mathrm{Cu} / \mathrm{D} 3$ fresca es comparable a la de $\mathrm{Au} / \mathrm{D} 3$, la estabilidad de $\mathrm{Cu} / \mathrm{D} 3$ es significativamente menor que la de $\mathrm{Au} / \mathrm{D} 3$ o $\mathrm{Ag} / \mathrm{D} 3$ como se deduce de la desactivación gradual de $\mathrm{Cu} / \mathrm{D} 3$ que se observa en la figura 4.22 y los valores de TON estimados para $\mathrm{Cu} / \mathrm{D} 3$ que son menores que para los otros dos catalizadores. Esta menor estabilidad de $\mathrm{Cu} / \mathrm{D} 3$ parece ser causada por la mayor tendencia de $\mathrm{Cu}$ a sufrir oxidación en las condiciones de la reacción de Fenton comparado con la mayor inercia mostrada por $\mathrm{Au}$ o Ag (figuras 4.21 y 4.22). ${ }^{16,17,21}$
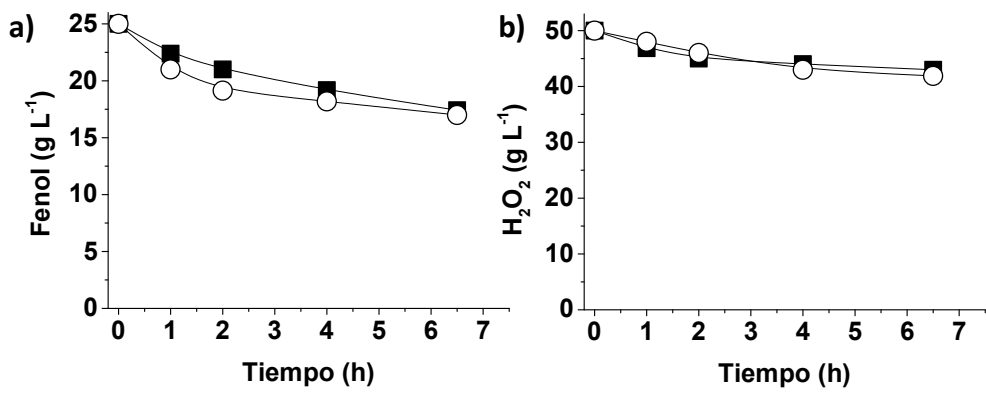

Figura 4.24. Perfiles temporales correspondientes al ensayo de productividad y reusabilidad para la degradación de fenol (a) y para la descomposición de $\mathrm{H}_{2} \mathrm{O}_{2}$ (b) usando $\mathrm{Cu} / \mathrm{D} 3$ como catalizador bajo irradiación solar natural. 
Leyenda: $1^{\circ}(\circ)$ y $2^{\circ}$ uso ( $(\mathbf{)}$.Condiciones de reacción: catalizador $(5 \mathrm{mg}, 200$ $\mathrm{mg} \mathrm{L}^{-1} ; 0.0063 \mathrm{mM}$ de Cu NPs soportado), fenol (25 $\left.\mathrm{g} \mathrm{L}^{-1} ; 26.6 \mathrm{mM}\right), \mathrm{H}_{2} \mathrm{O}_{2}$ $\left(50 \mathrm{~g} \mathrm{~L}^{-1} ; 147 \mathrm{mM}\right), \mathrm{pH} 4$. Concentración de fenol obtenida por HPLC y de $\mathrm{H}_{2} \mathrm{O}_{2}$ por espectrofotometría, como se indica en el capítulo 8 , sección experimental.

Un punto final que merece ser estudiado es el mecanismo de la descomposición catalítica del fenol empleando $\mathrm{Cu} / \mathrm{D} 3$ como catalizador. Este punto fue estudiado, por un lado, determinando los productos que se forman en etapas iniciales de la degradación del fenol. La formación de catecol, hidroquinona y $p$-benzoquinona, fue confirmada por HPLC. La figura 4.25 presenta los perfiles temporales para la concentración de catecol, hidroquinona y $p$-benzoquinona que aparecen en la degradación del fenol usando $\mathrm{Cu} / \mathrm{D} 3$ como catalizador y un exceso de $\mathrm{H}_{2} \mathrm{O}_{2}$ de 5.5 equivalentes respecto al fenol. Se observó que usando 5.5 equivalentes de $\mathrm{H}_{2} \mathrm{O}_{2}$, todos los compuestos cíclicos derivados del fenol desaparecen completamente con el tiempo de reacción en las condiciones indicadas, tal como se muestra en la figura 4.25 . 
a)

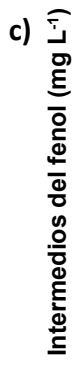
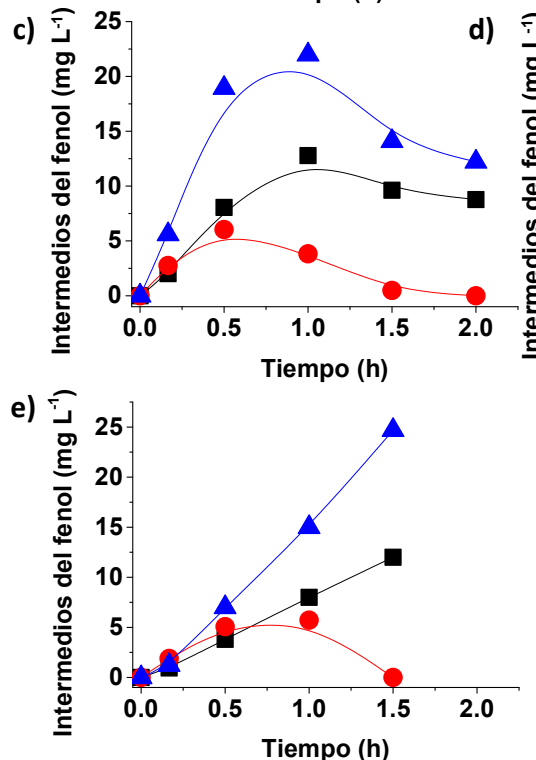

b)

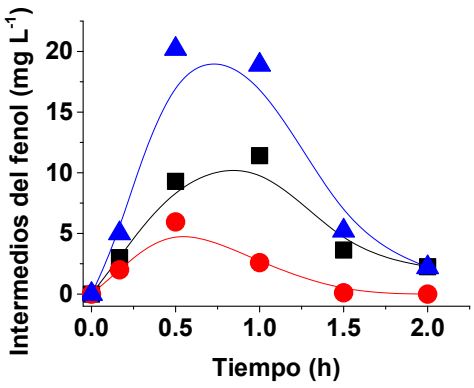

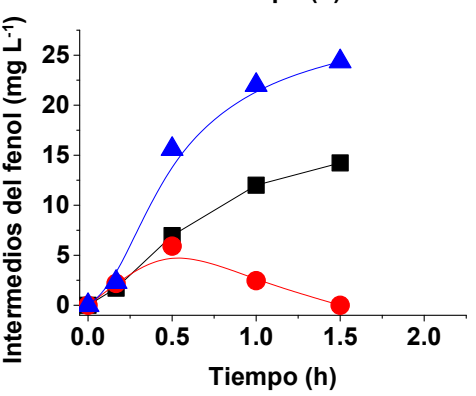

Figura 4.25. Influencia del ratio molar de $\mathrm{H}_{2} \mathrm{O}_{2}$ respecto a fenol para la degradación del fenol y de sus principales intermedios de reacción (catecol, hidroquinona y $p$-benzoquinona) usando $\mathrm{Cu} / \mathrm{D} 3$ bajo irradiación solar natural. Leyenda: Ratio molar de $\mathrm{H}_{2} \mathrm{O}_{2}$ respecto a fenol de 5.5 (a), 4 (b), 3 (c), 2 (d) y 1 (e) equivalentes; catecol $(\boldsymbol{\Delta})$, hidroquinona ( $(\mathbf{)})$ y $p$-benzoquinona $(\bullet)$. Condiciones de reacción: catalizador $\left(5 \mathrm{mg}, 200 \mathrm{mg} \mathrm{L}^{-1} ; 0.0063 \mathrm{mM} \mathrm{de} \mathrm{Cu}\right)$, fenol $\left(100 \mathrm{mg} \mathrm{L}^{-1} ; 1.06 \mathrm{mM}\right), \mathrm{H}_{2} \mathrm{O}_{2}$ según se indica en la leyenda, $\mathrm{pH}$ inicial 4. Concentración de fenol e intermedios obtenida por HPLC y de $\mathrm{H}_{2} \mathrm{O}_{2}$ por espectrofotometría, como se indica en el capítulo 8 , sección experimental.

Es interesante hacer notar que en las condiciones de reacción y considerando no sólo la degradación de fenol sino también sus intermedios de reacción, los cuales son más tóxicos (catecol, 
hidroquinona y $p$-benzoquinona), ${ }^{39-41}$ la actividad catalítica de $\mathrm{Cu} / \mathrm{D} 3$ es incluso mucho más alta que aquellas que muestran otros catalizadores de $\mathrm{Cu}$ soportado en los otros materiales empleados en el presente capítulo, es decir, $\mathrm{Cu} / \mathrm{AC} 3, \mathrm{Cu} / \mathrm{NT} 3$ y Cu/TiO 2 (figura 4.26).

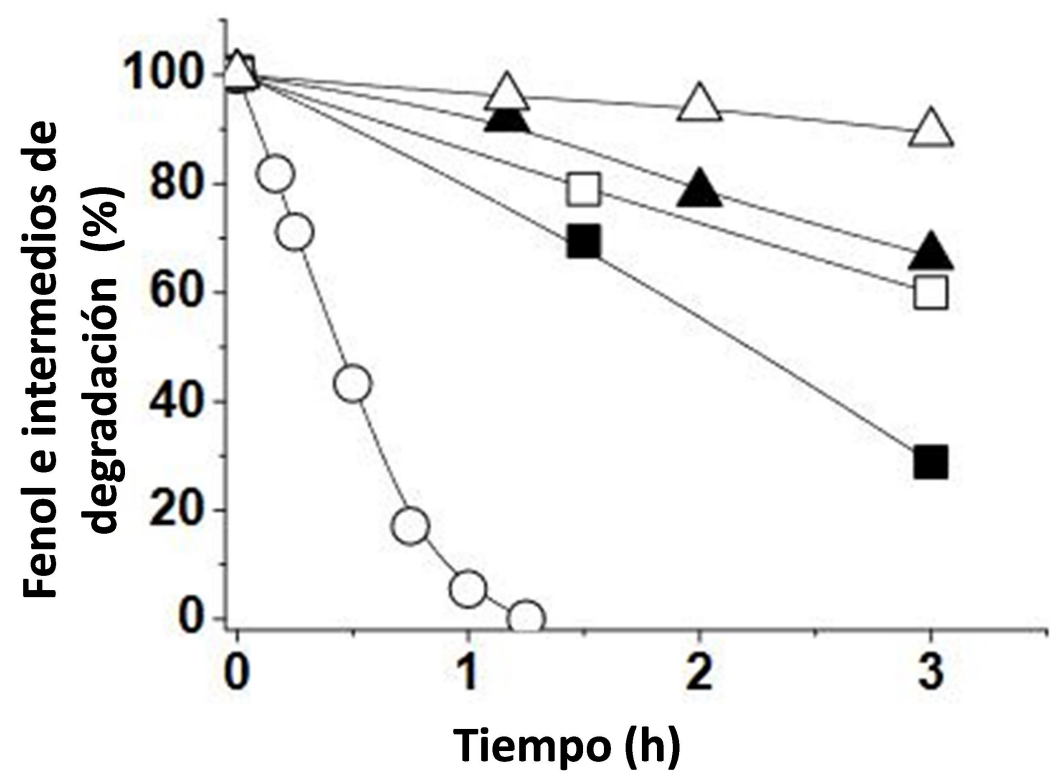

Figura 4.26. Perfil temporal de degradación del fenol y de sus principales intermedios de reacción (catecol, hidroquinona y $p$-benzoquinona) usando $\mathrm{Cu} / \mathrm{D} 3$ (०), $\mathrm{Cu} / \mathrm{AC} 3(\boldsymbol{\bullet}), \mathrm{Cu} / \mathrm{NT} 3(\boldsymbol{\Delta}), \mathrm{Cu} / \mathrm{TiO}_{2}(\square)$ y $\mathrm{Cu} / \mathrm{TiO}_{2} \sin \mathrm{H}_{2} \mathrm{O}_{2}$ como oxidante $(\Delta)$ como catalizadores bajo irradiación solar natural. Condiciones de reacción: catalizador $\left(5 \mathrm{mg}, 200 \mathrm{mg} \mathrm{L}^{-1} ; 0.0063 \mathrm{mM} \mathrm{de} \mathrm{Cu}\right)$, fenol $\left(100 \mathrm{mg} \mathrm{L}^{-1} ; 1.06 \mathrm{mM}\right), \mathrm{H}_{2} \mathrm{O}_{2}\left(200 \mathrm{mg} \mathrm{L}^{-1} ; 5.88 \mathrm{mM}\right), \mathrm{pH}$ inicial 4. Concentración de fenol e intermedios obtenida por HPLC y de $\mathrm{H}_{2} \mathrm{O}_{2}$ por espectrofotometría, como se indica en el capítulo 8 , sección experimental.

Conviene hacer notar que el ataque electrofílico del radical $\mathrm{HO}^{\circ}$ al fenol convierte a este inicialmente en catecol e hidroquinona, los cuales son los productos primarios que sufren reacciones consecutivas con radicales $\mathrm{HO}^{\circ}$, formándose $p$-benzoquinona y otros productos (ecuaciones 4.1 y 4.2). ${ }^{5,14,21}$ De esta manera, durante el curso de la reacción, el fenol sin reaccionar junto con los productos de degradación primarios y secundarios estarían presentes en la fase acuosa. 
Nanopartículas de cobre soportadas sobre nanopartículas de diamante como catalizador eficiente y de buena relación de coste-actividad para la reacción de Fenton asistida por luz solar natural

$$
\begin{aligned}
& \mathrm{H}^{+}+\mathrm{OH}^{-} \longrightarrow \mathrm{H}_{2} \mathrm{O} \\
& 2 \mathrm{H}_{2} \mathrm{O}_{2} \longrightarrow 2 \mathrm{H}_{2} \mathrm{O}+\mathrm{O}_{2}
\end{aligned}
$$

Basados en el mecanismo generalmente aceptado para la reacción de Fenton catalizada por $\mathrm{Fe}^{2+}$, se propone un mecanismo de reacción en el esquema 4.1. ${ }^{4,5,7}$ Como puede verse en ese esquema, los átomos de $\mathrm{Cu}(0)$ serían capaces de reducir una molécula de $\mathrm{H}_{2} \mathrm{O}_{2}$ por adición de un electrón, lo que conduciría a la generación de un radical $\mathrm{OH}$. Este radical migraría a la fase acuosa debido a la falta de interacción con la superficie de $\mathrm{D} 3$. El átomo de $\mathrm{Cu}(\mathrm{I})$ se reduciría de nuevo al estado $\mathrm{Cu}(0)$ por una segunda molécula de $\mathrm{H}_{2} \mathrm{O}_{2}$ la cual resultaría oxidada al estado de oxígeno molecular.

a)

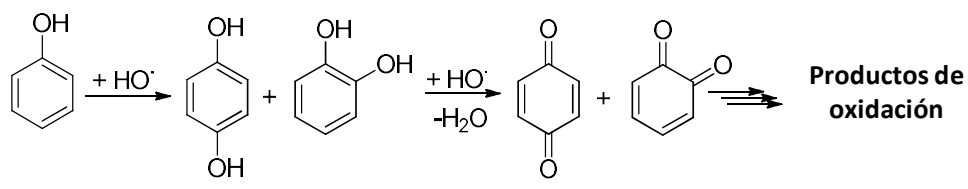

b)

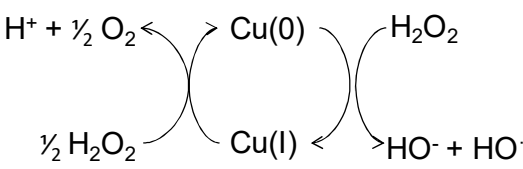

Esquema 4.1. (a) Mecanismo de reacción general para la degradación del fenol por acción del radical hidroxilo; (b) mecanismo de reacción propuesto para la descomposición de $\mathrm{H}_{2} \mathrm{O}_{2}$ a radicales $\mathrm{HO}^{\circ}$ sobre $\mathrm{Cu} / \mathrm{D} 3$ como catalizador.

Una evidencia sólida confirmando la generación de radicales libres $\mathrm{HO} \cdot$ durante la descomposición de $\mathrm{H}_{2} \mathrm{O}_{2}$ por $\mathrm{Cu} / \mathrm{D} 3$ pudo ser obtenida mediante espectroscopía de EPR usando 5,5-dimetil-1pirrolidona N-óxido (DMPO) como atrapador de radicales, observando la formación del aducto DMPO-OH. El espectro de EPR del aducto DMPO$\mathrm{OH}$ contiene información estructural basada en la constante de acoplamiento hiperfina que permite la asignación a esta estructura sin ambigüedad. ${ }^{42}$ La figura 4.27 muestra una comparación del espectro experimental de EPR registrado por descomposición de $\mathrm{H}_{2} \mathrm{O}_{2}$ en 
presencia de DMPO por la acción de $\mathrm{Cu} / \mathrm{D} 3$ como catalizador bajo iluminación de luz solar natural con el espectro teórico de EPR para el aducto DMPO-OH. El buen ajuste entre los espectros experimental y teórico apoyan firmemente la generación de radicales $\mathrm{HO}^{\circ}$ a partir de $\mathrm{H}_{2} \mathrm{O}_{2}$ promovido por la acción de $\mathrm{Cu} / \mathrm{D} 3$. $^{42}$
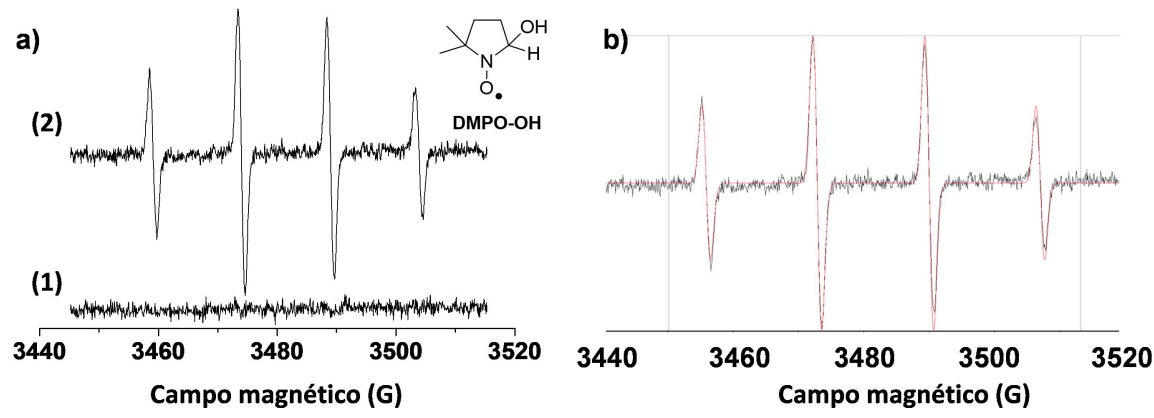

Figura 4.27. a) Espectro de EPR utilizando DMPO y $\mathrm{H}_{2} \mathrm{O}_{2}$ en ausencia de catalizador (1) o en presencia de $\mathrm{Cu} / \mathrm{D} 3$ como catalizador (2) bajo irradiación solar natural; b) espectro de EPR experimental (línea negra) y simulado (línea roja) usando las constantes de acoplamiento hiperfinas descritas para el aducto DMPO-OH (ver estructura en la figura), a saber $A_{H} G=A_{N} G=14.9$ Hz. Condiciones de reacción: catalizador $\left(100 \mathrm{mg} \mathrm{L}^{-1}\right)$, DMPO $\left(1000 \mathrm{mg} \mathrm{L}^{-}\right.$ ${ }^{1}$ ), ratio molar de $\mathrm{H}_{2} \mathrm{O}_{2}$ respecto a fenol de 1 equivalente, $\mathrm{pH} 4$, tiempo de reacción 5 minutos.

\subsection{Conclusiones}

En el presente capítulo se ha mostrado que la superficie de D NPs convenientemente acondicionada es adecuada para soportar $\mathrm{Cu}$ NPs de pequeño tamaño de partícula $(3.7 \mathrm{~nm})$. La muestra resultante, $\mathrm{Cu} / \mathrm{D} 3$ (relación molar $\mathrm{Cu} / \mathrm{Fenol}$ 0.237) exhibe una actividad catalítica destacable por irradiación con luz solar como catalizador de Fenton. Comparada con otros soportes, la superficie de D previamente tratada conduce a una mejor eficiencia catalítica, un hecho que se puede entender considerando la inercia de la superficie de las partículas de D. Una comparación de la actividad catalítica de $\mathrm{Cu} / \mathrm{D} 3$ con la de otros materiales análogos tales como $\mathrm{Au} / \mathrm{D} 3$ y Ag/D3 muestran que aunque la actividad de la muestra fresca $\mathrm{Cu} / \mathrm{D} 3$ es comparable a la de los otros catalizadores metálicos soportados en D3, la estabilidad en las condiciones de reacción 
Nanopartículas de cobre soportadas sobre nanopartículas de diamante como catalizador eficiente y de buena relación de coste-actividad para la reacción de Fenton asistida por luz solar natural

de $\mathrm{Cu} / \mathrm{D} 3$ es menor, probablemente debido a la mayor tendencia de $\mathrm{Cu}$ a sufrir oxidación comparada con la de los otros metales nobles. Se alcanzó un valor de TON de 52600 empleando la muestra $\mathrm{Cu} / \mathrm{D} 3$ mientras que usando las muestras $\mathrm{Au} / \mathrm{D} 3$ y $\mathrm{Ag} / \mathrm{D} 3$ los valores son considerablemente más elevados, específicamente, 458000 y 472000 , respectivamente. El mecanismo de reacción del catalizador $\mathrm{Cu} / \mathrm{D} 3$ también implica la generación de radicales libres $\mathrm{HO}^{\circ}$ como se determina por espectroscopía de EPR y análisis de los productos de reacción. Por consiguiente, aunque debido a su mayor abundancia relativa, los catalizadores basados en cobre son atractivos comparados con los de otros metales de transición nobles o críticos, resulta que la eficiencia catalítica de $\mathrm{Cu} / \mathrm{D} 3$ es inferior a la de $\mathrm{Au} / \mathrm{D} 3$ y Ag/D3 los cuales continúan como catalizadores de referencia en la reacción de Fenton asistida por luz solar.

\subsection{Referencias}

[1] K. Ayoub, E. D. van Hullebusch, M. Cassir, A. Bermond, J. Hazard. Mater., 2010, 178, 10-28.

[2] M. N. Chong, B. Jin, C. W. K. Chow, C. Saint, Water Res., 2010, 44, 2997-3027.

[3] S. Malato, P. Fernández-Ibáñez, M. I. Maldonado, J. Blanco, W. Gernjak, Catal. Today, 2009, 147, 1-59.

[4] M. Pera-Titus, V. García-Molina, M. A. Baños, J. Giménez, S. Esplugas, Appl. Catal. B, 2004, 47, 219-256.

[5] J. J. Pignatello, E. Oliveros, A. MacKay, Crit. Rev. Environ. Sci. Technol., 2006, 36, 1-84.

[6] S. R. Pouran, A. R. A. Aziz, V. M. A. W. Daud, J. Ind. Eng. Chem., 2015, 21, $53-69$.

[7] E. Neyens, J. Baeyens, J. Hazard. Mater., 2003, 98, 33-50.

[8] S. Navalón, A. Dhakshinamoorthy, M. Álvaro, H. García, Chem. Rev., 2014, 114, 6179-6212.

[9] A. D. Bokare, W. Choi, J. Hazard. Mater., 2014, 275, 121-135.

[10] S. Chiron, A. Fernández-Alba, A. Rodríguez, E. García-Calvo, Water Res., 2000, 34, 366-377.

[11] J. Herney-Ramirez, M. A. Vicente, L. M. Madeira, Appl. Catal. B, 2010, 98, 10-26.

[12] C. Wang, H. Liu, Z. Sun, Int. J. Photoenergy, 2012, 801694.

[13] A. Dhakshinamoorthy, S. Navalón, M. Álvaro, H. García, ChemSusChem, 2012, 5, 46-64.

[14] S. Navalón, M. Álvaro, H. García, Appl. Catal. B, 2010, 99, 1-26. 
[15] S. Navalón, A. Dhakshinamoorthy, M. Álvaro, H. García, ChemSusChem, 2011, 4, 1712-1730.

[16] R. Martín, S. Navalón, J. J. Delgado, J. J. Calvino, M. Álvaro, H. García, Chem. Eur. J., 2011, 17, 9494-9502.

[17] S. Navalón, R. Martín, M. Álvaro, H. García, Angew. Chem. Int. Ed., 2010, 49, 8403-8407.

[18] S. Navalón, R. Martín, M. Álvaro, H. Garcia, ChemSusChem, 2011, 4, 650-657.

[19] S. Navalón, M. De Miguel, R. Martín, M. Álvaro, H. García, J. Am. Chem. Soc., 2011, 133, 2218-2226.

[20] S. Navalón, D. Sempere, M. Álvaro, H. García, ACS Appl. Mater. Interfaces, 2013, 5, 7160-7169.

[21] J. C. Espinosa, S. Navalón, M. Álvaro, H. García, ChemCatChem, 2015, 7, 2682-2688.

[22] D. Sempere, S. Navalón, M. Dančíková, M. Álvaro, H. García, Appl. Catal. B, 2013, 142-143, 259-267.

[23] J. C. Scaiano, J. C. Netto-Ferreira, E. Alarcon, P. Billone, C. J. Bueno-Alejo, C. O. L. Crites, M. R. Decan, C. Fasciani, M. Gonzalez-Bejar, G. L. Hallett-Tapley, M. Grenier, K. L. McGilvray, N. L. Pacioni, A. Pardoe, L. Rene-Boisneuf, R. Narbonne-Schwartz, J. Silvero, K. G. Stamplecoskie, T. L. Wee, Pure Appl. Chem., 2011, 83, 913-930.

[24] J. C. Scaiano, K. G. Stamplecoskie, G. L. Hallett-Tapley, Chem. Commun., 2012, 48, 4798-4808.

[25] B. Subash, B. Krishnakumar, M. Swaminathan, M. Shanthi, Langmuir, 2013, 29, 939-949.

[26] C. Mondal, J. Pal, M. Ganguly, A. K. Sinha, J. Jana, T. Pal, New J. Chem., 2014, 38, 2999-3005.

[27] M. I. Litter, Appl. Catal. B, 1999, 23, 89-114.

[28] K. C. Chanderia, S. Kumar, J. Sharma, R. Ameta, P. B. Punjabi, Arabian J. Chem., 2012, 10, S205 - S2011.

[29] F. L. Y. L. Lam, A. C. Yip, X. Hu, Ind. Eng. Chem. Res., 2007, 46, 3328-3333.

[30] A. C. Pradhan, B. Nanda, K. M. Parida, M. Das, Dalton Trans, 2013, 42, 558-566.

[31] A. C.-K. Yip, F. L.-Y. Lamb, X. Hu, Chem. Commun., 2005, 32183220 .

[32] A. Dhakshinamoorthy, S. Navalon, D. Sempere, M. Alvaro, H. Garcia, Chem. Commun., 2013, 49, 2359-2361.

[33] R. Martín, M. Álvaro, J. R. Herance, H. García, ACS Nano, 2010, 4, 65-74.

[34] T. L. Thompson, J. T. Yates Jr., Chem. Rev., 2006, 106, 4428-4453.

[35] A. Dhakshinamoorthy, S. Navalón, D. Sempere, M. Alvaro, H. Garcia, ChemCatChem, 2013, 5, 241-246.

[36] R. Martín, S. Navalón, M. Álvaro and H. García, Appl. Catal. B, 2011, 103, 246-252. 
Nanopartículas de cobre soportadas sobre nanopartículas de diamante como catalizador eficiente y de buena relación de coste-actividad para la reacción de Fenton asistida por luz solar natural

[37] G. Zelmanov, R. Semiat, Water Res., 2008, 42, 3848-3856.

[38] C. M. Chanquía, L. Andrini, J. D. Fernández, M. E. Crivello, F. G. Requejo, E. R. Herrero, G. A. Eimer, J. Phys. Chem. C, 2010, 114, $12221-12229$.

[39] H. Chen, J. Yao, F. Wang, Y. Zhou, K. Chen, R. Zhuang, M. M. F. Choi, G. Zaray, Sci. Total Environ., 2010, 408, 1043-1049.

[40] A. Quintanilla, J. A. Casas, A. F. Mohedano, J. J. Rodríguez, Appl. Catal. B, 2006, 67, 206-216.

[41] A. Quintanilla, J. A. Casas, J. J. Rodriguez, Appl. Catal. B, 2010, 93, 339-345.

[42] M. J. Burkitt, R. P. Mason, Proc. Natl. Acad. Sci. U. S. A., 1991, 88, 8440-8444.

[43] R. M. Sellers, Analyst, 1980, 105, 950-954. 


\section{Capítulo 5}

Nanopartículas de óxido de hierro soportadas sobre nanopartículas de diamante como catalizador en la reacción de Fenton foto-asistida por luz visible 



\subsection{Introducción}

Como se ha venido comentando en capítulos anteriores, los procesos de oxidación avanzada (POA) se encuentran entre las técnicas más comunes para la degradación de contaminantes en agua. ${ }^{1-7} \mathrm{El}$ principal objetivo de las técnicas de POA es la generación de especies de oxígeno reactivas capaces de degradar e incluso mineralizar los compuestos orgánicos presentes en el agua., ${ }^{2,3}$ Generalmente las técnicas de POA se emplean en aquellas aguas que contienen compuestos tóxicos, recalcitrantes que no son biodegradables y que, por tanto, no pueden ser eliminados por tratamientos convencionales biológicos. ${ }^{3,8}$ Entre las diferentes técnicas POA, la reacción de Fenton y en especial su variante asistida por luz se encuentran entre los procesos preferidos para la generación de radicales hidroxilo, que son altamente agresivos, a partir del agua oxigenada que es un reactivo ampliamente disponible (ecuaciones 5.1 y 5.2 ).

$$
\begin{aligned}
& \mathrm{Fe}^{2+}+\mathrm{H}_{2} \mathrm{O}_{2} \longrightarrow \mathrm{Fe}^{3+}+\mathrm{HO}^{+}+\mathrm{HO}^{-} \\
& \mathrm{Fe}(\mathrm{OH})^{2+} \longrightarrow \mathrm{Fe}^{2+}+\mathrm{HO}^{\circ}
\end{aligned}
$$

Los principales inconvenientes son, como se viene comentando, los siguientes: ${ }^{5,9,10}$

i) Los valores de $\mathrm{pH}$ ácidos que se requieren en el tratamiento a fin de estabilizar los aquocomplejos de los iones de hierro.

ii) El uso de una fuente de irradiación con emisión en ultravioleta.

iii) La necesidad de eliminar las especies de hierro tras el proceso con la consiguiente formación de fangos y lodos.

iv) Los altos excesos de $\mathrm{H}_{2} \mathrm{O}_{2}$ necesarios para conseguir altos grados de eliminación de contaminante debido a la descomposición espuria del agua oxigenada.

Estos problemas asociados con los procesos de Fenton homogéneos pueden ser parcialmente resueltos mediante el empleo de catálisis heterogénea. ${ }^{3,11-14}$ Los sólidos más comúnmente empleados como catalizadores heterogéneos de Fenton son los aluminosilicatos, ${ }^{11}$ 
materiales a base de carbono ${ }^{14}$ y nanopartículas metálicas o de óxidos metálicos coloidales o soportadas. ${ }^{13}$

En el campo de NPs metálicas, nuestro grupo ha descrito que las NPs metálicas que exhiben bandas de absorción en la región visible asociadas a la vibración plasmónica tales como $\mathrm{Au}^{8}{ }^{8} \mathrm{Ag}^{15}$ y $\mathrm{Cu}^{16}$ soportadas sobre superficies de diamante (D) modificado con tamaño de nanopartícula se encuentran entre los catalizadores más eficientes para promover la reacción de foto-Fenton heterogénea bajo iluminación con luz visible o solar incluso a valores de $\mathrm{pH}$ próximos a la neutralidad. Es importante hacer notar que fotocatalizadores análogos usando otros soportes basados en carbono tales como grafito (Gr), carbón activo (AC) o nanotubos de carbono de varias paredes (MWCNTs) dan lugar a actividades y eficiencias menores en este proceso. Además de metales nobles soportados en $\mathrm{D}$, por motivos de sostenibilidad es de interés desarrollar otras alternativas basadas en metales más abundantes y de menor coste. Uno de los principales problemas asociados con el uso de metales de transición no nobles soportados como catalizadores de la reacción de foto-Fenton heterogénea es su baja estabilidad en las fuertes condiciones de oxidación así como la existencia de lixiviado del metal en un notable porcentaje. ${ }^{13}$ Por consiguiente, el desarrollo de un soporte apropiado que ancle fuertemente e inmovilice las NP de metales no nobles sin disminuir su eficiencia como fotocatalizador a valores de $\mathrm{pH}$ neutros continúa siendo un reto en esta área. ${ }^{13,14}$ En el capítulo anterior hemos descrito que las $\mathrm{Cu}$ NPs soportadas sobre D son un catalizador para la reacción de foto-Fenton heterogénea con iluminación por luz visible incluso a valores de $\mathrm{pH}$ próximos a la neutralidad. ${ }^{16}$ Sin embargo, las $\mathrm{Cu}$ NPs soportadas sobre D sufren desactivación con el uso debido a la oxidación de la especie de cobre reducida que actúa como catalizador convirtiéndose en especies de $\mathrm{Cu}$ (II) inactivas, lo que obliga a procesos de reactivación del catalizador consistentes en su reducción química antes de proceder a su reúso.

En el presente capítulo se va a describir que las NP de óxidos de Fe soportados sobre superficies hidroxiladas de D modificadas presentan una alta actividad y eficiencia en términos de consumo de $\mathrm{H}_{2} \mathrm{O}_{2}$ en la reacción de foto-Fenton heterogénea usando tanto luz visible natural como artificial incluso a valores de $\mathrm{pH}$ próximos a la neutralidad. Más aún el catalizador sólido es fácilmente recuperable por filtración, lavado 
con agua básica y, posteriormente, puede ser reutilizado sin necesidad de ningún tratamiento químico de reducción. Es importante hacer notar que el lixiviado de hierro del catalizador sólido a la disolución puede ser casi completamente suprimido llevando a cabo el proceso a valores de $\mathrm{pH}$ superiores a seis. El proceso heterogéneo puede acoplarse con un tratamiento biológico aerobio a fin de purificar soluciones acuosas modelo conteniendo fenol como molécula sonda. Espectroscopía de absorción ultrarrápida indica que las $\mathrm{Fe}_{\mathrm{ox}} \mathrm{NPs}$ sobre la superficie de D NPs hidroxiladas (D3) se comportan como un semiconductor teniendo lugar procesos de separación de carga fotoinducida por iluminación con luz visible. Las evidencias experimentales indican que la principal especie reactiva de oxígeno generada por el óxido de hierro soportado sobre D es el radical hidroxilo como es conocido que ocurre en la reacción de Fenton convencional.

\subsection{Resultados y discusión}

\subsubsection{Preparación y caracterización de catalizadores}

Esta sección describe los datos de caracterización de los catalizadores que han sido preparados en el presente capítulo. En el primer paso, la superficie del material a base de carbono comercial (D, $\mathrm{AC}$ o bien $\mathrm{Gr}$ ) fueron modificadas por tratamiento de los sólidos con una reacción de Fenton homogénea, seguido o no por un proceso de reducción química con hidrógeno a alta temperatura tal como se ha descrito ya en capítulos anteriores para el $\mathrm{Ag}$ y el $\mathrm{Cu}$ soportados sobre D. ${ }^{15,16} \mathrm{El}$ propósito del tratamiento químico con hidrógeno es eliminar impurezas e introducir grupos funcionales en la superficie del soporte a base de carbono que haga que esta superficie sea más adecuada para depositar en una etapa ulterior NPs metálicas de pequeño tamaño, particularmente en comparación con los tamaños de estas NPs metálicas que se obtienen cuando se depositan NPs metálicas directamente sobre los soportes comerciales. El tratamiento térmico con hidrógeno de los materiales a base de carbono se lleva a cabo a $500{ }^{\circ} \mathrm{C}$ dando lugar a la formación de una superficie más homogénea donde predominan los grupos hidroxilo. La presencia de grupos hidroxilo en los diferentes materiales a base de carbono ha resultado ser beneficiosa para conseguir NPs metálicas de pequeño tamaño que además resultan inmovilizadas sobre el material a base de carbono, sobre todo en comparación de materiales análogos 

catalizador en la reacción de Fenton foto-asistida por luz visible

donde no se ha llevado a cabo este tratamiento. ${ }^{15,16}$ De acuerdo con estos precedentes, la distribución de tamaño de partícula promedio más pequeña y la desviación estándar más estrecha de las NPs de hierro soportadas en los diferentes materiales a base de carbono objeto de estudio fueron conseguidas también en el presente capítulo cuando se usaron muestras previamente tratadas con la reacción de Fenton y posteriormente sometidas a reducción química con hidrógeno (Tabla 5.1, entradas 3, 6, 9). En el caso de los soportes a base de carbono tratadas con la reacción de Fenton, la distribución de tamaños de partícula y su desviación estándar es también más pequeña que la correspondiente para muestras donde se depositan estas NPs sobre sustratos comerciales (Tabla 5.1, entradas 2, 5, 8 frente a 1,4 y 7) para el material más apropiado como soporte, las $\mathrm{Fe}_{\mathrm{ox}}$ NPs más pequeñas se consiguieron sobre D3, observándose que un aumento en el contenido de hierro de 0.2 a $1 \%$ en peso causa sólo una influencia pequeña en la distribución de tamaño de partícula promedio (tabla 5.1, entradas 9 y 19)

\begin{tabular}{|c|c|c|c|c|c|}
\hline \multicolumn{6}{|c|}{$\begin{array}{l}\text { Tabla 5.1. Lista de catalizadores ( } 0.2 \% \text { en peso de contenido en metal). } \\
\text { Objeto de estudio en el presente capítulo, con indicación del tamaño de } \\
\text { partícula promedio y velocidades iniciales de reacción así como conversiones } \\
\text { a tiempo final en la degradación del fenol. }\end{array}$} \\
\hline Entrada & Catalizador & $\begin{array}{l}\text { Tamaño } \\
\text { medio de } \\
\text { partícula } \\
\text { metálica y } \\
\text { desviación } \\
\text { estándar } \\
(\mathrm{nm})^{\mathrm{a}}\end{array}$ & $\begin{array}{l}\text { Velocidad } \\
\text { inicial de } \\
\text { reacción } \\
\left(\mathrm{mM} \mathrm{h}^{-1}\right)^{\mathrm{e}}\end{array}$ & $\begin{array}{l}\text { Conversión } \\
\text { de fenol a } \\
3.2 \mathrm{~h}(\%)\end{array}$ & $\begin{array}{l}\text { Frecuencia } \\
\text { del } \\
\text { número de } \\
\text { ciclos }\left(\mathrm{h}^{-1}\right)\end{array}$ \\
\hline 1 & $\mathrm{Fe}_{\text {ox }} / \mathrm{AC} 1$ & $19.2 \pm 3.1$ & 0.07 & 35 & 16.2 \\
\hline 2 & $\mathrm{Fe}_{\mathrm{ox}} / \mathrm{AC} 2$ & $14.1 \pm 2.4$ & 0.11 & 46 & 21.3 \\
\hline 3 & $\mathrm{Fe}_{\mathrm{ox}} / \mathrm{AC} 3$ & $12.2 \pm 2.1$ & 0.11 & 72 & 33.4 \\
\hline 4 & $\mathrm{Fe}_{\mathrm{ox}} / \mathrm{Gr} 1$ & $18.5 \pm 2.5$ & 0.11 & 50 & 23.2 \\
\hline 5 & $\mathrm{Fe}_{\mathrm{ox}} / \mathrm{Gr} 2$ & $15.2 \pm 1.9$ & 0.21 & 74 & 34.3 \\
\hline 6 & $\mathrm{Fe}_{\mathrm{ox}} / \mathrm{Gr} 3$ & $13.1 \pm 1.5$ & 0.21 & 80 & 37.1 \\
\hline 7 & $\mathrm{Fe}_{\mathrm{ox}} / \mathrm{D} 1$ & $5.2 \pm 1.7$ & 0.13 & 63 & 29.2 \\
\hline 8 & $\mathrm{Fe}_{\mathrm{ox}} / \mathrm{D} 2$ & $4.1 \pm 1.1$ & 0.26 & 75 & 34.8 \\
\hline 9 & $\mathrm{Fe}_{\mathrm{ox}} / \mathrm{D} 3$ & $2.2 \pm 0.5$ & 0.62 & 100 & 46.4 \\
\hline 10 & $\mathrm{Fe}_{\mathrm{ox}} / \mathrm{D} 3^{\mathrm{b}}$ & $2.4 \pm 0.4$ & 0.31 & 90 & 41.7 \\
\hline 11 & $\mathrm{Cu} / \mathrm{D} 3^{\mathrm{c}}$ & $3.7 \pm 2.7$ & 0.77 & 100 & 46.4 \\
\hline 12 & $\mathrm{Ag} / \mathrm{D}^{\mathrm{c}}{ }^{\mathrm{s}}$ & $3.2 \pm 2.7$ & 0.77 & 100 & 46.4 \\
\hline
\end{tabular}




\begin{tabular}{|c|c|c|c|c|c|}
\hline $\begin{array}{l}\text { Tabla 5. } \\
\text { en metal } \\
\text { tamaño } \\
\text { conversic }\end{array}$ & $\begin{array}{l}\text { 1. (Continuad } \\
\text { ). Objeto de } \\
\text { e partícula } p \\
\text { nes a tiempo }\end{array}$ & $\begin{array}{l}\text { Lista de } \\
\text { tudio en } \\
\text { nedio y ve } \\
\text { al en la de }\end{array}$ & $\begin{array}{l}\text { lizadore } \\
\text { resente } \\
\text { dades in } \\
\text { lación de }\end{array}$ & $\begin{array}{l}2 \% \text { en pes } \\
\text { itulo, con } \\
\text { les de reac } \\
\text { nol. }\end{array}$ & $\begin{array}{l}\text { contenido } \\
\text { ación del } \\
\text { así como }\end{array}$ \\
\hline Entrada & Catalizador & $\begin{array}{l}\text { Tamaño } \\
\text { medio de } \\
\text { partícula } \\
\text { metálica y } \\
\text { desviación } \\
\text { estándar } \\
(\mathrm{nm})^{\mathrm{a}}\end{array}$ & $\begin{array}{l}\text { Velocidad } \\
\text { inicial de } \\
\text { reacción } \\
\left(\mathrm{mM} \mathrm{h}^{-1}\right)^{\mathrm{e}}\end{array}$ & $\begin{array}{l}\text { Conversión } \\
\text { de fenol a } \\
3.2 \mathrm{~h}(\%)\end{array}$ & $\begin{array}{l}\text { Frecuencia } \\
\text { del } \\
\text { número de } \\
\text { ciclos }\left(\mathrm{h}^{-1}\right)\end{array}$ \\
\hline 13 & $\mathrm{Fe}_{\mathrm{ox}} / \mathrm{TiO}_{2}$ & $4.9 \pm 2.7$ & 1.17 & 92 & 42.7 \\
\hline 14 & $\mathrm{TiO}_{2}{ }^{\mathrm{d}}$ & - & 0.38 & 49 & - \\
\hline $\begin{array}{l}\text { [a] Tama } \\
\text { de DF-S } \\
\text { la muest } \\
\text { descritos } \\
\text { empleada } \\
\text { Catalizad } \\
\text { 4. irradia }\end{array}$ & $\begin{array}{l}\text { de partícu } \\
\text { M present } \\
1 \% \text { en p } \\
\text { los capi } \\
\text { allí. [d] } \\
\text { (100 mg } \\
\text { n con luz }\end{array}$ & $\begin{array}{l}\text { metálica pr } \\
\text { s en las fig } \\
\text {. [c] Esto } \\
\text { os } 3 \text { y } 4 \\
\text { contiene } \\
\text {, fenol ( } 10 \\
\text { ar simulada }\end{array}$ & $\begin{array}{l}\text { edio estin } \\
5.1 \text { a } 5 . \\
\text { atalizado } \\
\text { orrespon } \\
\text { etal. [e] } \\
\left.\mathrm{g} \mathrm{L}^{-1}\right), \mathrm{H}\end{array}$ & $\begin{array}{l}\text { a partir d } \\
\text { b] Contenis } \\
\text { han side } \\
\text { a las mis } \\
\text { ndiciones } \\
\text { (200 mg I }\end{array}$ & $\begin{array}{l}\text { s imágenes } \\
\text { n metal de } \\
\text { reviamente } \\
\text { s muestras } \\
\text { reacción: } \\
\text { pH inicial }\end{array}$ \\
\hline
\end{tabular}

A fin de poner en contexto la actividad catalítica de estos materiales basados en $\mathrm{Fe}_{\text {ox }}$ NPs soportados en diferentes materiales a base de carbono, se estudiaron también catalizadores análogos basados en $\mathrm{Ag}$ o Cu NPs soportados sobre D3, así como $\mathrm{Fe}_{\mathrm{ox}} / \mathrm{TiO}_{2}$ como fotocatalizador de referencia (Tabla 5.1, entradas 11-13).

La presencia de NPs de óxidos de hierro fue confirmada por medio de un análisis de EDX de las imágenes de TEM (figuras 5.5 y 5.8). 
a)

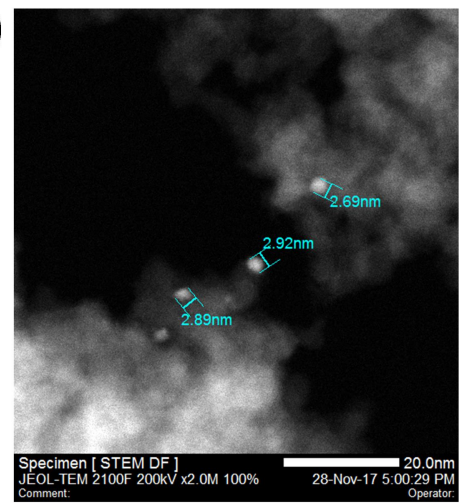

b)

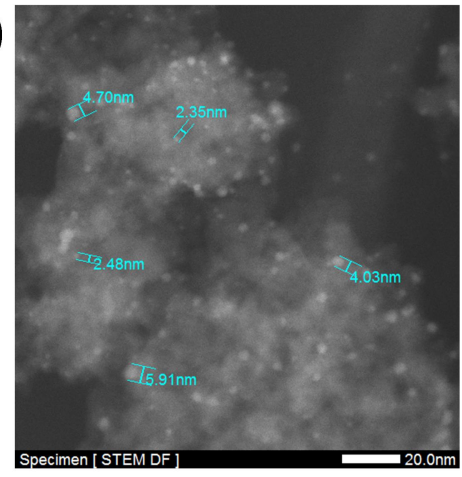

c)

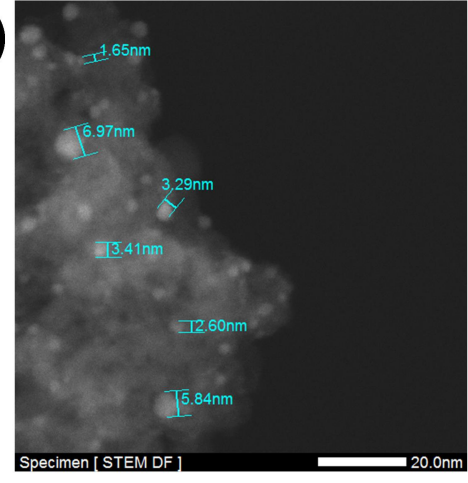

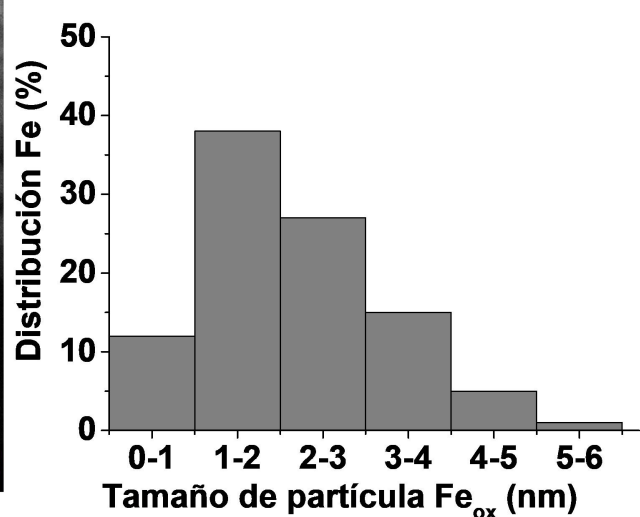
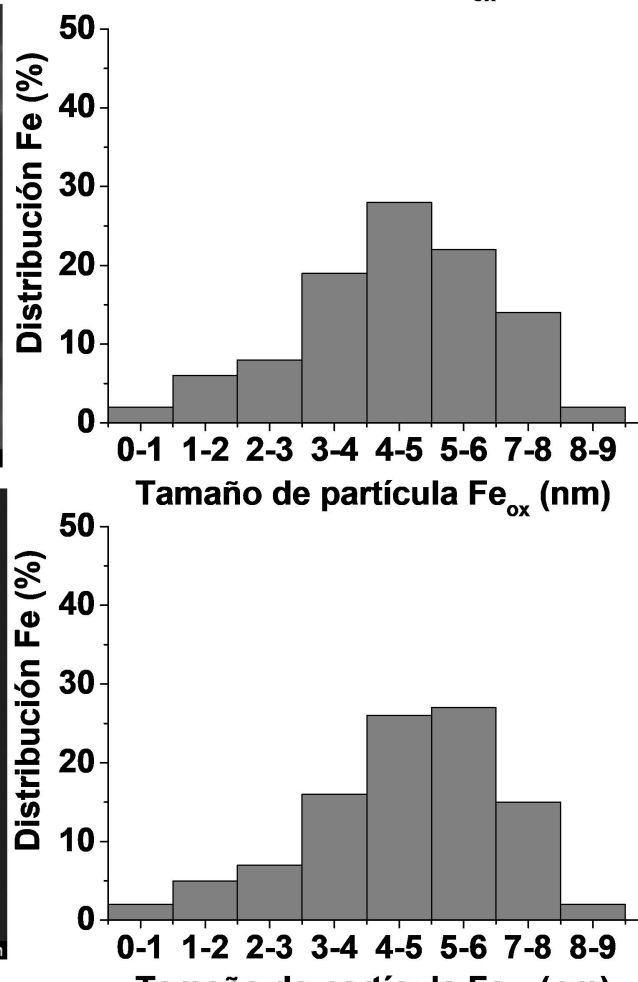

Tamaño de partícula $\mathrm{Fe}_{\mathrm{ox}}(\mathrm{nm})$

Figura 5.1. Imágenes de DF-STEM e histogramas de distribución de tamaño de partícula para la muestra fresca (a), usada 4 veces (b) y usada 8 veces (c) de $\mathrm{Fe}_{\mathrm{ox}}(0.2 \%$ en peso $) / \mathrm{D} 3$. 


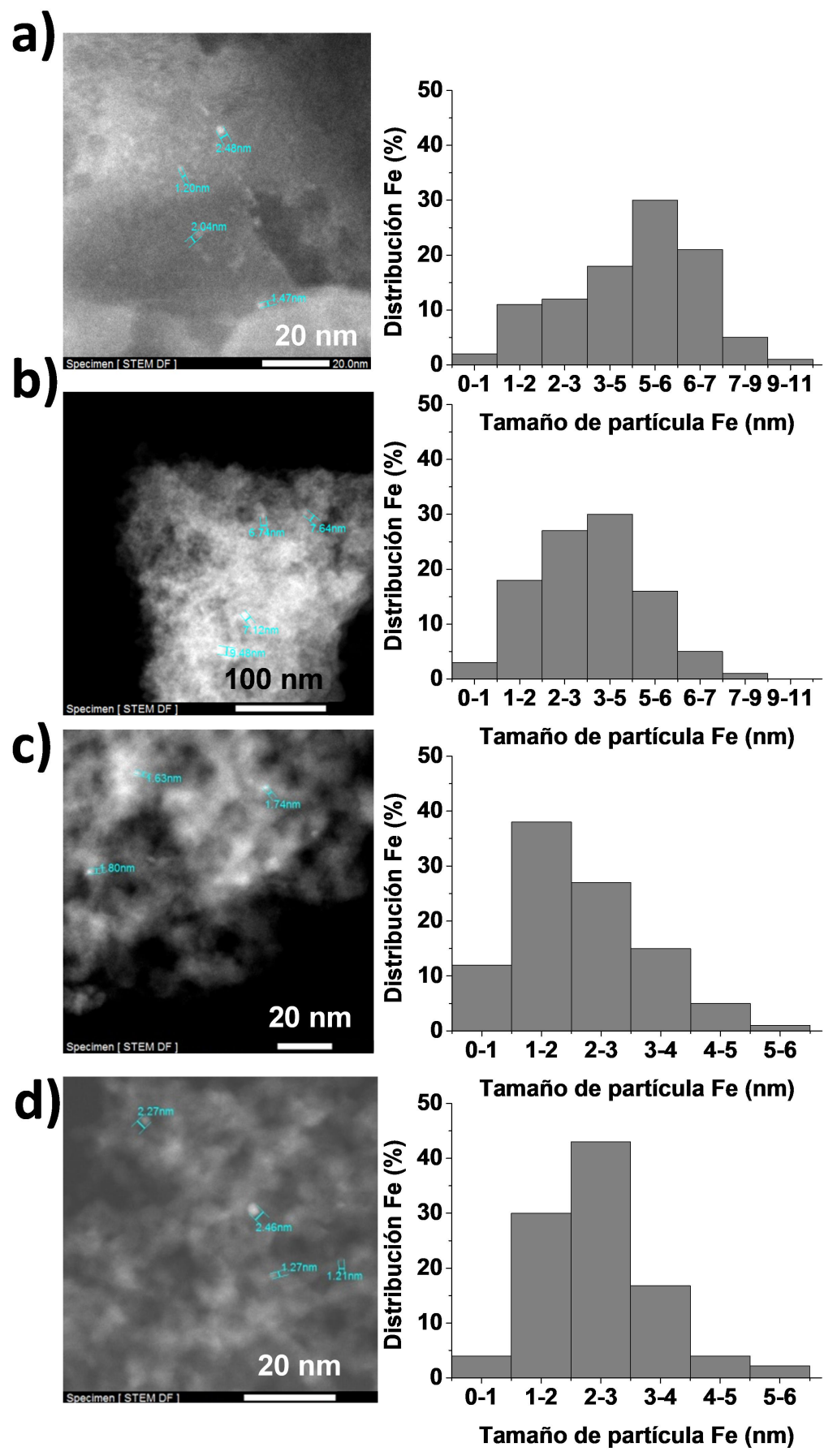


Figura 5.2. Imágenes de DF-STEM e histogramas de distribución de tamaño de partícula para los catalizadores de $\mathrm{Fe}_{\mathrm{ox}} \mathrm{NPs}(0.2 \%$ en peso) soportados en D1 (a), D2 (b), D3 (c) y Fe ox $(1 \%$ en peso)/D3 (d).
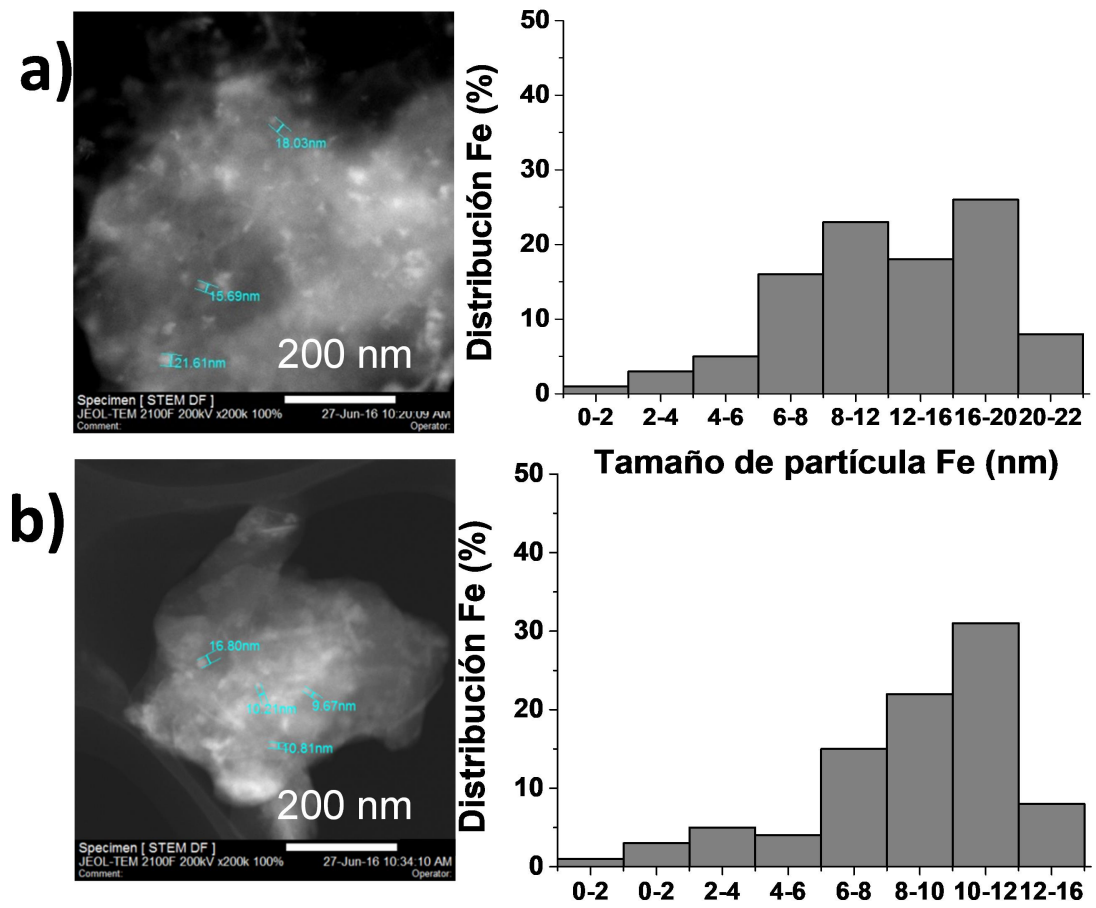

c)
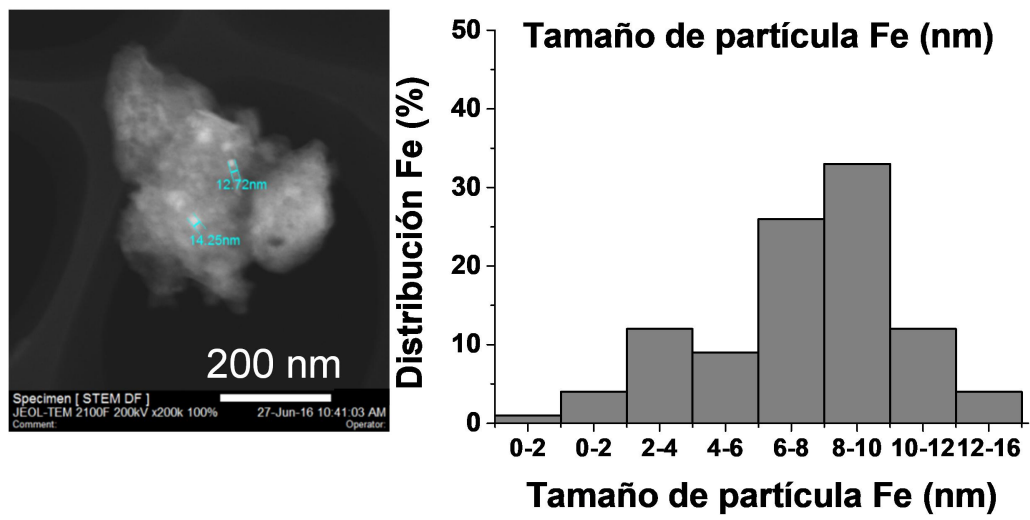

Figura 5.3. Imágenes de DF-STEM e histogramas de distribución de tamaño de partícula para los catalizadores de $\mathrm{Fe}_{\mathrm{ox}} \mathrm{NPs}(0.2 \%$ en peso) soportados en AC1 (a), AC2 (b) y AC3 (c). 
a)
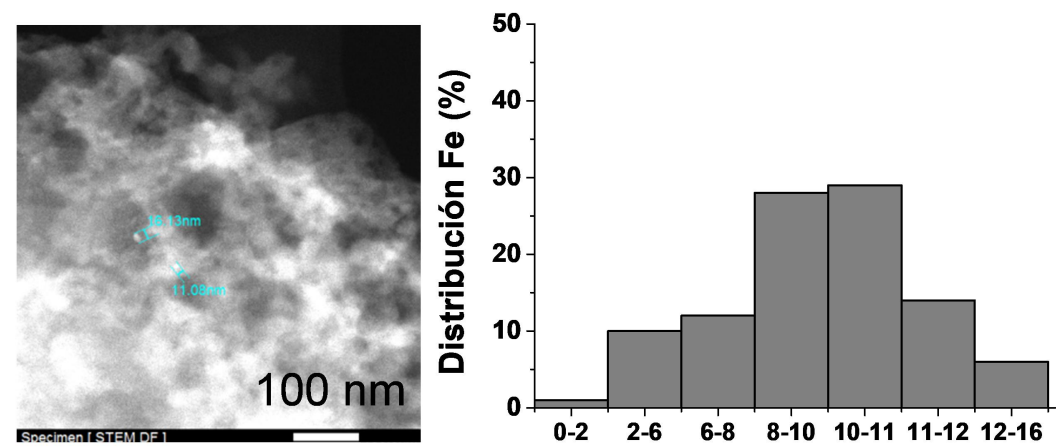

b)
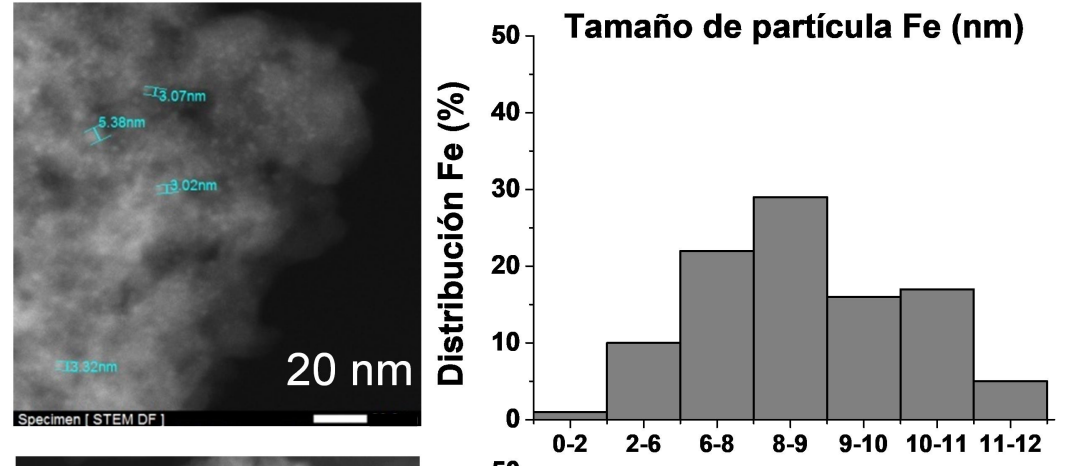

c)
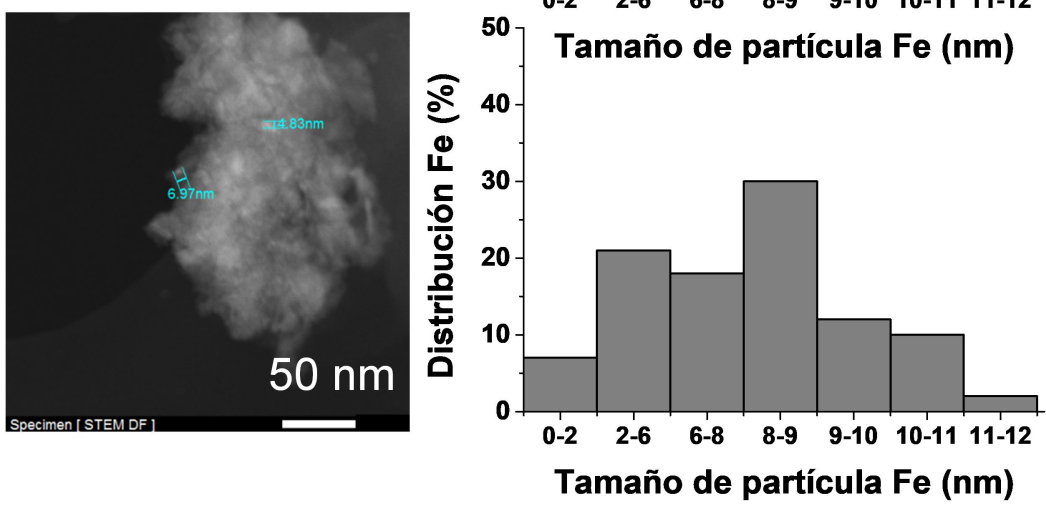

Figura 5.4. Imágenes de DF-STEM e histogramas de distribución de tamaño de partícula para los catalizadores de $\mathrm{Fe}_{\mathrm{ox}} \mathrm{NPs}(0.2 \%$ en peso) soportados en Gr1 (a), Gr2 (b) y Gr3 (c). 
a)

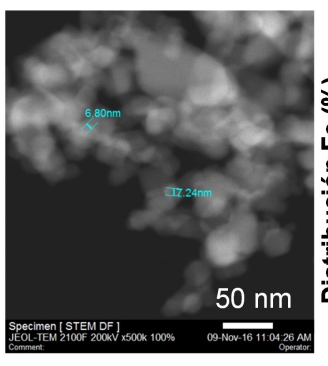

b)

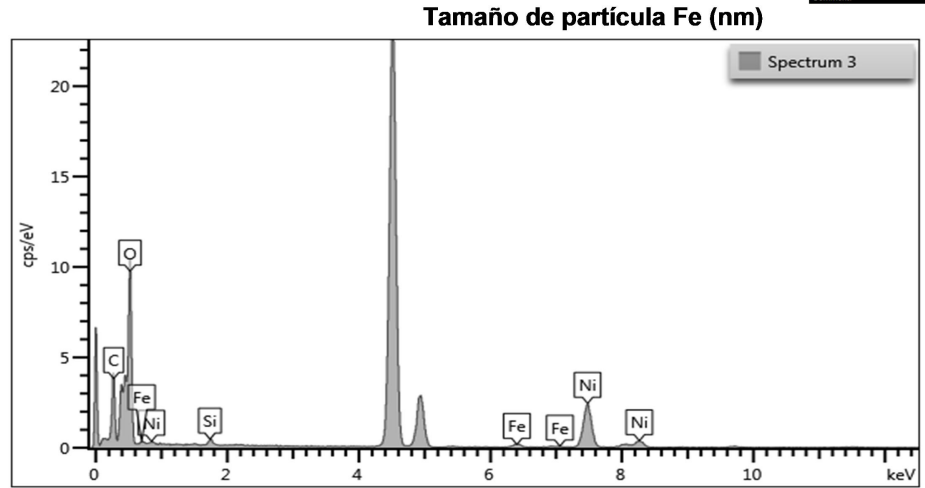

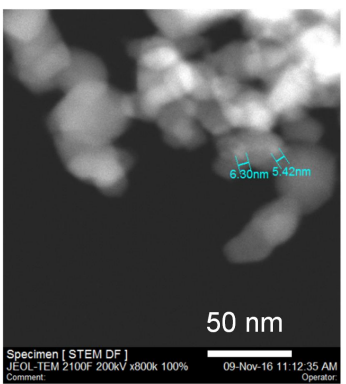

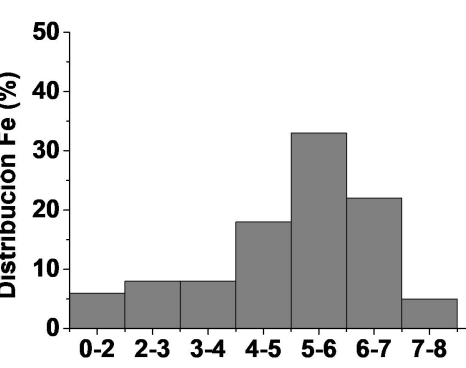

$\begin{array}{lllllll}0-2 & 2-3 & 3-4 & 4-5 & 5-6 & 6-7 & 7-8\end{array}$

Figura 5.5. Imágenes de DF-STEM e histograma de distribución de tamaño de partícula para el catalizador de $\mathrm{Fe}_{\mathrm{ox}} \mathrm{NPs}(0.2 \%$ en peso) soportado sobre $\mathrm{TiO}_{2}$ (a) y análisis representativo de EDX (b). El Ni detectado en el análisis de EDX se debe a la composición de la rejilla utilizada como porta muestras en el TEM. 
a)
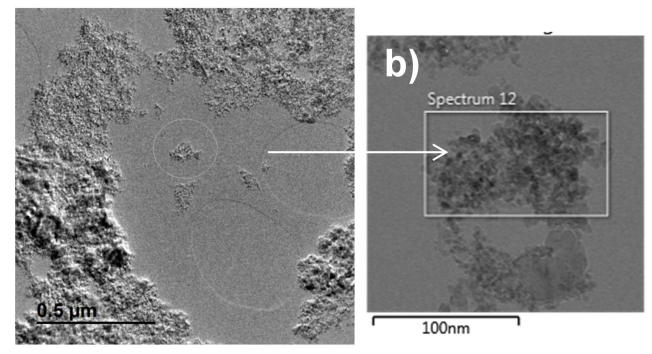

c)

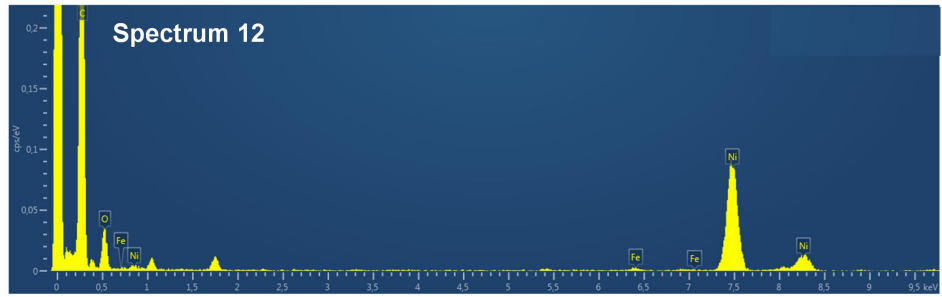

d)

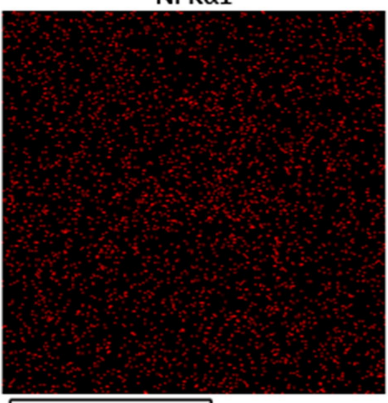

$100 \mathrm{~nm}$ o K $\alpha 1$
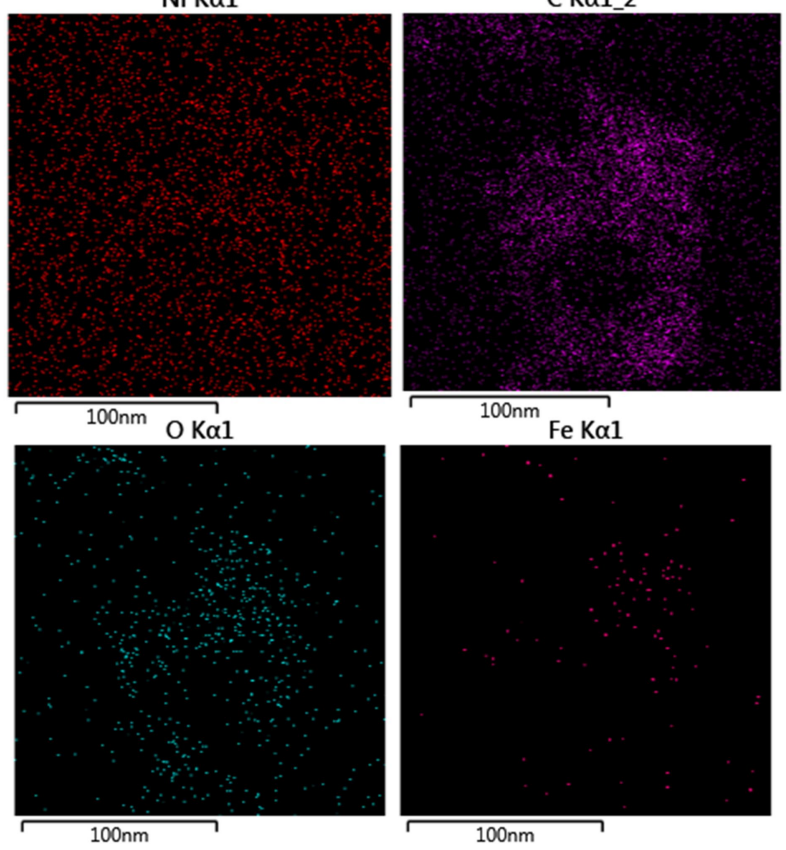

Figura 5.6. Imágenes de DF-STEM (a, b), análisis de EDX (c) y mapeo elemental de EDX (d) para la muestra $\mathrm{Fe}_{\mathrm{ox}}(0.2 \%$ en peso)/D3. El Ni presente en las imágenes c y d corresponde a la composición de la rejilla utilizada como porta muestras en el TEM. 
Nanopartículas de óxido de hierro soportadas sobre nanopartículas de diamante como catalizador en la reacción de Fenton foto-asistida por luz visible
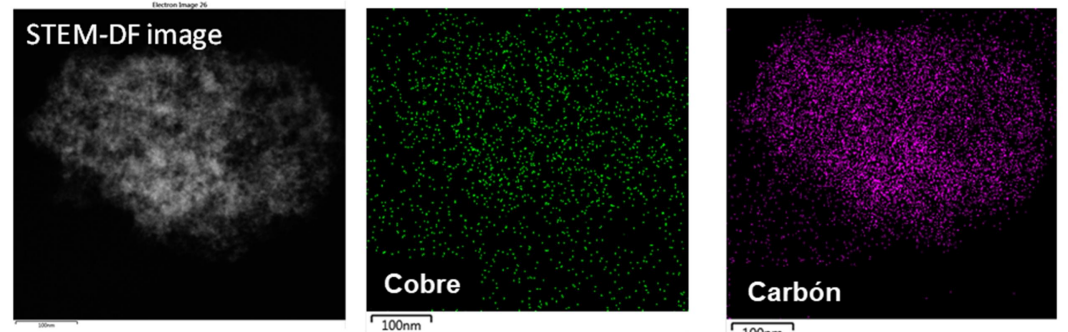

a)
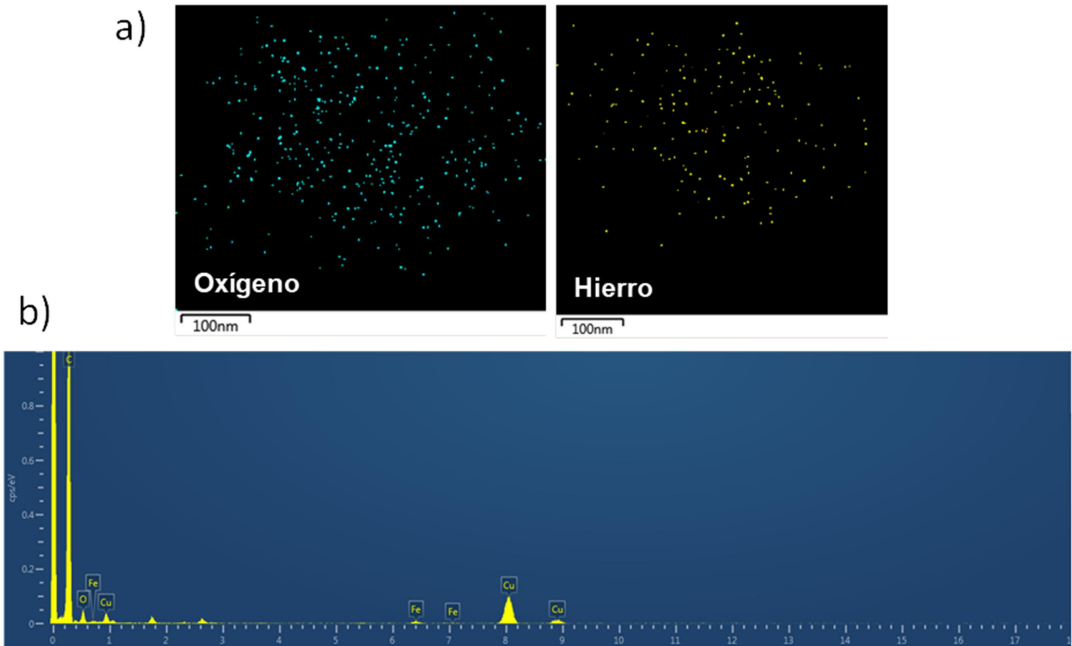

Figura 5.7. Imagen de DF-STEM y mapeo elemental de EDX (a), y análisis representativo de EDX (b) para la muestra $\mathrm{Fe}_{\mathrm{ox}}(0.2 \%$ en peso)/D3 utilizando una rejilla de $\mathrm{Cu}$ como porta muestras, observando así la ausencia del $\mathrm{Ni}$ presente en las figuras 5.5 y 5.6 y sí la presencia de $\mathrm{Cu}$ debido a la composición de la rejilla de TEM. 


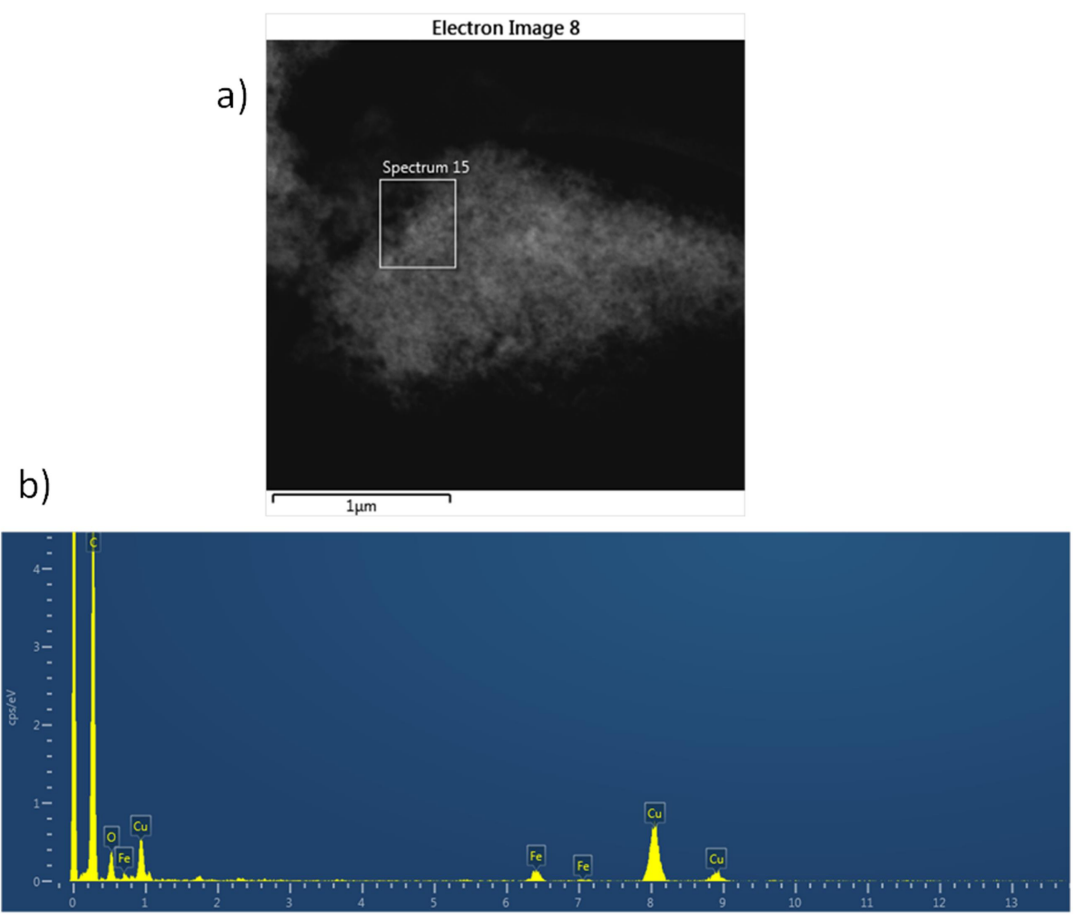

Figura 5.8. Imagen de DF-STEM (a) y análisis representativo de EDX (b) para la muestra $\mathrm{Fe}_{\mathrm{ox}}(0.2 \%$ en peso)/D3 utilizando una rejilla de $\mathrm{Cu}$ como porta muestras, observando así la ausencia del Ni presente en las figuras $5.5 \mathrm{y}$ 5.6 y sí la presencia de $\mathrm{Cu}$ debido a la composición de la rejilla de TEM.

Las medidas de difracción de rayos $\mathrm{X}$ en polvo para el catalizador $\mathrm{Fe}_{\mathrm{ox}}(0.2 \%$ en peso)/D3, que es la muestra que presenta una distribución de tamaño de partícula más pequeño, no permitió la observación de ninguno de los picos de difracción característicos para las diferentes fases del $\mathrm{Fe}$ o los distintos óxidos de $\mathrm{Fe}$ (figura 5.9). Este hecho podría ser un reflejo del pequeño tamaño de las Fe NPs y de la buena dispersión de estas Fe NPs sobre el soporte D3 tal como se evidencia en las imágenes de TEM (figura 5.1). ${ }^{15,16}$ Las medidas de UVVis mediante reflectancia difusa revelan la presencia de bandas de absorción características de los óxidos de hierro tales como $\mathrm{Fe}_{2} \mathrm{O}_{3}$ (figura 5.10). ${ }^{21}$ La formación de óxidos de hierro debe ocurrir espontáneamente durante la exposición al ambiente debido a la oxidación de las Fe NPs por $\mathrm{O}_{2} \mathrm{y} \mathrm{H}_{2} \mathrm{O}_{2} .{ }^{22}$ 

catalizador en la reacción de Fenton foto-asistida por luz visible

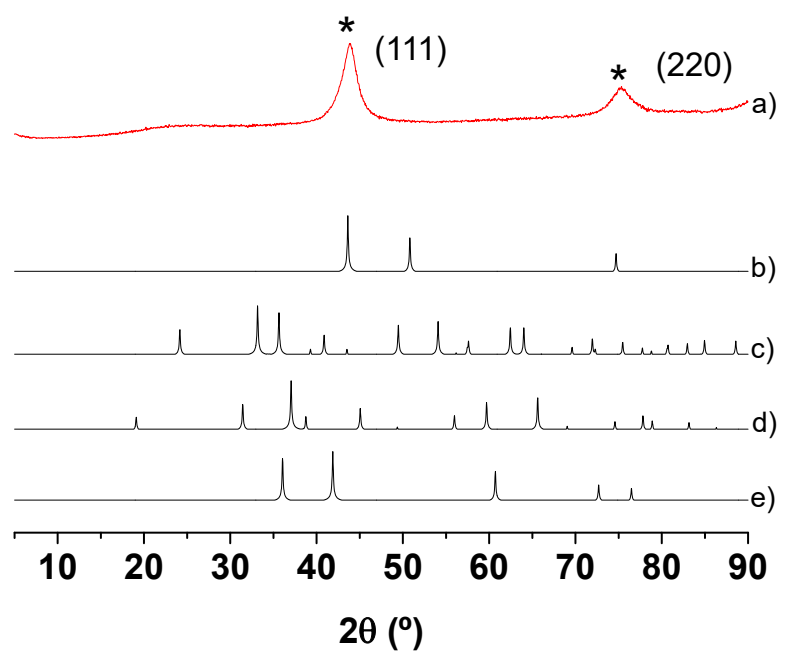

Figura 5.9. Difractogramas de PXRD de Feox NPs soportadas sobre D 3 al $0.2 \%$ en peso (a), comparados con los picos de difracción teóricos de $\mathrm{Fe}(\mathrm{b})$, $\mathrm{Fe}_{2} \mathrm{O}_{3}$ (c), $\mathrm{Fe}_{3} \mathrm{O}_{4}$ (d) y $\mathrm{FeO}($ e). Los patrones de difracción característicos del diamante aparecen indicados $(*)$. La anchura de los picos de difracción es un reflejo de su pequeño tamaño de partícula.

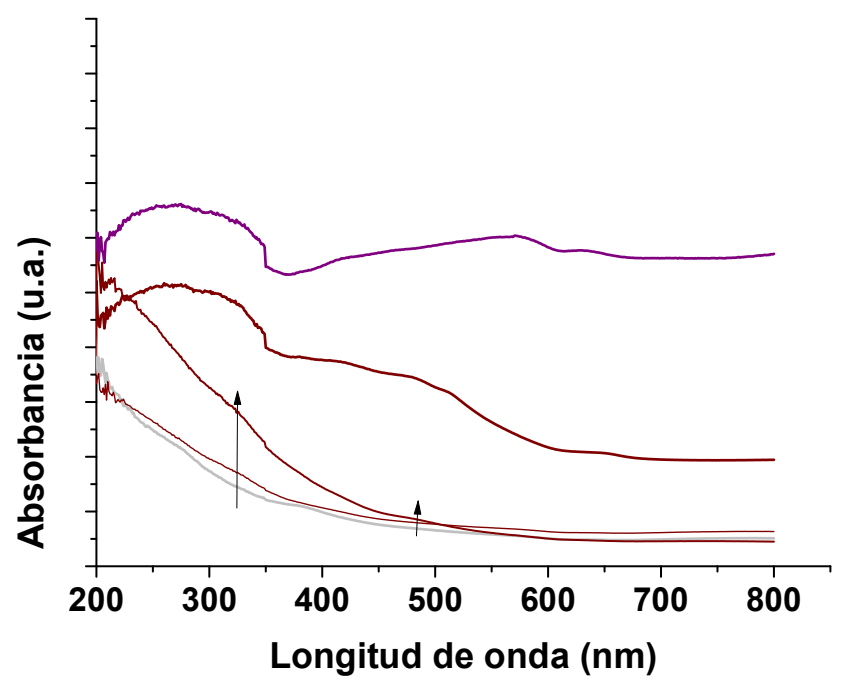

Figura 5.10. Espectros de reflectancia difusa de $\mathrm{D} 3$ (a), $\mathrm{Fe}_{\mathrm{ox}}(0.2 \%$ en peso)/D3 (b), $\mathrm{Fe}_{\mathrm{ox}}\left(1 \%\right.$ en peso)/D3 (c), estándar $\mathrm{Fe}_{2} \mathrm{O}_{3}$ (d) y estándar $\mathrm{Fe}_{3} \mathrm{O}_{4}$ (e). 
Los experimentos de control demostraron que las Fe NPs metálicas sin estar soportadas que fueron preparadas por reducción química de $\mathrm{Fe}$ (III) por $\mathrm{NaBH}_{4}{ }^{16}$ sufrieron oxidación por exposición al ambiente tal como demuestran los cambios en los espectros de UV-Vis de absorción y su cambio en la apariencia visual de la disolución que se convierte en marrón transcurridos unos pocos minutos debido a la oxidación espontanea de Fe NPs a NPs de óxido de hierro bajo condiciones atmosféricas (ver fotografías en la figura 5.11).
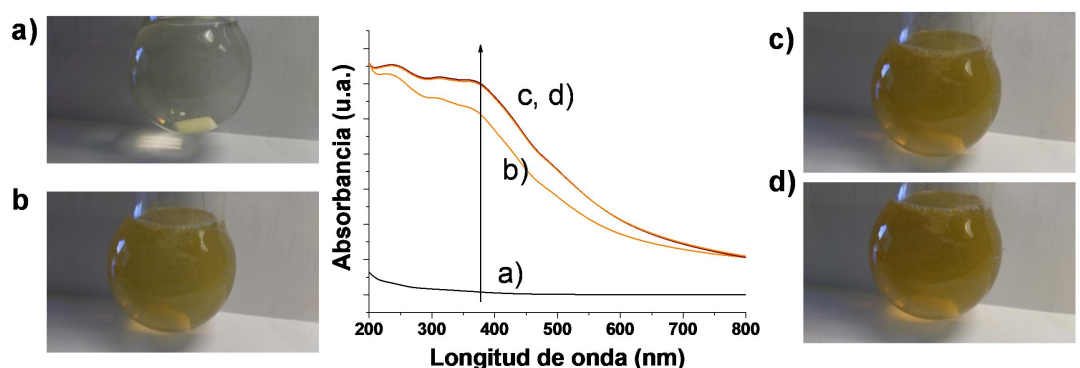

Figura 5.11. Fotografías y espectros de UV-Vis de $\mathrm{Fe}(\mathrm{III})$ en disolución antes (a) y después de la adición de $\mathrm{NaBH}_{4}$ recogidas a 1 (b), 5 (c) y 24 horas (d).

La presencia de óxidos de hierro soportados sobre D3 fue también establecida mediante espectroscopía de FTIR donde las características bandas de vibración Fe-O correspondientes a los óxidos de hierro pudieron ser observadas en la zona de entre $700 \mathrm{y} 400 \mathrm{~cm}^{-1}$ para las muestras de $\mathrm{Fe}_{\mathrm{ox}}(0.2$ y $1 \%$ en peso)/D3 así como para muestras comerciales de $\mathrm{Fe}_{2} \mathrm{O}_{3}$ y $\mathrm{Fe}_{3} \mathrm{O}_{4}$ (figura 5.12). ${ }^{23} \mathrm{El}$ análisis por EPR de la muestra $\mathrm{Fe}(0.2 \%$ en peso $) / \mathrm{D} 3$ confirma la presencia de $\mathrm{Fe}(\mathrm{III})$ tal como puede observarse en la figura 5.13. ${ }^{24}$ Merece comentar que las especies de $\mathrm{Fe}(\mathrm{II})$ son transparentes en espectroscopía de EPR. El análisis por XPS de las muestras $\mathrm{Fe}(0.2 \%$ en peso)/D3 y $\mathrm{Fe}(1.0 \%$ en peso)/D3 confirman que la superficie de las Fe NPs está compuesta principalmente por especies de $\mathrm{Fe}(\mathrm{III})$ (figura 5.14). ${ }^{25}$ De esta manera todos los datos de caracterización disponibles indican que las NPs soportadas sobre D3 están constituidas principalmente por óxidos de hierro. 


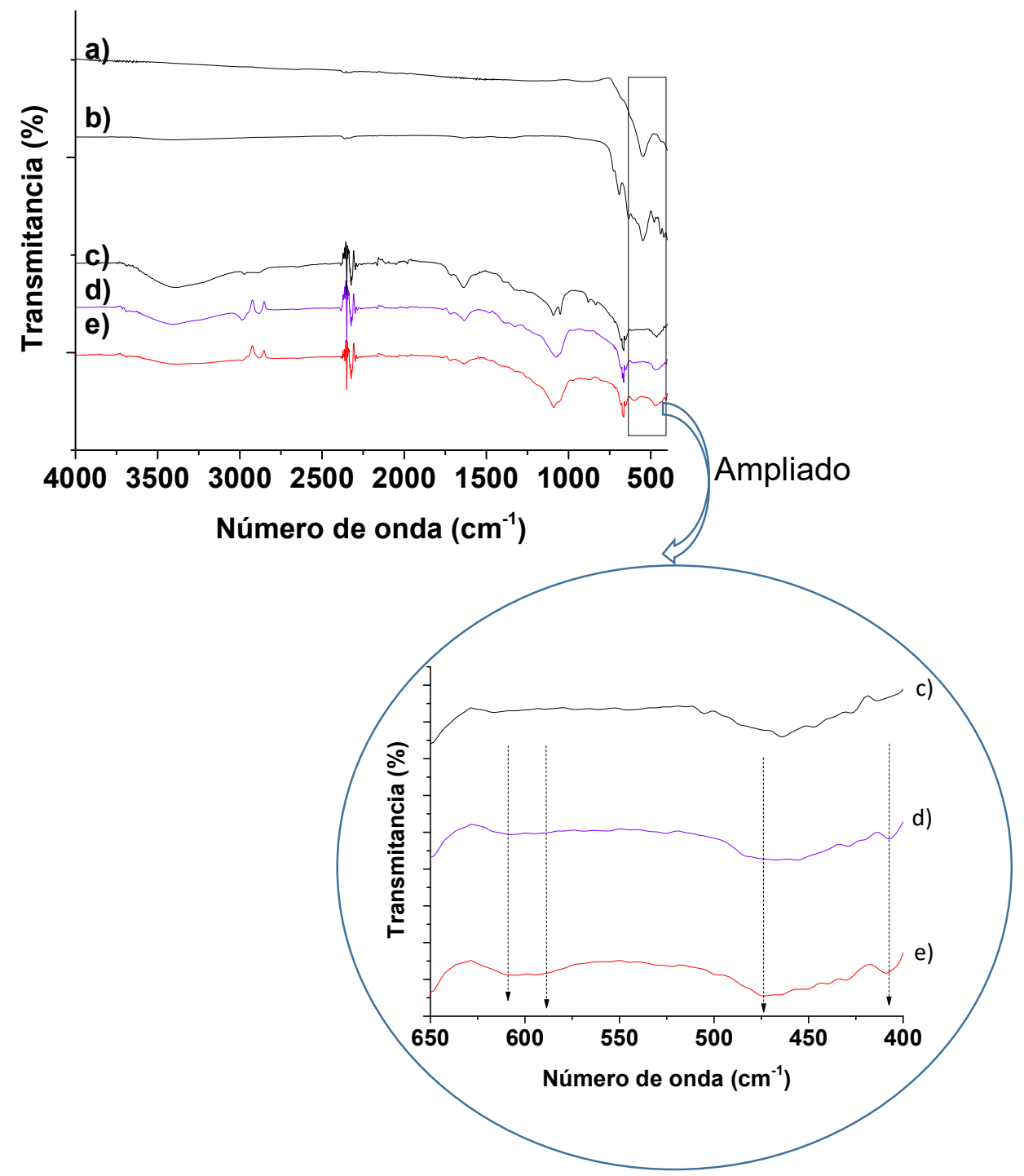

Figura 5.12. Espectros de FT-IR de $\mathrm{Fe}_{3} \mathrm{O}_{4}$ comercial (a), $\mathrm{Fe}_{2} \mathrm{O}_{3}$ comercial (b), $\mathrm{D} 3$ (c), $\mathrm{Fe}_{\mathrm{ox}}\left(0.2 \%\right.$ en peso)/D3 (d), $\mathrm{Fe}_{\mathrm{ox}}(1 \%$ en peso)/D3 (e). La imagen presenta una ampliación de la zona encuadrada para las muestras de D3 (c), $\mathrm{Fe}_{\text {ox }}\left(0.2 \%\right.$ en peso)/D3 (d), $\mathrm{Fe}_{\text {ox }}(1 \%$ en peso)/D3 (e), y las flechas indican las bandas de vibración de Fe-O. 


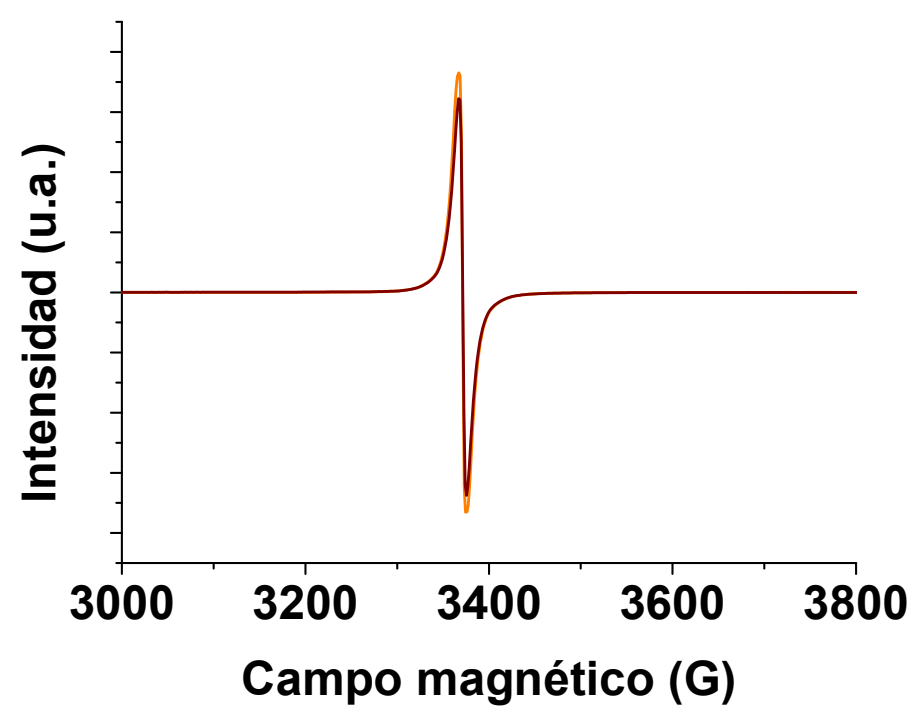

Figura 5.13. Espectro de EPR de la muestra fresca de $\mathrm{Fe}_{\mathrm{ox}}(0.2 \%$ en peso)/D3 (línea roja) y la muestra de $\mathrm{Fe}_{\mathrm{ox}}(0.2 \%$ en peso)/D3 tras cuatro usos catalíticos consecutivos (línea negra).
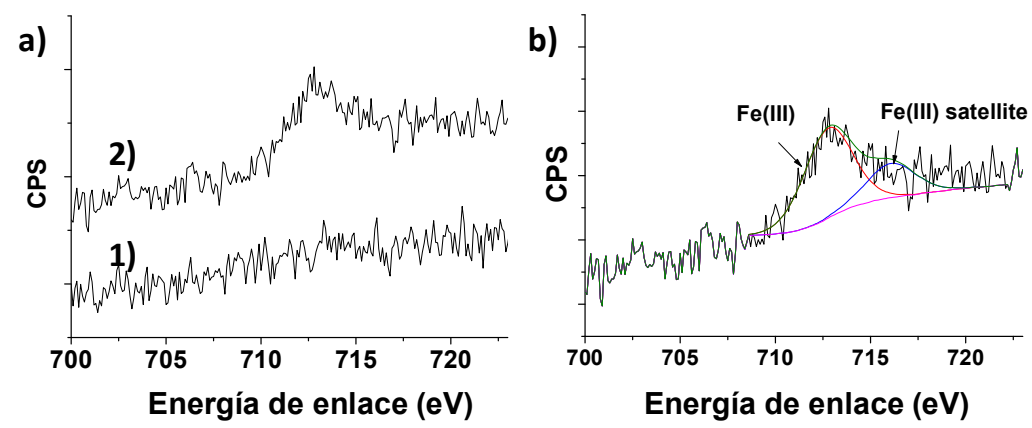

Figura 5.14. Espectros de XPS del pico de $\mathrm{Fe} 2 \mathrm{p}$ para las muestras de $\mathrm{Fe}_{\mathrm{ox}}\left(0.2 \%\right.$ en peso)/D3 (a1), $\mathrm{Fe}_{\mathrm{ox}}(1 \%$ en peso)/D3 (a2). Deconvolución del espectro de $\mathrm{Fe} 2 \mathrm{p}$ para la muestra $\mathrm{Fe}_{\mathrm{ox}}(1 \%$ en peso)/D3 (b).

\subsubsection{Actividad fotocatalítica}

La actividad fotocatalítica de los materiales preparados ha sido evaluada en la degradación de fenol y descomposición de $\mathrm{H}_{2} \mathrm{O}_{2}$ bajo irradiación de luz solar simulada. Se seleccionó el fenol como contaminante modelo en base a su mayor toxicidad y su baja biodegradabilidad en los tratamientos biológicos convencionales. ${ }^{8,26}$ Los 
experimentos de control preliminares se llevaron a cabo de la siguiente forma:

i) Por irradiación con luz solar simulada de fenol y $\mathrm{H}_{2} \mathrm{O}_{2}$ en ausencia de catalizador;

ii) Por irradiación con luz solar simulada de fenol en presencia de $\mathrm{Fe}_{\text {ox }} / \mathrm{D} 3$ pero en ausencia de $\mathrm{H}_{2} \mathrm{O}_{2}$;

iii) Por irradiación con luz solar simulada de fenol y $\mathrm{H}_{2} \mathrm{O}_{2}$ en presencia de los tres soportes de D sin contener Fe;

iv) Llevando a cabo la reacción de fenol $\mathrm{y}_{2} \mathrm{O}_{2}$ en presencia de $\mathrm{Fe}_{\text {ox }} / \mathrm{D} 3$ en la oscuridad, observando un pequeño grado de desaparición de fenol y descomposición de $\mathrm{H}_{2} \mathrm{O}_{2}$.

Las figuras 5.15 y 5.16 muestran los resultados de estos experimentos de control, los cuales confirman que la combinación de óxido de hierro, luz solar simulada y $\mathrm{H}_{2} \mathrm{O}_{2}$ es necesaria para conseguir altos porcentajes en la de gradación de fenol.
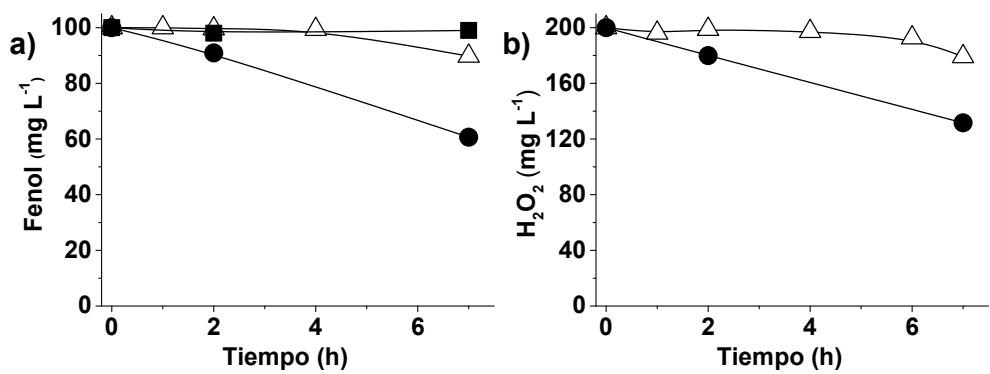

Figura 5.15. Perfil temporal de degradación del fenol (a) y descomposición de $\mathrm{H}_{2} \mathrm{O}_{2}$ (b) para los experimentos de control llevados a cabo a $\mathrm{pH} 4$ utilizando $\mathrm{Fe}_{\text {ox }}\left(0.2 \%\right.$ en peso)/D3 como catalizador $\left(100 \mathrm{mg} \mathrm{L}^{-1}\right)$ en ausencia de irradiación $(\Delta)$; bajo irradiación solar simulada pero en ausencia de catalizador (•); bajo irradiación solar simulada pero en ausencia de $\mathrm{H}_{2} \mathrm{O}_{2}$ como oxidante (-). Concentración de fenol obtenida por HPLC y de $\mathrm{H}_{2} \mathrm{O}_{2}$ por espectrofotometría, como se indica en el capítulo 8 , sección experimental. 

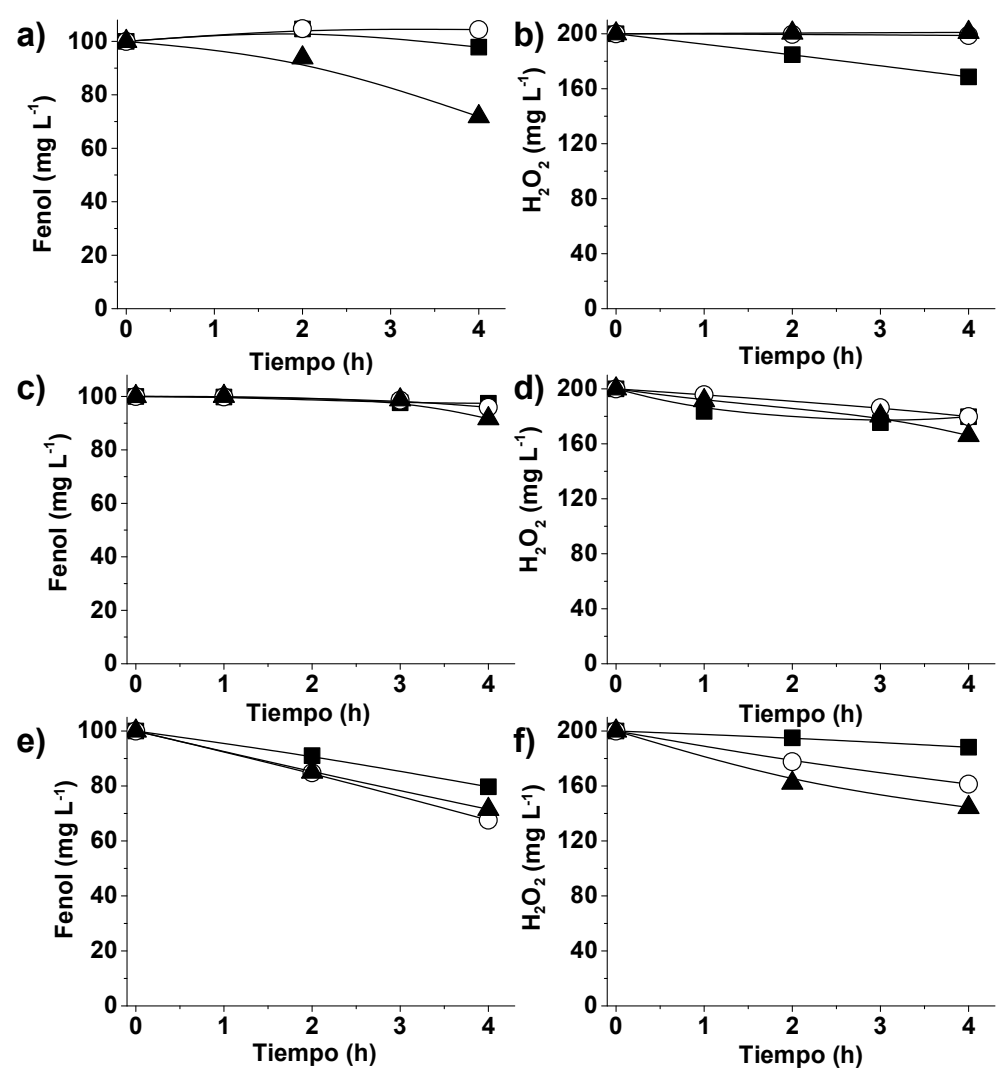

Figura 5.16. Perfiles temporales de degradación del fenol (a, c, e) y descomposición de $\mathrm{H}_{2} \mathrm{O}_{2}$ (b, d, f) utilizando como catalizadores carbón activo $(a, b)$, nanopartículas de diamante (c, d) y grafito (e, f). Leyenda: a, b) AC1

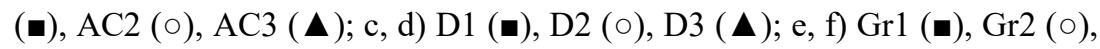
Gr3 (ム). Condiciones de reacción: catalizador $\left(5 \mathrm{mg}, 100 \mathrm{mg} \mathrm{L}^{-1}\right)$, fenol (100 mg L $\left.\mathrm{L}^{-1}\right), \mathrm{H}_{2} \mathrm{O}_{2}\left(200 \mathrm{mg} \mathrm{L}^{-1}\right)$, pH 4, irradiación solar artificial simulada. Concentración de fenol obtenida por HPLC y de $\mathrm{H}_{2} \mathrm{O}_{2}$ por espectrofotometría, como se indica en el capítulo 8, sección experimental.

A la vista de estos resultados preliminares, se estudió la actividad fotocatalítica de las $\mathrm{Fe}_{\text {ox }}$ NPs soportadas sobre D NPs modificadas por tratamientos químicos en la degradación del fenol y descomposición de $\mathrm{H}_{2} \mathrm{O}_{2}$. Se comprobó que la muestra $\mathrm{Fe}_{\mathrm{ox}}(0.2 \%$ en peso $) / \mathrm{D} 3$ fue la que exhibe una actividad fotocatalítica mayor comparada con las muestras $\mathrm{Fe}_{\mathrm{ox}} / \mathrm{D} 2$ y $\mathrm{Fe}_{\mathrm{ox}} / \mathrm{D} 1$. Este hecho puede ser atribuido al tamaño de partícula 
promedio menor de esta muestra y a su distribución más uniforme sobre el soporte D3 (ver datos en la tabla 5.1 y figura 5.17).
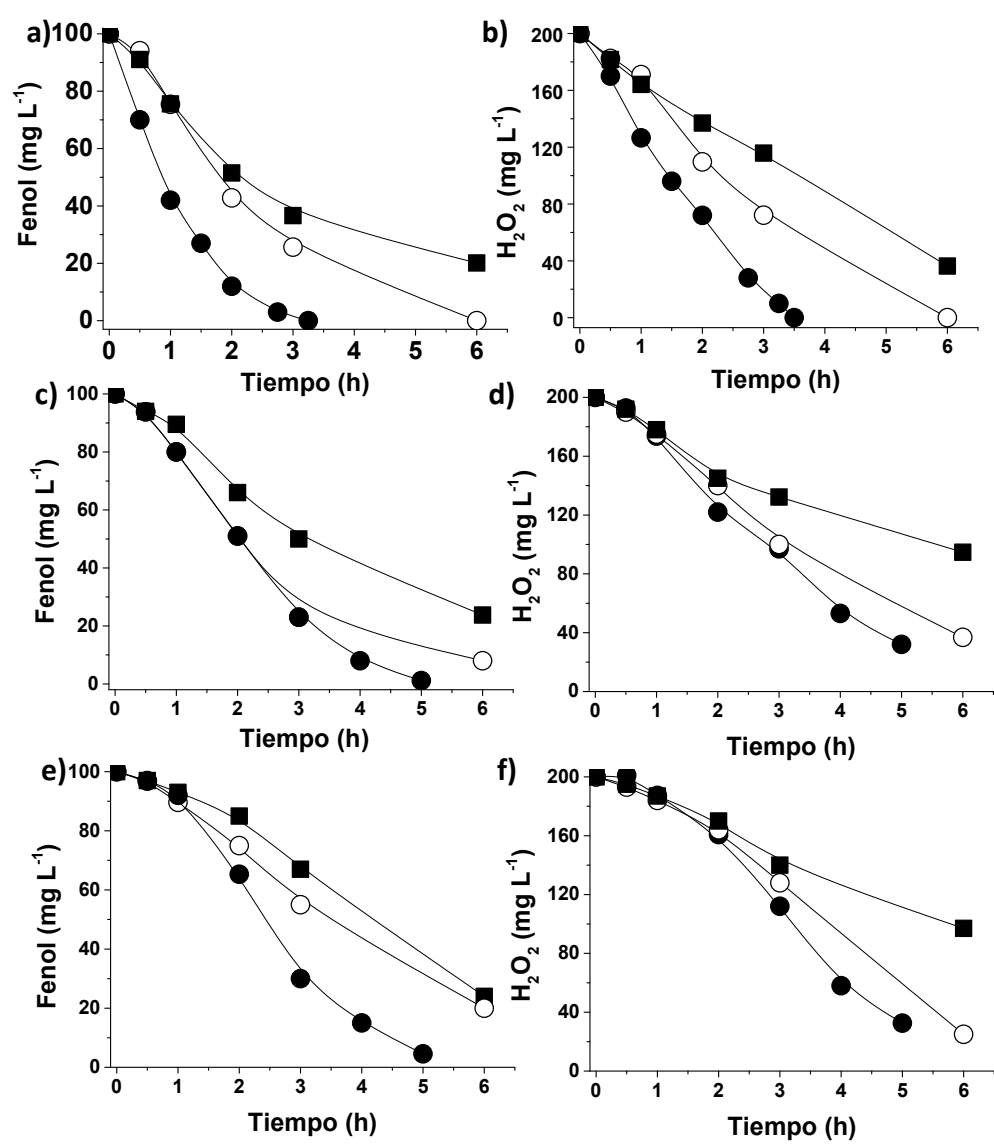

Figura 5.17. Perfiles temporales de degradación del fenol (a, c, e) y descomposición de $\mathrm{H}_{2} \mathrm{O}_{2}(\mathrm{~b}, \mathrm{~d}, \mathrm{f})$ utilizando como catalizadores $\mathrm{Fe}_{\mathrm{ox}} \mathrm{NPs}$ soportados sobre materiales basados en carbono tales como $\mathrm{Fe}_{\mathrm{ox}}(0.2 \%$ en peso)/D (a, b), $\mathrm{Fe}_{\text {ox }}\left(0.2 \%\right.$ en peso)/Gr (c, d) y $\mathrm{Fe}_{\text {ox }}(0.2 \%$ en peso)/AC (e, f) bajo irradiación solar artificial simulada. Leyenda: Soportes carbonosos comerciales (घ), soportes carbonosos tratados con la reacción de Fenton (०), soportes carbonosos tratados con la reacción de Fenton y reducidos por tratamiento con $\mathrm{H}_{2}(\bullet)$. Condiciones de reacción: catalizador $(5 \mathrm{mg}, 0.0071$ $\mathrm{mM}$ de hierro soportado), fenol (100 mg L$\left.{ }^{-1} ; 1.06 \mathrm{mM}\right), \mathrm{H}_{2} \mathrm{O}_{2}\left(200 \mathrm{mg} \mathrm{L}^{-1}\right.$; $5.88 \mathrm{mM}), \mathrm{pH}$ inicial $4,20{ }^{\circ} \mathrm{C}$. Concentración de fenol obtenida por HPLC y 
de $\mathrm{H}_{2} \mathrm{O}_{2}$ por espectrofotometría, como se indica en el capítulo 8, sección experimental.

La adsorción de fenol sobre $\mathrm{Fe}_{\mathrm{ox}} / \mathrm{D} 3$ se consideró inferior al 3\% en base a medidas de adsorción y, por consiguiente, la influencia de la adsorción en las medidas de degradación de fenol puede ser considerada despreciable. La actividad de $\mathrm{Fe}_{\mathrm{ox}} / \mathrm{D} 3$ es también mayor que la de fotocatalizadores análogos basados en $\mathrm{Fe}_{\mathrm{ox}} / \mathrm{AC} 3$ y $\mathrm{Fe}_{\mathrm{ox}} / \mathrm{Gr} 3$ (figura 5.18).
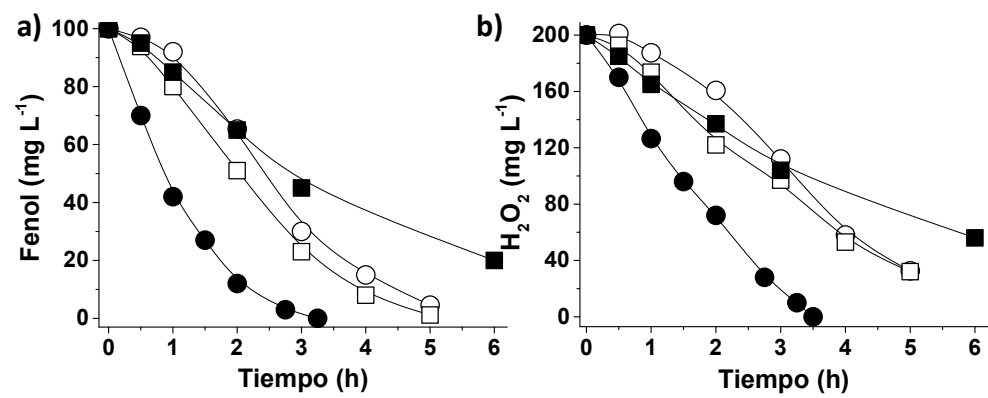

Figura 5.18. Perfiles temporales de degradación del fenol (a) y descomposición de $\mathrm{H}_{2} \mathrm{O}_{2}$ (b) utilizando como catalizadores $\mathrm{Fe}_{\mathrm{ox}}(0.2 \%$ en peso)/D3 (•), $\mathrm{Fe}_{\text {ox }}\left(0.2 \%\right.$ en peso)/Gr3 (口) y $\mathrm{Fe}_{\text {ox }}(0.2 \%$ en peso)/AC3 (०) bajo irradiación solar artificial simulada, y $\mathrm{Fe}_{\mathrm{ox}}(0.2 \%$ en peso)/D3 en ausencia de irradiación (-). Condiciones de reacción: catalizador $\left(5 \mathrm{mg}, 200 \mathrm{mg} \mathrm{L}^{-1}\right.$; $0.0071 \mathrm{mM}$ ), fenol (100 mg L$\left.{ }^{-1} ; 1.06 \mathrm{mM}\right), \mathrm{H}_{2} \mathrm{O}_{2}\left(200 \mathrm{mg} \mathrm{L}^{-1} ; 5.88 \mathrm{mM}\right), \mathrm{pH}$ inicial 4, intensidad de irradiación $\left(100 \mathrm{~mW} \mathrm{~cm} \mathrm{~cm}^{-2}\right), 20^{\circ} \mathrm{C}$. Concentración de fenol obtenida por HPLC y de $\mathrm{H}_{2} \mathrm{O}_{2}$ por espectrofotometría, como se indica en el capítulo 8 , sección experimental.

Los datos de actividad muestran que independientemente del soporte a base de carbono (D, AC, o Gr), la modificación de la superficie por un tratamiento de Fenton usando un catalizador homogéneo, seguido por tratamiento térmico con hidrógeno a temperatura elevada es un procedimiento adecuado para obtener muestras donde el tamaño de las $\mathrm{Fe}_{\mathrm{ox}}$ NPs es pequeño y así poder conseguir una mayor actividad catalítica (tabla 5.1 y figura 5.2). La actividad catalítica de las $\mathrm{Fe}_{\text {ox }} \mathrm{NPs}$ soportadas en materiales a base de carbono tratadas por Fenton pero sin reducción química (AC2, D2 y Gr2) son mayores que las que se consiguen con las muestras de materiales comerciales como soporte (AC1, D1, y Gr1). Estos datos están de acuerdo con estudios previos que demuestran las 
ventajas de conseguir superficies donde predominen grupos hidroxilo en el soporte a fin de conseguir estabilizar las NPs metálicas de pequeño tamaño. Es importante indicar que la actividad catalítica de la muestra de fotocatalizador más activa $\left(\mathrm{Fe}_{\mathrm{ox}} / \mathrm{D} 3\right)$ es casi el doble que en la de las $\mathrm{Fe}_{\mathrm{ox}}$ NPs sin soportar, un hecho que puede ser explicado en base a la aglomeración que sufren las $\mathrm{Fe}_{\mathrm{ox}} \mathrm{NPs}$ sin soportar tras su preparación (figura 5.11). ${ }^{27} \mathrm{La}$ muestra de $\mathrm{Fe}_{\mathrm{ox}} / \mathrm{D} 3$ conteniendo $0.2 \%$ de $\mathrm{Fe}$ en peso exhibe una actividad catalítica mayor que una muestra similar conteniendo el $1 \%$ en peso ( 5 veces mayor en el contenido en hierro), un hecho que puede ser comprendido considerando que la mayor dispersión de $\mathrm{Fe}_{\mathrm{ox}} \mathrm{NPs}$ y la distribución de tamaño de partícula promedio es algo menor para la muestra con menor contenido en hierro (tabla 5.1 y figura 5.19). Es una observación general en catálisis heterogénea que un aumento en la carga metálica sobre el soporte resulta en números de turnover menores debido a la tendencia general de aumento del tamaño de partícula y disminución de la dispersión metálica con el aumento de carga. ${ }^{16,28}$
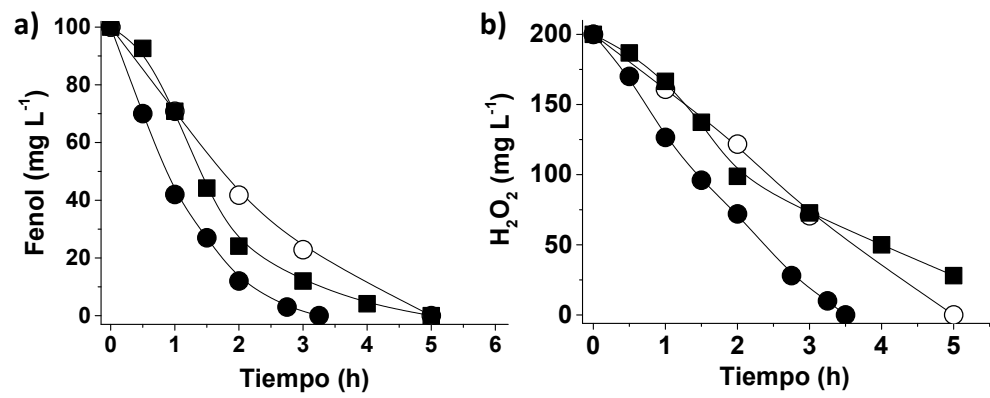

Figura 5.19. Perfiles temporales de degradación del fenol (a) y descomposición de $\mathrm{H}_{2} \mathrm{O}_{2}$ (b) utilizando $\mathrm{Fe}_{\text {ox }}\left(0.2 \%\right.$ en peso)/D3 (•), $\mathrm{Fe}_{\text {ox }}(1 \%$ en peso)/D3 (-) o $\mathrm{Fe}_{\mathrm{ox}}$ NPs sin soportar (०) bajo irradiación solar artificial simulada. Condiciones de reacción: catalizador $(0.0071 \mathrm{mM}$ de hierro soportado o sin soportar), fenol (100 mg L $\left.\mathrm{L}^{-1} ; 1.06 \mathrm{mM}\right), \mathrm{H}_{2} \mathrm{O}_{2}\left(200 \mathrm{mg} \mathrm{L}^{-1}\right.$; $5.88 \mathrm{mM}$ ), $\mathrm{pH}$ inicial $4,20^{\circ} \mathrm{C}$. Concentración de fenol obtenida por HPLC y de $\mathrm{H}_{2} \mathrm{O}_{2}$ por espectrofotometría, como se indica en el capítulo 8, sección experimental.

Conviene hacer notar que la eficiencia de $\mathrm{Fe}_{\mathrm{ox}} / \mathrm{D} 3$ es mayor que la del fotocatalizador de referencia $\mathrm{Fe}_{\mathrm{ox}} / \mathrm{TiO}_{2}$, el cual descompone 
rápidamente $\mathrm{H}_{2} \mathrm{O}_{2}$, pero sin conseguir una degradación completa del fenol (tabla 5.1 y figura 5.20). Como ha sido descrito con anterioridad, el $\mathrm{TiO}_{2}$ descompone $\mathrm{H}_{2} \mathrm{O}_{2}$ en $\mathrm{H}_{2} \mathrm{O}$ y $\mathrm{O}_{2}$ sin generar una alta densidad de especies de oxígeno reactivas capaces de degradar fenol. ${ }^{15}$ Esta observación pudo ser confirmada usando $\mathrm{TiO}_{2}$ en ausencia de hierro y observando que el $\mathrm{H}_{2} \mathrm{O}_{2}$ descompone completamente pero sin conseguir la degradación completa del fenol (figura 5.20). Además, la concentración final del fenol y sus compuestos intermedios de degradación es cero cuando se usa $\mathrm{Fe}_{\mathrm{ox}} / \mathrm{D} 3$, mientras que la suma de las concentraciones de todos estos productos en el caso de emplear como catalizadores $\mathrm{Fe}_{\text {ox }} / \mathrm{TiO}_{2}$ o $\mathrm{TiO}_{2}$ todavía resultan ser 50 y $89 \mathrm{mg} \mathrm{L}^{-1}$ respectivamente (figura 5.21).
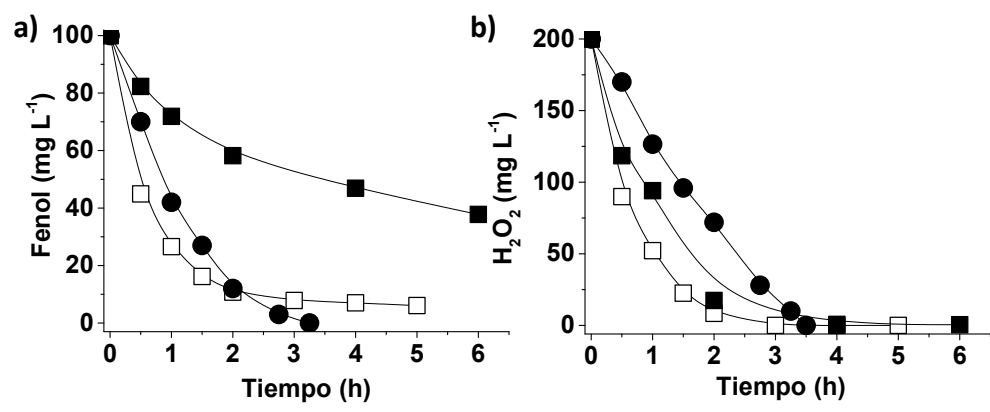

Figura 5.20. Perfiles temporales de degradación de fenol (a) y descomposición de $\mathrm{H}_{2} \mathrm{O}_{2}$ (b) usando $\mathrm{Fe}_{\mathrm{ox}}\left(0.2 \%\right.$ en peso)/D3 (•), $\mathrm{Fe}_{\mathrm{ox}} / \mathrm{TiO}_{2}$ (口) $\mathrm{o}_{\mathrm{TiO}_{2}}(\mathbf{\square})$ como catalizadores de foto-Fenton heterogéneos bajo irradiación con luz solar. Condiciones de reacción: catalizador $(5 \mathrm{mg}, 200 \mathrm{mg}$ $\left.\mathrm{L}^{-1} ; 0.0071 \mathrm{mM}\right)$, fenol (100 mg L $\left.\mathrm{g}^{-1} ; 1.06 \mathrm{mM}\right), \mathrm{H}_{2} \mathrm{O}_{2}\left(200 \mathrm{mg} \mathrm{L}^{-1} ; 5.88 \mathrm{mM}\right)$, $\mathrm{pH}$ inicial 4, intensidad de irradiación $\left(100 \mathrm{~mW} \mathrm{~cm}^{-2}\right)$, temperatura $20^{\circ} \mathrm{C}$. Concentración de fenol obtenida por HPLC y de $\mathrm{H}_{2} \mathrm{O}_{2}$ por espectrofotometría, como se indica en el capítulo 8, sección experimental. 

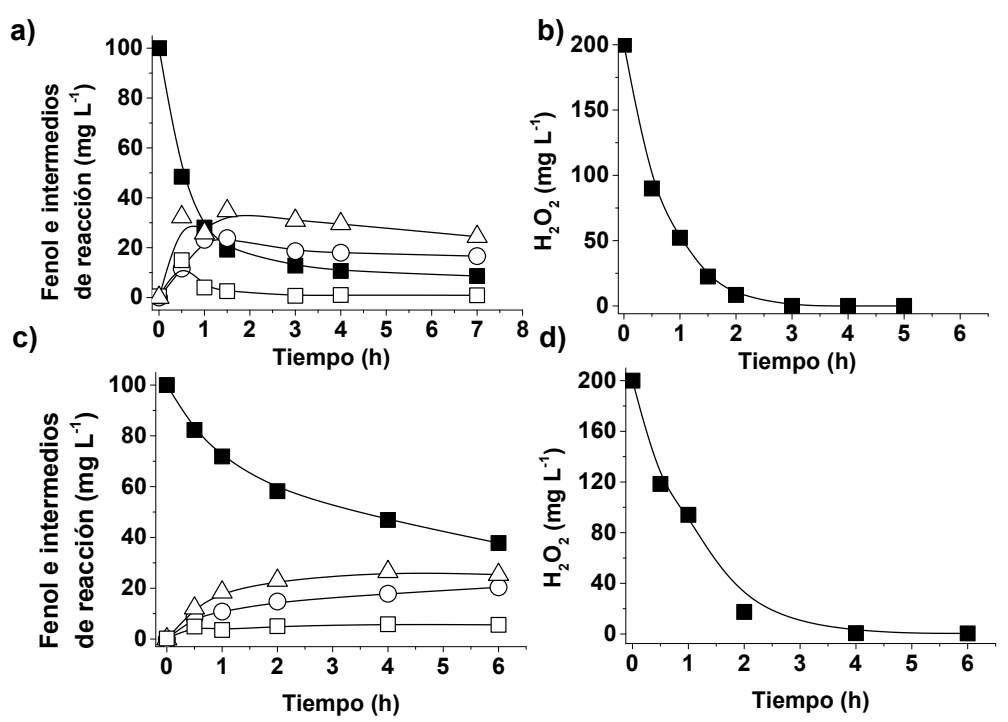

Figura 5.21. Concentración del fenol y de sus principales intermedios de reacción formados en su degradación ( $\mathrm{a}, \mathrm{c}$ ), y descomposición de $\mathrm{H}_{2} \mathrm{O}_{2}(\mathrm{~b}, \mathrm{~d}$ ) utilizando $\mathrm{Fe}_{\mathrm{ox}} / \mathrm{TiO}_{2}$ (a, b) y $\mathrm{TiO}_{2}$ (c, d) bajo irradiación con luz solar. Leyenda: Fenol (匹), catecol $(\Delta)$, hidroquinona (०) y p-benzoquinona ( $\square$ ). Condiciones de reacción: catalizador $(5 \mathrm{mg}, 0.0071 \mathrm{mM}$ de hierro soportado sobre $\mathrm{TiO}_{2}$, o $5 \mathrm{mg}$ de $\mathrm{TiO}_{2}$ ), fenol (100 mg L$\left.{ }^{-1} ; 1.06 \mathrm{mM}\right), \mathrm{H}_{2} \mathrm{O}_{2}\left(200 \mathrm{mg} \mathrm{L}{ }^{-}\right.$ ${ }^{1}$; $5.88 \mathrm{mM}$ ), $\mathrm{pH}$ inicial $4,20{ }^{\circ} \mathrm{C}$. Concentración de fenol obtenida por HPLC y de $\mathrm{H}_{2} \mathrm{O}_{2}$ por espectrofotometría, como se indica en el capítulo 8, sección experimental.

La actividad fotocatalítica del catalizador más activo preparado en el presente capítulo, $\mathrm{Fe}_{\mathrm{ox}} / \mathrm{D} 3$, fue comparada también con la de catalizadores análogos soportados sobre D3 basados en $\mathrm{Ag}$ y $\mathrm{Cu}$ NPs (tabla 5.1 y figura 5.22). Ag/D3 mostró una actividad fotocatalítica mayor comparado con $\mathrm{Fe}_{\mathrm{ox}} / \mathrm{D} 3$ y $\mathrm{Cu} / \mathrm{D} 3$. Este hecho no es completamente inesperado puesto que $\mathrm{Ag} / \mathrm{D} 3$ es uno de los fotocatalizadores más activos jamás descritos para la reacción de foto-Fenton heterogénea bajo irradiación con luz visible. ${ }^{15}$ Sin embargo, sería ventajoso reemplazar la plata por otros metales de transición de menor coste, manteniendo sin embargo, la actividad catalítica elevada. En este sentido, $\mathrm{Cu} / \mathrm{D} 3$ ha sido considerado como una alternativa al uso de Ag/D3. Sin embargo, como hemos visto en el capítulo precedente, $\mathrm{Cu} / \mathrm{D} 3$ sufre una desactivación severa durante la reacción, un hecho que ha sido atribuido a la oxidación 
parcial de las $\mathrm{Cu}$ NPs a especies de $\mathrm{Cu}$ inactivas. ${ }^{16} \mathrm{De}$ hecho, la actividad de la muestra usada $\mathrm{Cu} / \mathrm{D} 3$ se puede recuperar en alguna medida reduciendo de nuevo en etilenglicol en caliente la muestra de $\mathrm{Cu} / \mathrm{D} 3$ usada como catalizador, que ha resultado parcialmente oxidada. Como se comentará más adelante, $\mathrm{Fe}_{\mathrm{ox}} / \mathrm{D} 3$ puede ser reusado varias veces sin necesidad de tratamientos de reducción química adicionales como resulta ser necesario en el caso de $\mathrm{Cu} / \mathrm{D} 3$.
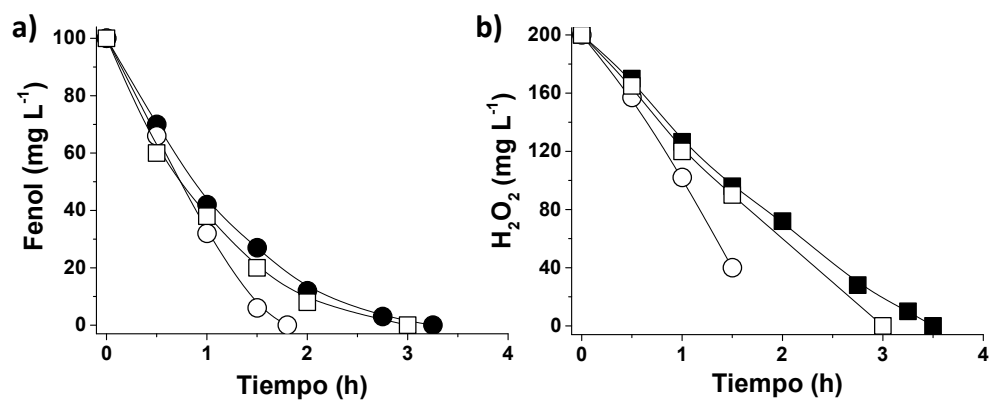

Figura 5.22. Perfiles temporales de degradación de fenol (a) y descomposición de $\mathrm{H}_{2} \mathrm{O}_{2}$ (b) usando $\mathrm{Ag}(\circ), \mathrm{Cu}$ (口) o $\mathrm{Fe}_{\text {ox }}$ (ロ) NPs soportadas sobre D3 bajo irradiación solar artificial simulada. Condiciones de reacción: catalizador $(0.0071 \mathrm{mM}$ de NPs metálicas soportadas en D3), fenol (100 mg L$\left.{ }^{-1} ; 1.06 \mathrm{mM}\right), \mathrm{H}_{2} \mathrm{O}_{2}\left(200 \mathrm{mg} \mathrm{L}^{-1} ; 5.88 \mathrm{mM}\right)$, pH inicial 4, $20{ }^{\circ} \mathrm{C}$. Concentración de fenol obtenida por HPLC y de $\mathrm{H}_{2} \mathrm{O}_{2}$ por espectrofotometría, como se indica en el capítulo 8, sección experimental.

Una de las limitaciones actualmente más importantes tanto en catálisis homogénea como heterogénea es cómo conseguir promover la reacción de foto-Fenton a valores de $\mathrm{pH}$ neutros sin emplear excesos extremadamente elevados de $\mathrm{H}_{2} \mathrm{O}_{2}{ }^{1,9}$ Típicamente el proceso de fotoFenton está limitado a valores de $\mathrm{pH}$ ácidos. La figura 5.23 muestra que el material $\mathrm{Fe}_{\mathrm{ox}} / \mathrm{D} 3$ puede actuar como un fotocatalizador eficiente en el rango de valores iniciales de $\mathrm{pH}$ entre 4 y 6 cuando la muestra es irradiada con luz solar simulada a $20{ }^{\circ} \mathrm{C}$. Es interesante hacer notar que las irradiaciones con luz solar natural en condiciones ambientales (971 $\mathrm{mW} \mathrm{cm}{ }^{-2}, 28^{\circ} \mathrm{C}$ ) pueden ampliar los valores de $\mathrm{pH}$ iniciales en los que se puede llevar acabo la reacción, usando un exceso de $\mathrm{H}_{2} \mathrm{O}_{2}$ de cinco veces, hasta el valor de $\mathrm{pH}$ de seis unidades. Sin embargo, los perfiles temporales de la reacción presentan un período de inducción que indica que la reacción resulta acelerada a medida que procede y el valor de $\mathrm{pH}$ 
disminuye desde el valor inicial. Resultados similares han sido observados usando el catalizador basado en Ag NPs soportadas sobre D3. ${ }^{15}$
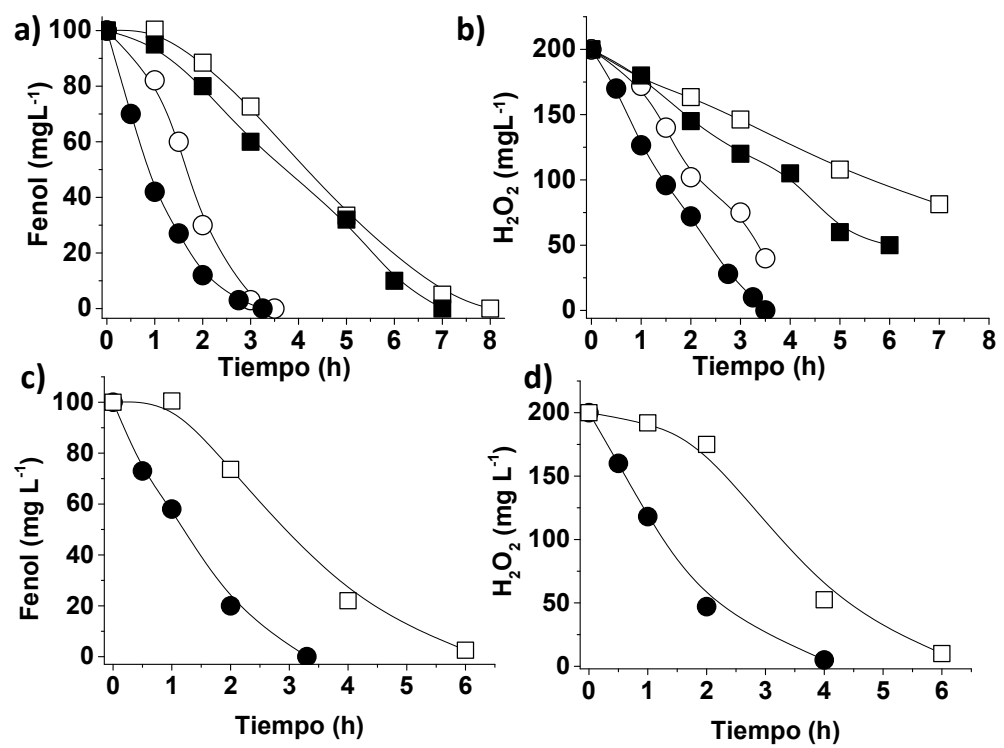

Figura 5.23. Perfiles temporales para la degradación del fenol (a, c) y descomposición de $\mathrm{H}_{2} \mathrm{O}_{2}(\mathrm{~b}, \mathrm{~d})$ usando $\mathrm{Fe}_{\mathrm{ox}}(0.2 \%$ en peso)/D3 a un valor de pH inicial de $4(\bullet), 4,5(\circ)$, pH $5(\bullet)$ y pH 6 (口) bajo irradiación con luz solar simulada $(\mathrm{a}, \mathrm{b})$ y natural $\left(\mathrm{c}, \mathrm{d} ; 28^{\circ} \mathrm{C}\right)$. Condiciones de reacción: catalizador (5 mg, $200 \mathrm{mg} \mathrm{L}^{-1}$; $\left.0.0071 \mathrm{mM}\right)$, fenol (100 mg L $\left.{ }^{-1}\right), \mathrm{H}_{2} \mathrm{O}_{2}\left(200 \mathrm{mg} \mathrm{L}^{-1}\right), \mathrm{pH}$ indicado, temperatura $20^{\circ} \mathrm{C}$. Concentración de fenol obtenida por HPLC y de $\mathrm{H}_{2} \mathrm{O}_{2}$ por espectrofotometría, como se indica en el capítulo 8, sección experimental.

La influencia de la concentración de $\mathrm{H}_{2} \mathrm{O}_{2}$ en la actividad catalítica para la degradación de fenol usando $\mathrm{Fe}_{\mathrm{ox}} / \mathrm{D} 3$ fue igualmente evaluada. $\mathrm{H}_{2} \mathrm{O}_{2}$ es un reactivo químico relativamente costoso $\mathrm{y}$, por consiguiente, la optimización de su consumo es necesaria a fin de mantener bajos los costes de operación del proceso de foto-Fenton. ${ }^{13,14}$ Conviene hacer notar que la reacción de foto-Fenton heterogénea usando $\mathrm{Fe}_{\mathrm{ox}} / \mathrm{D} 3$ como catalizador se puede combinar con un tratamiento biológico en condiciones aerobias a fin de obtener un efluente biodegradable no ecotóxico, empleando para ello la mínima cantidad de 
$\mathrm{H}_{2} \mathrm{O}_{2}$. La figura 5.24 muestra que la degradación de fenol se puede conseguir bajo condiciones de irradiación con luz solar simulada y $\mathrm{H}_{2} \mathrm{O}_{2}$ a una relación $\mathrm{H}_{2} \mathrm{O}_{2}$ a fenol tan baja como 4, aunque con esta relación la ecotoxicidad es todavía demasiado elevada debido a la presencia de subproductos (ver más adelante). La biodegradabilidad en agua se estima en base a la relación entre el valor de $\mathrm{BOD}_{5}$ y $\mathrm{COD}^{8}{ }^{8}$ La materia orgánica presente en agua es considerada biodegradable cuando la relación entre los valores de $\mathrm{BOD}_{5}$ a $\mathrm{COD}$ es mayor que 0.4. El fenol y varios de sus subproductos no son biodegradables en el tratamiento biológico aerobio convencional y son compuestos tóxicos. ${ }^{8}$ En el caso del fenol, el término "ecotoxicidad" está relacionado con la ausencia de subproductos de degradación tales como catecol, hidroquinona y $p$-benzoquinona, que son incluso más tóxicos que el propio fenol. ${ }^{8}$ En el presente capítulo se observó que la relación molar $\mathrm{H}_{2} \mathrm{O}_{2}$ a fenol más baja para conseguir un efluente biodegradable $\left(\mathrm{BOD}_{5} / \mathrm{COD}>0.4\right.$, figura 5.24) y no ecotóxico (figura 5.24) es de 5.5. Este resultado compara favorablemente con otros catalizadores de Fenton basados en metales de transición que típicamente emplean grandes excesos de $\mathrm{H}_{2} \mathrm{O}_{2}$ y no es infrecuente que el exceso sea superior a 1000 a fin de conseguir una baja ecotoxicidad. ${ }^{13,14}$ Conviene indicar aquí que la relación molar teórica de $\mathrm{H}_{2} \mathrm{O}_{2}$ a fenol necesaria para la completa mineralización del fenol exclusivamente por $\mathrm{H}_{2} \mathrm{O}_{2}$ es de 14 . Sin embargo, en el presente caso las reacciones se llevaron a cabo en condiciones aeróbicas y el oxígeno atmosférico debe contribuir a la degradación de fenol, disminuyendo la cantidad de $\mathrm{H}_{2} \mathrm{O}_{2}$ necesaria. En nuestro caso, usando una relación molar de $\mathrm{H}_{2} \mathrm{O}_{2}$ a fenol de 5.5, trabajando a pH 4 bajo irradiación con luz solar simulada, se consiguió una reducción en el valor de TOC del 75\%. Además, el material orgánico residual a tiempo final de reacción fue analizado llevando a cabo la eliminación del agua, sililación del residuo y análisis por GC-MS de la muestra. Estos análisis revelaron cantidades pequeñas de los ácidos tartárico, fumárico y oxálico, los cuales estaban acompañados por porcentajes menores de compuestos desconocidos. 
a)

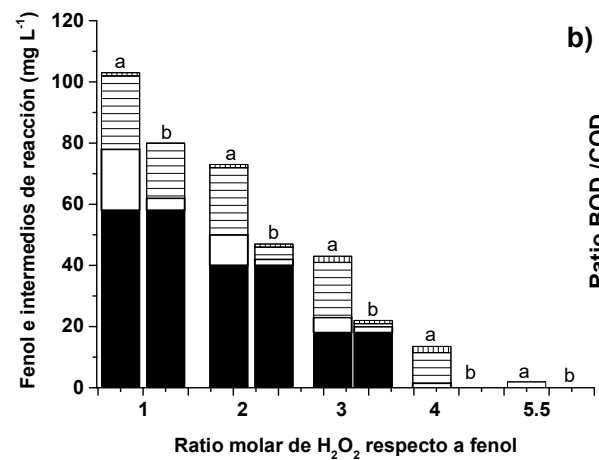

b)

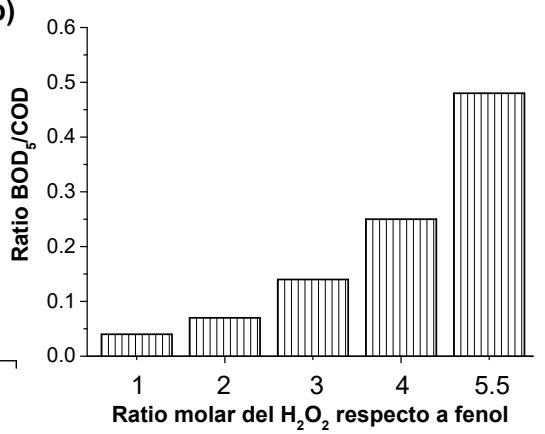

Figura 5.24. Influencia de la relación molar $\mathrm{H}_{2} \mathrm{O}_{2}$ a fenol en la concentración final de fenol e intermedios de reacción (gráfica a) y sobre la biodegradabilidad del efluente resultante (gráfico b). Leyenda: a) fenol (barra negra), hidroquinona (barra blanca), catecol (líneas horizontales) y $p$ benzoquinona (líneas verticales). Valores iniciales de $\mathrm{BOD}_{5}$ y $\mathrm{COD}$ de la disolución de fenol $\left(100 \mathrm{mg} \mathrm{L}^{-1}\right)$ son de 0 y $150 \mathrm{mg} \mathrm{L}^{-1}$, respectivamente. La concentración de fenol y sus intermedios de reacción se refiere al punto en el que el $\mathrm{H}_{2} \mathrm{O}_{2}$ ha sido completamente descompuesto. Concentración de fenol e intermedios obtenida por HPLC y de $\mathrm{H}_{2} \mathrm{O}_{2}$ por espectrofotometría, como se indica en el capítulo 8, sección experimental.

La estabilidad de la muestra $\mathrm{Fe}_{\text {ox }} / \mathrm{D} 3$ como catalizador fue evaluada llevando a cabo ocho reúsos consecutivos tanto a $\mathrm{pH} 4$ como a pH 6, determinando los perfiles temporales en la reacción y midiendo las concentraciones de hierro lixiviadas desde el catalizador sólido a la disolución. Conviene remarcar que el catalizador $\mathrm{Fe}_{\mathrm{ox}} / \mathrm{D} 3$ se puede recuperar fácilmente por filtración, lavado con agua básica antes de emplearse en una nueva reacción. La figura 5.25 presenta la actividad catalítica inicial para la muestra $\mathrm{Fe}_{\mathrm{ox}} / \mathrm{D} 3$ con el reúso a $\mathrm{pH}$ 4, observándose una ligera disminución de la actividad, aunque todavía se consigue una degradación completa del fenol. Los análisis de ICP-OES de la disolución tras el filtrado del catalizador muestran una concentración de hierro que disminuye de 7.8 a $6.5 \mu \mathrm{g} \mathrm{L}^{-1}$ desde el primer uso hasta el octavo. Estas concentraciones de hierro son mucho menores que las que permiten las regulaciones europeas en recursos acuáticos naturales, que son de un valor de $0.2 \mathrm{mg} \mathrm{L}^{-1}{ }^{29}$ Sin embargo, estos valores representan una pérdida de hierro desde el catalizador sólido a la 
disolución entre el 1.2 y el $2 \%$ en peso respecto a la cantidad de hierro inicial del catalizador fresco. Experimentos de control usando sales de $\mathrm{Fe}(\mathrm{II})$ o $\mathrm{Fe}(\mathrm{III})$ a las concentraciones determinadas para la cantidad de hierro lixiviada muestra mucha menor actividad en la reacción homogénea que la que se observa para $\mathrm{Fe}_{\mathrm{ox}} / \mathrm{D} 3$ (figura 5.26).

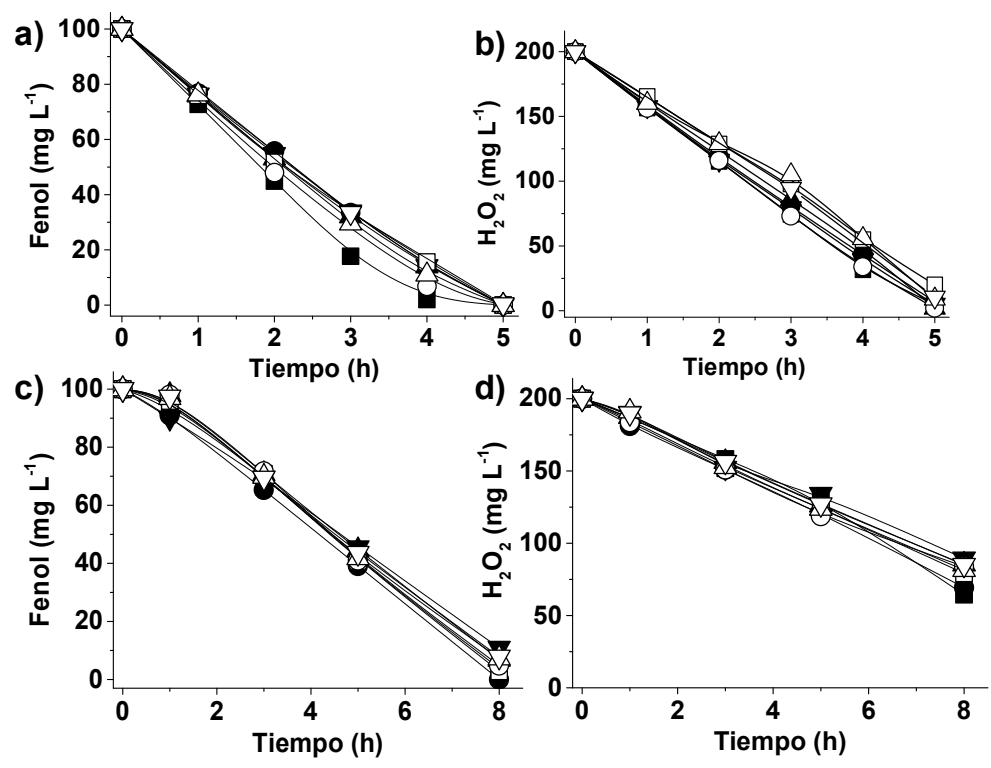

Figura 5.25. Experimentos de reusabilidad del catalizador en la degradación de fenol (a) y descomposición de $\mathrm{H}_{2} \mathrm{O}_{2}$ (b) a pH inicial de 4, y degradación de fenol (c) y descomposición de $\mathrm{H}_{2} \mathrm{O}_{2}$ (d) a $\mathrm{pH} 6$ usando $\mathrm{Fe}_{\mathrm{ox}}(0.2 \%$ en peso)/D3 como catalizador heterogéneo de Fenton asistido por irradiación con luz visible. Leyenda: primer uso $(\mathbf{\bullet}), 2^{\circ}(\bullet), 3^{\circ}(\mathbf{\Delta}), 4^{\circ}(\boldsymbol{\nabla}), 5^{\circ}(\square), 6^{\circ}$ $(\circ), 7^{\circ}$ uso $(\triangle)$ y $8^{\circ}$ uso $(\nabla)$. Condiciones de reacción: catalizador $(5 \mathrm{mg}, 200$ $\mathrm{mg} \mathrm{L}^{-1}$ ), fenol (100 mg L $\left.\mathrm{m}^{-1}\right), \mathrm{H}_{2} \mathrm{O}_{2}\left(200 \mathrm{mg} \mathrm{L}^{-1}\right), \mathrm{pH} \mathrm{4}$, irradiación por luz solar simulada. Concentración de fenol obtenida por HPLC y de $\mathrm{H}_{2} \mathrm{O}_{2}$ por espectrofotometría, como se indica en el capítulo 8, sección experimental. 

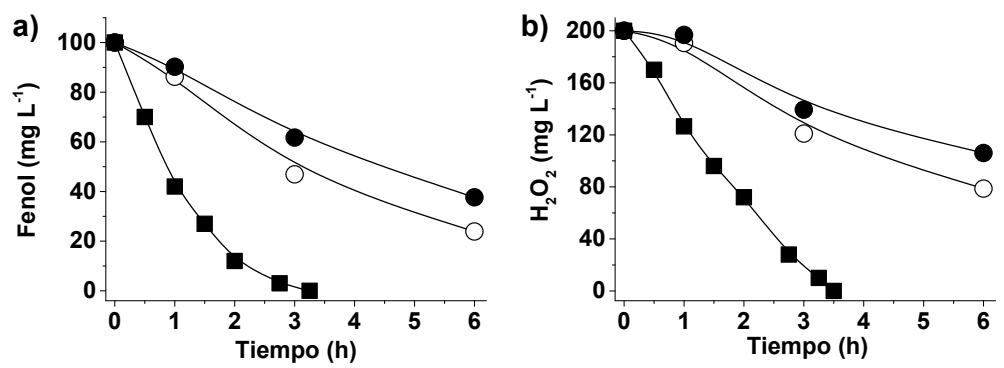

Figura 5.26. Perfiles temporales para la degradación del fenol (a) y descomposición de $\mathrm{H}_{2} \mathrm{O}_{2}$ (b) usando $\mathrm{Fe}_{\mathrm{ox}}(0.2 \%$ en peso)/D3 como catalizador heterogéneo (ロ), o sales de $\mathrm{Fe}(\mathrm{II})(\mathrm{\circ})$ o $\mathrm{Fe}(\mathrm{III})(\bullet)$ como catalizadores homogéneos. Condiciones de reacción: Catalizador: $\mathrm{Fe}_{\mathrm{ox}}(0.2 \%$ en peso)/D3 (200 mg L ${ }^{-1}, 0.4 \mathrm{mg} \mathrm{L}^{-1}$ de $\mathrm{Fe}$ ) o sales de $\mathrm{Fe}\left(0.0078 \mathrm{mg} \mathrm{L}^{-1}\right)$ correspondiente a la cantidad encontrada como lixiviado al final de la reacción al utilizar el catalizador heterogéneo; fenol (100 mg L${ }^{-1}$; $\left.1.06 \mathrm{mM}\right), \mathrm{H}_{2} \mathrm{O}_{2}\left(200 \mathrm{mg} \mathrm{L}^{-1}\right.$; $5.88 \mathrm{mM}$ ), $\mathrm{pH}$ inicial 4 , temperatura $20^{\circ} \mathrm{C}$. Concentración de fenol obtenida por HPLC y de $\mathrm{H}_{2} \mathrm{O}_{2}$ por espectrofotometría, como se indica en el capítulo 8, sección experimental.

Es importante mencionar que un test de productividad usando un gran exceso de fenol respecto a hierro al disminuir la cantidad de $\mathrm{Fe}_{\mathrm{ox}} / \mathrm{D} 3$, trabajando a $\mathrm{pH}$ inicial de 4 , permite estimar un número de ciclos acumulados (TON) de 38000 (figura 5.27). Uno de los catalizadores de foto-Fenton heterogéneos más activos basados en Ag NPs soportadas en D3 alcanzó un valor de TON en condiciones similares de en torno a 472000. ${ }^{15}$ Considerando que el metal de hierro es mucho más abundante, asequible y barato que la plata, $\mathrm{Fe}_{\mathrm{ox}} / \mathrm{D} 3$ puede ser un catalizador eficiente y de bajo precio comparado con el uso de la Ag y otros metales nobles, empleado en la reacción de foto-Fenton heterogénea mediante irradiación con luz visible. 

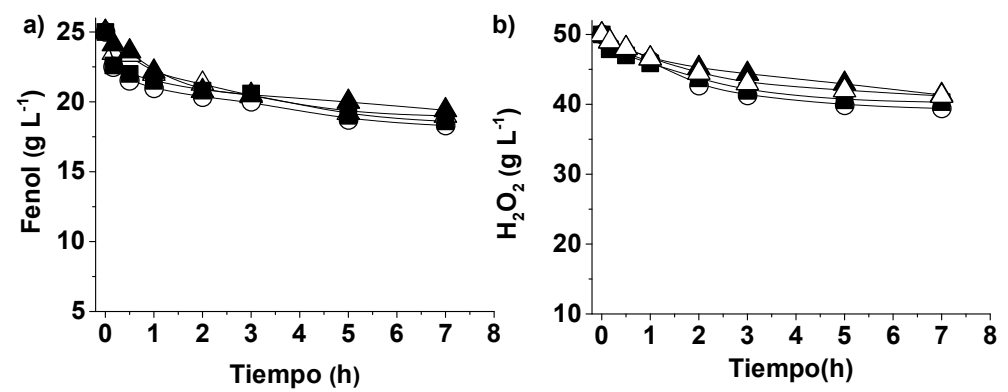

Figura 5.27. Perfiles temporales correspondientes al ensayo de productividad y reusabilidad para la degradación de fenol (a) y para la descomposición de $\mathrm{H}_{2} \mathrm{O}_{2}$ (b) usando $\mathrm{Fe}_{\text {ox }}(0.2 \%$ en peso)/D3 como catalizador bajo irradiación solar artificial simulada. Leyenda: $1^{\circ}(\mathbf{\square}), 2^{\circ}(\circ), 3^{\circ}(\mathbf{\Delta})$ y $4^{\circ}$ uso $(\Delta)$. Condiciones de reacción: catalizador $\left(5 \mathrm{mg}, 0.0071 \mathrm{mM}\right.$ de $\mathrm{Fe}_{\mathrm{ox}} \mathrm{NPs}$ soportadas sobre D3), fenol $\left(25 \mathrm{~g} \mathrm{~L}^{-1} ; 265 \mathrm{mM}\right), \mathrm{H}_{2} \mathrm{O}_{2}\left(50 \mathrm{~g} \mathrm{~L}^{-1} ; 1.47 \mathrm{M}\right)$, $\mathrm{pH}$ inicial $4,20^{\circ} \mathrm{C}$, intensidad de irradiación $\left(100 \mathrm{~mW} \mathrm{~cm}^{-2}\right)$. Concentración de fenol obtenida por HPLC y de $\mathrm{H}_{2} \mathrm{O}_{2}$ por espectrofotometría, como se indica en el capítulo 8, sección experimental.

Las medidas de TEM para la muestra usada cuatro veces $(3.7 \pm$ $2.7 \mathrm{~nm})$ y 8 veces $(4.6 \pm 3.0 \mathrm{~nm})$ del catalizador $\mathrm{Fe}_{\mathrm{ox}} / \mathrm{D} 3$ indican que las $\mathrm{Fe}_{\mathrm{ox}}$ NPs sufren agregación respecto al catalizador fresco $(2.2 \pm 0.5 \mathrm{~nm})$ (figura 5.1), pero este crecimiento en la dimensión de las partículas parece que no se refleja en la actividad catalítica del material. Conviene notar que el catalizador $\mathrm{Cu} / \mathrm{D} 3$ sufre desactivación severa tras el reúso debido a la oxidación parcial de las especies de $\mathrm{Cu}$ reducidas $\mathrm{y}$, por consiguiente, la reducción por el método del poliol fue necesaria en aquel caso a fin de recuperar, aunque sea parcialmente, la actividad catalítica. De esta manera, la fácil reusabilidad, probablemente debido a la actividad de Fenton de las especies Fe oxo-hidroxi con esta autoxidación de intermedios, determina la superioridad de la muestra $\mathrm{Fe}_{\mathrm{ox}} / \mathrm{D} 3$ respecto a $\mathrm{Cu} / \mathrm{D} 3$. Conviene mencionar que la muestra $\mathrm{Fe}_{\mathrm{ox}} / \mathrm{D} 3$ pudo ser fácilmente reutilizada hasta ocho veces trabajando a valores de $\mathrm{pH}$ alrededor de seis, observándose en este valor de $\mathrm{pH}$ un lixiviado de hierro inferior al $0.3 \%$ respecto al total de hierro soportado sobre D3 (figura 5.25). Es interesante hacer notar que a pH de 6, la agregación de las partículas de óxido de hierro fue insignificante tanto para la muestra usada cuatro veces $(2.4 \pm$ $1.8 \mathrm{~nm})$, como para la usada en ocho reacciones consecutivas $(2.8 \pm 2.1$ 
$\mathrm{nm})$, comparado con la muestra fresca de $\mathrm{Fe}_{\mathrm{ox}} / \mathrm{D} 3(2.2 \pm 0.5 \mathrm{~nm})$ (figura 5.28). Esta mayor estabilidad del catalizador de $\mathrm{Fe}_{\text {ox }} / \mathrm{D} 3$ a valores de $\mathrm{pH}$ iniciales de 6 comparada con el valor inicial de 4 podría ser probablemente debido a la menor solubilidad de las especies de Fe en condiciones próximas a la neutralidad tal como indican los valores de hierro lixiviado para estas muestras.
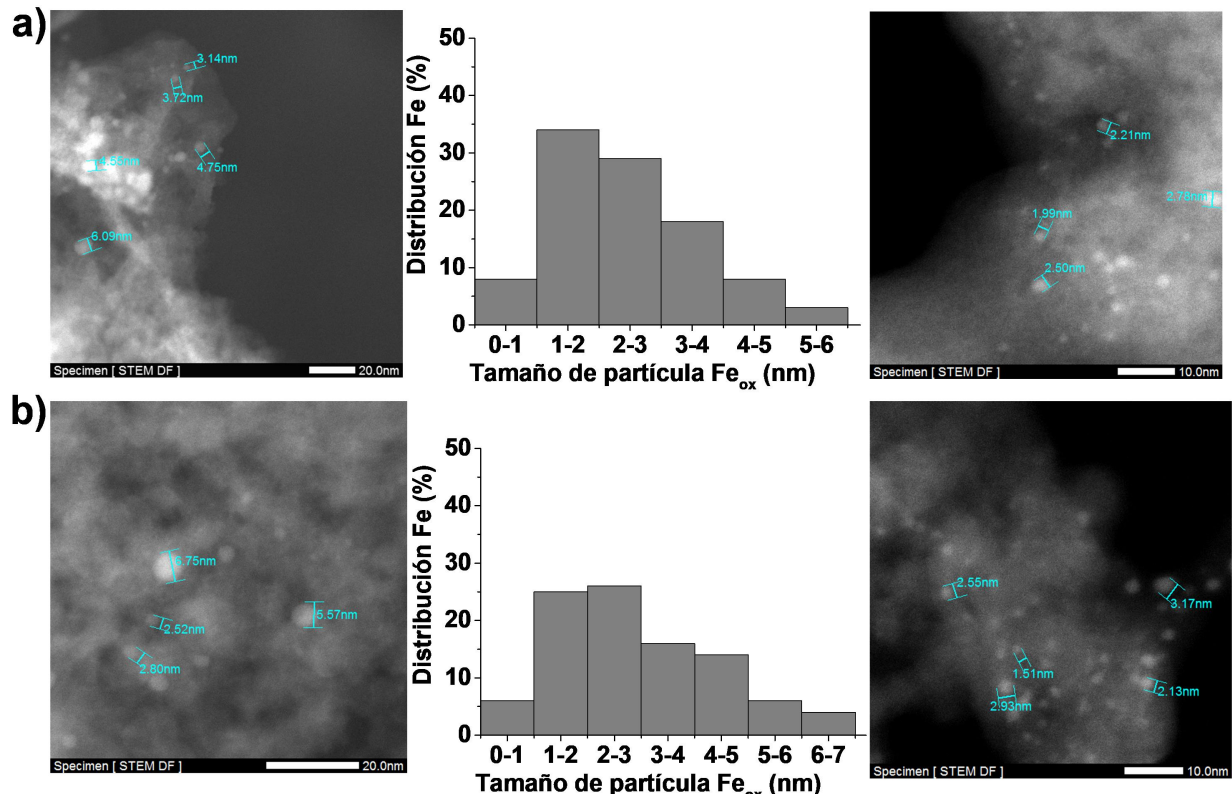

Figura 5.28. Imágenes de DF-STEM e histogramas de distribución de tamaño de partícula para la muestra de $\mathrm{Fe}_{\mathrm{ox}}(0.2 \%$ en peso)/D3 usada cuatro veces (a) y usada 8 veces (b) a pH 6.

Como se ha comentado anteriormente, aunque el procedimiento de preparación debe formar inicialmente nanopartículas metálicas de $\mathrm{Fe}(0)$ estas se convertirían espontáneamente en especies de hierro oxihidroxi indefinidas. Parece también probable que las especies de hierro oxihidroxi presentes en las muestras frescas de $\mathrm{Fe}_{\mathrm{ox}} / \mathrm{D}$ sufran algún envejecimiento bajo las condiciones de reacción debido a la acción de $\mathrm{H}_{2} \mathrm{O}_{2}$. A fin de obtener alguna información que apoye esta hipótesis, los catalizadores empleados a ambos valores de $\mathrm{pH}$ inicial 4 y 6 fueron caracterizados por diferentes técnicas espectroscópicas. La figura 5.29 muestra una comparación de los espectros de FT-IR y reflectancia difusa 
$\mathrm{UV}-\mathrm{V}$ is para las muestras frescas y usadas de $\mathrm{Fe}_{\mathrm{ox}} / \mathrm{D} 3$ tanto a valores de pH de 4 como 6. Como puede verse en esta figura 5.29, la espectroscopía FT-IR muestra la aparición de bandas de vibración nuevas a 622 y 500 $\mathrm{cm}^{-1}$ para el material $\mathrm{Fe}_{\mathrm{ox}} / \mathrm{D} 3$ usado a ambos valores de $\mathrm{pH}$ iniciales de 4 y 6. La espectroscopía óptica de reflectancia difusa de los catalizadores usados a ambos valores de $\mathrm{pH}$ también revela un aumento de la absorción en la región entre 420 y $570 \mathrm{~nm}$. Se propone que estas variaciones espectroscópicas están relacionadas con los cambios en la composición de los óxidos de hierro. A fin de obtener más información sobre la posible oxidación de las $\mathrm{Fe}_{\mathrm{ox}}$ NPs soportadas sobre D3, se llevó a cabo la caracterización de $\mathrm{Fe}_{\mathrm{ox}} \mathrm{NPs}$ frescas con muestras tratadas similarmente en las condiciones de la reacción de Fenton (figura 5.30). Como era de esperar, también en este caso el tratamiento de $\mathrm{Fe}_{\mathrm{ox}}$ NPs bajo las condiciones de reacción condujeron a cambios en los espectros de FT-IR, Raman y reflectancia difusa UV-Vis, aunque no se observaron cambios en el pico correspondiente a $\mathrm{Fe} 2 \mathrm{p}$ en el análisis por XPS, probablemente debido al solapamiento entre las señales de $\mathrm{FeO}, \mathrm{Fe}_{2} \mathrm{O}_{3}$ y $\mathrm{FeOOH}$, tal como ha sido previamente descrito en la bibliografía. ${ }^{30-32}$ Por consiguiente, se puede concluir que, tanto el material $\mathrm{Fe}_{\text {ox }} / \mathrm{D} 3$ como las $\mathrm{Fe}_{\text {ox }}$ NPs sin soportar sufren cambios en la composición de sus óxidos bajo las condiciones de reacción en presencia de $\mathrm{H}_{2} \mathrm{O}_{2}$ bien a pHs iniciales de 4 como de 6 .
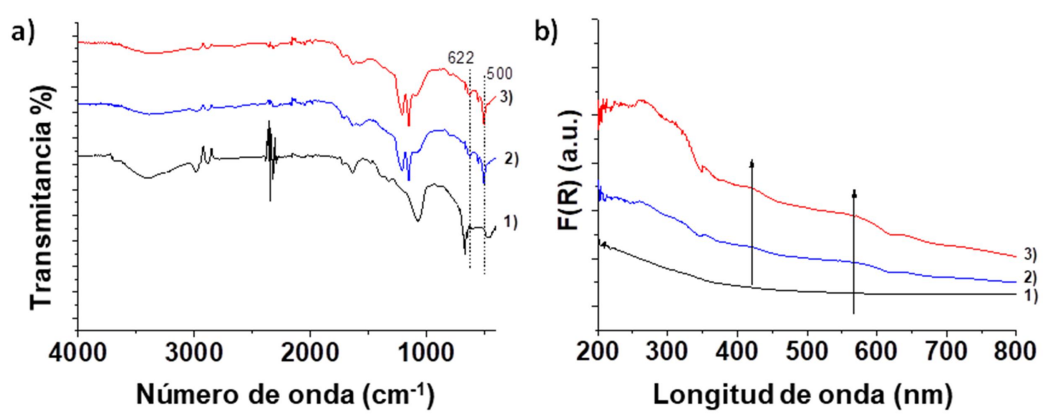

Figura 5.29. Espectros de FT-IR (a) y reflectancia difusa (b) del catalizador $\mathrm{Fe}_{\mathrm{ox}} / \mathrm{D} 3$ fresco (1), y usado a pH 4 (2) y a pH 6 (3). 
a)

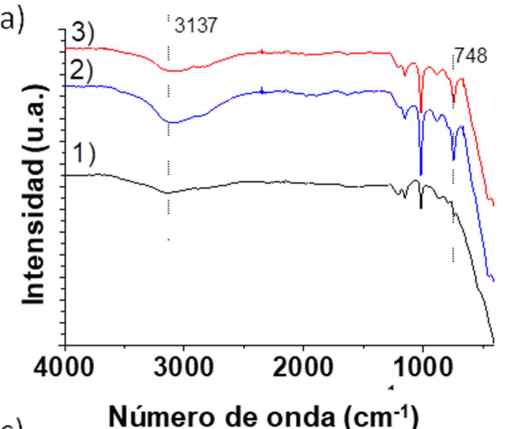

c)

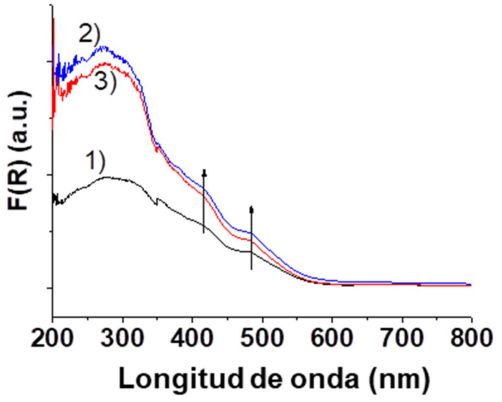

b)

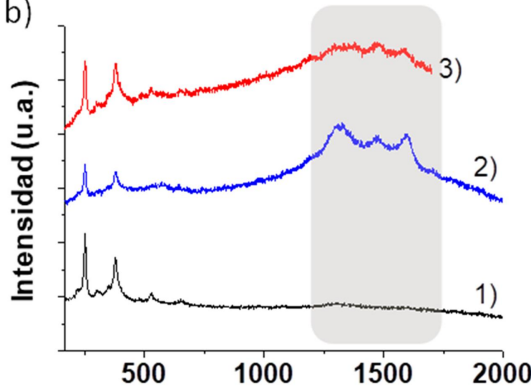

d)

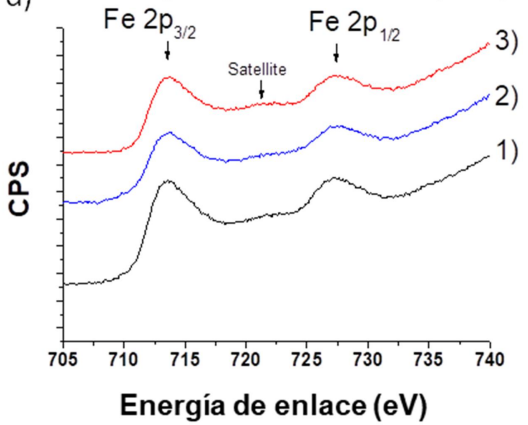

Figura 5.30. Espectros de FT-IR (a), raman (b), reflectancia difusa (c) y XPS (d) del catalizador de $\mathrm{Fe}_{\mathrm{ox}}$ NPs sin soportar fresco (1), y usado a pH 4 (2) y a pH 6 (3).

\subsubsection{Mecanismo de reacción}

El mecanismo de reacción más ampliamente aceptado para las reacciones fotocatalítica de óxidos metálicos semiconductores implican la separación de carga como la etapa principal que sigue a la absorción de luz. ${ }^{33} \mathrm{~A}$ fin de proporcionar alguna información sobre el mecanismo de acción de la muestra de $\mathrm{Fe}_{\mathrm{ox}} / \mathrm{D} 3$ como fotocatalizador, se llevó a cabo un estudio mediante espectroscopía de adsorción transitoria, usando una suspensión en acetonitrilo de $\mathrm{Fe}_{\mathrm{ox}} / \mathrm{D} 3$, por excitación con un láser operando a $532 \mathrm{~nm}$. Esta longitud de onda de luz visible debería inducir la fotorespuesta en esta muestra debido a la absorción en la zona del visible que presentan las nanopartículas de óxido de hierro. Tras excitación de la suspensión de $\mathrm{Fe}_{\mathrm{ox}} / \mathrm{D} 3$, se observó un espectro de absorción transitoria que decae en la escala de tiempos de microsegundos, y que se caracteriza por una absorción continua que cubre el rango completo de longitudes de onda (figura 5.31). El espectro de absorción 
transitoria de una suspensión de acetonitrilo de D3 tomada como blanco también fue registrado bajo las mismas condiciones de irradiación, observando en este caso, como era esperable, una señal transitoria despreciable, lo que está de acuerdo con la falta de absorción de luz a 532 $\mathrm{nm}$ por este material.

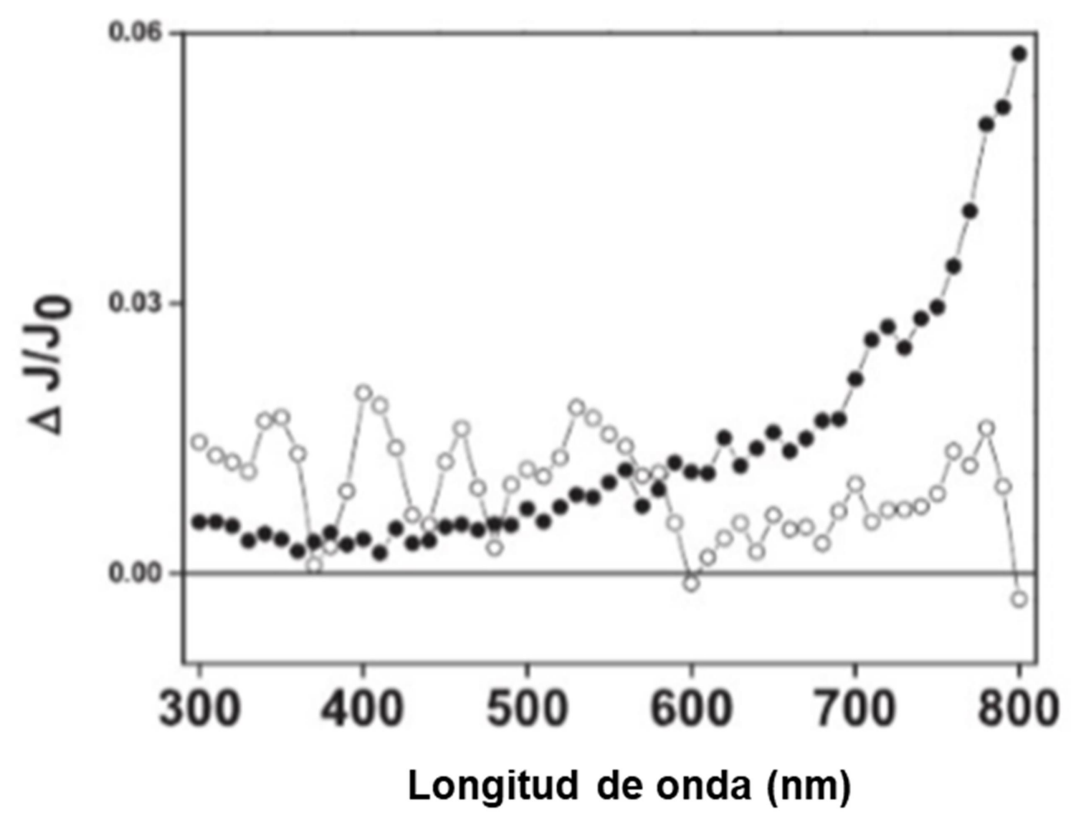

Figura 5.31. Espectros de absorción transitoria de una suspensión de acetonitrilo $\left(5 \mathrm{mg} \mathrm{mL}^{-1}\right)$ de $\mathrm{Fe}_{2} \mathrm{O}_{3}$ sin soportar $(\bullet)$ y $\mathrm{Fe}_{\text {ox }}(0.2 \%$ en peso)/D3 (०) registrados $90 \mu \mathrm{s}$ tras el pulso de laser de $532 \mathrm{~nm}$ bajo atmósfera de argón.

A fin de asignar la señal transitoria registrada para la muestra $\mathrm{Fe}_{\mathrm{ox}} / \mathrm{D} 3$, se registró también el espectro de absorción de una suspensión en acetonitrilo de una muestra de $\mathrm{Fe}_{2} \mathrm{O}_{3}$ NPs sin soportar, la cual fue sintetizada empleando el mismo procedimiento experimental seguido para sintetizar la muestra de $\mathrm{Fe}_{\mathrm{ox}} / \mathrm{D} 3$. Una absorción continua cubriendo todo el rango de longitudes de onda y creciendo en intensidad hacia la zona roja del espectro fue registrada tras excitación de las muestras de $\mathrm{Fe}_{2} \mathrm{O}_{3}$ NPs sin soportar (figura 5.31). En ambos casos, el perfil temporal de las señales midiendo a diferentes longitudes de onda (400 y $500 \mathrm{~nm}$ ) fueron prácticamente coincidentes (figura 5.32), sugiriendo que se trata de una 
única especie transitoria absorbiendo en este rango de longitudes de onda. Atribuimos este espectro de absorción transitoria al estado de la separación de cargas generado por absorción de luz con electrones y huecos localizados en diferentes centros en $\mathrm{Fe}_{2} \mathrm{O}_{3} \mathrm{NPs}$ o en $\mathrm{Fe}_{\text {ox }}$ depositado sobre D3. ${ }^{34,35}$ En el caso de $\mathrm{Fe}_{2} \mathrm{O}_{3}$ NPs en ausencia de soporte $\mathrm{D}$, una banda de absorción muy intensa aparece a longitudes de onda largas $(>750 \mathrm{~nm})$ a tiempos largos tras la excitación. Basados en la literatura, esta banda de absorción a longitudes de onda larga puede ser atribuida a la absorción de electrones solvatados en agua, apoyando de esta manera la eyección de electrones promovida por la absorción de un fotón. ${ }^{34}$

A fin de confirmar la naturaleza de las especies transitorias generadas tras el pulso de láser, se llevaron a cabo experimentos de inhibición empleando $\mathrm{O}_{2}$ y $\mathrm{CH}_{2} \mathrm{Cl}_{2}$ como aceptores de electrones. ${ }^{35,36} \mathrm{La}$ figura 5.32 muestra que el espectro de absorción transitoria tras excitación con un pulso de láser a $532 \mathrm{~nm}$ de una suspensión en acetonitrilo $\left(5 \mathrm{mg} \mathrm{mL}^{-1}\right)$ de $\mathrm{Fe}_{\mathrm{ox}} / \mathrm{D} 3$ es inhibida en la región desde 500 hasta $700 \mathrm{~nm}$ cuando cualquiera de los dos agentes atrapadores de electrones, bien $\mathrm{O}_{2} \circ \mathrm{CH}_{2} \mathrm{Cl}_{2}$, estaban presentes. Por consiguiente, la banda de absorción desde 500 a $700 \mathrm{~nm}$ del espectro de absorción transitoria registrado en la escala de tiempo de $\mu$ s se puede atribuir a electrones fotogenerados accesibles a los inhibidores por localizarse en la superficie externa de las partículas de $\mathrm{Fe}_{\mathrm{ox}} / \mathrm{D} 3$. 

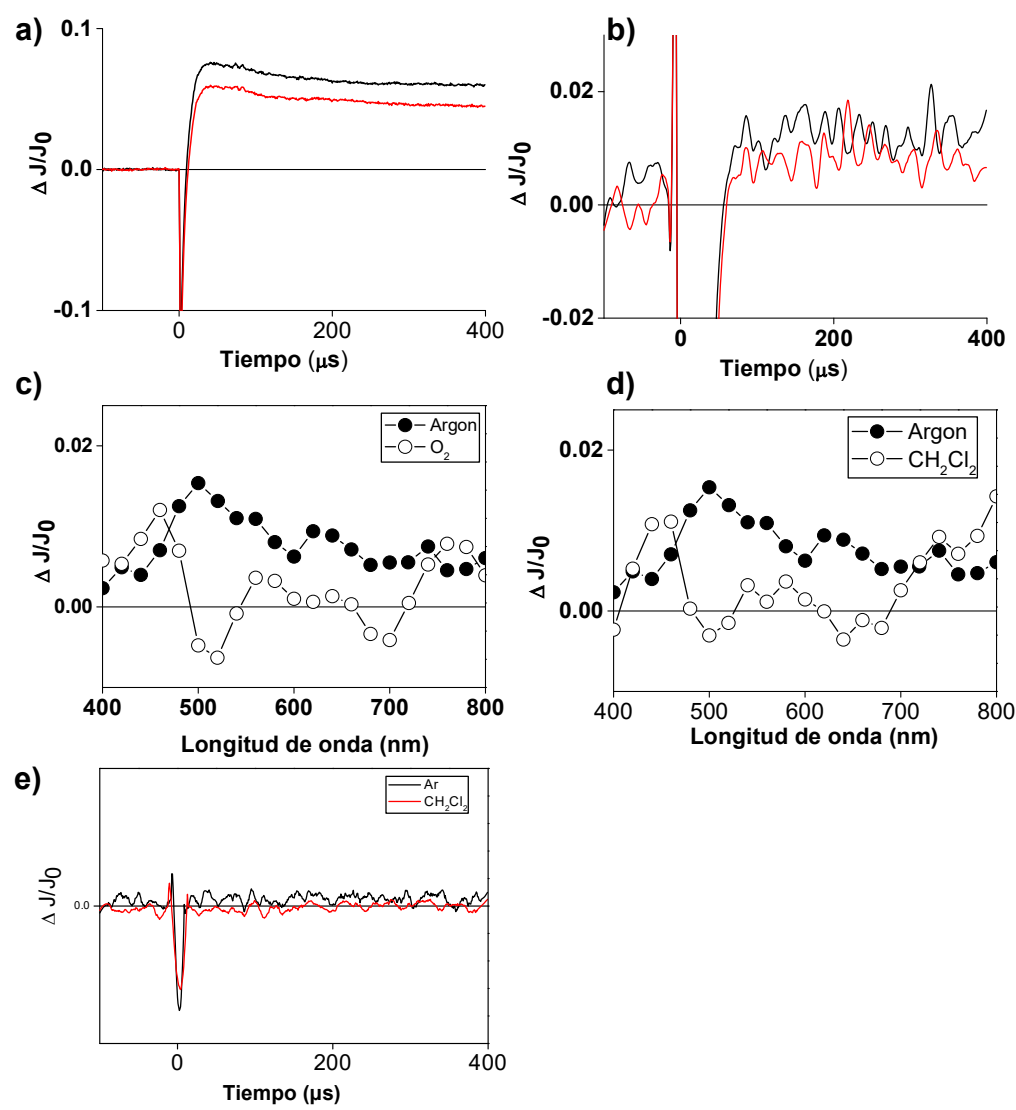

Figura 5.32. Perfiles temporales de las señales transitorias registradas a 400 (línea negra) y $500 \mathrm{~nm}$ (línea roja) registradas tras excitación con un pulso de láser de $532 \mathrm{~nm}$ bajo atmósfera de argón para $\mathrm{Fe}_{2} \mathrm{O}_{3}$ NPs sin soportar (a) y $\mathrm{Fe}_{\text {ox }}(0.2 \%$ en peso $) / \mathrm{D} 3$ (b) suspendidas en acetonitrilo $\left(5 \mathrm{mg} \mathrm{mL} \mathrm{mL}^{-1}\right)$. c) Espectros de absorción transitoria UV-Vis de una suspensión en acetonitrilo de la muestra $\mathrm{Fe}_{\text {ox }}(0.2 \%$ en peso)/D3 registrada $90 \mu$ s tras excitación con un láser a $532 \mathrm{~nm}$ bajo atmósfera de argón $(\bullet), \mathrm{O}_{2}(\circ)$. d) Idéntica gráfica a c) registrada bajo argón $(\bullet)$ o en presencia de $\mathrm{CH}_{2} \mathrm{Cl}_{2}(\circ)$. e) Perfiles temporales de las señales transitorias registradas a $500 \mathrm{~nm}$ obtenidas tras excitación con un pulso de láser a $532 \mathrm{~nm}$ bajo atmósfera de argón (línea negra) y en presencia de $\mathrm{CH}_{2} \mathrm{Cl}_{2}$ (línea roja) como aceptor de electrones para una suspensión en acetonitrilo $\left(5 \mathrm{mg} \mathrm{ml}^{-1}\right) \mathrm{de} \mathrm{Fe}_{\mathrm{ox}}(0.2 \%$ en peso $) / \mathrm{D} 3$.

Además de estudios con resolución temporal, se llevaron también a cabo experimentos cinéticos usando inhibidores a fin de determinar la 
posible naturaleza de las posibles especies reactivas de oxígeno implicadas en la reacción de Fenton asistida por luz con $\mathrm{Fe}_{\mathrm{ox}} / \mathrm{D} 3$. Así, se observó que la presencia de DMSO como inhibidor selectivo de radical hidroxilo para completamente la actividad fotocatalítica (figura 5.33). Sin embargo, la presencia de $p$-benzoquinona como inhibidor selectivo de radical hidroperoxilo fue despreciable en la reacción fotocatalítica, indicando que los radicales hidroxilo son la principal especie de oxígeno reactiva implicada en la reacción de foto-Fenton catalizada por $\mathrm{Fe}_{\mathrm{ox}} / \mathrm{D} 3$.

Se empleó la técnica de EPR para confirmar mediante atrapamiento la naturaleza de la principal especie reactiva de oxígeno que se genera durante la reacción fotocatalítica heterogénea usando $\mathrm{Fe}_{\mathrm{ox}} / \mathrm{D} 3$. La figura 5.33 muestra el acuerdo que existe entre el espectro de EPR teórico calculado para el aducto DMPO-OH empleando la constante de acoplamiento hiperfina descrita en la literatura comparada con el espectro de EPR experimental. ${ }^{37}$ La detección del aducto DMPO-OH junto con la influencia de la presencia de DMSO en la reacción y la falta de influencia de la $p$-benzoquinona, confirman que la principal especie reactiva de oxígeno generada en la reacción usando $\mathrm{H}_{2} \mathrm{O}_{2}$ como oxidante y $\mathrm{Fe}_{\mathrm{ox}} / \mathrm{D} 3$ como catalizador responsable de la degradación del fenol debe ser el radical hidroxilo.
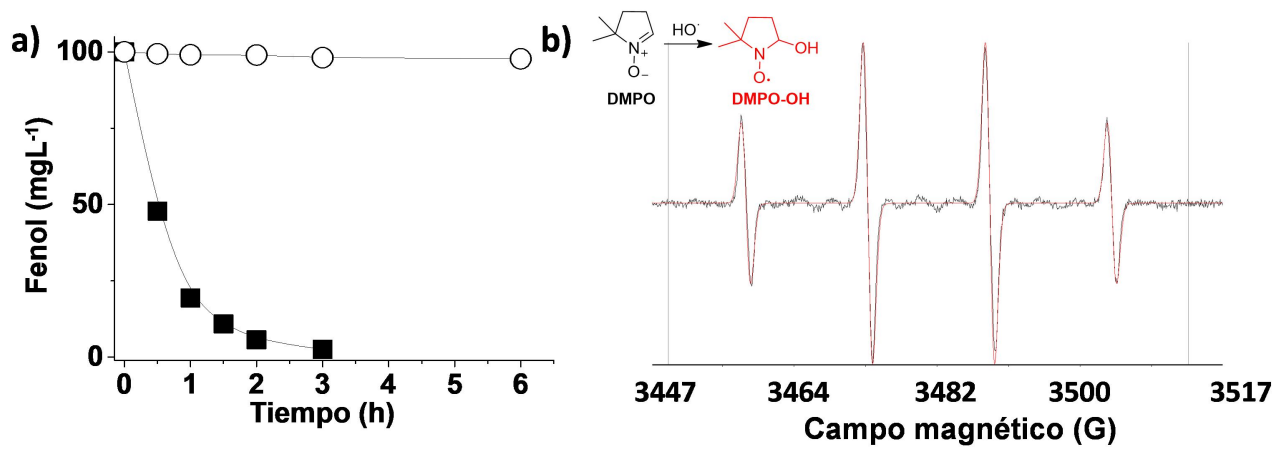

Figura 5.33. a) Degradación de fenol usando $\mathrm{Fe}_{\mathrm{ox}}(0.2 \%$ en peso $) / \mathrm{D} 3$ como catalizador en presencia de DMSO como aditivo ( $\circ$ ) y en ausencia de DMSO (घ). b) Espectro de EPR de la señal experimental (línea negra) y espectro simulado (línea roja) para el aducto DMPO-OH (constante de acoplamiento hiperfina $A_{H} / G=A_{N} / G=14.80 \mathrm{~Hz}$ ). Condiciones de reacción: a) Catalizador $\mathrm{Fe}_{\text {ox }}\left(0.2 \%\right.$ en peso)/D3 (200 mg L ${ }^{-1} ; 0.0071 \mathrm{mM}$ de $\left.\mathrm{Fe}\right)$, fenol $\left(100 \mathrm{mg} \mathrm{L}^{-1}\right.$; $1.06 \mathrm{mM}), \mathrm{H}_{2} \mathrm{O}_{2}\left(200 \mathrm{mg} \mathrm{L}^{-1} ; 5.88 \mathrm{mM}\right), \mathrm{pH} 4$, en presencia o en ausencia de 
DMSO (1 mL). b) Catalizador (200 $\left.\mathrm{mg} \mathrm{L}^{-1}\right)$, DMPO $\left(1000 \mathrm{mg} \mathrm{L}^{-1}\right)$, relación molar $\mathrm{H}_{2} \mathrm{O}_{2}$ a DMPO igual a 1 , reacción con luz solar simulada, tiempo de reacción 5 minutos.

Así, se propone que la irradiación de $\mathrm{Fe}_{\mathrm{ox}}$ genera electrones y huecos. Los electrones serían capturados por el oxígeno ambiental o las moléculas de $\mathrm{H}_{2} \mathrm{O}_{2}$, formando especies reactivas de oxígeno, preferentemente radicales $\mathrm{HO}^{\circ}$. Estos radicales atacarían al fenol produciendo su degradación. Los huecos fotogenerados serían consumidos por especies dadoras de electrones presentes en el medio de reacción, $\mathrm{H}_{2} \mathrm{O}_{2}$, fenol y $\mathrm{H}_{2} \mathrm{O}$. La captura de huecos por $\mathrm{H}_{2} \mathrm{O}_{2}$ fue demostrada mediante un experimento de control mediante el cual se determinó la formación de $\mathrm{O}_{2}$ (el producto de atrapamiento de un hueco positivo por $\mathrm{H}_{2} \mathrm{O}_{2}$ ). La cantidad de $\mathrm{O}_{2}$ generada en el proceso disminuye en un $66 \%$ cuando el fenol en la concentración usada en el presente capítulo se encuentra presente, lo que indica que este compuesto aromático también compite por el atrapamiento de huecos. La velocidad de descomposición de $\mathrm{H}_{2} \mathrm{O}_{2}$ se ve acelerada por la presencia de fenol, indicando que los electrones y huecos fotogenerados se consumen más rápidamente cuando el fenol está presente, confirmando el papel del fenol como aceptor de huecos. La función de las NPs de diamante debería ser actuar como soporte facilitando una alta dispersión de las $\mathrm{Fe}_{\mathrm{ox}} \mathrm{NPs}$ de pequeño tamaño y proporcionar una superficie inerte que permita la migración de los radicales hidroxilo a la fase acuosa como radicales libres. ${ }^{16}$ Es conocido que la mayoría de las superficies de óxidos metálicos atrapan $\mathrm{HO}^{\circ}$, los cuales permanecen asociados a las partículas ${ }^{38}$ y en este sentido el comportamiento de las NPs de diamante sería de gran importancia. ${ }^{15,16}$

\subsection{Conclusiones}

El presente capítulo ha descrito la preparación de NPs de óxido de hierro soportadas en NPs de diamante comerciales tratados con la reacción de Fenton homogénea seguido de tratamiento térmico por hidrógeno $\left(\mathrm{Fe}_{\mathrm{ox}} / \mathrm{D} 3\right)$. Se ha establecido que este material es un catalizador adecuado para la reacción de Fenton heterogénea asistida por luz visible. El material $\mathrm{Fe}_{\mathrm{ox}} / \mathrm{D} 3$ exhibe un comportamiento catalítico mejor que otros catalizadores análogos basados en materiales carbonosos con soportes tales como $\mathrm{AC}$ o $\mathrm{Gr}$ así como fotocatalizadores de referencia como 
Nanopartículas de óxido de hierro soportadas sobre nanopartículas de diamante como catalizador en la reacción de Fenton foto-asistida por luz visible

$\mathrm{Fe}_{\mathrm{ox}} / \mathrm{TiO}_{2}$. Aunque la actividad de $\mathrm{Fe}_{\mathrm{ox}} / \mathrm{D} 3$ es mucho menor que la de la muestra $\mathrm{Ag} / \mathrm{D} 3, \mathrm{Fe}_{\text {ox }} / \mathrm{D} 3$ es activo incluso a valores de $\mathrm{pH}$ próximos a la neutralidad. El proceso de Fenton fotoasistido heterogéneo usando $\mathrm{Fe}_{\mathrm{ox}} / \mathrm{D} 3$ ha sido complementado con tratamiento biológico aeróbico consiguiendo un efluente biodegradable con ecotoxicidad tolerable, empleando tan sólo en el proceso 4 equivalentes de $\mathrm{H}_{2} \mathrm{O}_{2}$ respecto de fenol a la concentración inicial. La característica más sobresaliente de $\mathrm{Fe}_{\mathrm{ox}} / \mathrm{D} 3$ respecto a otros catalizadores análogos basados en metales de transición soportados en D NPs que han sido previamente descritos en la literatura son la fácil reusabilidad sin necesidad de etapas de reactivación y la alta actividad para la degradación de fenol y descomposición de $\mathrm{H}_{2} \mathrm{O}_{2}$ bajo irradiación con luz visible, consiguiéndose valores de TON acumulados alrededor de 38000 .

De esta manera, los resultados presentados en este capítulo confirman que la superficie de diamante es adecuada para soportar NPs metálicas que actúen como centros activos en la generación de radicales hidroxilo. Estos radicales hidroxilo son libres para difundir a la disolución acuosa consiguiendo de esta manera una alta eficiencia en la degradación de contaminantes orgánicos.

\subsection{Referencias}

[1] J.J. Pignatello, E. Oliveros, A., Crit. Rev. Environ. Sci. Technol, 2006, 36, 1-84.

[2] M. Pera-Titus, V. García-Molina, M.A. Baños, J. Giménez, S., Appl. Catal. B: Environ., 2004, 219-256.

[3] S.R. Pouran, A.R.A. Aziz, V.M.A.W. Daud, J. Ind. Eng. Chem., 2015, 21, 53-69.

[4] K. Ayoub, E.D. van Hullebusch, M. Cassir, A. Bermond, J. Hazard. Mater., 2010, 178, 10-28.

[5] M.N. Chong, B. Jin, C.W.K. Chow, C. Saint, Water Res., 2010, 44, 2997-3027.

[6] S. Malato, P. Fernández-Ibáñez, M.I. Maldonado, J. Blanco, W. Gernjak, Cat. Today, 2009, 147, 1-59.

[7] E. Neyens, J. Baeyens, J. Hazard. Mater., 2003, 98, 33-50.

[8] S. Navalon, R. Martin, M. Alvaro, H. Garcia, ChemSusChem, 2011, 4, 650-657.

[9] A.D. Bokare, W. Choi, J. Hazard. Mater., 2014, 275, 121-135 
[10] S. Chiron, A. Fernandez-Alba, A. Rodriguez, E. Garcia-Calvo, Water Res., 2000, 34, 366-377.

[11] J. Herney-Ramirez, M.A. Vicente, L.M. Madeira, Appl. Catal. B: Environ., 2010, 98, 10-26

[12] C. Wang, H. Liu, Z. Sun, J. Photoenergy, 2012, 801694.

[13] A. Dhakshinamoorthy, S. Navalon, M. Alvaro, H. Garcia, ChemSusChem, 2012, 5, 46-64.

[14] S. Navalon, A. Dhakshinamoorthy, M. Alvaro, H. Garcia, ChemSusChem, 2011, 4, 1712-1730.

[15] J.C. Espinosa, S. Navalón, M. Álvaro, H. García, ChemCatChem, 2015, 7, 2682-2688.

[16] J.C. Espinosa, S. Navalón, M. Álvaro, H. García, Catal. Sci. Technol., 2016, 6, 7077-7085.

[17] D. Sempere, S. Navalon, M. Dančíková, M. Alvaro, H. Garcia, Appl. Catal. B: Environ., 2013, 142-143, 259-267.

[18] A. Dhakshinamoorthy, S. Navalon, D. Sempere, M. Alvaro, H. Garcia, Chem. Commun., 2013, 49, 2359-2361.

[19] American Public Health Association, American Water Works Association, Water Pollution Control Federation, Washington DC, USA (20th ed.), 1999.

[20] R.M. Sellers, Analyst, 1980, 105, 950-954.

[21] T.K. Townsend, E.M. Sabio, N.D. Browning, F.E. Osterloh, Energy Environ. Sci., 2011, 4, 4270-4275.

[22] L.F. Greenlee, J.D. Torrey, R.L. Amaro, J.M. Shaw, Environ. Sci. Technol., 2012, 46, 12913-12920.

[23] S. Basavaraja, D.S. BalajiMahesh, D. Bedre, D. Raghunandan, P.M. Prithviraj Swamy, A. Venkataraman, Bull. Mater. Sci., 2011, 34, 1313-1317.

[24] L. Gianni, J.L. Zweier, A. Levy, C.E. Myers, J. Biol. Chem., 1985, 11, 6820-6826.

[25] O. Allahdin, S.C. Dehou, M. Wartel, P. Recourt, M. Trentesaux, J. Mabingui, A. Boughriete, Chem. Eng. Res. Des., 2013, 91, 27322742.

[26] H. Babich, D.L. Davis, Toxicol. Pharm., 1981, 133, 90-109.

[27] J. Virkutyte, R.S. Varma, Chem. Sci., 2011, 2, 837-846.

[28] M. Haruta, Chem. Rec., 2003, 3, 75-87.

[29] Council Directive 98/83/EC of 3 November 1998 on the quality of water intended for human consumption.

[30] M.C. Biesinger, B.P. Payne, A.P. Grosvenord, L.W.M. Lau, A.R. Gerson, R.S.C. Smart, Appl. Surf. Sci., 2011, 257, 2717-2730.

[31] D.L.A. de Faria, S.V. Silva, M.T. de Oliveira, J. Raman Spectrosc., 1997, 28, 873-878.

[32] D.M. Sherman, Am. Miner., 1985, 70, 1262-1269.

[33] W. Wu, C. Jiang, V.A.L. Roy, Nanoscale, 2015, 7, 38-58.

[34] H.G. Baldoví, B. Ferrer, M. Álvaro, H. García, J. Phys. Chem. C, 2014, 118, 9275-9282. 
Nanopartículas de óxido de hierro soportadas sobre nanopartículas de diamante como catalizador en la reacción de Fenton foto-asistida por luz visible

[35] B.C. Fitzmorris, J.M. Patete, J. Smith, X. Mascorro, S. Adams, S.S. Wong, J.Z. Zhang, ChemSusChem, 2013, 6, 1907-1914.

[36] M. Alvaro, P. Atienzar, A. Corma, B. Ferrer, H. Garcia, M.T. Navarro, J. Phys. Chem. B, 2005, 109, 3696-3700.

[37] M.J. Burkitt, R.P. Mason, Proc. Natl. Acad. Sci. U. S. A., 1991, 8, 8440-8444.

[38] Y. Nosaka, A. Nosaka, ACS Energy Lett., 2016, 1, 356-35. 


\section{Capítulo 6}

\section{Grafenos como carbocatalizadores de la reacción de Fenton}





\subsection{Introducción}

La gran mayoría de procesos químicos a escala industrial son catalíticos y gran parte de ellos usan metales de transición como componentes activos. ${ }^{1}$ Por motivos de sostenibilidad y competitividad, es importante desarrollar catalizadores que estén basados en materiales renovables. La catálisis a base del empleo de materiales de carbono (carbocatálisis) es un campo que ha surgido en los últimos años y que va dirigido al desarrollo de catalizadores libres de metales a base de compuestos y materiales carbonosos. $^{2-4}$ La carbocatálisis se ha beneficiado en gran medida de la disponibilidad de nuevas formas alotrópicas del carbono. ${ }^{3}$ Particularmente teniendo en cuenta su fácil preparación y sus notables propiedades,${ }^{5,6}$ los grafenos están atrayendo un interés creciente como carbocatalizadores. ${ }^{2,3,7}$

En el campo de la carbocatálisis, uno de los retos es demostrar que estos materiales basados en carbono pueden actuar también como catalizadores en reacciones que hasta el momento se consideran que pueden ser promovidas exclusivamente por metales. En el presente capítulo se va a describir que los grafenos en ausencia de cualquier metal son carbocatalizadores altamente eficientes para la reacción de Fenton. Recientemente nuestro grupo ha descrito que nanoescamas de nitruro de boro de unas pocas capas, de alrededor de $20 \mathrm{~nm}$ de tamaño lateral, pueden actuar como catalizador de Fenton, aunque se ha descrito que este material requiere un exceso de 11 equivalentes de $\mathrm{H}_{2} \mathrm{O}_{2}$ para ser eficiente. ${ }^{8}$ El nitruro de boro es isoestructural con el grafeno y, por consiguiente, es también de interés determinar la actividad catalítica de materiales grafénicos para esta reacción. Un precedente relacionado con el presente estudio ha descrito la decoloración del colorante naranja II empleando 200 equivalentes de $\mathrm{H}_{2} \mathrm{O}_{2}$ y utilizando óxido de grafeno reducido ( $\mathrm{rGO}$, de sus siglas en inglés, reduced Graphene Oxide), obtenido por irradiación con rayos gamma proveniente de ${ }^{60} \mathrm{Co}$ del óxido de grafeno ( $\mathrm{GO}$, de sus siglas en inglés, Graphene Oxide), en una disolución acuosa bajo atmósfera de nitrógeno. Se ha descrito que el proceso implica la generación de radicales $\mathrm{HO}^{\circ}$, pero no se ha conseguido todavía ninguna evidencia experimental o espectroscópica que apoye esta propuesta. $^{9}$ 
Como se ha venido comentando en capítulos anteriores, la reacción de Fenton consiste en la generación de radicales hidroxilo por reducción de $\mathrm{H}_{2} \mathrm{O}_{2}$, promovida típicamente por $\mathrm{Fe}^{2+}$ (ecuaciones $6.1 \mathrm{y}$ 6.2). ${ }^{10,11}$ El radical hidroxilo es, después del átomo de flúor, la especie química más oxidante que puede existir en agua y es capaz de atacar prácticamente a cualquier compuesto orgánico. Por ello, la aplicación más común de la reacción de Fenton es la mineralización de contaminantes orgánicos en agua mediante el empleo de un exceso de $\mathrm{H}_{2} \mathrm{O}_{2}$ a $\mathrm{pHs}$ ácidos, empleando como reactivo cantidades estequiométricas de sales de $\mathrm{Fe}^{2+} \cdot 11,12$

$$
\begin{aligned}
& \mathrm{Fe}^{2+}+\mathrm{H}_{2} \mathrm{O}_{2} \longrightarrow \mathrm{Fe}^{3+}+\mathrm{HO}^{+}+\mathrm{HO}^{-} \\
& \mathrm{Fe}^{3+}+\mathrm{H}_{2} \mathrm{O}_{2} \longrightarrow \mathrm{Fe}^{2+}+\mathrm{HOO}^{-} \mathrm{H}^{+}
\end{aligned}
$$

Debido a los crecientes problemas ocasionados por la escasez y baja calidad de las aguas superficiales, los procesos de oxidación avanzada basados en la reacción de Fenton han ido ganando importancia como una de las tecnologías más importantes para el tratamiento de aguas residuales y la mejora de su calidad. El objetivo de esta reacción ha sido el desarrollo de catalizadores que eviten la necesidad de emplear cantidades estequiométricas de sales de $\mathrm{Fe}(\mathrm{II})$ y que a la vez permitan el uso eficiente de $\mathrm{H}_{2} \mathrm{O}_{2} \cdot{ }^{13-15}$ En general, las reacciones de Fenton catalíticas usan excesos muy grandes de $\mathrm{H}_{2} \mathrm{O}_{2}$, comúnmente superior a los 1000 equivalentes con respecto a la cantidad de contaminante. ${ }^{15}$ Sería importante mostrar que los carbocatalizadores en ausencia de cualquier metal pueden promover eficientemente la reacción de Fenton con cantidades cuasi estequiométricas de $\mathrm{H}_{2} \mathrm{O}_{2}$. En el presente capítulo se presentarán datos que demuestran que este objetivo puede conseguirse usando como catalizador rGO. El rGO como catalizador no sufre desactivación, consiguiendo un número de ciclos por centro (TON, de sus siglas en inglés, TurnOver Number) tan alto como 4540 y 15023 para la desaparición del fenol y el consumo de $\mathrm{H}_{2} \mathrm{O}_{2}$, respectivamente. Basados en datos experimentales y cálculos a nivel teórico del funcional de densidad, se propone que los centros activos presentes en el carbocatalizador son subestructuras del tipo quinona/hidroquinona. 


\subsection{Resultados y discusión}

\subsubsection{Preparación y caracterización de materiales}

A fin de cubrir un amplio rango de posibilidades, se preparó una serie de grafenos con el objetivo de evaluar la actividad catalítica como catalizadores de Fenton. La lista incluye $\mathrm{GO}^{16}$ y $\mathrm{rGO}^{17}{ }^{17}$ así como una muestra de grafeno ${ }^{16}$ y un grafeno dopado con nitrógeno, ${ }^{16,18,19}$ obtenidos por pirólisis de alginato y quitosano, respectivamente. Tal como se ha comentado con suficiente detalle anteriormente, los residuos carbonosos grafíticos obtenidos en la pirólisis del quitosano se transforman por exfoliación en un grafeno dopado con nitrógeno. ${ }^{19}$ Además de G y (N)G, se incluyeron en el estudio dos muestras más de grafenos dopados con boro $((\mathrm{B}) \mathrm{G}$ y $(\mathrm{B}, \mathrm{N}) \mathrm{G})$ que se obtienen por pirólisis de los boratos del alginato y quitosano, respectivamente. ${ }^{16} \mathrm{La}$ pirólisis de los ésteres de ácidos inorgánicos de los polisacáridos conduce a la incorporación de elementos dopantes en algunos heteroátomos en la estructura del grafeno. (B)G y (N)G exhiben propiedades opuestas como semiconductores de tipo $\mathrm{p}$ y $\mathrm{n}$ que pueden ser relevantes en el contexto de activación del $\mathrm{H}_{2} \mathrm{O}_{2}{ }^{13-16}$ Todos los materiales basados en grafeno que se estudian en el presente capítulo han sido descritos con anterioridad, habiéndose publicado su caracterización con suficiente detalle. ${ }^{16-19}$ La tabla 6.1 resume la lista de materiales estudiados en este capítulo, sus precursores correspondientes y sus composiciones elementales. Aunque los materiales grafénicos han sido obtenidos a partir de precursores diferentes y los procedimientos de preparación podrían influir su comportamiento catalítico más allá de su composición, se espera que las diferencias que se observen en el comportamiento catalítico se correlacionen fundamentalmente con la presencia de elementos dopantes en la estructura de grafeno. Las propiedades espectroscópicas de los grafenos, particularmente los espectros de raman y de XPS, así como la cristalinidad de los materiales a nivel microscópico y su configuración de monocapa en suspensiones acuosas, determinada por AFM, son coincidentes con los datos ya publicados para estos materiales. ${ }^{16-19}$

Así, todos los materiales presentan en espectroscopía raman las bandas $2 \mathrm{D}, \mathrm{G}$ y $\mathrm{D}$ con una relación de intensidades entre los picos $\mathrm{G} / \mathrm{D}$ entre 1.3 y 1.6 tal como se muestra en la figura 6.1. La técnica de XPS muestra la presencia de los elementos dopantes esperados, permitiendo la determinación de sus porcentajes tal como se indica en la tabla 6.1 , y se 
muestra en las figuras 6.2 a 6.7. Además el análisis de los picos de C1s y $\mathrm{N} 2 \mathrm{p}$ indica para estos elementos la proporción de los tipos de átomos presentes en la muestra. La microscopia electrónica de transmisión confirma la alta cristalinidad de las muestras, como se puede observar en la figura 6.8. La configuración de monocapa de los grafenos dopados en las condiciones de reacción se confirma midiendo en AFM la altura vertical de las capas de los materiales grafénicos. La figura 6.9 presenta algunas de estas medidas.

\begin{tabular}{|c|c|c|c|c|}
\hline \multirow[b]{2}{*}{ Material } & \multirow[b]{2}{*}{ Precursores } & \multicolumn{3}{|l|}{ Componentes } \\
\hline & & C1s & B1s & N1s \\
\hline G & Alginato & $\begin{array}{lc}\left(\mathrm{CC}_{3}\right)^{\mathrm{a}} & 89.1 \\
\left(\mathrm{CC}_{2} \mathrm{O}\right)^{\mathrm{b}} & 10.9\end{array}$ & - & - \\
\hline (B)G & $\begin{array}{l}\text { Alginato + ácido } \\
\text { bórico }\end{array}$ & $\begin{array}{ll}\left(\mathrm{CC}_{3}\right) & 86.2 \\
\left(\mathrm{CC}_{2} \mathrm{O}\right) & 12.4 \\
\end{array}$ & $\left(\mathrm{BC}_{3}\right)^{\mathrm{d}} 1.2$ & - \\
\hline$(\mathrm{N}) \mathrm{G}$ & Quitosano & $\begin{array}{ll}\left(\mathrm{CC}_{3}\right) & 64.2 \\
\left(\mathrm{CC}_{2} \mathrm{~N}\right)^{\mathrm{c}} & 31.4 \\
\end{array}$ & - & $\begin{array}{ll}\left(\mathrm{NC}_{3}\right)^{\mathrm{e}} & 1.7 \\
\left(\mathrm{NC}_{2}\right)^{\mathrm{f}} & 1.6\end{array}$ \\
\hline$(\mathrm{B}, \mathrm{N}) \mathrm{G}$ & $\begin{array}{l}\text { Quitosano + ácido } \\
\text { bórico }\end{array}$ & $\begin{array}{ll}\left(\mathrm{CC}_{3}\right) & 51.2 \\
\left(\mathrm{CC}_{2} \mathrm{~N}\right) & 39.4 \\
\end{array}$ & $\begin{array}{ll}\left(\mathrm{BC}_{3}\right) & 3.0\end{array}$ & $\begin{array}{ll}\left(\mathrm{NC}_{3}\right) & 1.3 \\
\left(\mathrm{NC}_{2}\right) & 5.0\end{array}$ \\
\hline GO & $\begin{array}{l}\text { Método Hummers } \\
\text { del grafito }\end{array}$ & $\begin{array}{lr}\left(\mathrm{CC}_{3}\right) & 13.4 \\
\left(\mathrm{CC}_{2} \mathrm{O}\right) & 40.3 \\
\left(\mathrm{CCO}_{2}\right) & 43.9 \\
\left(\mathrm{CO}_{3}\right) & 2.5 \\
\end{array}$ & & \\
\hline $\mathrm{rGO}$ & $\begin{array}{l}\text { Reducción } \\
\text { térmica del GO }\end{array}$ & $\begin{array}{ll}\left(\mathrm{CC}_{3}\right) & 74.2 \\
\left(\mathrm{CC}_{2} \mathrm{O}\right) & 13.8 \\
\left(\mathrm{CCO}_{2}\right) & 12.0 \\
\end{array}$ & & \\
\hline $\begin{array}{l}{ }^{\mathrm{a}} \text { Carbono } \\
\text { Boro graf }\end{array}$ & $\begin{array}{l}\text { afítico; }{ }^{\mathrm{b}} \text { Carbo } \\
\text { o; }{ }^{\mathrm{e}} \text { Nitrógeno }\end{array}$ & $\begin{array}{l}\text { ido a Oxígeno; } \\
\text { ico; }{ }^{\mathrm{f}} \text { Nitrógeno }\end{array}$ & $\begin{array}{l}\text { Carbono uni } \\
\text { iridínico }\end{array}$ & a Nitrógeno; \\
\hline
\end{tabular}



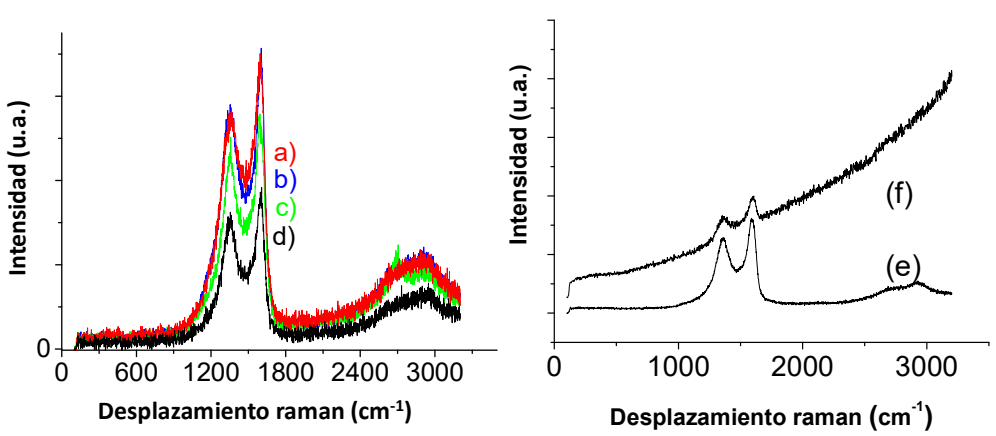

Figura 6.1. Espectro raman del (N)G (a), G (b), (B)G (c), (B,N)G (d), rGO (e) y GO (f).

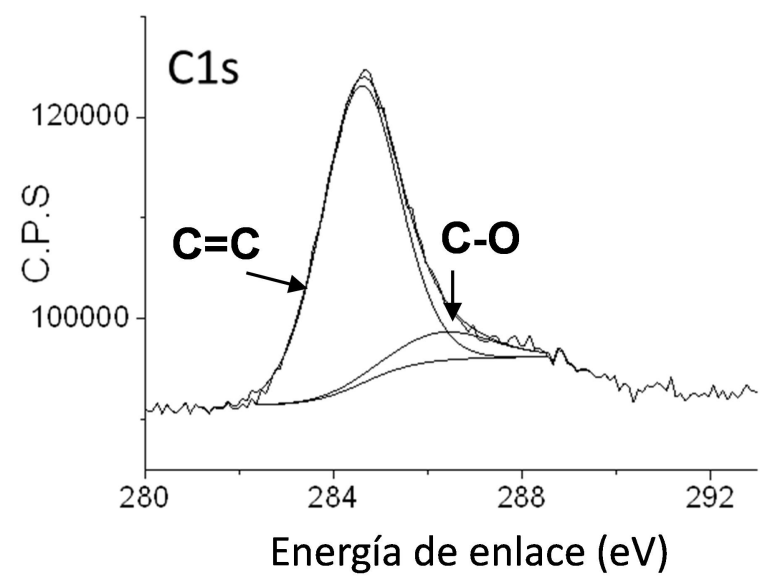

Figura 6.2. Espectro de XPS para una muestra de G junto con la deconvolución individual de los picos $\mathrm{C} 1 \mathrm{~s}$. 


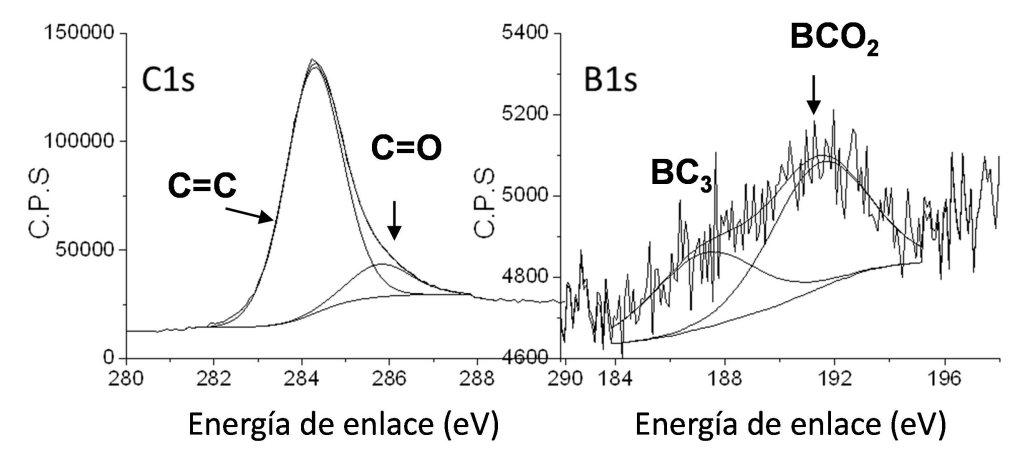

Figura 6.3. Espectro de XPS para una muestra de (B)G junto con la deconvolución individual de sus componentes.
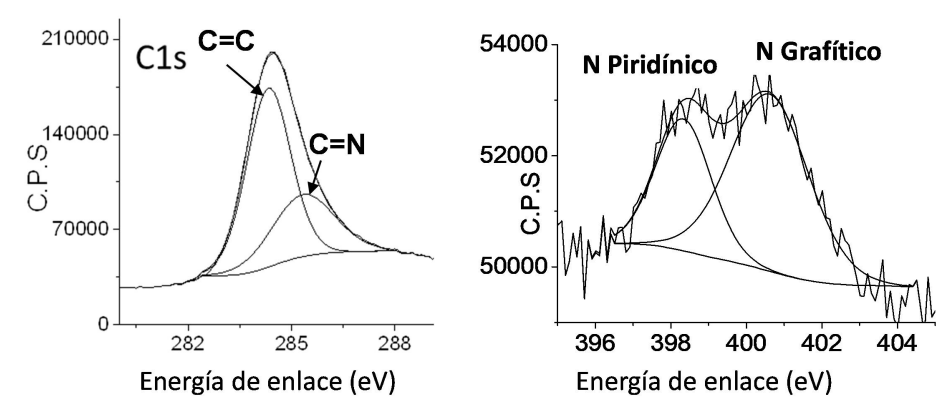

Figura 6.4. Espectro de XPS para una muestra de $(\mathrm{N}) \mathrm{G}$ junto con la deconvolución individual de sus componentes.

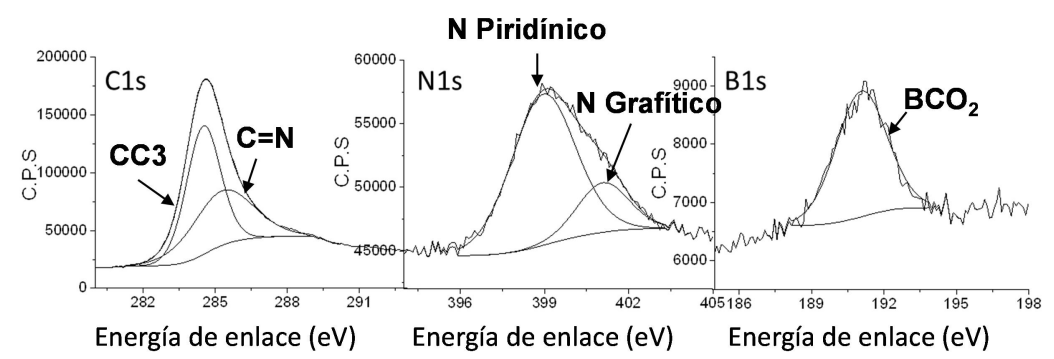

Figura 6.5. Espectro de XPS para una muestra de $(B, N) G$ junto con la deconvolución individual de sus componentes. 


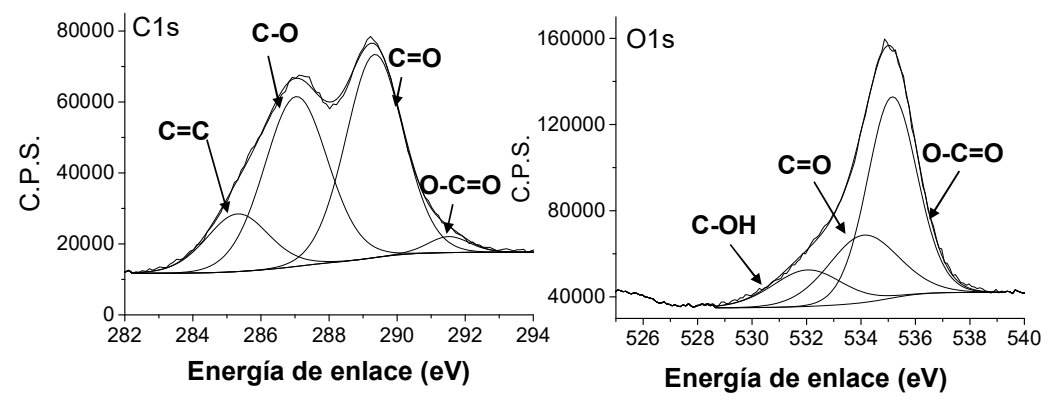

Figura 6.6. Espectro de XPS para una muestra de GO junto con la deconvolución individual de sus componentes.
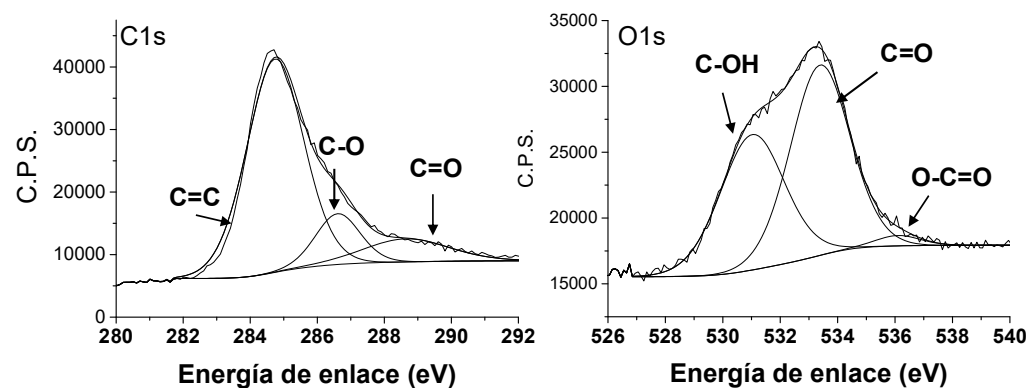

Figura 6.7. Espectro de XPS para una muestra de rGO junto con la deconvolución individual de sus componentes.

a)

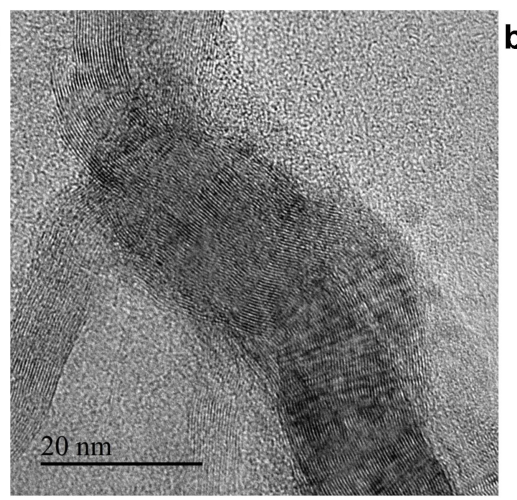

b)

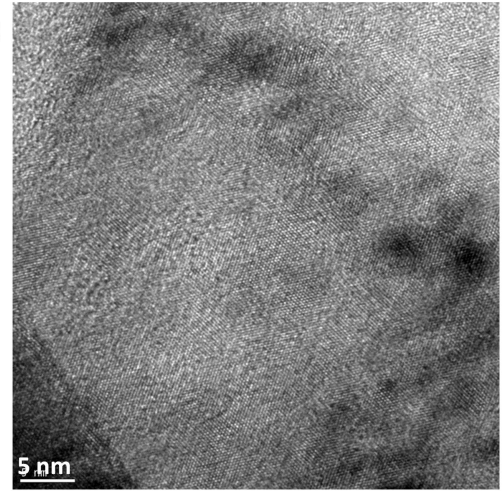

Figura 6.8. Imágenes de TEM en las que se muestra la alta cristalinidad de una muestra de rGO (a) y una muestra de (N)G (b). 


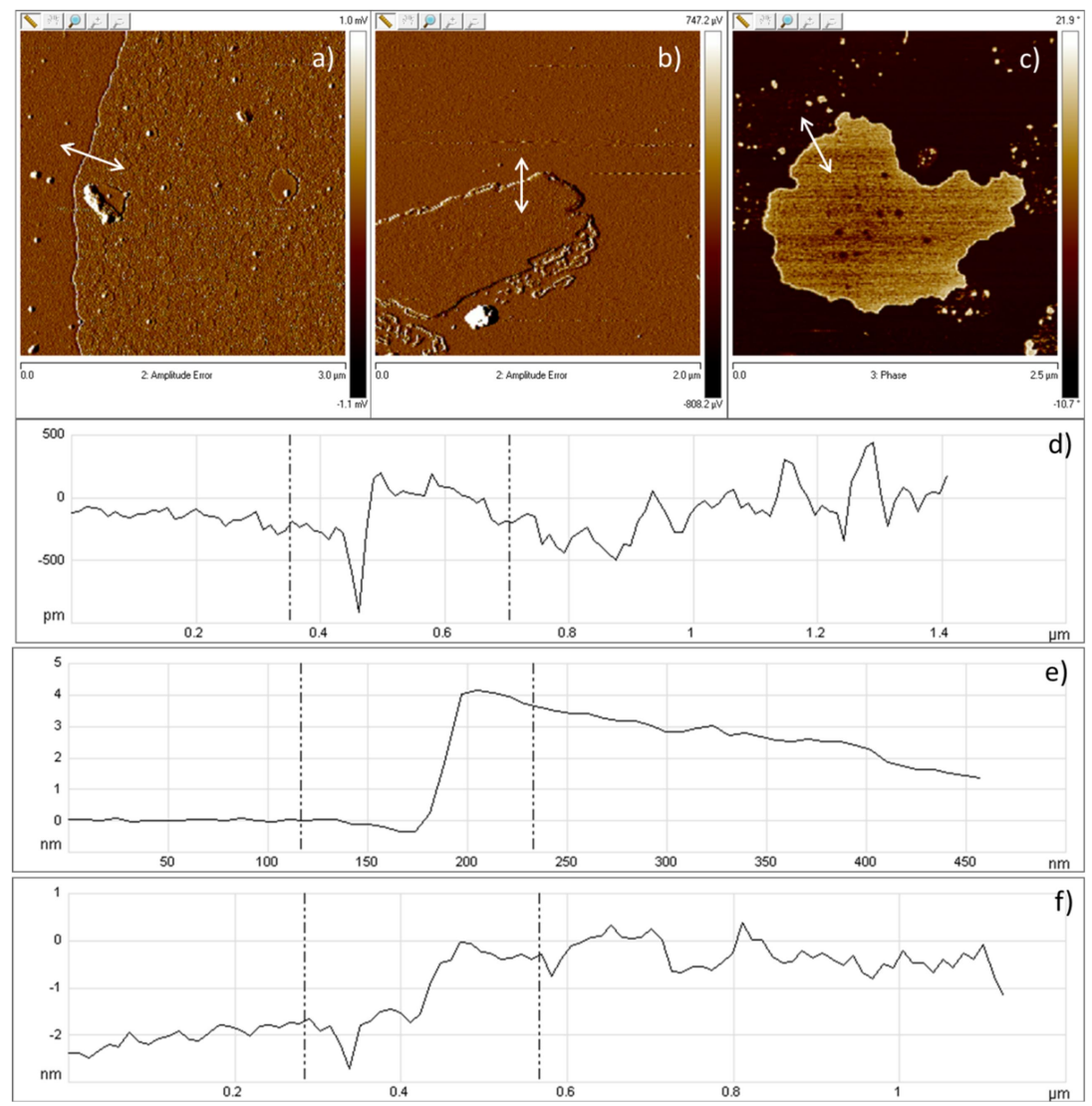

Figura 6.9. Imágenes de $A F M$ del $(B) G(a), G(b)$ y $(B, N) G(c)$. Las gráficas $\mathrm{d}$, e, y f muestran las variaciones de altura a lo largo de las líneas blancas indicadas en las imágenes a, b y c, respectivamente.

A efectos de comparación, el estudio del presente capítulo incluye además muestras comerciales de grafito y de nanotubos de carbono de pared múltiple (MWCNTs, de sus siglas en inglés, Multi Walled Carbon Nanotubes), así como MWCNTs purificados y sometidos a acortamiento químico. Estos materiales no grafénicos basados principalmente en carbono se ensayaron igualmente como catalizadores de Fenton. La tabla 6.2 resume las propiedades más relevantes de estos materiales y la figura 6.10 presenta algunos datos de caracterización importantes. 


\begin{tabular}{|c|c|c|c|c|}
\hline \multirow[t]{2}{*}{ Material } & \multirow[t]{2}{*}{ Procedencia } & \multirow[t]{2}{*}{ Características } & \multicolumn{2}{|c|}{$\begin{array}{l}\text { Ratio molar de carbono } \\
\text { a hidrógeno y de } \\
\text { carbono a oxígeno }\end{array}$} \\
\hline & & & $\mathrm{C} / \mathrm{H}$ & $\mathrm{C} / \mathrm{O}$ \\
\hline $\begin{array}{l}\text { Carbón } \\
\text { activo }\end{array}$ & Sigma Aldrich & $\begin{array}{l}\text { Norit SX ultra, activado con } \\
\text { vapor y lavado con ácido, } \\
\text { altamente purificado, muestra } \\
\text { en polvo. }\end{array}$ & - & - \\
\hline Grafito & Sigma Aldrich & $\begin{array}{l}\text { Muestra en polvo, tamaño de } \\
\text { partícula inferior a } 20 \mathrm{~nm} .\end{array}$ & - & - \\
\hline MWCNTs & NanoAmor & $\begin{array}{l}\text { 10-20 nm de diámetro, } 10-30 \\
\mu \mathrm{m} \text { de longitude, } 95 \% \text { pureza, } \\
200-350 \mathrm{~m}^{2} \mathrm{~g}^{-1} \text {, trazas de } \\
\text { partículas metálicas }\end{array}$ & 58.4 & 77.0 \\
\hline $\begin{array}{l}\text { MWCNTs- } \\
\mathrm{HNO}_{3}\end{array}$ & $\begin{array}{l}\text { MWCNTs } \\
\text { purificados }\end{array}$ & $\begin{array}{l}\text { Ausencia de partículas } \\
\text { metálicas }\end{array}$ & 29.9 & 11.6 \\
\hline $\begin{array}{l}\text { MWCNTs- } \\
\mathrm{HNO}_{3} / \mathrm{H} 2 \mathrm{SO}_{4}\end{array}$ & $\begin{array}{l}\text { MWCNTs } \\
\text { acortados }\end{array}$ & Tubos más cortos & 23.8 & 11.0 \\
\hline
\end{tabular}
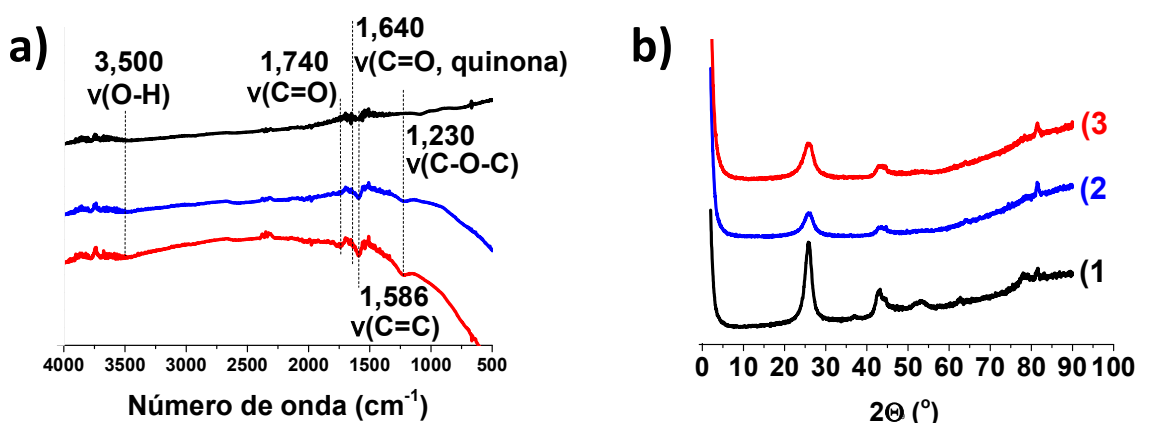

Figura 6.10. Espectro de ATR-FTIR (a) y difracción de rayos X (b) de una muestra de MWCNTs comercial (1, en negro), MWCNTs tratados con $\mathrm{HNO}_{3}$ (2, en azul) y MWCNTs tratados con $\mathrm{HNO}_{3} / \mathrm{H}_{2} \mathrm{SO}_{4}$ (3, en rojo). 


\subsubsection{Actividad catalítica}

A fin de evaluar la actividad de los materiales grafénicos como carbocatalizadores para la reacción de Fenton se eligió el fenol como molécula sonda, determinando su desaparición con el tiempo empleando en la mayoría de los casos 5.5 equivalentes de $\mathrm{H}_{2} \mathrm{O}_{2}$ como oxidante. Además de la desaparición del fenol, se siguió igualmente los perfiles temporales del consumo de $\mathrm{H}_{2} \mathrm{O}_{2}$ para cada reacción. Existen abundantes ejemplos en la literatura donde se utiliza el fenol como molécula sonda para evaluar la actividad catalítica de catalizadores conteniendo metales. La principal diferencia en el presente estudio es el bajo exceso de $\mathrm{H}_{2} \mathrm{O}_{2}$ (5.5 equivalentes). ${ }^{13-15}$ El perfil temporal de la reacción dependió de la naturaleza del catalizador grafénico. Las figuras 6.11 y 6.12 muestran estos perfiles temporales. Experimentos de adsorción de fenol llevados a cabo independientemente demuestran que los materiales $G$ y carbón activo son los que poseen la mayor capacidad de adsorción (alrededor del $30 \%)$, seguido por rGO (20\%), mientras que la adsorción sobre materiales dopados con boro y/o nitrógeno y el GO presentan una capacidad de adsorción baja $(<10 \%)$, figura 6.13$)$. Los valores de adsorción medidos se correlacionan con la intensidad de las fuerzas intermoleculares $\pi-\pi$ entre el fenol y el material adsorbente, así como con la dispersabilidad de los materiales en agua. En el caso de G, AC y rGO, la combinación de la presencia de grupos funcionales oxigenados y el carácter aromático de los materiales, permite una notable dispersabilidad de estos sólidos en agua y muestran una adsorción de fenol significativa. ${ }^{20}$ En contraste, el carácter hidrofóbico de $\mathrm{G}$ dopado con $\mathrm{B}$ o $\mathrm{N}$ hace más difícil la dispersabilidad en agua de los mismos y, por consiguiente, la adsorción de fenol. En contraste, $\mathrm{GO}$, con una alta población de grupos funcionales oxigenados (contenido en $\mathrm{O}$ entorno al 50\% en peso) se dispersa muy bien en agua, pero su elevada hidrofilicidad hace la adsorción de fenol difícil. Además, un control en ausencia de cualquier catalizador mostró que ni el fenol ni el $\mathrm{H}_{2} \mathrm{O}_{2}$ se descomponen por sí mismos, para los mismos tiempos de reacción, tal como muestra la figura 6.13. Igualmente, un control sobre la degradación de fenol en presencia de $\mathrm{G}$ pero en ausencia de $\mathrm{H}_{2} \mathrm{O}_{2}$ indica que éste no sufre conversión alguna en estas condiciones. 

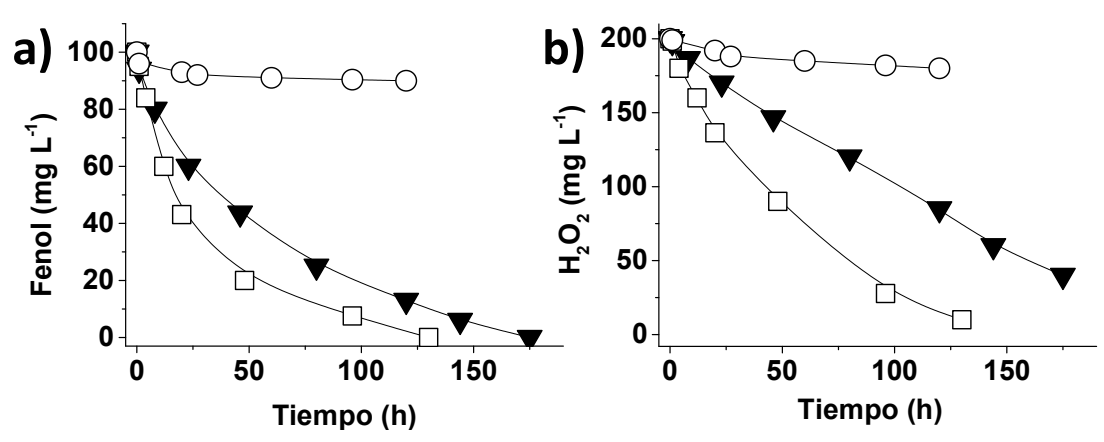

Figura 6.11. Perfiles temporales de degradación de fenol (a) y consumo de $\mathrm{H}_{2} \mathrm{O}_{2}$ (b) usando catalizadores grafénicos. Leyenda: $\mathrm{G}(\square)$, rGO ( $\left.\boldsymbol{\nabla}\right)$ y GO (०). Condiciones de reacción: catalizador $\left(5 \mathrm{mg}, 200 \mathrm{mg} \mathrm{L}^{-1}\right)$, fenol (100 mg $\left.\mathrm{L}^{-1}, 1.06 \mathrm{mM}\right), \mathrm{H}_{2} \mathrm{O}_{2}\left(200 \mathrm{mg} \mathrm{L}^{-1}, 5.88 \mathrm{mM}\right), \mathrm{pH} \mathrm{3}$, temperatura $20^{\circ} \mathrm{C}$. Concentración de fenol obtenida por HPLC y de $\mathrm{H}_{2} \mathrm{O}_{2}$ por espectrofotometría, como se indica en el capítulo 8 , sección experimental.
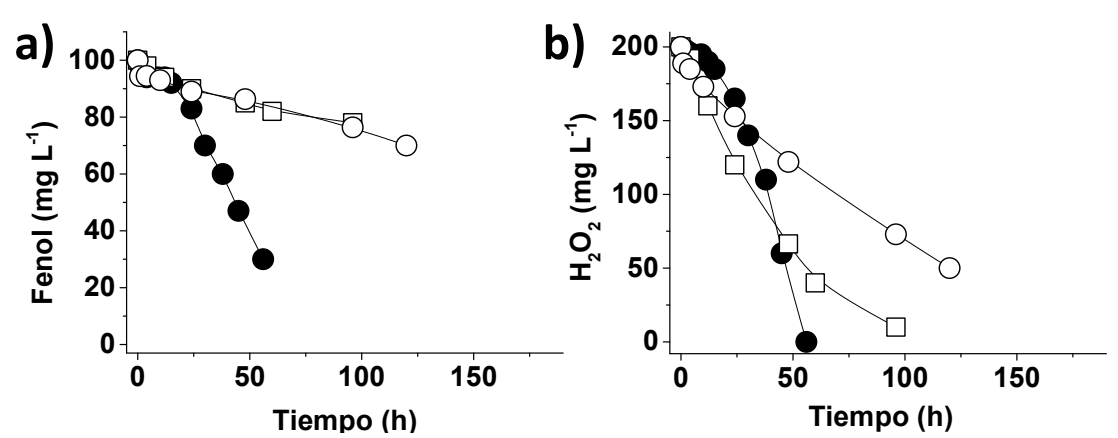

Figura 6.12. Perfiles temporales de degradación de fenol (a) y consumo de $\mathrm{H}_{2} \mathrm{O}_{2}$ (b) usando catalizadores grafénicos. Leyenda: (B)G $(\bullet)$, (N)G (口) y $(\mathrm{B}, \mathrm{N}) \mathrm{G}(\mathrm{\circ})$. Condiciones de reacción: catalizador $\left(5 \mathrm{mg}, 200 \mathrm{mg} \mathrm{L}^{-1}\right)$, fenol (100 mg L $\left.\mathrm{m}^{-1}, 1.06 \mathrm{mM}\right), \mathrm{H}_{2} \mathrm{O}_{2}\left(200 \mathrm{mg} \mathrm{L}^{-1}, 5.88 \mathrm{mM}\right), \mathrm{pH} \mathrm{3}$, temperatura 20 ${ }^{\circ} \mathrm{C}$. Concentración de fenol obtenida por HPLC y de $\mathrm{H}_{2} \mathrm{O}_{2}$ por espectrofotometría, como se indica en el capítulo 8 , sección experimental. 
a)
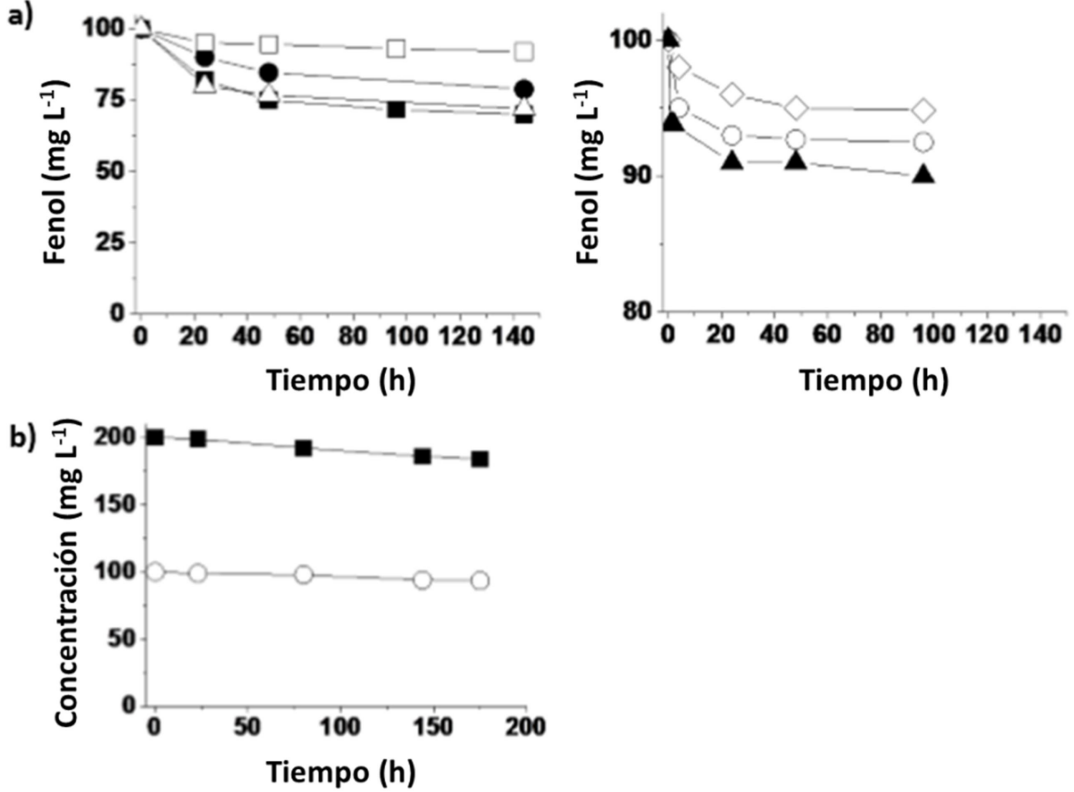

Figura 6.13. Experimentos de adsorción de fenol (a) empleando como

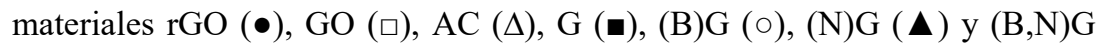
$(\diamond)$. Condiciones de adsorción: fenol $\left(100 \mathrm{mg} \mathrm{L}^{-1}\right)$, material carbonoso (5 $\left.\mathrm{mg}, 200 \mathrm{mg} \mathrm{L}^{-1}\right), \mathrm{pH} 3,20^{\circ} \mathrm{C}$. b) Experimento de control en ausencia de catalizador para la degradación de fenol (०) y la descomposición de $\mathrm{H}_{2} \mathrm{O}_{2}$ (匹). Condiciones de reacción: fenol (100 mg L $\left.{ }^{-1}, 1.06 \mathrm{mM}\right), \mathrm{H}_{2} \mathrm{O}_{2}(200 \mathrm{mg}$ $\left.\mathrm{L}^{-1}, 5.88 \mathrm{mM}\right), \mathrm{pH} 3$, temperatura $20^{\circ} \mathrm{C}$. Concentración de fenol obtenida por HPLC, como se indica en el capítulo 8, sección experimental.

De acuerdo con los resultados indicados en la tabla 6.3 , el orden de actividad de los carbocatalizadores evaluados fue $\mathrm{G} \approx \mathrm{rGO}>(\mathrm{B}) \mathrm{G}>$ $(\mathrm{B}, \mathrm{N}) \mathrm{G}>(\mathrm{N}) \mathrm{G}>\mathrm{GO}$. Puesto que la actividad catalítica de estas muestras de grafeno corresponde a suspensiones monocapa o de unas pocas capas, este orden no es probablemente debido a diferencias en área superficial, sino que más probablemente sea debido a la presencia de un número diferente de centros activos. 


\begin{tabular}{|c|c|c|c|c|c|c|c|}
\hline $\begin{array}{l}\text { Carbo- } \\
\text { catalizador }\end{array}$ & $\begin{array}{l}\text { Conversión } \\
\text { de fenol } \\
(\%)\end{array}$ & $\begin{array}{l}\text { Conversión } \\
\text { de } \mathrm{H}_{2} \mathrm{O}_{2} \\
(\%)\end{array}$ & $\begin{array}{l}\mathbf{r}_{0} \text { fenol } \\
(\mathrm{mM} / \mathrm{h})\end{array}$ & $\begin{array}{l}\mathbf{r}_{0} \mathrm{H}_{2} \mathrm{O}_{2} \\
(\mathrm{mM} / \mathrm{h})\end{array}$ & $\begin{array}{l}\text { Ratio } \\
\text { molar } \\
\mathrm{H}_{2} \mathrm{O}_{2^{-}} \\
\text {fenol }^{\mathbf{b}}\end{array}$ & $\begin{array}{l}\text { Ea } \\
\text { fenol } \\
(\mathrm{kJ} \\
\left.\mathrm{mol}^{-1}\right)^{\mathrm{c}}\end{array}$ & $\begin{array}{l}\mathrm{Ea} \\
\mathrm{H}_{2} \mathrm{O}_{2} \\
(\mathrm{~kJ} \\
\left.\mathrm{mol}^{-1}\right)^{\mathrm{c}}\end{array}$ \\
\hline G & 100 & 95 & 0.042 & 0.147 & 5.2 & 31 & 31 \\
\hline rGO & 100 & 80 & 0.038 & 0.146 & 4.3 & 30 & 30 \\
\hline (B)G & 70 & 100 & 0.030 & 0.090 & 7.9 & 34 & 28 \\
\hline$(\mathbf{N}, \mathbf{B}) \mathbf{G}$ & 49 & 100 & 0.023 & 0.170 & 15.1 & 38 & 24 \\
\hline$(\mathbf{N}) G$ & 18 & 100 & 0.011 & 1.765 & 23.9 & 39 & 18 \\
\hline GO & 7 & 3 & 0.002 & 0.009 & 5.5 & 54 & 48 \\
\hline
\end{tabular}

[a] Condiciones de reacción: catalizador $\left(200 \mathrm{mg} \mathrm{L}^{-1}\right)$, fenol $\left(100 \mathrm{mg} \mathrm{L}^{-1}, 1.06 \mathrm{mM}\right)$, $\mathrm{H}_{2} \mathrm{O}_{2}\left(200 \mathrm{mg} \mathrm{L}^{-1}, 5.88 \mathrm{mM}\right), \mathrm{pH} 3$, temperatura $20^{\circ} \mathrm{C}$, tiempo de reacción indicado en las figuras 6.11 y 6.12 ; [b] medido a tiempo final de reacción de hasta 150 horas; [c] determinado a partir del gráfico de Arrhenius correspondiente.

Para los mejores catalizadores ( $\mathrm{G}$ y rGO), los perfiles temporales de desaparición de fenol y consumo de $\mathrm{H}_{2} \mathrm{O}_{2}$ coinciden, indicando que el $\mathrm{H}_{2} \mathrm{O}_{2}$ se consume exclusivamente en la degradación del fenol y no en la descomposición espuria de este reactivo. En el otro extremo, la muestra (N)G descompone el $\mathrm{H}_{2} \mathrm{O}_{2}$ a una velocidad mucho mayor que la desaparición de fenol $\left(r_{0}\left(\mathrm{H}_{2} \mathrm{O}_{2}\right) / r_{0}(\right.$ fenol $)=160$ para la muestra de $\left.(\mathrm{N}) \mathrm{G}\right)$, indicando que en este caso otros procesos además de la reacción de Fenton están teniendo lugar, como ocurre en la gran mayoría de 
catalizadores metálicos descritos hasta ahora (tabla 6.3). ${ }^{13-15}$ La falta de actividad catalítica de la muestra GO es destacable e indica que los grupos funcionales oxigenados presentes en GO no pueden actuar como centros activos de la reacción. Existen descritos en la bibliografía modelos de GO compatibles con los datos de análisis químico y de espectroscopía para RMN ${ }^{13} \mathrm{C}$, IR y XPS de este material, que muestran que el contenido de oxígeno extremo en este caso determina la presencia de ácidos carboxílicos, epóxidos, cetonas y otros grupos funcionales oxigenados con una casi completa ausencia de aromaticidad y enlaces dobles $\mathrm{C}=\mathrm{C}$ conjugados. ${ }^{6,21}$

En el caso de (B)G, la desaparición de fenol exhibe un período de inducción, no tan acusado para el consumo de $\mathrm{H}_{2} \mathrm{O}_{2}$ (ver las figuras 6.12 y 6.14) que es atribuible al lixiviado de $\mathrm{B}$, como revela el análisis por ICP de la disolución. Estos datos cinéticos están, por otra parte, de acuerdo con los datos teóricos mostrados en la figura 6.14 y 6.15. Considerando los datos catalíticos, la muestra de rGO es la más conveniente y el carbocatalizador más eficiente en la reacción de Fenton.

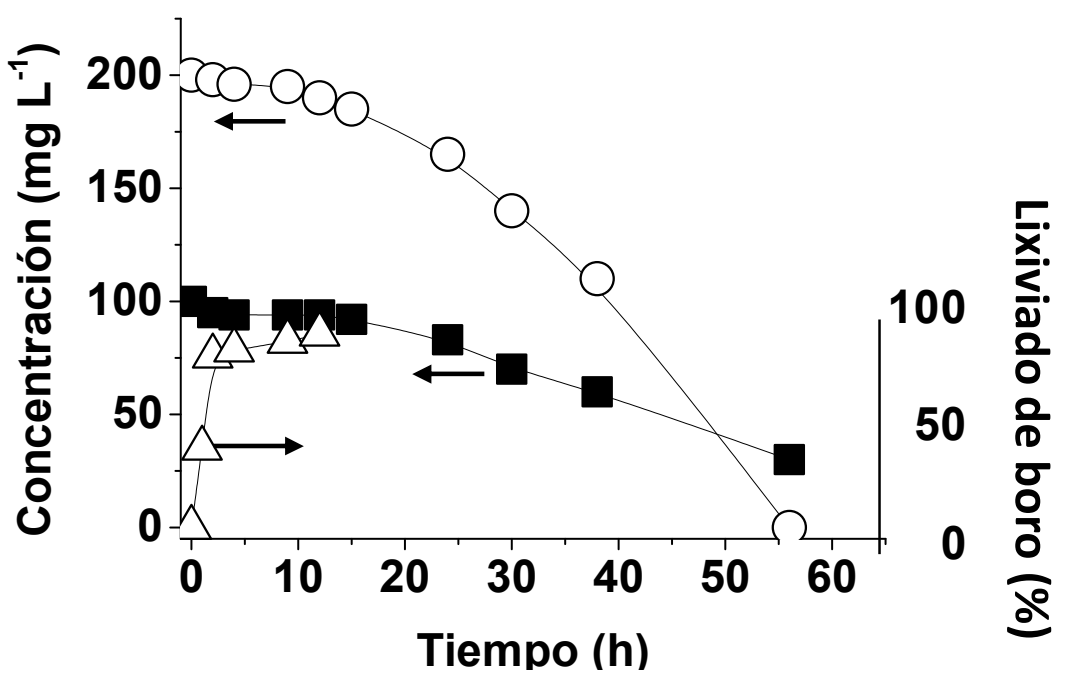

Figura 6.14. Degradación de fenol y descomposición de $\mathrm{H}_{2} \mathrm{O}_{2}$ utilizando (B)G como catalizador. Leyenda: concentración de fenol (घ), consumo de $\mathrm{H}_{2} \mathrm{O}_{2}(\mathrm{O})$ y porcentaje de lixiviado de boro $(\Delta)$. Condiciones de reacción: catalizador (5 mg, $200 \mathrm{mg} \mathrm{L}^{-1}$ ), fenol (100 mg L $\left.\mathrm{m}^{-1}, 1.06 \mathrm{mM}\right), \mathrm{H}_{2} \mathrm{O}_{2}(200 \mathrm{mg}$ $\left.\mathrm{L}^{-1}, 5.88 \mathrm{mM}\right), \mathrm{pH} 3$, temperatura $20{ }^{\circ} \mathrm{C}$. Concentración de fenol obtenida por HPLC, como se indica en el capítulo 8, sección experimental. 


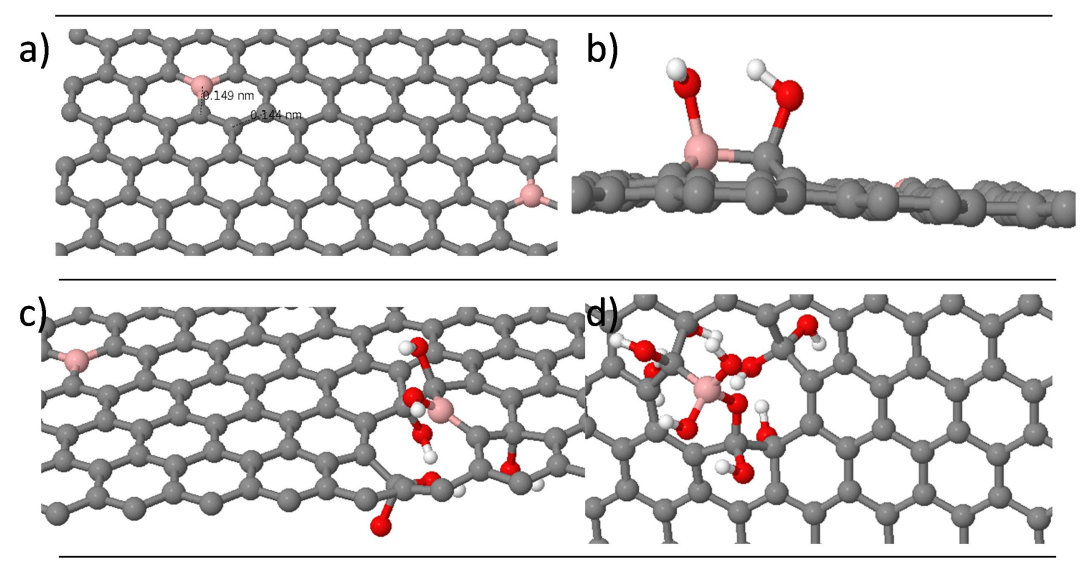

Figura 6.15. a) Estructura de (B)G usada en cálculo teórico, donde los átomos de color gris representan los átomos de carbono y los de color rosa al boro; b) Estructura del (B)G tras la absorción de una molécula de $\mathrm{H}_{2} \mathrm{O}_{2}$; c) Estructura tras la absorción de tres moléculas de $\mathrm{H}_{2} \mathrm{O}_{2}$, en la cual se debería producir la rotura del enlace C-B; d) Absorción de una quinta molécula de $\mathrm{H}_{2} \mathrm{O}_{2}$, produciendo la rotura del segundo enlace C-B.

El análisis de los productos de descomposición de fenol indica la formación de hidroquinona, catecol y $p$-benzoquinona (esquema 6.1). De acuerdo con el mecanismo aceptado para la reacción de Fenton, un equivalente de Fenol consumiría un equivalente de radicales $\mathrm{HO}^{\circ}$ para formar catecol e hidroquinona y, entonces, al menos dos equivalentes más para formar $p$-benzoquinona y ácidos dicarboxílicos. Por consiguiente, el consumo mínimo de $\mathrm{H}_{2} \mathrm{O}_{2}$ por mol de fenol descompuesto sería de 3 equivalentes. Las gráficas de conversión frente a tiempo para la desaparición de fenol y consumo de $\mathrm{H}_{2} \mathrm{O}_{2}$ con rGO como catalizador (figura 6.11) indican que se trata de un catalizador muy eficiente, con una relación $r_{0}\left(\mathrm{H}_{2} \mathrm{O}_{2}\right) / r_{0}(\mathrm{fenol})=3.8$, lo que indica que al menos el $79 \%$ del $\mathrm{H}_{2} \mathrm{O}_{2}$ descompone generando radicales $\mathrm{HO}^{\circ}$ (figura 6.16). Más aun, usando rGO como catalizador una relación molar $\mathrm{H}_{2} \mathrm{O}_{2} /$ fenol de 5.5 es suficiente para producir la degradación completa de fenol y la de sus intermedios de mayor toxicidad, a saber, hidroquinona, $p$-benzoquinona y catecol (ver figuras 6.17 a 6.19). Experimentos adicionales con hidroquinona y catecol como material de partida fueron igualmente llevados a cabo. Como era de esperar estos dihidroxibencenos isoméricos sufren también degradación en las condiciones de reacción empleadas en 
el presente capítulo (ver nota a pie de tabla en la tabla 6.3 y leyenda de la figura 6.19).

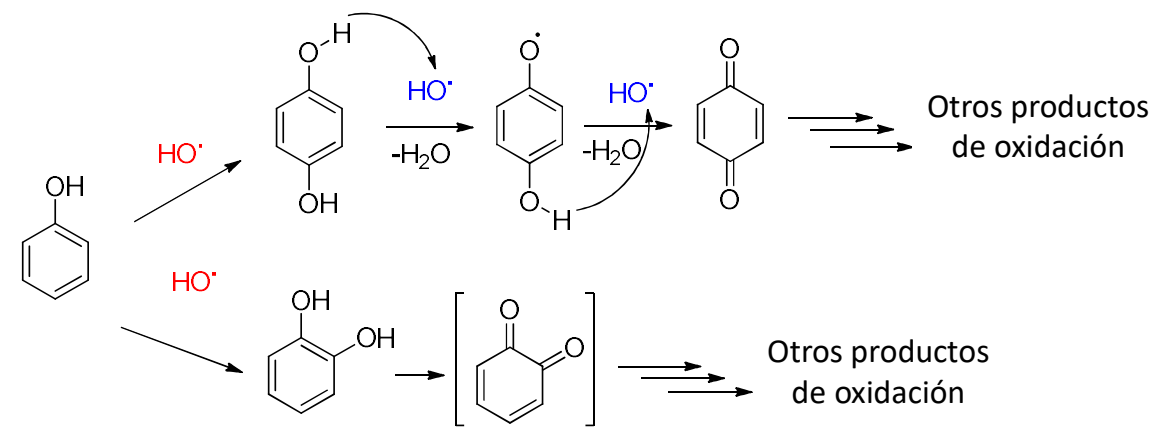

HO como electrófilo HO como agente secuestrador de hidrógeno

Esquema 6.1. Mecanismo de degradación del fenol por radicales hidroxilo.

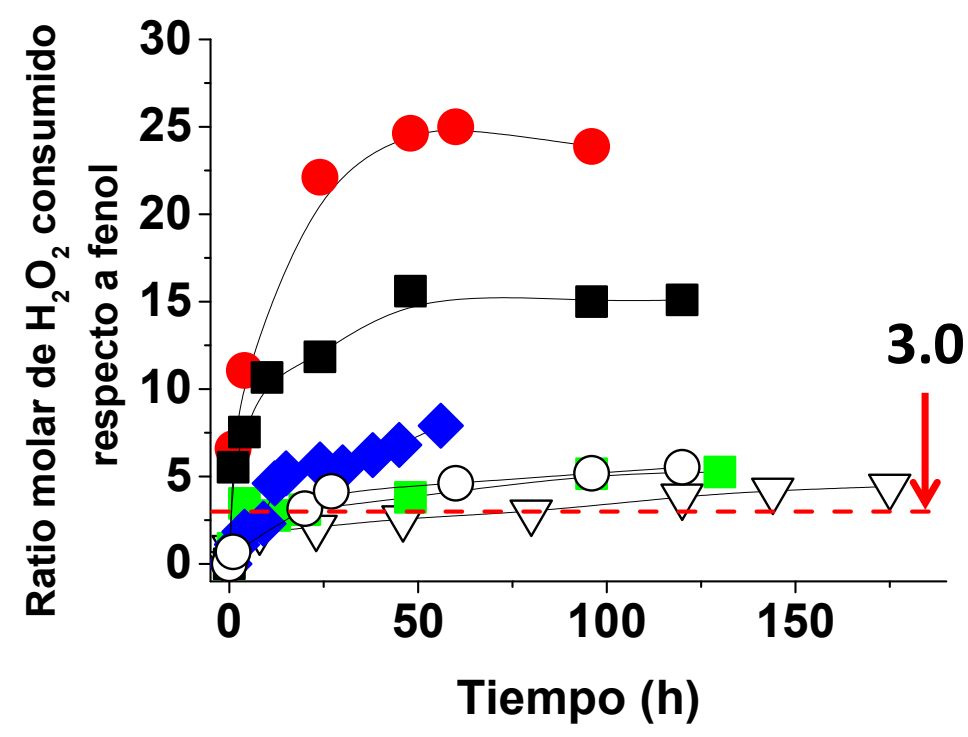

Figura 6.16. Perfil temporal del ratio molar de $\mathrm{H}_{2} \mathrm{O}_{2}$ consumido con respecto al fenol degradado utilizando los diferentes materiales grafénicos descritos como carbocatalizadores. Leyenda: $(\mathrm{N}) \mathrm{G}(\bullet$, en rojo), (N,B)G $(\boldsymbol{\bullet}),(\mathrm{B}) \mathrm{G}(\diamond$, en azul), GO (०), G ( $\square$, en verde) y rGO $(\nabla)$. Condiciones de reacción: catalizador (5 mg, $\left.200 \mathrm{mg} \mathrm{L}^{-1}\right)$, fenol (100 mg L-1, $\left.1.06 \mathrm{mM}\right), \mathrm{H}_{2} \mathrm{O}_{2}(200 \mathrm{mg}$ $\left.\mathrm{L}^{-1}, 5.88 \mathrm{mM}\right), \mathrm{pH} 3$, temperatura $20{ }^{\circ} \mathrm{C}$. Concentración de fenol obtenida por HPLC y de $\mathrm{H}_{2} \mathrm{O}_{2}$ por espectrofotometría, como se indica en el capítulo 8, sección experimental. 

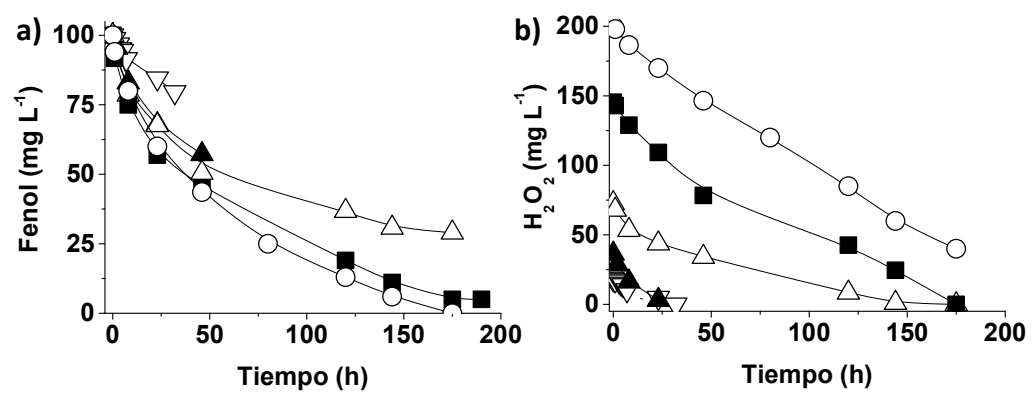

Figura 6.17. Perfiles temporales de degradación de fenol (a) y consumo de $\mathrm{H}_{2} \mathrm{O}_{2}$ (b) usando rGO como catalizador. Leyenda: Ratio molar de $\mathrm{H}_{2} \mathrm{O}_{2}$ respecto a fenol de $0.5(\nabla), 1.0(\mathbf{\Delta}), 2.0(\Delta), 4.0(\mathbf{\bullet})$ y $5.5(\circ)$. Condiciones de reacción: catalizador $\left(5 \mathrm{mg}, 200 \mathrm{mg} \mathrm{L}^{-1}\right)$, fenol $\left(100 \mathrm{mg} \mathrm{L}^{-1}, 1.06 \mathrm{mM}\right)$, $\mathrm{H}_{2} \mathrm{O}_{2}$ según se indica, pH 3, temperatura $20{ }^{\circ} \mathrm{C}$. Concentración de fenol obtenida por HPLC y de $\mathrm{H}_{2} \mathrm{O}_{2}$ por espectrofotometría, como se indica en el capítulo 8 , sección experimental.

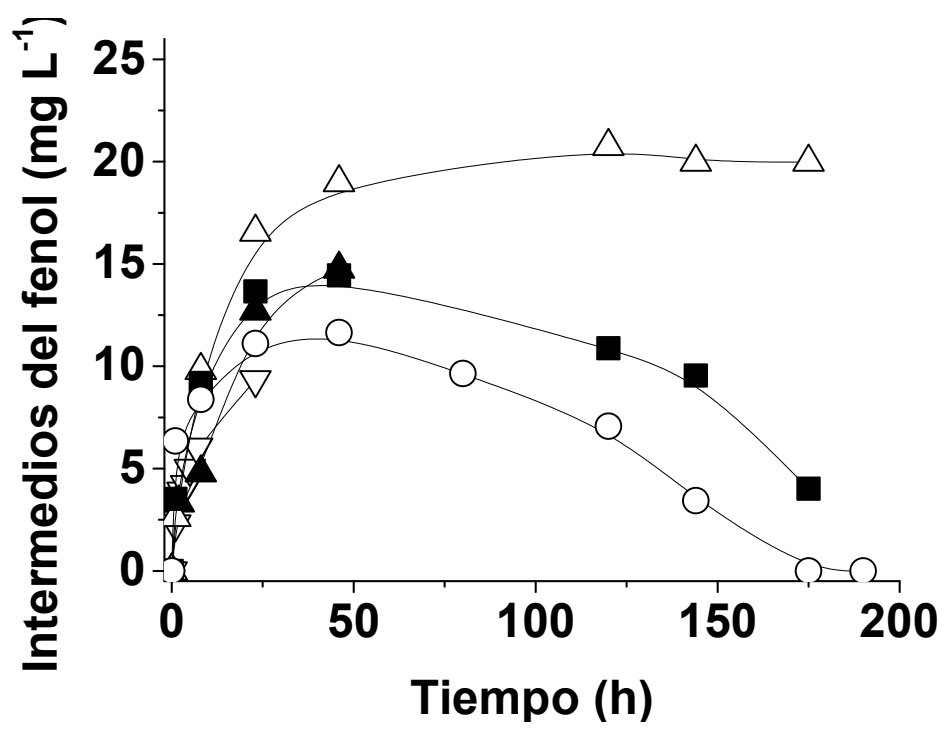

Figura 6.18. Evolución de la degradación de los intermedios del fenol (hidroquinona, catecol y $p$-benzoquinona) en función del ratio molar de $\mathrm{H}_{2} \mathrm{O}_{2}$ respecto a fenol. Leyenda: Ratio molar de $\mathrm{H}_{2} \mathrm{O}_{2}$ respecto a fenol de $0.5(\nabla)$, $1.0(\mathbf{\Delta}), 2.0(\Delta), 4.0(\mathbf{\bullet})$ y $5.5(\circ)$. Condiciones de reacción: catalizador $(5$ $\mathrm{mg}, 200 \mathrm{mg} \mathrm{L}^{-1}$ ), fenol (100 mg L $\left.\mathrm{m}^{-1}, 1.06 \mathrm{mM}\right), \mathrm{H}_{2} \mathrm{O}_{2}$ según se indica, $\mathrm{pH} 3$, temperatura $20^{\circ} \mathrm{C}$. Concentración de fenol e intermedios obtenida por HPLC 
y de $\mathrm{H}_{2} \mathrm{O}_{2}$ por espectrofotometría, como se indica en el capítulo 8, sección experimental.
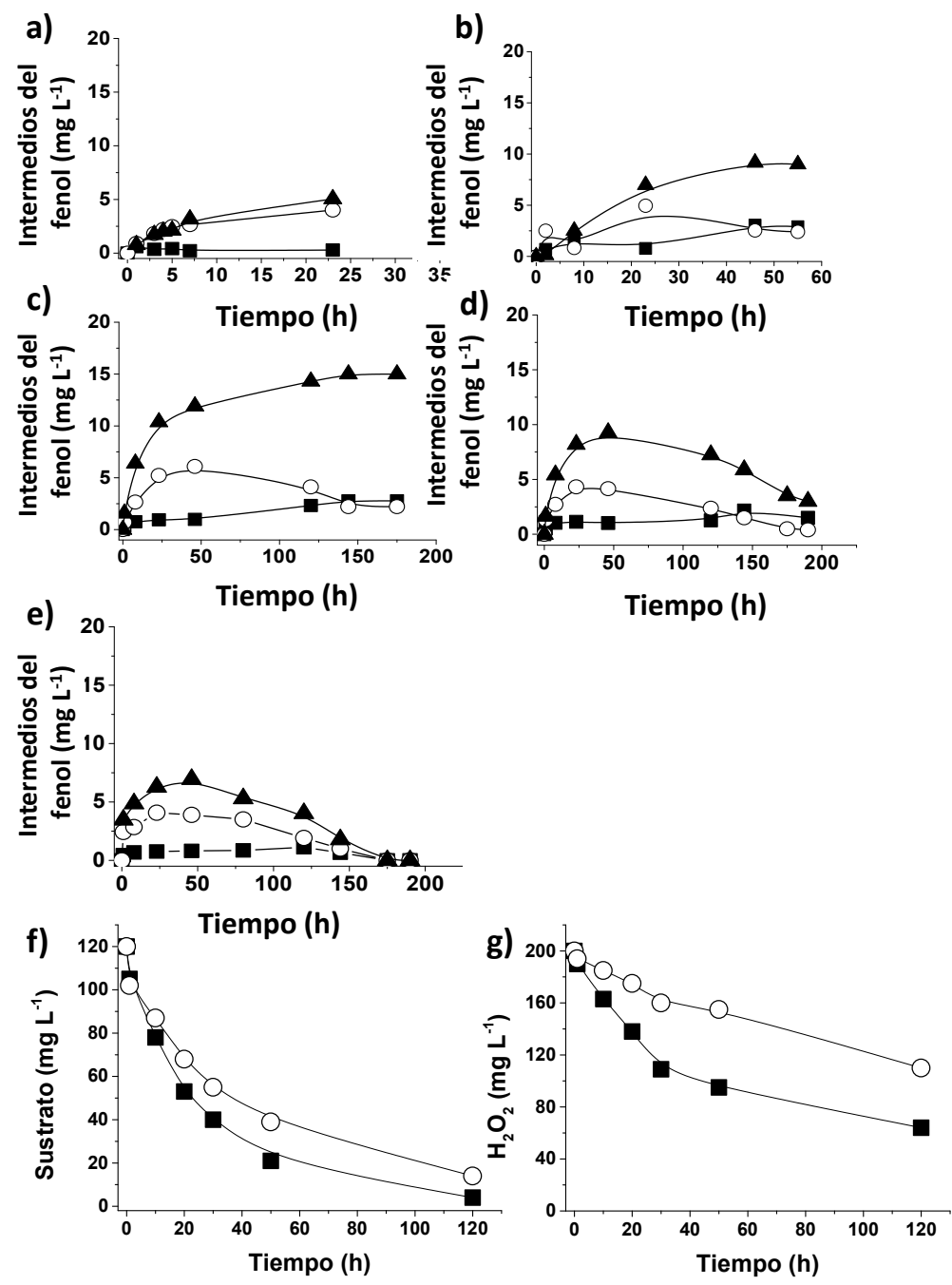

Figura 6.19. Perfiles temporales de la conversión de hidroquinona (๘), catecol (०) y $p$-benzoquinona ( $\Delta$ ) en función del ratio molar de $\mathrm{H}_{2} \mathrm{O}_{2}$ respecto a fenol. Leyenda: Ratio molar de $\mathrm{H}_{2} \mathrm{O}_{2}$ respecto a fenol de 0.5 (a), 1.0 (b), 2.0 (c), 4.0 (d) y 5.5 (e). Condiciones de reacción: catalizador $(5 \mathrm{mg}$, $\left.200 \mathrm{mg} \mathrm{L}^{-1}\right)$, fenol $\left(100 \mathrm{mg} \mathrm{L}^{-1}, 1.06 \mathrm{mM}\right), \mathrm{H}_{2} \mathrm{O}_{2}$ según se indica, $\mathrm{pH} \mathrm{3}$, 
temperatura $20^{\circ} \mathrm{C}$. Las gráficas f) y g) corresponden a la desaparición de hidroquinona (-) y catecol (०), y su correspondiente descomposición de $\mathrm{H}_{2} \mathrm{O}_{2}$. Condiciones de reacción: catalizador $\left(200 \mathrm{mg} \mathrm{L}^{-1}\right)$, organomolécula (1.06 mM), $\mathrm{H}_{2} \mathrm{O}_{2}\left(200 \mathrm{mg} \mathrm{L}^{-1}, 5.88 \mathrm{mM}\right), \mathrm{pH} \mathrm{3}$, temperatura $20{ }^{\circ} \mathrm{C}$. Concentración de fenol obtenida por HPLC y de $\mathrm{H}_{2} \mathrm{O}_{2}$ por espectrofotometría, como se indica en el capítulo 8 , sección experimental.

Una de las características de la reacción de Fenton es su gran dependencia con el $\mathrm{pH}$. En el presente caso, se determinó que rGO podría operar en un intervalo de pHs estrecho entre 2 y 4 (ver figura 6.20). Valores de $\mathrm{pH}$ inferiores protonarían el $\mathrm{H}_{2} \mathrm{O}_{2}$, desfavoreciendo la formación de radicales hidroxilo (ecuaciones 6.3 y 6.4), mientras que valores de $\mathrm{pH}$ más elevados que 5 producirían un aumento de la concentración de iones hidroperóxido, conduciendo a una disminución tanto de $\mathrm{H}_{2} \mathrm{O}_{2}$ como del radical $\mathrm{HO}^{\circ}$ (ecuaciones 6.5 y 6.6). ${ }^{22}$ Además, aumentando los valores de $\mathrm{pH}$ disminuye el potencial de oxidación de los radicales $\mathrm{HO}^{\circ}$.

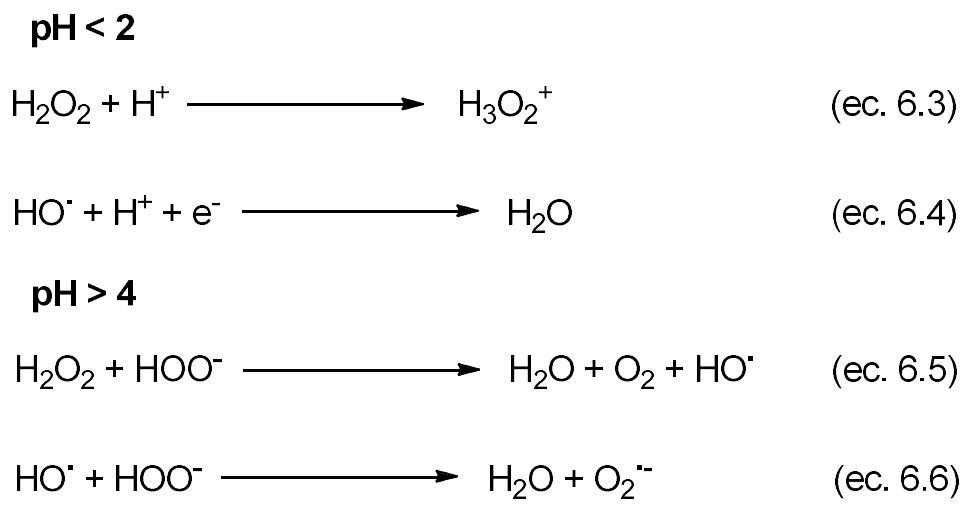




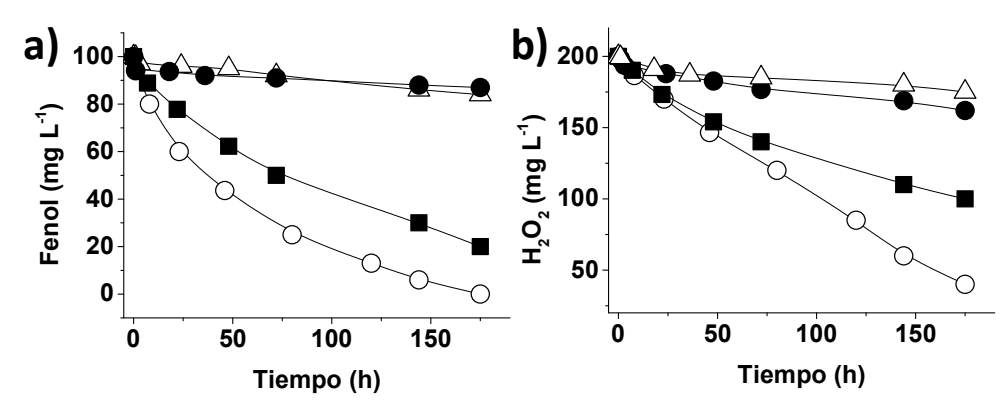

Figura 6.20. Perfiles temporales de degradación de fenol (a) y consumo de $\mathrm{H}_{2} \mathrm{O}_{2}$ (b), usando rGO como catalizador, en función del $\mathrm{pH}$ inicial de la reacción. Leyenda: $\mathrm{pH} 2(\boldsymbol{\bullet}), \mathrm{pH} 3(\circ), \mathrm{pH} 4(\Delta)$ y pH $5(\bullet)$. Condiciones de reacción: catalizador ( $\left.5 \mathrm{mg}, 200 \mathrm{mg} \mathrm{L}^{-1}\right)$, fenol (100 mg L $\left.\mathrm{m}^{-1}, 1.06 \mathrm{mM}\right), \mathrm{H}_{2} \mathrm{O}_{2}$ (200 mg L $\mathrm{m}^{-1}, 5.88 \mathrm{mM}$ ), pH según se indica en la leyenda, temperatura $20{ }^{\circ} \mathrm{C}$. Concentración de fenol obtenida por HPLC y de $\mathrm{H}_{2} \mathrm{O}_{2}$ por espectrofotometría, como se indica en el capítulo 8, sección experimental.

La estabilidad del catalizador y su máxima productividad son aspectos de gran importancia en catálisis. A fin de probar la estabilidad y determinar la productividad de rGO, se llevaron a cabo una serie de reúsos consecutivos en los cuales la relación de fenol $\left(1000 \mathrm{mg} \mathrm{L}^{-1}\right)$ a rGO (50 $\left.\mathrm{m} \mathrm{L}^{-1}\right)$ se aumentó por un factor de 40, permitiendo que la reacción transcurra por períodos de tiempo largos (ver figura 6.21).
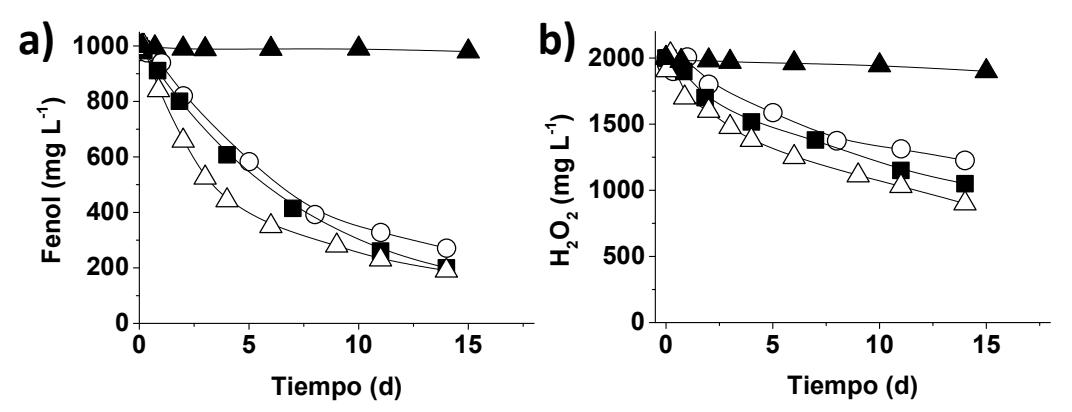

Figura 6.21. Test de productividad para la degradación de fenol (a) y consumo de $\mathrm{H}_{2} \mathrm{O}_{2}$ (b), usando rGO como catalizador. Leyenda: $1^{\circ}$ uso (o), $2^{\circ}$ $(\square), 5^{\circ}$ uso $(\Delta)$. Además se llevó a cabo un nuevo test de productividad en ausencia de catalizador $(\boldsymbol{\Delta})$. Condiciones de reacción: catalizador $(2.5 \mathrm{mg}$, $50 \mathrm{mg} \mathrm{L}^{-1}$ ), fenol (1000 mg L $\left.{ }^{-1}, 10.6 \mathrm{mM}\right), \mathrm{H}_{2} \mathrm{O}_{2}$ (2000 mg L $\left.\mathrm{L}^{-1}, 58.8 \mathrm{mM}\right), \mathrm{pH}$ 
3 , temperatura $20^{\circ} \mathrm{C}$. Concentración de fenol obtenida por HPLC y de $\mathrm{H}_{2} \mathrm{O}_{2}$ por espectrofotometría, como se indica en el capítulo 8 , sección experimental.

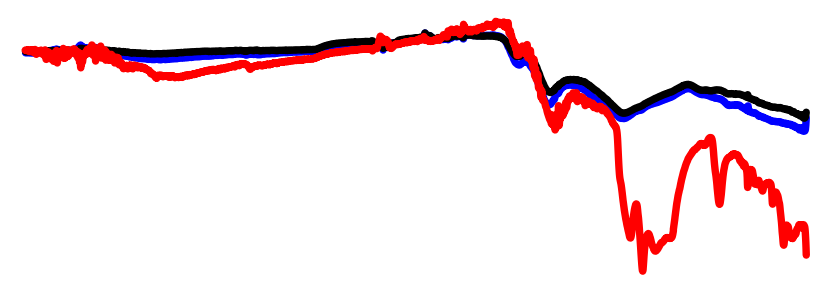

\section{$4000 \quad 3000 \quad 2000 \quad 1000$ Número de onda $\left(\mathrm{cm}^{-1}\right)$}

\begin{tabular}{|c|c|c|}
\hline & & $\mathrm{C} / \mathrm{O}$ \\
\hline rGO (fresco) & 9.74 & 5.93 \\
\hline rGO (2o uso) & 5.80 & 3.34 \\
\hline rGO (5' uso) & 1.72 & 1.31 \\
\hline
\end{tabular}

Figura 6.22. FT-IR y análisis elemental del catalizador de rGO fresco (en negro), de primer uso (en azul) y de quinto uso (en rojo), empleado en los test de productividad (figura 6.21).

Cinco reúsos consecutivos fueron llevados a cabo consiguiendo la reacción de concentraciones de fenol y $\mathrm{H}_{2} \mathrm{O}_{2}$ tan elevadas como $3.95 \mathrm{y}$ $4.73 \mathrm{~g} \mathrm{~L}^{-1}$ respectivamente, con sólo $50 \mathrm{mg} \mathrm{L}^{-1}$ de rGO (una cuarta parte de la cantidad de rGO habitualmente empleada en el procedimiento de reacción general). Se observó un aumento ligero en la actividad catalítica con el reúso de rGO. Este hecho se atribuye a una mejor dispersabilidad de rGO en agua con los reúsos debido a la hidroxilación suave que sufre el rGO en estas condiciones (figura 6.22). Conviene hacer notar que el contenido de oxígeno residual de rGO (aproximadamente 15\% en peso) hace posible su dispersión en medio acuoso por sonicación, haciendo posible su empleo como catalizador. Normalmente, aunque el GO es 
altamente dispersable en agua debido a su hidrofilicidad, la reducción de GO a rGO disminuye considerablemente la hidrofilicidad. En el presente caso, debido al contenido de oxígeno residual de rGO, este material permanece disperso en agua al ser sometido a ultrasonidos. ${ }^{20}$ Sin embargo, tras su uso como catalizador de Fenton se notó que tan sólo por agitación o por sonicación suave era posible obtener suspensiones estables del material rGO previamente usado. Es de destacar que una relación molar $\mathrm{H}_{2} \mathrm{O}_{2}$ / fenol de tan solo 3.3 es suficiente para llevar a cabo la degradación completa de fenol. De nuevo, en ausencia de catalizador la reacción no tiene lugar (figura 6.21). Desgraciadamente, el desconocimiento de la estructura de los centros activos en rGO no hace posible una determinación precisa de los valores de números de ciclos (TON). Sin embargo, ha sido establecido por XPS que los centros con subestructura tipo quinona en $\mathrm{rGO}$ pueden llegar a representar entre el 2 y el $5 \%$ en peso en este material. ${ }^{23}$ Como se discutirá más adelante, los centros de tipo quinona son posiblemente los centros activos y su porcentaje se puede estimar mediante la descomposición del pico en XPS C1s experimental en componentes individuales y la cuantificación del porcentaje de carbonos con estructura $\mathrm{C}=\mathrm{O}$. Considerando que el porcentaje de centros activos esté en esta proporción determinada mediante XPS en base a la fracción $\mathrm{C}=\mathrm{O}$, entonces, una estimación del valor de TON acumulado conseguido para $\mathrm{rGO}$ como carbocatalizador sería de 4540 y 15023 para la degradación de fenol y consumo de $\mathrm{H}_{2} \mathrm{O}_{2}$, respectivamente. Este TON es más alto que algunos descritos para varios catalizadores basados en metales de transición. ${ }^{13,15}$ Este valor es, sin embargo, aún dos órdenes de magnitud menor que el que se ha descrito para los mejores catalizadores de Fenton, basados en Au NPs (458459), ${ }^{24,25}$ y Ag NPs (472000), que ya han sido descritos en los capítulos anteriores. Los carbocatalizadores basados en $\mathrm{G}$ están, sin embargo, aún abiertos a optimización mediante el diseño de centros activos, y el valor de TON acumulado medido aquí debe considerarse como la primera estimación en el campo de la carbocatálisis. Las muestras de grafeno especialmente diseñadas con un alto contenido en estructuras de tipo quinona, en lugar de tan solo unos cuantos por ciento, podrían permitir optimizar considerablemente la actividad catalítica.

Hay que hacer notar que, además de pares redox del tipo quinona/hidroquinona, podrían también ser posibles centros activos con heteroátomos para promover la reacción de Fenton. En el caso de $(\mathrm{N}) \mathrm{G}$ 
hemos comprobado que ocurre una descomposición considerable de $\mathrm{H}_{2} \mathrm{O}_{2}$ que no está asociada con la generación de radicales libres $\mathrm{HO}^{\circ}$. Esta observación está de acuerdo con trabajos previos publicados. ${ }^{26}$ Estos centros son probablemente algunos de los diferentes tipos de átomos de nitrógeno presentes en el material (N)G. En el caso de (B)G, se encontró que los átomos de boro no eran estables sobre $\mathrm{G}$ y lixivian a la disolución mientras que descomponen $\mathrm{H}_{2} \mathrm{O}_{2}$ de forma espuria. Esto indica de nuevo que los átomos de boro son centros de la descomposición de $\mathrm{H}_{2} \mathrm{O}_{2}$.

Es importante destacar que la posibilidad de que trazas de manganeso fueran las responsables de la actividad catalítica observada se descartó durante los ensayos de productividad, llevando a cabo experimentos de productividad adicionales en los cuales iones $\mathrm{Mn}^{2+}$ fueron añadidos deliberadamente a la disolución en el rango de concentraciones de ppm $(50 \mu \mathrm{g})$, tanto en ausencia como en presencia de rGO, observando la falta de actividad (en ausencia de rGO) o la no variación de actividad con respecto al uso de rGO (contenido de Mn inferior a $100 \mathrm{ppm}$ ), tal como muestra la figura 6.23. Conviene hacer notar que GO (no rGO) es la muestra con la contaminación por $\mathrm{Mn}^{2+}$ mayor (150 ppm) y esta muestra es, sin embargo, la menos activa (ver tabla 6.3). Por consiguiente, no existe relación aparente entre las posibles impurezas metálicas y la actividad catalítica en la reacción de Fenton. 

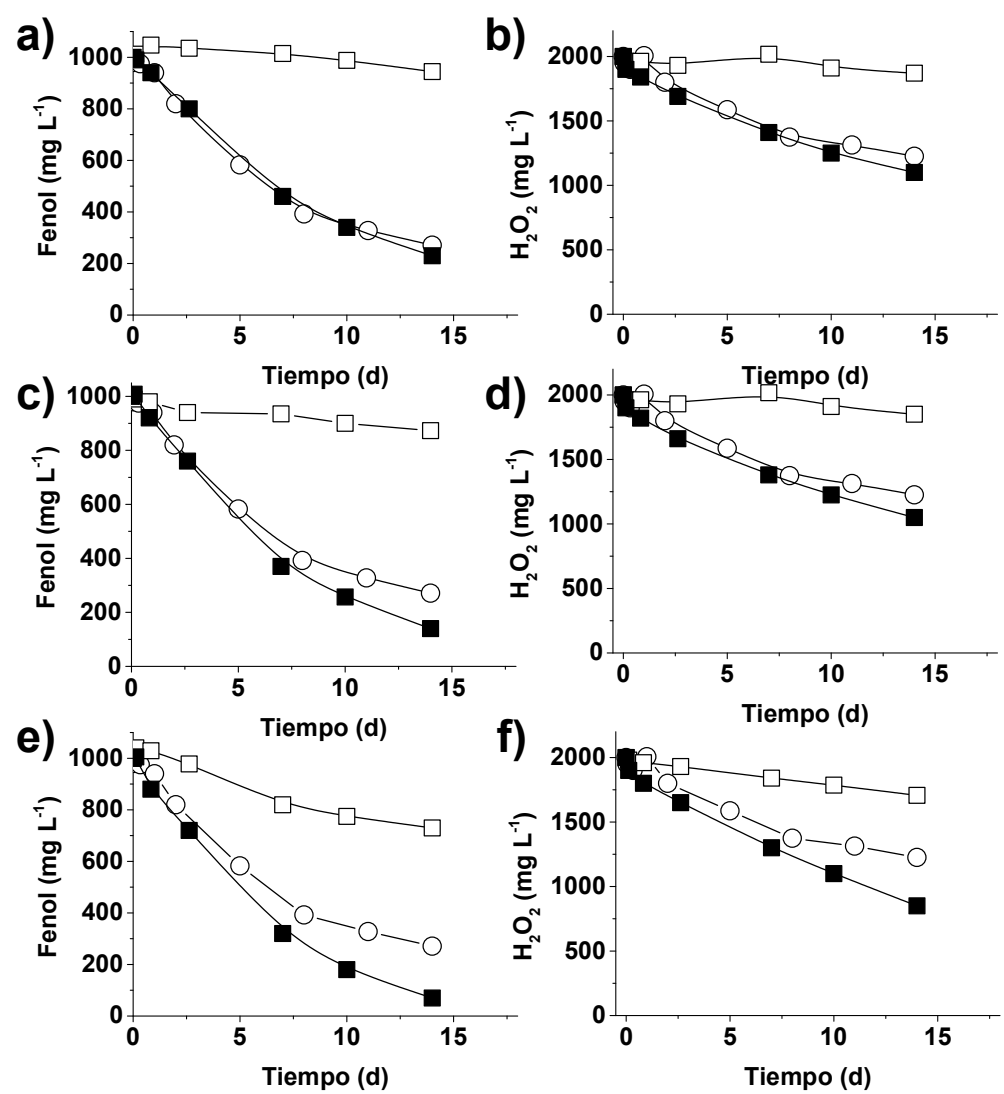

Figura 6.23. Influencia de la presencia de trazas de $\mathrm{Mn}^{2+}$ en la degradación de fenol (a, c, e) y la descomposición de $\mathrm{H}_{2} \mathrm{O}_{2}$ (b, d, f). Leyenda: a, b) 0.005 $\mathrm{mg} \mathrm{L}^{-1} \mathrm{Mn}^{2+}$; c, d) $0.05 \mathrm{mg} \mathrm{L}^{-1} \mathrm{Mn}^{2+}$; e, f) $0.1 \mathrm{mg} \mathrm{L}^{-1} \mathrm{Mn}^{2+}$; en ausencia de $\mathrm{rGO}$, en presencia de $\mathrm{Mn}^{2+}(\square)$; en presencia de rGO, en ausencia de $\mathrm{Mn}^{2+}$ (०); en presencia de $\mathrm{rGO}$ y $\mathrm{Mn}^{2+}(\mathbf{a})$. Condiciones de reacción: catalizador (2.5 mg, $\left.50 \mathrm{mg} \mathrm{L}^{-1}\right)$, fenol (1000 mg L-1 $\left.10.6 \mathrm{mM}\right), \mathrm{H}_{2} \mathrm{O}_{2}\left(2000 \mathrm{mg} \mathrm{L}^{-1}, 58.8\right.$ $\mathrm{mM}), \mathrm{pH} 3$, temperatura $20^{\circ} \mathrm{C}$. Concentración de fenol obtenida por HPLC y de $\mathrm{H}_{2} \mathrm{O}_{2}$ por espectrofotometría, como se indica en el capítulo 8, sección experimental.

La energía de activación (Ea) de desaparición de fenol y descomposición de $\mathrm{H}_{2} \mathrm{O}_{2}$ fue estimada para una serie de grafenos llevando a cabo la reacción a diferentes temperaturas entre 20 y $80{ }^{\circ} \mathrm{C}$ (los resultados se muestran en la tabla 6.3 y las figuras $6.24-6.29$ ). Se observó que el valor de Ea para el catalizador más eficiente para la 
degradación de fenol y descomposición de agua oxigenada eran coincidentes resultando un valor de $30 \mathrm{KJ}$ mol.
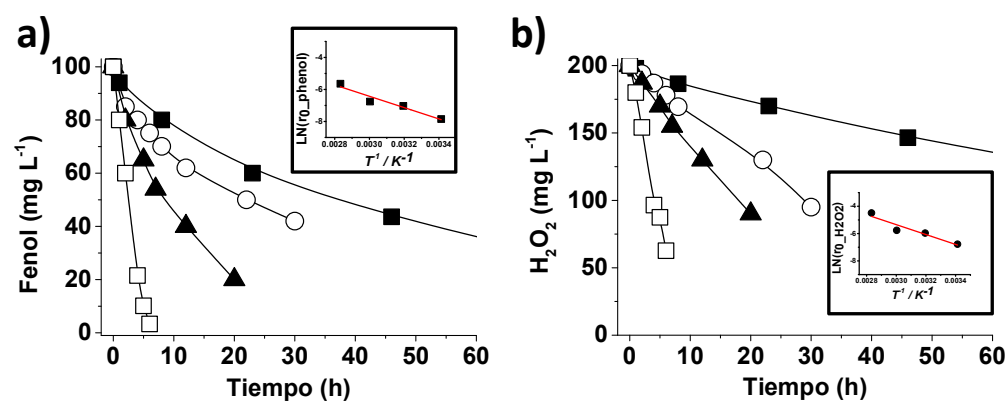

Figura 6.24. Perfiles temporales de degradación de fenol (a) y consumo de $\mathrm{H}_{2} \mathrm{O}_{2}$ (b), usando rGO como catalizador, en función de la temperatura. El cuadro interior muestra el ajuste de Arrhenius para la determinación de la energía de activación para sendas gráficas. Condiciones de reacción: catalizador (5 mg, $200 \mathrm{mg} \mathrm{L}^{-1}$ ), fenol (100 mg L-1 $\left.1.06 \mathrm{mM}\right), \mathrm{H}_{2} \mathrm{O}_{2}(200 \mathrm{mg}$ $\left.\mathrm{L}^{-1}, 5.88 \mathrm{mM}\right), \mathrm{pH} 3$, temperatura según se indica en la leyenda. Leyenda: 80 ${ }^{\circ} \mathrm{C}(\square), 60{ }^{\circ} \mathrm{C}(\boldsymbol{\Delta}), 40{ }^{\circ} \mathrm{C}($ ( ) $)$ y $20{ }^{\circ} \mathrm{C}(\boldsymbol{\square})$. Concentración de fenol obtenida por HPLC y de $\mathrm{H}_{2} \mathrm{O}_{2}$ por espectrofotometría, como se indica en el capítulo 8, sección experimental.
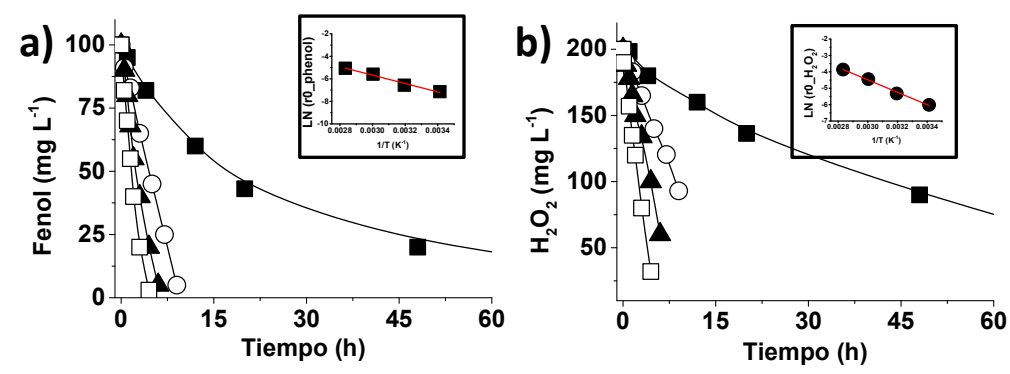

Figura 6.25. Perfiles temporales de degradación de fenol (a) y consumo de $\mathrm{H}_{2} \mathrm{O}_{2}$ (b), usando $\mathrm{G}$ como catalizador, en función de la temperatura. El cuadro interior muestra el ajuste de Arrhenius para la determinación de la energía de activación para sendas gráficas. Condiciones de reacción: catalizador (5 mg, $200 \mathrm{mg} \mathrm{L}^{-1}$ ), fenol (100 mg L-1, $\left.1.06 \mathrm{mM}\right), \mathrm{H}_{2} \mathrm{O}_{2}(200 \mathrm{mg}$ $\left.\mathrm{L}^{-1}, 5.88 \mathrm{mM}\right), \mathrm{pH} 3$, temperatura según se indica en la leyenda. Leyenda: 80 
${ }^{\circ} \mathrm{C}(\square), 60{ }^{\circ} \mathrm{C}(\boldsymbol{\Delta}), 40{ }^{\circ} \mathrm{C}(\mathrm{\circ})$ y $20{ }^{\circ} \mathrm{C}(\boldsymbol{\square})$. Concentración de fenol obtenida por HPLC y de $\mathrm{H}_{2} \mathrm{O}_{2}$ por espectrofotometría, como se indica en el capítulo 8, sección experimental.
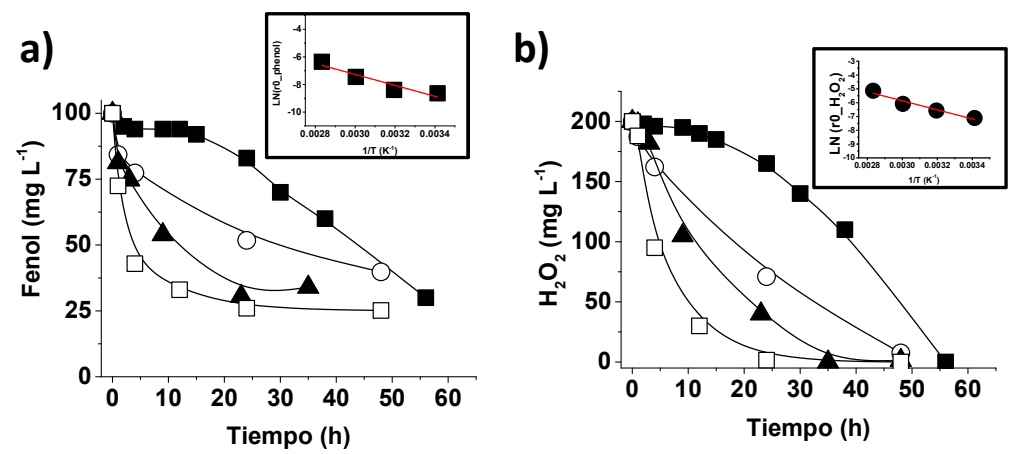

Figura 6.26. Perfiles temporales de degradación de fenol (a) y consumo de $\mathrm{H}_{2} \mathrm{O}_{2}$ (b), usando (B) $\mathrm{G}$ como catalizador, en función de la temperatura. El cuadro interior muestra el ajuste de Arrhenius para la determinación de la energía de activación para sendas gráficas. Condiciones de reacción: catalizador (5 mg, $200 \mathrm{mg} \mathrm{L}^{-1}$ ), fenol (100 mg L-1, $\left.1.06 \mathrm{mM}\right), \mathrm{H}_{2} \mathrm{O}_{2}(200 \mathrm{mg}$ $\left.\mathrm{L}^{-1}, 5.88 \mathrm{mM}\right), \mathrm{pH} 3$, temperatura según se indica en la leyenda. Leyenda: 80 ${ }^{\circ} \mathrm{C}(\square), 60{ }^{\circ} \mathrm{C}(\boldsymbol{\Delta}), 40{ }^{\circ} \mathrm{C}(\mathrm{\circ})$ y $20{ }^{\circ} \mathrm{C}(\boldsymbol{\square})$. Concentración de fenol obtenida por HPLC y de $\mathrm{H}_{2} \mathrm{O}_{2}$ por espectrofotometría, como se indica en el capítulo 8, sección experimental.
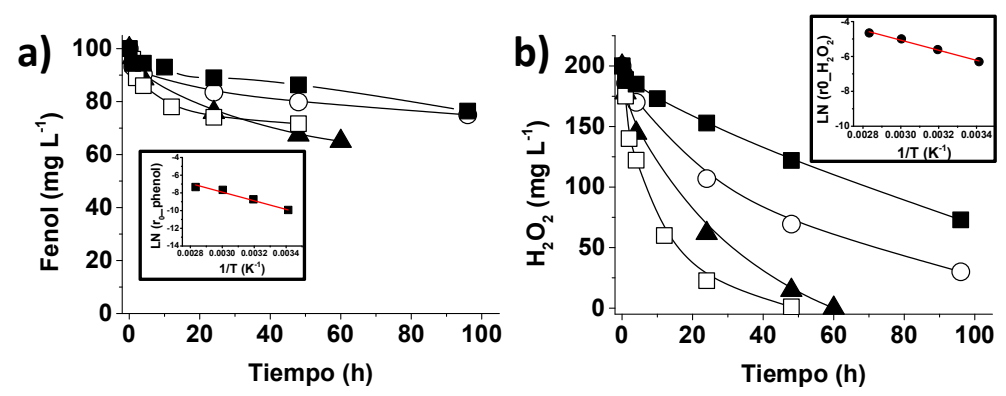

Figura 6.27. Perfiles temporales de degradación de fenol (a) y consumo de $\mathrm{H}_{2} \mathrm{O}_{2}$ (b), usando $(\mathrm{B}, \mathrm{N}) \mathrm{G}$ como catalizador, en función de la temperatura. El cuadro interior muestra el ajuste de Arrhenius para la determinación de la energía de activación para sendas gráficas. Condiciones de reacción: catalizador (5 mg, $200 \mathrm{mg} \mathrm{L}^{-1}$ ), fenol (100 mg L-1, $\left.1.06 \mathrm{mM}\right), \mathrm{H}_{2} \mathrm{O}_{2}(200 \mathrm{mg}$ $\left.\mathrm{L}^{-1}, 5.88 \mathrm{mM}\right), \mathrm{pH} 3$, temperatura según se indica en la leyenda. Leyenda: 80 ${ }^{\circ} \mathrm{C}(\square), 60{ }^{\circ} \mathrm{C}(\boldsymbol{\Delta}), 40{ }^{\circ} \mathrm{C}(\mathrm{\circ})$ y $20{ }^{\circ} \mathrm{C}(\boldsymbol{\square})$. Concentración de fenol obtenida 
por HPLC y de $\mathrm{H}_{2} \mathrm{O}_{2}$ por espectrofotometría, como se indica en el capítulo 8, sección experimental.
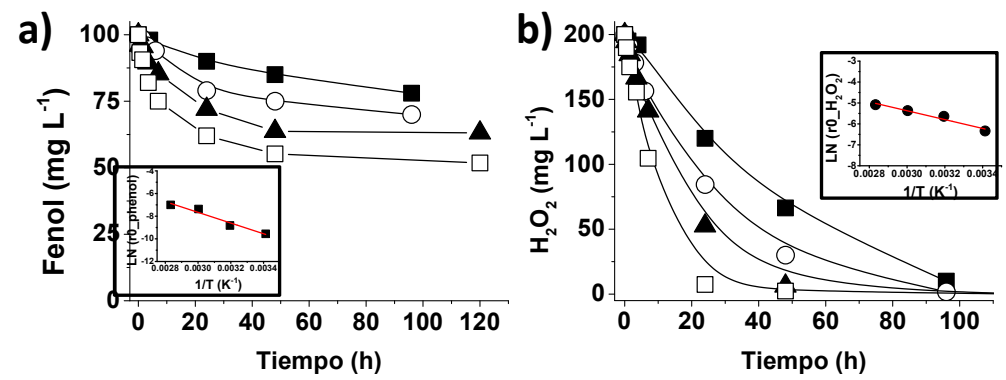

Figura 6.28. Perfiles temporales de degradación de fenol (a) y consumo de $\mathrm{H}_{2} \mathrm{O}_{2}$ (b), usando (N)G como catalizador, en función de la temperatura. El cuadro interior muestra el ajuste de Arrhenius para la determinación de la energía de activación para sendas gráficas. Condiciones de reacción: catalizador (5 mg, $200 \mathrm{mg} \mathrm{L}^{-1}$ ), fenol (100 mg L $\left.\mathrm{m}^{-1}, 1.06 \mathrm{mM}\right), \mathrm{H}_{2} \mathrm{O}_{2}(200 \mathrm{mg}$ $\left.\mathrm{L}^{-1}, 5.88 \mathrm{mM}\right), \mathrm{pH} 3$, temperatura según se indica en la leyenda. Leyenda: 80 ${ }^{\circ} \mathrm{C}(\square), 60{ }^{\circ} \mathrm{C}(\mathbf{\Delta}), 40{ }^{\circ} \mathrm{C}\left(\right.$ ( ) y $20{ }^{\circ} \mathrm{C}(\mathbf{\bullet})$. Concentración de fenol obtenida por HPLC y de $\mathrm{H}_{2} \mathrm{O}_{2}$ por espectrofotometría, como se indica en el capítulo 8 , sección experimental.
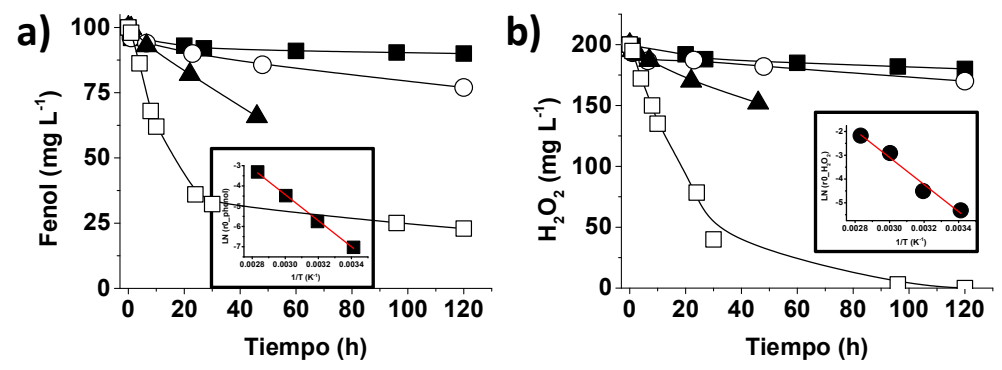

Figura 6.29. Perfiles temporales de degradación de fenol (a) y consumo de $\mathrm{H}_{2} \mathrm{O}_{2}$ (b), usando $\mathrm{GO}$ como catalizador, en función de la temperatura. El cuadro interior muestra el ajuste de Arrhenius para la determinación de la energía de activación para sendas gráficas. Condiciones de reacción: catalizador (5 mg, $\left.200 \mathrm{mg} \mathrm{L}^{-1}\right)$, fenol (100 mg L-1 $\left.1.06 \mathrm{mM}\right), \mathrm{H}_{2} \mathrm{O}_{2}(200 \mathrm{mg}$ $\left.\mathrm{L}^{-1}, 5.88 \mathrm{mM}\right), \mathrm{pH} 3$, temperatura según se indica en la leyenda. Leyenda: 80 ${ }^{\circ} \mathrm{C}(\square), 60{ }^{\circ} \mathrm{C}(\boldsymbol{\Delta}), 40{ }^{\circ} \mathrm{C}(\mathrm{\circ})$ y $20{ }^{\circ} \mathrm{C}(\boldsymbol{\bullet})$. Concentración de fenol obtenida por HPLC y de $\mathrm{H}_{2} \mathrm{O}_{2}$ por espectrofotometría, como se indica en el capítulo 8 , sección experimental. 
El hecho de que los dos procesos (desaparición de fenol y descomposición de $\mathrm{H}_{2} \mathrm{O}_{2}$ ) exhiban el mismo valor de Ea está de acuerdo con que la reacción de Fenton sea el único proceso que ocurre, y con que la generación de radical $\mathrm{HO}^{\circ}$ a partir de $\mathrm{H}_{2} \mathrm{O}_{2}$ sea la etapa determinante de la velocidad, responsable de la Ea. Así, una vez que los radicales $\mathrm{HO}^{\circ}$ son generados, estos reaccionarían con el fenol o dihidroxibencenos, esencialmente sin ninguna energía de activación y, por consiguiente, la Ea de la degradación del fenol y generación de radicales $\mathrm{HO}^{*}$ serían coincidentes. También es destacable que el valor Ea sea relativamente bajo y comparable con el descrito para los catalizadores de Fenton heterogéneos más eficientes basados en $\mathrm{Au}$ y Ag NPs soportadas sobre nanopartículas de diamante. ${ }^{25}$ Para otros carbocatalizadores menos eficientes tales como $(\mathrm{N}) \mathrm{G}$, los valores de Ea de degradación de fenol son mayores que los de la descomposición de $\mathrm{H}_{2} \mathrm{O}_{2}$, lo que implica que la barrera de descomposición de $\mathrm{H}_{2} \mathrm{O}_{2}$ es menor y que el ataque al fenol requiere activación adicional. Esta discrepancia entre la Ea para la descomposición de $\mathrm{H}_{2} \mathrm{O}_{2}$ y Ea mayor para la desaparición del fenol aumenta a medida que la eficiencia del catalizador para generar radicales $\mathrm{HO}^{\circ}$ disminuye.

La eficiencia de rGO para generar radicales $\mathrm{HO}^{\circ}$ en la descomposición de $\mathrm{H}_{2} \mathrm{O}_{2}$ se puede estimar llevando a cabo un experimento con un gran exceso de fenol respecto a $\mathrm{H}_{2} \mathrm{O}_{2}$. Estas condiciones, usando un exceso grande de fenol, son opuestas a las que generalmente se usan cuando el objetivo es la degradación de fenol, pero bajo estas condiciones desfavorables para la degradación de fenol la mayoría de radicales $\mathrm{HO}^{\circ}$ deberían atacar preferentemente al fenol formando catecol, hidroquinona y $p$-benzoquinona. De esta manera, cuantificando estos productos con respecto al consumo de $\mathrm{H}_{2} \mathrm{O}_{2}$, se puede determinar indirectamente el porcentaje de $\mathrm{H}_{2} \mathrm{O}_{2}$ descompuesto que ha generado radicales libres $\mathrm{HO}^{\circ}$ (esquema 6.1). Las medidas en estas condiciones han establecido que al menos el $82 \%$ del consumo de $\mathrm{H}_{2} \mathrm{O}_{2}$ se correlaciona con la transformación de fenol en catecol, hidroquinona y $p$-benzoquinona (figuras 6.19 y 6.30). A medida que la reacción procede, esta eficiencia disminuye aparentemente debido a la reacción de radicales hidroxilo con los productos primarios en lugar de con el fenol. Esta eficiencia en la generación de radical $\mathrm{HO}^{\circ}$ es notablemente alta y justifica 
por qué no hay necesidad de un exceso mayor de $\mathrm{H}_{2} \mathrm{O}_{2}$ para degradar el fenol.

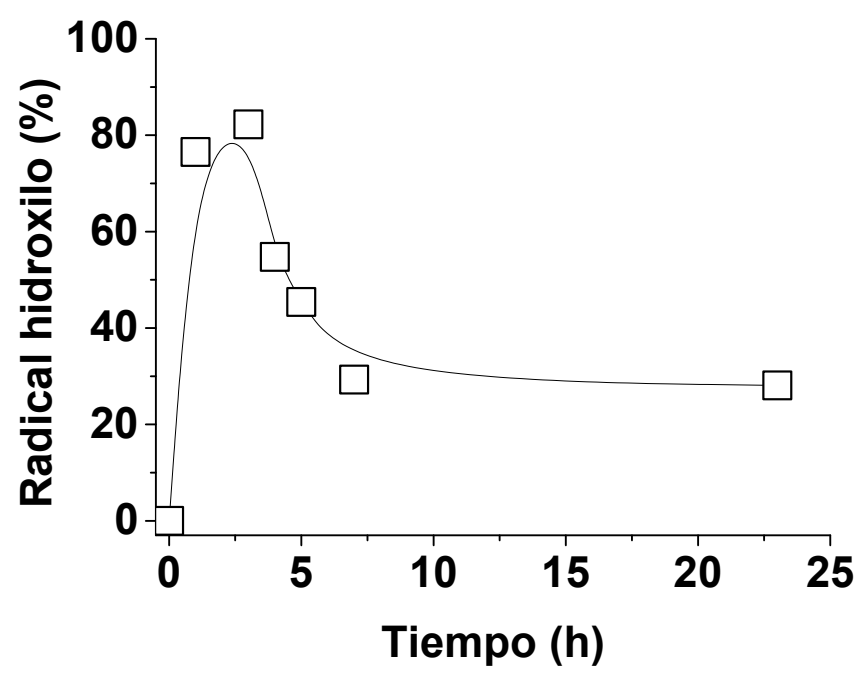

Figura 6.30. Evolución de la eficiencia en la generación de radicales hidroxilo frente al tiempo de reacción, determinada considerando la degradación de fenol y la aparición de sus principales intermedios de reacción (hidroquinona, catecol y $p$-benzoquinona) con respecto al $\mathrm{H}_{2} \mathrm{O}_{2}$ consumido. Condiciones de reacción: catalizador $\left(5 \mathrm{mg}, 200 \mathrm{mg} \mathrm{L}^{-1}\right)$, fenol (100 mg L $\left.{ }^{-1}, 1.06 \mathrm{mM}\right), \mathrm{H}_{2} \mathrm{O}_{2}$ (0.5 equivalentes respecto a fenol), $\mathrm{pH} \mathrm{3,}$ temperatura $20{ }^{\circ} \mathrm{C}$. Concentración de fenol e intermedios obtenida por HPLC y de $\mathrm{H}_{2} \mathrm{O}_{2}$ por espectrofotometría, como se indica en el capítulo 8, sección experimental.

Evidencia a favor de la generación de radicales $\mathrm{HO}^{\circ}$ se obtuvo indirectamente mediante experimentos de inhibición de la degradación del fenol por DMSO. El DMSO es sabido que reacciona fácilmente con radicales $\mathrm{HO}^{\circ}$, conduciendo a la formación de radicales $\mathrm{CH}_{3}{ }^{\cdot}$ y ácido metanosulfínico (ecuación 6.7). ${ }^{27}$ Los experimentos de inhibición por DMSO en condiciones apropiadas utilizando rGO como catalizador indican que la degradación de fenol es inhibida completamente con un exceso molar de 10, DMSO respecto al fenol, probando indirectamente de esta manera que el mecanismo de la reacción de Fenton implica radicales HO (figura 6.31). 
$\left(\mathrm{CH}_{3}\right)_{2} \mathrm{SO}+\mathrm{OH} \longrightarrow \mathrm{CH}_{3} \mathrm{SO}_{2} \mathrm{H}+{ }^{\circ} \mathrm{CH}_{3}$

(ec. 6.7)

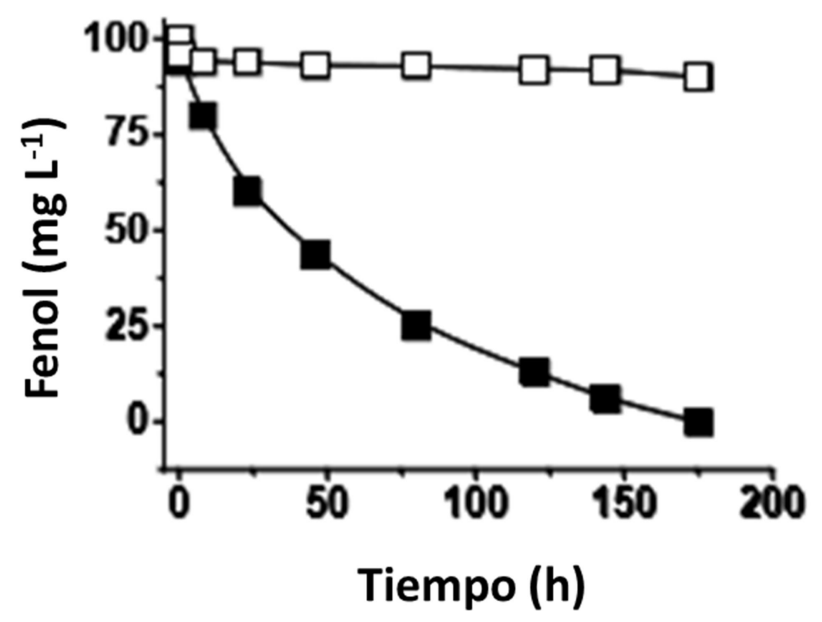

Figura 6.31. Degradación de fenol en ausencia ( $\square$ ) y en presencia ( $\square$ ) de DMSO como atrapador de radicales. Condiciones de reacción: catalizador (5 $\left.\mathrm{mg}, 200 \mathrm{mg} \mathrm{L}^{-1}\right)$, fenol (100 mg L$\left.{ }^{-1}, 1.06 \mathrm{mM}\right), \mathrm{H}_{2} \mathrm{O}_{2}\left(200 \mathrm{mg} \mathrm{L}^{-1}, 5.88 \mathrm{mM}\right)$, ratio molar de DMSO respecto a $\mathrm{H}_{2} \mathrm{O}_{2} 10, \mathrm{pH} \mathrm{3,} 20^{\circ} \mathrm{C}$. Concentración de fenol obtenida por HPLC, como se indica en el capítulo 8 , sección experimental.

Una evidencia adicional a favor de la generación de radicales $\mathrm{HO}^{`}$ se pudo obtener mediante espectroscopía de resonancia electrónica paramagnética (EPR), utilizando fenil- $\alpha$-tert-butil nitrona (PBN) como agente de atrapamiento. Los espectros de EPR del aducto radical PBN$(\mathrm{OH})$ pudieron ser registrados como se muestra en la figura 6.32. Este espectro de EPR con estructura fina contiene información estructural y constituye una evidencia firme de la generación de radical $\mathrm{HO}^{\circ}$ a partir de $\mathrm{H}_{2} \mathrm{O}_{2}$ por rGO. Conviene hacer notar, sin embargo, que la espectroscopía EPR con PBN como agente de atrapamiento no es un procedimiento adecuado para cuantificar el porcentaje de radical $\mathrm{HO}^{\circ}$ generado por cada catalizador empleado debido a la degradación del propio PBN por los radicales $\mathrm{HO}^{\circ}$. Así, los ensayos de atrapamiento del radical $\mathrm{HO}^{\circ}$ por $\mathrm{PBN}$ deben ser tomados sólo como un procedimiento de detección. 
1)

(d)

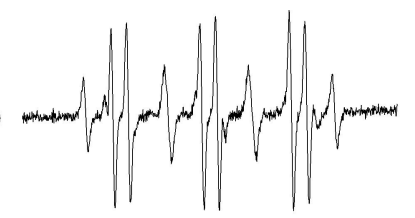

(c) (b)

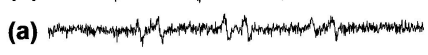

3440345034603470348034903500351035203448

Campo magnético (G)
2)

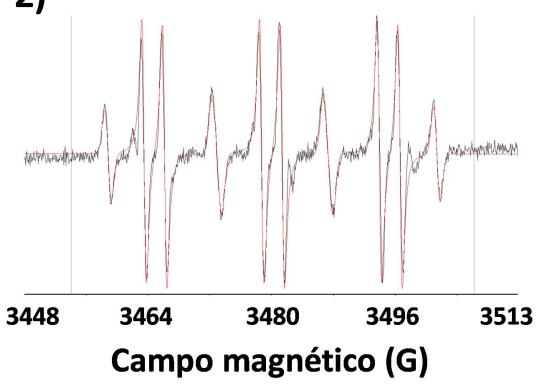

Figura 6.32. (1) Espectros de EPR de (a) $\mathrm{PBN}+\mathrm{H}_{2} \mathrm{O}_{2}$; (b) $\mathrm{rGO}+\mathrm{PBN}$; (c) $\mathrm{PBN}+\mathrm{H}_{2} \mathrm{O}_{2}$; (d) rGO $+\mathrm{H}_{2} \mathrm{O}_{2}+$ PBN. (2) Espectros de EPR de la muestra (d) y su mejor ajuste considerando el aducto $\mathrm{PBN}-\mathrm{OH}\left(\mathrm{AG}_{\mathrm{N}}=15.5\right.$ y $\mathrm{AG}_{\mathrm{H}}=2.7$ $\mathrm{Hz})$ y tert-butil aminoxil $\left(\mathrm{AG}_{\mathrm{N}}=14.58 \mathrm{~Hz}\right.$ y $\left.\mathrm{AG}_{\mathrm{H}}=13.90 \mathrm{~Hz}\right)$ coincidiendo con los valores descritos en la literatura. Condiciones de reacción para la obtención de los espectros de EPR: rGO $\left(200 \mathrm{mg} \mathrm{L}^{-1}\right)$, PBN (1.04 $\mathrm{mg} \mathrm{L}^{-1}$, $5.88 \mathrm{mM}$ ), relación molar $\mathrm{PBN} / \mathrm{H}_{2} \mathrm{O}_{2}=1: 1, \mathrm{pH} 3$, tiempo de reacción 45 minutos.

A fin de proporcionar un marco conceptual para racionalizar la actividad catalítica de grafenos en la reacción de Fenton, se llevaron a cabo cálculos de DFT con moléculas modelo de las posibles subunidades de hidroquinona que pudieran encontrarse en G. Es pertinente comentar que cálculos de DFT anteriores han predicho que los átomos de $\mathrm{N}$ en grafeno son capaces de descomponer $\mathrm{H}_{2} \mathrm{O}_{2}$ a $\mathrm{H}_{2} \mathrm{O}$ vía $\mathrm{N}-\mathrm{OH} .{ }^{26}$ En línea con estos cálculos, que en su momento no fueron contrastados experimentalmente, en el presente capítulo se ha observado que (N)G es capaz de efectuar en un grado considerable la descomposición de $\mathrm{H}_{2} \mathrm{O}_{2}$ sin generar radicales libres $\mathrm{HO}^{\circ}$ en disolución.

Nuestro estudio de DFT comenzó calculando la posibilidad de generación de $\mathrm{HO}^{\circ}$ a partir de $\mathrm{H}_{2} \mathrm{O}_{2}$, que sufre reducción con hidroquinona (esquema 6.2). Los cálculos indican que el proceso es termodinámicamente desfavorable por aproximadamente $2 \mathrm{eV}$ en una diferencia entre términos de alrededor de $130 \mathrm{eV}$. Cálculos similares predicen que la presencia de sustituyentes dadores de electrones en el anillo aromático disminuiría la endoergonicidad del proceso hasta valores positivos en torno a $0.16 \mathrm{eV}$. Otro modelo de subestructura tipo hidroquinona que pudiera estar presente en $\mathrm{G}$ y que posee anillos de 
benzopireno condensados, indica de nuevo que la generación de $\mathrm{HO}^{\circ}$ a partir de $\mathrm{H}_{2} \mathrm{O}_{2}$ por reducción de la unidad de hidroquinona debería ser ligeramente desfavorable por $1.1 \mathrm{eV}$ en una diferencia entre términos cuya magnitud es de alrededor de $400 \mathrm{eV}$. De esta manera, estos cálculos de DFT indican que el proceso de generación de $\mathrm{HO}^{\circ}$ por reducción química de $\mathrm{H}_{2} \mathrm{O}_{2}$ de hidroquinona es cuasi neutro desde el punto de vista de la energía, siendo esta situación ideal desde el punto de vista de la reversibilidad del ciclo catalítico. Está claro que cálculos adicionales usando modelos más completos de subestructuras de $\mathrm{G}$ serían necesarios, así como analizar las posibles etapas en el mecanismo de reacción para conseguir una comprensión más completa del origen de la actividad catalítica en grafenos para la reacción de Fenton.

a)
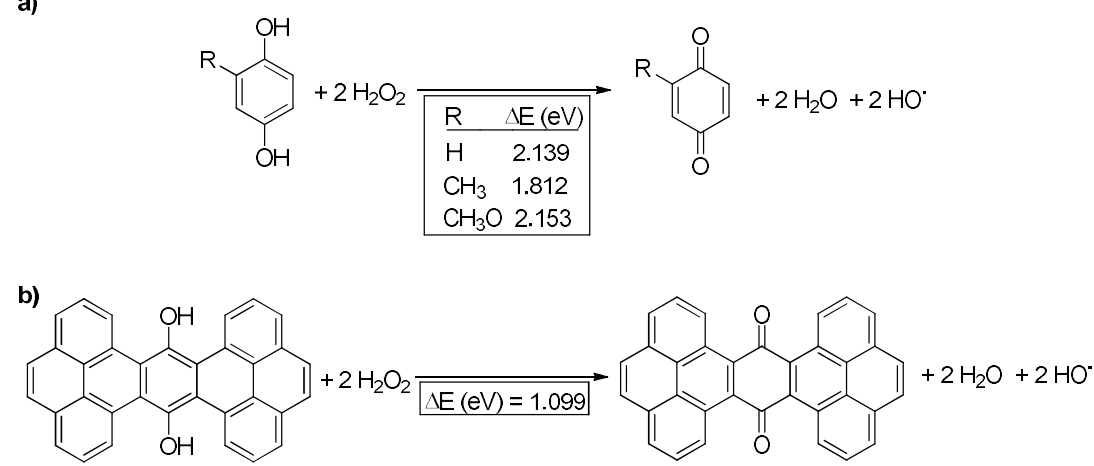

Esquema 6.2. Incremento de energía $(\Delta \mathrm{E})$ en la generación de radicales $\mathrm{HO}$ a partir de $\mathrm{H}_{2} \mathrm{O}_{2}$ por reducción con hidroquinona que pueden considerarse modelos de los centros activos presentes en grafenos.

A fin de proporcionar algún apoyo experimental a esta predicción sobre la naturaleza de los centros redox en $\mathrm{G}$, en el presente capítulo se seleccionó la $p$-benzoquinona y la hidroquinona como moléculas modelos simples de estructuras presentes en rGO. Con estas dos moléculas como organocatalizadores, se evaluó la actividad catalítica para la degradación de fenol y descomposición de $\mathrm{H}_{2} \mathrm{O}_{2}$ (figuras 6.33 a 6.35). Los dos organocatalizadores se comportaron similarmente, promoviendo ambos la reacción de Fenton. Además, la inhibición por DMSO (figura 6.35) de los radicales $\mathrm{HO}^{\circ}$ también confirma la generación de estas especies por reducción de $\mathrm{H}_{2} \mathrm{O}_{2}$ con hidroquinona. De forma análoga, la 2metoxihidroquinona y la 2-metil hidroquinona fueron 
organocatalizadores capaces de generar radicales $\mathrm{HO}^{*}$ por reducción de $\mathrm{H}_{2} \mathrm{O}_{2}$, como demuestra igualmente los experimentos de inhibición por DMSO (figura 6.36), a una mayor velocidad que la hidroquinona sin sustituyentes, mostrando un buen acuerdo con la influencia de sustituyentes dadores de electrones predicha por los cálculos (figura 6.36).

a)

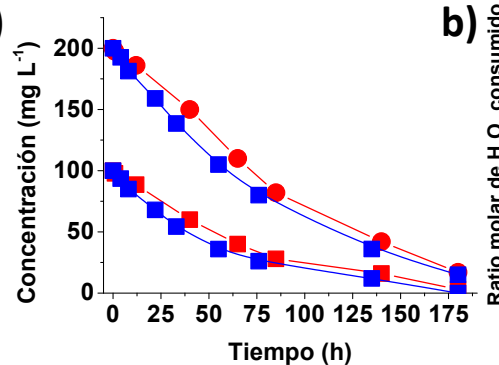

b) 음

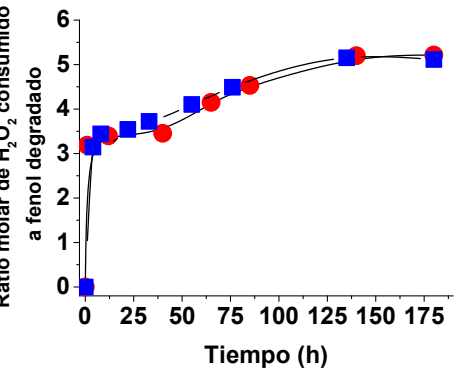

Figura 6.33. a) Degradación de fenol (๘) y descomposición de $\mathrm{H}_{2} \mathrm{O}_{2}(\bullet)$ utilizando $p$-benzoquinona (en rojo) o hidroquinona (en azul), como catalizadores. b) Ratio molar de $\mathrm{H}_{2} \mathrm{O}_{2}$ consumida respecto al fenol degradado utilizando $p$-benzoquinona $(\bullet)$ o hidroquinona $(\bullet)$ como catalizadores. Condiciones de reacción: organocatalizador $(0.106 \mathrm{mM})$, fenol $\left(100 \mathrm{mg} \mathrm{L}^{-1}\right.$, $\left.1.06 \mathrm{mM}), \mathrm{H}_{2} \mathrm{O}_{2}\left(200 \mathrm{mg} \mathrm{L}^{-1}, 5.88 \mathrm{mM}\right), \mathrm{pH} \mathrm{3}, 20^{\circ} \mathrm{C}\right)$. Concentración de fenol y organocatalizador obtenida por HPLC y de $\mathrm{H}_{2} \mathrm{O}_{2}$ por espectrofotometría, como se indica en el capítulo 8 , sección experimental.
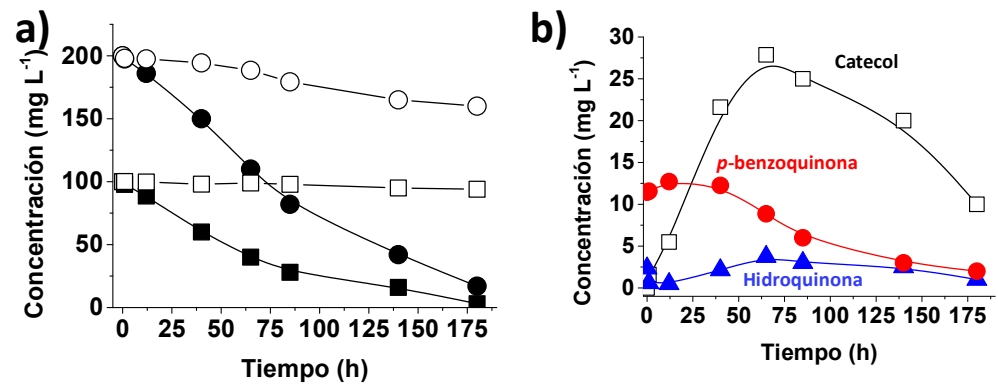

Figura 6.34. a) Degradación de fenol (•) y descomposición de $\mathrm{H}_{2} \mathrm{O}_{2}(\bullet)$ en presencia de DMSO (símbolo abierto) o en ausencia de DMSO (símbolo cerrado) utilizando $p$-benzoquinona como catalizador. b) Evolución de catecol ( $\square)$, $p$-benzoquinona $(\bullet)$ e hidroquinona $(\boldsymbol{\Delta})$ en ausencia de DMSO utilizando $p$-benzoquinona como catalizador. Condiciones de reacción: 
organocatalizador $(0.106 \mathrm{mM})$, fenol $\left(100 \mathrm{mg} \mathrm{L}^{-1}, 1.06 \mathrm{mM}\right), \mathrm{H}_{2} \mathrm{O}_{2}(200 \mathrm{mg}$ $\mathrm{L}^{-1}, 5.88 \mathrm{mM}$ ), ratio molar de DMSO respecto a $\mathrm{H}_{2} \mathrm{O}_{2}$ de $10, \mathrm{pH} 3,20{ }^{\circ} \mathrm{C}$. Concentración de fenol y organocatalizador obtenida por HPLC y de $\mathrm{H}_{2} \mathrm{O}_{2}$ por espectrofotometría, como se indica en el capítulo 8 , sección experimental.

a)

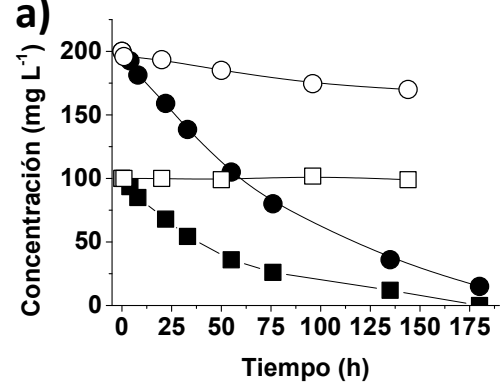

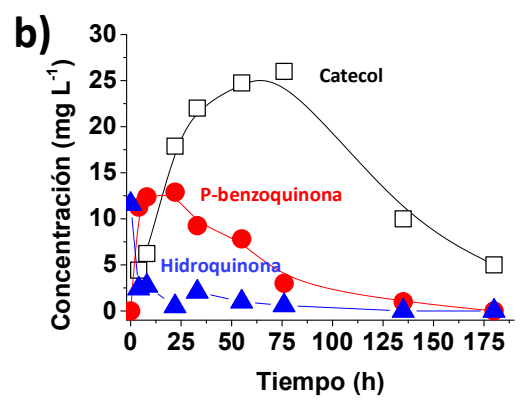

Figura 6.35. a) Degradación de fenol (•) y descomposición de $\mathrm{H}_{2} \mathrm{O}_{2}(\bullet)$ en presencia de DMSO (símbolo abierto) o en ausencia de DMSO (símbolo cerrado) utilizando hidroquinona como catalizador. b) Evolución de catecol $(\square), p$-benzoquinona $(\bullet)$ e hidroquinona $(\Delta)$ en ausencia de DMSO utilizando hidroquinona como catalizador. Condiciones de reacción: organocatalizador $(0.106 \mathrm{mM})$, fenol $\left(100 \mathrm{mg} \mathrm{L}^{-1}, 1.06 \mathrm{mM}\right), \mathrm{H}_{2} \mathrm{O}_{2}(200 \mathrm{mg}$ $\mathrm{L}^{-1}, 5.88 \mathrm{mM}$ ), ratio molar de DMSO respecto a $\mathrm{H}_{2} \mathrm{O}_{2}$ de $10, \mathrm{pH} 3,20{ }^{\circ} \mathrm{C}$. Concentración de fenol y organocatalizador obtenida por HPLC y de $\mathrm{H}_{2} \mathrm{O}_{2}$ por espectrofotometría, como se indica en el capítulo 8 , sección experimental.
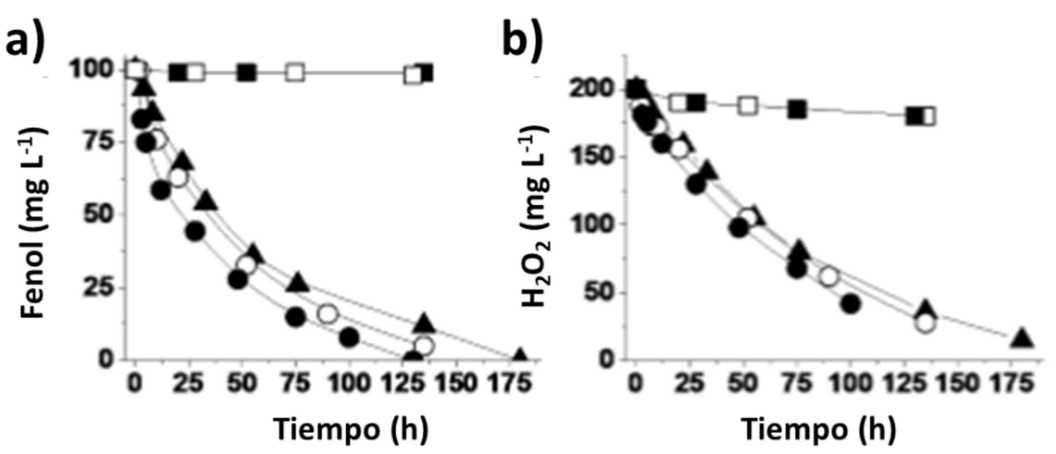

Figura 6.36. Degradación de fenol (a) y descomposición de $\mathrm{H}_{2} \mathrm{O}_{2}$ (b) utilizando hidroquinona $(\boldsymbol{\Delta})$, metoxihidroquinona $(\bullet)$ y metilhidroquinona ( $\circ$ ) como organocatalizadores. Degradación de fenol y descomposición de $\mathrm{H}_{2} \mathrm{O}_{2}$ utilizando metoxihidroquinona (a) o metilhidroquinona ( $\square$ ) en 
presencia de DMSO. Condiciones de reacción: organocatalizador $(0.106$ $\mathrm{mM})$, fenol $\left(100 \mathrm{mg} \mathrm{L}^{-1}, 1.06 \mathrm{mM}\right), \mathrm{H}_{2} \mathrm{O}_{2}\left(200 \mathrm{mg} \mathrm{L}^{-1}, 5.88 \mathrm{mM}\right)$, ratio molar de DMSO respecto a $\mathrm{H}_{2} \mathrm{O}_{2}$ de $10, \mathrm{pH} 3,20^{\circ} \mathrm{C}$. Concentración de fenol y organocatalizador obtenida por HPLC y de $\mathrm{H}_{2} \mathrm{O}_{2}$ por espectrofotometría, como se indica en el capítulo 8, sección experimental.

Finalmente, se evaluó la actividad catalítica de rGO frente a la de otros materiales basados en carbono, tales como grafito, MWCNTs y derivados. Se encontró que los otros materiales carbonosos también exhiben actividad catalítica para la degradación de Fenton del fenol (figura 6.37). Particularmente notable es la actividad catalítica de los nanotubos de carbono purificados tras su acortamiento químico, que para la degradación de fenol es similar a la que exhibe rGO. Merece hacerse notar que, sin embargo, durante el proceso, MWCNTs consume una cantidad significativamente más grande de $\mathrm{H}_{2} \mathrm{O}_{2}$ y, por consiguiente, la actividad catalítica de rGO es mucho mejor que las de grafito y MWCNTs en términos de eficiencia en la generación de $\mathrm{HO}^{\circ}$. Como se ha mencionado anteriormente, el catalizador óptimo de Fenton debería exhibir una selectividad completa en la descomposición de $\mathrm{H}_{2} \mathrm{O}_{2}$ en radicales hidroxilo. $\mathrm{Y}$ esto requiere que la $\mathrm{Ea}$ del consumo de fenol y la descomposición de $\mathrm{H}_{2} \mathrm{O}_{2}$ deban ser iguales, y que el número de equivalentes de $\mathrm{H}_{2} \mathrm{O}_{2}$ consumidos sea mínimo y próximo al valor teórico. Con respecto a la actividad catalítica del grafito, indicar que ha sido posible detectar la presencia de $\mathrm{G}$ a tiempos finales de reacción. Por consiguiente, el grafito podría actuar como un precursor de $\mathrm{G}$ que podría ser activo en la reacción. Esta hipótesis es consistente con la observación en el perfil temporal de la conversión de un período de inducción inicial (figura 6.36). Otro punto a destacar es el efecto positivo que el tratamiento oxidativo del material MWCNTs posee en su actividad catalítica, un hecho que puede ser atribuido a la generación de grupos funcionales oxigenados tales como quinona y/o hidroquinona. (Tabla 6.2. y figura 6.10). ${ }^{28}$ Conviene hacer notar, sin embargo, que no todos los grupos funcionales oxigenados serían activos para la descomposición tipo Fenton de $\mathrm{H}_{2} \mathrm{O}_{2}$ y que, de acuerdo con nuestra propuesta, sólo aquellas unidades hidroquinona/quinona de potencial redox suficiente podrían actuar como centros para la generación de radicales $\mathrm{HO}^{\circ}$, mientras que otros grupos funcionales oxigenados pueden descomponer $\mathrm{H}_{2} \mathrm{O}_{2}$ en agua y $\mathrm{O}_{2}$ sin formar radicales hidroxilo libres. En contraste, $\mathrm{AC}$ exhibe una actividad catalítica como catalizador para la degradación de fenol 
despreciable, promoviendo la desproporción de $\mathrm{H}_{2} \mathrm{O}_{2}$. La eliminación aparente de fenol observada para la muestra de AC corresponde simplemente a su adsorción (figura 6.37). En cualquier caso, los datos obtenidos sobre la actividad general de materiales de carbono, particularmente aquellos con estructura de grafeno, combinados con la actividad discutida anteriormente de $p$-benzoquinona e hidroquinona sustituidas, demuestran que el concepto de carbocatálisis para promover la reacción de Fenton es de general aplicación y podría llevar a desarrollo de un gran número de catalizadores libres de metales. A efectos de comparación, en las condiciones habitualmente empleadas en este capítulo, se estudió la actividad de un catalizador de referencia conteniendo nanopartículas de oro (1\% en peso; $10.8 \mathrm{~nm}$ de tamaño de partícula promedio) soportadas en nanopartículas de diamante tratada con Fenton, el cual ocasiona la degradación completa de fenol por $\mathrm{H}_{2} \mathrm{O}_{2}$ a pH 4 en 50 horas aproximadamente. ${ }^{24}$ Aunque menos activo, G o rGO como catalizadores libres de metales son capaces de llevar a cabo esta transformación en aproximadamente 150 horas a $\mathrm{pH} 3$ (figura 6.11) y podría representar un ejemplo de un catalizador con menor coste reemplazando metales nobles.

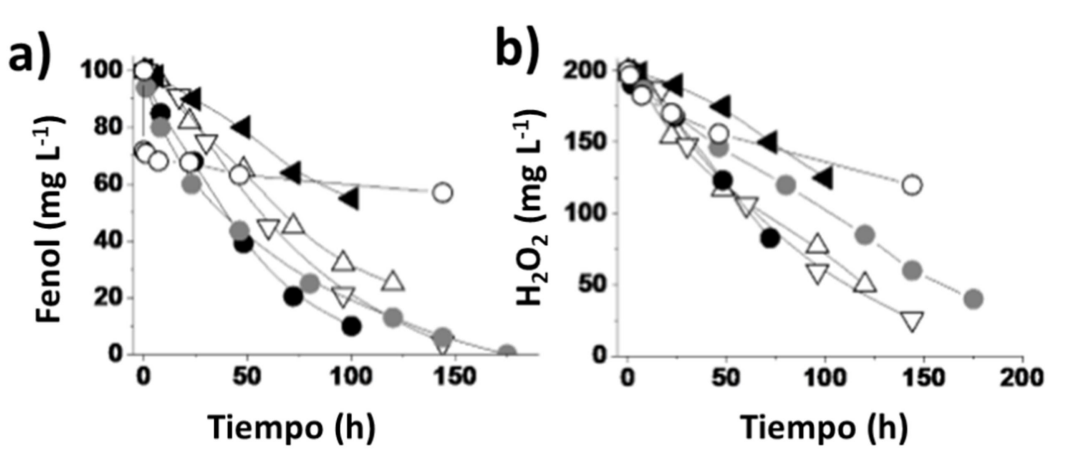

Figura 6.37. Degradación de fenol (a) y descomposición de $\mathrm{H}_{2} \mathrm{O}_{2}$ (b) utilizando diferentes catalizadores basados en carbono. Leyenda: rGO (•), CNTs- $\mathrm{HNO}_{3} / \mathrm{H}_{2} \mathrm{SO}_{4}(\bullet), \mathrm{CNTs}^{-} \mathrm{HNO}_{3}(\nabla)$, grafito $(\bullet), \mathrm{CNTs}(\Delta)$ y AC (o). Condiciones de reacción: catalizador $\left(5 \mathrm{mg}, 200 \mathrm{mg} \mathrm{L}^{-1}\right)$, fenol $\left(100 \mathrm{mg} \mathrm{L}^{-1}\right.$, $1.06 \mathrm{mM}), \mathrm{H}_{2} \mathrm{O}_{2}$ (200 mg L-1, $\left.5.88 \mathrm{mM}\right), \mathrm{pH} \mathrm{3,20}{ }^{\circ} \mathrm{C}$. Concentración de fenol obtenida por HPLC y de $\mathrm{H}_{2} \mathrm{O}_{2}$ por espectrofotometría, como se indica en el capítulo 8, sección experimental. 


\subsection{Conclusiones}

En el presente capítulo se ha demostrado que los grafenos pueden actuar como carbocatalizadores para la generación de radical hidroxilo a partir de $\mathrm{H}_{2} \mathrm{O}_{2}$, una reacción que hasta el momento presente ha sido descrita exclusivamente usando catalizadores conteniendo metales de transición. La composición y estructura de la muestra $\mathrm{G}$ determinan su actividad catalítica, que resultó máxima para rGO y G. En estos casos, la mínima selectividad hacia la generación de $\mathrm{HO}^{\circ}$ estimada fue del $82 \%$ y se alcanzaron valores de productividad muy elevados. Se observó incluso un aumento en la actividad con el reúso, pudiéndose llevar a cabo la reacción con pequeño exceso de $\mathrm{H}_{2} \mathrm{O}_{2}$. El concepto de catalizadores sin contener metales para la reacción de Fenton parece ser universal y esos catalizadores pueden estar basados en aquellos materiales que contengan ciertos grupos funcionales oxigenados, si estos actúan como centros redox del potencial adecuado para oxidar y reducir $\mathrm{H}_{2} \mathrm{O}_{2}$.

\subsection{Referencias}

[1] M. Stratakis, H. Garcia, Chem. Rev. 2012, 112, 4469-4506; R. Jana, T. P. Pathak, M. S. Sigman, Chem.Rev. 2011, 111, 1417-1492; T. Punniyamurthy, S.Velusamy, J. Iqbal, Chem. Rev. 2005, 105, 23292363; S. Navalón, M. Alvaro, H. Garcia, ChemCatChem 2013, 5, 3460-3480.

[2] D. R. Dreyer, C.W. Bielawski, Chem. Sci. 2011, 2, 1233-1240; C. Su, K. P. Loh, Acc. Chem. Res. 2013, 46, 2275-2285; D.S. Su, S. Perathoner, G. Centi, Chem. Rev. 2013, 113, 5782-5816.

[3] S. Navalon, A. Dhakshinamoorthy, M. Alvaro, H. Garcia, Chem. Rev. 2014, 114, 6179-6212.

[4] X.-K. Kong, C.-L. Chen,Q .-W. Chen, Chem. Soc. Rev. 2014, 43, 2841- 2857.

[5] D. R. Dreyer, R.S. Ruoff, C. W. Bielawski, Angew. Chem. Int. Ed. 2010, 49, 9336-9344; Angew.Chem. 2010, 122, 9524-9532.

[6] D. R. Dreyer, S. Park, C. W. Bielawski, R. S. Ruoff, Chem. Soc. Rev. 2010, 39, 228-240.

[7] A. Schaetz, M. Zeltner, W. J. Stark, ACS Catal. 2012, 2, 1267-1284; D.R. Dreyer, H.-P.Jia, C.W. Bielawski, Angew.Chem. Int. Ed. 2010, 49, 6813 ; Angew.Chem. 2010, 122, 6965-6816.

[8] A. Primo, S. Navalón, A.M. Asiri, H. García, Chem. Eur.J. 2015, 21, 324-330. 
[9] Y. Zhao, W.-F. Chen, C.-F. Yuan, Z.-Y. Zhu, L.-F. Yan, Chin. J. Chem. Phys. 2012, 25, 335-338.

[10] J. J. Pignatello, E. Oliveros, A. Mackay, Crit. Rev. Environ. Sci. Technol. 2006, 36, 1-84.

[11] E. Neyens, J. Baeyens, J. Hazard. Mater, 2003, 98, 33-50.

[12] M. Pera-Titus, V. García-Molina, M. A. Baños, J. Giménez, S. Esplugas, Appl. Catal. B 2004, 47, 219-256.

[13] S. Navalón, M. Álvaro, H. García, Appl. Catal. B 2010, 99, 1-26.

[14] S. Navalón, A. Dhakshinamoorthy, M. Álvaro, H. García, ChemSusChem 2011, 4, 1712-1730.

[15] A. Dhakshinamoorthy, S. Navalón, M. Álvaro, H. García, ChemSusChem 2012, 5, 46-64.

[16] A. Dhakshinamoorthy, A. Primo, P. Concepción, M. Alvaro, H. García, Chem. Eur.J. 2013, 19, 7547-7554.

[17] L.-Y. Meng, S.-J. Park, Adv. Mater. Res. 2010, 123-125, 787-790; C.D. Zangmeister, Chem. Mater. 2010, 22, 5625-5629; M. Jin, H.Y. Jeong, T.H. Kim, K. P. So, Y. Cui, W. J. Yu, E.J.R a, Y. H. Lee, J. Phys. D 2010, 43, 275402.

[18] A. Primo, P. Atienzar, E. Sánchez, J. M. Delgado, H. García, Chem. Commun. 2012, 48, 9254-9256.

[19] A. Primo, E. Sánchez, J. M. Delgado, H. García, Carbon 2014, 68, $777-783$.

[20] D. Koniosa, M. M. Stylianakis, E. Stratakis, E. Kymakis, J. Colloid Interface Sci. 2014, 430, 108-112.

[21] D. R. Dreyer, A.D. Todd, C.W. Bielawski, Chem. Soc. Rev. 2014, 43, 5288- 5301.

[22] A. Mahmood, S.A li, H. Saleem, T. Hussain, Asian J. Chem. 2011, 23, 3875-3878; C.M. Silva, P.L. Silva, J.R. Pliego, Int. J. Quantum Chem. 2014, 114, 501-507; J.-H. Sun, S.-P. Sun, G.-L. Wang, L.-P. Qiao, Dyes Pigm. 2007, 74, 647-652.

[23] A. Bagri, C. Mattevi, M. Acik, Y. J. Chabal, M. Chhowalla, V. B. Shenoy, Nat. Chem. 2010, 2, 581-587; S. Choudhary, H.P. Mungse, O. P. Khatri, Chem. Asian J. 2013, 8, 2070-2078.

[24] S. Navalón, R. Martín, M. Álvaro, H. García, Angew.Chem. Int. Ed. 2010, 49, 8403-8407; Angew.Chem. 2010, 122, 8581-8585.

[25] R. Martín, S. Navalón, J.J. Delgado, J.J. Calvino, M. Álvaro, H. García, Chem. Eur.J .2011, 17, 9494-9502.

[26] P. Wu, P. Du, H. Zhang, C. Cai, Phys. Chem. Chem. Phys. 2013, 15, 6920- 6928.

[27] M. J. Burkitt, R. P. Mason, Proc. Natl. Acad. Sci. USA 1991, 88, 8440- 8444; S. Navalón, R. Martín, M. Álvaro, H. García, ChemSusChem. 2011, 4, 650-657; S. Navalon, D. Sempere, M. Álvaro, H. García, ACS Appl. Mater. Interfaces 2013, 5, 7160-7169.

[28] P. Slobodian, P. Riha, P. Cavallo, C. A. Barbero, R. Benlikaya, U. Cvelbar, D . Petras, P. Saha, J. Nanomater. 2014, 589627; J.Zhang, H. Zou, Q. Qing, Y. Yang, Q. Li, Z. Liu, X. Guo, Z. Du, J. Phys. 
Capitulo 6

Chem. B, 2003, 107, 3712-3718; D.B. Mawhinney, V. Naumenko, A. Kuznetsova, J.J.T. Yates, J. Am. Chem. Soc. 2000, 122, 23832374. 



\section{Capítulo 7}

Óxido de grafeno reducido como

catalizador libre de metales en la reacción tipo

Fenton asistida por luz 



\subsection{Introducción}

Como se viene comentando, existe un interés considerable en explotar el potencial que poseen los grafenos como catalizadores libres de metales. $^{1-5}$ En ausencia de metales, los grafenos exhiben actividad catalítica en la oxidación de compuestos bencílicos, ${ }^{6,7}$ alcoholes, ${ }^{6,8}$ y aminas $^{9}$ así como en la hidrogenación de enlaces múltiples $\mathrm{C}^{-\mathrm{C}^{10}} \mathrm{y}$ compuestos nitro aromáticos, ${ }^{11}$ entre otras reacciones. ${ }^{2-4,12}$ Uno de los retos en carbocatálisis por Gs es demostrar que estos materiales pueden exhibir actividad catalítica para reacciones que hasta ahora se creían que eran promovidas exclusivamente por metales, tales como acoplamientos $\mathrm{C}-\mathrm{C}$, condensaciones, transposiciones y algunos tipos de oxidaciones. ${ }^{2-4}$ En este contexto, la reacción de Fenton consiste, como ya se ha indicado, en la generación de radicales $\mathrm{HO}^{\circ}$ en agua por la reducción monoelectrónica de $\mathrm{H}_{2} \mathrm{O}_{2}$. El reactivo típico para la reacción de Fenton es $\mathrm{Fe}^{2+}$, el cual es usado comúnmente en cantidades estequiométricas. ${ }^{13,14} \mathrm{En}$ el capítulo anterior hemos descrito que el rGO es un catalizador libre de metales adecuado para promover la reacción de Fenton a valores de $\mathrm{pH}$ ácidos (pH aproximadamente 3). ${ }^{15} \mathrm{Si}$ se considera que GO y otros tipos de Gs pueden ser usados como semiconductores ${ }^{16}$ y que una alternativa para la reacción de Fenton es, como se ha indicado anteriormente, la reacción de foto-Fenton, ${ }^{14,17}$ es de interés ampliar los estudios del capítulo 6 sobre la actividad catalítica de rGO como catalizador de Fenton para determinar si la luz puede asistir también en este caso la reacción de Fenton catalizada por rGO. ${ }^{15}$ En el proceso de foto-Fenton más simple, una sal de $\mathrm{Fe}^{2+}$ en cantidades catalíticas se irradia con luz UV-Vis a fin de promover la reacción de Fenton. ${ }^{14,28}$ En el mecanismo de reacción afectado, la irradiación de iones $\mathrm{Fe}^{3+}$ hidratados a longitudes de onda en torno a $300 \mathrm{~nm}$ conduce a la reducción de $\mathrm{Fe}^{3+}$ a $\mathrm{Fe}^{2+}$ y la generación de un radical hidroxilo a partir de la oxidación de las moléculas de agua fuertemente asociadas a los iones $\mathrm{Fe}^{3+} \cdot{ }^{14,18} \mathrm{~A}$ continuación, el ion $\mathrm{Fe}^{2+}$ reaccionaría espontáneamente con $\mathrm{H}_{2} \mathrm{O}_{2}$ para formar $\mathrm{Fe}^{3+}$ y un segundo radical hidroxilo, cerrando así el ciclo catalítico basado en el par $\mathrm{Fe}^{3+} / \mathrm{Fe}^{2+}$.

Las ecuaciones 7.1 y 7.2 muestran las dos etapas del mecanismo que consisten en la reducción fotoinducida de $\mathrm{Fe}^{3+}$ y la oxidación espontánea de $\mathrm{Fe}^{2+} \cdot 14,18,19$ 


$$
\begin{aligned}
& \mathrm{Fe}^{2+}+\mathrm{H}_{2} \mathrm{O}_{2} \underset{\mathrm{pH} 3\left(\mathrm{H}_{2} \mathrm{SO}_{4}\right)}{\longrightarrow} \mathrm{Fe}^{3+}+\mathrm{HO}^{\prime}+\mathrm{HO}^{-} \\
& \mathrm{Fe}(\mathrm{OH})_{2}{ }^{+} \underset{\mathrm{pH} 3\left(\mathrm{H}_{2} \mathrm{SO}_{4}\right)}{\stackrel{\mathrm{UVNi}}{\longrightarrow}} \mathrm{Fe}^{2+}+\mathrm{HO}^{-}
\end{aligned}
$$

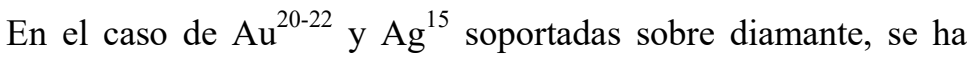
descrito que la irradiación con luz solar natural puede asistir la actividad de estos materiales como catalizadores de Fenton. Las Au NPs y Ag NPs exhiben una banda de absorción característica en la región del visible conocida generalmente como la banda del plasmón. ${ }^{23}$ Tras excitación de las $\mathrm{Au}$ NPs y Ag NPs en las respectivas bandas de plasmón, varios procesos fotofísicos pueden tener lugar, incluyendo la fotoeyección de electrones desde el metal al $\mathrm{H}_{2} \mathrm{O}_{2}$, resultando en la generación de radicales hidroxilo. ${ }^{15,21}$ A la vista de estos precedentes, y si se considera que GO y Gs relacionados pueden sufrir separación de cargas fotoinducida, ${ }^{24}$ es importante establecer la posible influencia de la luz en la actividad catalítica de estos materiales como catalizadores de Fenton sin contener metales. Este capítulo describe que la luz asiste la reducción monoelectrónica de $\mathrm{H}_{2} \mathrm{O}_{2}$ debido a la presencia de $\mathrm{rGO}$ como fotocatalizador.

\subsection{Resultados y discusión}

Como en los capítulos anteriores, se seleccionó el fenol como molécula sonda para establecer la operación de la reacción de Fenton. Se midió tanto la desaparición del fenol como el consumo de $\mathrm{H}_{2} \mathrm{O}_{2}$ en función del tiempo de reacción. Las medias de AFM sobre el grado de exfoliación de $\mathrm{rGO}$ en las condiciones de reacción mostraron una distribución de espesor de capa de entre 0.4 a $2.2 \mathrm{~nm}$ con una media de 1 $\mathrm{nm}$ aproximadamente (figura 7.1). Esto corresponde a una situación en la que la suspensión contiene un rGO de aproximadamente $1-4$ capas. También en las primeras fases del estudio se determinó la posible influencia de los iones $\mathrm{Mn}^{2+}$ que pudieran contaminar la muestra de rGO sobre la degradación del fenol, tipo foto-Fenton asistida por luz. Es conocido que GO puede estar contaminado por iones $\mathrm{Mn}^{2+}$ provenientes de la etapa de la oxidación del grafito. El análisis químico establece que el contenido de $\mathrm{Mn}$ en rGO es de 40 ppm. ${ }^{2,15}$ A fin de discutir la posible actividad catalítica de las trazas de $\mathrm{Mn}^{2+}$ que pudieran estar como impurezas, se llevó a cabo un experimento control en el que $\mathrm{MnSO}_{4}$, que 
podría formarse en la oxidación de Hummers, en una cantidad que corresponde a $0.14 \mathrm{mg} \mathrm{L}^{-1}$ fue añadida a propósito. Los resultados demuestran que la presencia de $\mathrm{Mn}^{2+}$ en este rango de concentraciones no muestra ninguna influencia (figura 7.2).

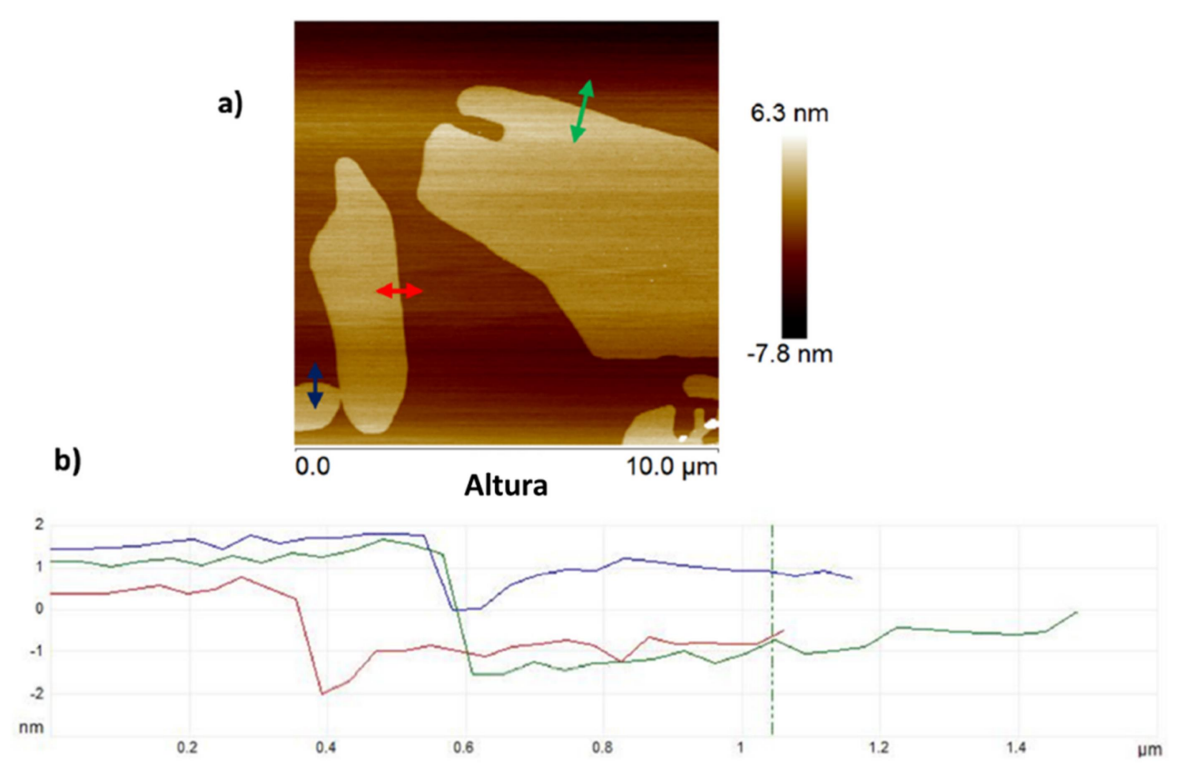

Figura 7.1. Imagen de AFM de una muestra de rGO (a) y perfil de variaciones de altura correspondientes a las líneas representadas en la imagen a), en verde, rojo y azul.

a)

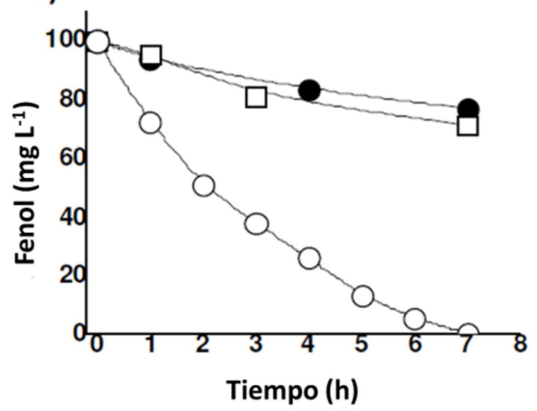

b)

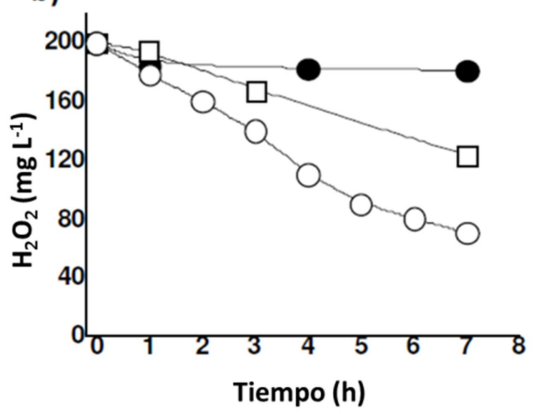

Figura 7.2. Perfiles temporales para la degradación de fenol (a) y descomposición de $\mathrm{H}_{2} \mathrm{O}_{2}$ (b) bajo irradiación con luz solar artificial simulada, 
utilizando GO (•), rGO reducido parcialmente (口) y rGO (०) como catalizadores. Condiciones de reacción: Catalizador $\left(5 \mathrm{mg}, 200 \mathrm{mg} \mathrm{L}^{-1}\right)$, fenol (100 mg L $\left.{ }^{-1} ; 1.06 \mathrm{mM}\right), \mathrm{H}_{2} \mathrm{O}_{2}\left(200 \mathrm{mg} \mathrm{L}^{-1} ; 5.88 \mathrm{mM}\right), \mathrm{pH}$ 3. Concentración de fenol obtenida por HPLC y de $\mathrm{H}_{2} \mathrm{O}_{2}$ por espectrofotometría, como se indica en el capítulo 8 , sección experimental.

La influencia del valor de $\mathrm{pH}$ inicial en la actividad catalítica de rGO para promover la degradación de Fenton del fenol en la oscuridad o bajo radiación con luz solar simulada se presenta en la figura 7.3 y la 7.4. A pHs por debajo de 5.0, el rGO fue capaz de promover la desaparición de fenol aumentando en actividad con la disminución del valor de $\mathrm{pH}$ inicial, disminuyendo en el rango entre 4.5 y 3.0. Es importante destacar que en todos los casos, además de la desaparición del fenol, el consumo de $\mathrm{H}_{2} \mathrm{O}_{2}$ aumenta por irradiación con luz solar natural con respecto a un experimento bajo las mismas condiciones en la oscuridad (figura 7.4). Experimentos de control llevados a cabo en ausencia de rGO por tratamiento de fenol con $\mathrm{H}_{2} \mathrm{O}_{2}$ a $\mathrm{pH} 3$ iluminados por luz solar natural a $\mathrm{pH} 3$, y la presencia de rGO expuesto a luz solar natural, pero en ausencia de $\mathrm{H}_{2} \mathrm{O}_{2}$ muestran una conversión despreciable (figura 7.5). Estos experimentos preliminares prueban convincentemente que la irradiación con luz solar aumenta la actividad catalítica de rGO para la reacción de foto-Fenton. Esto disminuye los tiempos atribuidos para completar la degradación del fenol desde $150 \mathrm{~h}$ en la oscuridad hasta menos de $7 \mathrm{~h}$ bajo iluminación con luz solar. Este tiempo más corto es una consecuencia de la mayor velocidad de generación de radicales $\mathrm{HO}^{\circ}$ a partir del $\mathrm{H}_{2} \mathrm{O}_{2}$ mediante un proceso similar al indicado en la ecuación 7.1. Más aun, la irradiación con luz solar natural puede mitigar la gran dependencia de la actividad catalítica de la reacción de Fenton con el $\mathrm{pH}^{14,25}$ En otras palabras, aunque en la oscuridad rGO sólo exhibe actividad catalítica para valores de $\mathrm{pH}$ por debajo de 3.5 , la irradiación amplía el rango de pHs a 4.5 (figura7.3 y 7.4), lo cual es de gran importancia en el tratamiento de aguas residuales. La operación de la degradación de fenol de tipo Fenton asistida por luz solar a valores de $\mathrm{pH}$ algo superiores que el proceso análogo en la oscuridad sería una consecuencia de la mayor eficiencia de generación de radicales $\mathrm{HO}^{\circ}$ a partir de $\mathrm{H}_{2} \mathrm{O}_{2}$ por irradiación. 

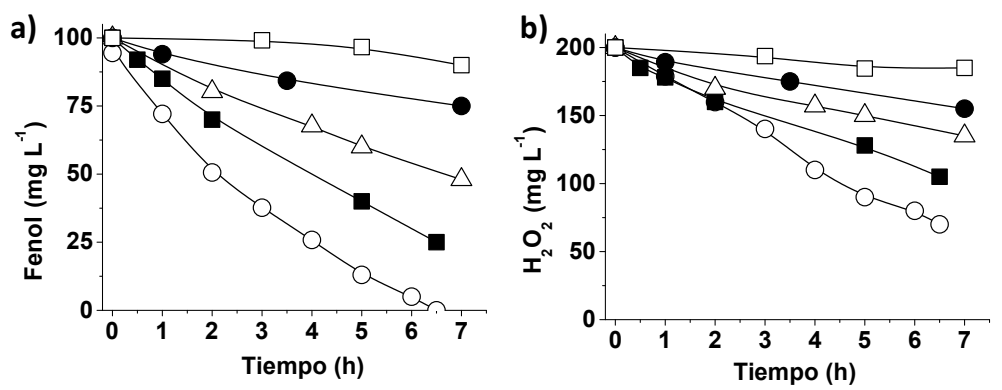

Figura 7.3. Perfiles temporales para la degradación de fenol (a) y descomposición de $\mathrm{H}_{2} \mathrm{O}_{2}$ (b) bajo irradiación con luz solar natural, utilizando rGO como catalizador, en función del valor de $\mathrm{pH}$ inicial. Leyenda: $\mathrm{pH} 3.0$ $(\circ), 3.5(\bullet), 4.0(\Delta), 4.5(\bullet)$ y $5.0(\square)$. Condiciones de reacción: Catalizador (5 mg, $\left.200 \mathrm{mg} \mathrm{L}^{-1}\right)$, fenol (100 mg L $\left.\mathrm{mg}^{-1} 1.06 \mathrm{mM}\right), \mathrm{H}_{2} \mathrm{O}_{2}\left(200 \mathrm{mg} \mathrm{L}^{-1} ; 5.88\right.$ $\mathrm{mM}), \mathrm{pH}$ según se indica en la leyenda. Concentración de fenol obtenida por HPLC y de $\mathrm{H}_{2} \mathrm{O}_{2}$ por espectrofotometría, como se indica en el capítulo 8, sección experimental. 

la reacción tipo Fenton asistida por luz

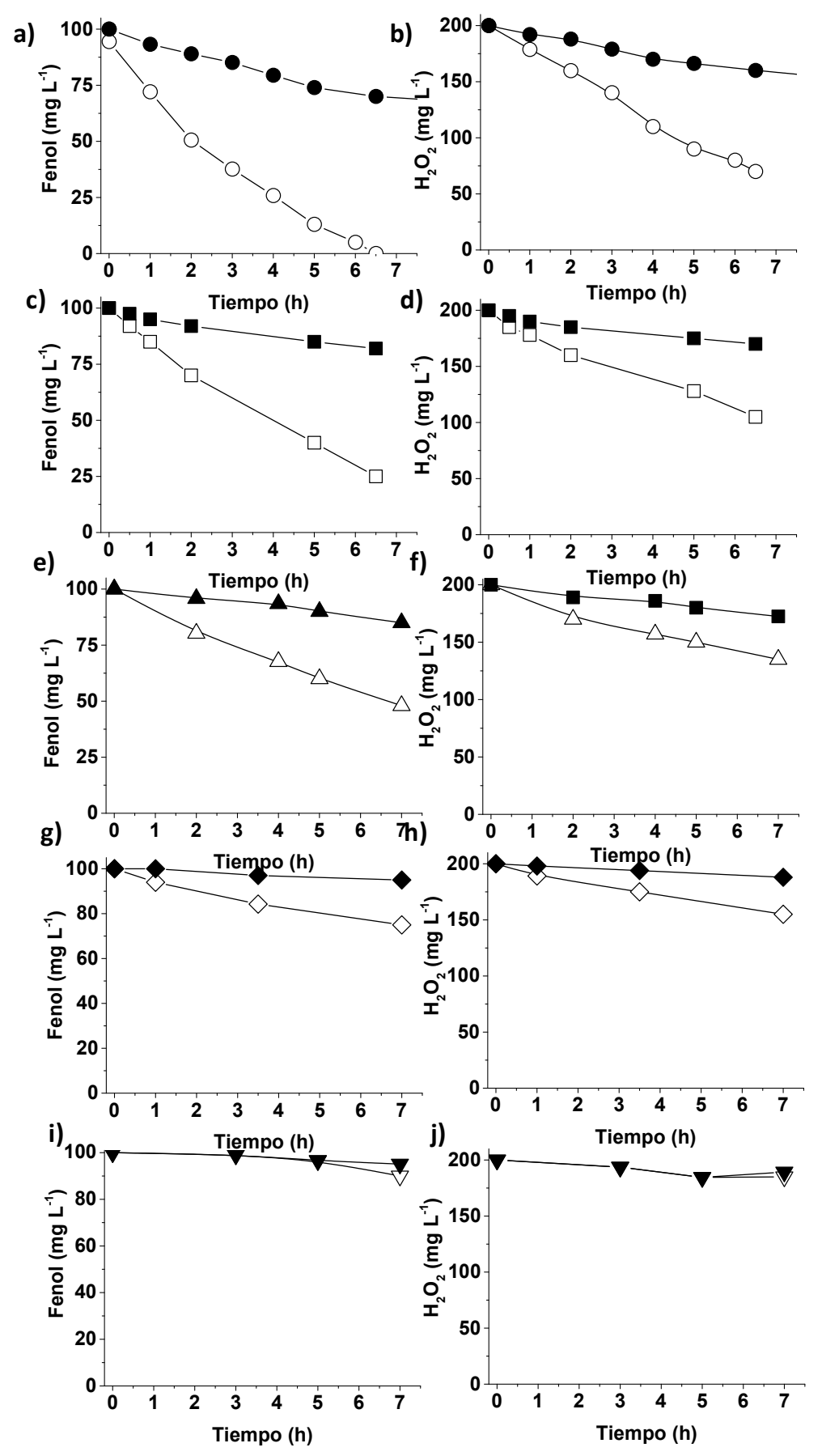


Figura 7.4. Perfiles temporales para la degradación de fenol (a) y descomposición de $\mathrm{H}_{2} \mathrm{O}_{2}$ (b) utilizando $\mathrm{rGO}$ como catalizador en ausencia de irradiación (símbolos cerrados) o en presencia de irradiación solar natural (símbolos abiertos), en función del valor de $\mathrm{pH}$ inicial. Leyenda: $\mathrm{pH} 3.0$ (a, b), $3.5(\mathrm{c}, \mathrm{d}), 4.0(\mathrm{e}, \mathrm{f}), 4.5(\mathrm{~g}, \mathrm{~h})$ y $5.0(\mathrm{i}, \mathrm{j})$. Condiciones de reacción: Catalizador (200 mg L $\mathrm{m}^{-1}$ ), fenol (100 mg L $\left.\mathrm{m}^{-1} ; 1.06 \mathrm{mM}\right), \mathrm{H}_{2} \mathrm{O}_{2}(5 \mathrm{mg}, 200 \mathrm{mg}$ $\left.\mathrm{L}^{-1} ; 5.88 \mathrm{mM}\right), \mathrm{pH}$ según se indica en la leyenda. Concentración de fenol obtenida por HPLC y de $\mathrm{H}_{2} \mathrm{O}_{2}$ por espectrofotometría, como se indica en el capítulo 8 , sección experimental.
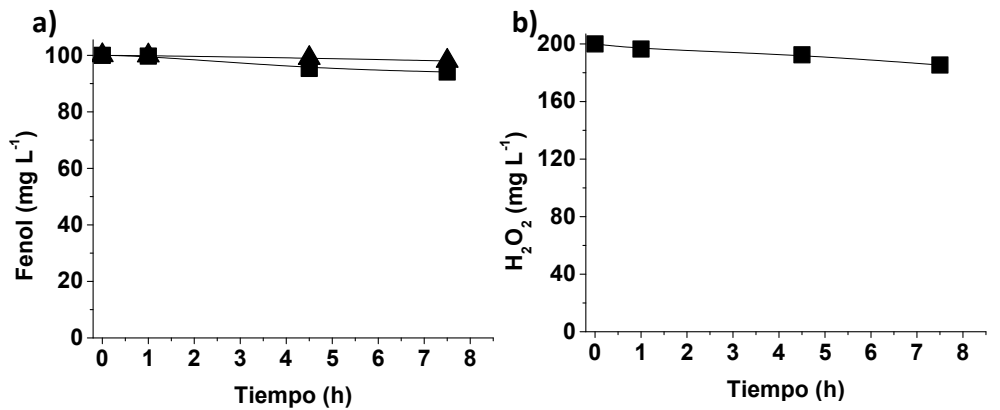

Figura 7.5. Perfiles temporales para la degradación de fenol (a) y descomposición de $\mathrm{H}_{2} \mathrm{O}_{2}$ (b) bajo irradiación solar natural en ausencia de catalizador ( $\boldsymbol{\bullet}$ ), y en presencia de catalizador pero en ausencia de $\mathrm{H}_{2} \mathrm{O}_{2}(\boldsymbol{\Lambda})$. Condiciones de reacción: Catalizador, si procede $\left(5 \mathrm{mg}, 200 \mathrm{mg} \mathrm{L}^{-1}\right)$; fenol (100 mg L-1 $1.06 \mathrm{mM}$ ); $\mathrm{H}_{2} \mathrm{O}_{2}$, si procede (200 mg L $\left.\mathrm{L}^{-1} ; 5.88 \mathrm{mM}\right) ; \mathrm{pH} 3$. Concentración de fenol obtenida por HPLC y de $\mathrm{H}_{2} \mathrm{O}_{2}$ por espectrofotometría, como se indica en el capítulo 8, sección experimental.

En este contexto, un objetivo constante en la catálisis en la reacción de Fenton es desarrollar un material eficiente que pueda operar a valores de $\mathrm{pH}$ próximos a la neutralidad con el mínimo exceso de $\mathrm{H}_{2} \mathrm{O}_{2}$. ${ }^{26-}$ ${ }^{28} \mathrm{El} \mathrm{H}_{2} \mathrm{O}_{2}$ es un reactivo químico relativamente costoso y la cantidad que se emplee en la reacción de Fenton debe ser optimizada para asegurar que el proceso es económicamente atractivo. ${ }^{26,27}$ De acuerdo con esto, en el presente capítulo se optimizó el exceso de $\mathrm{H}_{2} \mathrm{O}_{2}$ requerido en la degradación de fenol en la reacción de Fenton asistida por luz, promovida por rGO a un valor de $\mathrm{pH}$ inicial de 3 . Los resultados se muestran en la figura 7.6. Esta figura muestra que son necesarios 5.5 equivalentes de $\mathrm{H}_{2} \mathrm{O}_{2}$ para conseguir la desaparición completa del fenol en menos de 7 horas. El empleo de tan solo 4 equivalentes de $\mathrm{H}_{2} \mathrm{O}_{2}$ resulta en un 
consumo completo de $\mathrm{H}_{2} \mathrm{O}_{2}$ a las $7 \mathrm{~h}$ sin alcanzar la desaparición completa de fenol. Excesos molares de $\mathrm{H}_{2} \mathrm{O}_{2}$ más bajos resultan en conversiones de fenol incluso menores cuando se alcanza el consumo completo de $\mathrm{H}_{2} \mathrm{O}_{2}$.
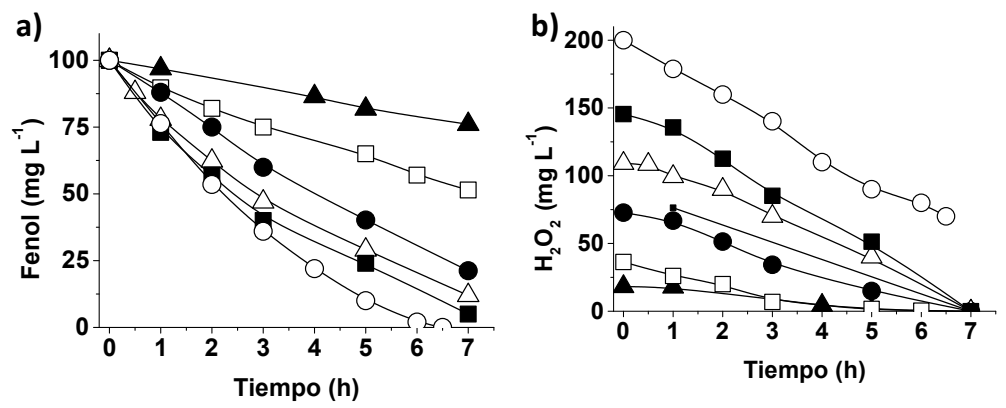

Figura 7.6. Influencia de la relación molar $\mathrm{H}_{2} \mathrm{O}_{2}$ /fenol en a) degradación del fenol y b) descomposición de $\mathrm{H}_{2} \mathrm{O}_{2}$ empleando rGO como catalizador bajo iluminación con luz solar natural. Leyenda: relación molar $\mathrm{H}_{2} \mathrm{O}_{2}$ /fenol de 0.5 $(\Delta), 1.0(\square), 2(\bullet), 3(\Delta), 4(\bullet)$ y $5.5(\circ)$. Condiciones de reacción: catalizador $\left(5 \mathrm{mg}, 200 \mathrm{mg} \mathrm{L}^{-1}\right)$, fenol $\left(100 \mathrm{mg} \mathrm{L}^{-1} ; 1.06 \mathrm{mM}\right)$, relación molar $\mathrm{H}_{2} \mathrm{O}_{2}$ /fenol según se indica en la leyenda. Concentración de fenol obtenida por HPLC y de $\mathrm{H}_{2} \mathrm{O}_{2}$ por espectrofotometría, como se indica en el capítulo 8, sección experimental.

Desde el punto de vista del tratamiento de aguas residuales, además de fenol, los compuestos aromáticos que se forman como intermedios en el proceso deben igualmente ser descompuestos, ya que estos intermedios presentan una toxicidad superior a la del fenol. ${ }^{29}$ Es conocido que el ataque de radicales hidroxilo al fenol resulta en la formación de hidroquinona, catecol y $p$-benzoquinona, los cuales son considerablemente más tóxicos que el fenol. ${ }^{15,29}$ Por consiguiente, el exceso óptimo de $\mathrm{H}_{2} \mathrm{O}_{2}$ debe conducir no solo a la desaparición completa del fenol, sino también a la descomposición de hidroquinona, catecol y $p$ benzoquinona. Aunque el empleo de 5.5 equivalentes de $\mathrm{H}_{2} \mathrm{O}_{2}$ resulta en la desaparición completa de fenol, hidroquinona, catecol y $p$ benzoquinona (figuras 7.7 y 7.8), el empleo de sólo 4 equivalentes de $\mathrm{H}_{2} \mathrm{O}_{2}$ resulta en la presencia no sólo de una concentración residual de fenol, sino más importante aún en una concentración significativa de hidroquinona acompañada de algo de catecol y $p$-benzoquinona (figura 7.8). Por consiguiente, el exceso mínimo de $\mathrm{H}_{2} \mathrm{O}_{2}$ para el proceso fue de 
5.5 equivalentes. Este exceso de $\mathrm{H}_{2} \mathrm{O}_{2}$ requerido para degradar el fenol y sus intermedios de reacción aromáticos tan bajo compara favorablemente con los resultados de un estudio relacionado que usa nitruro de boro como catalizador libre de metales para la reacción de Fenton, donde son necesarios 11 equivalentes de $\mathrm{H}_{2} \mathrm{O}_{2}$. Es importante hacer notar que rGO es un fotocatalizador libre de metales que se comporta similarmente a algunos de los catalizadores de foto-Fenton más activos basados en $\mathrm{Au}^{21}$ o $\mathrm{Ag},{ }^{30}$ ambos metales soportados en diamante pretratado a fin de aumentar la eficiencia en la descomposición de $\mathrm{H}_{2} \mathrm{O}_{2}$ a radicales hidroxilo. Otros estudios en los cuales se ha utilizado un catalizador conteniendo metales emplean excesos de $\mathrm{H}_{2} \mathrm{O}_{2}$ en torno a 1000 y a veces hasta $100000 .^{27}$

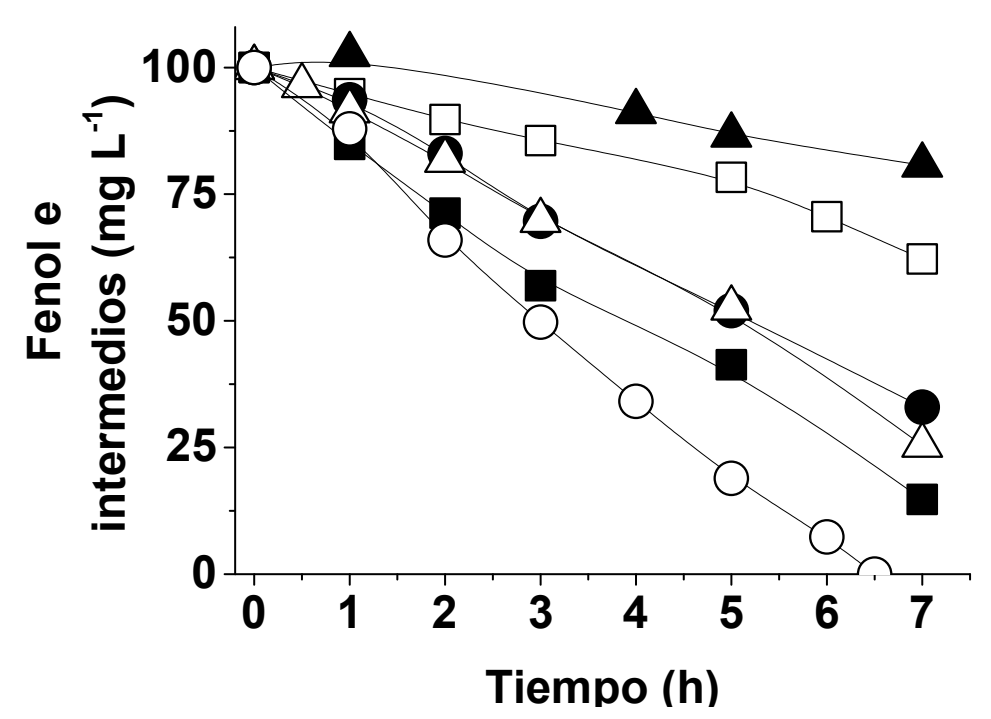

Figura 7.7. Influencia de la relación molar $\mathrm{H}_{2} \mathrm{O}_{2}$ /fenol para la degradación de fenol y sus principales intermedios, utilizando rGO como catalizador bajo irradiación solar natural. Leyenda: relación molar $\mathrm{H}_{2} \mathrm{O}_{2} /$ fenol de $0.5(\boldsymbol{\Delta}), 1.0$ $(\square), 2(\bullet), 3(\Delta), 4(\bullet)$ y $5.5(\circ)$. Condiciones de reacción: catalizador $(5 \mathrm{mg}$, $\left.200 \mathrm{mg} \mathrm{L}^{-1}\right)$, fenol $\left(100 \mathrm{mg} \mathrm{L}^{-1} ; 1.06 \mathrm{mM}\right.$ ), relación molar $\mathrm{H}_{2} \mathrm{O}_{2} /$ fenol según se indica en la leyenda, $\mathrm{pH} 3$. Concentración de fenol e intermedios obtenida por HPLC y de $\mathrm{H}_{2} \mathrm{O}_{2}$ por espectrofotometría, como se indica en el capítulo 8, sección experimental. 

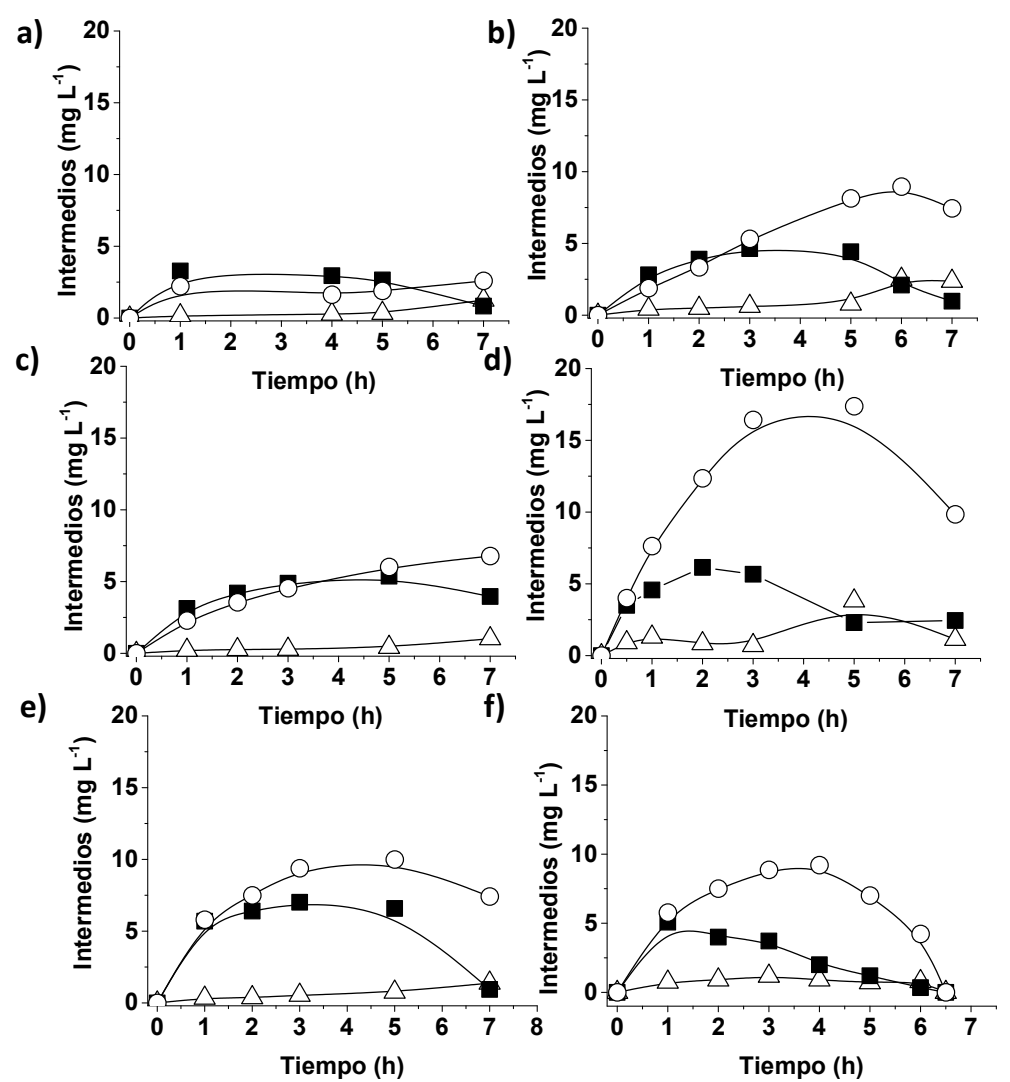

Figura 7.8. Influencia de la relación molar $\mathrm{H}_{2} \mathrm{O}_{2}$ /fenol en la evolución de

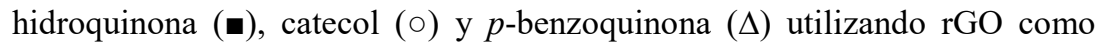
catalizador bajo irradiación solar natural. Leyenda: relación molar $\mathrm{H}_{2} \mathrm{O}_{2} /$ fenol de 0.5 (a), 1.0 (b), 2 (c), 3 (d), 4 (e) y 5.5 (f). Condiciones de reacción: catalizador (5 mg, $\left.200 \mathrm{mg} \mathrm{L}^{-1}\right)$, fenol $\left(100 \mathrm{mg} \mathrm{L}^{-1} ; 1.06 \mathrm{mM}\right)$, relación molar $\mathrm{H}_{2} \mathrm{O}_{2} /$ fenol según se indica en la leyenda, $\mathrm{pH}$ 3. Concentración de fenol e intermedios obtenida por HPLC y de $\mathrm{H}_{2} \mathrm{O}_{2}$ por espectrofotometría, como se indica en el capítulo 8 , sección experimental.

Por consiguiente, rGO descompone $\mathrm{H}_{2} \mathrm{O}_{2}$ a radicales $\mathrm{HO}$ eficientemente, lo cual se confirmó también por espectroscopía de EPR y experimentos de inhibición.

Una vez se seleccionaron los valores de $\mathrm{pH}$ adecuados y el exceso molar de $\mathrm{H}_{2} \mathrm{O}_{2}$ óptimo, se llevaron a cabo una serie de 
experimentos de reúsos que emplean la misma muestra de rGO en presencia de un gran exceso de fenol $\left(1000 \mathrm{mg} \mathrm{L}^{-1}\right)$ con respecto al catalizador $\left(200 \mathrm{mg} \mathrm{L}^{-1}\right)$. Los resultados se muestran en la figura 7.9. rGO fue capaz de promover la degradación de disoluciones acuosas concentradas de fenol 8 veces consecutivas sin que se aprecie una disminución en su actividad catalítica. Una comparación de los perfiles temporales mostrados en la figura 7.9 demuestra la fotoestabilidad del rGO bajo condiciones de foto-Fenton. Se observó que la actividad catalítica de la muestra de rGO usada incluso aumenta gradualmente. Aunque la reusabilidad de algunos carbocatalizadores bajo condiciones altamente oxidantes en otros procesos de oxidación avanzada ha sido baja, ${ }^{2}$ éste no parece ser el caso bajo las condiciones de reacción empleadas en este capítulo, tal como evidencia la figura 7.9. Ello es debido probablemente a las condiciones suaves de los experimentos. Un aumento similar de la actividad catalítica ha sido observado previamente para rGO en el capítulo anterior en ausencia de luz, atribuyéndose este efecto a pequeñas modificaciones en $\mathrm{rGO}$ por introducción de grupos hidroxilo sobre la lámina de $\mathrm{rGO}$. Los radicales $\mathrm{HO}^{\circ}$ se encuentran entre las especies químicas más agresivas que pueden estar presentes en agua y son capaces de atacar virtualmente a cualquier compuesto orgánico. ${ }^{13,14}$ Por consiguiente, se propone que una cierta proporción de los radicales $\mathrm{HO}^{\circ}$ podrían atacar a rGO produciendo un cierto grado de hidroxilación. ${ }^{15}$ La consecuencia de esta hidroxilación es que con el reúso, rGO deviene más hidrofílico y más fácilmente dispersable de lo que lo era la muestra inicial de rGO, siendo aun convenientemente recuperable por filtración. En el cuarto uso, la agitación magnética es suficiente para dispersar totalmente el catalizador rGO que viene siendo reusado, no siendo necesaria la sonicación de la muestra. 

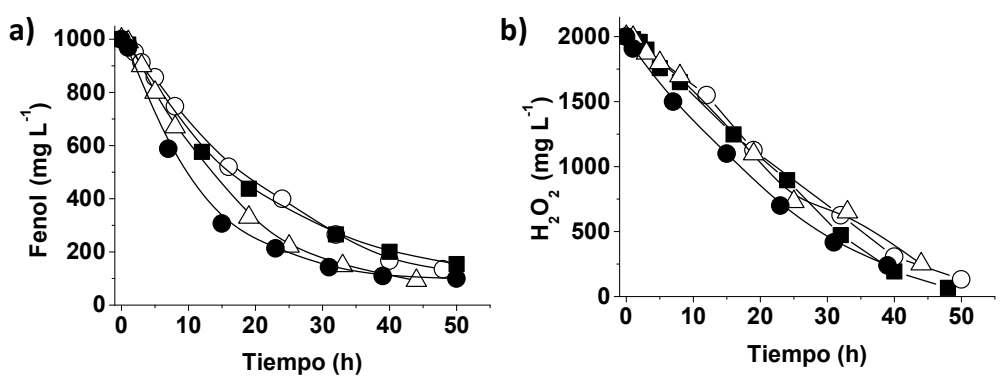

Figura 7.9. Ensayos de productividad para la degradación de fenol (a) y descomposición de $\mathrm{H}_{2} \mathrm{O}_{2}$ (b) empleando $\mathrm{rGO}$ como catalizador bajo irradiación con luz solar simulada. Leyenda: $1^{\circ}$ uso $(0), 2^{\circ}$ uso $(\mathbf{\square}), 4^{\circ}$ uso $(\Delta)$ y $8^{\circ}$ uso $(\bullet)$. Condiciones de reacción: catalizador $\left(5 \mathrm{mg}, 200 \mathrm{mg} \mathrm{L}^{-1}\right)$, fenol (1000 mg L $\left.{ }^{-1}\right), \mathrm{H}_{2} \mathrm{O}_{2}\left(2000 \mathrm{mg} \mathrm{L}^{-1}\right)$, $\mathrm{pH}$ inicial 3, irradiación con luz solar simulada. Concentración de fenol obtenida por HPLC y de $\mathrm{H}_{2} \mathrm{O}_{2}$ por espectrofotometría, como se indica en el capítulo 8 , sección experimental.

La propuesta de hidroxilación gradual de rGO con el uso como catalizador de la reacción de Fenton está apoyada por los datos de análisis químico, comparando la relación atómica $\mathrm{C} / \mathrm{O}$ de la muestra fresca (5.9) con la de la muestra tras 5 usos consecutivos (2.7). Más aun, para la muestra de rGO usada cinco veces, la espectroscopía de IR muestra un aumento claro en la intensidad de la banda de absorción que aparece aproximadamente al número de onda de $1200 \mathrm{~cm}^{-1}$ y que corresponde a la vibración de alargamiento del enlace $\mathrm{C}-\mathrm{O}$, lo cual apoya el aumento en el grado de hidroxilación del rGO con el uso (figura 7.10). Esta banda a $1200 \mathrm{~cm}^{-1}$ va acompañada por una banda de absorción muy ancha de alargamiento del enlace $\mathrm{O}-\mathrm{H}$ que aparece entre 3600 y $2700 \mathrm{~cm}^{-1}$ (figura 7.10). La espectroscopía fotoelectrónica de rayos $X$ (XPS) correspondiente a los picos $\mathrm{C} 1 \mathrm{~s}$ y $\mathrm{O} 1 \mathrm{~s}$ del catalizador fresco y del que ha sido usado cinco veces muestra un desplazamiento de los valores hacia energías de enlace más altas. Este hecho es atribuible a la introducción de grupos funcionales oxigenados en $G$ (figura 7.11). Merece ser destacado que aunque el desplazamiento del pico de O1s de rGO pudiera sugerir su conversión parcial en GO, la presencia de un $46.2 \%$ de átomos de carbono grafénicos en el pico de XPS para C1s muestra que la muestra debe ser considerada aún como rGO. De esta manera, los datos de caracterización confirman que la morfología y las principales características de rGO se mantienen durante el reúso exhaustivo con un 
cierto grado de hidroxilación adicional. El hecho de que el catalizador rGO pueda ser reusado en un número de reacciones consecutivas en presencia de una cantidad elevada de fenol muestra la alta estabilidad de rGO como catalizador de foto-Fenton. Sin embargo, como el espectro de XPS cambia, podría ser que a largo plazo la actividad catalítica de rGO cambiara, bien por desactivación o incluso alcanzando una actividad estacionaria para un numero de usos mucho mayor. Aparentemente en casos en los que la estabilidad de los carbocatalizadores en procesos de oxidación avanzada es bajo, el flujo de radicales $\mathrm{HO}^{\circ}$ debería ser mucho mayor que en las condiciones de reacción empleadas en este capítulo, las cuales causan un daño significativo en la estructura del material.

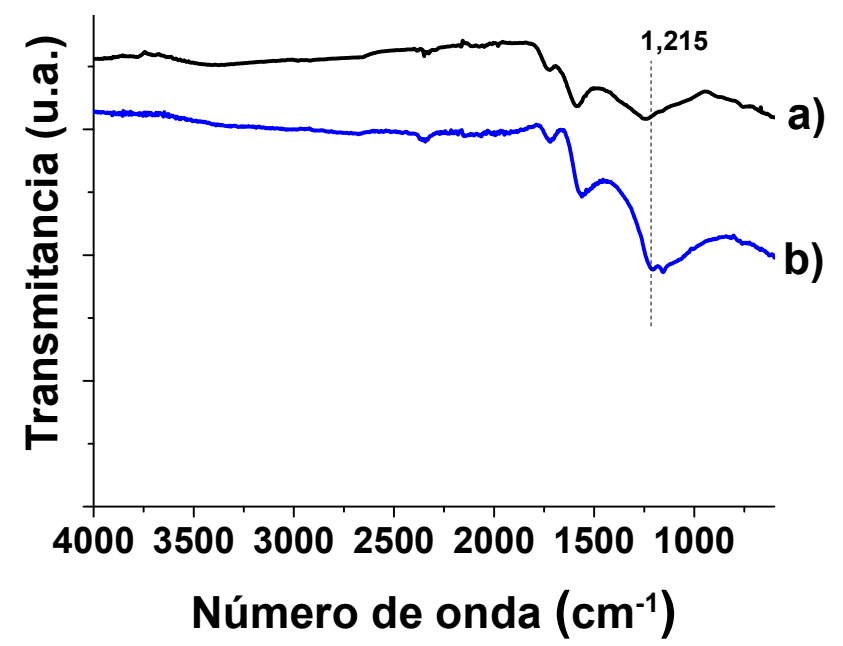

Figura 7.10. Espectro de FT-IR de una muestra de rGO fresca (a) y usada 5 veces (b), en los ensayos de productividad. 
a)
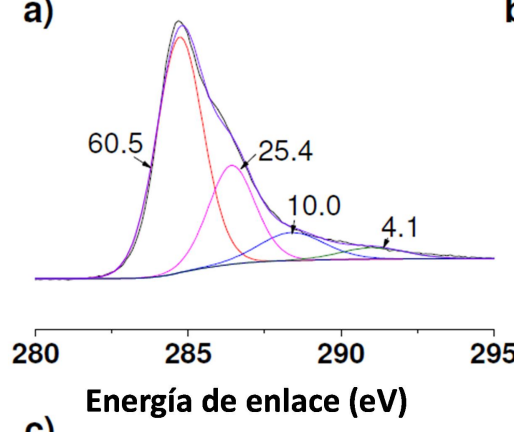

c)

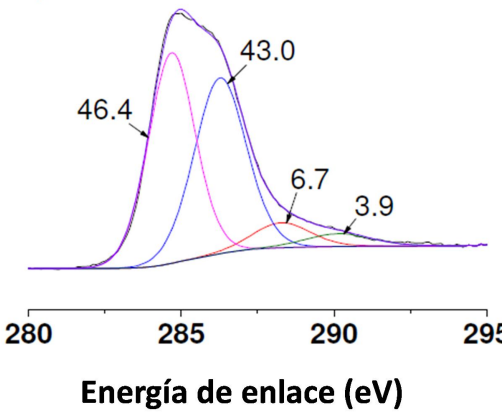

b)

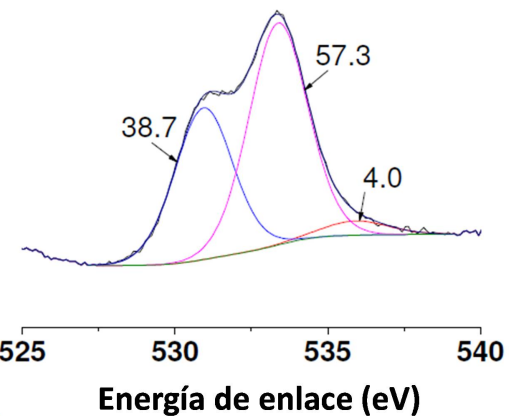

d)

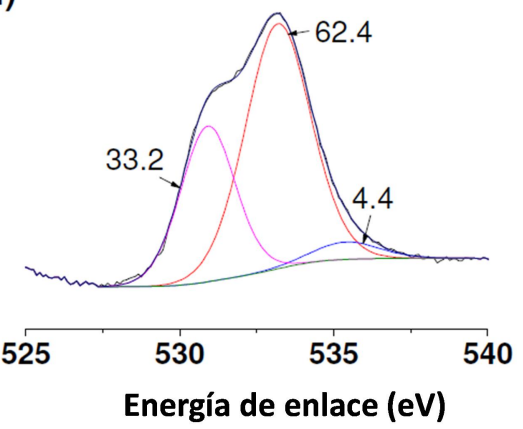

Figura 7.11. Espectros de XPS de una muestra de rGO fresca (a, b) y reusada 5 veces (c, d) en los ensayos de productividad. Leyenda: picos $\mathrm{C} 1 \mathrm{~s}(\mathrm{a}, \mathrm{c}) \mathrm{y}$ picos $\mathrm{O} 1 \mathrm{~s}(\mathrm{~b}, \mathrm{~d})$. Nota: Los números representan el porcentaje del área bajo la curva.

Con respecto al mecanismo de reacción y particularmente a fin de proporcionar evidencia que apoye la generación de radicales $\mathrm{HO}^{\circ}$ en la reacción de Fenton fotoasistida promovida por rGO, se llevaron a cabo estudios de espectroscopía de EPR usando PBN como agente de atrapamiento. Hemos visto en capítulos anteriores que el $\mathrm{PBN}$ reacciona con los radicales $\mathrm{HO}^{\circ}$ generados para dar el radical $\mathrm{PBN}-\mathrm{OH}^{\circ}$, que es estable y que puede ser detectado usando espectroscopía de estado estacionario. Los resultados obtenidos se resumen en la figura 7.12. Una comparación del espectro de EPR experimental con el espectro simulado para el aducto PBN-OH muestra un ajuste de gran calidad, ${ }^{31}$ lo cual prueba la generación de radicales $\mathrm{HO}^{\circ}$ en la reacción de Fenton fotoasistida promovida por rGO. 
a)

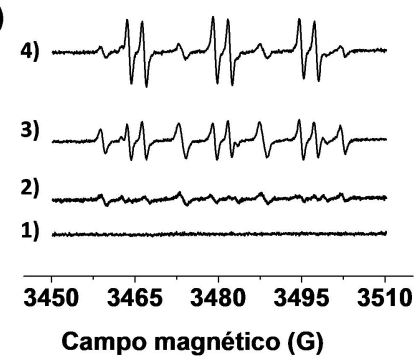

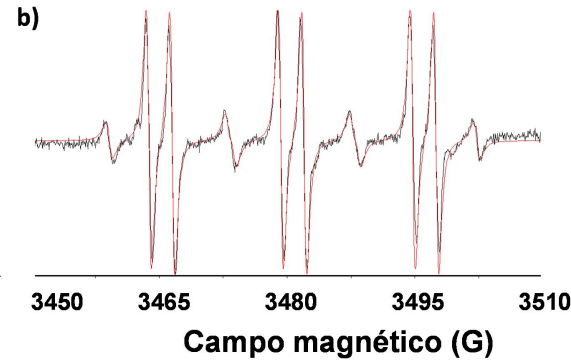

b)

Campo magnético (G)

Figura 7.12. a) Espectros de EPR de 1) $\mathrm{PBN}+\mathrm{H}_{2} \mathrm{O}+$ irradiación con luz solar; 2) $\mathrm{rGO}+\mathrm{PBN}+\mathrm{H}_{2} \mathrm{O}_{2}+$ irradiación con luz solar natural; 3) $\mathrm{rGO}+$ PBN $+\mathrm{H}_{2} \mathrm{O}_{2}+$ condiciones en la oscuridad; 4) $\mathrm{rGO}+\mathrm{PBN}+\mathrm{H}_{2} \mathrm{O}_{2}+$ irradiación con luz solar. b) Espectros de EPR de la muestra (4) y su mejor ajuste considerando el aducto PBN-OH $\left(\mathrm{AG}_{\mathrm{N}}=15.5 \mathrm{~Hz}\right.$ y $\left.\mathrm{AG}_{\mathrm{H}}=2.7 \mathrm{~Hz}\right)$ y tert-butil aminoxil $\left(\mathrm{AG}_{\mathrm{N}}=14.58 \mathrm{~Hz}\right.$ y $\left.\mathrm{AG}_{\mathrm{H}}=13.90 \mathrm{~Hz}\right)$, los cuales coinciden con los valores descritos en la bibliografía. ${ }^{31}$ Condiciones de reacción: rGO (200 mg L $\mathrm{m}^{-1}$, PBN (1041 $\mathrm{mg} \mathrm{L}^{-1}$ ), relación molar $\mathrm{PBN} / \mathrm{H}_{2} \mathrm{O}_{2}$ 1, pH 3, tiempo de reacción 15 minutos.

Otro procedimiento general para establecer la implicación de radicales $\mathrm{HO}^{\circ}$ en el proceso es la observación de inhibición por la presencia de DMSO. ${ }^{20,31}$ Es conocido que el DMSO reacciona con radicales $\mathrm{HO}^{\circ}$ a una velocidad de reacción similar a la del fenol. ${ }^{32} \mathrm{De}$ acuerdo con esto, si la degradación de fenol por $\mathrm{H}_{2} \mathrm{O}_{2}$ se lleva a cabo en presencia de cantidades crecientes de DMSO en exceso con respecto al fenol, entonces la desaparición del fenol debería ser más lenta y eventualmente llegaría a parar, dependiendo del exceso de DMSO presente como inhibidor de radicales $\mathrm{HO}^{\circ}$. Si el DMSO no es añadido en exceso, entonces debido a las velocidades de reacción similares de $\mathrm{HO}^{\circ}$ con DMSO y fenol, el pequeño efecto de la presencia de DMSO haría que el experimento de inhibición no fuera concluyente. Para la reacción de Fenton fotoasistida catalizada por rGO, un exceso de DMSO conduce a una inhibición casi completa de la degradación de fenol (figura 7.13). 

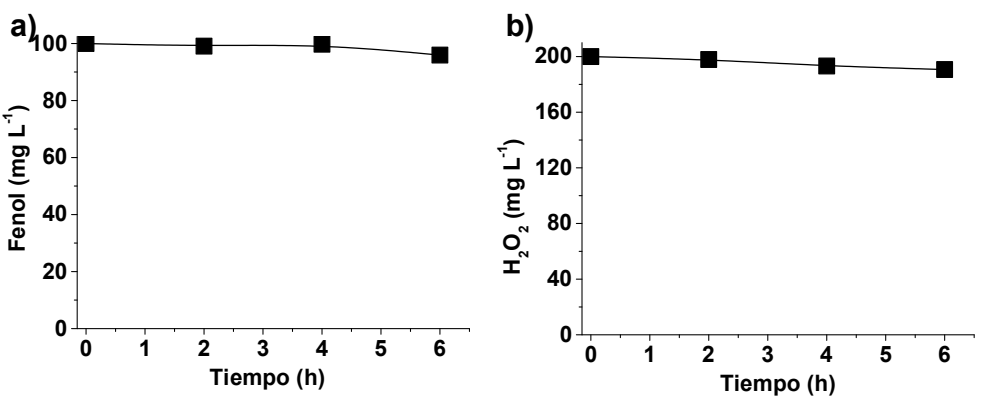

Figura 7.13. Perfiles temporales para la degradación de fenol (a) y descomposición de $\mathrm{H}_{2} \mathrm{O}_{2}$ (b) utilizando $\mathrm{rGO}$ como catalizador bajo irradiación solar natural en presencia de DMSO. Condiciones de reacción: Catalizador (5 mg, $\left.200 \mathrm{mg} \mathrm{L}^{-1}\right)$, fenol $\left(100 \mathrm{mg} \mathrm{L}^{-1} ; 1.06 \mathrm{mM}\right), \mathrm{H}_{2} \mathrm{O}_{2}(200 \mathrm{mg}$ $\left.\mathrm{L}^{-1} ; 5.88 \mathrm{mM}\right)$, DMSO (4.6 g L $\left.\mathrm{L}^{-1} ; 58.8 \mathrm{mM}\right), \mathrm{pH}$ 3. Concentración de fenol obtenida por HPLC y de $\mathrm{H}_{2} \mathrm{O}_{2}$ por espectrofotometría, como se indica en el capítulo 8 , sección experimental.

Con respecto al empleo de rGO como catalizador libre de metales, uno de los puntos clave es determinar la naturaleza de los centros activos. ${ }^{2,3,5}$ En el capítulo anterior, que describe la actividad catalítica de rGO en la reacción de Fenton, se propuso que subestructuras del tipo hidroquinona/ $p$-benzoquinona presentes en $\mathrm{rGO}$, a causa de una cantidad residual de grupos funcionales oxigenados, podrían ser responsables de la actividad catalítica actuando como centros redox reversibles en rGO ${ }^{35}$ En el presente estudio sobre la actividad asistida por luz, es de interés igualmente proporcionar datos sobre la naturaleza de los centros activos. Con el propósito de establecer una correlación entre el contenido de oxígeno y la actividad catalítica, se preparó una muestra adicional con un contenido en oxígeno (aproximadamente 33\%) entre el que posee GO (aproximadamente 44\%) y el que posee rGO (aproximadamente 18\%), siguiendo un procedimiento previamente descrito que se basa en la reducción controlada de $\mathrm{rGO}$ por hidracina $(0.1 \mathrm{~mL}$ hidracina/g GO) a 90 ${ }^{\circ} \mathrm{C}$ (muestra denominada parcial rGO) ${ }^{38}$ Los resultados obtenidos se muestran en la figura 7.14. Estos datos permiten establecer una relación general entre el contenido en oxígeno y la actividad catalítica para la reacción de Fenton. Cuanto mayor es la reducción parcial de GO a rGO mayor es la actividad catalítica. Esta correlación es compatible con la formación de subestructuras $p$-benzoquinona/hidroquinona que aparecen en la reconstrucción parcial de átomos de carbono sp2 a partir de GO. Un 
apoyo adicional de la propuesta sobre la naturaleza de los centros activos se pudo obtener seleccionando hidroquinona y 2-metoxihidroquinona como moléculas modelos simples para los centros activos presentes en rGO, estudiando la actividad catalítica de estos modelos. Una ventaja adicional del uso de la 2-metoxihidroquinona es que este compuesto no puede derivar de la oxidación de fenol y puede ser distinguido claramente de los productos de la oxidación de fenol. Sin embargo, aunque la hidroquinona no puede ser diferenciada del producto de degradación del fenol correspondiente que aparece cuando la reacción progresa, el punto clave es la comparación de la velocidad de degradación inicial en ausencia y en presencia de hidroquinona, el cual debe ser mayor a medida que aumenta la concentración inicial de este compuesto. Como se ha descrito anteriormente, la presencia de un sustituyente metoxi que disminuye el potencial redox de la hidroquinona aumenta la actividad catalítica de este compuesto en la oscuridad. ${ }^{15}$ Fue importante observar que la irradiación con luz solar natural aumenta la actividad catalítica obtenida para la hidroquinona y la 2-metoxihidroquinona. La actividad catalítica de estas dos moléculas aromáticas para la reacción de Fenton y foto-Fenton se presenta en la figura 7.15. Los experimentos de inhibición con DMSO también confirman que estas dos moléculas aromáticas simples son capaces de generar radicales hidroxilo a partir de $\mathrm{H}_{2} \mathrm{O}_{2}$. Por consiguiente, los datos presentados en la figura 7.15 apoyan que en el caso de rGO, los fragmentos que posean estructuras hidroquinona son activos en el proceso fotoasistido de Fenton de degradación de fenol.
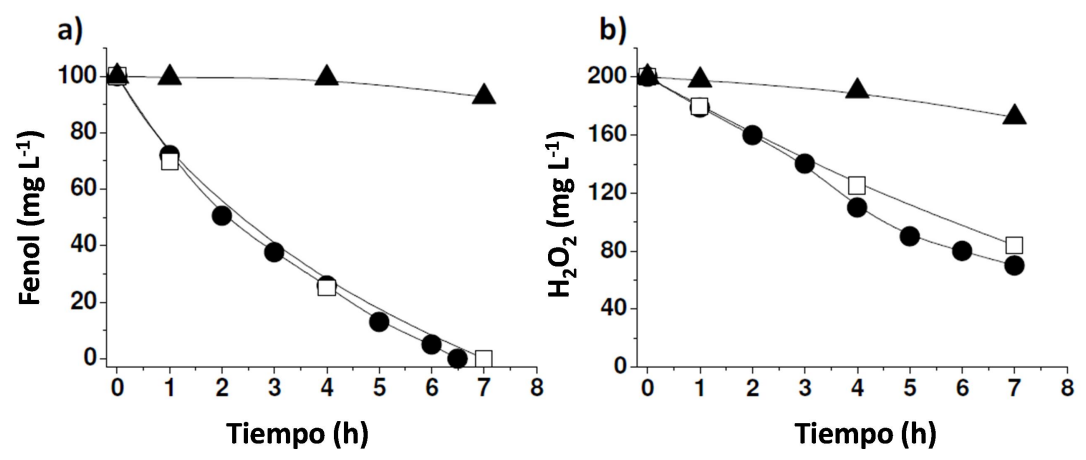

Figura 7.14. Perfiles temporales para la degradación de fenol (a) y descomposición de $\mathrm{H}_{2} \mathrm{O}_{2}$ (b) utilizando rGO como catalizador bajo irradiación solar artificial simulada y con o sin adición de $\mathrm{MnSO}_{4}$. Leyenda: 
rGO (•); rGO en presencia de $\mathrm{MnSO}_{4} 0.14 \mathrm{mg} \mathrm{L}^{-1}(\square)$; en ausencia de catalizador, pero en presencia de $\mathrm{MnSO}_{4} 0.14 \mathrm{mg} \mathrm{L}^{-1}(\boldsymbol{\Delta})$. Condiciones de reacción: Catalizador ( $\left.5 \mathrm{mg}, 200 \mathrm{mg} \mathrm{L}^{-1}\right)$, fenol $\left(100 \mathrm{mg} \mathrm{L}^{-1} ; 1.06 \mathrm{mM}\right), \mathrm{H}_{2} \mathrm{O}_{2}$ (200 mg L $\left.\mathrm{m}^{-1} ; 5.88 \mathrm{mM}\right), \mathrm{pH}$ 3. Concentración de fenol obtenida por HPLC y de $\mathrm{H}_{2} \mathrm{O}_{2}$ por espectrofotometría, como se indica en el capítulo 8 , sección experimental.

a)

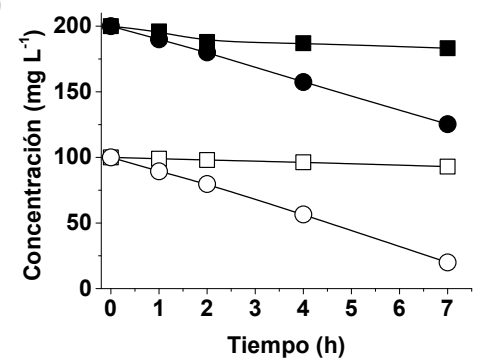

b)

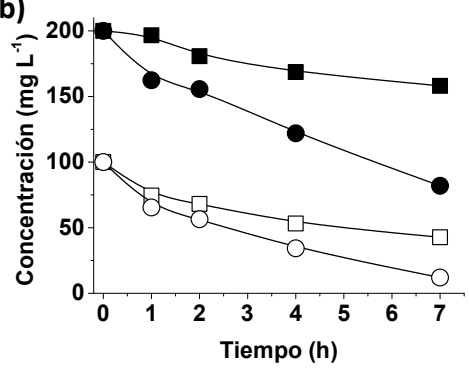

Figura 7.15. Perfiles temporales para la degradación de fenol (símbolos abiertos) y descomposición de $\mathrm{H}_{2} \mathrm{O}_{2}$ (símbolos cerrados) utilizando hidroquinona (a) o 2-metoxihidroquinona (b) como organocatalizador en ausencia de irradiación $(\bullet, \square)$ o en presencia de irradiación solar natural $(\bullet$, ○). Condiciones de reacción: Organocatalizador $(0.106 \mathrm{mM})$, fenol $(100 \mathrm{mg}$ $\left.\mathrm{L}^{-1} ; 1.06 \mathrm{mM}\right), \mathrm{H}_{2} \mathrm{O}_{2}\left(200 \mathrm{mg} \mathrm{L}^{-1} ; 5.88 \mathrm{mM}\right), \mathrm{pH}$ 3. Concentración de fenol obtenida por HPLC y de $\mathrm{H}_{2} \mathrm{O}_{2}$ por espectrofotometría, como se indica en el capítulo 8 , sección experimental.

De acuerdo con lo anterior, una propuesta mecanística plausible paralela a las ecuaciones 7.1 y 7.2 se propone en el esquema 7.1 a fin racionalizar la actividad catalítica de rGO en la degradación de Fenton asistida por luz. Más aún, evidencias adicionales a favor del mecanismo presentado en el esquema 7.1 se pudieron obtener contactando hidroquinona o $p$-benzoquinona con $\mathrm{H}_{2} \mathrm{O}_{2}$ y midiendo la evolución de $\mathrm{O}_{2}$ bajo las condiciones de reacción. Aunque no se observó evolución de $\mathrm{O}_{2}$ para la reacción de hidroquinona y $\mathrm{H}_{2} \mathrm{O}_{2}$, sí que se observó evolución de $\mathrm{O}_{2}$ en la reacción de la $p$-benzoquinona y $\mathrm{H}_{2} \mathrm{O}_{2}$. Estos resultados se presentan en la tabla 7.1. 

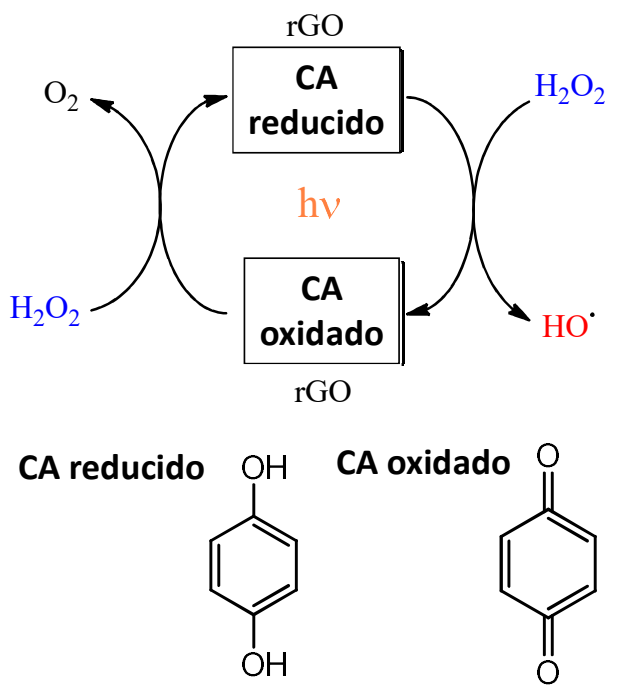

Esquema 7.1. Propuesta mecanística para la generación de radicales hidroxilo a través del par redox hidroquinona/ $p$-benzoquinona como centros activos en rGO.

Tabla 7.1. Descomposición de $\mathrm{H}_{2} \mathrm{O}_{2}$ y evolución de $\mathrm{O}_{2}$ en presencia de $p$ benzoquinona e hidroquinona como organocatalizadores en solución acuosa. Condiciones de reacción: Organocatalizador $(0.41 \mathrm{mM}), \mathrm{H}_{2} \mathrm{O}_{2}(23.5 \mathrm{mM})$, $\mathrm{pH} 3$.

\begin{tabular}{|l|c|c|c|}
\hline & $\begin{array}{c}\mathbf{H}_{2} \mathbf{O}_{2} \text { descompuesto } \\
(\mathbf{m m o l})\end{array}$ & $\begin{array}{c}\mathbf{O}_{2} \text { generado } \\
(\mathbf{m L})\end{array}$ & $\begin{array}{c}\mathbf{O}_{2} \text { generado } \\
(\mathbf{m m o l})\end{array}$ \\
\hline Hidroquinona & 0.0573 & 0 & 0 \\
\hline$p$-Benzoquinona & 0.0825 & 1.0 & 0.0410 \\
\hline
\end{tabular}

Una manera alternativa de entender la actividad catalítica de rGO para promover la reacción fotoasistida de Fenton se basa en la actividad fotocatalítica descrita para $\mathrm{rGO}^{34}$ De acuerdo con esta actividad fotocatalítica, tras absorción de luz tendría lugar la fotogeneración de electrones y huecos en rGO, y tanto los electros como los huecos serían atrapados por $\mathrm{H}_{2} \mathrm{O}_{2}$, viniendo a resultar en la generación de $\mathrm{HO}^{\circ}$ en la símil reacción en la cual los electrones se transfieren a $\mathrm{H}_{2} \mathrm{O}_{2}$. Los huecos positivos serían atrapados por $\mathrm{H}_{2} \mathrm{O}_{2}$ o por el oxígeno generado en el medio (esquema 7.2). Sin embargo, la inhibición de $\mathrm{h}^{+}$por $\mathrm{H}_{2} \mathrm{O}_{2}$ parece 
más improbable puesto que la generación de hidrógeno a partir de agua por $\mathrm{rGO}$ siempre requiere agentes dadores de electrones sacrificiales para tener lugar.

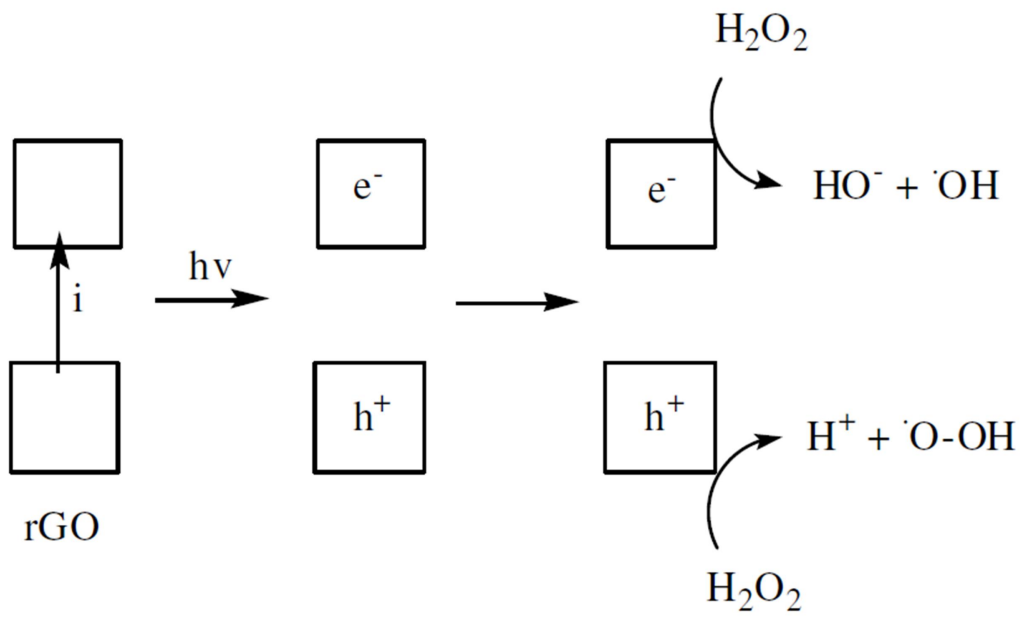

Esquema 7.2. Racionalización de la actividad del rGO en la reacción de Fenton asistida con luz solar basada en su comportamiento como semiconductor.

Si se considera la cantidad total acumulada de fenol degradado en los ocho ensayos consecutivos de productividad (400 mg; figura 7.9), después de sustraer el porcentaje relativamente pequeño (en torno al $5 \%$, figura 7.5) observado en las reacciones de control en ausencia de rGO causado por la reacción fotoquímica directa del fenol con agua oxigenada, y se cogiera el contenido de oxígeno basado en el análisis por XPS respecto al peso toral de rGO, se consigue estimar un valor de TON de 383. Está claro que este valor de TON está basado en asunciones respecto a la naturaleza de los centros activos de rGO que se suponen asociados con subestructuras hidroquinona-quinona y que incluiría procesos en la oscuridad (poco importantes, figura 7.4) y asistidos por la luz (de mayor proporción) promovidos por rGO tras descontar un 5\% de degradación no catalizada. Se propone también que la degradación de fenol, en la oscuridad y fotoasistida, que tiene lugar simultáneamente en proporciones diferentes durante la reacción, ocurre en los mismos tipos de centros catalíticos. En otras palabras, en el presente nivel de entendimiento, este valor de TON debe ser tomado con precaución, pero, aunque todavía lejos 
de los conseguidos para catalizadores basados en metales de transición, prueban que el proceso promovido por rGO es realmente catalítico.

Finalmente, la actividad catalítica de rGO para la degradación de Fenton fotoasistida del fenol se comparó con la de otros materiales relacionados, a saber, GO, grafito y carbón activo (AC). La diferencia entre rGO y GO es su contenido en oxígeno (aproximadamente 50 y $10 \%$ en peso para $\mathrm{GO}$ y rGO, respectivamente) y la estructura de la lámina, que en el caso de rGO debe ser un porcentaje de átomos de carbono con hibridación sp2 considerablemente mayor que para el GO, y con la existencia de regiones y dominios con conjugación $\pi .^{2,15,35}$ La actividad catalítica de rGO es considerablemente mayor que la de GO (figura 7.16). Más aun, aunque en el caso de GO se observó también la influencia de la irradiación como en el caso de rGO, en el caso de GO resultó ser considerablemente menor. Para el grafito se observó una influencia positiva similar de la irradiación con luz solar y la actividad catalítica de la reacción iluminada se encuentra entre la de rGO y GO. Así, aunque GO ha mostrado actividad catalítica bajo irradiación UV, por ejemplo en la generación de hidrógeno, su baja fotorespuesta bajo irradiación con luz visible debido a su ancho de banda limita en gran medida la actividad fotocatalítica de este material en la degradación de foto-Fenton del fenol por luz solar.
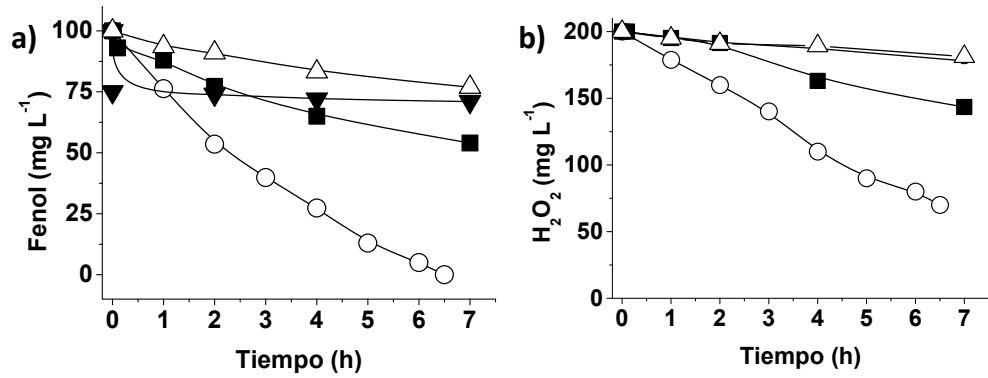

Figura 7.16. a) Degradación del fenol y b) descomposición de $\mathrm{H}_{2} \mathrm{O}_{2}$ en presencia de rGO $(\circ), \mathrm{GO}(\Delta)$, grafito $(\boldsymbol{\bullet})$ y $\mathrm{AC}(\boldsymbol{\nabla})$ como fotocatalizadores. Condiciones de reacción: catalizador (5 mg, $\left.200 \mathrm{mg} \mathrm{L}^{-1}\right)$, fenol $\left(100 \mathrm{mg} \mathrm{L}^{-1}\right.$; $1.06 \mathrm{mM}), \mathrm{H}_{2} \mathrm{O}_{2}\left(200 \mathrm{mg} \mathrm{L}^{-1} ; 5.88 \mathrm{mM}\right), \mathrm{pH} \mathrm{3}$, irradiación con luz solar natural. Concentración de fenol obtenida por HPLC y de $\mathrm{H}_{2} \mathrm{O}_{2}$ por espectrofotometría, como se indica en el capítulo 8, sección experimental. 
En el caso de AC no se observó degradación significativa del fenol, como se puede deducir de la curva de conversión frente al tiempo para la descomposición de $\mathrm{H}_{2} \mathrm{O}_{2}$ comparada con la desaparición del fenol (figura 7.16). La disminución inicial en la concentración de fenol que tiene lugar a tiempos de contacto muy cortos fue debida a la fisisorción de fenol sobre AC. La ausencia de actividad de AC como fotocatalizador es compatible con la propuesta de que subestructuras del tipo quinona/hidroquinona en el grafeno son los pares redox que promueven la degradación del fenol de tipo Fenton. Así, no ocurre descomposición de $\mathrm{H}_{2} \mathrm{O}_{2}$ sobre $\mathrm{AC}$ (figura 7.16). Es interesante hacer notar que el perfil temporal presenta un período de inducción en el caso del grafito. Se podría atribuir este período de inducción a la existencia en un cierto grado de exfoliación espontánea del grafito por oxidación parcial por $\mathrm{H}_{2} \mathrm{O}_{2}$, lo que conduce a la generación de capas de $\mathrm{G}$ con algún grado de grupos funcionales oxigenados en la fase acuosa, por lo que aumentaría la actividad catalítica, transcurrido un cierto período de inducción. Estas láminas de $\mathrm{G}$ junto con $\mathrm{H}_{2} \mathrm{O}_{2}$ y luz formarían algún tipo de $\mathrm{G}$ hidroxilado que es estructuralmente similar a rGO, lo que explica su actividad catalítica tras un período de inducción.

\subsection{Conclusiones}

En el presente capítulo se ha descrito que la luz solar natural asiste y aumenta la actividad catalítica de rGO en la degradación tipo Fenton del fenol con un exceso relativamente bajo de $\mathrm{H}_{2} \mathrm{O}_{2}$. La activación con luz aumenta la actividad catalítica de rGO hacia valores neutros de $\mathrm{pH}$ en aproximadamente una unidad. Bajo estas condiciones, rGO incluso aumenta su eficiencia con el reúso, lo cual ha sido atribuido a una mejor y más fácil dispersabilidad del rGO en agua tras su uso. La espectroscopía de EPR y los experimentos de quenching por DMSO apoyan la generación de radicales hidroxilo, y los modelos con estructura de hidroquinona sugieren que este tipo de funcionalidad sería responsable de la actividad catalítica observada, que no sería exclusiva del rGO, sino que sería una actividad general para cualquier catalizador basado en carbono sin contener metales, cuya actividad sería función de la densidad de estos centros activos.

De esta manera los resultados presentados en este capítulo constituyen un ejemplo adicional del uso de grafenos como catalizadores 
libres de metales en un tipo de reacción que ha venido siendo considerado como exclusivo de catalizadores conteniendo metales de transición. Estudios adicionales deberían ir dirigidos a expandir la aplicación de rGO

y materiales relacionados como catalizadores de foto-Fenton para otros contaminantes orgánicos y en muestras reales.

\subsection{Referencias}

[1] D.R. Dreyer, R.S. Ruoff, C.W. Bielawski, Angew. Chem. Int. Ed. 2010, 49, 9336-9344; Angew. Chem. 2010, 122, 9524-9532; D. R. Dreyer, C. W. Bielawski, Chem. Sci. 2011, 2, 1233-1240; X.-K. Kong, C.-L. Chen, Q.-W. Chen, Chem. Soc. Rev. 2014, 43, 28412857; Y. Zhai, Z. Zhu, S. Dong, ChemCatChem 2015, 7, 28062815; H. Hu, J. H. Xin, H. Hu, X. Wang, Y. Kong, Appl. Catal. B 2015, 492, 1-9.

[2] S. Navalon, A. Dhakshinamoorthy, M. Álvaro, H. García, Chem. Rev. 2014, 114, 6179-6212.

[3] C. Su, K. P. Loh, Acc. Chem. Res. 2013, 46, 2275-2285.

[4] D. S. Su, S. Perathoner, G. Centi, Chem. Rev. 2013, 113, 57825816.

[5] J. Albero, H. García, J. Mol. Catal. A 2015, 408, 296-309.

[6] D. R. Dreyer, H.-P. Jia, C. W. Bielawski, Angew. Chem. Int. Ed. 2010, 49, 6813-6816; Angew. Chem. 2010, 122, 6965-6968.

[7] A. Dhakshinamoorthy, A. Primo, P. Concepción, M. Álvaro, H. García, Chem. Eur. J. 2013, 19, 7547-7554; Y. Gao, G. Hu, J. Zhong, Z. Shi, Y. Zhu, D. S. S. Su, J. Wang, X. Bao, D. Ma, Angew. Chem. Int. Ed. 2013, 52, 2109-2113; Angew. Chem. 2013, 125, 2163-2167; G. Lv, H. Wang, Y. Yang, T. Deng, C. Chen, Y. Zhu, X. Hou, ACS Catal. 2015, 5, 5636-5646.

[8] J. Long, X. Xie, J. Xu, Q. Gu, L. Chen, X. Wang, ACS Catal. 2012, 2, 622-631.

[9] C. Su, M. Acik, K. Takai, J. Lu, S.-j. Hao, Y. Zheng, P. Wu, Q. Bao, T. Enoki, Y. J. Chabal, K. P. Loh, Nat. Commun. 2012, 3, 1298; X.H. Li, M. Antonietti, Angew. Chem. Int. Ed. 2013, 52, 4572-4576; Angew. Chem. 2013, 125, 4670-4674.

[10] T. I. Perhun, I. B. Bychko, A. I. Trypolsky, P. E. Strizhak, Theor. Exp. Chem. 2013, 48, 367-370; A. Primo, F. Neatu, M. Florea, V. Parvulescu, H. García, Nat. Commun. 2014, 5, 5291.

[11] Y. Gao, D. Ma, C. Wang, J. Guan, X. Bao, Chem. Commun. 2011, 47, 2432-2434.

[12] B. Basu, S. Kundu, D. Sengupta, RSC Adv. 2013, 3, 22130-22134; V. Schwartz, W. Fu, Y.-T. Tsai, H. M. Meyer III, A.J. Rondinone, J. Chen, Z. Wu, S. H. Overbury, C. Liang, ChemSusChem 2013, 6, 840-846; J.-H. Yang, G. Sun, Y. Gao, H. Zhao, P. Tang, J. Tan, A.H. Lu, D. Ma, Energy Environ. Sci. 2013, 6, 793-798. 
[13] E. Neyens, J. Baeyens, J. Hazard. Mater. 2003, 98, 33-50.

[14] J. J. Pignatello, E. Oliveros, A. Mackay, Crit. Rev. Environ. Sci. Technol. 2006, 36, 1-84.

[15] J. C. Espinosa, S. Navalón, A. Primo, M. Moral, J. F. Sanz, M. Álvaro, H. García, Chem. Eur. J. 2015, 21, 11966-11971.

[16] Z. Sun, Q. Ye, C. Chi, J. Wu, Chem. Soc. Rev. 2012, 41, 7857-7889; Q. Xiang, J. Yu, M. Jaroniec, Chem. Soc. Rev. 2012, 41, 782-796; N. Zhang, M.-Q. Yang, S. Liu, Y. Sun, Y.-J. Xu, Chem. Rev. 2015, 115, 10307 - 10377; M.-Q. Yang, N. Zhang, M. Pagliaro, Y.-J. Xu, Chem. Soc. Rev. 2014, 43, 8240-8254; N. Zhang, Y.-J. Xu, CrystEngComm 2016, 18, 24-37.

[17] K. Ayoub, E. D. van Hullebusch, M. Cassir, A. Bermond, J. Hazard. Mater. 2010, 178, 10-28; M. N. Chong, B. Jin, C. W. K. Chow, C. Saint, Water Res. 2010, 44, 2997-3027; S. R. Pouran, A. R. A. Aziz, W. M. A. W. Daud, J. Ind. Eng. Chem. 2015, 21, 53-69.

[18] I. P. Pozdnyakov, E. M. Glebov, V. F. Plyusnin, V. P. Grivin, Y. V. Ivanov, D. Y. Vorobyev, N. M. Bazhin, Pure Appl. Chem. 2000, 72, 2187-2197.

[19] M. Pera-Titus, V. García-Molina, M. A. Baños, J. Giménez, S. Esplugas, Appl. Catal. B 2004, 47, 219-256.

[20] S. Navalón, R. Martín, M. Álvaro, H. García, ChemSusChem 2011, 4, $650-657$.

[21] S. Navalón, M. De Miguel, R. Martín, M. Álvaro, H. García, J. Am. Chem. Soc. 2011, 133, 2218-2226.

[22] D. Sempere, S. Navalón, M. Dancikova., M. Álvaro, H. García, Appl. Catal. B 2013, 142-143, 259-267.

[23] J. C. Scaiano, J. C. Netto-Ferreira, E. Alarcon, P. Billone, C. J. Bueno-Alejo, C.-O. L. Crites, M. Decan, C. Fasciani, M. GonzálezBejar, G. Hallett-Tapley, M. Grenier, K. L. McGilvray, N. L. Pacioni, A. Pardoe, L. Rene-Boisneuf, R. Schwartz-Narbonne, M. J. Silvero, K. G. Stamplecoskie, T.-L. Wee, Pure Appl. Chem. 2011, 83, 913-930; J. C. Scaiano, K. G. Stamplecoskie, G. L. HallettTapley, Chem. Commun. 2012, 48, 4798-4808.

[24] F. D’Souza, O. Ito, Sci. Prog. 2013, 96, 369-397; J. D. RoyMayhew, I. A. Aksay, Chem. Rev. 2014, 114, 6323-6348.

[25] A. D. Bokare, W. Choi, J. Hazard. Mater. 2014, 275, 121-135.

[26] A. Dhakshinamoorthy, S. Navalón, M. Álvaro, H. García, ChemSusChem 2012, 5, 46-64; S. Navalón, M. Álvaro, H. García, Appl. Catal. B 2010, 99, 1-26.

[27] S. Navalón, A. Dhakshinamoorthy, M. Álvaro, H. García, ChemSusChem 2011, 4, 1712-1730.

[28] S. Navalón, A. Dhakshinamoorthy, M. Álvaro, H. García, Coord. Chem. Rev. 2016, 312, 99-148.

[29] J. A. Zazo, J. A. Casas, C. B. Molina, A. Quintanilla, J. J. Rodriguez, Environ. Sci. Technol. 2007, 41, 7164-7170. 
[30] J. C. Espinosa, S. Navalón, M. Moral, M. Álvaro, H. García, ChemCatchem 2015, 7, 2682-2688.

[31] M. J. Burkitt, R. P. Mason, Proc. Natl. Acad. Sci. USA, 1991, 88, 8440-8444.

[32] Y.-N. Wang, J. Chen, X. Li, S. Zhang, X. Qiao, QSAR Comb. Sci. 2009, 28, 1309-1316; J. S. Beckman, T. W. Beckman, J. Chen, P. A. Marshall, B. A. Freeman, Proc. Natl. Acad. Sci. USA, 1990, 87, 1620-1624.

[33] N. Morimoto, T. Kubo, Y. Nishina, Sci. Rep. 2016, 6, 21715.

[34] C. Chen, W. Cai, M. Long, B. Zhou, Y. Wu, D. Wu, Y. Feng, ACS Nano 2010, 4, 6425-6432; T. F. Yeh, C. Y. Teng, S. J. Chen, H. Teng, Adv. Mater. 2014, 26, 3297-3303; T.-F. Yeh, F.-F. Chan, C.T. Hsieh, H. Teng, J. Phys. Chem. C, 2011, 115, 22587-22597.

[35] D. R. Dreyer, S. Park, C. W. Bielawski, R. S. Ruoff, Chem. Soc. Rev. 2010, 39, 228-240.

[36] A. Primo, M. Puche, O. D. Pavel, B. Cojocaru, A. Tirsoaga, V. Parvulescu, H. García, Chem. Commun. 2016, 52, 1839-1842. 



\section{Capítulo 8}

\section{Sección experimental}





\subsection{Síntesis de materiales}

\subsubsection{Funcionalización de materiales carbonosos empleados como soporte}

Como se ha descrito en los capítulos 3,4 y 5, diferentes materiales carbonosos han sido empleados como soportes de nanopartículas metálicas para su uso como catalizadores en la reacción de foto-Fenton heterogénea con luz solar. Estos materiales carbonosos son: nanopartículas de diamante (D), carbón activo (AC), nanotubos de carbono (NT) y grafito (Gr). Para la síntesis de diferentes tipos de catalizadores, estos materiales han sido funcionalizados mediante uno o dos procesos consecutivos. Así, los materiales comerciales, denominados mediante el número 1 (D1, AC1, NT1, Gr1), fueron sometidos a oxidación mediante la oxidación homogénea de Fenton. Concretamente, $500 \mathrm{mg}$ del material comercial se suspenden en $200 \mathrm{~mL}$ de $\mathrm{H}_{2} \mathrm{O}_{2}$ y se añade $1.5 \mathrm{~mL}$ de una disolución acuosa de $\mathrm{Fe}_{2} \mathrm{SO}_{4} 0.25 \mathrm{M}$. Esta suspensión se mantiene en un baño de ultrasonidos durante 3 horas. Una vez finalizada la reacción, el material se recupera por filtración y se lava mediante reiteradas centrífugas con una disolución acuosa diluida de $\mathrm{H}_{2} \mathrm{SO}_{4}$ ( $\mathrm{pH}$ 3) hasta la completa eliminación de las trazas de Fe. La presencia de $\mathrm{Fe}$ en el sobrenadante tras cada centrífuga se puede determinar mediante la adición de unas gotas de disolución de KSCN 0.1 $\mathrm{M}$, que toma un color rojizo en presencia de hierro. Una vez eliminado el hierro, el material se lava con agua destilada mediante centrífuga hasta obtener un $\mathrm{pH}$ neutro y finalmente se recupera por filtración. A este material oxidado por la reacción de Fenton homogénea se le denomina mediante el número 2 (D2, AC2, NT2, Gr2). Finalmente, los materiales carbonosos fueron sometidos a un segundo proceso de funcionalización, en este caso de hidrogenación. El material en polvo se dispone en un reactor de hidrogenación, con un flujo de hidrógeno de $100 \mathrm{~mL} \min ^{-1}$, a $500{ }^{\circ} \mathrm{C}$ durante 5 horas, con una rampa de $8{ }^{\circ} \mathrm{C} \mathrm{min}^{-1}$. A estos materiales resultantes se los denomina con el número 3 (D3, AC3, NT3, Gr3).

\subsubsection{Deposición de nanopartículas metálicas}

La síntesis de los catalizadores metálicos se realiza mediante la deposición de nanopartículas metálicas sobre los diferentes soportes descritos en los diferentes capítulos de la presente tesis doctoral, ya sean carbonosos o no (véase $\mathrm{TiO}_{2}$ ). La deposición metálica se realiza por el método del poliol. Concretamente, se suspende el soporte $(200 \mathrm{mg})$ en etilenglicol $(80 \mathrm{~mL})$ y se añade el metal en disolución acuosa $(1 \mathrm{~mL})$ en la concentración correspondiente a la carga metálica deseada en el catalizador, típicamente $0.2 \%$ en peso. Esta suspensión se calienta a $85^{\circ} \mathrm{C}$ y se agita durante 4.5 horas. Una vez finalizada la reacción, el material se 
lava mediante centrífuga con acetona para eliminar el etilenglicol, hasta 4 veces, y después se lava con agua para eliminar la acetona. Finalmente, el catalizador en polvo se recupera mediante liofilización.

\subsubsection{Síntesis de nanopartículas metálicas sin soporte}

Las nanopartículas metálicas sin soporte se sintetizaron mediante reducción con $\mathrm{NaBH}_{4}$. A una disolución acuosa del metal deseado, en una concentración determinada en función de la cantidad de metal que se pretende obtener, se añade otra disolución acuosa de $\mathrm{NaBH}_{4}$ en concentración 10 veces en exceso respecto al metal. La disolución se deja agitar a temperatura ambiente durante unas horas y posteriormente se lavan las nanopartículas sólidas con agua para eliminar el exceso de $\mathrm{NaBH}_{4}$. Finalmente se recupera el material por filtración.

\subsubsection{Síntesis de grafeno de alginato (G)}

Se toma alginato sódico comercial, procedente de algas marrones, como material de partida (Sigma Aldrich, Ref. A2033). Se introduce en un crisol de cerámica y se piroliza en un horno bajo atmósfera de argón a flujo de $100 \mathrm{~mL} \min ^{-1}$, a $900{ }^{\circ} \mathrm{C}$ durante 2 horas, con una rampa de $10^{\circ} \mathrm{C} \mathrm{min}^{-1}$. Una vez finalizado el proceso de pirólisis, el polvo grafítico obtenido se exfolia por ultrasonidos formando una dispersión en agua. Finalmente, tras la exfoliación, se centrifuga el material resultante para obtener las muestras de grafeno de pocas láminas en suspensión en agua.

\subsubsection{Síntesis de grafeno dopado con nitrógeno ((N)G)}

Se toma quitosano comercial de bajo peso molecular (Sigma Aldrich, Ref. 448869) como material de partida. Se introduce en un crisol de cerámica y se piroliza en un horno bajo atmósfera de argón a flujo de $100 \mathrm{~mL} \mathrm{~min}{ }^{-1}$, a $900{ }^{\circ} \mathrm{C}$ durante 2 horas, con una rampa de $10^{\circ} \mathrm{C} \mathrm{min}^{-1}$. Una vez finalizado el proceso de pirólisis, el polvo grafítico obtenido se exfolia por ultrasonidos formando una dispersión en agua. Finalmente, tras la exfoliación, se centrifuga el material resultante para obtener las muestras de $(\mathrm{N}) \mathrm{G}$ de pocas láminas en suspensión en agua.

\subsubsection{Síntesis de grafeno dopado con boro ((B)G)}

Se toma alginato sódico comercial como material de partida $(0.5$ g) y se introduce en una disolución acuosa de ácido bórico $(250 \mathrm{mg}$ de $\mathrm{H}_{3} \mathrm{BO}_{3}$ en $50 \mathrm{~mL}$ de agua). La mezcla se somete a ultrasonidos para conseguir una suspensión completa y, posteriormente, se deja evaporar el agua en una estufa a $100{ }^{\circ} \mathrm{C}$. El material resultante se introduce en un crisol de cerámica y se piroliza en un horno bajo atmósfera de argón a flujo de $100 \mathrm{~mL} \mathrm{~min}{ }^{-1}$, a $900^{\circ} \mathrm{C}$ durante 2 horas, con una rampa de $10{ }^{\circ} \mathrm{C}$ 
$\min ^{-1}$. Una vez finalizado el proceso de pirólisis, el polvo grafítico obtenido se exfolia por ultrasonidos formando una dispersión en agua. Finalmente, tras la exfoliación, se centrifuga el material resultante para obtener las muestras de (B)G de pocas láminas en suspensión en agua.

\subsubsection{Síntesis de grafeno dopado con nitrógeno y boro $((\mathrm{N}, \mathrm{B}) \mathrm{G})$}

Se toma quitosano comercial de bajo peso molecular como material de partida $(0.5 \mathrm{~g})$ y se introduce en una disolución acuosa de ácido bórico $\left(250 \mathrm{mg}\right.$ de $\mathrm{H}_{3} \mathrm{BO}_{3}$ en $25 \mathrm{~mL}$ de agua y $0.5 \mathrm{~mL}$ de ácido acético). El ácido acético adicional es necesario para una completa disolución del quitosano en agua. La mezcla se somete a ultrasonidos para conseguir una suspensión completa $\mathrm{y}$, posteriormente, se deja evaporar el agua en una estufa a $100{ }^{\circ} \mathrm{C}$. El material resultante se introduce en un crisol de cerámica y se piroliza en un horno bajo atmósfera de argón a flujo de $100 \mathrm{~mL} \min ^{-1}$, a $900{ }^{\circ} \mathrm{C}$ durante 2 horas, con una rampa de $10{ }^{\circ} \mathrm{C} \mathrm{min}^{-1}$. Una vez finalizado el proceso de pirólisis, el polvo grafítico obtenido se exfolia por ultrasonidos formando una dispersión en agua. Finalmente, tras la exfoliación, se centrifuga el material resultante para obtener las muestras de $(\mathrm{N}, \mathrm{B}) \mathrm{G}$ de pocas láminas en suspensión en agua.

\subsubsection{Síntesis de óxido de grafeno (GO)}

El óxido de grafeno se sintetizó mediante el método de Hummers, como ya se explica en el capítulo 6. Se toma grafito comercial (Sigma Aldrich, Ref. 332461) como material de partida (2 g), se mezcla con $1 \mathrm{~g}$ de $\mathrm{NaNO}_{3}$, se añade $\mathrm{H}_{2} \mathrm{SO}_{4}$ concentrado $(46 \mathrm{~mL}, 18 \mathrm{M})$ y se enfría la suspensión a $0{ }^{\circ} \mathrm{C}$. Con la mezcla en agitación se añade $\mathrm{KMnO}_{4}$ $(6 \mathrm{~g})$ paulatinamente, evitando la subida de la temperatura por encima de $20{ }^{\circ} \mathrm{C}$. Transcurrida una hora desde la adición completa del $\mathrm{KMnO}_{4}$, se calienta la mezcla a $35^{\circ} \mathrm{C}$ y se mantiene en agitación durante una hora. Posteriormente se adiciona agua $(92 \mathrm{~mL})$ paulatinamente, lo que aumenta la temperatura de reacción a $98{ }^{\circ} \mathrm{C}$, y se mantiene a esta temperatura durante 20 minutos. Después se diluye la suspensión a $280 \mathrm{~mL}$ con agua, seguido de adición de $\mathrm{H}_{2} \mathrm{O}_{2}$ ( $9 \mathrm{~mL}, 35 \%$ en volumen). Tras añadir el $\mathrm{H}_{2} \mathrm{O}_{2}$, la disolución se torna en un color amarillo por la presencia de los iones $\mathrm{Mn}^{2+}$.Se deja enfriar la mezcla, se recupera el sólido por filtración y se lava con $\mathrm{HCl}(1: 10,37 \%)$ y posteriormente con agua. Una vez lavado el material, se somete a ultrasonidos para conseguir la exfoliación de las láminas de óxido de grafeno en suspensión acuosa.

\subsubsection{Síntesis de óxido de grafeno reducido (rGO)}

Se toma el óxido de grafeno (GO), obtenido mediante el método de Hummers, como material de partida. Se introduce en un crisol de 
cerámica y se piroliza en un horno bajo atmósfera de argón a flujo de 100 $\mathrm{mL} \min ^{-1}$, a $300{ }^{\circ} \mathrm{C}$ durante 2 horas, con una rampa de $10{ }^{\circ} \mathrm{C} \min ^{-1}$. El material obtenido en polvo, reducido térmicamente bajo argón, es considerado óxido de grafeno reducido.

\subsubsection{Síntesis de MWCNT purificados}

El material empleado en el capítulo 6, denominado como MWCNTs purificados, se sintetiza por la oxidación de los nanotubos de carbono de pared múltiple con ácido nítrico. Se toma como material de partida MWCNT comerciales ( $1 \mathrm{~g})$ y se suspenden en una disolución acuosa de $\mathrm{HNO}_{3}(500 \mathrm{~mL}, 3 \mathrm{M})$. Esta mezcla se calienta y se deja agitando a reflujo durante 12 horas. Una vez finalizada la reacción, se deja enfriar y se lava reiteradamente con agua mediante centrífuga hasta eliminar el pH ácido de la fase acuosa. Finalmente se recupera el sólido por filtración.

\subsubsection{Síntesis de MWCNT purificados-acortados}

Para la síntesis del material denominado como MWCNT purificados-acortados, se toma como material de partida los MWCNT purificados que se han comentado en el apartado anterior. Se suspenden $150 \mathrm{mg}$ de este material en $8 \mathrm{~mL}$ de una disolución acuosa ácida formada por la mezcla de $\mathrm{H}_{2} \mathrm{SO}_{4}$ concentrado (96\%) y $\mathrm{HNO}_{3}$ (30\%), en proporciones de volumen de tres veces de sulfúrico por una de nítrico $(3: 1 \mathrm{v} / \mathrm{v})$. Esta suspensión se introduce en un baño de ultrasonidos a $60{ }^{\circ} \mathrm{C}$ y se deja sonicando durante una hora. Una vez finalizada la reacción, se deja enfriar y se lava reiteradamente con agua mediante centrífuga hasta eliminar el pH ácido de la fase acuosa. Finalmente se recupera el sólido por filtración.

\subsection{Técnicas de caracterización}

\subsubsection{Microscopía electrónica de transmisión (TEM)}

Los análisis de microscopía electrónica de transmisión (TEM) fueron llevados a cabo utilizando un microscopio JEOL JEM-1010 operando a $100 \mathrm{kV}$, y las imágenes de TEM de alta resolución (HRTEM) se obtuvieron mediante un microscopio JEOL JEM 2100F operando con un voltaje de aceleración de $200 \mathrm{kV}$ acoplado con un detector de rayos X de energía dispersiva (EDX) X-Max 80 (Oxford Instruments). El microscopio dispone de la unidad STEM y los detectores de imagen de campo claro y de campo oscuro de alto ángulo (HAADF), que permiten observar el contraste de fases con distinto número atómico. 


\subsubsection{Microscopía electrónica de barrido (SEM)}

Las imágenes de microscopía electrónica de barrido (SEM) se obtuvieron con un microscopio JEOL JSM-5410, y las imágenes de SEM de emisión de campo (FESEM), se tomaron con un instrumento Zeiss Ultra 55. Los análisis elementales por espectroscopía de rayos $\mathrm{X}$ de energía dispersiva (EDX) se realizaron con un detector de Oxford Instruments acoplado a estos microscopios.

\subsubsection{Microscopía de fuerza atómica (AFM) y perfilometría óptica}

La microscopía de fuerza atómica (AFM) es una técnica de análisis de superficies que permite estudiar las características físicas superficiales de un material y es de gran utilidad para estimar el espesor de películas finas sobre un sustrato, midiendo la diferencia de altura entre el sustrato y la superficie de la película. Las medidas de AFM se obtuvieron mediante un instrumento Multimode Nanoscope 3A con una resolución vertical subnanométrica y horizontal de unos $5 \mathrm{~nm}$. Las muestras se prepararon en suspensión del material a analizar en etanol, depositando una gota de la suspensión en cuestión sobre un sustrato de mica, atómicamente plano. Una vez evaporado el etanol se procede al barrido en modo "tapping", donde se produce contacto intermitente punta-muestra.

\subsubsection{Espectroscopía Raman}

La espectroscopía Raman es una técnica de análisis de especial utilidad en el caso de los materiales carbonosos. Consiste en el análisis de la dispersión de la luz que provoca un material al incidir sobre él un haz de luz monocromático. Los análisis se llevaron a cabo por medio de un instrumento Renishaw in Via Raman Microscope a temperatura ambiente con un láser de ion $\mathrm{Ar}$ de $514 \mathrm{~nm}$ como fuente de excitación acoplado a un microscopio óptico Lyca que permite determinar la zona de la muestra expuesta al haz láser que posee una superficie de $1 \mu \mathrm{m}^{2}$. Se registraron los espectros en la región de desplazamiento Raman de 0 a $3500 \mathrm{~cm}^{-1}$, con una resolución inferior a $4 \mathrm{~cm}^{-1}$, pudiendo realizar hasta 10 barridos en un tiempo total de acumulación de $100 \mathrm{~s}$. Para un correcto análisis es necesaria la comparación de los espectros obtenidos en diferentes puntos de la muestra. 


\subsubsection{Difracción de rayos $X$ (XRD)}

Los análisis de rayos $\mathrm{X}$ se obtuvieron utilizando un difractómetro Cubix-Pro de PANalytical, equipado con un detector PANalytical $\mathrm{X}^{\prime}$ Celerator. Se emplea una radiación monocromática de rayos $\mathrm{X}$ de $\mathrm{Cu}$ $\mathrm{K} \alpha\left(K_{1}=1.5406 \AA, K_{2}=1.5444 \AA, \mathrm{I}_{2} / \mathrm{I}=0.5\right)$ y un voltaje e intensidad de tubo de $45 \mathrm{kV}$ y $40 \mathrm{~mA}$, respectivamente. Se utiliza una rendija variable con un área de muestra irradiada de $5 \mathrm{~mm}$ y la longitud del brazo del goniómetro es de $200 \mathrm{~mm}$. Los difractogramas se obtuvieron a temperatura ambiente en el rango de ángulo $2 \theta$ entre 2 y $90^{\circ}$, con un incremento de $0.02^{\circ}(2 \theta)$.

\subsubsection{Espectrofotometría fotoelectrónica de rayos X (XPS)}

La espectroscopía fotoelectrónica de rayos X (XPS) es una técnica de caracterización para el análisis de superficies que permite la estimación de la estequiometria, el estado químico y la estructura electrónica de los elementos presentes en un material. El espectro de XPS se obtiene por irradiación con rayos $\mathrm{X}$, generalmente provenientes de un ánodo de $\mathrm{Al}$ o $\mathrm{Mg}$, midiendo la energía cinética y el número de electrones que escapan de la superficie de la muestra de análisis. Los XPS se obtuvieron mediante un espectrofotómetro SPECS equipado con un detector Phoibos 150-9MCD, que utiliza una fuente monocromática de rayos $\mathrm{X}$ de $\mathrm{Al} \mathrm{Ka}(1483.6 \mathrm{eV})$ operando a $50 \mathrm{~W}$. Las muestras se sometieron a un vacío previo en una precámara del equipo a $10^{-9} \mathrm{mbar}$. El tratamiento de los espectros, así como su cuantificación, se llevó a cabo utilizando el software CASA, y la corrección de carga de los espectros se realiza en base a la señal del carbono $\mathrm{C} 1 \mathrm{~s}$, que posee una energía de enlace conocida de $284.5 \mathrm{eV}$.

\subsubsection{Espectroscopía de infrarrojo por transformada de Fourier (FTIR)}

La absorción en el infrarrojo se produce por interacción de la radiación incidente con los niveles vibracionales de las moléculas. La intensidad de la absorción depende de las variaciones que produce la oscilación en el momento dipolar. Los espectros FTIR fueron registrados a temperatura ambiente en un espectrofotómetro Bruker Tensor 27.

\subsubsection{Análisis elemental por combustión (AE)}

El análisis elemental por combustión permite la determinación de la composición de un material en base a los elementos $\mathrm{C}, \mathrm{H}, \mathrm{S}$ y $\mathrm{N}$ presentes en su estructura, dando a conocer los porcentajes de cada elemento presentes en la muestra. La muestra se somete a combustión térmica desde 166 a $1800{ }^{\circ} \mathrm{C}$, en atmósfera de $\mathrm{O}_{2}$, cuantificando la transformación total de los componentes: $\mathrm{C}$ a $\mathrm{CO}_{2}, \mathrm{H}$ a $\mathrm{H}_{2} \mathrm{O}, \mathrm{N}$ a $\mathrm{N}_{2}$. 
Estos gases obtenidos se separan en un módulo de separación en el que se produce la adsorción selectiva de $\mathrm{CO}_{2}$, en columna de cobre, y $\mathrm{H}_{2} \mathrm{O}$, en columna de plata. La cuantificación se realiza mediante un detector de conductividad térmica, que primero mide el $\mathrm{N}_{2}$, que no ha sido retenido; después mide el $\mathrm{CO}_{2}$, que se desprende por desorción térmica, y por último mide el $\mathrm{H}_{2} \mathrm{O}$. El equipo utilizado para este tipo de análisis es un analizador Euro EA3000 Elemental Analyzer (EuroVector), empleando la sulfanilamida como patrón de referencia.

\subsubsection{Espectroscopía de plasma ICP-OES}

La espectroscopía de emisión de plasma de acoplamiento inductivo (ICP-OES) es una técnica de análisis que permite la determinación de la composición y la cuantificación de los metales presentes en un material. La técnica se basa en la excitación de los átomos de la disolución que se nebuliza en un plasma de alta temperatura, los átomos excitados caen al estado fundamental emitiendo un fotón de energía característica para cada átomo. La intensidad de dicha emisión es proporcional a la cantidad de metal presente en la muestra, así que de esta manera se puede cuantificar la cantidad presente de metal, relacionando los resultados adquiridos con los estándares obtenidos a partir de las rectas de calibrado de los patrones comerciales del metal a analizar. Las muestras se han analizado en un equipo Varian 715-ES ICP-Optical Emission Spectrometer. Para la determinación de la cantidad de metal presente en un catalizador, éste se suspende en agua regia $(30 \mathrm{mg}$ de catalizador en $10 \mathrm{~mL}$ de $\left.\mathrm{HCl}: \mathrm{HNO}_{3}(3: 1 \mathrm{v} / \mathrm{v})\right)$ durante unas horas para facilitar el lixiviado del metal a la disolución. Posteriormente, la muestra se filtra y se analiza la fase acuosa, para determinar la cantidad de metal presente en el catalizador. De la misma forma, la fase acuosa resultante al finalizar cada reacción se puede filtrar y analizar también por ICP para averiguar la cantidad de metal que puede lixiviar del metal durante la reacción.

\subsubsection{Análisis de termogravimetría (TGA)}

Los análisis de termogravimetría (TGA) estudian los procesos de descomposición térmica de los compuestos orgánicos, así como su estabilidad en función de la temperatura. Los análisis se llevaron a cabo con un aparato Mettler Toledo TGA/SDTA 851e en el rango de temperaturas de 20 a $900{ }^{\circ} \mathrm{C}$ a una velocidad de $10{ }^{\circ} \mathrm{C} \min ^{-1}$ y un flujo de aire de $20 \mathrm{~mL} \mathrm{~min}^{-1}$. 


\subsection{Procedimientos de reacción}

Todos los reactivos comerciales empleados se obtuvieron de Sigma-Aldrich y se han utilizado sin mayor purificación.

\subsubsection{Procedimiento general para la reacción de Fenton}

Las reacciones de Fenton fueron llevadas a cabo en matraces esféricos de vidrio de $250 \mathrm{~mL}$ de capacidad, en agitación magnética. La cantidad de catalizador determinada (especificada para cada reacción en sus respectivos capítulos) se suspende en $25 \mathrm{~mL}$ de una disolución acuosa de fenol de $100 \mathrm{mg} \mathrm{L}^{-1}$ mediante un baño de ultrasonidos. Una vez obtenida la suspensión completa del catalizador, se añade la cantidad de peróxido de hidrógeno correspondiente a una concentración de reacción de $200 \mathrm{mg} \mathrm{L}^{-1}$. Rápidamente se ajusta el $\mathrm{pH}$, utilizando un electrodo de pH (Crison 52 02), al valor deseado para la reacción y se toma la primera alícuota como tiempo cero de reacción. Las muestras (aproximadamente $1 \mathrm{~mL}$ ) se toman mediante una pipeta y se filtran con filtro de nylon de 0.2 $\mu \mathrm{m}$ de tamaño de poro, para su posterior análisis mediante HPLC y espectrofotómetro de UV-Vis. Ambas técnicas de análisis se explicarán más adelante. Periódicamente se realizará un control de la reacción y reajuste de $\mathrm{pH}$, si es necesario, debido a la generación de especies ácidas durante el proceso por la oxidación del fenol. En el caso de los ensayos de productividad, la reacción se lleva a cabo de la misma manera, modificando la concentración de sustrato y oxidante, según se indica para cada situación en los capítulos previos de la presente tesis doctoral.

\subsubsection{Procedimiento general para la reacción de foto-Fenton}

Las reacciones de foto-Fenton fueron llevadas a cabo de la misma manera que las de Fenton a excepción de la irradiación a la que se someten las reacciones. En este caso, los matraces de vidrio, una vez tomada la muestra a tiempo cero, se sitúan bajo una fuente de irradiación, ya sea natural (bajo la luz directa del sol) o artificial (bajo la irradiación de un simulador solar Newport Oriel Sol 1A, con una intensidad de luz de $100 \mathrm{~mW} \mathrm{~cm}^{-2}$ ).

\subsubsection{Procedimiento general para la determinación del mecanismo de reacción por inhibición}

Para la determinación del mecanismo de reacción por inhibición, se desarrolla la reacción en presencia de productos que reaccionen rápidamente con los radicales que se presuponen como responsables de la actividad catalítica. Así, si en estas condiciones se consigue una inhibición de la reacción, se obtiene una prueba indirecta de la formación de este tipo de radicales en el proceso. En el caso de la presente tesis doctoral se utiliza generalmente DMSO como atrapador de radicales $\mathrm{HO}^{\circ}$ 
en una concentración de un $10 \%$ molar en exceso con respecto al $\mathrm{H}_{2} \mathrm{O}_{2}$, que es la especie de la cual se generan los radicales hidroxilo.

\subsubsection{Procedimiento general para la determinación del mecanismo de reacción por atrapamiento de radicales}

Para la determinación del mecanismo de reacción por atrapamiento de radicales, se lleva a cabo la reacción en ausencia de sustrato, en este caso fenol, pero en presencia de un reactivo atrapador de radicales que posteriormente se va a analizar por EPR. Los atrapadores de radicales empleados en la presente tesis doctoral han sido PBN y DMPO, como se explica en los capítulos anteriores, que forman un complejo estable con los radicales presentes en la reacción y que son fácilmente observados por la técnica de EPR, que nos va a mostrar un espectro determinado en función del radical atrapado por estas moléculas, obteniendo así una prueba directa del tipo de radicales presentes en el proceso. El funcionamiento de la técnica de EPR se explica en el siguiente apartado.

\subsection{Procedimientos de análisis de las muestras de reacción}

\subsubsection{Análisis de las muestras de reacción por HPLC}

Las muestras filtradas de reacción se analizan por cromatografía líquida de alta resolución (HPLC). El equipo utilizado es un Agilent 1100 Series equipado con un muestreador automático con capacidad para 100 muestras y un detector de UV-Vis (photodiode-array, PDA). Para el análisis de las muestras se trabaja en fase reversa, utilizando como fase móvil una mezcla de metanol, agua y ácido acético (69\% metanol, $30 \%$ agua, $1 \%$ ácido acético), y como fase estacionaria una columna KromasilC18. Los reactivos e intermedios de reacción se determinan por su absorción en el espectro de ultravioleta, y se cuantifican utilizando una recta patrón para cada producto utilizando reactivos comerciales. Las bandas de absorción para cada producto se indican a continuación: hidroquinona, $289 \mathrm{~nm}$; $p$-benzoquinona, $245 \mathrm{~nm}$; catecol, $276 \mathrm{~nm}, \mathrm{y}$ fenol, $270 \mathrm{~nm}$.

\subsubsection{Análisis de las muestras de reacción por espectrofotometría de UV-Vis}

El análisis de la degradación de $\mathrm{H}_{2} \mathrm{O}_{2}$ como oxidante se lleva a cabo por espectrofotometría de UV-Vis. Para ello se necesita de un indicador que toma color amarillo en presencia de este oxidante. El indicador consiste en una disolución acuosa de $\mathrm{K}_{2}(\mathrm{TiO})\left(\mathrm{C}_{2} \mathrm{O}_{4}\right)_{2}$ en $\mathrm{H}_{2} \mathrm{SO}_{4} / \mathrm{HNO}_{3}$. Brevemente, se toman $2.5 \mathrm{~g}$ del sólido y se le añaden 25 
$\mathrm{mL}$ de $\mathrm{H}_{2} \mathrm{SO}_{4}$ concentrado (98\% en volumen) y $1 \mathrm{~mL}$ de $\mathrm{HNO}_{3}$ concentrado ( $65 \%$ en volumen), y se enrasa a $100 \mathrm{~mL}$ con $\mathrm{H}_{2} \mathrm{O}$. Este proceso se ha de realizar con excesivo cuidado y muy lentamente por las condiciones fuertemente ácidas, evitando el sobrecalentamiento de la mezcla. Para el análisis de las muestras, se toman $4.5 \mathrm{~mL}$ de $\mathrm{H}_{2} \mathrm{O}$ y se añade $0.5 \mathrm{~mL}$ de la muestra filtrada de reacción y $0.5 \mathrm{~mL}$ de indicador. Esta dilución es necesaria para obtener en todo momento una absorbancia inferior a 1 , lo que nos permite determinar la concentración de reactivo por la ley de Lambert-Beer. A continuación se mide la absorbancia de cada muestra a una longitud de onda de $420 \mathrm{~nm}$. La concentración de $\mathrm{H}_{2} \mathrm{O}_{2}$ se determina mediante una recta de calibrado preparada previamente en las mismas condiciones.

\subsubsection{Procedimiento para la determinación de la demanda biológica de oxígeno $\left(\mathrm{BOD}_{5}\right)$}

Tras la finalización de la reacción, una vez la concentración de $\mathrm{H}_{2} \mathrm{O}_{2}$ es cero, se el volumen de reacción y se toma la fase acuosa para la determinación de la $\mathrm{BOD}_{5}$. Este análisis se realiza en una botella de BOD comercial (Lovibond) de $300 \mathrm{~mL}$ de capacidad. La muestra se introduce en la botella y se añade el sedimento de una planta de tratamiento de aguas en concentración de $1 \mathrm{~g} \mathrm{~L}^{-1}$. La botella se cierra utilizando un tapón BOD-Sensor (Lovibond Oxidirect) y se almacena a $20{ }^{\circ} \mathrm{C}$ agitando continuamente durante 5 días. Una vez transcurrido este período, el sensor de $\mathrm{BOD}$ indica el valor de $\mathrm{BOD}_{5}$ para la muestra contenida, en mg $\mathrm{L}^{-1}$ de $\mathrm{O}_{2}$.

\subsubsection{Procedimiento para la determinación de la demanda química de oxígeno (COD)}

Para la determinación de la demanda química de oxígeno se utiliza el método del dicromato. Se toma la fase acuosa filtrada resultante de la reacción $(10 \mathrm{~mL})$ y se añade $\mathrm{K}_{2} \mathrm{Cr}_{2} \mathrm{O}_{7}$ en exceso conocido $(5 \mathrm{~mL}$ de una disolución $0.25 \mathrm{~N}$ ) como oxidante. A la mezcla se le añade $15 \mathrm{~mL}$ de disolución de $\mathrm{AgSO}_{4}$ en medio ácido (0.66 g en $100 \mathrm{~mL}$ de $\mathrm{H}_{2} \mathrm{SO}_{4}$ al $98 \%$ $\mathrm{v} / \mathrm{v})$, que va a actuar como catalizador, $\mathrm{y} \mathrm{HgSO}_{4}(200 \mathrm{mg})$, para eliminar los cloruros presentes en disolución. Se calienta a reflujo durante 2 horas. Una vez finalizada la oxidación, se diluye a $100 \mathrm{~mL}$ con agua destilada y se añaden unas gotas de ferroína como indicador. El exceso de dicromato se valora con una disolución de sulfato de hierro y amonio (sal de Mohr) $0.25 \mathrm{~N}$, hasta el cambio de color a rojo de la ferroína, determinando así la cantidad de $\mathrm{O}_{2}$ que ha reaccionado por diferencia. 


\subsubsection{Análisis del atrapamiento de radicales por resonancia paramagnética electrónica (EPR)}

Las muestras filtradas resultantes del ensayo en presencia de DMPO o PBN como atrapadores de radicales para su análisis por EPR son purgadas bajo burbujeo con flujo de argón durante 2 minutos, para eliminar el oxígeno presente en disolución. Una vez purgada cada muestra, se introduce en una cubeta de cuarzo como portamuestras para su análisis por EPR. Esta técnica expone a la muestra a un campo magnético de alta frecuencia, y es sensible a la presencia de electrones desapareados, detectando así la presencia de radicales. Los análisis se realizaron utilizando un espectrómetro Bruker EMX.

\subsubsection{Análisis de carbón orgánico total (TOC)}

Los análisis de carbón orgánico total permiten la determinación de la cantidad de materia orgánica presente en una muestra. Este tipo de análisis se realizó al medio de reacción filtrado resultante tras la reacción, lo que proporciona información acerca del porcentaje de materia orgánica que se ha oxidado por completo a $\mathrm{CO}_{2}$. El equipo empleado para esta técnica es un analizador High TOC Elementar II. 



\section{Capítulo 9}

Conclusiones 

A la vista de los resultados obtenidos en la presente tesis doctoral, se puede concluir que se han desarrollado una serie de catalizadores y fotocatalizadores basados en metales menos nobles que el oro o en ausencia total de metales, que son estables y reutilizables en la reacción de foto-Fenton, y que pueden actuar a valores de $\mathrm{pH}$ casi neutros. Más específicamente, las conclusiones de cada capítulo son las siguientes:

i) La modificación de la superficie de diamante mediante oxidación de Fenton y posterior reducción con hidrógeno es muy conveniente, ya que permite la preparación de materiales con nanopartículas metálicas de pequeño tamaño $(<5 \mathrm{~nm})$ fuertemente ancladas sobre la superficie y que no tienen tendencia a sufrir lixiviado en las condiciones indicadas para la reacción de foto-Fenton.

ii) El diamante como soporte de nanopartículas metálicas, cuando su superficie es convenientemente tratada, ha demostrado ser un sólido más adecuado, para la preparación de catalizadores y fotocatalizadores eficientes en la reacción de foto-Fenton, que otros materiales habitualmente empleados también para este fin, tales como óxidos metálicos y carbón activo.

iii) La plata en forma de nanopartículas de $2 \mathrm{~nm}$ de tamaño de partícula promedio, soportadas sobre nanopartículas de diamante previamente tratadas, es el catalizador más eficiente descrito hasta ahora para este proceso, alcanzando valores de turnover a pH 4 de 472000 , siendo además el material estable frente a reúso.

iv) Se ha observado que las nanopartículas de cobre, ancladas sobre la superficie de diamante funcionalizada, son catalizadores activos para la reacción de foto-Fenton, aunque los valores del número de ciclos son inferiores a los de la plata. Sin embargo, se ha observado desactivación del catalizador durante el uso, lo que exige una reactivación de las nanopartículas metálicas de cobre. El proceso de desactivación más probable parece ser la oxidación de $\mathrm{Cu}(0)$ y $\mathrm{Cu}(\mathrm{I})$ a $\mathrm{Cu}$ (II).

v) El catalizador basado en nanopartículas de óxido de hierro soportadas sobre superficie de diamante previamente tratada presenta un buen balance entre valores altos del número de 
ciclos y valores bajos de lixiviado y desactivación, además del bajo coste del metal. Este catalizador también ha demostrado ser más activo que otros análogos basados en nanopartículas de hierro soportadas sobre otros materiales y presenta una actividad catalítica interesante a valores de $\mathrm{pH}$ próximos a la neutralidad ( $\mathrm{pH}$ 6).

vi) El óxido de grafeno reducido ha resultado ser un catalizador y foto-catalizador eficiente que, en ausencia de metales, es capaz de promover la reacción de Fenton y foto-Fenton, activando la descomposición del agua oxigenada, reacciones que hasta los últimos años se pensaba que sólo podían ser promovidas por metales. Los ensayos experimentales han demostrado que en condiciones idóneas de reacción se genera el radical hidroxilo por acción de este material, estimándose como centros activos del catalizador las subestructuras tipo benzoquinona $\mathrm{e}$ hidroquinona presentes en la lámina de grafeno. 


\section{Resúmenes de la tesis doctoral}





\section{Resumen}

En los últimos años, el aumento de la contaminación tanto de la atmósfera como de los suelos y recursos hídricos del planeta ha alcanzado niveles en grado no aceptable por el medio ambiente. En el caso de la contaminación de aguas, ya sea por uso doméstico en aglomeraciones urbanas o por vertidos industriales, estos niveles han llevado a la necesidad de la exigencia del tratamiento de las aguas por necesidad y por ley. Por ello, es importante el desarrollo y optimización de nuevos procesos aplicables a la descontaminación de aguas. En este contexto, en la presente tesis doctoral se describe el desarrollo de nuevos catalizadores basados en carbono altamente eficientes en tratamientos de descontaminación de aguas residuales industriales. Estos materiales basados en carbono garantizan una mayor sostenibilidad de cara a los procesos convencionales de tratamientos de aguas. Así, en una primera parte de la tesis se describe el empleo de materiales carbonosos como soporte de nanopartículas metálicas, obteniendo catalizadores altamente eficientes y con una elevada actividad catalítica en la reacción de fotoFenton para el tratamiento de aguas residuales industriales. En la segunda parte de la tesis se describe el empleo de materiales grafénicos como catalizadores libres de metales para las reacciones de Fenton y fotoFenton, reacciones que hasta los últimos años se creía que sólo se podían llevar a cabo con catalizadores metálicos. 


\section{Resum}

En els últims anys, l'augment de la contaminació tant de l'atmosfera com dels sòls i recursos hídrics del planeta ha aconseguit nivells en grau no acceptable pel medi ambient. En el cas de la contaminació d'aigües, ja siga per ús domèstic en aglomeracions urbanes o per abocaments industrials, aquests nivells han portat a la necessitat de l'exigència del tractament de les aigües per necessitat i per llei. Per això, és important el desenvolupament i optimització de nous processos aplicables a la descontaminació d'aigües. En aquest context, en la present tesi doctoral es descriu el desenvolupament de nous catalitzadors basats en carboni altament eficients en tractaments de descontaminació d'aigües residuals industrials. Aquests materials basats en carboni garanteixen una major sostenibilitat de cara als processos convencionals de tractaments d'aigües. Així, en una primera part de la tesi es descriu l'ocupació de materials basats en carboni com a suport de nanopartícules metàl-liques, obtenint catalitzadors altament eficients $\mathrm{i}$ amb una elevada activitat catalítica en la reacció de foto-Fenton per al tractament d'aigües residuals industrials. En la segona part de la tesi es descriu l'ocupació de materials grafènics com a catalitzadors lliures de metalls per a les reaccions de Fenton $\mathrm{i}$ foto-Fenton, reaccions que fins als últims anys es creia que només es podien dur a terme amb catalitzadors metàl-lics. 


\begin{abstract}
In the last years, the increase in pollution of both the atmosphere and the soil and water resources of the planet has reached levels that are not acceptable to the environment. In the case of water pollution, either by domestic use in urban agglomerations or by industrial discharges, these levels have led to the need for the requirement of water treatment by necessity and by law. Therefore, it is important to develop and optimize new processes applicable to water decontamination. In this context, the present doctoral thesis describes the development of new highly efficient carbon-based catalysts in industrial wastewater decontamination treatments. These carbon-based materials ensure greater sustainability for the conventional water treatment processes. Thus, in a first part of the thesis it is described the use of carbonaceous materials as support for metal nanoparticles, obtaining highly efficient catalysts with a high catalytic activity in the photo-Fenton reaction for industrial wastewater treatments. The second part of the thesis describes the use of graphene materials as metal-free catalysts for the Fenton and photo-Fenton reactions, reactions that until recent years it was believed that could only be carried out with metal catalysts.
\end{abstract}






\section{Lista de publicaciones}





\section{Capítulo 3}

Silver Nanoparticles Supported on Diamond Nanoparticles as a Highly Efficient Photocatalyst for the Fenton Reaction under Natural Sunlight Irradiation

Juan Carlos Espinosa, Sergio Navalón, Mercedes Álvaro, Hermenegildo García.

Publicado en: ChemCatChem, 2015, 7, 2682 - 2688.

\section{Capítulo 4}

Copper nanoparticles supported on diamond nanoparticles as a cost-effective and efficient catalyst for natural sunlight assisted Fenton reaction

Juan Carlos Espinosa, Sergio Navalón, Mercedes Álvaro, Hermenegildo García.

Publicado en: Catalysis Science \& Technology, 2016, 6, 7077 - 7085.

\section{Capítulo 5}

Iron oxide nanoparticles supported on diamond nanoparticles as efficient and stable catalyst for the visible light assisted Fenton reaction

Juan Carlos Espinosa, Cristina Català, Sergio Navalón, Belén Ferrer, Mercedes Álvaro, Hermenegildo García.

Publicado en: Applied Catalysis B - Environmental, 2018, 226, 242 251. 


\section{Capítulo 6}

\section{Graphenes as Efficient Metal-Free Fenton Catalysts}

Juan Carlos Espinosa, Sergio Navalón, Ana Primo, Mónica Moral, Javier Fernández Sanz, Mercedes Álvaro, Hermenegildo García.

Publicado en: Chemistry - A European Journal, 2015, 21, 11966 11971.

\section{Capítulo 7}

Reduced Graphene Oxide as a Metal-Free Catalyst for the LightAssisted Fenton-Like Reaction

Juan Carlos Espinosa, Sergio Navalón, Mercedes Álvaro, Hermenegildo García.

Publicado en: ChemCatChem, 2016, 8, $2642-26848$. 